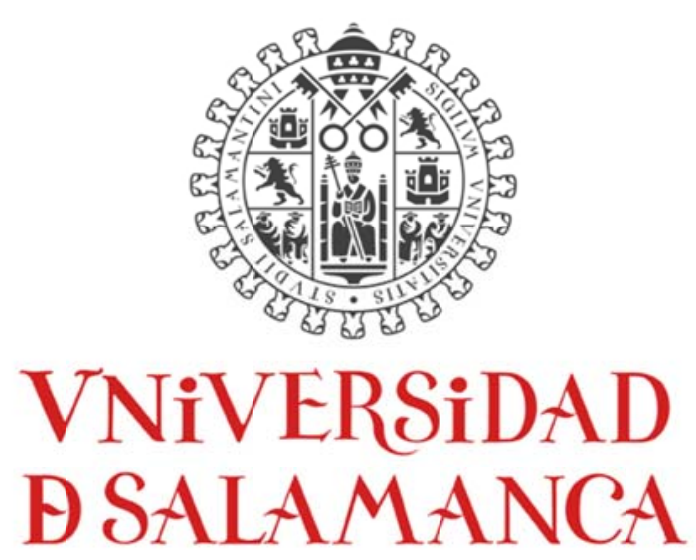

Departamento de Biblioteconomía y Documentación

\title{
LA CONVERGENCIA DE LOS SERVICIOS BIBLIOTECARIOS TELEMÁTICOS EN LA ENSEÑANZA UNIVERSITARIA E-LEARNING
}

\section{TESIS DOCTORAL}

Karla Vanessa Bonilla 



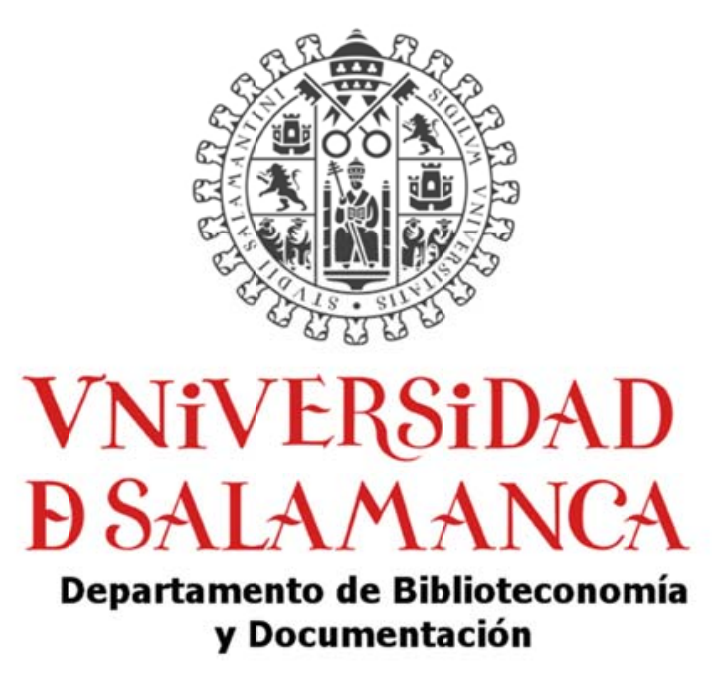

\section{LA CONVERGENCIA DE LOS SERVICIOS BIBLIOTECARIOS} TELEMÁTICOS EN LA ENSEÑANZA UNIVERSITARIA E-LEARNING

TESIS DOCTORAL

Presentada para la obtención del grado de Doctor en Documentación

Doctor José Antonio Merlo Vega

Director de Tesis
Karla Vanessa Bonilla

Doctoranda 
TESIS DOCTORAL

Título

La convergencia de los servicios bibliotecarios telemáticos en la enseñanza universitaria E-learning

Doctoranda

Karla Vanessa Bonilla

Director de tesis

Doctor José Antonio Merlo Vega

Departamento

Biblioteconomía y Documentación

Programa

Metodología y Líneas de Investigación en Biblioteconomía y Documentación

\section{Descriptores}

Servicios digitales / Bibliotecas / Enseñanza electrónica / E-learning / Evaluación de servicios en línea 


\section{Dedicatoria}

Al motor de mi existencia:

Mi Dios, mis hijas Andrea y Rebecca que dan color a mi vida.

Con infinito agradecimiento a mi amigo Pedro Luis

Con amor y admiración a mis padres por su ejemplo de lucha

Félix Bonilla y Rosa Amador

Evertwim y Mieke 


\section{Agradecimientos a los acompañantes de esta tesis:}

Mi agradecimiento y respeto a todas las personas que no dudaron en apoyarme de forma directa e indirecta para la realización de este trabajo de investigación.

Irene Veerman

\section{Especialmente a:}

Daisy Luisa Bravo Delgado

Julio Cubillo

José Antonio Merlo-Vega

Universidad de Wageningen

Ger Spikman, Marianne Renkema, Corrie van Zeist, Hans Fransen, Rob van Genderen, Ard Harting, Bertus Blankestijn y a todos mis colegas de la biblioteca WUR

Universidad Tecnológica de Delft

Paul Suijker y Nicoleta Nastase

Universidad de Utrecht

Eric Sieverts, Marja van de Bosch

Wim Karreman y Laurens Soumahu

Universidad de Salamanca

Ana Belén Hilario

Julio Alonso Arévalo

José Antonio Frías

Universidad de Barcelona

Ernest Abadal

Rosa Seguí

Universidad Pompeu Fabra

Lluís Codina 
ÍNDICE

PARTE I. INTRODUCCIÓN

19

Capítulo 1. Presentación de la tesis

1.1 Introducción $\quad 21$

1.2 Objetivos de la investigación $\quad 22$

1.3. Metodología de trabajo 23

1.3.1 Método utilizado 23

1.3.2 Áreas de conocimiento involucradas $\quad 23$

1.3.3 Parámetros considerados 24

1.3.4 Recopilación de información $\quad 26$

1.3.4.1 Bibliografía 26

$\begin{array}{ll}\text { 1.3.4.2 Recopilación de la información } & 26\end{array}$

$\begin{array}{ll}\text { 1.3.4.3 Procesamiento de los datos } & 27\end{array}$

1.4 Ejecución de los estudios de casos

$\begin{array}{ll}1.5 \text { Organización del contenido } & 29\end{array}$

1.6 Hipótesis $\quad 30$

1.6.1 Hipótesis verificadas $\quad 30$

1.6.2 Hipótesis de justificación del modelo 31

PARTE II. MARCO TEÓRICO 33

Capítulo 2. Análisis conceptual de los actuales modelos de bibliotecas 35

2.1 Introducción $\quad 35$

2.2 Evolución de la biblioteca tradicional $\quad 35$

2.2.1 Actuales modelos de biblioteca $\quad 36$

$\begin{array}{ll}\text { 2.2.2 Biblioteca electrónica versus recurso electrónico } & 37\end{array}$

$\begin{array}{ll}2.2 .3 \text { Biblioteca híbrida } & 38\end{array}$

2.2.3.1 Dimensiones de la biblioteca híbrida $\quad 39$

2.2.3.2 Descripción de la biblioteca híbrida $\quad 40$

2.2.4 Biblioteca digital $\quad 42$

2.2.4.1 Descripción de la biblioteca digital $\quad 43$

2.2.5 Biblioteca virtual 46

2.2.6 Centro de conocimientos 49

2.2.6.1 Antecedentes del modelo $\quad 49$

2.2.6.2 Desarrollo del modelo $\quad 50$

2.2.7 Centros de Recursos para el Aprendizaje y la Investigación (CRAI) 51

2.2.7.1 Descripción del CRAI $\quad 53$

2.2.8 Centros Virtuales de Información y Conocimiento (VKC) 56

2.2.8.1 Descripción del VKC $\quad 56$

2.3. Relación CRAI y VKC $\quad 60$

Capítulo 3. Análisis conceptual de la enseñanza electrónica (E-learning) 62

$\begin{array}{ll}3.1 \text { Introducción } & 62\end{array}$

3.2 Definición de enseñanza electrónica (E-learning) 63

3.2.1 E-learning 64

3.2.2 Componentes E-learning 66 
3.3 Aspectos pedagógicos y didácticos importantes 68

3.3.1. Modelos pedagógicos $\quad 68$

$\begin{array}{ll}\text { 3.3.2 Formas o modalidades E-learning } & 69\end{array}$

3.4 Estructura organizativa de E-learning 70

3.5 Estándares E-learning $\quad 71$

$\begin{array}{ll}\text { 3.5.1 Definición de estándares } & 71\end{array}$

$\begin{array}{ll}\text { 3.5.2 Tipos de estándares E-learning } & 72\end{array}$

3.5.3 Iniciativas de estándares E-learning $\quad 73$

$\begin{array}{ll}3.6 \text { Sistemas E-learning } & 75\end{array}$

$\begin{array}{ll}\text { 3.6.1 Clasificación de las plataformas E-learning } & 76\end{array}$

$\begin{array}{ll}\text { 3.6.2 Evolución de las plataformas E-learning } & 77\end{array}$

3.7 Inventario de plataformas E-learning LMS y CMS 80

3.8 Clasificación de servicios E-learning 87

PARTE III. CONVERGENCIAS Y ÁMBITO DE ACTUACIÓN DE LA BIBLIOTECA EN EL E-LEARNING 89 Capítulo 4. Puntos de encuentros entre Biblioteca y E-learning 91

$\begin{array}{ll}4.1 \text { Introducción } & 91\end{array}$

4.2 Áreas de acción de las bibliotecas $\quad 91$

4.3 Integración de los servicios bibliotecarios en el E-learning 93

4.4 Referencia digital $\quad 95$

4.4.1 Introducción al servicio de referencia digital 95

4.4.2 Concepto del servicio de referencia digital 96

4.4.3 Directrices para el diseño del servicio de referencia digital 99

4.4.3.1 Directrices básicas de la IFLA 99

$\begin{array}{ll}\text { 4.4.3.2 Directrices básicas de la RUSA } & 100\end{array}$

4.4.4 Proceso de comunicación del servicio de referencia digital 103

$\begin{array}{ll}\text { 4.4.5 Características del modelo de referencia digital } & 105\end{array}$

4.4.6 Modelos de servicio de referencia digital 107

4.4.7 Evaluación del servicio de referencia digital $\quad 110$

4.5 Alfabetización informacional 114

4.5.1 Introducción al servicio de alfabetización informacional 114

$\begin{array}{ll}\text { 4.5.2 Concepto de alfabetización informacional (ALFIN) } & 117\end{array}$

$\begin{array}{ll}\text { 4.5.3 Competencias transversales } & 118\end{array}$

4.5.4 Perspectivas de aplicación de la alfabetización informacional 119

$\begin{array}{ll}\text { 4.5.5 Tipos de alfabetización } & 121\end{array}$

4.5.6 Estudio de factibilidad para el diseño de una práctica ALFIN 123

$\begin{array}{ll}\text { 4.5.7 Modelos ALFIN } & 123\end{array}$

$\begin{array}{ll}4.6 \text { Repositorios para la educación } & 129\end{array}$

$\begin{array}{ll}\text { 4.6.1 Introducción al servicio de repositorios para la educación } & 129\end{array}$

$\begin{array}{ll}\text { 4.6.2 Conceptos relacionados } & 130\end{array}$

$\begin{array}{ll}\text { 4.6.2.1 Acceso abierto } & 131\end{array}$

$\begin{array}{ll}\text { 4.6.2.2 Colecciones digitales } & 131\end{array}$

$\begin{array}{ll}\text { 4.6.2.3 Metadatos } & 131\end{array}$

$\begin{array}{ll}\text { 4.6.2.4 Contenidos abiertos } & 133\end{array}$

$\begin{array}{ll}\text { 4.6.2.5 Objetos de aprendizaje } & 134\end{array}$ 
4.6.2.6 Portales 135

4.6.2.7 Repositorios 136

4.6.3 Importancia de los repositorios para la educación $\quad 139$

4.6.4 Interoperabilidad de los repositorios educacionales en E-learning 140

PARTE IV. ANÁLISIS DE SERVICIOS EN LINEA 143

Capítulo 5. Evaluación de servicios en línea E-learning y Biblioteca 145

$\begin{array}{ll}5.1 \text { Introducción } & 145\end{array}$

$\begin{array}{ll}5.2 \text { Estándares para evaluar servicios E-learning } & 145\end{array}$

5.2.1 Las prácticas de evaluación de servicios E-learning 146

5.2.2 Parámetros e indicadores para la evaluación de servicios del E-learning 148

5.3 Parámetros e indicadores para la evaluación de servicios en línea de la biblioteca 152

Capítulo 6 Propuesta metodológica para evaluar servicios en línea 158

$\begin{array}{ll}6.1 \text { Introducción } & 158\end{array}$

$\begin{array}{lr}6.2 \text { Guía metodológica } & 159\end{array}$

$\begin{array}{ll}\text { 6.2.1 Presentación de la guía } & 159\end{array}$

$\begin{array}{ll}\text { 6.2.2 Metodología de trabajo } & 159\end{array}$

6.2.2.1 Delimitación de objetivos 159

6.2.2.2 Escenarios identificados $\quad 160$

6.2.2.3 Definición de criterios $\quad 160$

6.3 Modelo de oferta de servicio de la biblioteca para E-learning 164

$\begin{array}{ll}6.3 .1 \text { Introducción } & 164\end{array}$

6.3.2 Propuesta de modelo de servicio de la biblioteca para E-learning 166

$\begin{array}{ll}\text { 6.3.3 Estructura del modelo } & 166\end{array}$

$\begin{array}{ll}6.3 .4 \text { Usuarios del modelo } & 168\end{array}$

$\begin{array}{ll}\text { 6.3.5 Aplicación del modelo } & 168\end{array}$

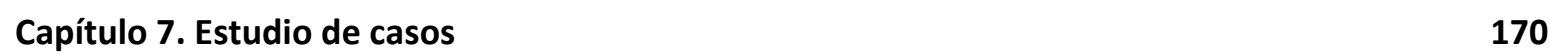

$\begin{array}{ll}7.1 \text { Introducción } & 170\end{array}$

7.2 Ámbitos geográficos de la investigación 171

7.3 Fases y parámetros considerados para el estudio de casos $\quad 174$

$\begin{array}{ll}7.4 \text { Descripción de casos } & 183\end{array}$

7.4.1 Universidad de Wageningen 183

7.4.1.1 Biblioteca de la Universidad de Wageningen $\quad 184$

7.4.1.2 Evaluación de la web de la Biblioteca de la WUR 189

7.4.1.3 Evaluación del servicio de cursos de formación de usuarios 194

7.4.1.4 Evaluación del servicio de referencia 199

7.4.1.5 Evaluación visual del acceso a los repositorios 201

7.4.1.6 Análisis SWOT de los servicios 203

7.4.2 Universidad Tecnológica de Delft (TUDelft) 209

7.4.2.1 Biblioteca Técnica de Delft (BTUD) 206

7.4.2.2 Evaluación general del sitio web de la BTUD 208

7.4.2.3 Evaluación del servicio de referencia $\quad 214$

7.4.2.4 Evaluación del servicio de cursos de formación de usuarios (ALFIN) 215 
7.4.2.5 Evaluación visual del acceso a los repositorios educacionales BTUDELFT 218

$\begin{array}{ll}\text { 7.4.2.6 Análisis SWOT de los servicios } & 219\end{array}$

7.4.3 Universidad Metropolitana de Ciencias de la Educación (UMCE) 221

7.4.3.1 Biblioteca de la Universidad Metropolitana de Ciencias de la Educación $\quad 222$

7.4.3.2 Evaluación general del sitio web de la Biblioteca UMCE 224

$\begin{array}{ll}\text { 7.4.3.3 Evaluación del servicio de referencia } & 228\end{array}$

7.4.3.4 Evaluación del servicio de cursos de formación de usuarios (ALFIN) 232

7.4.3.5 Análisis SWOT de los servicios 234

$\begin{array}{ll}\text { 7.4.4 Universidad EARTH } & 237\end{array}$

$\begin{array}{ll}\text { 7.4.4.1 Biblioteca de la Universidad EARTH } & 237\end{array}$

$\begin{array}{ll}\text { 7.4.4.2 Evaluación general del sitio web de la biblioteca } & 239\end{array}$

$\begin{array}{ll}\text { 7.4.4.3 Evaluación del servicio de referencia virtual } & 245\end{array}$

7.4.4.4 Evaluación del servicio de cursos de formación de usuarios (ALFIN) 246

7.4.4.5 Evaluación del servicio de acceso a los repositorios $\quad 249$

7.4.5.6 Análisis SWOT para introducir el modelo de servicios en programas E-learning250

7.4.5 Universidad de Sevilla 253

7.4.5.1 Antecedentes de la Universidad de Sevilla 253

7.4.5.2 Análisis general del sitio web de la Universidad de Sevilla 255

$\begin{array}{ll}\text { 7.4.5.3 Biblioteca de la Universidad de Sevilla } & 256\end{array}$

7.4.5.4 Evaluación de la web de la Biblioteca de la Universidad de Sevilla 259

$\begin{array}{ll}\text { 7.4.5.5 Evaluación del servicio de referencia } & 264\end{array}$

7.4.5.6 Evaluación del servicio de cursos de formación de usuarios (ALFIN) 270

7.4.5.7 Evaluación del servicio de repositorios para la educación 276

7.4.5.8 Análisis SWOT (FODA) de la Universidad de Sevilla 280

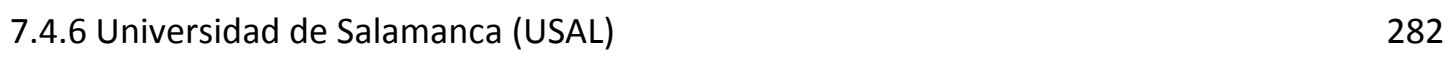

$\begin{array}{ll}\text { 7.4.6.1 Antecedentes generales } & 282\end{array}$

7.4.6.2 Servicio de Bibliotecas de la Universidad de Salamanca 284

7.4.6.3 Análisis del portal del Servicio de Bibliotecas de la USAL 286

$\begin{array}{ll}\text { 7.4.6.4 Evaluación del servicio de referencia } & 294\end{array}$

7.4.6.5 Evaluación del servicio de repositorios para la educación 299

7.4.6.6 Evaluación del servicio cursos de formación de usuarios (ALFIN) 307

$\begin{array}{ll}\text { 7.4.6.7 Análisis SWOT de la Universidad de Salamanca } & 312\end{array}$

$\begin{array}{ll}7.5 \text { Revisión general de los estudios de casos } & 315\end{array}$

$\begin{array}{ll}\text { 7.5.1 Perspectiva exterior de las bibliotecas } & 315\end{array}$

7.5.2 Diseños de sitio web y portales de las bibliotecas 316

$\begin{array}{ll}\text { 7.5.2.1 Servicios de referencia digital } & 318\end{array}$

$\begin{array}{ll}\text { 7.5.2.2 Servicios de alfabetización informacional } & 319\end{array}$

$\begin{array}{ll}\text { 7.5.2.3 Repositorios para la educación } & 320\end{array}$

$\begin{array}{ll}\text { 7.5.3 Puntos de atención: análisis DAFO/SWOT } & 321\end{array}$

PARTE V. APLICACIÓN PRÁCTICA, CONCLUSIONES Y RECOMENDACIONES 324

Capítulo 8. Guía para el diseño de servicios de información para E-learning 326

8.1 Introducción 326

$\begin{array}{ll}8.2 \text { Organización de la guía } & 326\end{array}$

$\begin{array}{ll}\text { 8.2.1 Objetivo de la guía } & 326\end{array}$ 
8.2.2 Elementos que deben considerarse en el diseño del servicio en línea para E-learning327

$\begin{array}{ll}\text { 8.2.2.1 Misión del servicio } & 327\end{array}$

$\begin{array}{ll}\text { 8.2.2.2 Paradigma de la oferta de servicio } & 327\end{array}$

$\begin{array}{ll}\text { 8.2.2.3 Estructura básica } & 328\end{array}$

$\begin{array}{ll}\text { 8.2.2.4 Funciones del modelo } & 330\end{array}$

$\begin{array}{ll}\text { 8.2.2.5 Funciones del (los) gestor(es) del servicio } & 330\end{array}$

8.3 Organización y gestión del servicio 330

8.3.1 Responsabilidad $\quad 330$

8.3.2 Política del servicio $\quad 332$

8.3.2.1 Procedimientos para el acceso 333

8.3.2.2 Controles estadísticos 334

8.3.3 Planificación 335

$\begin{array}{ll}\text { 8.3.3.1 Actividades } & 336\end{array}$

$\begin{array}{ll}\text { 8.3.3.2 Recursos } & 336\end{array}$

$\begin{array}{ll}\text { 8.3.3.3 Personal } & 336\end{array}$

8.3.4 Diseño de la interfaz $\quad 337$

$\begin{array}{ll}\text { 8.3.5 Aspectos legales } & 338\end{array}$

8.3.5.1 Contenido ilegal 339

$\begin{array}{ll}\text { 8.3.5.2 Derechos de autor y de copia } & 339\end{array}$

$\begin{array}{ll}\text { 8.3.6 Colaboración } & 340\end{array}$

8.3.7 Promoción y publicidad 342

8.4 Práctica del servicio 343

8.5. Directrices generales $\quad 350$

8.5.1 Directrices básicas para el componente de la referencia digital 350

8.5.2 Directrices básicas para el componente de la alfabetización informacional 352

8.5.3 Directrices básicas para el componente de los repositorios para la educación $\quad 355$

Capítulo 9 Conclusiones y recomendaciones generales 357

$\begin{array}{ll}9.1 \text { Introducción } & 357\end{array}$

9.2 Conclusiones $\quad 357$

9.2.1 Evaluación del modelo de biblioteca 357

$\begin{array}{ll}\text { 9.2.2 E-learning } & 358\end{array}$

9.2.3 Puntos de encuentros entre la biblioteca y E-learning 359

9.2.4 Implementación del modelo 362

9.3 Recomendaciones generales 362

$\begin{array}{ll}\text { BIBLIOGRAFÍA } & 365\end{array}$

Bibliografía citada 365

ANEXOS 393

Anexo 1. Gestores del servicio de referencia 393

Anexo 2. Evaluación de formación de habilidades y destrezas (Gestores del servicio) 398

Anexo 3. Gestores de servicios de repositorios educacionales 405 


\section{ÍNDICE DE TABLAS}

Tabla 1. Recursos informativos

Tabla 2. Nuevos elementos tecnológicos en el modelo de biblioteca tradicional

Tabla 3 Diferencia entre biblioteca virtual y digital

Tabla 4. Oferta de recursos de información de la biblioteca híbrida, biblioteca digital y el VKC

Tabla 5. Iniciativas de módulos de bibliotecas de OA en sistemas E-learning.

Tabla 6. Tres dimensiones del concepto E-learning

Tabla 7.Organización y gestión de la información y contenidos en procesos E-learning

Tabla 8. Áreas desarrolladas por los estándares E-learning

Tabla 9. Diferencias entre sistemas CBT y sistemas E-learning

Tabla 10. Resumen comparativo de los LMS y LCMS

Tabla 11. Categorización de servicios de E-learning y la Biblioteca

Tabla 12. Evolución de servicio de referencia.

Tabla 13. Características del servicio de referencia en dependencia de su tipología y nivel de desarrollo

Tabla 14. Diferencias de servicios involucrados con la referencia digital

Tabla 15. Aspectos básicos para la evaluación del servicio de referencia digital.

Tabla 16. Período de surgimiento de los modelos ALFIN

Tabla 17. Modelos de Alfabetización informacional

Tabla 18. Repositorios de objetos de aprendizaje que cumple con las normativas SCORM y los OA organizados por temas

Tabla 19. Perspectiva de la evaluación de servicios E-learning

Tabla 20. Criterios básicos para evaluar servicios E-learning

Tabla 21. Indicadores tradicionales para evaluar servicios de la biblioteca

Tabla 22. Diferencias en la evaluación de sitios web y los objetos digitales

Tabla 23. Perspectiva de la evaluación de servicios digitales.

Tabla 24. Enfoque tridimensional de evaluación de servicios en línea

Tabla 25. Escenarios en el desarrollo de la evaluación

Tabla 26. Escenarios identificados previos al estudio de casos

Tabla 27. Aplicación de parámetros en los servicios evaluados

Tabla 28. Aplicación de Técnicas e instrumentos en la revisión de servicios.

Tabla 29. Aspectos físicos y ergonómicos mejorados en el sitio web del SABUS

Tabla 30.Organización de los recursos de apoyo a la enseñanza

Tabla 31. Puntos de atención en el diseño del nuevo sitio del SABUS

Tabla 32. Estado de los sitios de las bibliotecas - Estudio de casos

Tabla 33. Análisis general de los sitios de las bibliotecas - Estudio de casos 
Tabla 34. Recursos mayormente utilizados para procesos de Comunicación Estudio de casos

Tabla 35. Estructura y recursos tecnológicos del de ALFIN - Estudio de casos

Tabla 36. Estado de los Repositorios - Estudio de casos

Tabla 37. Lista de iniciativas de aplicación de la Web 2.0 para actividades educativas y prestación de servicios

Tabla 38. Directrices generales para el diseño del componente

Referencia digital de modelo de servicio para E-learning.

Tabla 39. Directrices básicas para el diseño de repositorios para la educación

\section{ÍNDICE DE FIGURAS}

Figura 1.Sistema de transferencia de la información a partir de tres servicios básicos de la biblioteca

Figura 2. Entornos de la biblioteca híbrida

Figura 3. Componentes básicos del modelo biblioteca digital

Figura 4. Universidad de Hertfordshire

Figura 5. Universidad de Barcelona

Figura 6. Ejes de acción del CRAI

Figura 7. Modelo CRIA

Figura 8. Visualización de los componentes del CRAI en la web

Figura 9. Acercamiento sistémico del modelo VKC

Figura 10. Descripción general del modelo VKC

Figura 11. Ciclo de oferta y demanda

Figura 12. Interpretación del concepto E-learning según sus actores

Figura 13. Representación sistémica de E-learning

Figura 14. Modalidades de E- learning

Figura 15. Evolución histórica de los sistemas de gestión de contenidos

Figura 16. Confluencia del E-learning y la biblioteca en el proceso formativo

Figura 17. Contenidos de confluencia

Figura 18. Áreas de acción para el diseño de una oferta de servicio para E-learning

Figura 19. Componentes básicos del servicio de referencia digital

Figura 20. Prácticas de servicio de referencia digital vía chat

Figura 21. Comunicación sincrónica utilizada en la biblioteca para la prestación del servicio de referencia Figura 22.Tipología de servicios de referencia virtual

Figura 23. Representación del modelo conceptual de servicio de referencia digital

Figura 24. Aspectos básicos para la evaluación del servicio de referencia para E-learning

Figura 25. Espiral de acción de ALFIN. Fuente: Elaborada por María Pinto, 2009

Figura 26. ALFIN y la transferencia de información-conocimiento 
Figura 27. Caraterización de los contenidos educativos

Figura 28. Vínculos de los componentes E-learning en la prestación de servicios

Figura 29. Fundamento para la evaluación de servicios en línea

Figura 30. Grupo de Discusión Clay Construyendo eLearning

Figura 31. Representación de la estructura del modelo y cohesión con el E-learning

Figura 32. Interoperabilidad entre los sistemas LMS y CMS

Figura 33. Esquema metodológico para estudios de casos

Figura 34. Página principal del sitio web de la WUR

Figura 35. Biblioteca de la Universidad de Wageningen. Visualización desde el Portal de la WUR Figura 36. Portal Eduweb Support de la WUR

Figura 37. Groen Kennisnet. Servicio de apoyo a la educación e investigación agropecuaria

Figura 38. Oferta de servicios de la biblioteca de la WUR.

Figura 39. Oferta de repositorios y bases de datos de la biblioteca de la WUR

Figura 40. Oferta de recursos y cursos para la formación de usuario de la Biblioteca de la WUR

Figura 41. Visualización de cursos ofrecidos en Blackboard

Figura 42. Componentes de los cursos ofrecidos en Blackboard

Figura 43. Estructura modular de los cursos

Figura 44. Formas de seguimiento y evaluación del aprendizaje

Figura 45. Vías de localización de cursos ofrecidos en Eduweb

Figura 46. Servicio de referencia virtual de la Biblioteca WUR

Figura 47. Opciones del servicio de referencia de la Biblioteca WUR

Figura 48. Portal de acceso a los repositorios

Figura 49. Motores de búsqueda de la Biblioteca WUR

Figura 50. Página principal de la Universidad Tecnológica de Delft

Figura 51. Visualización de la biblioteca desde el portal principal de la TUDelft

Figura 52. Meta buscador "Discover" de TUDelft

Figura 53. Oferta de acceso a las bases de datos y repositorios de la BTUD

Figura 54. Buscadores general de la Biblioteca TUDelft

Figura 55. Ejemplo de petición de descarga de programa

Figura 56. Proceso de búsqueda en Discover.

Figura 57. Oferta de ALFIN

Figura 58. Aplicación de Blackboard de Biblioteca TUDelft

Figura 59. Oferta de cursos de la Biblioteca en Blackboard

Figura 60. Portal de la Universidad Metropolitana (UMCE).

Figura 61. Entrada principal del sitio web del sistema de Bibliotecas de la UMCE 
Figura 62. Práctica realizada en el sistema de búsqueda de la UMCE

Figura 63. Portal de acceso a repositorio de revistas científicas (UCME)

Figura 64. Portal de acceso a bases de datos bibliográficos internacionales (Dialnet) UCME

Figura 65. Oferta de servicio Guía Temática de la UMCE

Figura 66. Oferta de cursos de formación de usuarios de UMCE

Figura 67. Ejemplo de curso taller ofrecido por la Biblioteca como crédito académico

Figura 68. Estructura y organización de contenido de curso en Moodle

Figura 69. Campus de la Universidad Earth

Figura 70. Sitio web de la Biblioteca de la Universidad Earth

Figura 71. Puntos de acceso a los recursos e información de la Biblioteca de la Universidad Earth

Figura 72. Visualización del sistema de búsqueda en el catálogo de la Biblioteca de la Universidad Earth

Figura 73. Práctica de búsqueda avanzada en el catálogo

Figura 74. Visualización y despliegue del servicio de referencia virtual

Figura 75. Programas de formación de la Biblioteca de la Universidad Earth

Figura 76. Participación de la Biblioteca en el curso Taller INF 101-10 preparatorio de computación Earth

Figura 77. Despliegue de contenido del curso taller INF 101-10

Figura 78. Organización de contenidos del curso INF 101-10 Earth

Figura 79. Puntos de acceso a repositorios

Figura 80. Página principal del sitio web de la Universidad de Sevilla

Figura 81. Localización del portal de la biblioteca en Google

Figura 82. Portal inicial para llegar a los servicios de la biblioteca

Figura 83. Portal de la biblioteca

Figura 84. Catálogo Fama

Figura 85. Sitio Web del Servicio de Referencia virtual (Comunicación)

Figura 86. Disponibilidad de referencista en línea

Figura 87. Prueba de diálogo sincrónico

Figura 88. Servicio de mensajería de correo electrónico del Servicio de Referencia

Figura 89. Oferta de colección de referencia virtual

Figura 90. Servicio ALFIN

Figura 91. Organización de cursos ALFIN en la Universidad de Sevilla

Figura 92. Agenda y Oferta mensual de cursos ALFIN

Figura 93. Recursos para el aprendizaje e investigación

Figura 94. Oferta de acceso a repositorios para la Educación

Figura 95. Repositorios ROA de la Universidad de Sevilla

Figura 96. Estructura de Repositorio RODAS 
Figura 97. Portal de la Universidad de Salamanca

Figura 98. Portal de la biblioteca

Figura 99. Nuevo portal en proceso de construcción

Figura 100.Catatálogo general del sistema de bibliotecas de la USAL

Figura 101. Portada del catálogo del sistema de bibliotecas de la USAL

Figura 102.Ejercicio de búsqueda en el catálogo del sistema de bibliotecas de la USAL

Figura 103. Sistema de búsqueda BUCLE asociado a Wordcat.org

Figura 104. Servicio de Referencia de la USAL

Figura 105. Servicio de sugerencia y quejas del sitio del Sistema de bibliotecas de la USAL

Figura 106. Servicio de comunicación para establecer contacto con los referencistas

Figura 107. Servicio de comunicación con carácter informativo

Figura 108. Repositorios para la educación- SABUS Antiguo portal

Figura 109. Repositorios para la educación- SABUS Nuevo portal

Figura 110. Visualización de la página inicial de sitio Web Gredos

Figura 111. Repositorio Documental GREDOS

Figura 112. Ejemplo de búsqueda por fecha

Figura 113. Enlaces direccionales a otras fuentes y opción de formato de acceso al documento

Figura 114. Recursos de GREDOS

Figura 115. Posicionamiento de los repositorios de la USAL en Internet

Figura 116. Sistema de búsqueda y recuperación de GREDOS

Figura 117. Servicio de Formación del Sistema de Bibliotecas de la Universidad de Salamanca

Figura 118. Resultado de búsqueda en Google

Figura 119. Lógica del funcionamiento del modelo de oferta de servicio

Figura 120. Estructura del modelo de oferta de servicio

Figura 121. Fusión de las áreas de aplicación de la Web 2.0 para fines educativos al modelo de servicio con la práctica identificada 


\section{PRESENTACIÓN}

La incorporación de nuevos recursos informáticos y telemáticos a las bibliotecas ha permitido la creación de servicios y redes electrónicas tanto locales como externas, que facilitan el acceso a la información y mejoran los procesos de comunicación, creando nuevas formas de trabajo para la prestación de servicios. En esta línea la biblioteca tradicional se ha transformado en un modelo híbrido que proporciona servicio las 24 horas del día, dando acceso a los recursos tradicionales y a los recursos electrónicos, permitiendo ampliar su oferta de servicios a la comunidad universitaria. La integración de recursos y servicios en las bibliotecas es una práctica cotidiana. Ejemplos concretos de realizaciones de este modelo se localizan en España bajo el denominaciones como Centros de Recursos para el Aprendizaje y la Investigación (CRAI), en los Países Bajos se reconocen como Centros Virtuales de Información y Conocimiento (Virtuele Kennis Centra $=\mathrm{VKC}$ ) y en Estados Unidos son llamados Centro de Información y Conocimiento (Knowledge and Information Center).

Las bibliotecas académicas se han adaptado también a su misión de apoyo a la docencia, participando en actividades formativas y realizando actividades tales como la elaboración de guías tutoriales, digitalización de materiales para los cursos y la elaboración de bibliografías especializadas con sus respectivos enlaces a las fuentes. Aunque estas iniciativas en general surgen como respuestas a necesidades y demandas concretas, han motivado cambios en la forma de prestación de algunos servicios básicos, como por ejemplo el servicio de referencia digital, que intenta responder de forma inmediata las solicitudes de información mediante comunicaciones asincrónicas y sincrónicas; las actividades de alfabetización informacional (ALFIN), que ofrece cursos de formación de usuarios ofrecidos en algunos casos desde plataformas telemáticas, así como también el servicio de acceso a los repositorios para la educación. Son precisamente estos tres ámbitos (referencia digital, alfabetización informacional, repositorios educativos) donde la biblioteca universitaria realiza una función de apoyo a la educación de forma más decidida y útil.

En esta línea, siendo el objetivo de esta investigación demostrar la utilidad de la referencia digital, la alfabetización informacional y el acceso a los repositorios para la educación, como elementos básicos para la propuesta de un modelo de oferta de servicios integrado de apoyo a las actividades de enseñanza electrónica $\left(E\right.$-learning ${ }^{1}$ ), se presenta en esta tesis doctoral un estudio teórico-práctico sobre la convergencia de los servicios bibliotecarios universitarios y el E-learning. Para ello, se parte de un contexto teórico, tanto en el aspecto pedagógico como en el bibliotecario, para después ofrecer los resultados de diferentes estudios de casos realizados en instituciones universitarias ubicadas en cuatro países diferentes, que permitieron evidenciar la viabilidad del modelo que se propone junto a las conclusiones, como un mecanismo de sinergia entre el E-learning y la biblioteca universitaria.

\footnotetext{
${ }^{1}$ El término en inglés E-learning es utilizado en esta tesis para referirse a la educación telemática. Debido a que es un término de reconocimiento internacional, se empleará en su forma original en inglés, ya que se considera un término aceptado por la bibliografía profesional.
} 



\section{PARTE I INTRODUCCIÓN}

Los significativos avances tecnológicos han permitido solventar las limitaciones para la comunicación y el acceso a la información. Los problemas que conllevan las distancias se ven superado gracias a los mecanismos electrónicos que permiten ampliar las posibilidades de interactuación en la sociedad y acercarse al conocimiento. La idea de poder utilizar estas facilidades tecnológicas para que la biblioteca pueda apoyar el proceso de enseñanza electrónica representa la alternativa viable para generar una sinergia con el E-learning. En esta tesis se pretende constatar la posibilidad de constituir un puente entre biblioteca y educación, mediante la oferta de un servicio telemático ofrecido desde una plataforma de enseñanza electrónica.

Con este objetivo, la Parte I de esta investigación es una introducción al planteamiento lógico del tema de estudio. Se indican los aspectos generales de orden metodológico y organizativo que fueron necesarios para la delimitación de los objetivos y alcance de la investigación académica. Asimismo, en este apartado se destacan los diferentes procesos y actividades llevadas a cabo para el cumplimiento de los objetivos propuestos de esta investigación.

La primera parte de esta tesis doctoral está compuesta sólo del Capítulo 1, que quiere servir de introducción al trabajo realizado, exponiendo de forma sintética -ya que los contenidos se irán desarrollando en cada sección- cuáles han sido los puntos de partida, la metodología empleada en este trabajo doctoral, las aplicaciones concretas, las conclusiones y los resultados prácticos. 


\section{PARTE I. INTRODUCCIÓN}

\section{Capítulo 1. Presentación de la tesis}

1.1 Introducción

1.2 Objetivos de la investigación

1.3. Metodología de trabajo

1.3.1 Método utilizado

1.3.2 Áreas de conocimiento involucradas

1.3.3 Parámetros considerados

1.3.4 Recopilación de información

1.3.4.1 Bibliografía

1.3.4.2 Recopilación de la información

1.3.4.3 Procesamiento de los datos

1.4 Ejecución de los estudios de casos

1.5 Organización del contenido

1.6 Hipótesis

1.6.1 Hipótesis verificadas

1.6.2 Hipótesis de justificación del modelo 


\section{Capítulo 1. Presentación de la tesis}

\subsection{Introducción}

Las entidades académicas periódicamente invierten en la modernización de sus estructuras de funcionamiento. Una de las grandes inversiones actuales de las universidades apunta a mejorar la infraestructura tecnológica para la transferencia de información y comunicación con el fin de dinamizar los procesos internos, aumentar el universo de acción, agilizar los procesos de comunicación, reutilización y superar los niveles de competencia.

En este contexto la modalidad de educación a distancia a través de medios electrónicos asociados a Internet (conocido en inglés como E-learning), es de gran interés para universidades debido a que esta modalidad facilita ampliar la cobertura de los procesos educativos, la utilización y asociación de materiales de estudios en diferente cursos y sobre todo crear nuevas ofertas en espacios telemáticos.

Como causa y efecto de los cambios internos en las instituciones en las últimas décadas, se ha observado un creciente número de iniciativas impulsadas por bibliotecas académicas que ofrecen servicios virtuales de gran potencial para la docencia y la investigación, tanto para las modalidades presenciales como virtuales. La incorporación de estos servicios en cursos E-learning se realiza en algunas universidades como iniciativas pioneras y esfuerzos aislados pero con resultados exitosos. La creación de un puente entre los servicios de las bibliotecas y el E-learning promete un cambio promisorio, ya que por esa vía se podría asegurar que se lleven a cabo un conjunto de programas colaborativos capaces de incrementar la calidad y autenticidad de los contenidos de la educación, independientemente de la modalidad. Sin embargo, esto no es tarea fácil, al menos por tres razones:

1) Históricamente los cursos E-learning se han ofrecido y presentado como un producto acabado obtenible a través de un proceso conceptual y prácticamente cerrado a terceros actores y que cumple con determinadas normas que exige esta modalidad.

2) Ha existido poco interés del instructor y del estudiante del E-learning por hacer uso de los servicios digitales de información de las bibliotecas, en gran medida porque no están "alfabetizados" en el aprovechamiento de los servicios digitales de información como apoyo a los procesos de formación de la enseñanza y el fomento de actitudes de investigación en el individuo formante a distancia.

3) Las bibliotecas no están familiarizadas -salvo experiencias aisladas- con modelos abiertos para hacer funcionar de forma colaborativa sus servicios digitales en el contexto de otros sistemas informáticos tales como los campos virtuales.

Sin embargo las experiencias de prácticas de servicios en línea identificadas tanto del E-learning como de las bibliotecas, ocurren básicamente en las actividades de informar, orientar y facilitar el acceso. Esta coincidencia demuestra la posibilidad que la biblioteca académica pueda interactuar con el E-learning mediante una oferta de servicio en línea para el creciente mercado que supone la educación electrónica. Se trata entonces de un modelo que integre el servicio de referencia digital como mecanismo de información y comunicación; el servicio de alfabetización informacional como medio de formación y capacitación de los estudiantes E-learning y el servicio de repositorios para la educación como el punto de acceso al conocimiento. 
Ante este planteamiento la presente tesis ha tenido como objetivo demostrar científicamente la viabilidad y validez del modelo de servicio. Para este fin fue necesario realizar una revisión teórica de los antecedentes de los diferentes tipos de bibliotecas y modalidad de educación a distancia, a fin de conocer la base lógica en que se edificaron los servicios. Posteriormente la realización de un análisis de prácticas de los tres servicios considerados claves para el modelo propuesto, a fin de avanzar en la creación de una propuesta de oferta de servicio que disminuya la brecha entre el mundo de los servicios digitales de las bibliotecas y E-learning.

\subsection{Objetivos de la investigación}

El objetivo principal de esta tesis, es realizar una investigación que sirva como una aportación al desarrollo y fortalecimiento de las bibliotecas académicas, presentando una propuesta de modelo de acoplamiento y articulación entre los servicios digitales de las bibliotecas y las actividades académicas del E-learning, capaz de generar nuevas sinergias entre los usuarios y los contenidos, además de ser utilizado como un marco de referencia para la implementación y mejora de los servicios de información en línea.

En este contexto, el objetivo principal de la presente tesis ha sido orientando a la búsqueda e identificación de los puntos de convergencia entre el E-learning y la Biblioteca; necesarios para la definición y diseño de la propuesta del modelo de servicio de información de apoyo a la enseñanza electrónica y ofrecido desde una plataforma E-learning. El modelo integra como componentes esenciales la referencia digital, la alfabetización informacional y el acceso a los repositorios para la educación, que integrados, facilitan la transferencia de conocimiento.

El logro de este objetivo fundamental implicó cumplir con los siguientes cuatro objetivos específicos:

- Ejecución de un análisis teórico, conceptual, descriptivo y comparativo de los tipos de bibliotecas y modalidades de educación telemática, a fin de disponer de un marco teórico referencial del desarrollo de los servicios en línea de ambos e identificar las posibles relaciones de semejanzas y afinidades entre la biblioteca y el E-learning.

- Elaboración de una metodología de trabajo para la evaluación y caracterización de prácticas de aquellos servicios en línea acoplables a las actividades de E-learning y ofrecidos por bibliotecas universitarias ubicadas en América Latina y Europa.

- Ejecución de un estudio de casos con ocho entidades que, si bien no pueden ser consideradas estadísticamente o científicamente representativas, si fueron viables, para ejemplificar la práctica de los servicios y demostrar la funcionalidad del modelo mismo. El resultado de estudio de casos aporta un análisis descriptivo y evaluativo de las experiencias de servicios en línea de ocho bibliotecas universitarias ubicadas en América Latina y Europa.

- Elaboración de una propuesta concreta de modelo flexible de oferta de servicio de información en línea, ofrecido por la biblioteca desde cualquier plataforma E-learning como componente de apoyo a las actividades de formación a distancia semipresencial, la formación electrónica y como un posible medio de acercamiento al conjunto de experiencias de trabajo mixtos. 
En la búsqueda de dar cumplimiento a los objetivos planteados, se desarrolló un conjunto de acciones que fueron organizadas y ejecutadas a partir de la metodología de trabajo que se explica a continuación.

\subsection{Metodología de trabajo}

La realización de la presente tesis es el resultado de una serie de actividades y procesos ejecutados en fases de un período de seis años. La primera fase inicia con la revisión de literatura sobre aspectos teóricos y conceptuales de los servicios en línea ofrecidos por los actuales modelos de bibliotecas y los servicios de E-learning.

La segunda etapa implicó la búsqueda e identificación de los puntos de coincidencia entre E-learning y la Biblioteca, para este fin se efectuó una revisión teórica sobre aspectos organizativos de ambas, que permitió identificar los elementos de convergencia e insumos necesarios para el desarrollo de la siguiente fase que incluyó la definición y diseño de una propuesta de un modelo para la organización de servicios de información de apoyo a la enseñanza electrónica. La propuesta del modelo es diseñada para ser ofrecida desde una plataforma E-learning. Dicho modelo integra tres servicios básicos de la biblioteca: el servicio de referencia, la formación de habilidades y el acceso a los recursos de la biblioteca.

Siendo esta propuesta un resultado concluyente de esencial importancia para esta tesis, la etapa final consistió en la verificación de la funcionalidad del modelo mediante la ejecución de un estudio de caso, que consistió en una evaluación de servicios digitales en seis bibliotecas universitarias ubicadas en Países Bajos, España, Chile y Costa Rica.

\subsubsection{Método utilizado}

El desarrollo de la investigación tuvo como punto de partida el método científico inductivo. La aplicación de este método facilitó el estudio de las prácticas de servicios en línea ofrecidos por las seis bibliotecas seleccionadas como ejemplo de prácticas de los servicios en línea. La ejecución del estudio demandó el uso de diferentes métodos para captar la información necesaria, entre los que se destacan la observación orientada al funcionamiento del sitio mediante el uso de una matriz de diez parámetros para la evaluación de sitios web; entrevistas a gestores de los servicios mediante el uso de cuestionarios de preguntas abiertas y cerradas por cada servicio, considerado clave en el diseño del modelo.

Es importante indicar, que a través del estudio se logró conocer el nivel de desarrollo organizativo y tecnológico de cada una de las bibliotecas; asimismo analizar y clasificar las prácticas de los servicios., que a su vez permitió constatar las hipótesis planteadas y la consecución de objetivos presentados en esta tesis. De igual manera, la aplicación del razonamiento inductivo en el análisis de las prácticas permitió edificar la idea de una nueva estructura de organización de servicios que puede ser introducida como medio de apoyo en actividades de E-learning.

\subsection{2 Áreas de conocimiento involucradas}

El desarrollo de la investigación ha exigido profundizar en otras áreas del conocimiento vinculadas a las ciencias de la información y a las ciencias de la educación. Por lo tanto, se consideró necesario retomar aspectos teóricos de las siguientes áreas de conocimiento: 
a) Educación. Los nuevos modelos de bibliotecas se perfilan como centros de conocimiento y unidades de apoyo al proceso de enseñanza y aprendizaje. Profundizar en el rol de las bibliotecas en el proceso de educación a distancia en el espacio virtual (E-learning / aula virtual) demanda una revisión de los conceptos y objetivos en esta nueva modalidad de educación. En esta línea, el entendimiento de E-learning permitirá identificar el rol de la biblioteca en el proceso de transferencia de conocimiento e información en procesos educativos virtuales.

b) Psicología. Sin duda alguna, los cambios tecnológicos han generado una sensible modificación en la conducta humana. La adopción de un nuevo modelo dentro de un determinado entorno social implica la participación de individuos de diferentes edades, sexos y perfiles de formación, que, por sus características, cualidades y formación individuales, experimentan los cambios de manera muy diferente. Todo proceso de cambio puede generar un impacto psicológico positivo o negativo que requiere el seguimiento o monitoreo de los responsables de la implementación de programas, o nuevos modelos de trabajo, a fin de reducir riesgos laborales.

c) Comunicación. Como medio para la transferencia y generación de información, conocimiento y vínculo de unión en cualquier proceso social.

d) Economía. La selección de cualquier modelo de gestión se justifica en el análisis de viabilidad, rentabilidad y oportunidades para aumentar las capacidades y servicio y todo ello, a un menor costo.

e) Administración y gestión. La implantación de nuevos modelos implica un exigente y constante proceso organizativo que garantice el aprovechamiento y manejo de los recursos humanos y materiales disponibles.

f) Informática. En la actualidad, el intenso proceso de cambio se apoya en el constante desarrollo de la tecnología. La incorporación de las TIC'S, y el adecuado uso de ellas permitirán entender el enorme potencial que ofrecen en la evolución de los modelos de trabajos dirigidos a servicios.

\subsubsection{Parámetros considerados}

La ejecución del estudio de campo de esta investigación implicó la utilización de una guía metodológica para la evaluación de servicios en línea que fue elaborada a partir de estándares sugeridos por diferentes autores². La guía retoma para los objetivos de la investigación, diez parámetros para la caracterización y evaluación de los servicios ofrecidos desde una web:

1. Identidad del servicio

2. Actualización

3. Accesibilidad

4. Servicios básicos de la web

\footnotetext{
${ }^{2}$ Es un tema estudiado a nivel académico-científico. Ejemplo de algunos de ellas se citan en la bibliografía anexa en esta tesis.
} 


\section{Contenido}

6. Arquitectura de la información

7. Diseño de la interfaz

8. Posicionamiento

9. Sistema de búsqueda y recuperación

10. Usabilidad

Los parámetros anteriormente indicados fueron utilizados para determinar la operatividad de los sitios web y la funcionalidad de los siguientes tres servicios ofrecidos por las bibliotecas:

a) Referencia digital

b) Alfabetización informacional

c) Repositorios para la educación

La selección de estos servicios se justifica en la teoría sistémica, por cuanto estos tres servicios como una unidad, representan una unidad dinámica con presencia en los actuales modelos de bibliotecas, además en su integridad hacen posible el ciclo de transferencia de información.

Apoyados en la ciencia sistémica, es posible representar la funcionalidad de estos tres servicios como un sistema dinámico, visto la referencia digital como el canal de comunicación; la alfabetización como el mecanismo para capacitar al estudiante en la búsqueda de información, y finalmente los repositorios como el acceso al conocimiento.

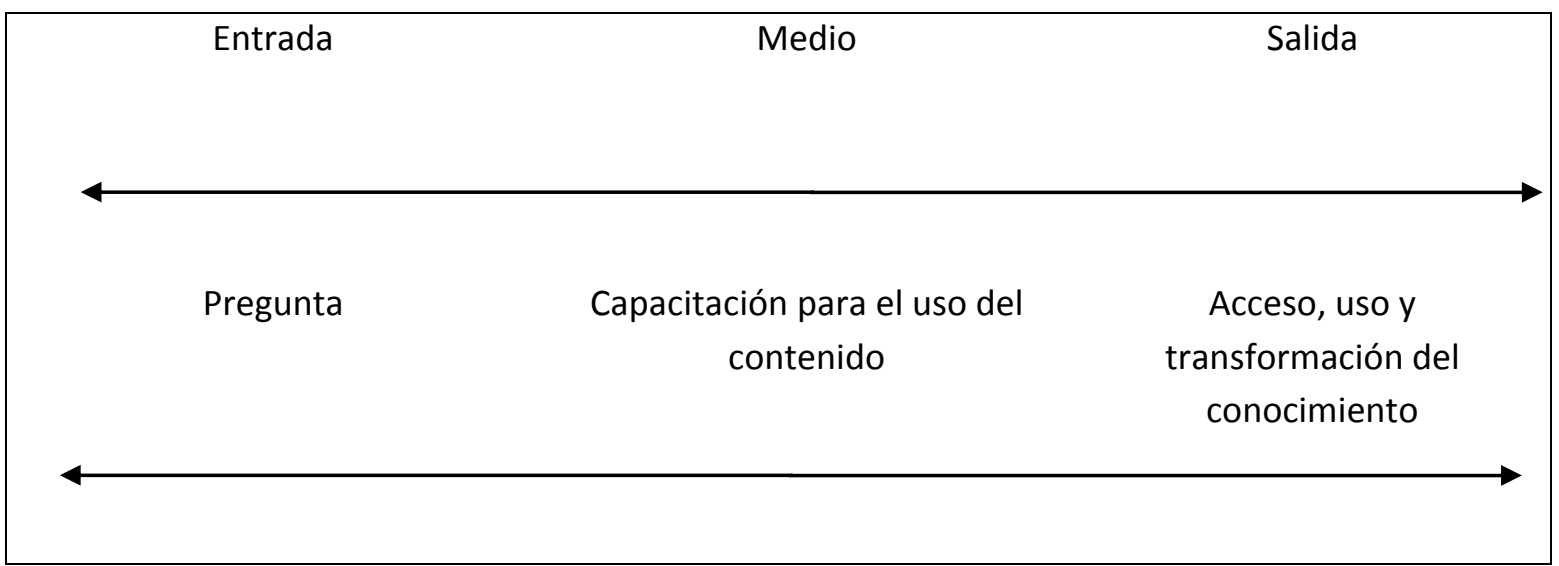

Figura 1.Sistema de transferencia de la información a partir de tres servicios básicos de la biblioteca. Fuente: Elaboración propia.

Vistos estos tres servicios como componentes de un sistema, es posible identificar el servicio de referencia digital como la entrada al sistema que permite al usuario aclarar dudas e identificar el rumbo de búsqueda. La alfabetización informacional se presenta como la oferta de cursos de formación de habilidades y destrezas (ALFIN) y medio para entender y aprender el uso de los recursos de información, y finalmente se incluyen los repositorios como el componente de la salida y retroalimentación del sistema, permitiendo el uso de la información y acceso al conocimiento, 
mediante el uso de la información el individuo modifica su estado de discernimiento y puede generar un nuevo aporte de conocimiento.

\subsubsection{Recopilación de información}

La recopilación de información se ha realizado a partir de diferentes criterios de selección y aplicando metodologías diversas, que se estimaron convenientes para la investigación y que son explicadas en los subapartados siguientes.

\subsubsection{Bibliografía}

Con el objetivo de orientar estratégicamente el proceso de búsqueda, identificación de la información necesaria para el desarrollo de la investigación y con miras a reducir al máximo las probabilidades de ruido o silencio, al momento de recuperar las fuentes, fueron definidos algunos criterios para delimitar el alcance de la literatura a utilizar en el estudio. Los criterios definidos para la revisión bibliográfica fueron:

1. Contenido: temas relacionados con modelos de bibliotecas modernas

2. Alcance idiomático: español, inglés, holandés

3. Alcance cronológico: Artículos 1990-2011 y para libros 1980 -2011

4. Alcance geográfico: Reino Unido de los Países Bajos, España y América Latina

5. Tipo de documentos: Fuentes primarias y secundarias

6. Formato: Analógico y digital

7 Accesibilidad: Fuentes disponibles en línea

El resultado final de la revisión bibliográfica se presenta como anexo, elaborada y ordenada alfabéticamente, según las norma ISO 690 12a ed. 1987. El primer listado incluye las referencias de los documentos utilizados y debidamente citados en el documento final de la investigación. El segundo listado incluye literatura complementaria

\subsubsection{Recopilación de la información}

El proceso de obtención de información necesaria demandó el uso adecuado de técnicas para su recopilación, tales como la investigación documental, la observación, entrevistas abiertas y cerradas (presenciales y virtuales), análisis sistémicos y comparativos y visitas institucionales para consulta a expertos.

Los diez parámetros indicados en el epígrafe 1.3.3 fueron la base para el diseño de una matriz general que fue utilizada como instrumento de referencia para la observación, descripción y evaluación de servicios ofrecidos por las bibliotecas universitarias. Esta matriz también fue utilizada como punto de partida para la elaboración de los cuestionarios utilizados en las entrevistas. Cabe destacar que no en todos los cuestionarios se incluyeron los diez parámetros. Las variantes entre los instrumentos fueron utilizados en dependencia de las características de cada servicio, la organización del contenido, y las facilidades de comunicación. 
La funcionalidad de los diferentes instrumentos se comprobó a través de una prueba hecha en la Universidad de Wageningen con un grupo de 5 estudiantes, 3 docentes y 2 funcionarios de la biblioteca. Los resultados obtenidos permitieron constatar la funcionalidad de los mismos y realizar algunos ajustes relacionados con la formulación de preguntas, como fue el caso de cerrar preguntas de opinión e incorporar un rango de satisfacción, a fin de poder tener respuestas más concretas.

Los problemas de distancia geográfica y de tiempo en el proceso de recopilación de información fueron resueltos, mediante el uso de diferentes medios de comunicación y visitas a algunas instituciones de los Países Bajos y España.

\subsubsection{Procesamiento de los datos}

El conjunto de información recopilada durante todo el trabajo de investigación, hizo posible generar un balance real e indispensable entre lo teórico y lo práctico para el logro de los objetivos y la comprobación de la hipótesis.

La información obtenida de la observación y de las pruebas hechas en los diferentes sitios web, fue procesada por institución a fin de elaborar la descripción y caracterización de cada biblioteca. Del mismo modo las respuestas de los cuestionarios y entrevistas se analizaron inicialmente por servicio. Posteriormente a fin de establecer relaciones comparativas entre las instituciones y sus servicios se utilizó la matriz estándar para el diagnóstico de fortalezas, debilidades, desafíos y oportunidades, conocido en España con el acrónimo DAFO, en América Latina como FODA y en inglés SWOT (Strengths, Weaknesses, Opportunities, and Threats). A lo largo de esta tesis se empleará comúnmente la terminología anglosajona para denominar este tipo de análisis.

Cabe destacar que para el manejo, organización de la información y la elaboración de tablas y gráficos de esta tesis, se utilizaron diferentes programas que ofrece el paquete Microsoft Office.

\subsection{Ejecución de los estudios de casos}

El punto de partida del trabajo de campo respondió a la filosofía de "aprender de las experiencias y buenas prácticas", es decir de la necesidad de valorar lo existente, por lo que ha sido intención de esta tesis reflejar lo mejor posible, los diferentes niveles de desarrollo en las iniciativas de servicios en línea, hecho por el cual, se ha prestado atención a las posibles limitaciones económicas y tecnológicas de los entornos. En este sentido, fue definido como universo de acción para el estudio la región de Europa y América Latina. En primer lugar por tratarse de dos regiones con diferencias económicas y culturales, y en segundo lugar por la facilidades existentes para acceder a la información por parte de la doctoranda.

En este contexto y en la búsqueda e identificación de bibliotecas viablemente accesibles a través de un sitio web en Internet y con alguna vinculación directa o indirecta con actividades E-learning, se constató la existencia de diversas e interesantes prácticas de servicios bibliotecarios prestados de forma telemática; no obstante, la selección de las instituciones analizadas en el presente estudio se justifica en el hecho que estas cumplían en totalidad los siguientes criterios importantes:

- Conexión y acceso libre al sitio web y sus partes

- Existencia de una clara oferta de servicio 
- Disponibilidad de acceso a los mismos

- Apertura para colaborar por parte de los encargados

- Acceso a información sin restricciones

- Posición geográfica de las instituciones (Europa y América Latina)

La aplicación de los criterios antes mencionados permitió reconocer algunas diferencias en los sitios web relacionadas con la conexión, navegación, oferta de recursos informativos en relación a los tres servicios de interés para esta tesis. De la revisión de diferentes sitios web de bibliotecas ubicadas en Europa y América Latina, se identificaron diferencias tanto en el tipo de infraestructura tecnológica, como en el uso y aplicación de recursos y programas informáticos que impactan considerablemente en la forma de ofertar, y prestar los servicios y que inciden en la calidad y rapidez de los mismos. Partiendo de estas diferencias identificadas fue posible caracterizar el grupo de bibliotecas visitadas en los siguientes tres grupos.

Grupo 1. Bibliotecas que están visibles en Internet a través de un sitio web. Ofrecen información descriptiva de la biblioteca y el servicio de acceso al catálogo propio de la institución y enlaces a sitios suscritos de publicaciones científicas. No ofrecen el servicio de referencia digital y cursos de formación de habilidades en línea. En ciertos casos algunos de estos están considerados como un proyecto futuro a corto plazo.

Grupo 2. Bibliotecas con rápida conexión, facilidades de navegación y acceso en todo sitio web de la institución y de la biblioteca. Ofrecen los servicios de referencia digital y acceso a catálogos. Disponen de una oferta de cursos de formación de habilidades como un servicio presencial que son ofrecidos a un determinado grupo como parte de un módulo o crédito académico. Actualmente a nivel institucional no tienen participación en los cursos de formación electrónica.

Grupo 3. Son instituciones académicas que se caracterizan por ser dinámicas, ofrecen una rápida conexión, navegación y acceso. En cada una de sus partes se observa la presencia de un enlace al sitio de la biblioteca. El sitio de la biblioteca ofrece información general y descriptiva tanto de la biblioteca como de sus servicios. Dispone de la oferta de los servicios de referencia digital, el acceso a repositorios y la oferta de cursos ALFIN y tutoriales. No fue posible acceder a los servicios de ALFIN debido a que se requiere contar con una clave.

Considerándose la anterior agrupación, se procedió a establecer contacto con los directores y jefes de las bibliotecas del grupo que disponían sitios con estructuras dinámicas de conexión, navegación y que además ofrecían los tres servicios de interés, a fin de conseguir el acceso temporal a estos servicios. Los resultados de repetidas solicitudes evidenciaron poca apertura o interés de ser evaluados, hecho que forzó limitar la muestra a seis instituciones ubicadas en los Países Bajos, España, Costa Rica y Chile que ofrecieron las facilidades para la realización del estudio.

Las instituciones involucradas en el estudio fueron:

\begin{tabular}{|l|l|}
\hline Universidad de Wageningen & Países Bajos \\
\hline Universidad Tecnológica de Delft & Países Bajos \\
\hline Universidad EARTH & Costa Rica \\
\hline Universidad Metropolitana de Ciencias de la Educación & Chile \\
\hline Universidad de Sevilla & España \\
\hline Universidad de Salamanca & España \\
\hline
\end{tabular}


Como se ha mencionado anteriormente, la selección de estas seis instituciones no corresponde a una muestra estadística o científicamente representativa. Su selección responde al hecho que las bibliotecas cumplen con los criterios definidos para la selección de la muestra y dada las características de los servicios, han permitido confirmar la viabilidad de implantar el modelo.

\subsection{Organización del contenido}

Los resultados finales de la investigación que seguidamente se presentan, se establecen en cinco partes, que en su totalidad se agrupan en nueve capítulos, más la correspondiente bibliografía y un apartado que incluye un conjunto de anexos.

En la primera parte de la presente tesis, se ofrece un capítulo introductorio de la misma exponiendo de forma detallada el proceso organizativo, metodológico y de culminación. La segunda parte corresponde al marco teórico de la investigación. Está compuesta de dos capítulos resultantes de la revisión de literatura sobre aspectos teóricos y conceptuales de los actuales modelos de bibliotecas y modelos de enseñanza E-learning. De forma global, este apartado ofrece la base teórica con una visión general e introductoria a las dos áreas analizadas en esta investigación: la biblioteca universitaria y la enseñanza E-learning.

La tercera parte contiene el capítulo cuatro que desarrolla los tres puntos de convergencia entre la Biblioteca y el E-learning, a partir de la que se posibilita el planteamiento de nuevas aplicaciones organizativas y tecnológicas entre ellos. Los ejes de acción que se identifican son: la comunicación, la orientación del estudiante y el acceso a la información y contenidos educativos. Asimismo, se identifican y propone para el desarrollo de ésta intersección los siguientes tres servicios ofrecidos por la biblioteca: a) el servicio de referencia, b) la alfabetización informacional (ALFIN) y c) el acceso a los repositorios de materiales para la educación.

Seguidamente en el apartado cuarto se presentan cuatros capítulos. El capítulo cinco en el que se exponen los estándares para la evaluación de servicios digitales tanto en el campo de las bibliotecas como en la educación electrónica. Partiendo de una revisión de literatura, se analizan e identifican los parámetros y criterios comunes. Posteriormente el capítulo seis se constituye de una propuesta para la evaluación de servicios en línea que incluye aspectos conceptuales y metodológicos necesarios para la ejecución del proceso de evaluación. Asimismo incluye un modelo de oferta de servicio de la biblioteca para E-learning. El modelo propuesto involucra tres tipos de servicios considerados básicos en procesos E-learning. Lo novedoso de la propuesta se centra en la organización y forma de prestación del servicio. Se trata de la unión de los tres servicios ofrecidos por la biblioteca en una sola oferta y operada desde una plataforma E-learning. El capítulo siete corresponde a todo el proceso de estudio de casos efectuado en seis bibliotecas universitarias ubicadas en Chile (1), Costa Rica (1), Países Bajos (2) y España (2). Esto fue realizado con el objetivo de evidenciar la factibilidad de la implementación del modelo. Posteriormente se analiza de forma integral las fortalezas, debilidades, oportunidades y amenazas (DAFO siglas reconocidas en español y en inglés SWOT) de cada biblioteca analizada.

La parte quinta corresponde a la última parte de la tesis. En ella se incluye el capítulo ocho que ofrece una guía para el diseño de prestación de servicios de información para E-learning, cuyo objetivo es actuar como instrumento de referencia de prácticas de servicios digitales. Seguidamente el capítulo nueve presenta las conclusiones y recomendaciones generales de todo el proceso de investigación. 
La tesis finaliza con el apartado de bibliografía citada y consultada, así como con un anexo en el que se reproducen los recursos metodológicos utilizados en la metodología de la elaboración y presentación de la presente tesis doctoral; concretamente, se exponen los formularios empleados para la toma de datos en las diferentes entrevistas realizadas con los gestores de información.

\subsection{Hipótesis}

Las tesis doctorales deben plantear hipótesis de partida, tanto para verificar metodologías como para ofrecer resultados objetivos. En el caso de esta investigación, se parte de una serie de hipótesis que fueron verificadas y que se definen en los párrafos siguientes, así como de otro conjunto de hipótesis mediante las que se quería demostrar la viabilidad del modelo presentado, que también se describen en este apartado.

\subsubsection{Hipótesis verificadas}

1. El desarrollo de esta tesis he permitido constatar la creciente incorporación de programas de formación académica semipresenciales y de E-learning en las universidades. Este hecho en combinación con la sobresaturación de información disponible en Internet, ha generado la necesidad de contar con servicios digitales que orientan la localización, uso y manejo de la información dentro de los diferentes cursos ofrecidos desde plataformas E-learning. Del mismo modo, el acelerado desarrollo y mejoramiento de las tecnologías exige en las estructuras educativas un nivel de flexibilidad y tolerancia a cambios, hecho que a la vez exige a los actuales modelos de bibliotecas ajustar sus servicios de acuerdo a las nuevas exigencias de los usuarios y miembros de las comunidades virtuales.

2. La revisión de las estructuras de los actuales modelos de biblioteca permitió identificar que el modelo predominante es la biblioteca híbrida. Estas integran diversos servicios digitales que debidamente organizados y orientados a contenidos concretos, pueden ser de gran valor en procesos de formación independientemente de la modalidad en que se presente la oferta.

3. Las experiencias de servicios en línea dirigidos a procesos de enseñanza E-learning están poco difundidas y sistematizadas, por lo que resulta necesario continuar realizando estudios que permitan la incorporación de las buenas prácticas, a fin de corregir, mejorar o facilitar el diseño de nuevos servicios de información.

4. La práctica actual demuestra que algunos servicios ofrecidos por la biblioteca vía Internet e Intranet desde plataformas E-learning sirven de apoyo a procesos de docencia. Las bibliotecas que participan en programas E-learning asumen la responsabilidad de la gerencia de los materiales de estudio y la responsabilidad de la alfabetización informacional. No obstante, estos servicios pueden ser orientados más allá de un apoyo a la docencia y actuar como un medio facilitador del ciclo de transferencia de conocimiento para todos los involucrados en el proceso de enseñanza de aprendizaje. Esta hipótesis se confirmó en la práctica observada y en el hecho que estos servicios se centran en tres puntos válidos tanto para el docente, investigador y el estudiante:

- Orientación hacia la localización de los recursos (servicio de referencia)

- La orientación sobre el uso de los recursos (formación de habilidades)

- El acceso a los contenidos (repositorios educativos) 


\subsubsection{Hipótesis de justificación del modelo}

5. La educación a distancia a través de recursos telemáticos, es el modelo de educación a distancia actualmente imperante. Muchas entidades universitarias tienen un componente Elearning dentro de su oferta educativa. Esto hecho les demanda contar con un modelo de biblioteca híbrido capaz de interactuar con el E-learning.

6. La biblioteca como facilitadora de recursos de información ya abastece de forma directa o complementaria de recursos de información en formatos electrónicos para el desarrollo de los contenidos para el desarrollo de los programas de estudios e investigación, sin embargo, los recursos no son actualmente aprovechables por el grupo de usuarios E-learning por las siguientes razones:

- Los estudiantes de E-learning se limitan a trabajar en la plataforma E-learning, motivo por el cual desconocen la existen de los recursos.

- No existe una oferta debidamente orientada ni específicamente estructurada a los contenidos de los cursos.

7. El modelo propuesto en esta tesis, representa ser una nueva oferta factible de integrar en la plataforma desde la cual E-learning ofrece servicios a sus estudiantes.

- Selectividad de contenido. Los contenidos ofrecidos en este servicio estarían obligatoriamente en correspondencia con la información necesaria para el desarrollo del proceso enseñanza aprendizaje. Es decir la oferta consiste en el acceso a los recursos electrónicos que existen dentro de la biblioteca, objetos de aprendizaje y recursos externos.

- La oferta como un trinomio. El modelo de servicio es pensado para cubrir tres necesidades básicas en el proceso de estudio o investigación.

a) la comunicación como un canal abierto entre el estudiante y la biblioteca a través de la referencia digital.

b) la necesidad de contar con capacidades y habilidades para el uso eficiente y ético de la información mediante la ejecución de acciones de alfabetización informacional.

c) el acceso a los contenidos a través de la consulta a los repositorios para la educación.

- Flexibilidad tecnológica. Todas las plataformas E-learning cumplen con el estándar para el intercambio de datos SCORM, hecho que admite instalar en la plataforma Elearning un enlace directo al servidor donde se encuentra el servicio ofrecido de la biblioteca.

- La implementación del modelo por parte de la biblioteca es factible. Los resultados de la revisión bibliográfica, el estudio de casos, las entrevistas realizadas y la bibliografía consultada demuestran la lógica modelo y la factibilidad como oferta atractiva para E-learning. 
8. El modelo se basa en tres servicios básicos ofrecidos por la biblioteca de forma telemática. Lo novedoso del servicio responde a la presentación de éste, como una oferta única, cuyo contenido se organiza en relación a los temas de los cursos y programas de estudios Elearning. 


\section{PARTE II \\ MARCO TEÓRICO}

La Parte II de esta tesis se ha organizado en dos capítulos que introducen los aspectos conceptuales de los modelos de biblioteca y de E-learning. El desarrollo de este apartado se ha considerado de esencial importancia, dada la necesidad de disponer de una base teórica para la investigación, partiendo de la identificación de las áreas de convergencia entre el E-learning y la biblioteca; así como la identificación de la factibilidad tecnológica para transferir información de un sistema de gesión de contenidos (CMS) a un sistema de gestión de contenidos para el aprendizaje, conocido como plataformas E-learning.

El Capítulo 2 se refiere específicamente al análisis de modelos de bibliotecas considerados relevantes para el entendimiento de la cambios ocurridos en los servicios. Para ello, se ofrecen descripciones y el estado de la cuestión de diferentes modelos de bibliotecas, partiendo de la biblioteca tradicional, pero detallando las características de las bibliotecas de colecciones electrónicas. Seguidamente el Capítulo 3 contiene un análisis conceptual sobre la enseñanza electrónica (E-learning). En este caso, además, se realiza una detallada enumeración de plataformas empleadas para la enseñanza telemática, como una base tecnológica que se ha considerado necesaria para la investigación.

En su conjunto ambos capítulos aportan el marco de referencia en la búsqueda de las áreas de convergencias entre ellos, que posteriormente se aborda con detenimiento en la Parte III. 


\section{PARTE II. MARCO TEÓRICO}

Capítulo 2. Análisis conceptual de los actuales modelos de bibliotecas

2.1 Introducción

2.2 Evolución de la biblioteca tradicional

2.2.1 Actuales modelos de biblioteca

2.2.2 Biblioteca electrónica versus recurso electrónico

2.2.3 Biblioteca híbrida

2.2.3.1 Dimensiones de la biblioteca híbrida

2.2.3.2 Descripción de la biblioteca híbrida

2.2.4 Biblioteca digital

2.2.4.1 Descripción de la biblioteca digital

2.2.5 Biblioteca virtual

2.2.6 Centro de conocimientos

2.2.6.1 Antecedentes del modelo

2.2.6.2 Desarrollo del modelo

2.2.7 Centros de Recursos para el Aprendizaje y la Investigación (CRAI)

2.2.7.1 Descripción del CRAI

2.2.8 Centros Virtuales de Información y Conocimiento (VKC)

2.2.8.1 Descripción del VKC

2.3. Relación CRAI y VKC

\section{Capítulo 3. Análisis conceptual de la enseñanza electrónica (E-learning)}

3.1 Introducción

3.2 Definición de enseñanza electrónica (E-learning)

3.2.1 E-learning

3.2.2 Componentes E-learning

3.3 Aspectos pedagógicos y didácticos importantes

3.3.1. Modelos pedagógicos

3.3.2 Formas o modalidades E-learning

3.4 Estructura organizativa de E-learning

3.5 Estándares E-learning

3.5.1 Definición de estándares

3.5.2 Tipos de estándares E-learning

3.5.3 Iniciativas de estándares E-learning

3.6 Sistemas E-learning

3.6.1 Clasificación de las plataformas E-learning

3.6.2 Evolución de las plataformas E-learning

3.7 Inventario de plataformas E-learning LMS y CMS

3.8 Clasificación de servicios E-learning 


\section{Capítulo 2. Análisis conceptual de los actuales modelos de bibliotecas}

\subsection{Introducción}

El proceso de transferencia de conocimiento está ligado a formas de comunicación, recursos de información y profesionales capaces de guiar, orientar y dar seguimiento al proceso de aprendizaje. La biblioteca académica históricamente ha sido encargada de resguardar los soportes de información y responsable de velar por la organización, sistematización y generación de servicios que garanticen la localización y uso de la información contenida en ellos. Si se hace un repaso en la historia de la biblioteca, el fundamento de esta misión no ha tenido variación. Desde la Antigüedad y en la presente época contemporánea la biblioteca ejerce el mismo rol de intermediación entre la información y los usuarios.

En la actualidad las transformaciones en los sistemas de educación apuntan cada vez más al uso de recursos y medios digitales para el desarrollo de ofertas educativas en línea, denominadas enseñanza electrónica (E-learning). Este hecho ha permitido generar a las universidades un nuevo mercado innovador cada vez más creciente y capaz de resolver los problemas de distancia, tiempo, altos costos y dar atención a clientela diversa. La gestión y uso de estos recursos de información electrónica dentro de las bibliotecas ha generado cambios en la organización y funcionamiento de la biblioteca misma y por consiguiente la transformación del modelo de biblioteca.

Con el objetivo de destacar los cambios tecnológicos para la gestión de información electrónica, en las siguientes páginas se presenta una descripción de los modelos de biblioteca tradicional, biblioteca electrónica, biblioteca híbrida, biblioteca digital, biblioteca virtual y los centros de información y conocimiento. Cabe destacar que gracias al análisis conceptual de la biblioteca, fue posible identificar cual es el modelo de biblioteca que cumple con las condiciones y requerimientos básicos para interactuar con el E-learning.

\subsection{Evolución de la biblioteca tradicional}

La sociedad del conocimiento como todo sistema experimenta constantes transformaciones sujetas a los entornos económicos, socioculturales, tecnológicos, y las nuevas necesidades y demandas sociales. La biblioteca como entidad responsable de organizar, resguardar y facilitar los soportes en que se registra el conocimiento, también ha tenido que cambiar la forma de gestión de estos.

Haciendo una revisión de la evolución de la biblioteca tradicional hacia los actuales modelos de bibliotecas, es posible constatar que el punto de partida fue la automatización de los catálogos y posteriormente la digitalización de su información y su resguardo en mecanismos electrónicos para su consulta.

De hecho la incorporación de ordenadores en las bibliotecas marca los cambios acontecidos en las formas de acceso a los contenidos y ha motivado las transformaciones en las estructuras organizativas de las bibliotecas hacia modelos más dinámicos y de rápido acceso. En la actualidad, la biblioteca tradicional se ha convertido en un modelo híbrido que aún experimenta cambios, hecho que genera confusiones conceptuales entre los diferentes prototipos de bibliotecas emergentes. 
El resultado de la revisión de diferentes libros y artículos sobre la evaluación ${ }^{3}$ de los cambios ocurridos en las bibliotecas, hicieron posible identificar que el éxito en la acogida de los actuales modelos de bibliotecas corresponde básicamente a los siguientes aspectos:

a. Satisfacciones de necesidades de información y comunicación. Los nuevos prototipos de bibliotecas ofrecen a los usuarios nuevas y variadas posibilidades para acceder a las fuentes de información. Asimismo, ofrecen nuevas alternativas de comunicación para interactuar con los autores de la misma.

b. Desarrollo de las colecciones. Para los bibliotecarios estos nuevos modelos de bibliotecas han representado la alternativa para la solución de los problemas de espacio físico; la posibilidad de mantener la actualización de la colección, ampliar su cobertura temática y una oportuna coyuntura para la generación de nuevos servicios.

c. Producción y distribución de información. El aumento en el uso del formato digital para la edición y publicación de revistas electrónicas ha permitido agilizar el proceso de distribución y la reducción de costos de las mismas. De igual manera, las agencias comerciales han logrado abrir un nuevo espacio de mercado, que va desde la comercialización del derecho de acceso a las fuentes de información como a productos no informativos. Ejemplos de estos son las formas de consultorías para el desarrollo de programas de gestión de contenidos etc.

\subsubsection{Actuales modelos de biblioteca}

Existen muchos documentos académicos que analiza y debaten los conceptos utilizados para referirse a un modelo ideal de biblioteca. En la bibliografía anexa a esta tesis, se citan algunos autores concretos, que concluyen que, la incorporación de información electrónica ha sido la premisa en el cambio surgido en la gestión de la información y el uso de formatos digitales. Caracterizan además, el surgimiento de modelos de bibliotecas por el nivel de desarrollo de aplicaciones tecnológicas de cada uno de ellos.

En la práctica, el uso de las distintas terminologías para determinar los cambios ocurridos en las bibliotecas, no suponen en la actualidad un problema conceptual, no obstante, durante los años de penetración de los recursos electrónicos en las bibliotecas, se emplearon de forma indiferente las denominaciones, hoy en desuso. En el contexto de esta investigación es importante hacer una revisión conceptual, a fin de identificar el modelo factible para la implementación del modelo de servicio telemático para E-learning.

Partiendo del análisis teórico realizado, se prestó atención a aquellos conceptos que repetidamente fueron expuestos para referirse a las bibliotecas que emplean recursos electrónicos para la transferencia de información y prestación de servicios. Estos conceptos fueron:

- Biblioteca electrónica

- Biblioteca híbrida

\footnotetext{
${ }^{3}$ Umberto Eco. 1999; Clara López Guzmán 2000; Marlery Sánchez Díaz; Juan Carlos Vega Valdés 2002; Julio Alonso Arévalo, 2006; José Antonio Cordón García; Raquel Gómez Díaz; Julio Alonso Arévalo. 2011.
} 
- Biblioteca digital

- Biblioteca virtual

- Centro de Información y Conocimientos ${ }^{4}$ (CRAI y VKC)

El análisis de cada uno de los conceptos antes listados implicó la revisión de las características de organización, contenido, servicios de usuarios y nivel de aplicación de las tecnologías de cada uno de ellos y que seguidamente se desarrollan.

\subsubsection{Biblioteca electrónica versus recurso electrónico}

El concepto de biblioteca electrónica surge entre los años 70 y 80 con la llegada de discos flexibles y los discos compactos (CD-ROM), que fueron utilizados fundamentalmente para ofrecer bases de datos con referencias bibliográficas. Diferentes y repetidas citaciones de autores referentes al concepto de biblioteca electrónica han permitido identificar que el término de biblioteca electrónica es utilizado para referirse a información secundaria disponible en formato papel y no a un modelo de biblioteca propiamente dicha.

Su definición se aplica al uso de un determinado conjunto de recursos o soportes electrónicos y periféricos (discos compactos, memorias portátiles, etc.) que almacenan un acervo de referencias bibliográficas y en algunos casos de contenidos que se encuentran disponibles físicamente en la colección de alguna biblioteca y que pueden ser digitalizadas en dependencia de la demanda.

En esta perspectiva, Clara López Guzmán (2000, p.12) fundamenta lo antes señalado al definir la biblioteca electrónica como "aquella que se vale de sistemas automatizados y de telecomunicaciones para una eficiente y eficaz gestión de materiales, principalmente disponible en papel". La autora además señala que "el uso de sistemas de telecomunicaciones hace posible que los usuarios puedan acceder a los recursos de información de manera remota o local. El principal producto final de este tipo de biblioteca es el catálogo y listas de las colecciones que se encuentran físicamente dentro de un edificio".

En esta misma línea, Ontalba y Ruipérez (2002, p.2) considera que "la biblioteca electrónica es la primera fase en la aplicación de las nuevas tecnologías en procesos documentales (automatización), permitiendo el acceso local a información en formato electrónico, aunque no implica el uso de telecomunicaciones ni de elementos digitales".

Las anteriores referencias, consideradas como ejemplo de muchas similares, demuestran que es difícil considerar el término de biblioteca electrónica como un modelo de biblioteca, pero si como un medio de acceso a fuentes de información primaria disponible en papel, pero no necesariamente en formato digital, a través de la consulta de dispositivos electrónicos. Cabe destacar que el uso de estos recursos electrónicos no está condicionado o exige la presencia de avanzadas tecnologías de comunicación (intranet o Internet).

En referencia a lo anterior y en correspondencia con los fines de esta investigación, el concepto de biblioteca electrónica no se considera relevante y aplicable para este estudio, sin embargo se

\footnotetext{
${ }^{4}$ Centro de Recursos para el Aprendizaje y la Investigación (CRAI) y Centros Virtuales de Información y Conocimiento (Virtuele Kennis Centra =VKC).
} 
considera importante destacar su importancia histórica, al representar éste el primer cambio significativo en las capacidades tecnológicas para el manejo de recursos electrónicos y el punto de partida hacia el modelo de biblioteca híbrida.

\subsubsection{Biblioteca híbrida}

Durante las lecturas se constató la existencia de diversas aplicaciones del concepto de biblioteca híbrida para referirse a un nuevo modelo de biblioteca con características diferentes, pero todas ellas con un componente tecnológico para la transferencia de información. Sin embargo, luego de examinar diversas aportaciones fue posible concluir lo siguiente:

- El modelo de biblioteca híbrida surge del cambio ocurrido en el modelo de biblioteca tradicional y se reconoce como el actual modelo de biblioteca imperante.

- La variante principal entre el modelo tradicional y el modelo híbrido surge a partir del uso y aplicaciones tecnológicas y de redes de telecomunicación que facilitan la generación de nuevas formas de organización y gestión de la información.

- El componente tecnológico es el medio que el modelo utiliza para permitir el acceso a los recursos de información disponible en formato digital, analógico y multimedia interno y externo a la biblioteca hibrida.

- Los recursos de información de la biblioteca híbrida están disponible en un sistema que puede ser accedido desde la red interna de la institución (Intranet) o a través de sitio web en Internet a través una conexión en Internet y acceder mediante enlaces a las ofertas de servicios de información presenciales y/o telemáticos.

- El modelo híbrido trasciende los límites físicos e incorpora nuevos espacios virtuales y nuevos puntos de acceso al conocimiento y la cultura con lo que el modelo logra ampliar la capacidad de oferta competitiva en relación al modelo tradicional.

Con el fin de fundamentar lo antes referido, en las siguientes páginas se presenta algunas citaciones y aportes conceptuales de algunos estudios del tema. Tatiana V. Resoba y Yuri E. Hohlov (2000) en su documento elaborado para el 66으 congreso de la IFLA, afirman que "el origen del modelo de biblioteca híbrida responde a la necesidad de convivir con la diversidad de información y de puntos de acceso al conocimiento y la cultura".

Sobre esta misma línea, Jesús Tramullas (2004, p. 5) sosteniente que "el concepto de biblioteca híbrida nace y evoluciona en Europa como respuesta a la necesidad de integrar las colecciones de información electrónicas de origen externo y las propias de la institución digitalizadas". El autor también señala la aplicación de las nuevas tecnologías que modifican su capacidad de oferta, haciendo el modelo más atractivo.

Bart van der Meij y Kees Westerkamp (2007), en concordancia con el señalamiento de Tramullas, afirman que la biblioteca híbrida es la transformación de la biblioteca tradicional especializada en una biblioteca que utiliza los espacios físicos y virtuales para ofrecer servicios de información tanto digital como analógica. 


\subsubsection{Dimensiones de la biblioteca híbrida}

La biblioteca híbrida depende de las aplicaciones en las redes telemáticas de comunicación para su interacción en dos ámbitos, en los que establece una combinación de procesos (físicos) y servicios (virtuales), mediante dinámicos procesos de comunicación, donde la web es el mediador entre lo digital y lo físico.

Jesús González Lorca y José Vicente Rodríguez Muñoz (2002 p.161) concuerdan con Tomas Saorín Pérez $\left(2002^{5}\right)$ sobre las dos siguientes dimensiones de la biblioteca híbrida:

- Dimensión real: Se refiere a la biblioteca como sistema físico. Todos los componentes internos son importantes para su funcionamiento, pero es el personal de la biblioteca quién garantiza y hace posible responder a las demandas de los usuarios en la dimensión virtual.

- Dimensión virtual: Se accede mediante la utilización de redes de comunicación (Intranet e Internet). La biblioteca es tratada desde el exterior como una fuente para satisfacer necesidades de información. En esta óptica el protagonista deja de ser el bibliotecario y el elemento principal es el usuario, ya que es el demandante.

En la siguiente figura se observa que el punto de convergencia en estas dos realidades es posible a través de procesos dinámicos de comunicación entre el bibliotecario de la biblioteca hibrida, quién gestiona los recursos analógicos y electrónicos y el demandante de esta. En lla siguiente figura se observa la convivencia de ambos modelos en entornos híbridos.

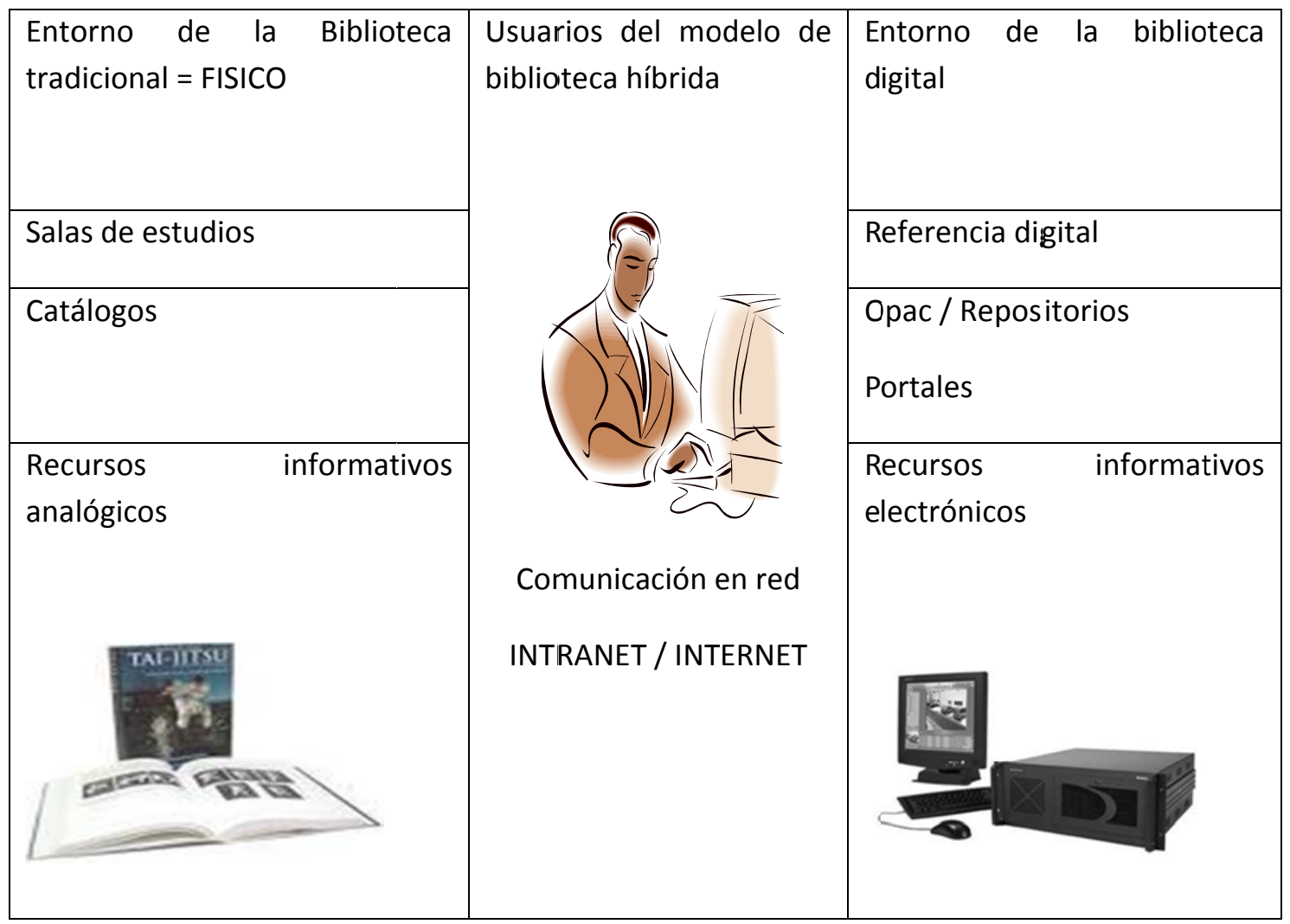

Figura 2. Entornos de la biblioteca híbrida. Fuente: Elaboración propia.

\footnotetext{
${ }^{5}$ Tómas Saorín Pérez presentó en el año 2002 en la Universidad de Murcia su tesis doctoral sobre Modelo conceptual para la automatización de bibliotecas en el contexto digital.
} 


\subsubsection{Descripción de la biblioteca híbrida}

\section{Recursos informativos}

El caudal informativo de la biblioteca híbrida corresponde a los recursos de información en formato analógico y digital. En la siguiente tabla se evidencia que la sumatoria de los recursos informativos del modelo de biblioteca tradicional y la integración de recursos electrónicos son en definitiva la oferta del modelo de biblioteca híbrida. En la tabla que a continuación se presenta se estable la diferencia entre la disponibilidad de los recursos informativos en los modelos de bibliotecas tradicional y el modelo híbrido.

\begin{tabular}{|l|l|l|}
\hline Disponibilidad de recursos informativos & Biblioteca tradicional & Biblioteca híbrida \\
\hline Colección en papel & SI disponen & SI disponen \\
\hline Información secundaria & SI disponen & SI disponen \\
\hline Material de referencia & SI disponen & SI disponen \\
\hline Colecciones especiales analógicas & SI disponen & SI disponen \\
\hline $\begin{array}{l}\text { Colecciones especiales texto completo en } \\
\text { formato digital }\end{array}$ & NO disponen & SI disponen \\
\hline $\begin{array}{l}\text { Colecciones de recursos de información } \\
\text { electrónico en formato electrónico } \\
\text { (publicaciones seriadas, periódicas, etc.) }\end{array}$ & SI disponen & SI disponen \\
\hline Bases de datos internas de referencia & SI disponen & SI disponen \\
\hline $\begin{array}{l}\text { Bases de datos internas de documentos } \\
\text { digitalizados }\end{array}$ & NO disponen & SI disponen \\
\hline Bases de datos externas de referencia & SI disponen & SI disponen \\
\hline
\end{tabular}

Tabla 1. Recursos informativos.

Fuente: Elaboración propia.

\section{Estructura física}

Hablar de la estructura física de la biblioteca híbrida, es referirse al típico edificio de la biblioteca tradicional, constituido por un vestíbulo o entrada principal (punto central de acceso = recepción); asimismo, es referirnos a salas de estudios con adecuado mobiliario, ordenadores, equipos para impresión, estantes y colecciones de recursos informativos en formato analógico y colecciones accesibles a través de soportes electrónicos.

\section{Infraestructura tecnológica}

El equipamiento tecnológico de la biblioteca híbrida, está principalmente sujeto a los recursos económicos institucionales y sobre todo, al proyecto de modernización institucional donde se encuentra la biblioteca inmersa, debido a que el cambio o transición en las tecnologías puede implicar cambios radicales de los equipos o bien la adaptación de las condiciones existentes.

Los recursos tecnológicos de la biblioteca híbrida se constituyen en medios tradicionales (teléfono, fax y correo postal) y recursos periféricos necesarios para hacer operar las redes de comunicación a lo interno y externo de la institución como son las redes locales (Intranet) y la Internet necesarias para los procesos de comunicación y acceso a la información, servicios internos y externos de la institución. 
Cabe destacar que la aplicación tecnológica dentro del modelo de biblioteca híbrida se observa en dos planos. La parte tangible (ordenadores y equipos periféricos de impresión, reproducción y comunicación) se visualiza físicamente en los equipos y aparatos electrónicos que hacen posible la manipulación de la información.

La parte intangible que corresponde a las aplicaciones y conjunto de indicaciones que el hombre define a través de lenguajes informáticos (paquetes de programas estándares) y que hacen posible el uso del funcionamiento de los sistemas de la infraestructura tecnológica.

La incorporación de nuevos elementos tecnológicos en el modelo de biblioteca tradicional, lo convierte en un modelo híbrido dinámico, con cobertura y oferta para la prestación de servicios. En la siguiente tabla se listan y comparan los componentes tecnológicos que disponen la biblioteca tradicional y el actual modelo híbrido.

\begin{tabular}{|l|l|l|}
\hline Componentes tecnológicos & Biblioteca tradicional & Biblioteca híbrida \\
\hline Ordenadores & SI dispone & SI dispone \\
\hline Servidor & NO dispone & SI dispone \\
\hline Lectores CD & NO dispone & SI dispone \\
\hline Escáner & SI dispone & SI dispone \\
\hline IP & NO dispone & SI dispone \\
\hline Buscadores & NO dispone & SI dispone \\
\hline Interfaces web / Opac & NO dispone & SI dispone \\
\hline Plataforma E-learning & NO dispone & NO dispone \\
\hline Intranet & NO dispone & SI dispone \\
\hline Internet & NO dispone & SI dispone \\
\hline Portales & NO dispone & NO dispone \\
\hline Accesibilidad multilingüe & NO dispone & SI dispone \\
\hline $\begin{array}{l}\text { Centro de edición de publicaciones } \\
\text { electrónicas }\end{array}$ & NO dispone & NO dispone \\
\hline $\begin{array}{l}\text { Normas ISO (estándares para el } \\
\text { procesamiento de información) }\end{array}$ & SI dispone & \\
\hline
\end{tabular}

Tabla 2. Nuevos elementos tecnológicos en el modelo de biblioteca tradicional.

Fuente: Elaboración propia.

\section{Personal}

Partiendo de la revisión de literatura efectuada, es posible señalar que el modelo de biblioteca híbrida demanda básicamente cuatro tipos de perfiles profesionales para la gestión del modelo:

- Bibliotecarios. Con una formación general que le permita liderar y direccionar la gestión del modelo de forma sistémica en conjunto con otros especialistas.

- Especialista en información. Corresponde al grupo de profesionales especializados en temas específicos de la colección, que velan por la calidad y veracidad de la misma. 
- Informáticos. Especialistas en informática que puedan ser capaces de trabajar en coordinación con los bibliotecólogos y especialistas en información a fin de edificar, actualizar y dar mantenimiento a la estructura tecnológica del modelo de biblioteca híbrida.

- Técnicos en procesamiento de información. Especialistas en la aplicación de estándares para la descripción, sistematización y organización de los recursos informativos que hacen posible el proceso de transferencia de la información y los documentos.

\section{Usuarios}

Los usuarios del modelo de la biblioteca híbrida se pueden reconocer en dos grandes categorías: los usuarios internos y externos a ella, que a su vez se agrupan de acuerdo al tipo de formato de información en las siguientes categorías:

a) Usuarios de entornos virtuales, que incluye a los usuarios que demandan información en formato digital legible y que acceden a los servicios a través de aparatos electrónicos y/o en línea.

b) Usuarios presenciales que se mantienen asiduos al local y colecciones físicas de la biblioteca híbrida y que establecen un balance entre la consulta física y la virtual.

\section{Servicios}

Los servicios que ofrece la biblioteca híbrida son la sumatoria de los servicios ofrecidos tradicionalmente por biblioteca tradicional y los nuevos servicios telemáticos de acceso a los recursos de información impresos, digitales y multimedia disponibles de modo interno y externo. Algunos servicios destacables son:

- Oferta de acceso a la información digital contenida o referida en soportes electrónicos.

- Disponibilidad en línea de documentos textos completos (escaneados a solicitud previa).

- Acceso a diferentes servicios administrativos a través de intranet.

- Acceso a los archivos personales de registros.

- Facilidad de comunicarse e interactuar vía email o chat.

\subsubsection{Biblioteca digital}

La biblioteca digital ha sido implementada con el objetivo de dinamizar el proceso de transferencia de la producción de información científica en formato digital, a fin de hacerla disponible a través de un sitio Web. El surgimiento de este modelo digital se presenta generalmente dentro de la biblioteca híbrida. Desde tiempo atrás, el concepto de biblioteca híbrida es utilizado como sinónimo de biblioteca digital. Si bien es cierto que entre ellos existen similitudes, son dos modelos. La diferencia radica en que el objetivo de la biblioteca digital es el desarrollo y gestión de colecciones digitales, en cambio la biblioteca híbrida gestiona todo tipo de recursos de información. Asimismo la información digital se realiza en la biblioteca híbrida con la digitalización de materiales como una medida de resguardo y solución a los problemas de espacio físico y/o almacenamiento. 
La biblioteca híbrida gestiona solicitudes concretas de artículos disponibles en papel para su escaneo y posteriormente su transferencia como un archivo en formato digital vía correo electrónico o bien mediante un dispositivo electrónico (por ejemplo CD-ROM) que pueden ser remitidos por correo postal. Es decir, las diferencias principales entre ambos modelos radican principalmente en los objetivos y fines para los cuales han sido creadas. Lo referido se fundamenta a continuación con las citaciones de algunos aportes a la definición del concepto de biblioteca digital.

Ángela María Arango, (2000, p.1) nos remite al documento publicado en la web del Digital Library Project, en que afirma que "el concepto de biblioteca digital no es únicamente el equivalente de repertorios digitalizados con métodos de gestión de la información"..."la biblioteca digital es un entorno donde se reúnen colecciones, servicios y personal que favorecen el ciclo completo de creación, difusión, uso y preservación de los datos para la información y el conocimiento".

Marlery Sánchez Díaz y Juan Carlos Vega Valdéz, $(2002$, p. 5) utilizan el término de biblioteca digital para referirse a un "conjunto de recursos de información en formato digital, que insertos en una estructura, son organizados para hacerlos disponibles a través del acceso electrónico local o a distancia por parte de una comunidad de usuarios". Antonia Ferrer Sapena y Fernanda Peset Mancebo $(2005$, p.17) complementan el anterior concepto y caracterizan "la biblioteca digital como un punto de interacción en que colecciones, servicios y usuarios participan en la creación, diseminación, uso y preservación de los datos e información misma".

En esta misma línea Donald J. Waters, (1998, p.2) define la biblioteca digital como "una organización que, provista de recursos tecnológicos y personal especializado, es capaz de seleccionar y dar estructura lógica a los conocimientos (información), preservarlos y hacerlos disponibles a los usuarios de una comunidad o grupos de comunidades virtuales".

Considerando las anteriores citaciones como marco de referencia, la definición de biblioteca digital que se aporta en esta tesis, es de un concepto concreto que se materializa como una entidad con estructura dinámica conformada por colecciones de documentos electrónicos y/o digitalizados debidamente organizados y de servicios ofrecidos desde conexiones remotas a través de intranet e Internet.

\subsubsection{Descripción de la biblioteca digital}

Como se ha indicado anteriormente, la biblioteca digital es un modelo que se desarrolla principalmente dentro de las bibliotecas especializadas y las bibliotecas académicas, por cuanto responde a objetivos concretos, funciones específicas y usuarios con vínculos o intereses temáticos. La biblioteca digital requiere contar con una estructura básica para la organización y gestión del contenido. Los tres elementos básicos requeridos para la implementación y gestión del modelo son los mismos de la biblioteca híbrida y que se ilustran en la figura 3.

\section{Recursos informativos}

La biblioteca digital dispone de un caudal de información en formato electrónico accesible a través de redes de comunicación, por lo que el proceso de transferencia de información puede ser interpretado como un acercamiento a la democratización de la información y conocimiento. 
Los recursos electrónicos de la biblioteca digital también pueden encontrarse en la biblioteca híbrida en formato analógico; debido a que las empresas editoriales proveedoras de suscripciones en paquetes combinados, brindan acceso al repositorio donde se encuentra el enlace a las publicaciones electrónicas y además ofrecen una versión de las mismas en formato impreso. Sin embargo, las bibliotecas prefieren recibir solo el formato electrónico y liberar los espacios físicos de almacenamiento de los materiales, para crear espacios de estudios para los usuarios.

Las tendencias de crecimiento de los recursos o colecciones digitales según señala Jesús Tramullas (2003) corresponden a la creciente oferta de suscripciones de proveedores, la producción institucional, la digitalización de documentos existentes en la biblioteca o institución y las nacientes bases de datos con interfaces web disponibles en Internet.

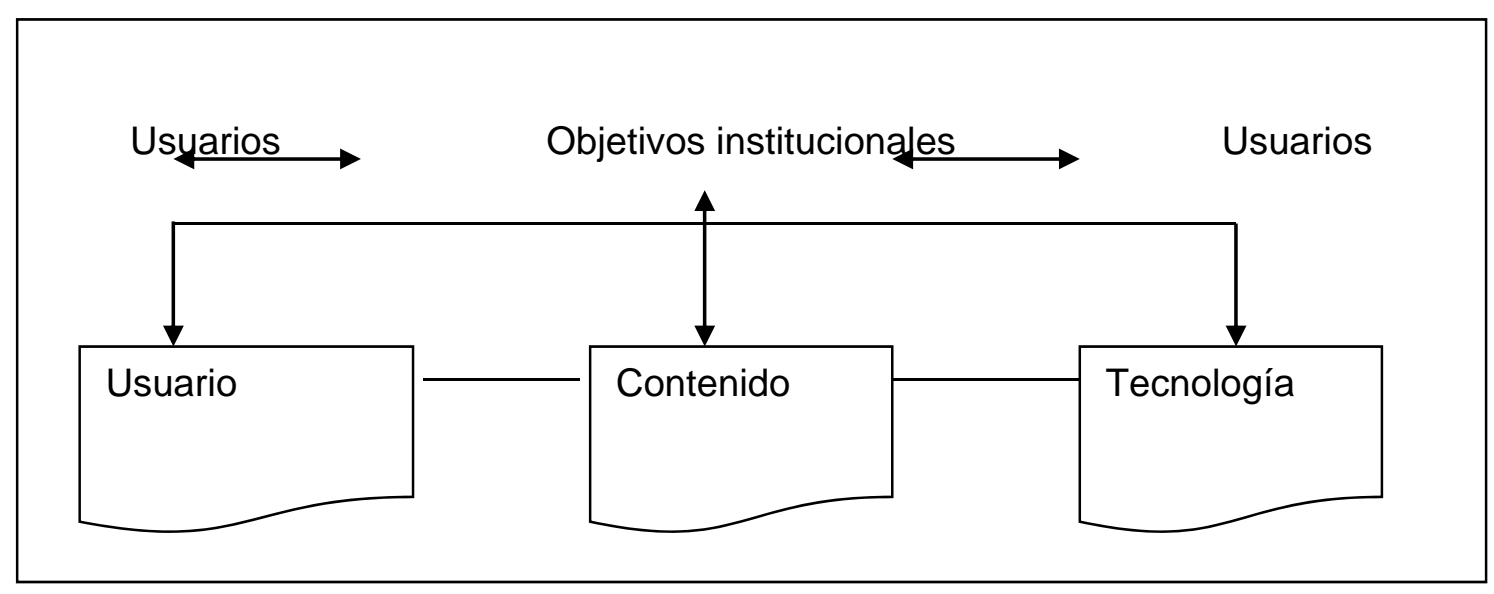

Figura 3. Componentes básicos del modelo biblioteca digital. Fuente: Elaboración propia.

\section{Estructura física}

La biblioteca digital como su nombre lo indica no cuenta con una estructura física como sucede con la biblioteca híbrida, por lo tanto no es posible referirnos a un edificio propiamente dicho con salas especiales de estudio. Esta biblioteca existe en espacios no tangibles y es accesible a modo de enlace que permite a los usuarios "estar consciente de su existencia" y utilizar los recursos de información. Cabe destacar que la intersección de estos dos modelos de bibliotecas representa ser la respuesta a la imponente demanda de los usuarios de contar con el acceso y uso de todos los posibles soportes de información. Los ejemplos más próximos de modelos de bibliotecas híbridas y bibliotecas digitales se encuentran en bibliotecas universitarias que ofrecen las facilidades a la comunidad de interactuar en un mundo físico y otro virtual, a través de servicios que permiten acceder a los recursos de información existente a nivel interno y externo a la biblioteca.

\section{Infraestructura tecnológica}

La infraestructura tecnológica de la biblioteca digital se caracteriza por su moderna capacidad de almacenamiento, organización, acceso a la información electrónica, el uso de programas informáticos y de aplicaciones a portales web desarrollados a partir de estándares para la gestión de contenidos; sin embargo las características tecnológicas pueden variar de acuerdo a la disponibilidad de recursos 
tecnológicos, económicos y de los constantes cambios del entorno en que se encuentran inmersas. Otro aspecto que influye en el diseño y característica del modelo corresponde a las nuevas necesidades de los usuarios, quienes demandan cada vez más facilidades para la producción normalizada de publicaciones digitales, incorporación de materiales de aprendizaje y mejoras significativas en los procesos de comunicación.

Las variantes que puedan existir entre dos o más modelos de biblioteca digitales no supone una limitante para que este pueda cumplir sus objetivos debido a que todos ellos disponen de una estructura básica, sin embargo cuanto más sea el uso de aplicaciones y recursos tecnológicos, mayores pueden ser las capacidades del sistema para ofrecer puntos de acceso a la información y de agilizar los procesos de respuesta a la demanda.

Aportes de estudios del tema han enumerado repetidamente algunos requerimientos básicos que debe cumplir la biblioteca digital para que pueda cumplir con la función que le compete. Algunos factores determinantes son la flexibilidad para ser compatible a otros sistemas, arquitectura distribuida en forma modular y facilidades multifacéticas que faciliten desarrollar diferentes niveles de personalización. El resultado de la revisión de literatura, permitió identificar los siguientes componentes como tecnologías habituales en el diseño del modelo de biblioteca digital.

Componentes tecnológicos:

- Programas de gestión de contenidos

- Ordenadores

- Servidor

- Lectores CD

- Escáner

- Protocolo de comunicación para Internet

- Sistemas de búsquedas (buscadores)

- Sitio Web

- Interfaces Web/Opac

- Opac (diseño y contenido debidamente configurado)

- Redes de comunicación

- Intranet e Internet

- Portales

- Accesibilidad multilingüe

- Normas ISO. (Estándares para el procesamiento de información)

\section{Personal}

Las aplicaciones tecnológicas impactan significativamente en la sociedad al punto que se han acortado las barreras o límites para interrelacionarse, transformando así, los patrones de comunicación, las relaciones sociales y la formación de profesionales, hecho que confronta al bibliotecario ante el reto de asumir diferentes roles. Igualmente debe ser capaz de ser gestor y usuario de las tecnologías de la información y comunicación, de funcionar como intermediario y facilitador de información para lo cual es necesario ser creativo y poseer altas capacidades de comunicación, ser formador y entrenador. 
En esta línea García-Reyes (2002 p. 43) en su documento "La biblioteca digital: impacto y transformaciones en los servicios bibliotecarios", destaca que el personal de la biblioteca digital debe poseer conocimientos y experiencia en el desarrollo, gestión de proyectos innovadores de bases de datos y de servicios de información. Esta afirmación pone en evidencia la necesidad urgente de promover un cambio dinámico en la gerencia o administración de información hacia entornos híbridos, donde los usuarios reciban las facilidades para la transformación o creación de conocimientos.

\section{Usuarios}

Los usuarios que se identifican en el modelo de biblioteca digital corresponden al mismo grupo de usuarios de entornos virtuales, que se encuentran generalmente (no obligatoriamente) inmersos en el modelo híbrido. En la actualidad se reconocen dos grupos de usuarios.

- Los usuarios de las bibliotecas digitales de acceso gratuito. Este grupo se caracteriza por utilizar frecuentemente los recursos de información científicos disponibles de forma gratuita a través del proyecto de acceso abierto, conocido en inglés como open Access.

- Los usuarios de las bibliotecas digitales académicas de acceso restringido.

Este grupo de usuarios virtuales se encuentran registrados en el sistema y acceden a los servicios y recursos a través de una clave de acceso. Las características y clasificación corresponden a la biblioteca híbrida.

\section{Servicios}

Los servicios de la biblioteca digital se caracterizan principalmente por el acceso a la información en formato digital. Ejemplos de algunos de éstos se listan a continuación:

- Acceso a los recursos de información disponibles en la intranet e Internet.

- Acceso a los recursos de información digitalizados contenido o referido en soportes electrónicos.

- Documentos y textos completos (escaneados a solicitud previa).

- Acceso a diferentes servicios administrativos a través de intranet.

- Acceso a los archivos personales de registros.

- Facilidad de comunicación e interacción vía correo electrónico y chat con los autores o personal de la biblioteca.

\subsubsection{Biblioteca virtual}

El concepto de biblioteca virtual es definido en esta tesis como una entidad organizada y edificada sobre la base de altas tecnologías y programaciones informáticas. Su flexible estructura tecnológica facilita la organización, gestión y acceso de colecciones electrónicas. El objetivo de este modelo está en correspondencia con los objetivos de la biblioteca tradicional, híbrida y digital de facilitar y hacer posible la transferencia de información, eliminando en lo posible barreras de tiempo y espacio. Para 
esto, el modelo se vale del entorno virtual a través de interfaces dinámicas y procesos de comunicación vía World Wide Web. Dada las características de la biblioteca virtual, se puede decir que es una evolución del modelo de biblioteca digital, pero no una sustitución de ésta. Sin embargo ambos términos son utilizados como sinónimos. Este hecho ocurre debido a que ambos modelos gestionan recursos de información electrónicos. La diferencia entre ambos ocurre en dos líneas.

\begin{tabular}{|c|c|}
\hline Biblioteca virtual & Biblioteca digital \\
\hline $\begin{array}{c}\text { El origen de su colección integra y gestiona } \\
\text { recursos generados en formato electrónicos }\end{array}$ & $\begin{array}{c}\text { El origen de su colección integra y gestiona } \\
\text { recursos electrónicos que previamente han } \\
\text { sido digitalizados }\end{array}$ \\
\hline $\begin{array}{c}\text { No depende de la estructura organizativa de } \\
\text { la biblioteca física }\end{array}$ & $\begin{array}{c}\text { Generalmente se encuentra inmersa como } \\
\text { parte de la biblioteca híbrida }\end{array}$ \\
\hline
\end{tabular}

Tabla 3 Diferencia entre biblioteca virtual y digital. Fuente: Elaboración propia.

Cabe destacar que el concepto de biblioteca virtual regularmente, también es utilizado en dos formas. Primero para referirse a la colección electrónica y segundo como un concepto amplio para caracterizar el conjunto de recursos Web's y sistemas externos de recursos de información.

Con el fin de fundamentar el aporte antes referidos, es necesario destacar algunas Citaciones de autores como Marialyse Délano S. (1988, p. 28) amplia lo antes señalado al referirse a este modelo como "un concepto basado en la capacidad de abrirse a las oportunidades y convertirse en una institución hacia el exterior". Clara López Guzmán (2002 p.12) agrega que este "utiliza la realidad virtual para mostrar una interfaz y emular un ambiente que sitúe al usuario dentro de una biblioteca tradicional, guiando al usuario a través de diferentes sistemas de información en diferentes sitios Webs, mediante enlaces con otros sistemas de cómputo y telecomunicaciones".

Los aportes citados se identifican de forma general, en el concepto estándar ofrecido por la Association of Research Libraries que describen la biblioteca virtual como "una entidad parte de un todo, que posee tecnologías adecuadas para el proceso de comunicación e información. Sus componentes se unen con diversos puntos de información y conocimiento a través de enlaces visibles y amigables para el usuario..." Ejemplos este modelo es la biblioteca virtual Miguel de Cervantes de España y la biblioteca virtual de la Organización inspección holandesa de la calidad tecnológica. ${ }^{6}$.

\section{Recursos informativos}

Ana María Talavera Ibarra (2001, p.4-14) considera que los recursos de la biblioteca virtual deben ser meramente electrónicos. Destaca como ejemplos concretos las bases de datos ya existentes, las diferentes fuentes contenidas en diversos soportes electrónicos que desde documentos digitalizados, colecciones multimedia, los recursos disponibles a través de suscripciones pagadas y los recursos externos de acceso abierto en la Internet. Asimismo se incluyen como parte de los recursos informativos de la biblioteca virtual los blog, wikis y páginas interactivas y sitios Word Wide Web institucionales con información académica confiable.

\footnotetext{
${ }^{6}$ Sitios Web de los ejemplos antes citados. Biblioteca Virtual Miguel de Cervantes de España http://www.cervantesvirtual.com/ y Organización inspección holandesa de la calidad tecnológica, http://www.kint.nl/index.php?option=com_content\&task=view\&id=30
} 


\section{Infraestructura tecnológica}

Identificar un patrón fijo de infraestructura tecnológica del modelo de biblioteca virtual resultó complejo debido a que la implementación del diseño puede variar en dependencia de los recursos y políticas institucionales del organismo que desee implementarlo; no obstante, es posible listar una serie de aspectos importantes y considerados básicos para el diseño e implementación del modelo:

- Necesidades de hardware y software

- Servidor con capacidades

- Routers o enrutador

- Sistemas eficientes de telecomunicaciones

- Formatos y lenguajes XML, HTML y SGML

- Motores de búsqueda con SQL

- Recursos tecnológicos para la digitalización

- Capacidad necesaria y expansiva de almacenamiento del sistema

- Sistemas de seguridad tanto para la información como para el usuario

- Cumplimiento de aspectos legales

- Diseño de la interfaz

- Aplicación de estándares para diseños de sitios y servicios Web

- Facilidades de acceso por parte del usuario

\section{Servicios de la biblioteca virtual}

Los servicios de la biblioteca virtual son diversos y se caracteriza por ser servicios de acceso inmediatos y se agrupan en cinco categorías:

- Acceso y recuperación de textos completos

- Acceso a recursos multi e hipermedias tales como video, tutoriales, etc.

- Servicios de gestión administrativa y espacio personal

- Comunicación. Facilidades para interactuar vía correo electrónico o Chat con los autores o personal de la biblioteca

- Acceso a bases de información geográfica

\section{Personal}

El profesional de la biblioteca virtual al igual que el de la biblioteca digital debe ser un profesional pro activo, capaz de definir estrategias para la organización y administración de diversos recursos de información y generar nuevos recursos y servicios en línea que puedan orientar el proceso de transferencia de información científica de forma eficiente y eficaz. Dada las características de la biblioteca virtual, el trabajo se organiza en dos líneas: las aplicaciones tecnológicas que son responsabilidad de los profesionales informáticos y la sistematización de información y el 
seguimiento a los procesos de oferta-demanda es responsabilidad del bibliotecario. Ambos que en conjunto diseñan las aplicaciones y nuevos servicios.

\section{Usuarios}

Los usuarios identificados en este modelo son diversos y difíciles de caracterizar, sin embargo es posible agruparlos en la siguiente categoría:

a. usuarios de las bibliotecas digitales de acceso abierto (open Access). Corresponde a cualquier persona que busca en Internet y utiliza la información disponible en los diferentes puntos de acceso abierto en Internet.

b. Usuarios que además utilizar los recursos de acceso abierto, dispone de claves de acceso a los recursos de uso restringido.

\subsubsection{Centro de conocimientos}

El Centro de conocimientos se reconoce como un modelo de sistema de información dinámico que ha sido desarrollado a partir de la unión de diferentes modelos de biblioteca híbrida, biblioteca digital, biblioteca virtual y diversos puntos de información de gestión logística y administrativa.

\subsubsection{Antecedentes del modelo}

La estructura de este modelo puede presentar variaciones en dependencia de las condiciones económicas, aplicaciones y recursos tecnológicos involucradas en su diseño. Los antecedentes históricos identificados del modelo corresponden a un estudio desarrollado en el 2001 por la organización SCP (Social en Cultureel Planbureau) de los Países Bajos que presentó oficialmente al Ministerio de Sanidad Publica, Bienestar y Deporte (Ministerie van Volksgezondheid, Welzijn en Sport) culminando en un inventario de Centros de Conocimiento (Kenniscentra, en adelante $\mathrm{KC})^{7} \mathrm{EI}$ documento oficial concluye lo siguiente:

\section{a. Análisis conceptual}

El concepto de Centro de Conocimiento puede variar según su función ejercida. Incluye diversos términos como: centro de conocimiento, instituto de conocimiento, banco de conocimientos, punto central de conocimiento y red de conocimientos.

Se identifican dos tipos importantes, los que forman parte de una organización y los que son una organización. Asimismo el documento concluye, que los Centros de Conocimiento pretenden ser más que un portal virtual, ya que son instituciones que tienen como objetivo la generación de conocimiento. Para esto, una de sus estrategias es el trabajo en cooperación con otras organizaciones.

En el momento de la realización del inventario, se observó que las entidades que disponen de centros de conocimiento corresponden a ministerios, oficinas comerciales, empresas de Internet,

\footnotetext{
${ }^{7}$ Kenniscentra in Nederland Sociaal en Cultureel Planbureau Den Haag, december 2002

Een inventariserend onderzoek naar kenmerken en groei van het aantal kenniscentra

Werkdocument 88 Dr. Evert Ketting.Documento disponible www.scp.nl
} 
centros y puntos de información turística. Las áreas de especialización de estos centros se ubican en gran medida en el sector salud, educación, cultura, medioambiente y tránsito.

\section{b. Funciones y actividades}

Las funciones y actividades básicas que se identifican en el modelo de Centro de conocimiento corresponden principalmente al desarrollo de acciones para facilitar el acceso al conocimiento a terceros, la recolección del conocimiento; la intermediación entre la demanda y la oferta de conocimiento; el mejoramiento, generación y el estímulo al uso y manejo del conocimiento. Es importante destacar que lo más sobresaliente en las funciones y actividades de este modelo en correspondencia a los otros es su grado de especialización temático.

\subsubsection{Desarrollo del modelo}

En la actualidad casi todas las bibliotecas Universitarias disponen de una moderna tecnología y de aplicaciones de redes locales que facilitan el proceso de comunicación que permiten aumentar la capacidad de difusión de la información institucional, ampliar los puntos de acceso para la recuperación y acceder a las publicaciones electrónicas nacionales e internacionales a través de catálogos temáticos y buscadores vía website en Internet sin embargo, los actuales sistemas de búsqueda y de recuperación de información no son suficientemente eficaces en el contexto de prestación de servicios tales como el acceso de información especializada, la comunicación directa con el escritor, servicio administrativo, capacitación e instrucción en línea sobre el uso de los recursos.

Este hecho justifica el surgimiento de un nuevo modelo integrador de los modelos de biblioteca híbrida, digital y virtual capaz de funcionar las 24 horas del día y accesible desde cualquier punto del globo terrestre y a menor costo. Este modelo es conocido como Centro de conocimiento tal como se identifica internacionalmente con diferentes nombres. Para fines de este estudio se destacará el modelo español "Centros de Recursos para el Aprendizaje y la Investigación (CRAI)" y los "Centros Virtuales de Información y Conocimiento (VKC)".

Nelly Mac Kee de Maurial $(2005, \text { p.9 })^{8}$ señala el origen del modelo como una entidad de apoyo a la educación y cultura, se establece oficialmente según la Declaración de la Sorbona para la armonización del Sistema de Educación Superior Europeo (EEES), iniciado el 25 de mayo de 1998 y reafirmada en las conferencias en Bolonia, 1999, Praga, 2001, Berlín , 2003 y Bergen (Noruega) 2005.

Los debates conceptuales sobre el término desde el seno de la biblioteca parten de la necesidad de generar nuevas formas para el acceso a la información. En este sentido Jesús Tramullas (2002, p.7) conceptualiza el origen del modelo a partir de la necesidad de ver la biblioteca como un proceso multifacético de transferencia de información con valor añadido iniciado desde la fuente al usuario. Tramullas señala que "...la biblioteca digital no puede limitarse a ser definida como una colección digitalizada con herramientas de gestión de información o documentos. La biblioteca digital debe configurarse como un centro de conocimiento, superando las funciones y el concepto que han sido aceptadas como clásicas hasta el momento".

\footnotetext{
${ }^{8}$ Conferencia magistral dictada en el XII Coloquio Internacional de Bibliotecarios convocado por la Universidad de Guadalajara en noviembre de 2005.
} 
Tramullas considera necesario aprovechar al máximo los recursos que ofrecen World Wide Web para trabajar el diseño de interfaces en entornos personalizados y/o corporativos virtuales para el desarrollo de investigaciones científicas y generación de conocimiento. En esta misma corriente Kees Westerkamp (2007) indica que el éxito de la transformación de la biblioteca a otros modelos tiene su base en el manejo de conocimiento, la administración de contenidos, los negocios inteligentes y el manejo de documentos sin límites de tiempo y espacio. Según su análisis, considera que estas bibliotecas especiales se transformarán en centros de conocimientos, prestando menos importancia al soporte (libro y/o documento) y centrando su interés en el contenido, es decir, en el conocimiento.

En concordancia con lo antes referido y retomando los aportes de otros autores, podemos concluir que el modelo es el resultado de la integración de los modelos de bibliotecas híbrida, digital y virtual, hecho por el cual se destaca y caracteriza por la diversidad de información que gestiona y el valor agregado que esta recibe. Asimismo el entorno virtual en que éste actúa lo posesiona como un punto de encuentro entre usuarios, científicos, entidades y la biblioteca. Otro aspecto a destacar es la facilidad que ofrece el modelo de combinar medios y programas de comunicación, le atribuye la flexibilidad para generar, modificar una diversidad de servicios tales como escritorios de investigaciones, punto de negocios y mercado, educación electrónica, manejo de conocimiento y gerencia de sitios, etc.

\subsubsection{Centros de Recursos para el Aprendizaje y la Investigación (CRAI)}

El Centro de Recursos para el Aprendizaje y la Investigación (CRAI) es un término reconocido por la Red de Biblioteca Universitarias Españolas (REBIUN) para referirse a un nuevo concepto de biblioteca relacionados con el modelo británico Centro de Recursos para el Aprendizaje (Learning Resource Center), nacido en escuelas de formación media ${ }^{9}$. Seguidamente se presentan dos figuras extraídas del sitio web de la Universidad de Hertfodshire y de la Universidad de Barcelona con el fin de poner de manifiesto la oferta amplia de servicios ofrecidos por el modelo.

Como se puede observar en las dos siguientes imágenes, lo más novedoso del modelo es que éste concentra su atención en tres ejes: a) el usuario en su proceso de formación, b) el manejo de contenido para solventar las necesidades y las demandas y c) la aplicación tecnológica como canal de interacción y transferencia de información y conocimiento.

Estos ejes están concebidos como una unidad que hacen posible el desarrollo de una serie de actividades y servicios que contribuyen al logro de objetivos educacionales y formativos. Tras las figuras en las que se reproducen las web de dos excelentes ejemplos del modelo que se está describiendo, se sistematiza esta triple relación en otra ilustración de elaboración propia.

Usuarios, contenidos y tecnologías serían los tres ejes sobre los que se desarrollan los centros de recursos para el aprendizaje y la investigación, que pueden tener otras denominaciones pero que siempre se articulan como unidades de apoyo a los usuarios de la biblioteca universitaria, mediante su oferta de servicios y contenidos informativos.

\footnotetext{
${ }^{9}$ Ejemplos del modelo Learning Resource Center y CRAl están disponible en el sitio http://www.herts.ac.uk/whyus/facilities/learning-facilities/Ircs/home.cfm . Consultado 30-09-2012. Y el sitio http://www.bib.ub.edu/es/apoyodocencia/_Consultado 30-09-2012.
} 


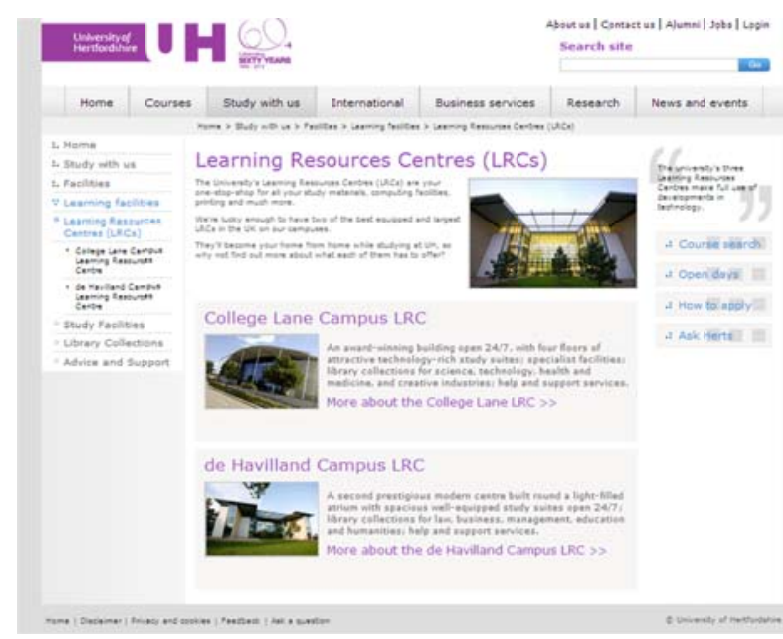

Figura 4. Universidad de Hertfordshire.

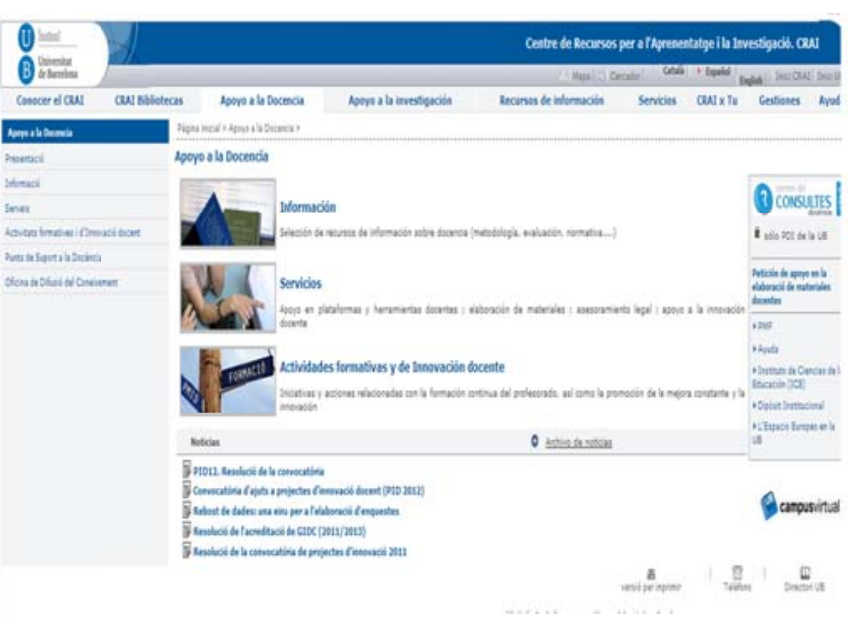

Figura 5. Universidad de Barcelona.

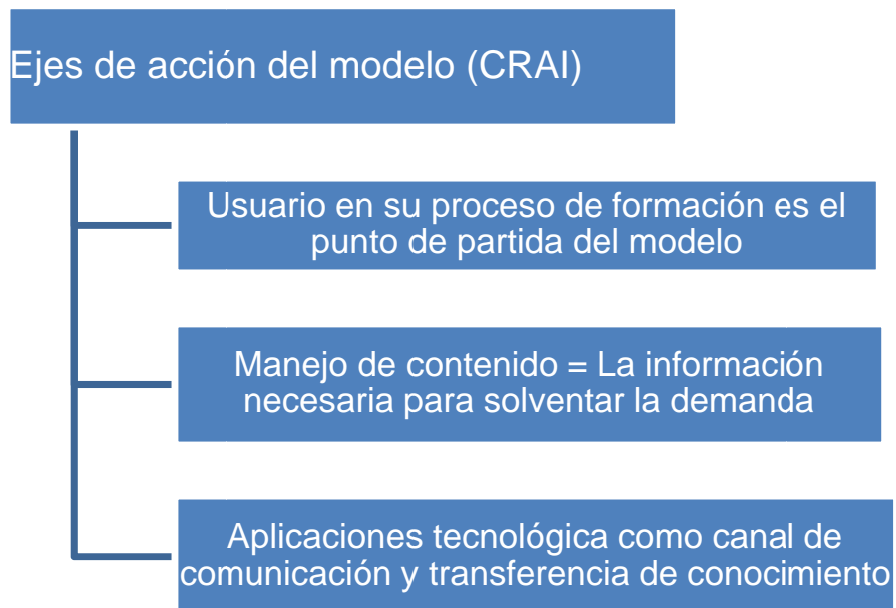

Figura 6. Ejes de acción del CRAI.

Fuente: Elaboración propia.

Con el objetivo de ampliar lo antes referido, se presentan a continuación algunos aportes conceptuales resultantes de la revisión de literatura y de diferentes prácticas en línea de este modelo.

Mabel Rocío Orozco $(2011$,$) afirma que la idea de CRAI surge del enfoque constructivista que$ describe la función del docente como facilitador del proceso de aprendizaje tomando en consideración la situación de los entornos físicos y emocionales, a fin de estimular las capacidades en el alumno para pensar, analizar, ser crítico y autónomo para aprender, hecho por el cual es considerado un proyecto institucional de servicios para la enseñanza, aprendizaje e investigación. La definición que aporta Mabel Rocío corresponde a la de un modelo integrado dinámico y flexible de información y servicios que actúa como soporte al nuevo modelo de aprendizaje electrónico y la producción de contenidos. 
Nelly Mac Kees de Maurial, (2005 p.3) señala que en un modelo "interactúan bibliotecólogos, informáticos, técnicos audiovisuales y asesores pedagógicos a fin de facilitar el aprendizaje cognitivo, solucionar problemas de acceso y uso de la información offline y online, logrando así optimizar todos los recursos y servicios que posee la universidad". Un texto visible en el sitio Web de la Universidad Rovira i Virgili (URV, 2010) ${ }^{10}$ señala que la misión del CRAl es estimular y apoyar el cumplimiento de los objetivos del aprendizaje, la docencia y la investigación a través de servicios de información.

Didac Martínez (2010, p.2) materializa el concepto de CRAI al indicar que "la biblioteca presencial se ha transformado a un centro de servicios para el aprendizaje abierto y con un amplio horario" y que a través de su oferta "estimula el encuentro social, científico y facilita la comunicación de la comunidad universitaria.

En esta línea cabe destacar que en América Latina también algunas universidades han implementado el modelo CRAI. En principio se observa el manejo de la misma definición que en los anteriores sitios españoles. Ejemplo de esto es la Universidad Panamericana del Campus Guadalajara ${ }^{11}$ que en su sitio Web describe su CRAI como "el espacio en el que se integran los servicios, herramientas y tecnologías de información que contribuyen a la formación permanente de la comunidad" Otro ejemplo es el Centro de Recursos para el Aprendizaje (CRA) ${ }^{12}$ de las bibliotecas escolares" de chile que ofrece el acceso a una serie de recursos de apoyo a la docencia y aprendizaje.

\subsubsection{Descripción del CRAI}

El CRAI tiene un rol importante en el proceso de planificación, y gestión de servicios universitarios relacionados con todos los frentes involucrados con el proceso de enseñanza-aprendizaje, la formación continua y la investigación. Para el logro de sus objetivos, participa y/o elabora propuestas organizativas, ejecuta programas y proyectos de servicio y ejecuta el funcionamiento y el comportamiento entre la oferta y la demanda.

Siendo el CRAI un modelo integrador de servicios cuenta con una estructura de funcionamiento constituida por los siguientes cuatro elementos.

1. Tecnología. Medio para el desarrollo de procesos de transferencia de información y conocimiento

2. Contenidos. Insumo esencial para la generación de servicios y productos

3. El usuario como demandante y razón de ser del CRAI

4. El personal. Gestores de servicios y mediadores en el proceso de enseñanza

En la figura 7 se muestra de forma gráfica la relación de estos cuatro elementos en torno a una misma entidad, llamada CRAI o CRIA, dependiendo de si la entidad da prioridad a la investigación o a la enseñanza. Además, con el objetivo de ejemplificar la práctica de lo reflejado en la anterior figura, se presenta en la figura 8 un ejemplo de implementación del modelo CRAl en la Universidad Pompeu Fabra, cuya oferta de servicios evidencia la presencia de estos cuatro elementos antes referidos.

\footnotetext{
${ }^{10}$ Véase texto completo de la definición del CRAI en el sitio http://www.urv.cat/universitat/unitats_administratives/crai/es_index.html

${ }^{11}$ Sitio CRAI de la Universidad Panamericana del Campus Guadalajara http://www.up.edu.mx/depto.aspx?doc=20410

12 Ejemplo de adaptación del modelo CRAl a bibliotecas escolares http://www.bibliotecas-cra.cl/index.htm
} 


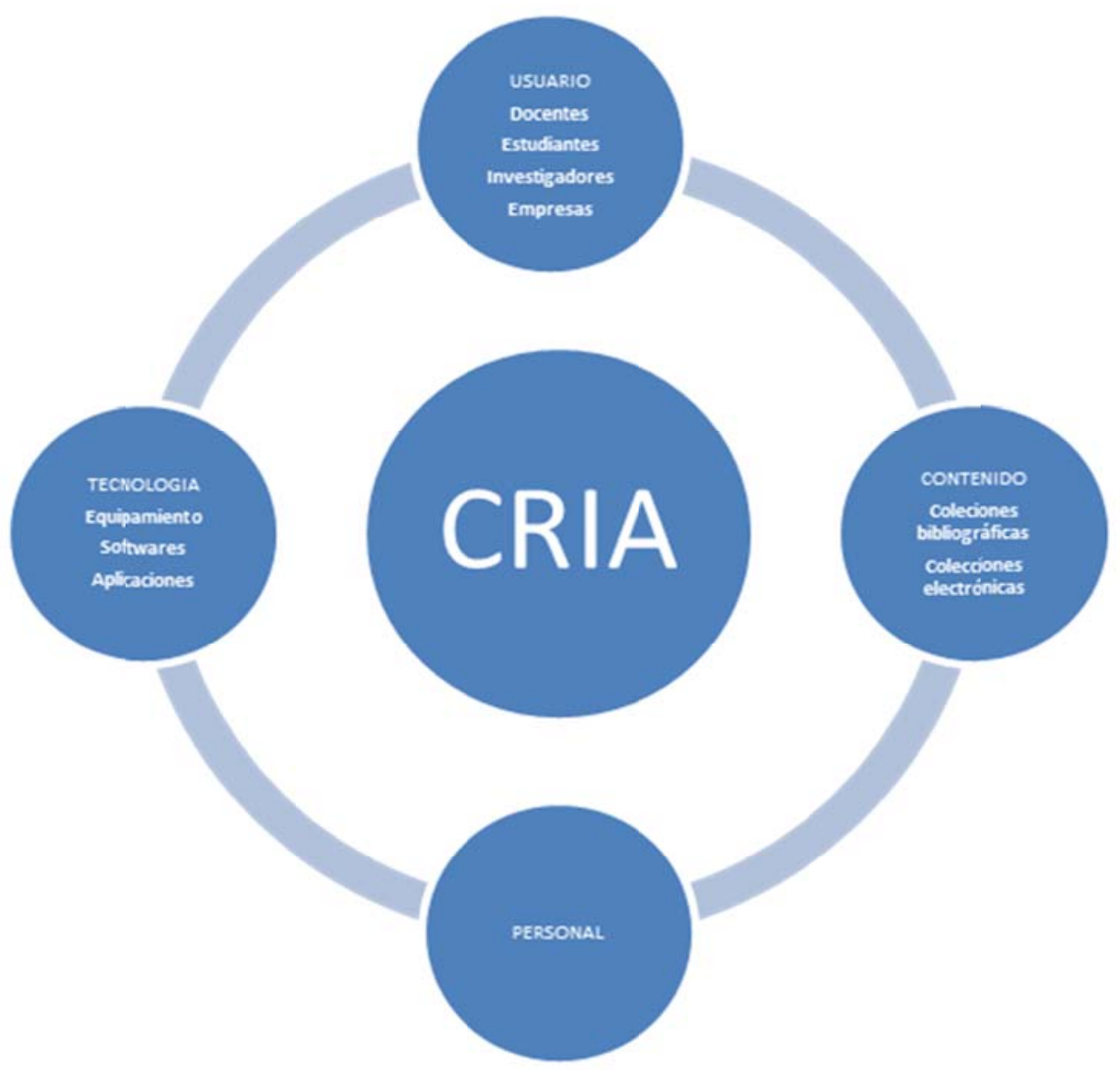

Figura 7. Modelo CRIA-CRAI Fuente: Elaboración propia.

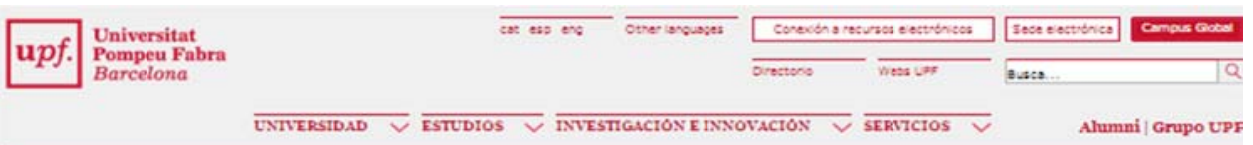

Biblioteca y TIC. Centro de Recursos para el Aprendizaje y la Investigación

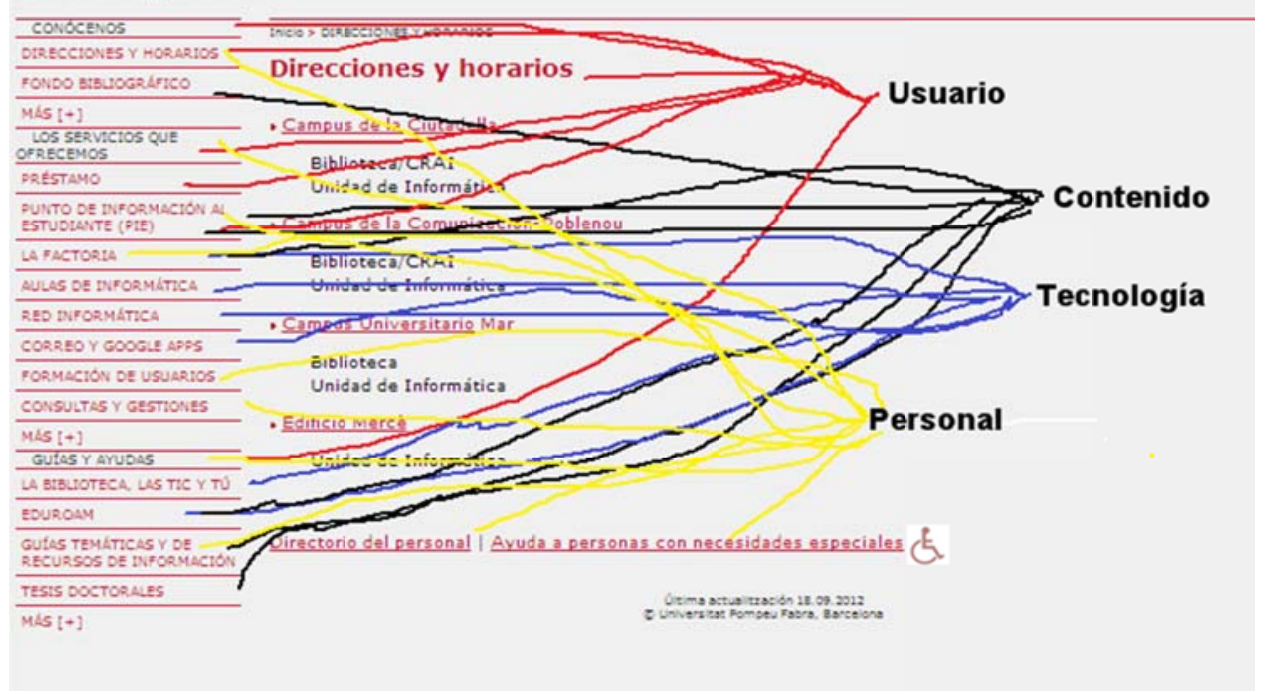

Figura 8. Visualización de los componentes del CRAI en la Web. Fuente: Elaboración propia. 


\section{Recursos informativos}

Partiendo del ejemplo de CRAI de la Universidad Pompeu Fabra, es posible identificar la variedad de recursos de información en línea con que dispone el modelo. Ejemplos casi obligatorios de recursos de información son los directorios, web temáticas, objetos de aprendizaje, tutoriales y guías de estudios, material multimedia, y los recursos identificables en los modelos de la biblioteca híbrida y biblioteca virtual.

\section{Estructura física del CRAI}

Las instalaciones físicas del CRAI son equivalentes al modelo de biblioteca híbrida. La variante en la estructura física en ambos modelos se presenta en el fortalecimiento de las áreas de estudios para el aprendizaje colectivo e individual. Se observan las facilidades para el desarrollo de programas de estudios y diversas prácticas en las aulas equipadas con estaciones de trabajo TIC, los laboratorios de computadoras, unidades de diseño gráfico y fotografía, televisión, equipos de transmisión multimedia y edición electrónica, salas de tutoría y de conferencias.

\section{Infraestructura tecnológica}

En el apartado de la estructura física del CRAI se ha mencionado la existencia de equipos y recursos informáticos que resulta físicamente visible por el usuario (hardware y periféricos). Para su funcionamiento, ésta infraestructura física requiere de un conjunto de programas y aplicaciones informáticas que no son tangibles por el usuario (software's), pero que son determinantes para garantizar el uso y funcionamiento de la estructura tecnológica física.

\section{Personal}

La gestión y buen funcionamiento del CRAI demanda la participación de un grupo diverso de profesionales que interactúan para la definición y prestación de servicios. Algunas funciones que se destacan como indispensables en el CRAI corresponden a bibliotecólogos, especialistas de materia, expertos en gestión de información e informáticos, técnicos audiovisuales, asesores pedagógicos, diseñadores gráficos, analistas y programadores, administradores de sistemas y de bases de datos, fotógrafos, editores, impresores, productores de video y de audio, contables, expertos en derecho de autor $\mathrm{y}$ administradores.

\section{Usuarios}

El centro de atención del modelo son los usuarios del mismo: los alumnos, los docentes, los investigadores y las empresas vinculadas a la Universidad.

\section{Servicios}

El CRAl es un centro integrador de servicios institucionales que ofrece desde una consulta hasta un entrenamiento. Los servicios que se destacan como estándares se listan a continuación:

- Servicio de información general de la universidad

- Servicio de biblioteca

- Servicio informático para los estudiantes

- Servicio de laboratorio de idiomas 
- Servicio de búsqueda activa de empleo

- Servicio de salas de estudio y aulas de reserva

- Servicio de soporte a la formación del profesor

- Servicio de creación y elaboración de materiales docentes y multimedia

- Servicio de presentaciones y debates entre otros

\subsubsection{Centros Virtuales de Información y Conocimiento (VKC)}

El modelo Centros Virtuales de Información y Conocimiento, reconocido en adelante con las siglas VKC, puede ser visto como un sinónimo del CRAI, ya que ambos parten de la filosofía de trabajo del modelo británico Learning Resource Center. El modelo fue implementado por primera vez en 2004 por la Universidad Tecnológica de Delft en los Países Bajos, como resultado de un cambio en las estrategias de ofrecimiento de los servicios y la necesidad de adopción de nuevos roles en la comunidad virtual. En este contexto la biblioteca híbrida creó centros especializados con recursos de información y especializados en formato electrónico de relevancia para el desarrollo de procesos de enseñanza e investigación.

En un principio, los centros creados cumplían con los mismos objetivos de la biblioteca híbridadigital, pero con la diferencia principal que este cumplía otras funciones orientadas a estimular la generación de conocimientos en procesos de enseñanza y formación continua, mediante la prestación de servicios en línea. Estos servicios son centralizados en un sistema institucional, que le permita actuar como punto de interacción entre docente-estudiante; investigador-investigador, departamentos y otras entidades prestadoras de servicios de apoyo a la docencia, etc. ${ }^{13}$

El uso de diferentes componentes y flexibles paquetes tecnológicos le permiten asumir ciertos roles en la implementación de programas educativos y proyectos académicos de investigación. Ejemplo de ello son los programas de capacitación de usuarios, generación de tutoriales, organización de materiales de estudios, entre otros. Una característica importante que se destaca en el modelo VKC es la novedosa aplicación tecnológica que se utiliza para el desarrollo de procesos de comunicación y la oferta de sus servicios y productos.

\subsubsection{Descripción del VKC}

EI VKC se constituye como un vehículo auxiliar para los sectores de educación, ciencia, investigación y del sector comercio. La estrategia de su creación responde a la idea de fortalecer las capacidades institucionales existentes, a fin de hacer atractiva la oferta de trabajo cooperativo nacional e internacional en pro de estimular la generación de conocimientos científicos validado por una comunidad académica.

Su objetivo principal es garantizar el acceso abierto las 24 horas del día, la oferta de nuevos servicios y productos de información especializados en entornos virtuales vía Intranet e Internet, a fin de estimular la generación e intercambio de conocimientos dentro de actividades académicas y de

\footnotetext{
${ }^{13}$ Ejemplos de este punto pueden ser la oficina de registro, archivos académicos, la unidad de publicaciones, oficina de atención al estudiante, librería, etc.
} 
investigación. EI VKC opera a través de sistemas de enlaces que permiten acceder a portales, videos, aulas, textos completos digitalizados, y vínculos en la comunidad virtual académica y servicios administrativos de la universidad. La siguiente figura presenta los componentes básicos del VKC.

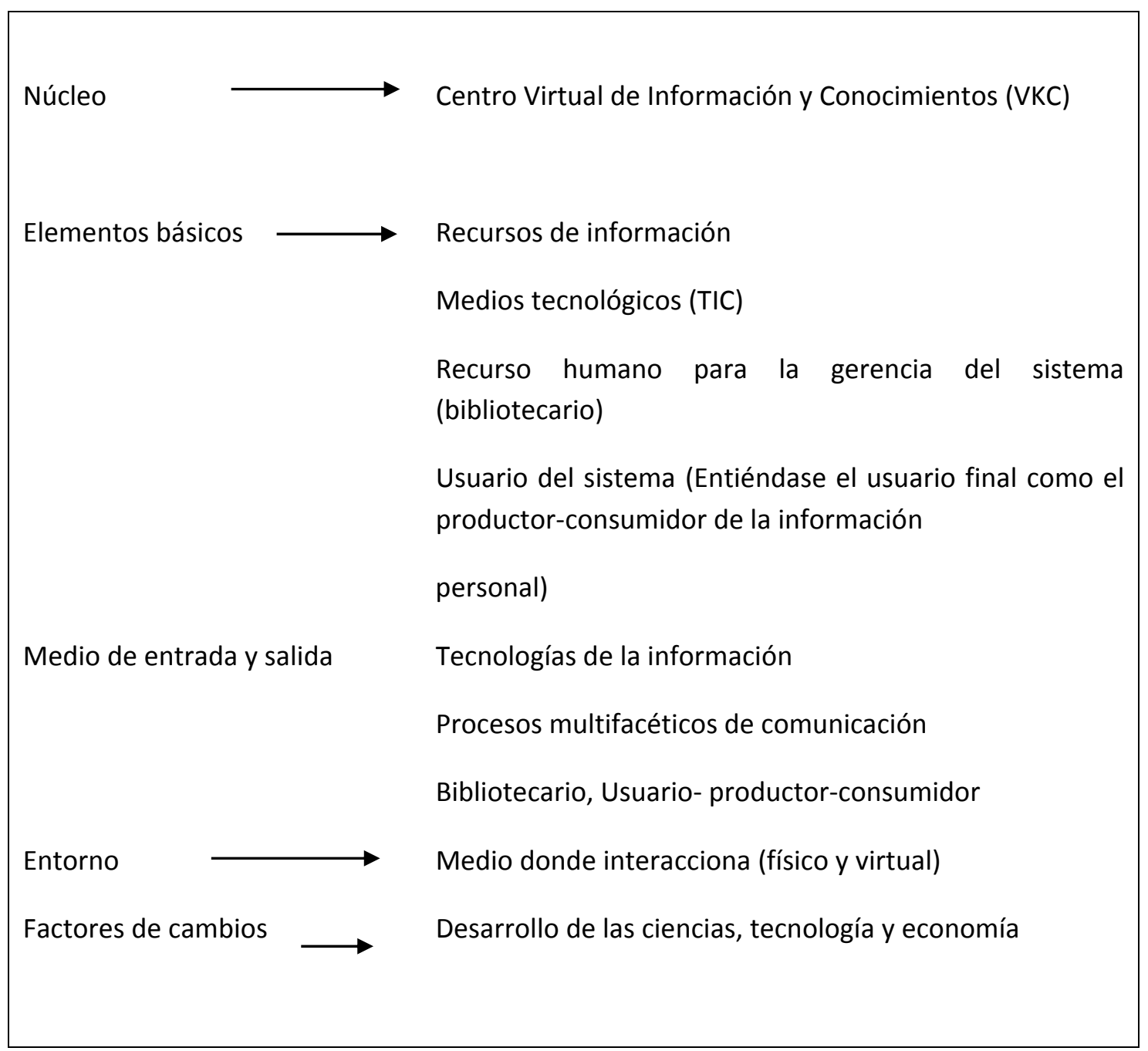

Figura 9. Acercamiento sistémico del modelo VKC.

Fuente: Elaboración propia

En la figura anterior se observan tres actores importantes: a) el usuario que se identifica como un ente generador de información y conocimiento desempeñando un rol activo y pro activo; b) el bibliotecario como intermediario y gestor del VKC; y C) la plataforma tecnológica como el componente esencial para el desarrollo del proceso de transferencia de información.

\section{Recursos Informativos}

EI VKC posee una gama de recursos informativos disponibles en la biblioteca híbrida, digital y virtual. Estos se encuentras centralizados en un sistema de gestión de contenidos que le permite vincular diferentes recursos, tales como recursos electrónicos, información académica científica, administrativa y diversa que se hace disponible de forma local y en línea. 
La plataforma tecnológica del VKC, le ofrece a la comunidad de usuarios establecer una conexión permanente a los diferentes servicios y a las fuentes de información contenidas en repositorios, catálogos, bases de datos y publicaciones electrónicas propias y de instituciones asociadas, a través de interfaces amigables en Intranet e Internet.

Los recursos informativos de valor agregado del VKC corresponden a la elaboración y gestión de materiales de apoyo a la docencia. Estos pueden variar desde la recopilación de información especializada, la generación de recursos multimedia como videos, tutoriales educativos para el uso de los recursos de aprendizaje, hasta la organización de recursos resultantes de procesos de comunicación, como es el caso de las conferencias satélites. Seguidamente se presenta en forma esquematizada la variedad de recursos ofrecidos por el modelo VKC.

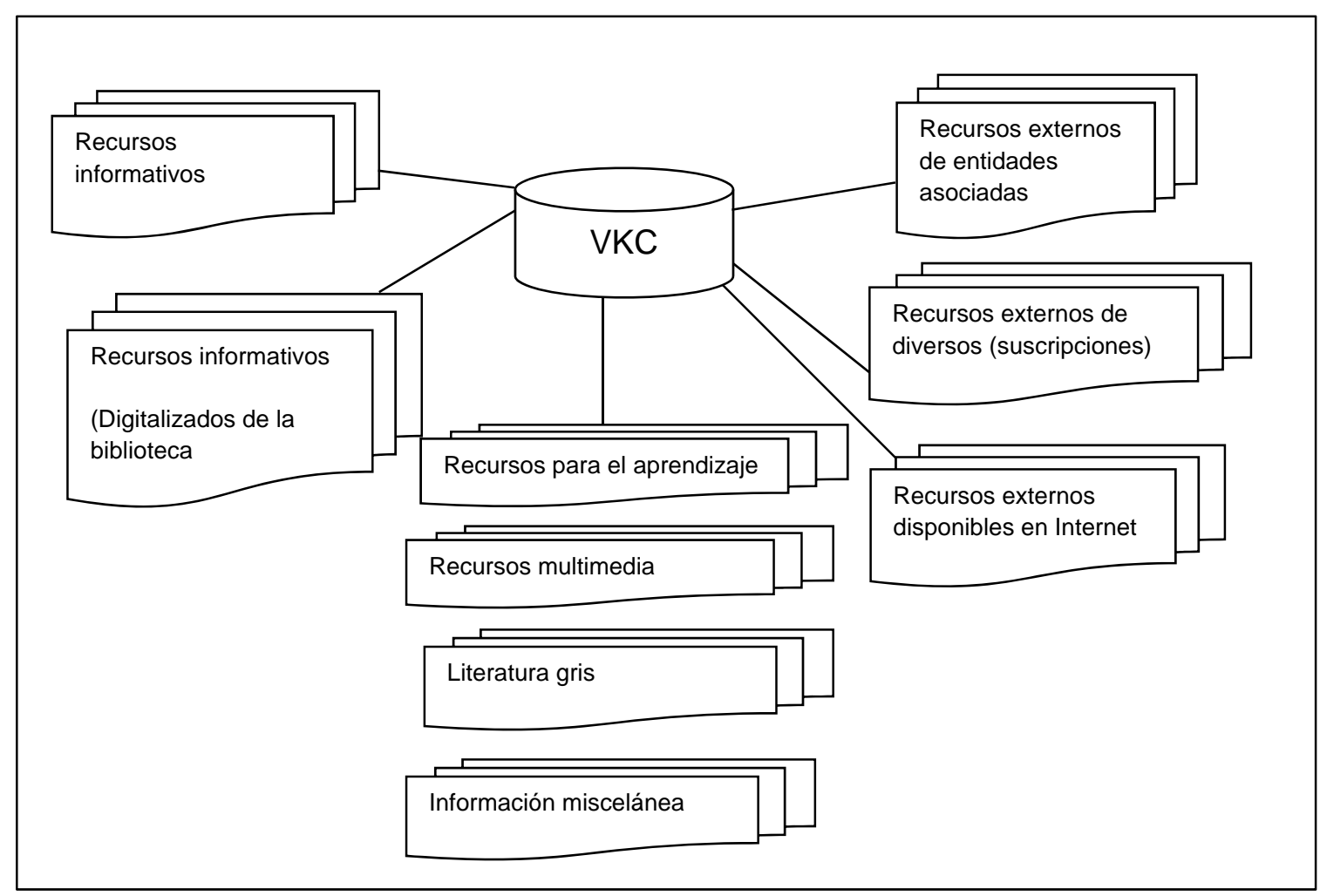

Figura 10. Descripción general del modelo VKC.

Fuente: Elaboración propia.

En forma de resumen y con el fin de establecer una relación comparativa y aportar elementos diferenciadores entre los recursos informativos y los modelos antes estudiados, se presenta a continuación una tabla comparativa de los recursos disponibles en la biblioteca híbrida, digital y el VKC. En esta tabla se representan algunos componentes de la biblioteca híbrida que se comparan con los de la biblioteca digital y con los que se pueden encontrar en el modelo VKC. Se trata de un inventario de componentes informativos, cuya presencia ha sido analizada en cada uno de los sistemas, a fin de comprobar si existen o no en cada uno de ellos. De esta forma, se puede disponer de una visualización simple desde las que se pueden comparar los tres tipos de sistemas informativos mencionados. 


\begin{tabular}{|l|l|l|l|}
\hline Componentes informativos & $\begin{array}{l}\text { Biblioteca } \\
\text { Hibrida }\end{array}$ & $\begin{array}{l}\text { Biblioteca } \\
\text { digital }\end{array}$ & VKC \\
\hline \multicolumn{1}{|c|}{ Disponibilidad de recursos } & & & \\
\hline Colección en papel (primaria y segundaria) & $\mathrm{SI}$ & $\mathrm{NO}$ & $\mathrm{SI}$ \\
\hline Colecciones especiales en papel & $\mathrm{SI}$ & $\mathrm{NO}$ & $\mathrm{SI}$ \\
\hline Colecciones especiales (formato digital) & $\mathrm{SI}$ & $\mathrm{SI}$ & $\mathrm{SI}$ \\
\hline $\begin{array}{l}\text { Bases de datos internas de referencias } \\
\text { (documentos digitalizados) }\end{array}$ & $\mathrm{SI}$ & $\mathrm{SI}$ & $\mathrm{SI}$ \\
\hline $\begin{array}{l}\text { Bases de datos externas de documentos } \\
\text { digitalizados }\end{array}$ & $\mathrm{SI}$ & $\mathrm{SI}$ & $\mathrm{SI}$ \\
\hline Recursos multimedia & $\mathrm{SI}$ & $\mathrm{SI}$ & $\mathrm{SI}$ \\
\hline Material académico de programas virtuales & $\mathrm{NO}$ & $\mathrm{NO}$ & $\mathrm{SI}$ \\
\hline Aulas virtuales & $\mathrm{NO}$ & $\mathrm{NO}$ & $\mathrm{SI}$ \\
\hline Información gris & $\mathrm{SI}$ & $\mathrm{SI}$ & $\mathrm{SI}$ \\
\hline Portales, RSS, Blogger & $\mathrm{NO}$ & $\mathrm{SI}$ & $\mathrm{SI}$ \\
\hline Información administrativa institucional & $\mathrm{NO}$ & $\mathrm{SI}$ & $\mathrm{SI}$ \\
\hline Google académico & $\mathrm{NO}$ & $\mathrm{NO}$ & $\mathrm{SI}$ \\
\hline $\begin{array}{l}\text { Diversos (noticias, variedades, } \\
\text { entretenimientos, etc.) }\end{array}$ & $\mathrm{NO}$ & $\mathrm{NO} / \mathrm{SI}$ & $\mathrm{SI}$ \\
\hline
\end{tabular}

Tabla 4. Oferta de recursos de información de la biblioteca híbrida, biblioteca digital y el VKC. Fuente: Elaboración propia.

\section{Estructura física}

La estructura física del modelo VKC corresponde al modelo de biblioteca híbrida. La existencia de un lugar y edificio físicamente accesible es fundamental, ya que representa el punto de encuentro de lo real y tangible con lo virtual. Asimismo la existencia de la biblioteca física es condicionante por cuanto la oferta de servicios de información no tiene límites de formatos, espacio y tiempo.

\section{Estructura tecnológica}

La estructura tecnológica se caracteriza por ser moderna y flexible basada en estándares y normativas capaz de responder a las funciones de procesos de comunicación, gestión de datos, gestión de colecciones digitalizadas, transferencia de gestión de información y como punto de encuentro en una comunidad académica virtual. La estructura tecnológica del VKC se puede clasificar al igual que el CRAI de componentes tecnológicos físicos y componentes intangibles como es el caso de programas y aplicaciones informáticas para el manejo de contenidos, textos, imagines y sonidos.

\section{Personal}

Para el buen funcionamiento del modelo VKC se requiere de profesionales con capacidades y habilidades ya antes citadas en el modelo de biblioteca híbrida, es decir, personal capaz de interactuar en entornos reales, físicos y virtuales. Por las características del modelo se han ampliado nuevas áreas y funciones de trabajo, tales como la producción de publicaciones electrónicas y la digitalización de colecciones, web master, programadores, gestor de pantallas (Board masters), jefe de redacción y consejo redactor. 


\section{Usuarios}

EI VKC posee una diversidad de usuarios reales y potenciales, es una entidad de trabajo cooperativo entre diversas instituciones, que cuenta a su vez a lo interno de estructuras con sus propias categorías y usuarios. Los usuarios del VKC están representados por toda la comunidad académica compuesta por estudiantes, investigadores, docentes y empleados de la universidad y del conjunto de posibles categorías correspondientes a cada una de las instituciones participantes (miembros) del modelo VKC. En este contexto podemos hablar de tres categorías:

- Usuarios físicos: aquellos que habiendo hecho uso del VKC también hacen uso de las instalaciones de la biblioteca del VKC.

- Usuarios intermedios: corresponde al grupo que hacen uso de los espacios físicos virtuales.

- Usuarios virtuales: aquellos que hacen uso de los recursos y de los servicios de forma meramente virtual.

\section{Servicios y productos}

La diversidad de recursos informativos internos y externos al VKC están disponibles las 24 horas del día desde cualquier punto terrestre a través de una conexión en Internet. A continuación se listan los servicios básicos considerados dentro del modelo, mencionados en el apartado correspondiente al modelo CRAI.

- Servicio de información general de la universidad

- Servicio de biblioteca

- Servicio informático para los estudiantes

- Servicio de laboratorio de idiomas

- Servicio de búsqueda activa de empleo

- Servicio de salas de estudio y aulas de reserva

- Servicio de soporte a la formación del profesor

- Servicio de creación y elaboración de materiales docentes y multimedia

- Servicio de presentaciones y debates entre otros

\subsection{Relación CRAI y VKC}

El análisis conceptual de los modelos de bibliotecas presentado en las páginas anteriores permitió identificar que el CRAl y el VKC son modelos resultantes de la evolución de la biblioteca híbrida que en alianza con otras instituciones conforma un centro corporativo y dinámico de información y 
conocimiento. Con el objetivo de manejar un concepto único y amplio en esta tesis, se concluye lo siguiente:

- El modelo CRAI y VKC son sistemas de gestión de información de contenidos que en combinación con otros programas y medios tecnológicos puede gestionar datos al mismo tiempo que puede interaccionar con procesos de comunicación.

- Su estructura flexible facilita generar nuevas formas para organizar y prestar servicios de apoyo a la docencia, el aprendizaje, la formación continua y la investigación.

- La credibilidad del modelo radica en el uso y aplicación de estándares, la aplicación de una moderna y adecuada infraestructura tecnológica y sobre todo de la selección y organización de los contenidos.

La funcionalidad del modelo genera de forma directa, un vínculo dinámico entre la biblioteca, el proceso de enseñanza y la comunidad de usuarios, por cuanto no pueden existir servicios sin contenido y no puede generarse una oferta sin demanda (usuarios). En la siguiente figura se visualiza la presencia del usuario en el modelo, como elemento clave en la salida y entrada de insumos de información y contenido para el diseño de servicios y la adaptación del proceso mismo de enseñanza.

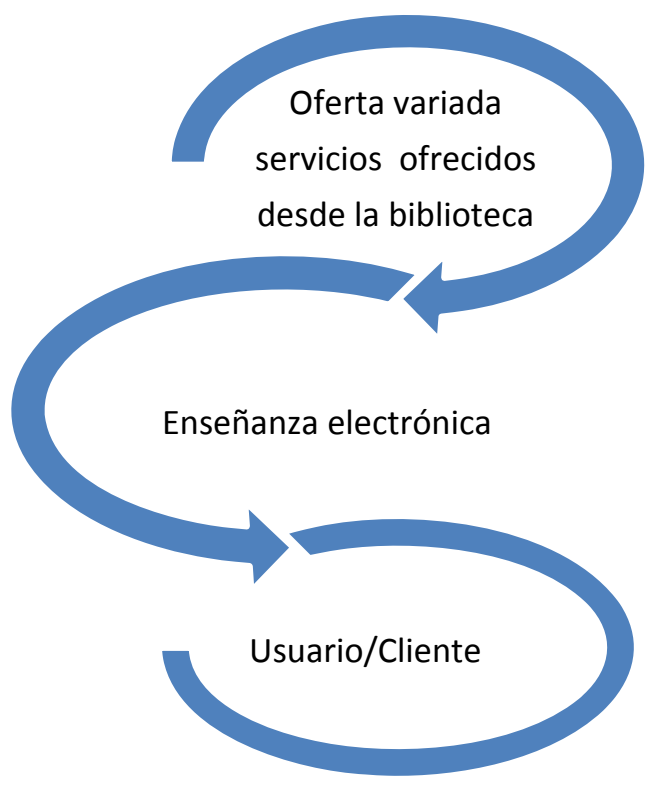

Figura 11. Ciclo de oferta y demanda. Fuente: Elaboración propia 


\section{Capítulo 3. Análisis conceptual de la enseñanza electrónica (E-learning)}

\subsection{Introducción}

El termino en inglés E-learning, es conocido internacionalmente para referirse a la modalidad de educación electrónica. Como resultado del análisis de los antecedentes de esta modalidad es posible afirmar que E-learning es una manifestación de la evolución de la modalidad de educación a distancia basado en mecanismos telemáticos.

La acogida de esta modalidad de educación se inicia en la década de los noventa y se caracteriza por el uso de medios electrónicos para la transmisión de conocimientos. Asimismo se destaca en este modelo educativo las adaptaciones didácticas y metodológicas realizadas en la forma flexible de enseñanza. lleana R Lorenzo Arieto (1999) señala que históricamente se distinguen tres fases evolutivas de la educación electrónica ${ }^{14}$ :

- El sistema de correspondencia postal y aparatos de radio difusión

- El sistema radio y televisión basado en el uso de computadores

- El sistema de computadores con sistemas interactivos en línea a través de Internet e intranet

El proceso de enseñanza aprendizaje se efectúa básicamente a través de un vínculo estrecho y coherente entre los materiales educativos, la asesoría o seguimiento del o los profesores y la evaluación continua para medición del aprendizaje y el logro de los objetivos propuestos. La gestión del proceso educativo dispone de una infraestructura administrativa y de un eficiente sistema para el desarrollo de procesos de comunicación y acceso a recursos de información, materiales de estudios y posibles fuentes de información complementaria.

En la actualidad los gestores del E-learning han desarrollo dentro de los sistemas de manejo de contenidos, un módulo denominado "biblioteca", a fin de almacenar los recursos necesarios para el docente y los materiales de cursos para los estudiantes denominados Objetos de Aprendizajes (OA), conocido también con el término en inglés Learning Object (LO).

Se trata de contenidos ${ }^{15}$ generalmente modulares para la instrucción, aprendizaje o enseñanza y se caracterizan por uno o varios elementos digitales y por su flexibilidad de ser reutilizable. En general, Clara López Guzmán y Francisco J. García Peñalvo (2006?) afirman que son recursos depositados en el módulo del curso por los docentes y profesionales de la educación.

La iniciativa del módulo dentro del sistema de gestión de contenidos de E-learning ha sido útil, pero también ha presentado muchas limitaciones para la exportación e importación de contenido, problema que ha venido solventándose los últimos años con el desarrollo de estándares internacionales. Algunos ejemplos de ellos son el estándar IEEE $1484.12-15^{16}$ referente al manejo de objetos de aprendizaje y protocolos de intercambio de datos, el estándar SCORM ${ }^{17}$ que consiste en un conjunto de especificaciones técnicas para la gestión de objetos de contenido para el aprendizaje $(\mathrm{OA})$, que son utilizados de forma compartida entre diferentes sistemas E-learning.

\footnotetext{
${ }^{14}$ Véase Información sobre los antecedentes históricos de la educación a distancia artículo de lleana R. Alfonso Sánchez disponible en línea en http://www.bvs.sld.cu/revistas/aci/vol11_1_03/aci02103.htm

${ }^{15}$ Ejemplo de estos pueden ser imágenes, fotografías, textos, multimedia, programas de instrucción.

${ }^{16} \mathrm{http}: / /$ www.ieee.org/index.html

${ }^{17}$ Mayor información sobre el estándar Scorm se identifica en el sitio http://www.scormsoft.com/scorm
} 
La práctica en el uso de las colecciones OA se reconoce en los sistemas E-learning como repositorios para la educación. Ellos son visibles en el sitio del sistema E-learning como un módulo de recursos para la educación, en algunos casos identificados bajo el término de biblioteca, repositorios o simplemente material de cursos. Con el fin de ilustrar los antes dicho la siguiente tabla muestra algunos ejemplos:

\begin{tabular}{|l|l|}
\hline $\begin{array}{l}\text { MERLOT = Multimedia Educational Resource for } \\
\text { Learning and Online Teaching }\end{array}$ & $\begin{array}{l}\text { Repositorio de reconocimiento internacional } \\
\text { de OA. }\end{array}$ \\
\hline $\begin{array}{l}\text { CAREO = Campus Alberta Repository of } \\
\text { Educational Objects }\end{array}$ & $\begin{array}{l}\text { Repositorio centralizado e independiente } \\
\text { que da acceso a objetos remotos y locales a } \\
\text { través de los metadatos contenidos en su } \\
\text { colección. Este repositorio tiene un enlace a } \\
\text { MERLOT }\end{array}$ \\
\hline CLOE =Co-operative Learning Object Exchange & $\begin{array}{l}\text { Proyecto de la Universidad de Waterloo en } \\
\text { el que participan 17 universidades de } \\
\text { Ontario para el uso y reutilización de objetos } \\
\text { de aprendizaje. El acceso a los recursos } \\
\text { restringido. }\end{array}$ \\
\hline http://cloe.on.ca & $\begin{array}{l}\text { Repositorio presentado como una biblioteca } \\
\text { digital que integra las colecciones propias de } \\
\text { las bibliotecas y los de recursos educativos } \\
\text { OA. }\end{array}$ \\
\hline SMETE = Science, Mathematics, Engineering and \\
Technology Education & $\begin{array}{l}\text { El proyecto es conocido como National } \\
\text { Library in Education Advisory Task Force. } \\
\text { Gestiona a un conjunto de materiales y } \\
\text { recursos electrónicos para la educación. }\end{array}$ \\
\hline GEM://www.smete.org/smete
\end{tabular}

Tabla 5. Iniciativas de módulos de bibliotecas de OA en sistemas E-learning.

Fuente: Ángel Poveda Polo (2011)

\subsection{Definición de enseñanza electrónica (E-learning)}

Algunos autores definen la enseñanza electrónica como un proceso de aprendizaje que se vale de medios electrónicos y del uso de Internet para actuar en un entorno virtual, entendido como telemático, a distancia o en línea. Los antecedentes históricos del término señalan que fue introducido por primera vez en octubre del 1999 en los Ángeles durante el seminario sobre el sistema terapia cognitiva o-behaviorana (cognitive-behavioral therapy $\mathrm{CBT})^{18}$ como un sinónimo de la educación a distancia.

Sin embargo, lo novedoso de E-learning es su componente de interacción y la comunicación en línea. Autores como Dirk Schneckenberg (2004, p. 143-156), consideran que este nuevo modelo de educación a distancia ha transformado la educación superior, no solo por las facilidades que ofrece para aumentar el perímetro de acción, sino por las posibilidades que este brinda para ampliar el mercado lucrativo, es decir, la comercialización de servicios de educación a distancia.

Durante la investigación documental fue posible encontrar diversas definiciones e interpretaciones de E-learning que son conceptualizadas de acuerdo a realidades concretas y que varían de acuerdo a los tipos y niveles de necesidades del proyecto educativo.

\footnotetext{
${ }^{18}$ Véase reseña histórica del término E-learning en el sitio http://www.leerbeleving.nl/wbts/1/history_of_elearning.html Consultado: 14 sept. 2012.
} 
Sin embargo el punto coincidente entre ellos son los fines y objetivos educativos de formación e instrucción. En la búsqueda de un concepto estándar y universal de E-learning, se presenta en las siguientes páginas definiciones consideradas relevantes para los fines de esta tesis y que contribuyen a generar una nueva visión conceptual de E-learning.

\subsubsection{E-learning}

En el portal de E-learning de los Países Bajos $(2008)^{19}$ se define éste como “Un proceso educativo que incorpora los recursos que ofrece la tecnología para la transferencia de información y comunicación (TICS). Dicho proceso se caracteriza por su flexibilidad y dinamismo para desarrollar áreas complejas, donde el proceso de comunicación se manifiesta de forma interactiva y el aprendizaje se torna más dinámico y colectivo".

Verónica Inoue ${ }^{20}$ destaca de su entrevista realizada con Elliot Masie (1999 p.1), empresario y autor de reconocidos libros sobre E-learning ${ }^{21}$, que el concepto debe ser visto como un paraguas de significados que se refieren a diferentes aplicaciones informáticas y procesos de transferencia de información y conocimiento de manera informal y poco estructurado. Masie señala que en la práctica el término E-learning es utilizado para referirse a cursos de formación formal que inicialmente se ofrecían por televisión. Wilfred Rubens $(2009$, p.3) y Francisco José García Peñalvo (2006) consideran que la finalidad E-learning responde a dos tendencias: la formación ligada al empleo como una iniciativa para mejorar los negocios (e-bussines, y comercialización en línea) y la formación académica científica y/o en actividades de capacitación.

José Miguel Gutiérrez Pequeño (2008 p. 234) 22 aporta una definición descriptiva al referirse a Elearning como "una herramienta formativa, con una dualidad pedagógica y tecnológica. Pedagógica en cuanto estos sistemas no deben ser meros contenedores de información digital, sino que deben transmitirla de acuerdo a unos modelos y patrones pedagógicamente definidos para afrontar los retos de los nuevos contextos. Tecnológica: debido a que todo el proceso de enseñanza-aprendizaje se sustenta en aplicaciones software's, principalmente desarrolladas en ambientes Web". Enrique Vílchez Quesada (2006), concuerda con lo anterior y agrega que se trata de un nuevo concepto educativo, donde tanto las TICS y los métodos didácticos se unen para lograr el diseño y evolución de cursos de capacitación y educación a distancia, predominando un uso de medios de comunicación vía tele e Internet.

La empresa brasileña de servicios de información Laboratorio de Tecnología en Banco de Dados (TecBD) ${ }^{23}$ en correspondencia con el aporte de Gutiérrez Pequeño, materializa el concepto de Elearning como un proceso de educación, el cual es accesible a través del uso de diversos medios de comunicación, facilitando de esta forma el uso de la información en diversos formatos, diferentes tiempos y sitios ilimitados. Según TecBD la administración de los medios tecnológicos está dirigida a estimular la generación, intercambio y apropiación de conocimiento entre estudiantes, expertos e instructores en espacios físicos y virtuales. En esta misma línea, Toral Marín y otros (2006) plantean la necesidad de analizar el concepto de forma integral desde las tres perspectivas siguientes: Conjunto de procesos y productos derivados de las nuevas tecnologías (TICS); Instrumento Web utilizado para dar instrucciones en línea, y Sistema de distribución de formación a distancia. Completando el aporte anterior Jorge A. Mendoza (2003, p.1), señala que el proceso educativo virtual adquiere diferentes magnitudes e implicaciones que varían según los objetivos, actores, forma

\footnotetext{
${ }^{19}$ Texto extraído y traducido del portal http://www.e-learning.nl/subpage.aspx?|1=4\&/2=29. Consultado: 14 sept. 2008.

${ }^{20}$ Véase listado de artículos y libros publicados por Elliot Masie en http://masie.com/Research-and-Articles/ Consultado: 14 sept. 2012.

${ }^{21}$ La visión de Elliot Masie respecto al desarrollo del E-learning en Latinoamérica. Entrevista a Elliot Masie 1999. p.1 Véase: http://www.learningreview.com/articulos-y-entrevistas-elearning.

22 Texto completo disponible en dialnet.unirioja.es/descarga/articulo/3002676.pdf Consultado 4 octubre 2012.

${ }^{23}$ Articulo completo disponible en http://www.sumar.biz/E-Learning.
} 
y contenido. En el siguiente esquema, se presenta a modo de resumen estructurado la categorización hecha por Jorge A. Mendoza sobre las diferentes apreciaciones del concepto E-learning.

\begin{tabular}{|l} 
Apropiación del \\
Concepto E-learning
\end{tabular}$\left\{\begin{array}{l}\begin{array}{l}\text { Informáticos. Conjunto de aplicaciones que hacen posible } \\
\text { de forma eficiente y eficaz la entrega de material } \\
\text { educativo vía cualquier medio electrónico, incluyendo el } \\
\text { Internet, Intranet, Intranets, audio, vídeo, red satelital, } \\
\text { televisión interactivo, CD y DVD, entre otros medios. } \\
\text { Educadores - formadores. Es el uso de tecnologías } \\
\text { de redes y comunicaciones para diseñar, seleccionar, } \\
\text { administrar, entregar y extender la educación. } \\
\text { Educando - formado. La posibilidad de acceder a cursos } \\
\text { o programas de capacitación y adiestramiento a través de } \\
\text { materiales disponibles para Web a través del Internet. }\end{array} \\
\hline\end{array}\right.$

Figura 12. Interpretación del concepto E-learning según sus actores.

Fuente: Elaboración propia

Desde otra perspectiva muy interesante Marc J. Rosenberg (2001), aporta un concepto sistémico y tridimensional. Rosenberg señala que E-learning se refiere al uso del Internet en combinación armónica con la TICS con el objetivo de solventar los problemas tiempo y espacio en los procesos de generación y transferencia de conocimiento. Este autor a diferencia de Jorge A. Mendoza no analiza el concepto desde el punto de vista de los actores, sino desde tres diferentes perspectivas lógicas: estructura, proceso y medio. Con el fin de sintetizar el análisis conceptual se presenta a continuación la siguiente tabla que a manera esquemática ofrece la perspectiva del autor.

\begin{tabular}{|c|c|c|}
\hline Concepto & Interpretación & Materialización \\
\hline $\begin{array}{l}\text { Estructura real } \\
\text { Es un sistema } \\
\text { organizado con } \\
\text { estructura y forma } \\
\text { determinada }\end{array}$ & $\begin{array}{l}\text { El concepto, idea, filosofía de trabajo dan } \\
\text { origen a la estructura } \\
\text { En esta perspectiva los elementos } \\
\text { determinantes son los actores, que dan } \\
\text { sentido a la existencia del sistema y } \\
\text { permite definir con claridad los objetivos, } \\
\text { fines y resultados }\end{array}$ & $\begin{array}{l}\text { Red de trabajo dinámica } \\
\text { Sistema de distribución } \\
\text { de formación y } \\
\text { conocimientos a } \\
\text { distancia }\end{array}$ \\
\hline $\begin{array}{l}\text { Proceso coherente, } \\
\text { dinámico e } \\
\text { interactivo } \\
\text { Permite el desarrollo } \\
\text { de programas de } \\
\text { formación e } \\
\text { instrucción }\end{array}$ & $\begin{array}{l}\text { La acción organizada a través de } \\
\text { instrucciones ordenadas que hacen } \\
\text { posible el desarrollo de un proceso de } \\
\text { enseñanza - aprendizaje }\end{array}$ & $\begin{array}{l}\text { Oportunidad a la } \\
\text { verdadera } \\
\text { democratización de la } \\
\text { educación } \\
\text { Conjunto de procesos y } \\
\text { productos derivados de } \\
\text { la aplicación de las } \\
\text { nuevas facilidades que }\end{array}$ \\
\hline
\end{tabular}




\begin{tabular}{|c|c|c|}
\hline & & ofrece las TICS \\
\hline $\begin{array}{l}\text { Medio o canal } \\
\text { Una o conjunto de } \\
\text { plataformas } \\
\text { tecnológicas bien } \\
\text { pensadas y diseñadas } \\
\text { para la transmisión y } \\
\text { generación de } \\
\text { conocimiento }\end{array}$ & $\begin{array}{l}\text { Visto como el conjunto de herramientas } \\
\text { físicas que permiten la administración, } \\
\text { gestión y orientación de recursos de } \\
\text { información. En esta línea se ejemplifican } \\
\text { los diferentes hardware's o equipos } \\
\text { periféricos para el desarrollo de procesos } \\
\text { de comunicación }\end{array}$ & $\begin{array}{l}\text { Programas estructurados } \\
\text { de aprendizajes vía } \\
\text { computador y programas } \\
\text { informáticos estándares } \\
\text { Instrumento web } \\
\text { utilizado para dar } \\
\text { instrucciones en línea }\end{array}$ \\
\hline
\end{tabular}

Tabla 6. Tres dimensiones del concepto E-learning. Fuente: Elaboración propia.

Considerando los aportes anteriormente citados, el concepto de E-learning debe ser interpretado en esta investigación como un término relativamente nuevo que procede del sistema de educación a distancia, por cuanto sus objetivos están dirigidos al proceso de enseñanza aprendizaje y la transferencia de conocimientos sistematizados.

Del mismo modo y apoyados en la ciencia sistémica, es posible conceptualizar y materializar el concepto E-learning, como un sistema de servicio cuyo objetivo principal es la formación particular o grupal de individuos.

Aunque este modelo educativo puede valerse de estándares definidos tanto pedagógicos, metodológicos y tecnológicos, E-learning como sistema adquiere características propias según los objetivos, la visión académica o empresarial, condición económica y sobre todo la tipología de sus usuarios, por lo que representa el punto de partida para la generación de contenidos, servicios y nivel de aplicación de la tecnología.

\subsubsection{Componentes E-learning}

Los componentes definidos como estándares E-learning identificados en el proceso de revisión de literatura concuerdan con el aporte teórico de Marc J. Rosenberg (2001). Se trata de elementos que son determinantes en el proceso de diseño, construcción e implementación de cualquier proyecto Elearning. Dependiendo de la importancia que la empresa o institución le otorgue a cada uno de ellos, así se determinarán las características de este como sistema y servicio.

\section{Usuarios}

El usuario determina en gran medida, la estructura y característica del sistema, programa o cursos educativos. Dependiendo de la tipología de usuarios y sus necesidades, E-learning puede adquirir una estructura formal o informal. De igual manera a partir de las características de los usuarios se definen las condiciones de acceso a la información (administrativa, didáctica, técnica y científica, complementaria, productos concretos) y la orientación personalizada en línea.

\section{Contenido}

En correspondencia al tipo y nivel de profundidad en que son abordados los contenidos de los programas y cursos E-learning, estos adquieren características particulares y en algunos casos es posible generar los módulos o unidades didácticas reutilizables que factiblemente pueden combinarse en otros planes formativos y en diferentes plataformas tecnológicas. 


\section{Tecnología}

La tecnología es considerada el medio para el desarrollo de procesos de comunicación y acceso a los programas E-learning. El nivel de aplicación de las tecnologías determina la capacidad del sistema para actuar de forma dinámica e interactiva. Con el objetivo de completar lo anteriormente afirmado, en la siguiente figura se interrelaciona el concepto y sus componentes a fin de acercarnos al enfoque sistémico de E-learning.

\section{Enfoque conceptual de E-learning --- > ESTRUCTURA / PROCESO /MEDIO}

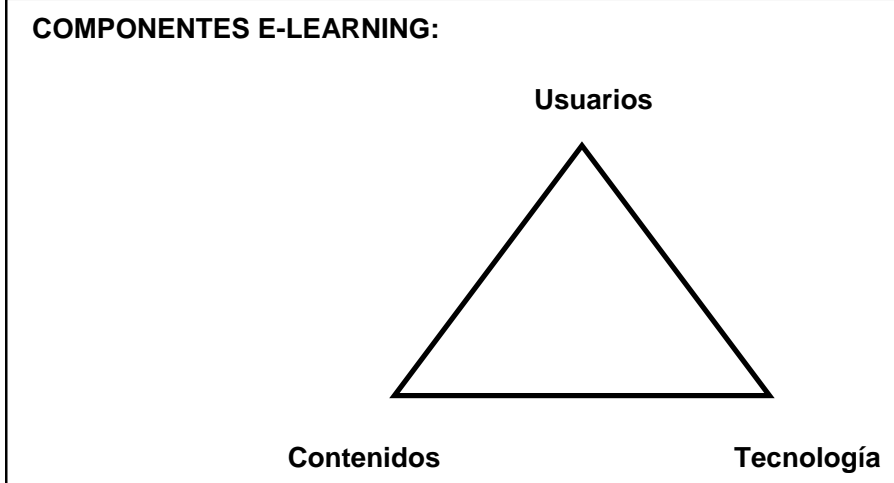

En las relaciones sistémicas entre estos componentes, se destaca la tecnología como punto de unión entre los usuarios y el contenido y es a su vez medio o canal para entrada y salida.

\section{Usuarios}

Dependiendo del nivel y Software-Hardware características de los usuarios se identifican y se seleccionan los contenidos. Se define el nivel de aplicación de las tecnologías

Contenidos

Conocimiento sistematizado

$$
\text { Internet e Intranet }
$$

\section{Grupo meta}

Razón de ser de los objetivos

Medio de salida

Puntos de acceso

Cursos E-learning

Productos
Permiten definir estrategias y medios pedagógicos didácticos para el desarrollo del proceso Enseñanza - Aprendizaje

Servicios 


\title{
3.3 Aspectos pedagógicos y didácticos importantes
}

Los nuevos desafíos para las universidades no se reducen sólo a la creación de programas educativos en espacios virtuales o al mejoramiento de las infraestructuras tecnológicas, sino a la búsqueda de modelos de enseñanza - aprendizajes flexibles a cambios tecnológicos y de otro tipo. En este contexto el personal docente deberá ser capaz de asumir una nueva serie de roles que no son sustituibles por los recursos o procesos automatizados; hecho que demanda a los docentes ir más allá de su actividad académica y asumir roles de comunicadores, pedagógicos-didácticos, de gestiónadministración, social y de apoyo técnico. En esta línea y en un ámbito internacional, se debaten dos modelos de enseñanza aprendizaje que tienen una fuerte influencia en el desarrollo de programas o cursos E-learning. Se trata de un modelo conductista y un modelo cognitivo - constructivista que a continuación se explican brevemente.

\subsubsection{Modelos pedagógicos}

\section{Modelo behaviorista - conductista}

Incorpora una Psicología conductista que identifica al alumno como un sujeto pasivo y receptor de los conocimientos transmitidos por el docente, profesor o instructor.

Modelo behaviorista - conductista

Docente - Profesor

Alumno - Estudiante $\longrightarrow$ Canal principal de transmisión de información y conocimiento

\section{Modelo cognitivo -constructivista de Piaget}

Este modelo parte de la idea que la construcción de conocimiento es continua y se caracteriza por la formación de estructuras asociadas a esquemas mentales, por tanto el aprendizaje direccionado como proceso construido por el estudiante y el aprendizaje es orientado o guiado por el docente. De esta forma este modelo estimula el desarrollo cognitivo del alumno, el desarrollo de habilidades grupales y por ende formas de trabajo cooperativas.

\section{Modelo cognitivo - constructivista de Piaget}

\author{
Docente - Profesor $\longrightarrow \quad$ Encamina el proceso de aprendizaje \\ Estimula la apropiación del conocimiento
}

Alumno-Estudiante $\longrightarrow \quad$ Receptor activo-proactivo 
Es importante señalar que del modelo cognitivo ha surgido el modelo cooperativista. Aunque este sigue la corriente constructivista de Piaget, centra mucho más atención al desarrollo de habilidades grupales y la socialización a través de discusiones entre pares y la valoración a los aspectos socioafectivos. Muy a pesar que ambos modelos son la base de prácticas educativas, en la actualidad, Elearning no responde estrictamente a ninguno de ellos, debido a que las características pedagógicas y didácticas en E-learning tienen su base en la tipología de estudiantes, los contenidos (tema y nivel de profundidad) y la disponibilidad y nivel de aplicación de las tecnologías. No obstante, esta afirmación no descarta la posibilidad que los modelos de Piaget y el modelo behaviorista se vean incorporados de forma combinada en determinados momentos del proceso enseñanza-aprendizaje E-learning.

\subsubsection{Formas o modalidades E-learning}

Existe un alto grado de flexibilidad en las formas y tiempos de docencias, razón por la cual, las políticas de docencia son definidas a partir de la tipología de usuarios, tipo de contenido, aspectos pedagógicos, aspectos metodológicos y los recursos económicos y tecnológicos disponibles. Actualmente existen dos categorías definidas para las formas y modalidades de docencias esta son: sincrónica y asincrónica. Algunos aportes en esta línea están disponibles en el portal de E-learning de los Países Bajos (web E-learning.nl), que son retomados en la siguiente tabla, a fin de ofrecer algunas pautas que permitan diferenciar los modelos E-learning a partir de su aplicación y práctica de estos. ${ }^{24}$

\begin{tabular}{|c|c|}
\hline $\begin{array}{l}\text { Modalidades } \\
\text { (proceso) }\end{array}$ & $\begin{array}{l}\text { FORMAL. Implica o se refiere a un proceso estructurado y sistemático } \\
\text { (objetivos-método-resultado) que se desarrolla en un espacio y tiempo } \\
\text { determinado. Ejemplo de esto son los procesos educativos y formativos } \\
\text { en empresas, institutos, etc. } \\
\text { INFORMAL. Se caracteriza por ser un proceso espontáneo que surge de } \\
\text { una necesidad concreta y se manifiesta como iniciativa del individuo que } \\
\text { experimenta la necesidad. }\end{array}$ \\
\hline $\begin{array}{l}\text { Metodología } \\
\text { (aspectos } \\
\text { pedagógicos) }\end{array}$ & $\begin{array}{l}\text { METODOLOGÍA. Las teorías de educación formal y regular tienen } \\
\text { influencia en el modelo E-learning, sin embargo no existe un modelo fijo } \\
\text { de enseñanza - aprendizaje. Lo que actualmente ocurre es una fuerte } \\
\text { tendencia a la incorporación de dos modelos de enseñanza aprendizaje: } \\
\text { a. El modelo conductista behaviorista y b. El modelo cognitivo - } \\
\text { constructivista de Piaget. }\end{array}$ \\
\hline Forma (tiempo) & $\begin{array}{l}\text { SINCRÓNICO. En esta forma de E-learning sobresale como característica } \\
\text { particular el factor tiempo y espacio que son determinantes y claramente } \\
\text { definidos. } \\
\text { ASINCRÓNICO. Contrariamente al sincrónico el factor tiempo y espacio no } \\
\text { están definidos, y existe flexibilidad. }\end{array}$ \\
\hline
\end{tabular}

Figura 14. Modalidades de E- learning.

Fuente: Elaboración propia.

\footnotetext{
${ }^{24}$ Texto traducido e interpretado por Karla Vanessa Bonilla. http://www.e-learning.nl/subpage.aspx?l1=4\&|2=29. Consultado 28 Ene 2009.
} 


\subsection{Estructura organizativa de E-learning}

Las estructuras organizativas E-learning obedecen a la aplicación de pensamientos teóricos de gestión de la información (conocimientos), sin embargo la estructuración y organización se materializa en el uso de medios tecnológicos (hardware y software) para la construcción de los programas educativos operables en espacios virtuales en los que se destacan los sistemas de gestión de aprendizaje virtual (LMS Learning Management System).

El diseño y construcción de facilidades, espacios y medios virtuales para el desarrollo de actividades E-learning en sus tres dimensiones funcionales: proceso - medio - estructura y en correspondencia con los objetivos, las necesidades y recursos disponibles son el punto de partida para la construcción de la estructura organizativa y funcional E-learning. Para completar estas propuestas y, extraído del mismo portal holandés antes citado, a continuación se indican algunos aspectos a tomar en consideración al momento de diseñar y/o gestar programas o actividades E-learning. ${ }^{25 .}$

1. Conocimiento y reconocimiento institucional. Se requiere experiencia institucional de gestión de programas E-learning como negocio-organización o empresa. En caso de carecer de este tipo de experiencias se recomienda las alianzas con otras instituciones expertas.

2. Gestión. Se refiere al proceso interno y de seguimiento a nivel interno del proyecto, es decir quién dirige, coordina las aplicaciones tecnológicas. En este aspecto es necesario prestar atención a entorno y cultura organizativa.

3. Financiero. Aspectos de inversión y rentabilidad. Los costos iniciales independientemente que son grandes, son recuperables en el tiempo. La inversión inicial debe ser vista como la sustitución de altos costos de logísticas, viajes, y del local donde se realizan las jornadas de formación y capacitación.

4. Competencias profesionales. Se refiere a la necesidad de contar con experiencia profesional y suficientes puntos de competencia para el buen manejo y gestión de proyectos y programas E-learning. Se requiere además de excelentes habilidades para el desarrollo de procesos de comunicación. Todas estas competencias se resumen en un grupo de especialistas en contenidos, diseñadores, especialistas en sistemas, programadores de software, expertos en media y gráficos.

5. Flexibilidad para cambios constantes. El éxito completo de E-learning está garantizado por la flexibilidad que este tenga para ajustarse o asimilar y adaptar los cambios tecnológicos y socioculturales. Esto se refiere no sólo a tecnologías, sino también al grupo de especialistas involucrados en los programas o proyectos.

En la tabla 7 se presentan algunos aspectos a considerar en la construcción de diseños de programas E-learning. Para su elaboración se han tenido en cuenta diferentes aspectos relacionados con la gestión de contenidos en un sistema formativo, su realización en un entorno virtual de aprendizaje telemático y las características derivadas de la administración o gestión del curso. Se trata de una representación básica que sirve para disponer de una visión esquemática de estos elementos.

\footnotetext{
${ }^{25}$ Texto traducido e interpretado por Karla Vanessa Bonilla

Fuente: Sitio web. http://www.e-learning.nl/Elearning.aspx Consultado 4 octubre 2012.
} 


\begin{tabular}{|c|c|c|}
\hline $\begin{array}{l}\text { Gestión de } \\
\text { contenidos }\end{array}$ & Entorno virtual & $\begin{array}{l}\text { Administración y gestión del } \\
\text { curso }\end{array}$ \\
\hline $\begin{array}{l}\text { Acceso a contenidos } \\
\text { autorizados } \\
\text { Metadatos y } \\
\text { repositorios } \\
\text { (Acceso a Información } \\
\text { propiamente dicha y } \\
\text { diversa) } \\
\text { Objetos de } \\
\text { aprendizaje }\end{array}$ & $\begin{array}{l}\text { Planificación del proceso de } \\
\text { enseñanza - aprendizaje } \\
\text { Diseño pedagógico } \\
\text { Construcción social - } \\
\text { Estímulo para la interacción } \\
\text { Modelo estándar pedagógico } \\
\text { Perspectiva cognoscitiva } \\
\text { estimulante del proceso } \\
\text { cognoscitivo } \\
\text { Perspectiva emocional } \\
\text { Puntos de motivación }\end{array}$ & $\begin{array}{l}\text { Registro y control de } \\
\text { estudiantes } \\
\text { Manejo del perfil de } \\
\text { estudiantes } \\
\text { Manejo de los servicios en } \\
\text { línea } \\
\text { Servicios de Referencia } \\
\text { Biblioteca } 2.0 \\
\text { Blog } \\
\text { Gestión de procesos de } \\
\text { comunicación }\end{array}$ \\
\hline
\end{tabular}

Tabla 7.Organización y gestión de la información y contenidos en procesos E-learning. Fuente: Elaboración propia

\subsection{Estándares E-learning}

La aplicación de estándares en programas educativos E-learning es un tema en constante desarrollo debido a que se requiere dar respuesta a las demandas de los usuarios y fundamentalmente por la necesidad de ajustes y actualización a los constantes cambios en las aplicaciones y/o modernización de las plataformas tecnológicas. Seguidamente se presenta el concepto estándar y algunas relevantes iniciativas de estándares de E-learning que sobresalen en el ámbito internacional.

\subsubsection{Definición de estándares}

Existe mucha convergencia sobre el concepto de estándar, pero en su mayoría existe coincidencia en la definición de estos estándares. La Organización Internacional de Estandarización / International Organization for Standardization (ISO) en su web ${ }^{26}$ define estándar como "un conjunto de especificaciones técnicas y criterios para ser utilizados constantemente como reglas, lineamientos o definiciones de características, para asegurar que materiales, productos, procesos y servicios sean adecuados para sus propios propósitos."

El British Standard Institute (BSI) también aporta en su sitio web ${ }^{27}$ una definición y análisis del término y define estándar como conjunto de especificaciones publicadas que establecen un lenguaje común que contiene una descripción técnica u otros criterios para ser usado constantemente ya sea como una regla, un lineamiento o una definición.

\footnotetext{
${ }^{26}$ La vinculación de la definición de estándar a los objetivos de la empresa ISO se amplía en el sitio web: http://www.iso.org/iso/home/standards.htm Consultado 4-octubre 2012

${ }^{27}$ De forma amplia se explica la definición de estándar en el sitio de la empresa Bsi. http://www.bsigroup.com/en/Standards-and-Publications/About-standards/What-is-a-standard/ Consultado 4-octubre 2012
} 
Desde una perspectiva aplicada a E-learning, Foix y Zavando (2002, p. 21), afirman que "Ios estándares E-learning son el vehículo a través del cual es posible dotar de flexibilidad a los contenidos e infraestructura".

\subsubsection{Tipos de estándares E-learning}

Durante el proceso de revisión de literatura sobre E-learning se identificaron dos tipos principales de estándares E-learning, los que fueron aprobados por organismos y empresas internacionales de normalización y los estándares de facto. Un ejemplo de adopción de estos dos tipos de estándares de E-learning corresponde al grupo de trabajo de E-learning de la empresa The MASIE Center $(2002)^{28}$ quien en su guía de trabajo integra y diferencia la siguiente clasificación de estándares:

Estándares con derechos legales reconocidos. Son legalmente reconocidos. Su existencia se justifica y materializa mediante una certificación jurídica y registro único proveniente de una institución formal y oficialmente reconocida.

Estándares de facto. Surgen cuando una mayoría adopta ciertas reglas o especificaciones para aplicar una tecnología específica. Los estándares de facto surgen de una necesidad individual o grupal. Son aplicables y funcionales pero carecen de un proceso de legitimación. Una vez que los estándares de facto son aplicables y reconocidos popularmente, el proceso de legitimación se convierte en una necesidad.

Estudios del tema en conformidad señalan además que la aplicación de cualquier tipo de estándares debe responder a los siguientes objetivos:

- Durabilidad - Disminuir el peligro de obsolescencia de los cursos.

-Interoperabilidad - Intercambio de información a través de diferentes aplicaciones LMS.

- Accesibilidad - Seguimiento al comportamiento de los alumnos.

- Re usabilidad - Los diferentes cursos y unidades de aprendizaje pueden ser utilizadas en combinaciones con otros cursos. Asimismo pueden ser nuevamente utilizados como unidades independientes.

-Viabilidad económica - La aplicación del estándar permite el aprovechamiento de la inversión, por cuanto la certificación garantiza la calidad de los cursos en el mercado.

- Comercialización -Los cursos, productos y servicios E-learning resultan amigables y fáciles de incorporar en otros sistemas. La utilización de estándares permite el manejo de estos en otras plataformas.

- Descentralización - para el desarrollo de los contenidos sin tener que recurrir a un especialista en informática de plataformas E-learning.

\footnotetext{
${ }^{28}$ Making sense of learning specifications and standards. The MASIE Center; S3 Working Group Membership. A Decision Maker's Guide to their Adoption March 8, 2002. Disponible en http://www.staffs.ac.uk/COSE/cosenew/s3_guide.pdf Consultado 4-octubre 2012.
} 


\subsubsection{Iniciativas de estándares E-learning}

El manejo del concepto estándar en la práctica para el desarrollo de procesos de formación telemáticos que faciliten el intercambio de información y comunicación, ha motivado el interés de organizaciones y empresas internacionales para desarrollar estándares universales que faciliten la cooperación y reutilización de recursos para la educación. Ejemplos concretos de estas iniciativas se presentan a continuación.

The Aviation Industry CBT Committe $(\text { AICC })^{29}$ fue creada en 1992 por el comité de trabajo Computer Based in Training con el objetivo de desarrollar normativas de homogeneización. Los aportes más relevantes fueron los estándares relacionados con los objetos de aprendizaje (LO Learning Objects), y relacionados con la interoperabilidad de las plataformas de aprendizaje (Learning Management System LMS). Las normativas reconocidas se listan a continuación.

AGR 001 AICC publications

AGR 002 Courseware

AGR 003 Digital Audio

AGR 004 Operating Windowing System

AGR 005 Computer Based Training (CBT) Peripheral Devices

AGR 006 Computer Managed Instruction

AGR 007 Courseware interchange

AGR 008 Digital video

AGR 009 Icon Standard: User Interface

AGR 010 Web-Based Computer- Managed Instruction

Institute of Electrical and Electronics Engineers (IEEE y eLearning Technologies Standards Committee $\left(\right.$ LTSC) ${ }^{30}$ Promueve las normas ISO. Remota y supera el trabajo de AICC creando una versión de metadatos ofrecida en la AGR010. Los aportes hasta el momento han sido la elaboración de normas técnicas, guías y prácticas para el uso informático con el objetivo de buscar la operatividad. Actualmente trabaja en forma coordinada con otras iniciativas dedicadas a la normalización en el ámbito de las tecnologías de la información para la educación y aprendizaje. Las aportaciones más relevantes son los estándares siguientes aportaciones:

- Aspectos generales

IEEE 1484.1 Modelo de referencia y arquitectura del sistema

- Metadatos

IEEE 1484.12 Objetos de aprendizaje Metadato

IEEE 1484.14 Semántica y enlaces de intercambios

IEEE 1484.15 Protocolos de intercambio de datos

- Sistema de manejo del aprendizaje (LMS)

IEEE 1484.11 Manejo de Instrucción

\footnotetext{
${ }^{29}$ Véase mayor detalle en el sitio http://www.aicc.org/joomla/dev.

${ }^{30}$ Véase mayor detalle en el sitio http://www.ieee.org/index.html.
} 
IEEE 1484.18 Plataformas y perfiles de medios de comunicación

IEEE 1484.20 Definición de competencias

IMS Global Learning Consortium, Inc. ${ }^{31}$ Conformado por instituciones públicas y privadas. Retoma y mejora las iniciativas desarrolladas por AUCC y la IEEE. Los aportes más significativos se resumen a la creación de una nueva forma de trabajo en fichero XML para la descripción de contenidos, logrando que cualquier LMS pueda cargar cualquier curso.

Las especificaciones de LMS constan de tres documentos principales:

a. El modelo de recurso de información como parte del sistema de manejo de la enseñanza (LMS- learning Resource Meta-data Information Model).

b. Recurso de aprendizaje XML con especificaciones de enlaces (Learning Resource XML Binding Specifications).

c. Recurso metadato con mejores prácticas y guía de implementación (Learning Resource Meta-Data Best practices and Implementation Guide).

Los estándares más reconocidos de IMS Global se listan a continuación:

- LOM - Learning Object Metadatos. Orienta el proceso de identificación, etiquetación y organización de los contenidos e información de los alumnos, a fin de que puedan interactuar.

- Content packaging - Empaquetamiento de contenidos. Ofrece las especificaciones para describir y empaquetar material de aprendizaje, facilitando la ubicación de los materiales en línea. Esta idea se ha aplicado como estándar dentro de diferentes LMS y ha sido comercializada por Microsoft bajo el nombre de LRN (Learning Resource Interchange).

- Question ad Test Interoperability (QTI) Interoperabilidad de Preguntas y Tests. Propone una estructura XML para codificar preguntas y tests en línea, facilitando así el intercambio y evaluación de los datos entre distintos LMS.

- Learner Information packaging LIP. Empaquetamiento de la información del alumno. Define estructuras XML para el intercambio de los alumnos con los diferentes sistemas de gestión del aprendizaje.

- Advanced Distributed Learning (ADL)- SCORM es una iniciativa creada en 1997 en los Estados Unidos para el desarrollo de guías para el diseño e implementación de programas educativos vía web. Retoma los aportes más valiosos referentes a los sistemas de descripción de cursos XML del LMS como punto de partida para crear su propio estándar SCORM (Shareable Content Object) Reference Model (modelo de referencia para objetivos de contenidos intercambiables).

Sus especificaciones al igual que la IMS se organizan en tres documentos separados y agrupados en dos grandes temas:

\footnotetext{
${ }^{31}$ Véase documento completo en el sitio http://www.imsglobal.org/specifications.html y en español un resumen presentado en el informe MEC en el sitio http://ares.cnice.mec.es/informes/11/contenido/25.htm.
} 
Scorm Overview. Ofrece la descripción general de la iniciativa ADL, un análisis SCORM y un resumen de las especificaciones técnicas.

Scorm Content Aggregation Model. Ofrece una guía para incorporar contenidos o información en cursos ya estructurados. Describe el Scorm content packaging, hace referencia a Learning Resource Meta-Data Model de IEEE -LTSC y el Learning Object Meta-Data (LOM) Specification de IMS y ARIADNE - Alliance of Remote Instructional Authoring and Distribution Networks for Europe.

Scorm Rum Time Enviroment. Incluye una guía para lanzar contenidos y darles seguimientos en un ambiente web. El libro es derivado del CMI001 (Guidelines for interoperability de AICC).

Partiendo de la lista de estándares antes señalados, se presenta la concordancia entre las diferentes iniciativas de estándares E-learning. En ella se puede observar la coincidencia entre los aspectos generales, manejo de gestión de cursos y una significativa variación en cuanto al manejo de información - contenidos.

\begin{tabular}{|l|l|}
\hline Estándares & Aspectos de contenidos - metadatos \\
\hline AICC & Desarrolla objetos de aprendizaje multimedia \\
\hline IEEE & Cuida de la semántica de los metadatos \\
\hline IMS & Estimula la aplicación de portales \\
\hline ADL - SCORM & $\begin{array}{l}\text { Promueve un modelo de recursos metadatos basados en el } \\
\text { uso de la web }\end{array}$ \\
\hline
\end{tabular}

Tabla 8. Áreas desarrolladas por los estándares E-learning.

Fuente: Elaboración propia

\subsection{Sistemas E-learning}

Analizar aspectos de plataforma tecnológica E-learning es hacer referencia al desarrollo o aplicaciones informáticas dirigidos a facilitar procesos de comunicación y transferencia de información a través de Internet e intranet en programas educativos presenciales, semipresenciales y E-learning. Diferentes empresas y organizaciones E-learning han desarrollado aplicaciones que están siendo utilizadas mundialmente para el desarrollo de programas educativos. Sin embargo, las prácticas de enseñanza-aprendizaje mediante el uso de computadoras preceden a la existencia y aplicación de Internet.

La educación electrónica incorpora el mismo concepto y objetivos de aprendizaje de la educación a distancia. La variante principal en E-learning es la forma y práctica de aplicación. El uso de redes de comunicación para el desarrollo de nuevos programas de educación a distancia ha marcado el inicio de una nueva modalidad de enseñanza y con esto nuevos entornos de aprendizaje denominados "plataformas E-learning" que tiene como principal objetivo "llenar vacíos" en la oferta en relación a las necesidades y demandas.

En esta línea, una plataforma E-learning puede ser definida como la base y medio para el desarrollo de procesos de comunicación, manejo de contenido y acceso a los estructurados programas Elearning, es decir, conjunto de programas (Sistemas de Manejo de Enseñanza LMS), que cumplen con características y estándares internacionales para el manejo de diversos tipos de información y contenido que son necesarios para el desarrollo de programas o cursos de educación a distancia vía Internet.

Kenneth Delgado (2005), define las plataformas como soportes de contenido que se valen de recursos de comunicación tales como email, chat, listas etc., con el objetivo de facilitar la 
administración y entrega de información. En esta línea Sharon Monti y Félix San Vicente (2006, p.3), textualmente definen "una plataforma E-learning es una herramienta tecnológica que funciona como un soporte para la enseñanza virtual, es decir, un software que permite distribuir contenidos didácticos y organizar cursos en línea".

Asimismo la empresa The Australian Flexible Learning Community define las plataformas E-learning como una infraestructura operada a través un servidor a modo de web, que es accesible a través de Intranet e Internet ${ }^{32}$ mediante un programa o software, que posibilita el contacto directo entre alumno y profesor en un espacio virtual.

\subsubsection{Clasificación de las plataformas E-learning}

En la actualidad, existen muchas iniciativas de plataformas E-learning que pueden ser clasificadas de forma general en los siguientes dos grupos. Primero las plataformas E-learning de código cerrado que se caracterizan por su capacidad de incorporar cursos diseñados o utilizados por terceros.

El segundo grupo son las plataformas E-learning de código abierto que son utilizadas para la construcción de cursos o contenidos a través del uso de tecnologías open source, sistemas operativos Linux, lenguaje PHP, Java, Pearl o las tecnologías Microsoft como sistema operativo Windows y lenguaje ASP.

Se caracterizan por su flexibilidad y capacidad para ser ajustable a diversas necesidades. Ampliando este aspecto José Valentín Álvarez Álvarez (2004, p.153-172), plantea otro nivel de clasificación de las plataformas que está en dependencia al origen y/o introducción dentro de la empresa y que a continuación se explican:

\section{Compradas}

Se trata de una plataforma predefinida para el desarrollo de programas E-learning. El proveedor se ajusta y está de acuerdo a las necesidades del cliente y las especificaciones de requerimientos hardware - software. Es decir, utiliza la misma plataforma base como estándar, pero las características propias se adquieren de acuerdo a los objetivos de las instituciones y los clientes.

\section{Alquiladas}

Se trata de una plataforma también predefinida la cual es adaptada a determinadas necesidades, no obstante el proveedor es el propietario y el único quien define los límites de acceso y las incorporaciones de nuevas aplicaciones. Asimismo la actualización y mantenimiento son responsabilidad de la entidad propietaria.

\section{Desarrolladas internamente}

Son aplicaciones informáticas que se desarrollan a lo interno de las instituciones. También son iniciativas que generalmente van surgiendo como respuesta a demandas y necesidades concretas. La limitación o desventaja de estas iniciativas, radica en que casi siempre tienen una visión corta, no cuentan con aplicación de estándares, implican mucha inversión de tiempo y dinero que muchas veces no ha sido previsto.

\footnotetext{
${ }^{32}$ The Australian Flexible Learning Community es una empresa especializadas en E-learning. Información sobre la empresa esta disponible en http://flexiblelearning.net.au/; http://flexiblelearning.net.au/ Consultado: 4-octubre 2012.
} 


\section{Acceso libre (Open Access, GPL)}

Son sistemas de gestión de contenidos de código abierto (Open Source Course) Estos son desarrollados como iniciativas particulares $y / 0$ institucionales pero en cumplimiento de determinados estándares y que se encuentran disponibles de acceso libre en Internet.

\subsubsection{Evolución de las plataformas E-learning}

El estudio de las plataformas exige la revisión sistémica de los procesos evolutivos de los programas computacionales de educación a distancia hasta llegar a las actuales plataformas E-learning, a fin de reconocer las variantes técnicas en sus estructuras.

El uso de recursos telemáticos en la modalidad de educación a distancia respondió a la necesidad de transferir conocimiento de forma visual y sonara. Con este fin se utilizaron cintas sonoras, videos de televisión, computadoras y hoy día de los recursos que ofrece la Internet.

Como es lógico la introducción de cada medio ha generado cambios no solo en las formas de transferir los contenidos, sino también en la metodología, didáctica y forma de gerencia. La revisión de los antecedentes históricos de la educación a distancia hasta la actual modalidad E-learning, permitió reconocer seis fases de la evolución de los modelos de sistemas educativos a distancia a través de computadoras que a continuación se explican.

1.- Aprendizaje basado en computadoras. (CBT = Computer Based Training). La función de este modelo era de servir como una herramienta facilitadora de acción complementaria al proceso de aprendizaje.

2.- Instrucción asistida a través de computadoras. (CAI = Computer Assisted Instruction). El enfoque está orientado al acompañamiento dentro y fuera del entorno físico. El estudiante nunca ésta sólo; el factor tiempo para el autoaprendizaje se torna flexible.

3.- Aprendizaje basado en Internet (IBT = Internet Based Training). La introducción de los medios de comunicación ofrecidos por la Internet incorpora y completa las funciones de los modelos anteriores y agrega una característica de dinámica en las relaciones entre educador y educando.

4.- Aprendizaje basado en web (WBT $=$ Web Based Training). Mantiene la característica dinámica en el proceso de aprendizaje. A través del uso de la web, integra aspectos de instrucción, comunicación, acompañamiento, seguimiento de forma interactiva sin límites de espacios y tiempo.

5.- Sistema de gestión del aprendizaje (LMS). Consiste en la utilización de un sistema de manejo de procesos de enseñanza aprendizaje. Incorpora todas las características y facilidades de los cuatros sistemas antes señalados. Se reconoce un sistema modular e integrado permite que sea utilizado para diversos propósitos de forma conjunta por diferentes actores. Se considera el punto de partida para el diseño de plataformas E-learning. Beth Davis y otros autores (2009) afirman que las primeras aplicaciones de los LMS operadas desde Internet ocurren con éxito aproximadamente en 1990.

6.- Sistemas de gestión de contenidos de aprendizaje (LCMS) Posteriormente a los LMS surge un nuevo modelo de plataforma que integra y completa las funciones CMS y LMS para Elearning. En la actualidad se conoce como E-learning Content Management System (LCMS) y representa ser la última versión de plataforma E-learning. 
Si tomamos textualmente la descripción anterior, podemos señalar que el desarrollo evolutivo de la plataforma E-learning actualmente se ubica en la forma de sistemas LCMS. Con el objetivo de sintetizar estas seis fases evolutivas, en un orden ascendente en la siguiente figura se resume dicho proceso evolutivo.

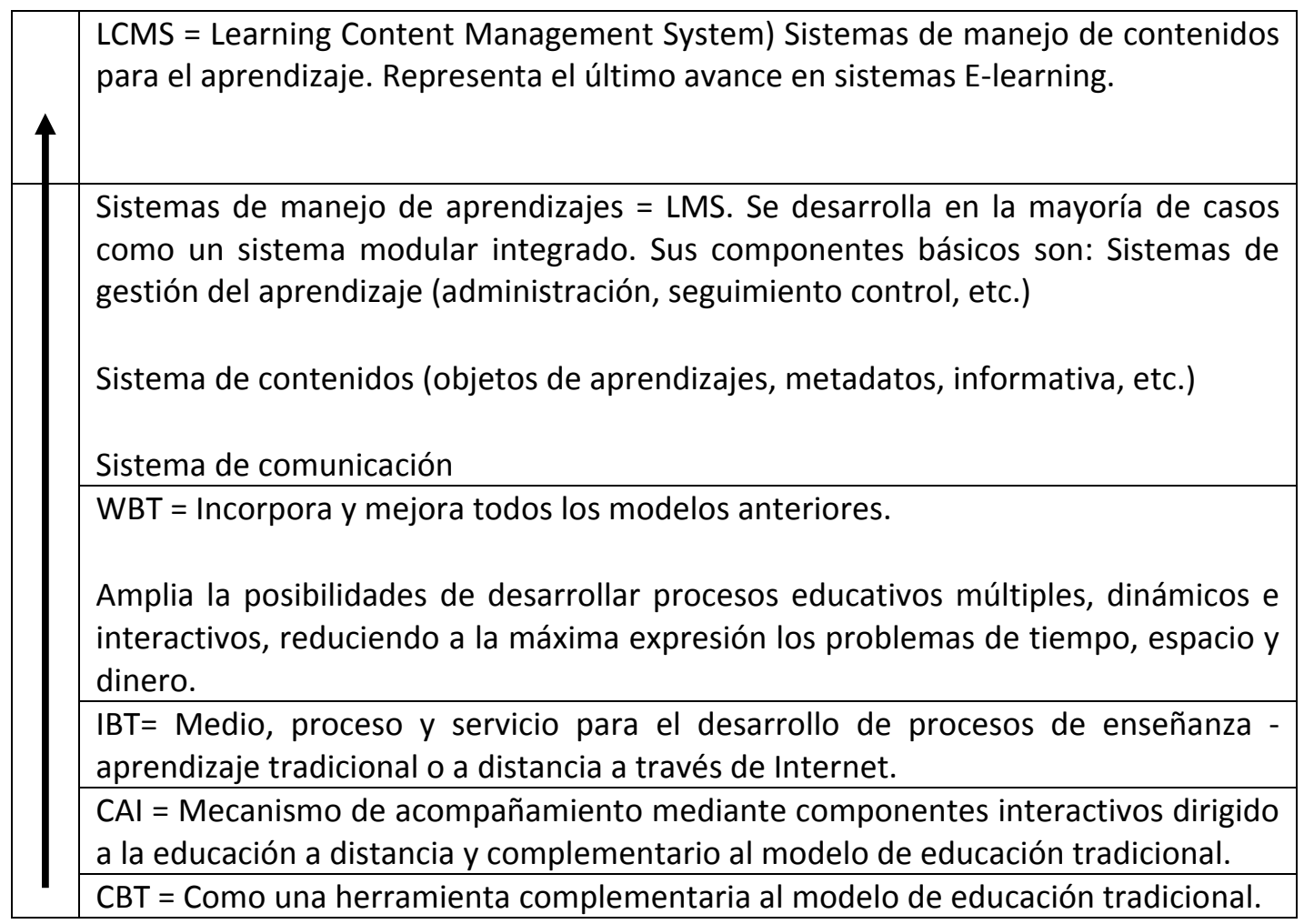

Figura 15. Evolución histórica de los sistemas de gestión de contenidos.

Fuente: Elaboración propia

En correspondencia con el análisis y en la búsqueda de encontrar diferencias entre los sistemas basados en computadoras y los basados en web (LMS E-learning, nuevamente Monti y San Vicente (2006 p.6), consideran que una plataforma E-learning a diferencia de la web funciona como un ambiente donde los estudiantes llevan a cabo actividades individuales de tipo con los contenidos del curso (autoaprendizaje), así como actividades con la comunidad (aprendizaje colaborativo). Asimismo, Josep M. Boneu (2007), en un artículo sobre plataformas E-learning, establece cinco diferencias generales que complementan el análisis evolutivo de estos sistemas. En la siguiente tabla se observan algunas diferencias marcadas y que a continuación se explican.

\begin{tabular}{|l|l|l|}
\hline Característica & Sistemas CBT & Plataformas E-learning \\
\hline Modelo pedagógico & Centrado en el profesor & Centrado en el alumno \\
\hline Finalidad & Distribuir contenidos & $\begin{array}{l}\text { Distribuir contenidos y } \\
\text { capturar el conocimiento }\end{array}$ \\
\hline $\begin{array}{l}\text { Tipo de componente } \\
\text { educativo }\end{array}$ & Curso completo & $\begin{array}{l}\text { Trozos de contenido u } \\
\text { objetos de aprendizajes }\end{array}$ \\
\hline Creación de contenido & Desde Cero & Reutilización de contenido \\
\hline $\begin{array}{l}\text { Tiempo requerido para el } \\
\text { aprendizaje }\end{array}$ & Días, semanas, meses & Horas \\
\hline
\end{tabular}

Tabla 9. Diferencias entre sistemas CBT y sistemas E-learning.

Fuente: Josep M. Boneu. Plataformas abiertas de e-learning para el soporte

de contenidos educativos abiertos, 2007. p.37. 
El mismo autor destaca tres diferencias importantes que son consideras premisas para el desarrollo de los Learn Management System (LMS), en comparación a los Computer Based Training (CBT).

Diferencia 1. Enfoque del modelo

Los CBT fueron pensados para facilitar el proceso de enseñanza - aprendizaje desde la perspectiva del modelo behaviorista conductista y con el fin de facilitar el trabajo del docente. En cambio, los sistemas LMS parten del modelo cognitivo -constructivista de Piaget con un objetivo: el desarrollo cognitivo del alumno, habilidades grupales y el trabajo cooperativo.

Diferencia 2. Modalidad y forma

Los CBT son vistos como un complemento para el acompañamiento y seguimiento de procesos y actividades dentro de cursos completos, siendo el punto más fuerte de estos sistemas la distribución de contenidos. Los sistemas LMS que además de cumplir con esta función, permite utilizar y reutilizar partes o todos los contenidos para otras actividades paralelas independientes de la modalidad y forma del curso.

Diferencia 3. Gestión y utilización de contenidos

La tercera diferencia es la reutilización de los contenidos. Los CBT desarrollan para cada curso nuevos contenidos, en cambio los sistemas LMS permiten la reutilización y adecuación de los mismos tantas veces como sea necesario. Algunos autores consideran que el origen de la plataforma E-learning se debe al mejoramiento de los Sistemas de Manejo de Contenido $(C M S)^{33 .}$ Otros opinan que es el resultado de la integración de diferentes sistemas como es el caso del LCMS (unión de lo CMS y LMS) que tiene como base aplicaciones basadas en web, donde se da más atención a los contenidos y no la web misma como medio.

En un intento de aportar al correcto manejo de ambos conceptos, se presenta a continuación una tabla extraída del sitio web de la empresa Brandon Hall ${ }^{34}$ y traducida al castellano por Josep M Boneu (2007), en la que establece una diferencia entre los sistemas LMS y los CLMS, aspecto que es necesario tener claro antes de introducirse a la revisión del uso de estas plataformas en la biblioteca.

\begin{tabular}{|l|l|l|}
\hline Usos & LMS & LCMS \\
\hline Usuarios a los que va dirigido & $\begin{array}{l}\text { Responsable de los } \\
\text { cursos, administradores } \\
\text { de formación, profesores } \\
\text { e instructores }\end{array}$ & $\begin{array}{l}\text { Diseñadores de contenido, } \\
\text { diseñadores de instructivos, } \\
\text { directores de proyectos }\end{array}$ \\
\hline $\begin{array}{l}\text { Gestión de clases, formación } \\
\text { centrada en el profesor }\end{array}$ & Sí (No siempre) & No dispone \\
\hline Administración & $\begin{array}{l}\text { Cursos, eventos de } \\
\text { capacitación y gestión } \\
\text { estudiantes }\end{array}$ & $\begin{array}{l}\text { Contenidos para el } \\
\text { aprendizaje y soporte para los } \\
\text { usuarios }\end{array}$ \\
\hline $\begin{array}{l}\text { Análisis de competencias - } \\
\text { habilidades }\end{array}$ & Sí & Sí (en algunos casos) \\
\hline $\begin{array}{l}\text { Informe del rendimiento y } \\
\text { seguimiento de los participantes }\end{array}$ & Enfoque principal & Enfoque secundario \\
\hline
\end{tabular}

\footnotetext{
${ }^{33}$ Los sistemas Content Management Systeem (CMS) son también conocidos como Course Management Systeem y Web Content Management (WCM).

${ }^{34}$ El sitio Web del Grupo Brandonhall ofrece otros interesantes artículos sobre el tema veáse http://www.brandonhall.com/ Consultado 3 octubre 2012.
} 


\begin{tabular}{|l|l|l|}
\hline en la formación & & \\
\hline Colaboración entre usuarios & Si dispone & Si dispone \\
\hline $\begin{array}{l}\text { Mantiene una base de datos de los } \\
\text { usuarios y sus perfiles }\end{array}$ & Si dispone & No dispone \\
\hline Agenda de eventos & Si dispone & No dispone \\
\hline $\begin{array}{l}\text { Herramientas para la creación de } \\
\text { contenidos }\end{array}$ & Si dispone & No dispone \\
\hline $\begin{array}{l}\text { Organización de contenidos } \\
\text { reutilizables }\end{array}$ & No siempre & Sí \\
\hline $\begin{array}{l}\text { Herramienta para la evaluación } \\
\text { integrada para hacer exámenes }\end{array}$ & $\begin{array}{l}\text { Sí (la mayoría de LMS } \\
\text { tienen esta capacidad) }\end{array}$ & $\begin{array}{l}\text { Sí (la mayoría tienen esta } \\
\text { capacidad) }\end{array}$ \\
\hline Herramienta de flujo de trabajo & No dispone & Sí (en algunas ocasiones) \\
\hline $\begin{array}{l}\text { Comparte datos del estudiante con } \\
\text { un sistema Ero (Enterprise } \\
\text { requeriment planning) }\end{array}$ & Si dispone & No dispone \\
\hline $\begin{array}{l}\text { Evaluación dinámica y aprendizaje } \\
\text { adaptativo }\end{array}$ & No dispone & Si dispone \\
\hline $\begin{array}{l}\text { Distribución de contenido } \\
\text { Cuente: Elaborada por Josep M Boneu, 2007. p.5. }\end{array}$ \\
\hline $\begin{array}{l}\text { Control de navegación e interfaz } \\
\text { del estudiante }\end{array}$ & No dispone & Si dispone \\
\hline
\end{tabular}

\subsection{Inventario de plataformas E-learning LMS y CMS}

Resultan incontables la actual oferta de plataformas, programas y servicios ofrecidos para el desarrollo de cursos E-learning y en la actualidad presenta ser un mercado creciente, por lo que resulta difícil ofrecer en este apartado un inventario completo de sistemas E-learning. Sin embargo, habiéndose utilizado como referencia inventarios y estudios comparativos de plataformas E-learning existentes durante los años 2010 y $2011^{35}$, se identificó un número de 28 plataformas más utilizadas en el mundo. Con el objetivo de ofrecer mayor detalle, se incluye a continuación una descripción de estas plataformas.

El inventario de plataformas E-learning que a continuación se describen es el resultado de una revisión de fuentes de información en diversos formatos y de la consulta en Internet de la oferta visible. Los parámetros para la revisión y selección de las plataformas, correspondió obligatoriamente a que debían ser Sistemas de Gestión de procesos de aprendizajes que integraran biblioteca o Sistemas de Gestión de Contenidos. Se prestó atención a los aspectos idiomáticos (necesariamente debían incluir español e inglés), flexibilidad de costos y de requerimientos tecnológicos. Como resultado final de la revisión de fuentes y sitios web, se presenta a continuación un inventario.

Plataforma E-learning

\section{WebCT}

http://www.webct.com

\section{Descripción general y características}

WebCT es reconocido como uno de los primeros sistemas de manejo de actividades de aprendizaje (LMS) aplicado en el ámbito de la educación superior. Es

\footnotetext{
${ }^{35}$ Se ofrece un inventario de plataformas, con una descripción de sus características y funcionalidades más importantes.
} 


\section{Plataforma E-learning}

\section{Descripción general y características}

usado actualmente por 10 millones de estudiantes en 80 países del mundo.

Permite las construcciones de comunidades y el desarrollo de cursos virtuales, ofreciendo al instructor posibilidad de desarrollar discusiones en pantallas, email y chat. Es un programa que facilita la incorporación de contenido y páginas web.

\section{Blackboard}

http://www.blackboard.net
Blackboard puede ser definido como "entorno electrónico de aprendizaje” (DLO o ELO).

Ha sido diseñado para facilitar el manejo de la información necesaria para el desarrollo de cursos a distancia, tales como programa, horarios, noticias, enlaces a textos, sitios URL. Se conocen a la fecha 6 versiones. Blackboard es en definitiva una plataforma creada para el manejo de contenidos de cursos virtuales y la administración de procesos de educación a distancia utilizando el sistema web.

\section{The Learning Manager}

http://www.thElearningmanager.com
Facilita el desarrollo de materiales, contenidos y la usabilidad y reusabilidad de los mismos.

Está basado en una estructura de modular flexible que le permite ajustar el sistema a las necesidades, objetivos y características de las instituciones.

\section{TopClass}

http://www.wbtsystems.com

\section{E-College}

http://www.ecollege.com
Es un sistema diseñado para actividades E-learning (LMS). Su flexible estructura está basada en estándares AICC y SCORM.
Pearson eCollege se traduce como una empresa proveedora de servicios técnicos para el desarrollo de cursos E-learning. Ofrece una moderna plataforma tecnológica y un sistema dinámico y flexible para el manejo de programas de aprendizaje (LMS). Este sistema interactúa de forma combinada con servicios de web e interfaces de programas de aplicación (APIs) y el sistema de gestión de cursos (CMS, Course Management System).

\section{Courseware http://www.courseware.nl/}

Es un sistema LMS creado para el desarrollo y gestión de actividades E-learning. Permite realizar las actividades clásicas en un proceso de enseñanzaaprendizaje de orden metodológico y didáctico, facilitando la planificación, seguimiento y evaluación.

7. Laureate Online Education B.V. Es una red de instituciones académicas de nivel superior 
Plataforma E-learning

http://www.uol.ohecampus.com

http://www.ecollege.com/index.lear

n

\section{ATutor}

http://www.atutor.ca

\section{Descripción general y características}

en la cual participan más de 45 instituciones del mundo.

Se caracteriza por el uso de la tecnología para el desarrollo de programas de educación a distancia. Esta empresa ha desarrollado sus propias aplicaciones que son integradas en un solo paquete (LMS).

\section{Claroline \\ http://www.claroline.net/}

Es un recurso web dirigido a procesos de aprendizaje que incorpora plataformas LCMS y LMS flexibles que facilitan el desarrollo de cursos y programas de educación. Asimismo ofrece las condiciones para la constitución de redes sociales.
Definido como un recurso abierto multilingüe (35 idiomas) y plataforma LMS para el efectivo desarrollo y gestión de cursos en línea. Hasta 2009 estaba utilizado en 101 ciudades. La flexibilidad del sistema permite el desarrollo de actividades corporativas, lo cual también hace posible la constitución de comunidades virtuales.

\section{Desire2Learn}

http://www.desire2learn.com
Sistema de gestión de aprendizaje (LMS) desarrollado para procesos de enseñanza en línea. Incorpora una serie de servicios y productos que facilitan el desarrollo de portafolios y repositorios para el aprendizaje.

La nueva versión de Desire2Learn 2GO e incorpora además el componente BlackBerry Mobile que expande su uso desde teléfonos móviles.

\section{Dokeos 2.0}

http://www.dokeos.com/es
Es un sistema LMS para la gestión de aprendizaje Hace disponible tres tipos de versiones que responden a diferentes objetivos:

Dokeos Libre - Software Libre, siempre será libre para descargar

Dokeos PRO - Software Libre con soporte comercial y extensiones empresariales

Dokeos MEDICAL - Software Libre con soporte comercial y extensiones médicas

Por la flexibilidad, Dokeos permite utilizar plantillas e importar cursos completos basados en SCORM. Cuenta con un buen sistema para ejecutar procesos de evaluación, seguimiento interactivo y conversión de documento Word, Power Point.

\section{The E-learning Guild}

http://www.Elearningguild.com/content.cfm?selec
Es una red o grupo de trabajo especializado en Elearning. El objetivo es actuar como punto de encuentro de los profesionales vinculados con actividades Elearning, a fin de intercambiar experiencias. Su objetivo 
Plataforma E-learning

tion=doc 1538

\section{Descripción general y características}

principal es el desarrollo de servicios y productos de apoyo al proceso enseñanza - aprendizaje. The Elearning Guild ha desarrollado una plataforma LMS que trabaja a modo de Web 2.0.

\section{EZRO: EZ Reusable Learning Objects}

http://ezro.devis.com
Es una plataforma de gestión de contenidos (CMS Course Management System) creada por el Departamento de Trabajo del Gobierno de los Estados Unidos, que utiliza el perfil de objetos de aprendizaje (LOM) y los estándares SCORM.

Los objetos de contenido incluyen texto, vídeo y audio que pueden ser compartidos, modificados o reformateados para una web tradicional, o bien para un curso online o para una comunidad de interés.

\section{HotChalk}

http://www.hotchalk.com/mydesk/i ndex.php/what-is-hotchalk
Es un sistema de gestión de procesos de aprendizajes (LMS) en un ambiente web que incorpora una flexible posibilidad de ajustar el CMS a las necesidades y realidades de los usuarios. Del mismo modo hace uso de herramientas de comunicación interactivas.
15. ILIAS

http://www.ilias.de/docu/goto_docu _root_1.html

ILIAS es un sistema abierto para el manejo de recursos E-learning (LMS) basado en un diseño de web. Su diseño cumple con los estándares SCORM 2004, SCORM 1.2 y AICC. Los módulos E-learning son creados en formato XML que facilita incorporar el uso de archivo multimedia. La versión ILIAS 4.0 integra un editor de contenido PHP/JVA chat, tutoriales que permiten el desarrollo de foros interactivos.

ILIAS es un sistema flexible de gestión del aprendizaje (LMS), soportes estándares LOM, Metadatos IMS QTI

(Test \& Assessment Tool) ofrece las facilidades para el manejo de repositorios, manejo de contenidos, procesos de comunicación manejos y control del aprendizaje.

\section{Jackson Creek Software}

http://www.emc2library.com
Sistema creado para el manejo de aprendizaje (LMS). A fin de facilitar todo el proceso que implica el desarrollo de cursos E-learning. La flexibilidad del sistema le permite desarrollar cursos de forma colaborativa con diversas instituciones.

Sistema LMS desarrollado a partir de las normas SCORM, involucra una serie de herramientas para el desarrollo de procesos enseñanza-aprendizaje en línea. Asimismo incorpora aplicaciones para procesos auto evaluativos, desarrollo de conferencias. Cuenta además 
Plataforma E-learning

con componentes de gestión de contenidos

JoomlaCMS.
En realidad se trata de una empresa que ha desarrollado (2009) un reconocido sistema LMS flexible y adaptable a las necesidades y realidades de las instituciones y usuarios. Aunque es un software comercial, existen diferentes versiones ajustables al alcance económico de los clientes.

\section{Meridian KSI}

http://www.meridianksi.com
Software que se caracteriza por ser flexible y facilitar la gestión de contenidos, medios de comunicación social, procesos de gestión y evaluación de procesos de aprendizaje. Ofrece servicios a empresas grandes y pequeñas, facilitando el acceso a más a un sistema de contenidos, con más de 15.000 títulos. Aunque su objetivo es ofrecer aprendizaje, distribuir conocimientos, y perfeccionar las habilidades de negocio, puede ser utilizado en otras áreas. Sus clientes consisten en organizaciones tales como Bread, Specialty Equipment Market Association, EE.UU. Fuerza Aérea, la Marina de EE.UU., Whirlpool y más de 80 instituciones federales, estatales y gobiernos locales entre otros.

\section{Lectureshare}

http://www.lectureshare.com
Es considerado como una plataforma E-learning que permite a los instructores gestionar y transferir diferentes tipos de material de estudios (anuncios, programas, notas, multimedia, textos, gráficos, fotos, entre otros). Los estudiantes reciben notificaciones a través de mensajes de textos en sus teléfonos, RSS feed o vía correo electrónico. Actualmente ofrece la facilidad de agregar y llevar un sin número de cursos paralelamente.

\section{Moodle}

http://moodle.org
Moodle (Modular Object -Oriented Dynamic Learning Environment $=$ Entorno de Aprendizaje Dinámico Orientado a Objetos y Módulos), es un sistema de gestión de cursos de código abierto (Open Source Course Management System, CMS) y conocido también como Sistema de Gestión del Aprendizaje (Learning Management System, LMS) o como Entorno de Aprendizaje Virtual (Virtual Learning Environment, VLE).

Actualmente se posiciona como una de las plataformas más utilizadas en el mundo. 
Plataforma E-learning

http://www.saba.com

\section{Descripción general y características}

California, Estados Unidos que ha desarrollado el Saba Learning Suite para el desarrollo de cursos E-learning integrado haciendo posible las videoconferencias y aulas virtuales. Los productos de Saba pueden instalarse de forma integrada, sin poner en riesgo el soporte para la administración de hardware, redes, bases de datos y seguridad, así como de instalación de aplicaciones y actualizaciones.

\section{OLAT (Online Learning and Trading = Formación en línea y capacitación)}

http://www.olat.org
Es un sistema de manejo de aprendizaje (LMS) desarrollado en Java y distribuido gratuitamente por la Universidad de Zurich. Permite el uso de diversos recursos de aprendizaje como Podcast, blog, la asignación de temas, calendario entre otros.

Asimismo permite el desarrollo de búsquedas de texto completo, la reparación de las notificaciones y registro de nuevos archivos de herramientas estadísticas.

\section{Sakai Project}

http://sakaiproject.org/new-sakaifaq

http://sakaiproject.org/productoverview
Sakai es un proyecto abierto de colaboración y aprendizaje implementado en 200 universidades de todo el mundo. Se reconoce como un sistema de gestión de cursos (CMS). El proyecto Sakai utiliza para la enseñanza y el aprendizaje cumple con las mismas características de Blackboard y Moodle.

Sakai es un sistema flexible, permite adaptar la plataforma a las necesidades de interoperabilidad para el aprendizaje en procesos de colaboración mediante un sistema de permisos. Incluye en su plataforma el componente Open Source Portfolio que permite la integración sin fisuras a los recursos de la biblioteca (Saka-library).

\section{SharePointLMS}

http://www.sharepointlms.com/feat ures

http://www.sharepointlms.com/com pare/2.html
SharePoint es una plataforma E-learning basado en estándares SCORM 1.2 y 2004. El uso de Microsoft Office SharePoint Server 2007 se realiza de forma combinada con la plataforma WSS3.0. Integra un conjunto de herramientas de E-learning que facilitan la gestión de cursos y el desarrollo y manejo de materiales. Este software está integrado con Microsoft Office Communication Server 2007.

Es importante señalar que SharePoint LMS fue diseñado como LMS y supera la versión de SharePoint Learning Kit (SLK) oficialmente ofrecido por Microsoft Learning Gateway

\section{Spiral Universe}

Spiral 2.0 es un espacio virtual creado a través de un software que facilita a las escuelas públicas, 
Plataforma E-learning

http://www.spiraluniverse.com

\section{Descripción general y características}

independientes, subvencionadas y universidades, aumentar sus niveles de eficiencia, reducir costos, mejorar su gestión y administración.

Opera con un sistema de módulos que se han diseñado desde cero y que pueden adaptarse a una amplia variedad de escuelas en todas partes del mundo. Integra además diferentes herramientas que están estrechamente vinculadas entre sí para eliminar tareas redundantes, simplificar el intercambio de datos, y asegurar la integridad de los datos.

\section{Thinking Cap}

http://www.thinkingcap.com
Es un sistema de manejo de contenidos Learning Content Management System (CMS) que se ajusta a los estándares SCORM 2004. Se caracteriza por las facilidades que ofrece para el manejo amigable de los contenidos, creación de metadatos, la estructuración semántica de los objetos de estudio y sobre todo por la posibilidad de poder compartirlos. Asimismo ofrece la posibilidad de realizar búsqueda rápida de las distintas bibliotecas LCMS.

Thinking Cap incorpora un software Semantic Knowledge Management (SKM) Incorpora un software de Gestión del Conocimiento Semántica (SKM) que permite realizar prácticas de catalogación y estructuración semántica de los objetos que se pueden compartir, así como la reutilización de los recursos.

\section{TotalLMS}

http://www.sumtotalsystems.com
Sistema (LMS) de simple configuración modular, creado con el objetivo de facilitar el trabajo de control y seguimiento y la colaboración entre educadores, actividades de administración y de aprendizajes presenciales y no presenciales. Ha sido pensado para dar respuestas a demandas de capacitación y actualización de empresas y la industria.

Se constituye de los siguiente componentes:

TotalLMS: Permite la generación de capacidades para el desarrollo de actividades de aprendizaje, la presentación de informes de gran alcance y la captura de conocimientos informales.

Totallntegration: Asegura la compatibilidad directa entre el LMS y las aplicaciones de acuerdo las necesidades de los usuarios.

TotalVCS: permite desarrollar eficientes procesos de comunicación y la colaboración en línea. 


\subsection{Clasificación de servicios E-learning}

La introducción del E-learning como nueva modalidad de enseñanza telemática, exige por parte de las entidades públicas y privadas de formación un alto grado de competitividad. Esta una de las tantas razones del porque utilizan plataformas E-learning que cumplen con estándares internacionales y disponen de un espacio seguro en la Internet, garantizando así la privacidad y seguridad a los clientes.

Las universidades, no estando ajenas a esta situación, han dado un paso adelante en la búsqueda de la democratización del acceso del conocimiento e iniciado con una modalidad hibrida ${ }^{36}$ con algunas prácticas en Internet y de recursos World Wide.

Una estrategia seguida por estas instituciones ha sido la de mejorar e integrar las unidades de servicios, facilitando así el acceso a los diferentes puntos de información y productos institucionales desde un solo portal. En este contexto la biblioteca ha sido llamada a facilitar el proceso de transferencia información y/o conocimiento. La generación de nuevos servicios o la transformación de los existentes les caracterizan por ser más personalizados, es decir por el acompañamiento individual de los usuarios sin límites de tiempo y fronteras.

Partiendo de la descripción de los programas LMS para E-learning realizada en el apartado 3.7 fue posible agrupar la diversidad de servicios en tres grandes grupos que seguidamente se exponen:

\section{1/ Servicio de gestión administrativa}

Estos servicios son definidos y desarrollados mediante la aplicación de programas LMS que facilitan la organización de los servicios y los cursos parciales o programas educativos completos a dos niveles jerárquicos y que a continuación se explican:

- Gestores del curso. Son facilidades que ofrece el programa para manejar de forma flexible los cambios en la definición, ejecución y finalización del programa o curso E-learning. Asimismo permite la adecuación metodológica, la creación de espacios personalizados y grupales para la interacción social.

- Estudiantes. Representan los servicios y son dirigidos al grupo meta. Generalmente se presentan como productos bien estructurados, servicios de referencia las 24 horas del día, con el objetivo de satisfacer necesidades de información que puedan surgir en el trayecto del proceso de enseñanza aprendizaje.

\section{2/ Servicio de orientación, seguimiento y evaluación}

El objetivo de estos servicios es orientar y estimular el proceso enseñanza - aprendizaje. Se trata de servicios que a través de los recursos multimedia generan estímulos de acompañamientos y pruebas que permiten evaluar el nivel de aprendizaje logrado. Algunos casos concretos son el servicio de orientación asincrónica y/o sincrónica, en el cual se estable una relación de doble vía entre el estudiante - docente; el acompañamiento a los alumnos por módulos, la realización de pruebas de espacios abiertos y pruebas de respuesta cortas; la generación de herramienta para autores y la elaboración de reportes estadísticos.

\footnotetext{
${ }^{36}$ Modalidades híbridas de formación se refiere a una combinación de modalidades presenciales y el E-learning. Amplio concepto de esta modalidad mixta la desarrollan Sandra Rosales-Gracia, et.al (2008) en http://www.scielo.org.mx/scielo.php?pid=S0185-27602008000400002\&script=sci_arttext.
} 


\section{3/ Servicio de comunicación y acceso a los contenidos}

La comunicación y el acceso a los contenidos son determinantes dentro del proceso enseñanza aprendizaje de E-learning. A través de los servicios de comunicación se desarrolla un proceso lineal y dinámico de comunicación entre el docente y el alumno. Una vez realizada la revisión de un significativo número de sitios web y como resultado de dicho análisis, se pudo constatar que existe una veintena de tecnologías diferentes aplicables a las modalidades semipresenciales y al E-learning. Los recursos más utilizados para procesos de comunicación asincrónica corresponden al uso de correo electrónico desde servidores institucionales, o servidores públicos como Hotmail, Yahoo, Gmail. Para procesos de comunicaciones sincrónicas se destacan el chat y el Skype. Otros medios corresponden a sistemas de conferencia o debates grupales y foros de discusión en línea a través de sistemas comerciales y/o gratuitos. Asimismo otros recursos como portales, web 2.0, blogs colaborativos, wikis, Flickr, RSS, Twitter entre otros, son utilizados para desarrollo de cursos, generación, difusión de conocimiento y/o publicación de información.

Para el manejo de contenidos, algunos sistemas E-learning han generado un módulo denominado biblioteca dentro del sistema E-learning (LMS), aunque esta iniciativa resulta funcional, el proceso de aprendizaje exige la consulta a contenidos externos que generalmente se ubican en la biblioteca híbrida propiamente dicha. En este contexto la participación de la biblioteca de forma directa o indirecta dentro de las plataformas E-learning se realiza a través de la gestión de glosarios, catálogos, tutoriales y enlaces a textos completos. Un ejemplo concreto se visualiza en el sitio Web de la Universidad Tecnológica de Delft ${ }^{37}$ en la que se proyecta la biblioteca misma como núcleo centro central de enseñanza.

\footnotetext{
${ }^{37}$ Página principal de la Biblioteca de la Universidad de Delft con noticias generales de la Universidad http://www.library.tudelft.nl.
} 


\section{PARTE III CONVERGENCIAS Y ÁMBITO DE ACTUACIÓN DE LA BIBLIOTECA EN EL E-LEARNING}

El incremento en el uso de avanzadas tecnologías para la transferencia de información, conocimiento y comunicación en las instituciones académicas ha generado un cambio en sus estrategias de organización y la introducción de una nueva oferta educativa E-learning. Esta modalidad, como parte del sistema universitario, requiere hacer uso de los recursos internos y externos de la Universidad para la definición, selección y sistematización de los contenidos. En este contexto, la actual gestión servicios y recursos electrónicos del modelo de biblioteca híbrida, representa ser un momento oportuno para el establecimiento de sinergias con el E-learning.

Siendo uno de los objetivos de esta tesis presentar de forma objetiva el rol que puede ejercer la biblioteca académica como gestora de servicios de apoyo a la docencia y la formación continua dentro de programas E-learning, la Parte III de esta tesis incluye un análisis conceptual, descriptivo del E-learning, que además de introducir el tema, busca establecer puntos de encuentros entre la biblioteca académica y el E-learning.

La tercera parte de esta investigación doctoral está integrada por el Capítulo 4, que se ha querido ofrecer de forma independiente, para mostrar de forma exclusiva dónde los servicios bibliotecarios telemáticos convergen o pueden converger con la formación que se ofrece en línea. En este capítulo, se desarrollan los tres grandes ámbitos en los que la biblioteca universitaria puede apoyar de forma más útil al E-learning: los servicios de referencia digital, las acciones encaminandas a la alfabetización informacional y la aportación de contenidos a repositorios educativos. 


\section{PARTE III. CONVERGENCIAS Y ÁMBITO DE ACTUACIÓN DE LA BIBLIOTECA EN EL E-LEARNING}

\section{Capítulo 4. Puntos de encuentros entre la biblioteca y E-learning}

4.1 Introducción

4.2 Áreas de acción de las bibliotecas

4.3 Integración de los servicios bibliotecarios en el E-learning

4.4 Referencia digital

4.4.1 Introducción al servicio de referencia

4.4.2 Concepto del servicio de referencia digital

4.4.3 Directrices para el diseño del servicio de referencia digital

4.4.3.1 Directrices básicas de la IFLA

4.4.3.2 Directrices básicas de la RUSA

4.4.4 Proceso de comunicación del servicio de referencia digital

4.4.5 Características del modelo de referencia digital

4.4.6 Modelos de servicio de referencia digital

4.4.7 Evaluación del servicio de referencia digital

4.5 Alfabetización informacional

4.5.1 Introducción al servicio de alfabetización informacional

4.5.2 Concepto de Alfabetización Informacional (ALFIN)

4.5.3 Competencias transversales

4.5.4 Perspectivas de aplicación de la alfabetización informacional

4.5.5 Tipos de alfabetización

4.5.6 Estudio de factibilidad para el diseño de una práctica ALFIN

4.5.7 Modelos ALFIN

4.6 Repositorios para la educación

4.6.1 Introducción al servicio

4.6.2 Conceptos relacionados

4.6.2.1 Acceso abierto

4.6.2.2 Colecciones digitales

4.6.2.3 Metadatos

4.6.2.4 Contenidos abiertos

4.6.2.5 Objetos de aprendizaje

4.6.2.6 Portales

4.6.2.7 Repositorios

4.6.3 Importancia de los repositorios para la educación

4.6.4 Interoperabilidad de los repositorios educacionales en E-learning 


\section{Capítulo 4. Puntos de encuentros entre Biblioteca y E-learning}

\subsection{Introducción}

En los capítulos dos y tres se ha presentado un fundamento teórico del E-learning y la biblioteca. La existencia de una similitud lógica y coherente entre ambos corresponde al principio básico de facilitar información con propósitos educativos a través de servicios en línea. Con el objetivo de ampliar esta aseveración, en el presente capítulo se reflexiona sobre las áreas de involucramiento de los servicios de la biblioteca como apoyo en el E-learning, partiendo de que existen tres grandes ámbitos de convergencia entre las bibliotecas y la enseñanza telemática: los servicios de referencia, las acciones de formación en información y el acceso a recursos a través de repositorios.

\section{2 Áreas de acción de las bibliotecas}

Con el fin de destacar cómo las bibliotecas pueden colaborar con el E-learning, se necesitó una búsqueda de espacios para interpolar algunos servicios básicos de la biblioteca. En el estudio realizado se identificaron las áreas de acción que tiene la biblioteca para generar una sinergia con el E-learning y que se localizan en su función formativa e informativa, así como en el abastecimiento de información.

La confluencia desde el punto de vista formativo es posible debido a que ambos tienen como objetivo la formación del individuo pero en diferentes contextos. La biblioteca se orienta a formar habilidades y actitudes en los estudiantes de como buscar y usar la información éticamente y el Elearning a través del docente, instruye al estudiante en la aplicación de la información en hechos concretos. Ambos procesos de forma complementaria contribuyen a la formación integral del individuo y su participación en tareas sociales y/o científicas.

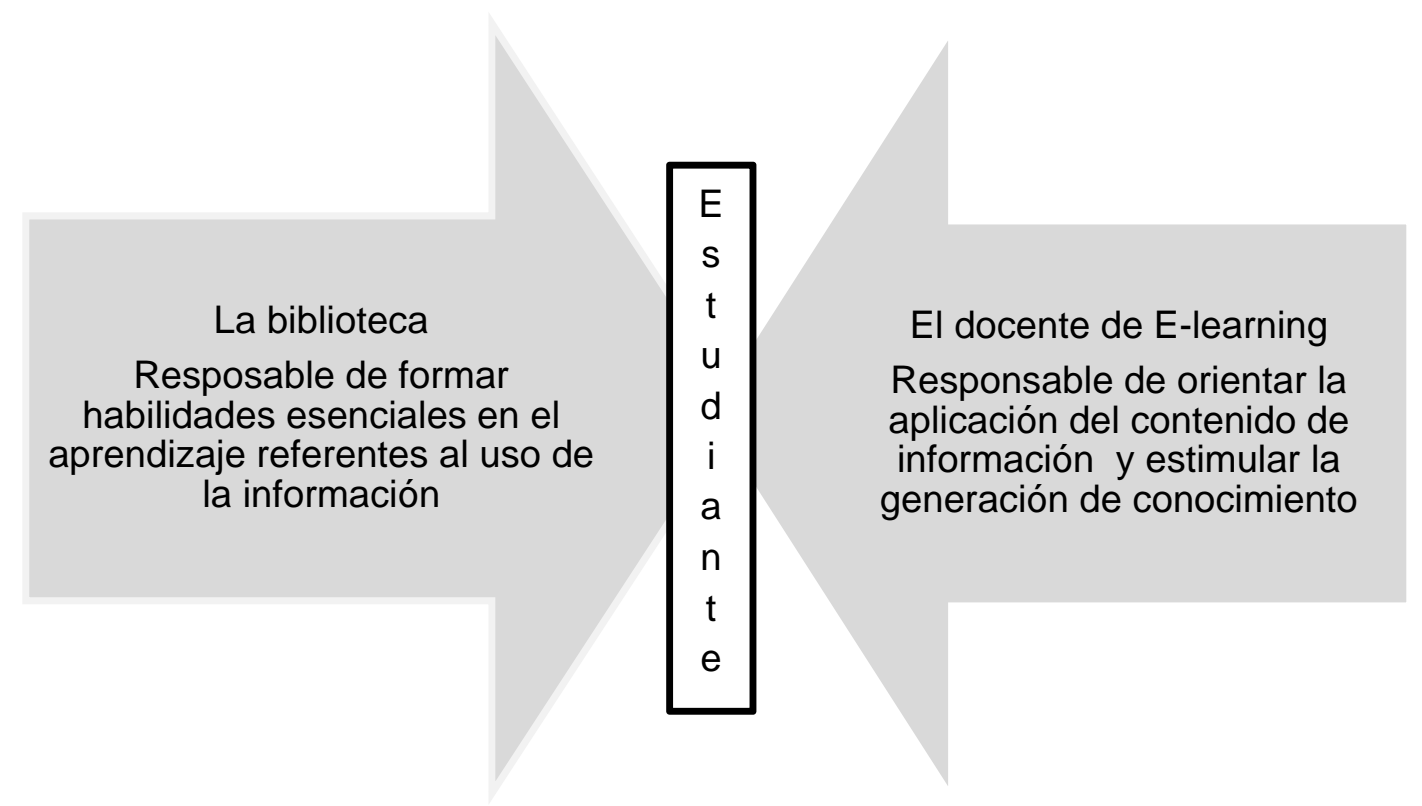

Figura 16. Confluencia del E-learning y la biblioteca en el proceso formativo. Fuente: Elaboración propia. 
En la práctica, otro vínculo de acoplamiento entre la biblioteca y el E-learning corresponde al suministro de información o contenido. En ambos casos la transferencia de información se realiza a través de la prestación de servicios de información. En el caso específico de la biblioteca, esto es posible, debido a que los actuales modelos de biblioteca operan como sistemas flexibles que le permiten ofrecer una variedad de servicios de información y gestionar los objetos de aprendizajes a través de recursos telemáticos. En el caso de E-learning no existen limitaciones técnicas en las plataformas (LMS y LCMS) para interoperar con el sistema de manejo de contenido de la biblioteca. Con el objetivo de ilustrar lo antes señalado, la siguiente figura ejemplifica algunos contenidos de confluencia.

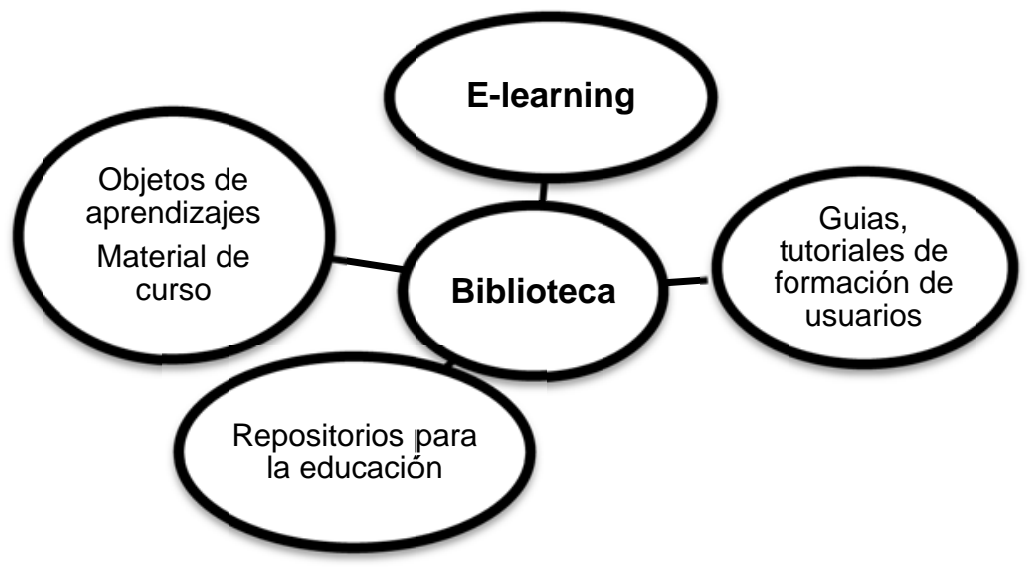

Figura 17. Contenidos de confluencia. Fuente: Elaboración propia.

Considerándose necesario demostrar la veracidad de lo antes señalado y de identificar otros aspectos concretos de intersección entre los servicios del E-learning y la biblioteca, fue aplicada a la biblioteca la caracterización de los servicios de E-learning, presentada en el capítulo tres. El resultado de ésta práctica, reflejó tres áreas concretas de acoplamiento que seguidamente se explican.

\begin{tabular}{|l|l|l|}
\hline Orientación de los Servicios & E-learning & Biblioteca \\
\hline $\begin{array}{l}\text { Servicios de gestión } \\
\text { administrativa }\end{array}$ & $\begin{array}{l}\text { Recursos y servicios para } \\
\text { la gestión y desarrollo de } \\
\text { los cursos: } \\
\text { Ingreso, controles } \\
\text { seguimiento, etc. }\end{array}$ & $\begin{array}{l}\text { Generación de es pacio personal (My } \\
\text { library) para hacer posible la } \\
\text { disponibilidad de la oferta de } \\
\text { recursos y servicios informativos }\end{array}$ \\
\hline $\begin{array}{l}\text { Servicios de orientación, } \\
\text { seguimiento y evaluación }\end{array}$ & $\begin{array}{l}\text { Objetivo de orientar y } \\
\text { estimular el proceso de } \\
\text { enseñanza y aprendizaje. }\end{array}$ & $\begin{array}{l}\text { Orientación de usuarios mediante } \\
\text { curso sobre manejo y uso de } \\
\text { recursos informativos, cursos sobre } \\
\text { técnicas de citaciones, cursos sobre } \\
\text { técnicas de búsquedas y } \\
\text { recuperación de información }\end{array}$ \\
\hline
\end{tabular}




\begin{tabular}{|c|c|c|}
\hline $\begin{array}{l}\text { Servicios de comunicación y } \\
\text { acceso a los contenidos }\end{array}$ & $\begin{array}{l}\text { Se establece un proceso } \\
\text { de comunicación lineal } \\
\text { entre la información } \\
\text { (metadatos, repositorios, } \\
\text { objetos de aprendizajes, } \\
\text { portales, etc.) y los } \\
\text { usuarios del sistema. En } \\
\text { esta línea se considera } \\
\text { importante diferenciar } \\
\text { tres tipos de contenidos: } \\
\text { Los correspondientes y } \\
\text { obligatorios a la materia } \\
\text { del curso } \\
\text { Los complementarios y } \\
\text { de referencias } \\
\text { Los de acceso abierto }\end{array}$ & $\begin{array}{l}\text { Servicio de referencia digital y el } \\
\text { acceso a la información: } \\
\text { Portales } \\
\text { Acceso a material de estudios } \\
\text { obligatorios a la materia del curso } \\
\text { Los complementarios y de } \\
\text { referencias } \\
\text { Los de acceso abierto }\end{array}$ \\
\hline
\end{tabular}

Tabla 11. Categorización de servicios de E-learning y la Biblioteca.

Fuente: Elaboración propia.

De lo antes reflejado es posible concluir que los servicios de gestión al acceso de contenidos, la comunicación informativa y la formación del usuario son los tres ejes de acción e interacción entre la biblioteca y el E-learning. En este contexto y retomando al análisis presentado en el capítulo dos, sobre los modelos de bibliotecas, es importante destacar que en el actual siglo XXI, estos modelos cuentan con capacidades tecnológicas para el uso combinado de recursos impresos, digitales, multimedia considerados básicos para generar el ciclo de transferencia de información y estimular el diálogo directo entre docente-estudiante; estudiante-investigador, investigador-investigador.

\subsection{Integración de los servicios bibliotecarios en el E-learning}

La variedad de servicios en línea ofrecidos por la biblioteca que pueden ser utilizados como apoyo a la enseñanza e investigación es diversa y creciente. Algunos ejemplos de servicios seguidamente se presentan e ilustran agrupados de acuerdo a sus fines en tres áreas de convergencia con las diferentes modalidades de enseñanza.

Las tres áreas de convergencia que se están delimitando son los ámbitos en los que las bibliotecas universitarias están ofreciendo servicios telemáticos que, en todos los casos, se relacionan de forma muy directa con las actividades propias de los sistemas de enseñanza a distancia en línea. En la figura 18 se describen estas áreas, que también son identificadas en los siguientes párrafos, junto a ejemplos de cursos de formación y recursos informativos. 


\section{Referencia digital}

Función: informar y comunicar

\section{Alfabetización informacional}

Función: formación de usuarios en habilidades y destrezas para la búsqueda y recuperación de información.

\section{Repositorios para la educación}

Finalidad: Facilitar el acceso (uso) a la información
- Preguntas frecuentes

- Pregunte al bibliotecario

- Cursos de formación de usuarios de la biblioteca híbrida

- Técnicas de citación y gestión bibliográfica

- Metodología de la investigación documental

- Herramientas para el docente

- Catálogos en línea: Acceso a los catálogos de la biblioteca

- Repositorios: Acceso a repositorios

- Tutoriales y guía de la biblioteca

- Recursos para el aprendizaje

- Aplicaciones en teléfonos móviles

- Colecciones digitales (libros, revistas y documentos electrónicos)

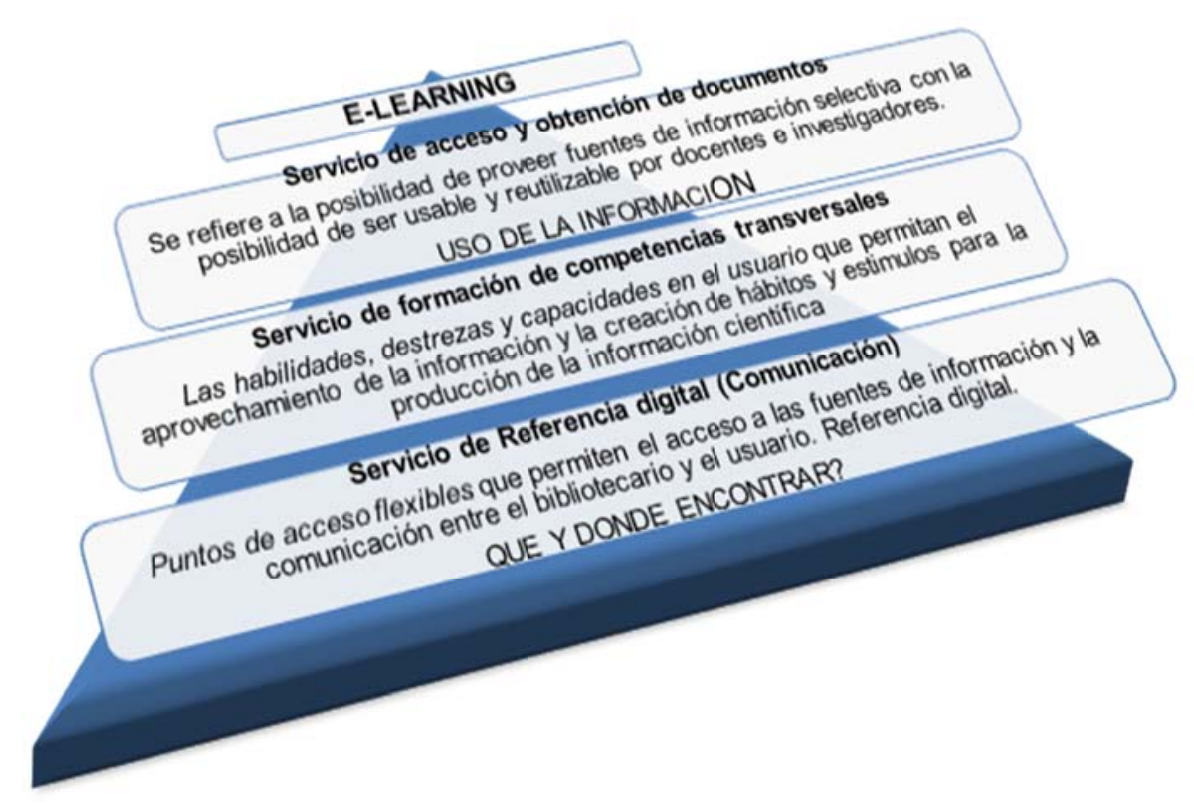

Figura 18. Áreas de acción para el diseño de una oferta de servicio para E-llearning. Fuente: Elaboración propia.

Los siguientes apartados se destinan a identifica y desarrollar las tres áreas de convergencia entre la biblioteca y el E-learning. Estos aportados se han concebido dentro de la necesidad de incluir una contextualización teórica, que permita disponer de las bases para la aplicación de la metodología propuesta y para la creación de una propuesta que concrete cómo las bibliotecas pueden integrar en la formación E-learning sus servicios de información (referencia digital), de formación (ALFIN) y acceso a recursos (repositorios). 


\subsection{Referencia digital}

La incorporación de recursos de Internet y el uso de plataformas E-learning por parte de la biblioteca ha permitido que esta pueda ofrecer servicios en línea de apoyo en actividades docentes del Elearning y de enseñanza semipresencial también conocida como B-learning ${ }^{38}$. La creciente y variada oferta de servicios de información por parte de la biblioteca requiere un punto de información dinámico, sencillo, rápido que permita al estudiante o docente llegar y hacer uso del servicio y recursos necesitados, es decir, la existencia de un servicio de referencia que oriente y refiera el usuario a la fuente.

\subsubsection{Introducción al servicio de referencia digital}

Datos históricos del servicio de referencia señalan que este servicio fue iniciado a través de medios de telecomunicación, a menudo en tiempo real. Los usuarios utilizaban el teléfono o el fax para comunicarse con los bibliotecarios, sin estar físicamente presente. Posteriormente se introdujo los recursos telemáticos que permitió ampliar la capacidad de oferta de la información, responder a demandas de usuarios que por algún motivo no pueden llegar físicamente a la biblioteca. Cabe destacar que el valor añadido que adquiere este servicio radica principalmente en la aplicación de recursos tecnológicos para generar procesos de comunicación dinámicos y en la mayoría de casos interactivos para orientar, situar, referir o transferir información al usuario. ${ }^{39}$

Una excelente reseña histórica del servicio de referencia es ofrecida por Ramón Alberto Manso Rodríguez (2010) quien en su tesis doctoral aporta el siguiente panorama evolutivo del servicio

\begin{tabular}{|l|l|}
\hline Siglo XIX & $\begin{array}{l}\text { El concepto de servicio referencia surge de un articulo "Personal relations between } \\
\text { librarians and reader", publicado por Samuel Swett Green }{ }^{40} \text { en } 1876 \text { en la revista } \\
\text { American Library. }\end{array}$ \\
\cline { 2 - 2 } & $\begin{array}{l}\text { Entre los años } 1880 \text {-1890 surge la necesidad de un acompañamiento especial para } \\
\text { las lecturas e investigación. Este hecho marco el origen del servicio de referencia. } \\
-1883 \text { - Reference assistence } \\
-1887 \text { - Assistence to users } \\
-1890 \text { Assitence to readers }\end{array}$ \\
\hline Siglo XX & $\begin{array}{l}\text { En } 1978 \text { Se introduce el teléfono }{ }^{41} \\
\text { Se introduce los catálogos en línea (Online Public Access Catalog (OPAC). }\end{array}$ \\
\cline { 2 - 3 } & A mitad de la década de los ochenta surge el primer modelo de servicio de \\
\hline
\end{tabular}

\footnotetext{
${ }^{38}$ B-learning (blended learning) es un término referido para la modalidad de educación a distancia semipresencial. Para disponer de mayor información del concepto B-learning véase : b-learning4all.eu/.../Analysis-

of_Training_Needs_Blearning4All_3.pdf.

${ }^{39}$ Las evolución de los distintos medios para la prestación del servicio de referencia fueron estudiados por Joseph E, Straw (2001) en su artículo From magicians to teachers: the development of electronic reference in libraries: 1930-2000.

${ }^{40}$ El artículo se encuentra disponible en: http://pacificreference.pbworks.com/f/Personal+Relations+Between+Librarians+and+Readers.pdf

${ }^{41}$ Según datos históricos extraídos de libro Reference and Information Services: An Introduction. Richard E Bopp; Linda C. Smith (2001).
} 


\begin{tabular}{|c|c|}
\hline & $\begin{array}{l}\text { referencia impulsado por la Universidad de Maryland, reconocido como "Electronic } \\
\text { Access to Reference"EARS } \\
\text { 1992-1995 El modelo de servicio de referencia es fortalecido con la creación del } \\
\text { proyecto de preguntas a una base de datos. El proyecto ERIC }{ }^{43} \text { orientado a la } \\
\text { comunidad académica por The Educational Resource center y la Tecnology at } \\
\text { Syracose university. }\end{array}$ \\
\hline Siglo XXI & $\begin{array}{l}\text { En la actualidad existe el servicio adquiere un reconocimiento académico y es } \\
\text { ofrecido a través espacios virtuales a través de medios telemáticos. Ejemplos } \\
\text { concretos de estas prácticas son los modelos de } \\
\text { - Pregunta al bibliotecarios en la modalidad Chat } \\
\text { Servicio de preguntas al bibliotecario (ask a librarians) } \\
\text { Servicio de preguntas frecuentes } \\
\text { Referencista educador (Educator's reference desk) }\end{array}$ \\
\hline
\end{tabular}

Tabla 12. Evolución de servicio de referencia.

Fuente: Basado de la tesis doctoral de Alberto Manso Rodríguez (2010 p 10-15)

y Richard E Bopp; Linda C. Smith (2001 p.3-5)

\subsubsection{Concepto del servicio de referencia digital}

Partiendo de los antecedentes del servicio de referencia es posible señalar que desde la incorporación de medios telemáticos se ha generado una transformación en las formas de prestar el servicio. En dependencia del uso o aplicación de los recursos tecnológicos, se le han atribuido de forma indiscriminada términos aditivos como virtual, electrónico, digital, real, espacial etc. Paralelamente y desde otra perspectiva práctica, existe una fuerte tendencia a confundir el servicio, visto como acción profesional del bibliotecario con las fuentes de referencia utilizadas como puede ser el caso de una aplicación web, un directorio de citas bibliográficas, etc.).

Esta confusión ocurre debido a que tanto la fuente como el servicio "refiere, orienta, sitúa o transfiere" a lo que se busca, esto, no justifica el inadecuado uso, debido a que se trata de dos cosas diferentes. Primero cabe aclarar que la diferencia fundamental entre la fuente y el servicio obedece a que el servicio es una acción dinámica de doble vía (pregunta-respuesta) y las fuentes son recursos de consulta que el individuo hace uso de ellas una vez que es consciente que están allí y a su vez utilizarlas. El servicio por el contrario es el medio por el cual se orienta y difunde su existencia.

En la búsqueda de una definición estándar del servicio de referencia digital, capaz de ser aplicable como elemento básico en la propuesta modelo de servicio integrado para E-learning ofrecido en esta tesis, fue necesaria la revisión de diferentes aportes conceptuales de organizaciones internacionales. Seguidamente se presenta a modo de resumen el análisis conceptual:

\footnotetext{
${ }^{42}$ Texto completo en http://www.ncbi.nlm.nih.gov/pmc/articles/PMC406264/pdf/mlab00376-0026.pdf.

${ }^{43}$ R. David Lankes, Pauline Shostack (2003) http://quartz.syr.edu/rdlankes/Publications/Journals/nescRT.pdf.
} 


\begin{tabular}{|c|c|}
\hline $\begin{array}{l}\text { IFLA } \\
\text { The International Federation of Library } \\
\text { Associations and Institutions } \\
\text { http://archive.ifla.org/VII/s36/pubs/dr } \\
\text { g03-s.htm }\end{array}$ & $\begin{array}{l}\text { Federación Internacional de las Asociaciones e } \\
\text { Instituciones Bibliotecarias IFLA (2009) reconoce esta } \\
\text { necesidad y señala que "los términos "referencia virtual", } \\
\text { "referencia digital", "servicios de información en } \\
\text { Internet", "referencia permanente" y "referencia en } \\
\text { tiempo real" son intercambiables para describir los } \\
\text { servicios de referencia que utilizan tecnología digital de } \\
\text { una u otra forma"44. }\end{array}$ \\
\hline $\begin{array}{l}\text { RUSA } \\
\text { Reference and User Services } \\
\text { Association } \\
\text { http://www.ala.org/rusa/ }\end{array}$ & $\begin{array}{l}\text { La Referencia virtual tiene origen a partir del uso de } \\
\text { recursos electrónicos y redes de telecomunicación para la } \\
\text { prestación de servicios y atención a los clientes sin que } \\
\text { estos estén físicamente presentes. El servicio se } \\
\text { caracteriza por el proceso de comunicación dinámico a } \\
\text { través sistema de chat, videoconferencia, correo } \\
\text { electrónico y mensajería instantánea. }\end{array}$ \\
\hline $\begin{array}{l}\text { ALA } \\
\text { American Library Association } \\
\text { http://www.ala.org }\end{array}$ & $\begin{array}{l}\text { El servicio de referencia es visto como el punto de } \\
\text { entrada al sistema de la biblioteca, a través del cual los } \\
\text { usuarios pueden, desde diferentes puntos físicos o de } \\
\text { medios electrónicos acceder a al servicio mediante } \\
\text { correo electrónico, portales, servicios de voz en Internet, } \\
\text { chat, mensajería instantánea y la consulta remota a una } \\
\text { base de datos y sitios web. }\end{array}$ \\
\hline $\begin{array}{l}\text { Association of Research Libraries (ARL) } \\
\text { http://www.arl.org }\end{array}$ & $\begin{array}{l}\text { Servicio de referencia es una transacción efectuada por el } \\
\text { personal de la biblioteca para transmitir información - } \\
\text { conocimiento en el uso de una o más fuentes de } \\
\text { información. } \\
\text { Las fuentes de información que reconoce la ARL son: } \\
\text { a) el material impreso y no impreso } \\
\text { b) legibles por máquina bases de datos (incluyendo } \\
\text { enseñanza asistida por computadora), } \\
\text { c) los propios catálogos de la biblioteca y los registros de } \\
\text { otras explotaciones } \\
\text { d) otras bibliotecas e instituciones a través de la } \\
\text { comunicación o remisión } \\
\text { e) las personas, tanto dentro como fuera de la biblioteca. }\end{array}$ \\
\hline $\begin{array}{l}\text { National Center for Education } \\
\text { Statistics (NCES) } \\
\text { http://nces.ed.gov }\end{array}$ & $\begin{array}{l}\text { El servicio de referencia es considerado como una } \\
\text { transacción, que implica el conocimiento, el uso, } \\
\text { recomendaciones, interpretación, o instrucción en el uso } \\
\text { de una o más fuentes de información por un miembro del } \\
\text { personal de la biblioteca. } \\
\text { Las fuentes de información incluyen materiales impresos }\end{array}$ \\
\hline
\end{tabular}

\footnotetext{
${ }^{44}$ IFLA. The International Federation of Library Associations and Institutions (IFLA). Recomendaciones para el servicio de referencia digital, Abril 2009. http://archive.ifla.org/VII/s36/pubs/drg03-s.htm.
} 


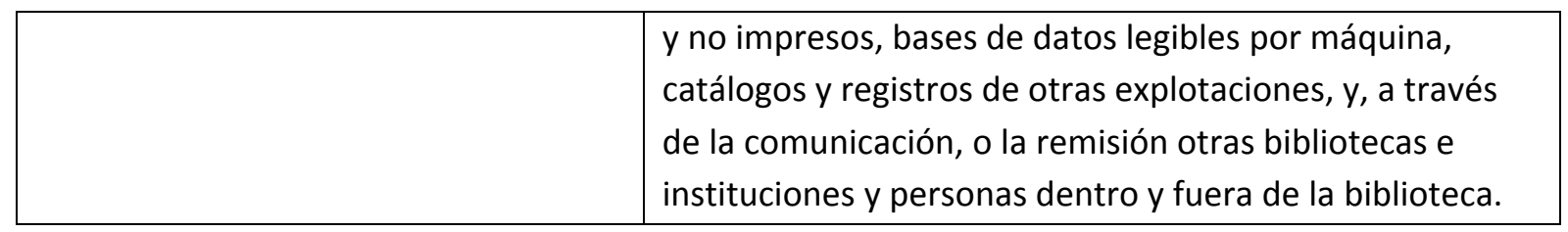

De las definiciones anteriores, se refleja que el uso de recursos telemáticos para la prestación del servicio de la referencia, genera la tendencia de atribuirle con calificativo de virtual o digital, para distinguirlo del servicio de referencia tradicionalmente ofrecido. En este contexto y para fines de esta tesis se adopta como concepto único el de "Referencia digital" y se retoma el aporte teórico de José Antonio Merlo Vega que se presenta en las siguientes líneas.

José Antonio Merlo Vega (2009, p.167) define el concepto de referencia digital como "el servicio bibliotecario que atiende peticiones de información de forma telemática, empleando tecnologías digitales para la comunicación con los usuarios". El concepto ofrecido por Merlo Vega no es aislado, parte de la misión, objetivos institucionales y que se constituye en la práctica a través del trabajo referencista, los contenidos, las aplicaciones informáticas y los recursos telemáticos que facilita el proceso de comunicación (sincrónica y asincrónica) entre el usuario y el sistema de la biblioteca y el acercamiento a las redes sociales. De forma resumida se ilustran a continuación los componentes básicos del servicio de referencia digital.

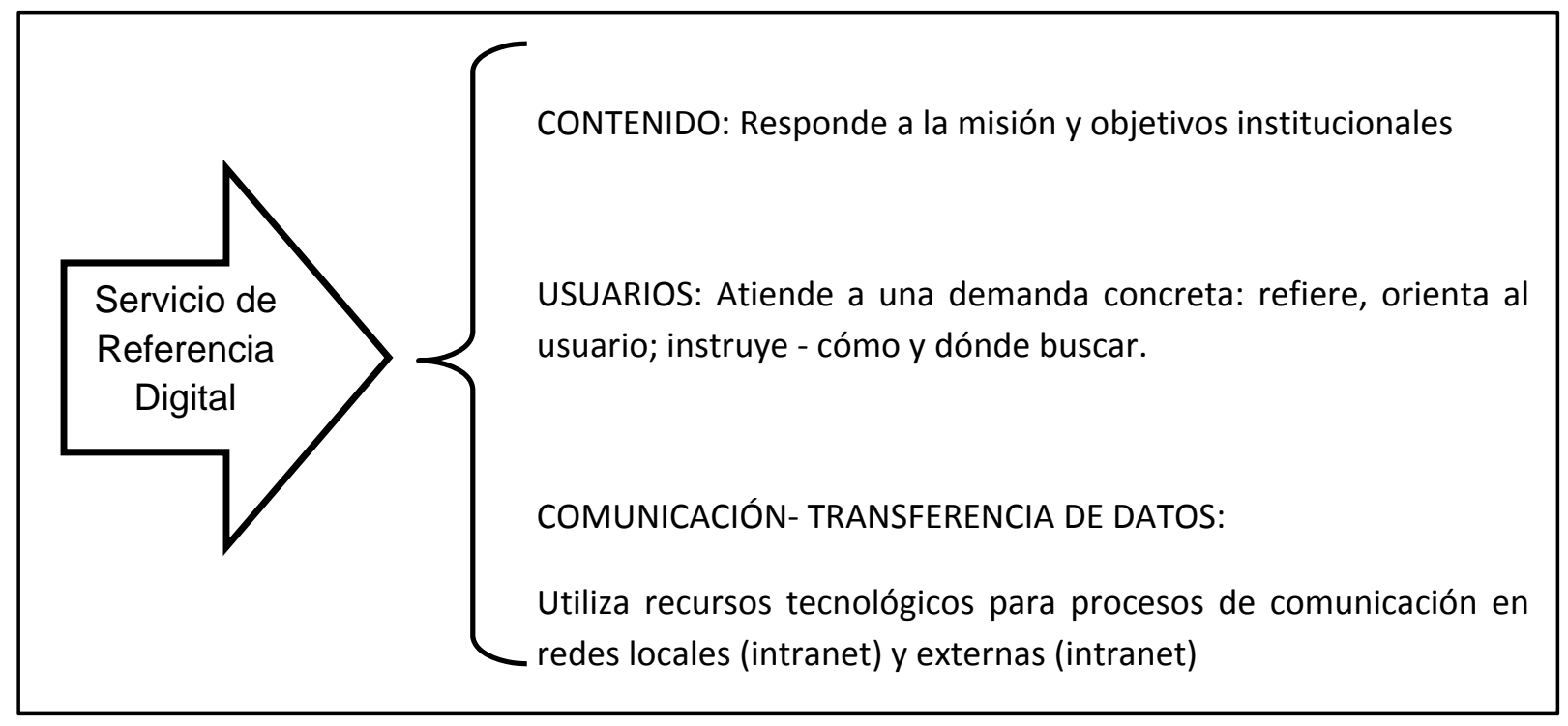

Figura 19. Componentes básicos del servicio de referencia digital. Fuente: Elaboración propia.

De acuerdo con las aportaciones conceptuales descritas hasta el momento, hay que destacar las teorías de Charles A. Bunge y Richard E. Bopp (2001) para quienes todo servicio de referencia debe cumplir con los siguientes objetivos: 
a. Información Involucra diferentes tipos de servicios. Consiste en proveer datos concretos (direcciones, teléfono, nombres, etc.), búsquedas bibliográficas, préstamos interbibliotecarios y entrega de documentos.

b. Orientación

Generalmente ofrecido por el especialista en la materia quien analiza la consulta, determina el nivel de profundidad de respuesta y selecciona orienta la fuente de información requerida para la respuesta. Se caracteriza por el diálogo directo sincrónico o asincrónico entre el especialista en información y el usuario.

c. Instrucción

El usuario recibe una instrucción de cómo y dónde identificar las fuentes de información y cómo utilizarlas. Tradicionalmente se conoce como el servicio de formación de habilidades en los usuarios (Alfabetización informacional).

\subsubsection{Directrices para el diseño del servicio de referencia digital}

Introducirnos a la organización del servicio de referencia digital, ha requerido la revisión de normativas estándares y de algunas prácticas en línea, que han sido analizadas e incluidas en el apartado siete, referente al estudio de casos. El resultado de esta revisión fue evidente la necesidad de disponer de un proyecto que incluya las acciones que implican el diseño y puesta en práctica del servicio. Asimismo fue posible identificar las existencias de directrices básicas para el diseño e implementación del servicio de referencia digital. Estas directrices emitidas por la IFLA y la RUSA, son en la actualidad utilizadas internacionalmente como estándares. Con el objetivo de introducirnos en ellas en las siguientes páginas se presenta una breve descripción de las mismas extraídas de los manuales disponibles en sus respectivos sitios web.

\subsubsection{Directrices básicas de la IFLA}

El grupo de trabajo de referencia digital de la IFLA, orientan "examinar los procedimientos y políticas institucionales existentes y establecer en qué grado se pueden ver afectados por la transición a un entorno digital" ${ }^{45}$. Asimismo ellos consideran que el proceso de organización y planificación del servicio de referencia digital debe ajustarse al entorno y condiciones en que se va a implementar el servicio de referencia digital. Literalmente se afirma que "el ámbito de los servicios que se prestan debería estar basado en una planificación realista y en los recursos financieros disponibles, así como en las necesidades que se observen en la comunidad a la que se sirve" ${ }^{46}$.

En esta línea el grupo de trabajo de la IFLA recomienda de forma general dar atención a los siguientes aspectos:

1. Grupo de trabajo. Orienta la creación de un grupo de trabajo que ejecute un estudio de viabilidad para identificar la demanda y posibilidad de oferta del servicio.

\footnotetext{
${ }^{45}$ The Public Library Service: Guidelines for Development http://archive.ifla.org/VII/s8/proj/gpl.htm\#7.

${ }^{46}$ Ibid The Public Library Service: Guidelines for Development.
} 
2. Plan de acción. Recomienda disponer de un plan de trabajo que oriente el diseño del servicio y permita definir en forma sistémica los siguientes aspectos:

- Los objetivos

- Alcance del servicio en relación a sus usuarios

- Alcance del servicio en relación a la temática

- Alcance del servicio en relación a tecnología disponible

- Recursos humano

- Recursos tecnológicos

- Tipo de programas informáticos a utilizar

- Metodología para la prestación del servicio

- Relación costo- beneficio

- Sostenibilidad del servicio

-Relaciones de cooperación con otras instituciones (locales, regionales, etc.)

- Evaluación del servicio (metodología, periodos)

3. Organización del servicio. Destaca que el servicio debe ser organizado bajo una visión sistémica. Para esto la IFLA orienta definir documentos orientativos para la definición y puesta en práctica del servicio. En este sentido la organización del proceso de prestación de servicio adquiere una estructura lógica y en correspondencia con la demanda. Los aspectos considerados fundamentales para la organización del servicio se listan a continuación:

- Política de servicio

- Perfiles ocupacionales del personal

- Plan de formación y actualización profesional (usuario y referencista)

- Diseño de la interfaz

- Aspectos legales

- Publicidad y Promoción

- Evaluación y calidad

- Colaboración

\subsubsection{Directrices básicas de la RUSA}

Otro aporte significativo de directrices para el diseño e implementación del servicio de referencia es ofrecido por la The Reference and User Services Association (RUSA). Se trata de una sección de trabajo de la American Library Association (ALA). El grupo está conformado por profesionales referencistas, siendo su objetivo estimular y apoyar la excelencia en la prestación de servicios de servicios de referencia e información ha elaborado una serie de documentos normativos para el 
diseño, organización, prestación, seguimiento y evaluación de los servicios que se encuentran disponibles en su sitio web $^{47}$.

La RUSA en su documento oficial (2004), considera la práctica del servicio de referencia digital como un proceso de transferencia de información mediante un proceso de comunicación en dos líneas. La biblioteca y el usuario. El usuario consulta, demanda información y la biblioteca analiza, interpreta, evalúa y recomienda alternativas para satisfacer las necesidades de información. Indica además que el servicio tiene como áreas fijas: la accesibilidad, intereses, comprensión oral, formas de preguntar y mecanismo de búsqueda y seguimiento. El documento además reconoce como resultado de la integración de recursos telemáticos las siguientes categorías de prestación del servicio:

- Prestación general del servicio. Lineamientos aplicables a cualquier tipo de interacción de la referencia, tanto en persona como transacciones remotas.

- Prestación personalizada del servicio. Pautas adicionales específicas para encuentros cara a cara.

- Prestación remata del servicio Pautas adicionales específicas para encuentros sincrónicos o asincrónicos, donde las tradicionales señales visuales y no verbales no existen.

La revisión y actualización de las directrices emitidas en el 2004, efectuada en el $2010^{48}$ se orienta en el diseño e implementación de un servicio de referencia digital implica la necesidad de atender los siguientes aspectos:

1. Integración del servicio de referencia tradicional. El servicio de referencia digital o virtual tiene como base el servicio de referencia tradicional.

2. Estudio de viabilidad. Resulta un instrumento valioso para identificar la importancia del servicio, reconocer las necesidades y demanda reales, a fin de diseñar una adecuada oferta de servicio.

3. Elaboración de un proyecto. Disponer de un proyecto coherente para el diseño del servicio es disponer de una herramienta de orientación para su organización e implementación exitosa.

4. Costos y sostenibilidad. Elaboración de un presupuesto real de los costos que implica el servicio de referencia virtual permitirá garantizar la permanencia del servicio. Permite además asegurar un compromiso a todos los niveles de gestión de la institución y el personal.

5. Planificación. Establecimiento de un plan que articule el servicio.

6. Infraestructura tecnológica. Involucra la selección de programas y nivel de aplicaciones informáticas y recursos telemáticos necesarios. Es importante dar atención a los aspectos de compatibilidad y actualización de estos recursos.

\footnotetext{
${ }^{47}$ Los documentos normativos de la RUSA para el diseño y prestación del servicio de referencia en el sitio http://www.ala.org/rusa/resources/guidelines.

${ }^{48}$ Véase documento completo en http://www.ala.org/rusa/sites/ala.org.rusa/files/content/resources/guidelines/virtualreference-se.pdf.
} 
7. Contenido. Desarrollo de la Colección y disponibilidad de recursos de referencia electrónica y concesión de licencias para el uso de recursos por parte de los usuarios.

8. Evaluación. Se recomienda ejecutar procesos de evaluación periódica, tanto del sistema, personal y clientela. En esta línea se recomienda considerar el aprendizaje de otras experiencias institucionales similares.

9. Prestación de servicio. Es necesario tener claro políticas para la prestación del servicio, en la cual se defina claramente el público objetivo (s) o clientela.

10. Parámetros de uso. Delimitar el nivel de servicio que se proporciona, quién lo brinda y a quiénes, tiempo de respuestas, formas de comunicación, uso de respuestas predeterminadas, etc. Este aspecto es importante debido a que en dependencia del nivel de servicio se determinará los tipos de preguntas que el servicio ha de responder.

11. Personal. El servicio de referencia debe ser una responsabilidad compartida entre el personal para asegurar la continuidad del servicio. La selección del personal referencista debe ser realizada sobre la base de la capacidad, interés, manejo de contenido y disponibilidad. Debe ser un profesional flexible a cambios; disponer de habilidades de comunicación y para la formación de usuarios e interaccionar con clientes virtuales. En el documento de la RUSA "Competencias profesionales para bibliotecarios de referencia y servicios al usuario." Se listan con detalles las competencias profesionales esenciales para referencia exitosa y servicios ${ }^{49}$

12. Colaboración. Algunas bibliotecas pueden optar por proporcionar servicios de referencia virtual en colaboración con otras bibliotecas para diversos objetivos. No de ellos es el acceso a recursos de información, contactos profesionales. En esta línea es importante tener en cuenta la interoperabilidad de las plataformas tecnológicas. Asimismo es necesario definir claramente la responsabilidad de la administración centralizada y la coordinación del servicio cooperativo.

13.- Organización de los servicios. El servicios de referencia digital debe incluir todos los recursos posibles (en persona, por teléfono, y virtual) para asegurar la calidad del servicio mismo. Es de vital importancia establecer procedimientos para referir a un cliente virtual (el asunto en cuestión) al punto adecuado donde el encontrará la respuesta a su pregunta.

14. Infraestructura/Instalaciones. Aunque si bien se trata de un servicio de referencia virtual. La RUSA recomienda la incorporación de servicio de referencia tradicional. En este contexto recomienda proporcionar al personal con el espacio, mobiliario, equipos necesarios para cumplir con los objetivos del trabajo. Otro punto de atención es la actualización de equipos, programas y los soportes de apoyo a los todos clientes.

15. Finanzas. Se debe incluir en el presupuesto del servicio la asignación específica de fondos para cubrir los costos del personal, los equipos, programas, servicios de conectividad, mobiliarios, capacitación, publicidad, y el espacio para apoyar este servicio.

\footnotetext{
${ }^{49}$ Traducción realizada por Karla Vanessa del documento original disponible http://www.ala.org/rusa/resources/guidelines/profesional.
} 
16. Comercialización. Se recomienda desarrollar e implementar un plan de mercadeo que incluya aspectos de difusión y evaluación de la satisfacción del enfoque oferta-demanda.

17. Evaluación y mejora. Evaluar la eficacia y la eficiencia del servicio de referencia digital es fundamental. El proceso de evaluación debe ser a lo interno con el personal y externo con los clientes. Para la evaluación es posible utilizar métodos tales como el análisis de las estadísticas de uso, la retroalimentación de los clientes y la revisión de transcripciones. Los resultados de las evaluaciones contribuyen a mejorar el servicio, según sea necesario.

18. Políticas de privacidad. La base de los procesos de comunicación en el servicio de referencia digital es la privacidad entre los clientes y el personal de la biblioteca a excepto cuando sea requerido por la ley. La RUSA recomienda desarrollar políticas de privacidad para las transacciones involucradas en la prestación del servicio que incluya los horarios en que las transcripciones estén a disposición del público. Es necesario además informar a los clientes que sus preguntas pueden ser incluidas en una base de datos para uso de la biblioteca.

\subsubsection{Proceso de comunicación del servicio de referencia digital}

El proceso de comunicación y de consulta puede ser sincrónico (simultáneo) o bien asincrónico como es el caso del servicios de preguntas y respuestas más frecuentes sobre temas especializados y en algunos casos puede ocurrir mediante una combinación híbrida de ambos a fin de acertar en las respuestas. Online Computer Library Center $(\mathrm{OCLC})^{50}$ y la biblioteca del Congreso ${ }^{51}$ caracterizan el servicio de referencia como un modelo estándar de servicio de comunicación que debe ser visto como un punto de información (Question Point). El concepto señala que la referencia virtual es sinónimo de digital y distingue en él dos categorías:

\section{A/ Servicio de referencia digital sincrónica}

Es definido como el proceso de comunicación directa y simultánea desde un sistema de red local o internet presentando una consulta entre el bibliotecario y el usuario. Algunos ejemplos de este servicio se reconocen en forma de conversaciones a través de programas que facilitan el diálogo directo ya sea con opción de cámara de video o bien texto. Es decir, sesiones de chat y voz sobre IP, por la cual el usuario y el bibliotecario se comunican en tiempo real.

Las aplicaciones más reconocidas al momento de finalizar esta investigación correspondieron a una comunicación sincrónica en forma de chat ofrecida a través de los programas Messenger, Skype, Facebook, Twitter, entre otras.

Usualmente el servicio de comunicación sincrónica se ubica a lado izquierdo de la página web de la biblioteca. La oferta se visualiza como opciones logo o palabras que enlazan a las opciones chat, para video conferencia, aplicaciones telefónicas en portátil. Con el fin de ilustrar lo antes referido se presentan algunos ejemplos extraídos de Internet de instituciones ubicadas de Estados Unidos, Países Bajos, Australia.

\footnotetext{
${ }^{50}$ Detalle del concepto en http://www.oclc.org/americalatina/es/questionpoint/about/virtual/default.htm.

${ }^{51}$ Véase ejemplo del servicio en el sitio web de la library congres: http://www.loc.gov/rr/program/orientation.html.
} 


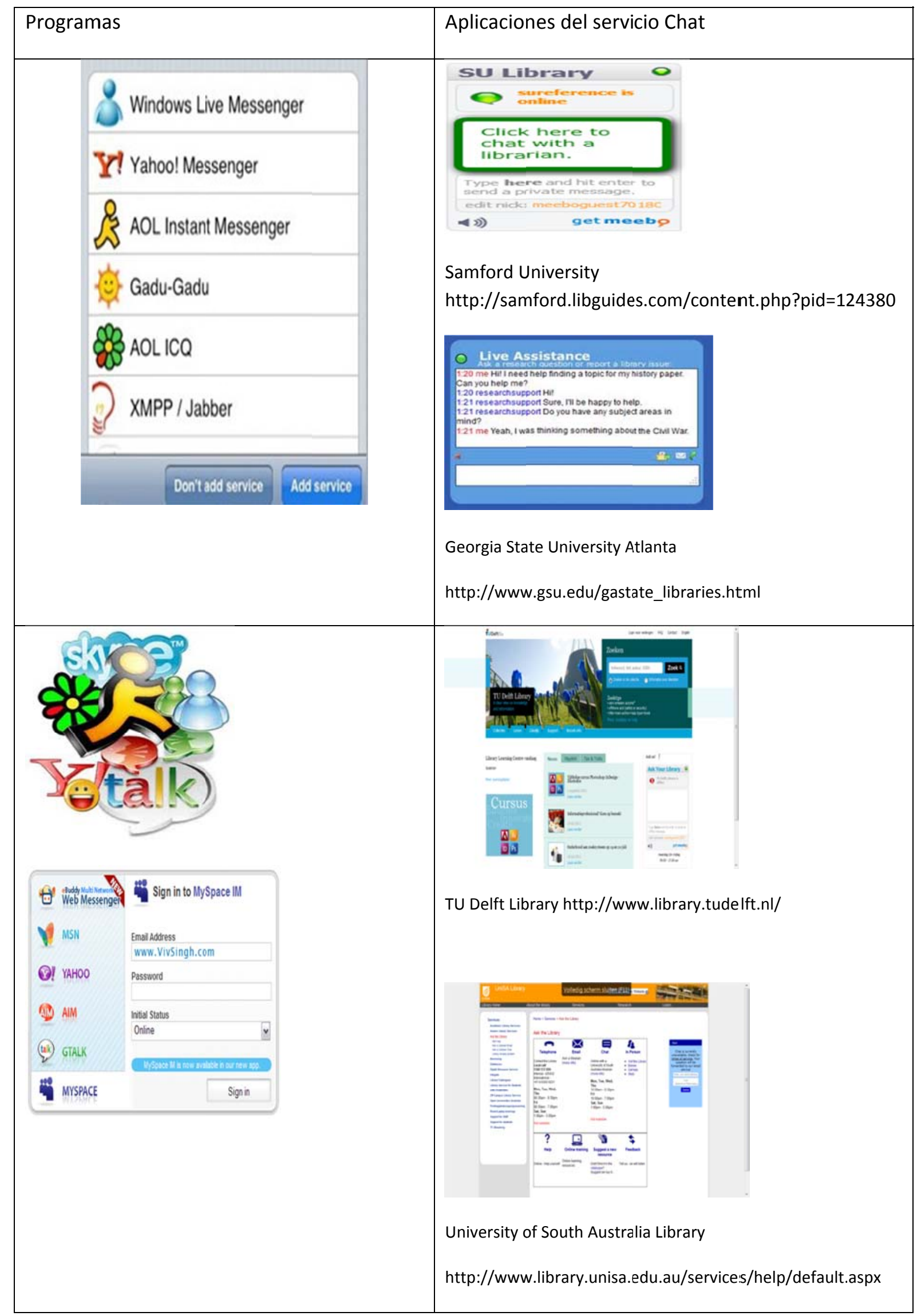

Figura 20. Prácticas de servicio de referencia digital vía chat. Fuente: Elaboración propia. 


\section{B/ Servicios de comunicación asincrónicos}

Este servicio se refiere a la posibilidad de establecer un proceso de comunicación entre el usuario y la biblioteca sin que este implique una acción simultánea, es decir no existe la coincidencia de tiempo. Ejemplos citables son el correo electrónico, formularios web para expresar la consulta o pregunta y el uso de recursos de redes sociales como Blogs, Slider share, Flickr, y entornos virtuales para incrementar las posibilidades de presentar preguntas a la biblioteca.

La siguiente figura tomada de la reflexión de Susana Agudo Prado (2010 p.3-4) se presenta de forma esquemática las diferentes formas actuales de comunicación sincrónica utilizadas en la biblioteca para la prestación del servicio de referencia.

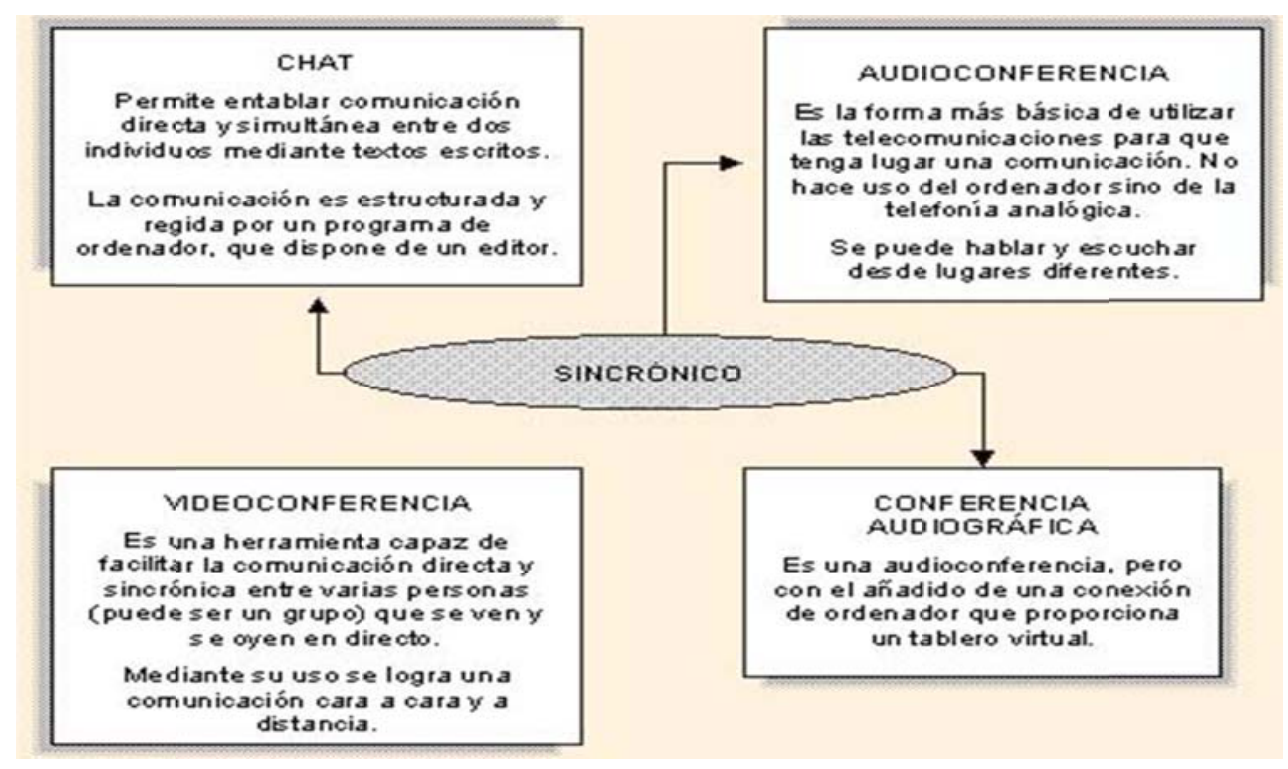

Figura 21. Comunicación sincrónica utilizada en la biblioteca para la prestación del servicio de referencia. Fuente: Susana Agudo Prado. El uso comunicativo de las TIC en educación social, 2010 p.3-4.

La tendencia del modelo de referencia digital se encamina a un servicio constituido como medio para la interacción entre la biblioteca y el usuario a fin de facilitar la transferencia de conocimiento e información, en el cual el usuario pregunta y la biblioteca responde. En un acercamiento al modelo de servicio de referencia digital se constató que las actuales herramientas de comunicación (sincrónica y asincrónica,) son portales, web, bases de datos de preguntas frecuentes (FAQs), tutoriales en línea, secciones de orientación para investigadores, programas cooperativos entre otros y que están disponibles durante las 24 horas y 7 días de la semana.

\subsubsection{Características del modelo de referencia digital}

José Antonio Merlo Vega (2009, p. 179) señala que "las características y servicios bibliotecarios de la referencia digital se pueden clasificarse en función de diversos criterios, como son la tipología de las bibliotecas que responden a los usuarios, el tipo de consultas que atienden, los medios tecnológicos 
que emplean, la especialización temática, etc." todas ello ligado a los objetivos de la institución en la que están inmersa, debido a que estos determinarán el nivel de contenido, la apertura y cobertura del servicio. En esta misma línea Ramón Alberto Manso Rodríguez (2007) $)^{52}$ aporta una clasificación de los servicios como se muestra en la siguiente figura.

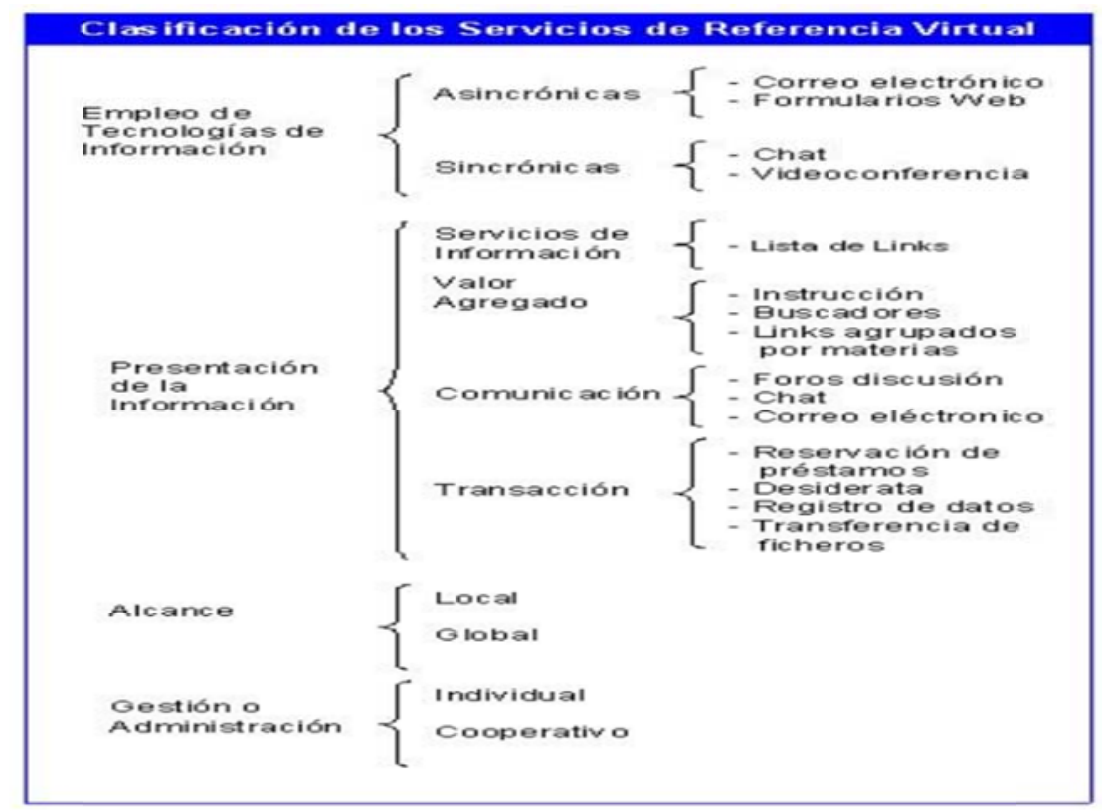

Figura 22.Tipología de servicios de referencia virtual. Fuente: Ramón Alberto Manso Rodríguez 2007

Partiendo de la anterior clasificación del servicio, cabe destacar que en dependencia del tipo de servicio, desarrollo tecnológico y organizativo del servicio de referencia digital, se le atribuyen las siguientes características:

\begin{tabular}{|l|l|}
\hline $\begin{array}{l}\text { Factores incidentes en el servicio } \\
\text { de referencia digital }\end{array}$ & Características \\
\hline $\begin{array}{l}\text { Disponibilidad y desarrollo de } \\
\text { aplicaciones tecnológicas }\end{array}$ & Sincrónico o asincrónico \\
\hline $\begin{array}{l}\text { Organización y presentación de la } \\
\text { información: }\end{array}$ & Ventanas, iconos, listas de enlaces \\
\hline Valor agregado & $\begin{array}{l}\text { Instrucción, agrupación de contenidos por } \\
\text { materias, buscadores }\end{array}$ \\
\hline Comunicación & $\begin{array}{l}\text { Diferentes alternativas de hacer contacto } \\
\text { con la biblioteca }\end{array}$ \\
\hline Alcance & $\begin{array}{l}\text { Puede ser un servicio abierto a todia una } \\
\text { población indiscriminada o ser de acceso }\end{array}$ \\
\hline
\end{tabular}

\footnotetext{
${ }^{52}$ Doctor de la Universidad de Granada. Su tesis aporta un modelo de referencia virtual basada en criterios de calidad y herramientas web 2.0. http://hera.ugr.es/tesisugr/19562871.pdf
} 


\begin{tabular}{|l|l|}
\hline & restringido y direccionado a un grupo meta. \\
\hline Gestión - administración & $\begin{array}{l}\text { Servicio individual o institucional o un } \\
\text { servicio cooperativo entre viarias } \\
\text { instituciones }\end{array}$ \\
\hline
\end{tabular}

Tabla 13. Características del servicio de referencia en dependencia de su tipología y nivel de desarrollo. Fuente: Elaboración propia.

\subsubsection{Modelos de servicio de referencia digital}

El servicio de referencia no sólo es ofrecido por las bibliotecas, algunos organismos públicos y empresas privadas ofrecen también este servicio. La diferencia entre ellos fundamentalmente radica en los objetivos y a su vez determina el tipo de modelo de servicio a implementar. En dependencia del modelo de servicio, José Antonio Merlo Vega (2009 p.186-188) ${ }^{53}$, distingue cinco diferentes prácticas de servicios que se presentan en la siguiente tabla:

\begin{tabular}{|l|l|}
\hline Modelo & Descripción \\
\hline bervicio de & $\begin{array}{l}\text { Es el servicio bibliotecario (independientemente del modelo de biblioteca) } \\
\text { que atiende peticiones de información en forma telemática. } \\
\text { Característica : } \\
\text { - De orden académico y científico } \\
\text { - Control de veracidad y autoridad de la información } \\
\text { Ejemplos: } \\
\text { Pregunte al bibliotecario - Universidad de Sevilla: } \\
\text { http://bib.us.es/servicios/pregunte/index-ides-idweb.html } \\
\text { Punto de información (Infopoint ) para la cooperación europea: } \\
\text { http://ec.europa.eu/europeaid/infopoint/index_en.htm } \\
\text { Mostrador de servicios (Servicedesk) } \\
\text { http://w3.tue.nl/en/services/library/about/helpdesk/ }\end{array}$ \\
\hline $\begin{array}{l}\text { Servicios de } \\
\text { información }\end{array}$ & $\begin{array}{l}\text { Estos servicios pueden ser ofrecidos por centros de documentación, } \\
\text { archivos, servicios (puntos) de información que pertenecen a instituciones } \\
\text { u organismos públicos. Se reconocen como servicios de atención al } \\
\text { ciudadano, consumidores o colectivos específicos } \\
\text { Ejemplos: } \\
\text { Sitios web en el que se ofrece direcciones, teléfono, comunicación } \\
\text { sincrónica, opciones de trámites en línea. Un ejemplo de esto es el sitio } \\
\text { web del gobierno de Canarias. http://www.gobcan.es/siac/ } \\
\text { Europa direct: http://europa.eu/europedirect/index_nl.htm }\end{array}$ \\
\hline expertos & $\begin{array}{l}\text { Es un servicio especializado gestionado y ofrecido por un grupo de } \\
\text { profesionales en una materia específica. El acceso puede ser gratuito o } \\
\text { privado, pagado. Ejemplo de este servicio son los sitios web o portales con } \\
\text { información orientativa a las posibles preguntas de Qué servicios, Quiénes, } \\
\text { Dónde, Qué. }\end{array}$ \\
\hline
\end{tabular}

\footnotetext{
${ }^{53}$ José Antonio Merlo Vega. Información y referencia en entornos digitales: desarrollo de servicios bibliotecarios de consulta, 2009, p. 188.
} 


\begin{tabular}{|l|l|}
\hline & Ejemplos: \\
& Médico en los Países Bajos: http://www.medischestartpagina.nl/ \\
& Creativo en los Países Bajos::http://www.ccaa.nl/ \\
& Biblioteca en los Países: http://bibliotheek.info-pagina.com/ \\
\hline Servicios de & $\begin{array}{l}\text { Son aplicaciones de buscadores que se ofrecen para que los usuarios } \\
\text { respuestas }\end{array}$ \\
& $\begin{array}{l}\text { Googlicen sus consultas. Existen en la actualidad aplicaciones en Yahoo, } \\
\text { que son posibles identificar generalmente por temas. Ejemplo de estos son } \\
\text { preguntas al doctor. } \\
\text { Ejemplos: } \\
\text { Médico en Estados Unidos: http://www.consultadr.com/ } \\
\text { Jurídico en España: http://www.iurisconsultas.com/1-abogados-online }\end{array}$ \\
\hline inteligentes & $\begin{array}{l}\text { Son programas informáticos especializados para recuperar información en } \\
\text { la Internet. Lo especial de estos buscadores es que los resultados } \\
\text { responden obligatoriamente a un conjunto de criterios y ponderaciones } \\
\text { que reducen la posibilidad de recuperar información que se ajuste a la } \\
\text { pregunta. } \\
\text { Ejemplos: } \\
\text { Buscador global (Países Bajos): http://www.vinden.nl/ } \\
\text { Buscador e identificador de cajeros automáticos (España) } \\
\text { http://www.4b.es/localizador-de-cajeros-4b }\end{array}$ \\
\hline
\end{tabular}

Tabla 14. Diferencias de servicios involucrados con la referencia digital.

Fuente: Elaboración propia basada en el texto de José Antonio Merlo Vega (2009).

\section{Modelo de servicio aplicable a E-learning}

De los anteriores aportes señalados, se destaca la existencia de una relación condicionada entre los usuarios - contenido y tecnología, relación que también se identifica en las estructuras organizativas del E-learning y los modelos de bibliotecas. Asimismo es posible retomar los aportes teóricos de Merlo Vega y las directrices generales de la IFLA (2009) y la RUSA como una sola unidad la definición para concebir un punto de partida para el diseño del modelo del servicio de referencia digital aplicable a los objetivos de la presente tesis y que se representa gráficamente en la figura 23.

\section{Objetivos y misión del servicio de referencia digital}

El servicio de referencia digital está en coherencia con los objetivos, misión y visión institucional donde se encuentran inmersos. En el contexto de las prácticas E-learning deben ser capaces de orientar, situar, referir o transferir información y fomentar en el individuo su capacidad de informarse. El servicio deberá facilitar a los usuarios el camino para encontrar las respuestas a sus .preguntas.

\section{Contenido}

El contenido de las respuestas debe ser estrictamente coherente y en correspondencia a los contenidos de los cursos o programas E-learning. Las respuestas y las fuentes utilizadas deberán ser rígidamente evaluadas a partir de los siguientes aspectos: objetividad y precisión del contenido, autoridad, actualidad, y dominio del sitio web. 


\section{Tecnología}

Los recursos telemáticos y nivel de aplicaciones tecnológicas del servicio de referencia estarán en dependencia de los objetivos, condiciones presupuestarias, entornos y el usuario meta. Se considera como básico el manejo de programas de gestión de contenidos, gestión de recursos multimedia y programas para desarrollo de procesos de comunicación y transferencia de archivos que puedan interactuar en plataformas E-learning.

\section{Usuario, capacidades, habilidades y entorno.}

Este se considera importante en el sentido que se puede contar con un buen diseño basado en normas, disponer de aplicaciones tecnológicas coherentes, actuales y amigables, pero si el usuario no cuenta con las capacidades y habilidades para usarla, el servicio no tendrá demanda. En este contexto es fundamental tener claro quiénes son el grupo meta, su nivel de conocimiento en el uso de la tecnología y estar conscientes de las características y limitaciones del entorno.

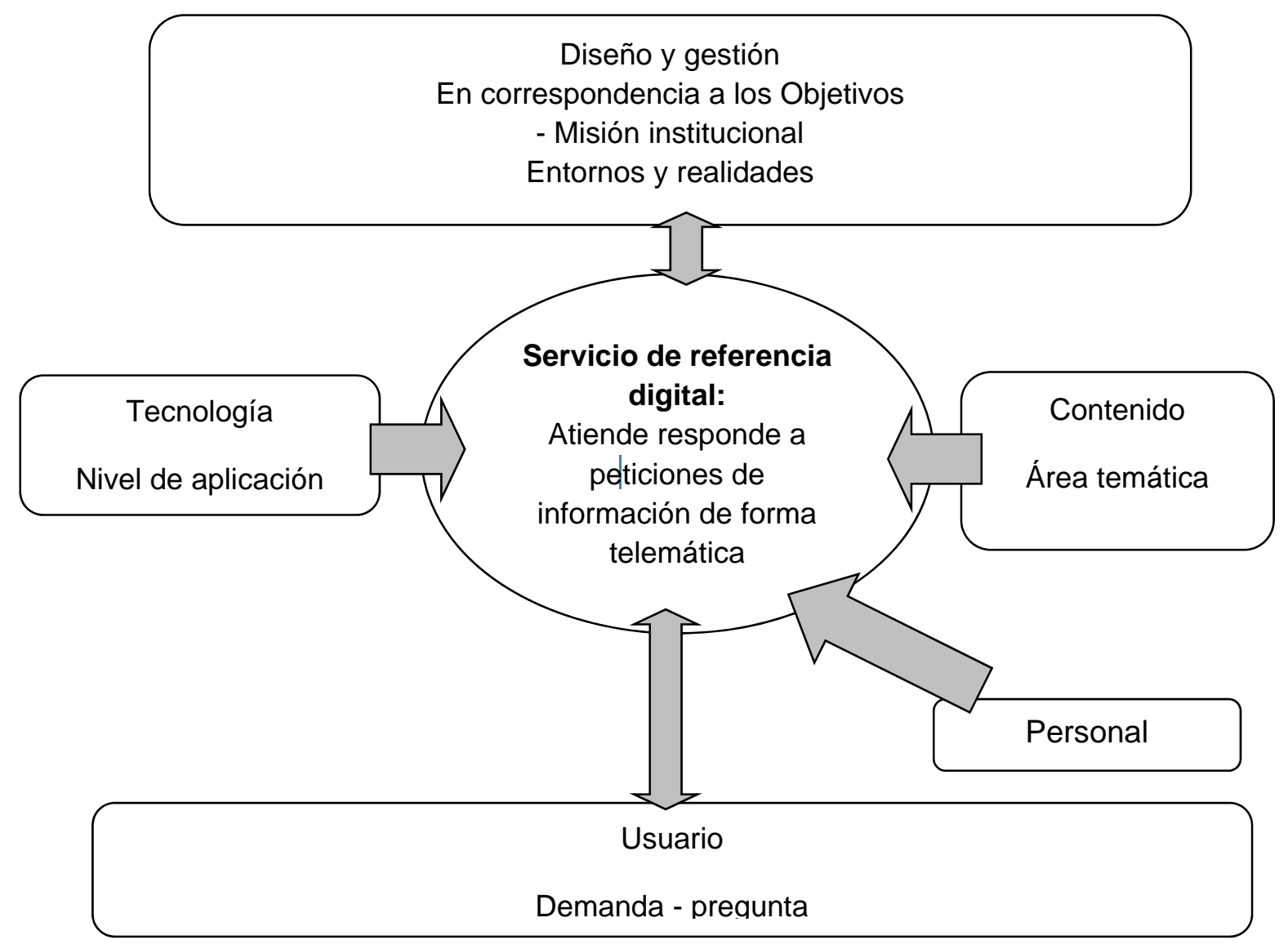

Figura 23. Representación del modelo conceptual de servicio de referencia digital. Fuente: Elaboración propia

\section{Personal}

Las competencias esenciales del bibliotecario en la referencia digital ${ }^{54}$ se centran en aspectos comunicativos, tecnológicos e informacionales, por tanto se requiere que el referencista en línea sea un profesional proactivo y flexible a cambios. Silvina Angelozzi (2011) y otros estudios de la materia reconocen siguientes competencias básicas y necesarias del referencista:

\footnotetext{
${ }^{54}$ La relación de competencias que se enuncian han sido tomada de: Silvina Angelozzi. Competencias del bibliotecario referencista en el siglo XXI Escuela de Bibliotecología, Universidad Nacional de Córdoba. Buenos Aires, 2011.
} 
- Conocimiento de las obras de referencia tradicional y automatizada.

- Capacidad e interés de aprendizaje permanente.

- Habilidad para incorporar la perspectiva de los usuarios en la creación de productos, servicios y programas de referencia e investigación de la biblioteca. En el caso de capacitación de usuarios se deben diferenciar los estilos de aprendizaje y personalizar la instrucción.

- Habilidades de relación y de comunicación: escucha activa, empatía, disponibilidad, manejo y resolución del conflicto, flexibilidad, efectiva expresión oral y escrita.

- Habilidad para la instrucción o enseñanza.

- Curiosidad intelectual, relacionada con el estar abierto a los acontecimientos exteriores y a las novedades tanto en lo relacionado con la propia ocupación, como en lo que interesa al usuario, aprovechar cualquier oportunidad para enriquecer los conocimientos y reflexionar.

- Manejo de conceptos, principios y técnicas de referencia y servicios; técnicas para recuperar, evaluar y sintetizar información de diversas fuentes; estructura de los recursos de información.

\subsubsection{Evaluación del servicio de referencia digital}

Existen diferentes metodologías para evaluar servicios ofrecidos en sitios web. Estas incluyen una serie de parámetros e indicadores que son aplicables de acuerdo al tipo de servicio e infraestructura tecnológica. En el caso específico de la referencia digital la evaluación se orienta básicamente al funcionamiento del sitio diseño de la web del servicio y el uso del mismo y el nivel de satisfacción de los usuarios.

Una metodología para la evaluación de servicios ofrecidos desde web frecuentemente citada en documentos académicos, es el aporte de Lluís Codina $(2000)^{55}$, quién orienta efectuar la evaluación a la funcionalidad del servicio valorando aspectos de diseño, contenido y uso. Para cada una de estas áreas, Codina recomienda utilizar seis parámetros relacionados entre sí que a continuación se listan.

- Autoría: adecuación y solvencia de la fuente.

- Contenido visto en su valor intrínseco y volumen de la información.

- Acceso a la información: navegación y recuperación.

- Ergonomía: comodidad y facilidad de utilización.

- Concordancia de luminosidad, es decir, la presencia y calidad de enlaces externos.

- Visibilidad en relación al número de enlaces que recibe de otros recursos.

\footnotetext{
${ }^{55}$ Codina, Lluís. Evaluación de recursos digitales en línea: conceptos, indicadores y métodos. Revista Española de Documentación Científica, 2000, vol. 23. No.1 p.9-44. http://redc.revistas.csic.es/index.php/redc/article/view/315.
} 
Olga Patricia Gama $(2008)^{56}$, en propuesta de modelo de servicio de referencia virtual para una biblioteca universitaria, destaca desde la perspectiva del usuario la necesidad de centrar la evaluación en tres líneas.

a. Satisfacción de las necesidades de Información.

b. Capacidad de respuesta del sistema.

c. El proceso de comunicación como medio de interacción entre el usuario- la información y el bibliotecario.

David Lankes; Melissa Gross y Charles R. McClure $(2003)^{57}$, señalan que la evaluación del servicio de referencia digital, no admite el uso de todos los estándares, sin embargo recomiendan los siguientes seis aspectos básicos para la medición estadística de la calidad de los servicios:

1. Cortesía y profesionalismo del personal referencista.

2. Precisión de las respuestas recibidas por un personal de referencia digital.

3. Satisfacción de los usuarios.

4. Porcentaje de uso del servicio.

5. Conocimiento. Nivel de conocimiento del grupo del servicio.

6. Costo real del servicio de referencia digital.

José Antonio Merlo Vega (2009, p. 333-345) analiza y amplía el aporte de Lankes; Gross y McClure (2003) al indicar la evaluación del servicio desde un enfoque sistémico, considerando los siguientes siete grupos como parte de la unidad que representa el servicio mismo y que extrae de la obra de Lankes, Gross y McClure (2003), que es una de las fuentes bibliográfica más completas en las que se establecen grupos de indicadores para la evaluación de la referencia digital:

Grupo 1. Demanda

- Número de preguntas recibidas

- Número de contestaciones

- Número total de respuestas

- Número total de preguntas

- Actividad total de la referencia

- Porcentaje de las preguntas de referencia digital total

- Tasa de respuestas completas en forma correcta

- Tiempo de conclusión de la referencia digital

\footnotetext{
${ }^{56}$ Propuesta de un modelo de diseño del servicio de referencia virtual para una biblioteca universitaria. Olga Patricia Gama. 2008. Universidad Javeriana.

${ }^{57}$ Lankes, David R.; Groos, Melissa; McClure, Charles R. (2003).Cost, Statistics, Measures, and Standards for Digital Reference Services: A Preliminary View R. Library Trends, Vol. 51, No. 3, Winter 2003, p. 401-413

https://www.ideals.illinois.edu/bitstream/handle/2142/8478/librarytrendsv51i3i_opt.pdf?sequence=1.
} 
Grupo 2. Comportamiento y capacidad

- Número de preguntas del servicio de referencia digital

- Tipo de preguntas recibidas en el servicio de referencia

- Número de re-envíos

- Tasa de saturación

- Recursos empleados por pregunta

- Tasa de retorno

- Número de sesiones de referencia digital

Grupo 3. Usabilidad y navegación

- Uso del servicio de referencia digital por día y semana

- Uso del servicio de referencia digital por hora y día

- Navegador del usuario

- Plataforma del usuario

Grupo 4 Acceso

- Conocimiento del servicio

- Accesibilidad del servicio

- Expectativas del servicio

- Otras fuentes empleadas por el usuario

- Razones para el uso

- Razones para el no uso

- Mejoras necesarias y servicios adicionales que se deben ofrecer

Grupo 5 Satisfacción

- Satisfacción con el personal del servicio

- Satisfacción con el sistema de respuesta

- Impacto del servicio en el usuario

- Datos demográficos de los usuarios

Grupo 6 Costos

- Costo del servicio de referencia

- Porcentaje del costo del servicio de referencia digital en relación al presupuesto total del servicio de referencia 
- Porcentaje del costo del servicio de referencia digital en relación al presupuesto total de la biblioteca

\section{Grupo 7. Eficiencia}

- Porcentaje de tiempo dedicado por el personal para supervisar la tecnología

- Porcentaje de tiempo dedicado para ayudar a los usuarios con tecnología

Lo antes reflejado, evidencia que repetidamente se destaca la importancia de tres aspectos básicos en el proceso de la evaluación. Se trata del diseño web del servicio, el contenido de la información en relación al usuario y la necesidad de evaluar el uso del servicio. Este hecho que se demuestra en la siguiente tabla que resume los aportes ya enunciados.

\begin{tabular}{|l|l|l|l|}
\hline Lluís Codina & Lankes Gross y McClure & Gama & Merlo Vega \\
\hline 2.Diseño & $\begin{array}{l}\text { 1. Cortesía y } \\
\text { profesionalismo. }\end{array}$ & $\begin{array}{l}\text { 1. Satisfacción de las } \\
\text { necesidades }\end{array}$ & 1. Demanda \\
3.Uso & $\begin{array}{l}\text { 2.Precisión de las respuestas } \\
\text { 2.Capacidad de } \\
\text { respuesta }\end{array}$ & $\begin{array}{l}\text { 2. Comportamiento y } \\
\text { capacidad de } \\
\text { conocimiento }\end{array}$ \\
& $\begin{array}{l}\text { 3. Satisfacción de los } \\
\text { usuarios. } \\
\text { 4. Porcentaje de uso del } \\
\text { servicio }\end{array}$ & 3. Comunicación \\
5. Conocimiento & $\begin{array}{l}\text { 3.Usabilidad y } \\
\text { navegación }\end{array}$ \\
6. Costos & 4cceso \\
\hline
\end{tabular}

Tabla 15. Aspectos básicos para la evaluación del servicio de referencia digital. Fuente: Elaboración propia.

Desde esta perspectiva y en el contexto de los objetivos de esta tesis, se concluye que la evaluación del modelo de servicio de referencia digital incluyente como componente en la propuesta de oferta de servicio para E-learning, deberá ser evaluada de forma sistémica a partir de un análisis de la oferta y demanda.

Para esto, se orienta organizar la evaluación en tres áreas: el diseño web, contenido y la usabilidad del servicio en correspondencia a la satisfacción de los usuarios. Cabe destacar que las características de cada una de estas áreas varían, hecho por lo que se deberá definir y utilizar los parámetros e indicadores específicos al caso. En la siguiente figura se ilustra esta triple evaluación. 


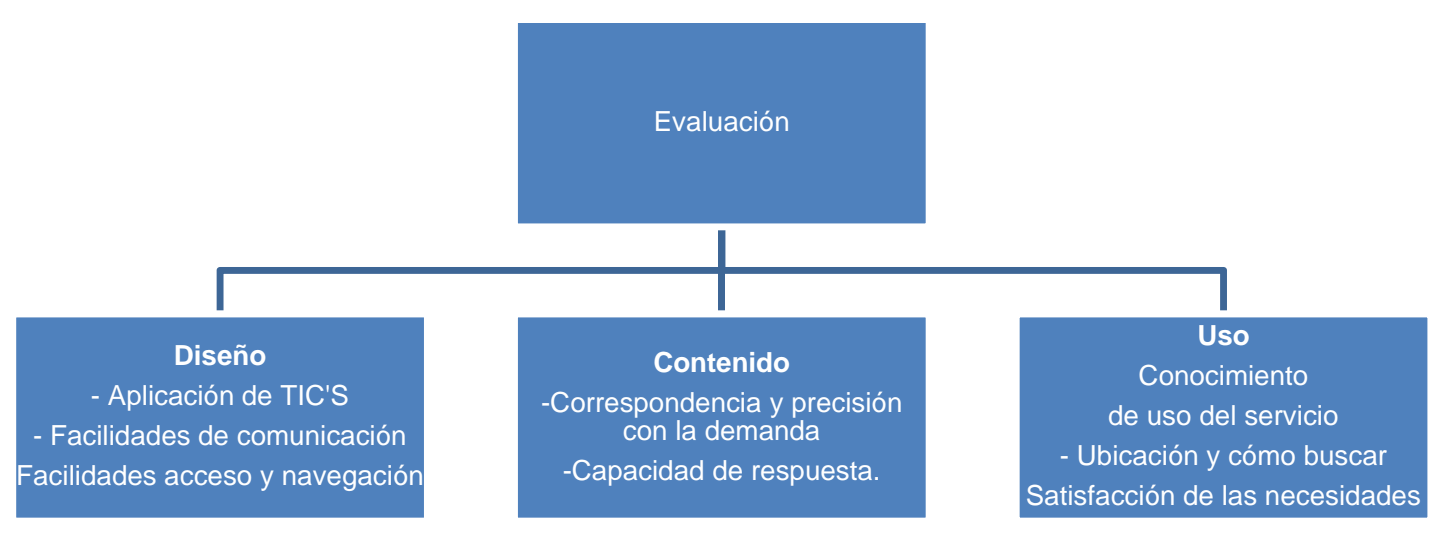

Figura 24. Aspectos básicos para la evaluación del servicio de referencia para E-learning. Fuente: Elaboración propia.

\subsection{Alfabetización informacional}

La formación en información, educación documental o alfabetización en información es el ámbito hacia el que las bibliotecas universitarias han enfocado sus servicios de forma más contundente. Además, la facilidad para emplear tecnologías y para ofrecer acciones formativas de forma telemática hacen que estos servicios sean esenciales como elementos de apoyo al aprendizaje. Sin duda, la alfabetización informacional es uno de los ámbitos de convergencia entre las bibliotecas universitarias y el E-learning.

\subsubsection{Introducción al servicio de alfabetización informacional}

La sobrevivencia en entornos cambiantes e influenciados por avanzada tecnologías exige en el individuo socialmente activo habilidades y destrezas en el uso de la información. Michael Middleton (1999) afirma que el aprendizaje en el uso correcto de la información, garantiza la apropiación y aplicación del adecuado conocimiento. Subraya además, que tanto el conocimiento tácito y explícito deben ser manejados como información. Middleton destaca la importancia de la presencia de ambos para la gestión del conocimiento y señala que si no están documentados explícitamente en un soporte, el conocimiento es compartido a través de conversaciones o reuniones presenciales o virtuales. Rebeca Garzón Clemente (2000) completa el aporte anterior al agregar ${ }^{58}$ que el apropiarse de la información adecuada, en el momento oportuno permite generar nuevos conocimientos que son difundidos a través de la comunicación formal e informal.

Andoni Rehecho Calderón (2010) p.12 desde un enfoque sistémico señala que, el adecuado uso de la información está ligado al aprendizaje a lo largo de la vida, por el hecho que el estado de conocimiento se transforma al igual que los entornos de su aplicación. Asimismo en un mismo nivel de importancia indica, que éste aprendizaje está vinculado a un proceso de multi-alfabetismo,

\footnotetext{
${ }^{58}$ Libro de buenas prácticas promovido por la Universidad a Distancia de Madrid http://www.buenaspracticaselearning.com/capitulo-15-metamorfosis-concepto-alfabetizacion-educacion-mediada-tecnologias.html.
} 
entendiéndose esto como el aprendizaje en el uso de los diferentes recursos telemáticos y el uso de redes de comunicación para el acceso a la información.

En esta línea la función de formación de usuarios por parte de las bibliotecas académicas, ha sido iniciada en el modelo de la biblioteca tradicional. En la actualidad ha experimentado transformaciones influenciadas por la diversidad de formatos, soportes de información y las aplicaciones tecnológicas que de forma directa también transforman las necesidades y demandas de formación.

\section{Importancia del servicio}

La sociedad en el siglo XXI se caracteriza por el uso masivo de los medios electrónicos para acceder a información, poder comunicarse, consolidar relaciones, trabajar en red y gestionar proyectos. De hecho la disponibilidad comercial de diferentes marcas y tipos de recursos telemáticos, contribuye a superar los problemas de tiempo, espacio y movimiento.

En la práctica la instalación de programas y/o aplicaciones específicas un sólo dispositivo electrónico, permiten acceder a diversos servicios de comunicación. Por ejemplo, desde un teléfono portátil, se puede acceder al servicio de telefonía, hacer fotos, hacer videos, obtener servicio de orientación y ubicación geográfica, programar rutas de viaje y recibir la conexión permanente a Internet.

De forma paralela, esta diversidad de oferta de medios electrónicos para la transferencia de información y comunicación, genera la necesidad de "aprender" a usarlos. Es decir, no se trata solo de aprender a encender un aparato, sino de saber la funcionalidad de cada una de sus aplicaciones para sacar buscar, evaluar, recuperar y utilizar la información de forma eficiente y aprovechar al máximo las facilidades que ofrece.

En el ámbito de la educación, la adopción de recursos electrónicos representa ser un valioso instrumento para el fomentar un proceso permanente de enseñanza-aprendizaje. Hecho que ha requerido que las entidades educativas asuman la responsabilidad de promover el desarrollo de habilidades y competencias para el uso adecuado y ético de los recursos y medios tecnológicos disponibles para acceder a la información.

La formación de los estudiantes a nivel universitario se orienta en dos líneas generales:

a) La formación en el uso de los programas informáticos y el uso de los recursos telemáticos. Tarea que es asumida por el equipo de informática de la institución.

b) La formación en el uso adecuado y ético de la información, que implica todo el proceso de transferencia de la información (buscar, localizar, recuperar, utilizar y generar nueva información). Para este efecto la biblioteca es llamada a promover cursos de formación de usuarios orientados a tres ejes:

1.- Promover el uso de los recursos y servicios de la biblioteca, conocido como formación de usuarios).

2.- Estimular habilidades y el aprendizaje de técnicas para la búsqueda, recuperación y uso adecuado de la información.

3.- La aplicación de técnicas para la citación y el uso de programas estándares. 
Las actividades impulsadas por la biblioteca para promover el aprendizaje de competencias y desarrollar habilidades en el uso de la información, se ha posesionado como una necesidad fundamental y complementaria en la formación del estudiantes, hecho por el cual es reconocida en el ámbito internacional como una tarea de 'alfabetización informacional (ALFIN). La importancia de las actividades de ALFIN radica en la necesidad de formar en el individuo capacidades, competencias, habilidades y aptitudes críticas y profesionales para el uso ético de la información ${ }^{59}$. Asimismo estas prácticas han motivado el intercambio de experiencia y la cooperación interinstitucional a través de redes de trabajo ${ }^{60}$.

En este sentido el aprendizaje adquirido por el formador (docente) como en el individuo en proceso de formación (estudiante), genera las capacidades para que ellos puedan reconocer y formular sus propias necesidades, gestionar y usar de forma crítica y ética la información disponible en los diferentes formatos ofrecidos desde de plataformas tecnológicas con miras a lograr sus objetivos y generar nuevos conocimientos.

Dada la importancia de ALFIN fue posible identificar iniciativas de grupos de cooperación profesional, organizados de forma local, regional e internacional cuyo objetivo es el de intercambiar experiencias y materiales ALFIN y el aprendizaje de la buenas prácticas. Algunos ejemplos de grupos de trabajo son:

\begin{tabular}{|c|c|}
\hline País & $\begin{array}{l}\text { ALFIN Colombia } \\
\text { Iniciativa operada mediante una aplicación Blogger. } \\
\text { http://alfincolombia.blogspot.nl }\end{array}$ \\
\hline Región & $\begin{array}{l}\text { ALFIN Iberoamérica } \\
\text { Iniciativa gestionada desde una aplicación en Google. } \\
\text { https://groups.google.com/group/alfin- } \\
\text { iberoamerica/browse_frm/month/2012-05 }\end{array}$ \\
\hline Internacional & $\begin{array}{l}\text { UNESCO. ALFIN (Information literacy) como parte de una } \\
\text { sección de trabajo. Los aportes y agenda del grupo están } \\
\text { disponibles a través del portal de la UNESCO: } \\
\text { http://portal.unesco.org } \\
\text { BLOG: http://information-literacy.blogspot.nl } \\
\text { IFLA. Dispone de una sección de trabajo cuyas actividades } \\
\text { puedes ser consultada desde el sitio del grupo de trabajo, } \\
\text { Linkedin, Twitter, Facebook, entre otros. } \\
\text { http://www.ifla.org/information-literacy } \\
\text { ALA. Sección de trabajo que dispone un sitio web para su } \\
\text { consulta. } \\
\text { http://www.ala.org/acrl/issues/infolit/overview/intro } \\
\text { Dispone de los siguientes recursos para la participación } \\
\text { en línea, Twitter, Facebook, Chat, Linkedin entre otros }\end{array}$ \\
\hline
\end{tabular}

\footnotetext{
${ }^{59}$ Afirmación oficial presentada en web del Espacio Europeo de Educación Superior (Bolonia) http://www.uab.es/servlet/Satellite.

${ }^{60}$ Declaración de Toledo sobre la alfabetización informacional. 2006. Bibliotecas por el aprendizaje permanente http://www.webcitation.org/5NrAiGhSS.
} 


\subsubsection{Concepto de alfabetización informacional (ALFIN)}

El concepto de "Alfabetización informacional" es un término actualmente normalizado y reconocido internacionalmente. Su composición debe ser entendida en primer plano como la acción de alfabetizar, es decir "proceso de aprendizaje evolutivo que progresivamente va incorporando capacidades y conocimientos para entender nuevos entornos de cada época"61.

Asimismo es un calificativo informacional que orienta y especifica el tipo de aprendizaje al uso de la información desde un enfoque sistémico. En este sentido la alfabetización informacional pretende contribuir a solventar el problema de desconocimiento generado por la diversidad de información dispersa que se encuentra almacenada en diferentes tipos de soportes, y cuya gestión es influenciada por las aplicaciones tecnológicas y recursos telemáticos que ofrecen cada vez mayores capacidades y facilidades para el intercambio de información.

Con el objetivo de generar una base teórica que fundamente el manejo del concepto de Alfabetización informacional anterior, se presentan a continuación algunos aportes conceptuales considerados relevantes en el contexto de esta tesis.

La American Library Association (ALA) ${ }^{62}$ define el proceso de aprendizaje en el uso de la información, como "un proceso de alfabetización, en el cual el individuo alfabetizado es capaz de reconocer cuándo necesita información, dispone de la capacidad para localizar, evaluar, y utilizar eficientemente la información requerida para lograr sus objetivos".

\section{Características}

Lovania Garmendia Bonilla (2005, p.1), afirma que la alfabetización informacional y el desarrollo de hábitos de investigación, es un proceso sistémico, gradual y constante que facilitan la generación de una cultura de información para el desempeño de cualquier persona en el mundo actual. La autora considera que: "toda institución bibliotecaria o unidad de información que se precie de responder a los requerimientos de la sociedad actual debe tener presente la importancia de la alfabetización informacional... Se debe estar listo para ubicarnos en la sociedad de la información o sociedad del conocimiento y dispuesta a entrar en ella".

En esta línea, Beatriz J. Ferroni (2004, p. 2), retoma el aporte literal de B. Ford. 1994 para referirse a ALFIN como "... concepto provocativo a la hora de dirigirse a un público variado y cambiante, con distinta preparación para el uso de las bibliotecas".

José A. Gómez Hernández (2007, p.44, 47), afirma que el término se aplica de forma asociativa a otros términos como cultura, economía, pedagogía y que ALFIN “... pretende o aspira ....incluir las competencias usualmente no trabajadas en la formación de usuarios, como él es caso de la evaluación de los recursos, comprensión, utilización, la formación de habilidades cognitivas relacionadas con trabajo en intranet; la metodología de trabajo y convivencia en la comunidad virtual; la elaboración de documentos colectivos... " a fin de estimular destrezas básicas que permitan a los usuarios acceder a la información adecuada y hacerla útil.

\footnotetext{
${ }^{61}$ Glosario. Foro Red. Alfabetización informacional. http://www.alfared.org/glosario.

${ }^{62}$ Véase http://www.ala.org/acrl/issues/infolit/overview/intro.
} 
María Lourdes Flores de la Fuente (2005, p.1-12) destaca que las prácticas de "la metodología de la instrucción del ALFIN parte del principio constructivista, ya el usuario puede buscar, inferir, deducir, investigar, seleccionar y sistematizar para lograr un aprendizaje significativo y construir su propia experiencia de aprendizaje". ${ }^{63}$

Retomando para esta tesis el aporte de la ALA y la caracterización antes reflejada, Alejandro Uribe Tirado (2008, p. 8-10), aporta un concepto sistémico que incluye los antes citados y se refiere a la alfabetización informacional como un "proceso de enseñanza-aprendizaje individual y colectivo que involucra diferentes estrategias didácticas y ambientes de aprendizaje dirigidos a estimular el alcance de los conocimientos, habilidades y actitudes (competencias) tanto en lo informático, comunicativo e informativo" Uribe Tirado señala además, que su objetivo es "lograr que él o el colectivo meta sea capaz de identificar sus necesidades de información, manejar la técnicas de búsquedas y localizar, seleccionar, organizar, evaluar y usar la información de manera crítica, ética desde sus potencialidades cognoscitivas, prácticas afectivas y conocimientos previos a fin de lograr producir conocimiento, que posteriormente será compartido y divulgado en forma adecuada".

\subsubsection{Competencias transversales}

La Asociación de Bibliotecas de Investigación y Universidad (Association of College and Research Libraries $(A C R L)^{64}$ en un documento oficial disponible en su sitio web, destaca que la competencia informacional son necesarias en todos los entornos de aprendizaje y niveles de educación. Asimism,o el documento del Proyecto Tuning Educational Structures in Europe $\left(2003\right.$, p.13) ${ }^{65}$ define la Competencia como "Una combinación dinámica de atributos, en relación a procedimientos, habilidades, actitudes y responsabilidades, que describen los encargados del aprendizaje de un programa educativo o lo que los alumnos son capaces de demostrar al final de un proceso educativo".

En esta línea la Red de Bibliotecas Universitarias y Científicas Españolas REBIUN (2007, p.1-2) ${ }^{66}$ señala que las competencias en información es una materia necesaria para cualquier titulado universitario de la sociedad del siglo XXI y, en consecuencia, debiera ser parte de los currículos formativos ofertados por las instituciones de educación por cuanto esta competencia favorece procesos de aprendizaje constructivistas del conocimiento y en consecuencia, permiten la implementación de modelos didácticos coherentes a la realidad cambiante.

En el ámbito del espacio europeo las competencias transversales son definidas como necesidad básica en la formación integral de un estudiante universitario, debido a que la posesión de éstas le permitirá adquirir los conocimientos y valores éticos y su desempeño como persona, profesional e investigador. Una descripción general de estas competencias es ofrecida desde el sitio web de la

\footnotetext{
${ }^{63}$ Aspecto que también hemos analizado cuando nos referíamos a procesos E-learning.

${ }^{64}$ Jerárquicamente se ubica como una división de la ALA. En el sitio de la ACRL están disponibles manuales y guías sobre ALFIN. http://www.ala.org/acrl/aboutacrl/directoryofleadership/discussiongroups/dgs.

${ }^{65}$ Proyecto Tuning fue financiado por la Comisión Europea en el marco del Programa Sócrates. Disponible en: http://www.relint.deusto.es/TUNINGProject/spanish/doc_fase1/Tuning\%20Educational.pdf Consultado 30-10-2012.

${ }^{66}$ Documento marco de REBIUN para la CRUE. Adquisición de competencias en información. Una materia necesaria en la formación universitaria http://www.rebiun.org.
} 
Universidad Autónoma de Barcelona, a través de un apartado referido al espacio europeo ${ }^{67}$. En este sitio se listan de forma general y literal, las competencias sugeridas:

a) Instrumentales: herramientas para el aprendizaje y la formación:

- Técnicas aprendizaje autónomo

- Análisis y síntesis

- Organización y planificación

- Resolución de problemas

- Toma de decisiones

- Habilidades formativas básicas

- Comunicación oral y escrita

- Conocimientos de lenguas extranjeras

b) Interpersonales: capacidades que permiten mantener una buena relación social:

- Trabajo en equipo de carácter interdisciplinario

- Razonamiento crítico

- Compromiso ético

- Reconocimiento de la diversidad y multiculturalidad

- Negociación

- Automotivación

c) Sistémicas: relacionadas con la gestión de la totalidad de la actuación (visión de conjunto):

- Adaptación a nuevas situaciones

- Creatividad

- Liderazgo

- Iniciativa y espíritu emprendedor

- Preocupación por la calidad

- Sensibilidad frente a temas medioambientales

- Gestión de proyectos y Gestión por objetivos

La Comisión mixta CRUE-TIC y REBIUN (2009 p.10) incorpora al anterior listado una nueva competencia referida a la formación de individuo en el uso y aplicación de las tecnologías de la información y comunicación para que este sea capaz de poder localizar, evaluar, utilizar y comunicar cualquier tipo de información para lograr sus objetivos. Esta competencias son reconocidas por REBIUN como competencias informáticas e informacionales que se enmarcan dentro de la Alfabetización informacional.

\subsubsection{Perspectivas de aplicación de la alfabetización informacional}

El diseño y aplicación de los programas de alfabetización informacional varían en dependencia de los "entornos - información - tecnología - servicios - especialistas con que se cuenta para desarrollar la práctica. En esta dirección Christine Susan Bruce (2003, p. 289), plantea la aplicación de ALFIN desde las siete perspectivas que a continuación se presenta.

\footnotetext{
${ }^{67}$ Universidad Autónoma de Barcelona. - Sitio web de consulta del Espacio Europeo de Educación Superior (Bolonia) http://www.uab.es/servlet/Satellite/bolonia/profesorado/competencias-transversales-1231747994766.html.
} 
Perspectiva 1: Tecnológica (uso de las tecnologías de la información)

Las tecnologías son vistas como medio para el acceso y la recuperación y comunicación. El objetivo es desarrollar las habilidades para el uso de estas tecnologías (alfabetización informática).

Perspectiva 2: Acceso a las fuentes de información

Localización de la información en las fuentes de información.

- Conocer las fuentes y sus estructuras

- Conocer las fuentes para usarlas con autonomía

- Conocer las fuentes y con flexibilidad e independientemente o con ayuda de un intermediario

3. Perspectiva3: Aprendizaje como proceso

Se da atención a las estrategias aplicadas por el usuario al afrontar situaciones nuevas en la que experimenta "desconocimiento" por falta de información.

4. Perspectiva 4: Uso o creación de un sistema para la organización y gerencia de información.

El control de la información se refiere a la ubicación, valor y conocimiento de manipulación de la misma para situaciones concretas y personales. El proceso de control puede lograrse a través de ficheros manuales, utilizando el cerebro o la memoria por medio de varias clases de enlaces y asociaciones o utilizando ordenadores que permiten el almacenamiento y la recuperación.

5. Perspectiva 5: Construcción del conocimiento

La construcción de una base personal de conocimientos que implica la utilización crítica de la información y la adopción de perspectivas personales. Su objetivo es motivar que los usuarios puedan realizar un análisis crítico y muy personal.

6. Perspectiva 6: Extensión del conocimiento

El uso de la información pero implicando una capacidad de introspección creativa. Esa intuición o introspección genera nuevas ideas o soluciones creativas.

7. Perspectiva 7: Concepción basada en el saber

Se trata de la utilización de la información en beneficio de los demás. Esto exige la adopción de valores personales independientemente de los contextos, emisión de juicios y la toma de decisiones.

De forma paralela a este planteamiento de Christine Susan Bruce, María Pinto plantea que estas perspectivas pueden o no estar en una espiral básica con diferentes fases de alfabetización. María Pinto aporta la siguiente figura para sintetizar las diferentes líneas de acción de ALFIN. 


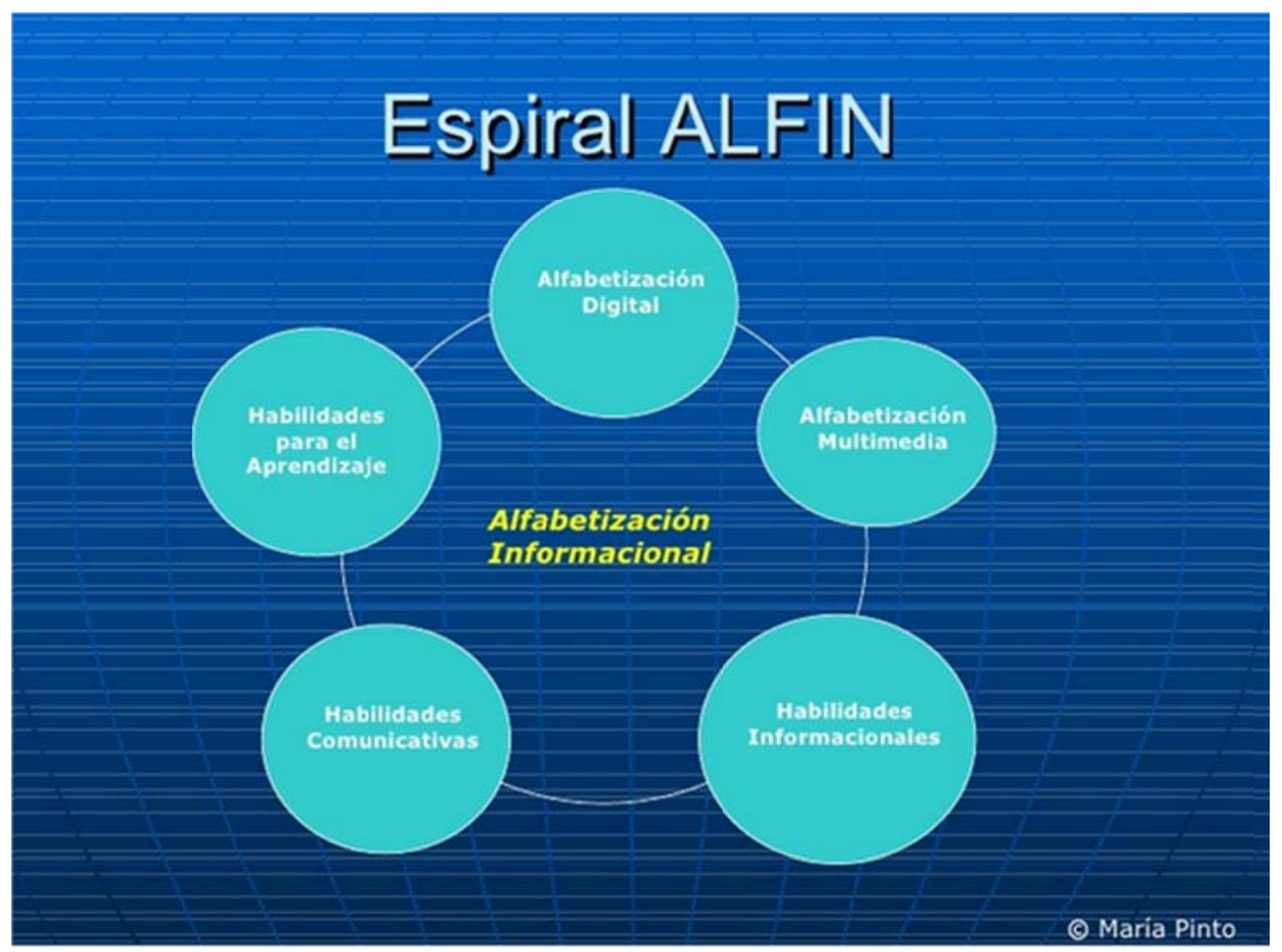

Figura 25. Espiral de acción de ALFIN. Fuente: Elaborada por María Pinto, $2009^{68}$.

\subsubsection{Tipos de alfabetización}

Durante la revisión de artículos y documentos sobre ALFIN, debidamente incluidos en la bibliografía, anexa se constató que previo y posterior a disponer de un concepto estándar del término, existe la tendencia de confundir y mezclar sin orden de jerarquía los tipos de alfabetización (informática, bibliotecaria, etc.).

La práctica demuestra que un gran número de instituciones educativas inician sus programas académicos con prácticas de alfabetización informacional para la formación de las competencias transversales. Bajo este hecho y en concordancia con lo expuesto por Bruce (2003) y María Pinto (2009), se reconocen los siguientes tipos de alfabetización informacional:

a. Alfabetización informática. Es conocida también bajo los sinónimos de alfabetización en nuevas tecnologías y alfabetización electrónica. Implica el uso de los medios tecnológicos. Su objetivo principal apunta al desarrollo de habilidades intelectuales y capacidades en el individuo, específicamente en el uso de los equipos y programas informáticos como paso previo para manejar la información contenida en estos recursos telemáticos.

\footnotetext{
${ }^{68}$ Marcos teóricos para la aplicación de ALFIN en distintos ámbitos. Ponencia inaugural del II Semimario ALFIN de Vilanova, Barcelona, 2009. Disponible en: http://www.slideshare.net/alfinred/ponencia-inaugural-del-ii-seminario-alfin-de-vilanova2009-por-mara-pinto.
} 
b. Alfabetización bibliotecaria. Se engloba el aprendizaje de técnicas y métodos para el desarrollo de habilidades y capacidades que garantizan un eficiente uso de la información, y por ende la toma de decisiones. Se describe como el proceso de enseñanza que apunta a la formación de habilidades y destrezas para buscar, identificar, seleccionar y utilizar de forma crítica la información.

c. Alfabetización en los medios. Este tipo de alfabetización es conocida también como alfabetización mediática o alfabetización en recursos multimedia. Orienta el aprendizaje al uso de los diferentes medios de comunicación de masas. Su objetivo es estimular la capacidad y actitud crítica en el individuo para consultar, comprender, producir y negociar significados en todos los tipos de medios de comunicación vinculados a la tecnología digital (televisión, cine, vídeo, páginas de Internet, radio, videojuegos y comunidades virtuales. ${ }^{69}$

\section{CONOCIMIENTO}

Requiere de

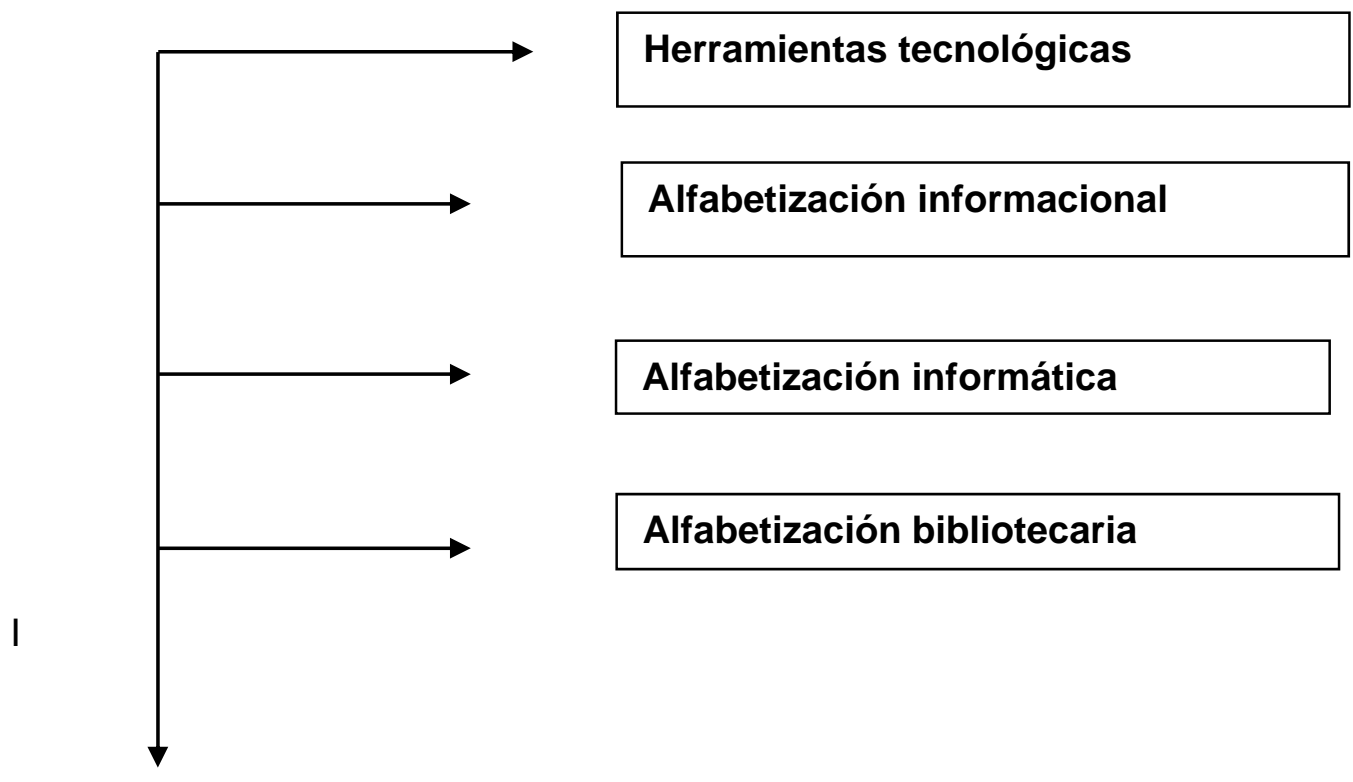

INFORMACIÓN

ORGANIZADA

Destrezas y habilidades

SISTEMATIZADA

Saber buscar, encontrar

Y ACCESIBLE

Generar y difundir conocimiento

Figura 26. ALFIN y la transferencia de información-conocimiento. Fuente: Elaboración propia.

\footnotetext{
${ }^{69}$ El tema de alfabetización mediática se aborda con detalles en el documento disponible en: http://europa.eu/legislation_summaries/information_society/strategies/I24112_es.htm.
} 


\subsubsection{Estudio de factibilidad para el diseño de una práctica ALFIN}

La alfabetización informacional en entornos virtuales representa una práctica para las bibliotecas académicas. Independientemente del modelo que corresponda para la biblioteca, tarde o temprano, ésta, deberá trazarse un plan de alfabetización interno y posteriormente multiplicarlo entre sus usuarios como parte del aprendizaje continuo. Autores citados en este apartado recomiendan antes de la implementación de cualquier modelo de programa ALFIN, realizar diagnósticos o estudios de factibilidad, a fin de categorizar los usuarios e identificar las necesidades y demandan reales. Con el fin de ofrecer un marco de referencia con aquellos aspectos considerados importantes para el diseño de un estudio de factibilidad, se resume a continuación los elementos básicos a considerar:

A) Diagnóstico situacional. Tiene como fin para identificar los posibles problemas de conocimientos, habilidades y destrezas de los estudiantes. El resultado de este estudio permitirá distinguir y definir las necesidades concretas para el desarrollo de programas de capacitación. Los medios más utilizados son encuestas, entrevistas, que puede ser presentadas directamente a los usuarios o bien estar disponibles en internet o en el sitio web de la biblioteca. La información reflejada en el diagnóstico permitirá caracterizar y organizar el grupo de usuarios por nivel de conocimiento, características socioculturales, etc., estableciéndose de esta manera tipologías claras de usuarios.

B) Definir estrategias de organización y planificación de programas de formación en correspondencia a las características de usuario, a fin de ajustar el tipo de alfabetización información a las necesidades del grupo meta.

C) Diseño y gestión de programas de alfabetización. Los programas y proyectos de alfabetización informacional deben ser vistos como un servicio de formación en habilidades informacionales, ofrecido por la biblioteca. La práctica demuestra que la alfabetización informacional se orienta generalmente a las siguientes capacitaciones:

- Orientación al uso de las bibliotecas

- Capacitación el uso de los recursos tecnológicos

- Formación en el uso de determinados software propios de la biblioteca

-Capacitación en el uso de determinados programas para la citación de literatura

\subsubsection{Modelos ALFIN}

Los modelos de alfabetización informacional parten del principio del ciclo de transferencia del documento digital adaptado a los cambios ocurridos por la generación, producción y acceso electrónico. En la actualidad existen muchos modelos que se podrían listar en este estudio, todos ellos responden al objetivo de generar habilidades y destrezas para poder localizar, evaluar y usar la información necesaria; sin embargo, con el fin de acotar este apartado, ha sido necesario limitar el análisis a modelos desarrollados en las dos últimas décadas y que son utilizados a nivel de Europa como Latinoamérica.

En la revisión de la literatura que se anexa en la bibliografía de esta tesis, se identificó repetidamente, un grupo de catorces modelos actualmente vigentes. Estos modelos surgen de iniciativas individuales y grupales entre el período de 1990 y 2007, y en los años posteriores se han 
generado nuevas versiones con significativas mejoras. El Informe APEI 5 - 2010 sobre alfabetización informacional incluye una revisión actualizada de estas corrientes, no obstante no se puede señalar la aparición de una nueva corriente teórica.

En la siguiente tabla se muestra el surgimiento cronológico de los modelos de alfabetización, iniciado a partir del año 1990. Cabe destacar que ha sido durante la última década, que estos se integran como base para las prácticas de los modelos precedentes.

\begin{tabular}{|c|c|c|c|c|c|c|c|}
\hline & $1990-5$ & $1995-8$ & 1999 & $2000-1$ & $2002-3$ & 2004-6 & 2007-10 \\
\hline BIG 6 & & & $\mathrm{x}$ & & & & \\
\hline SCONUL & & & & & & $\mathrm{X}$ & \\
\hline \multicolumn{8}{|l|}{ CAUL } \\
\hline CAUL / AZIL & & & & & $\mathrm{x}$ & & \\
\hline SHAPIRO & & $\mathrm{X}$ & & $\mathrm{X}$ & & & \\
\hline $8 \mathrm{Ws}$ & & & & & & & $\mathrm{x}$ \\
\hline AASL - AECT & $\mathrm{X}$ & $\mathrm{X}$ & & & & & \\
\hline BIG BLUE & $\mathrm{x}$ & & & & $\mathrm{x}$ & & \\
\hline CIUDAD JUÁREZ & & & & & & $\mathrm{x}$ & \\
\hline ACRL ALA & & & & $x$ & & & \\
\hline GAVILAN & & & & & & $x$ & \\
\hline KUHLL THUA & & & & & $x$ & & \\
\hline BARRY & $\mathrm{X}$ & $\mathrm{x}$ & & & & & \\
\hline IFLA & & & & & & $\mathrm{x}$ & \\
\hline
\end{tabular}

Tabla 16. Periodo de surgimiento de los modelos ALFIN.

Fuente: Elaboración propia.

De manera general, a fin de introducirnos en cada uno de ellos, en las siguientes páginas se presenta una descripción general, destacando las competencias atendidas por cada modelo. Para este fin se ha retomado como marco de referencia el inventario iniciado por Michael B. Eisenberg (2008, p.41), el análisis aportado por Alejandro Uribe Tirado (2008), la revisión de textos y sitios web descriptivos de los modelos. En la siguiente tabla se quiere ofrecer una visión conjunta de los modelos y de las habilidades que se recogen en cada uno de ellos. 


\begin{tabular}{|c|c|c|}
\hline Nombre del modelo & Fecha & Habilidades involucradas \\
\hline $\begin{array}{l}\text { Modelo Big6 } 6^{70} \\
\text { Autor: por Eisenbergy } \\
\text { Berkowits } \\
\text { Es un modelo sistémico y } \\
\text { curriculum educacional de } \\
\text { alfabetización informacional } \\
\text { y tecnológica que estimula el } \\
\text { pensamiento crítico }\end{array}$ & $\begin{array}{l}1990 \\
1999\end{array}$ & $\begin{array}{l}\text { Definición de tareas } \\
\qquad \text { Estrategias de búsqueda de información } \\
\text { Ubicación y acceso } \\
\text { Uso de la Información - Extrae la información pertinente } \\
\text { Síntesis } \\
\text { Evaluación } \\
\qquad \text { Evalúa el resultado obtenido (eficacia- eficacia) } \\
\text { del proceso de búsqueda, recuperación y uso }\end{array}$ \\
\hline $\begin{array}{l}\text { Modelo SCONUL } \\
\text { Retoma las mismas } \\
\text { directrices de trabajo de Big6 }\end{array}$ & $\begin{array}{l}1999 \\
2005\end{array}$ & $\begin{array}{l}\text { Identificar las necesidades de información } \\
\text { El reflexionar sobre las diferentes maneras para } \\
\text { satisfacerlas } \\
\text { Definir una estrategia para localizar las fuentes de } \\
\text { información } \\
\text { Maneras de localizarlas y acceder a ellas } \\
\text { Comparar y evaluar los recursos y fuentes de } \\
\text { información para seleccionar la que es relevante } \\
\text { Organizar, editar y transferirla a través de procesos de } \\
\text { comunicación } \\
\text { Sintetizarla, procesarla y transformarla en nuevos } \\
\text { conocimientos }\end{array}$ \\
\hline $\begin{array}{l}\text { Normas } \text { CAUL }^{72} \\
\text { El año } 2003 \text { esta iniciativa es } \\
\text { integrada al proyecto de } \\
\text { trabajo de la Asociación } \\
\text { ANSIL, se evalúo resultando } \\
\text { una segunda versión } 58 \\
\text { denominada "Marco para la } \\
\text { Alfabetización Informacional } \\
\text { en Australia y Nueva Zelanda: } \\
\text { principios, normas y } \\
\text { práctica": }\end{array}$ & $\begin{array}{l}2000 \\
2001\end{array}$ & $\begin{array}{l}\text { Recordar - Pensar y reconocer ciertas características; } \\
\text { recordar selectivamente } \\
\text { Resumir - Organizar las ideas en forma abreviada y } \\
\text { disponerlas en una secuencia que tenga significado } \\
\text { Parafrasear - Formular las ideas con palabras propias }\end{array}$ \\
\hline $\begin{array}{l}\text { El modelo Council of } \\
\text { Australian University } \\
\text { Librarians (CAUL - ANZIIL). }^{73} \\
\text { Se retoman y amplían las } \\
\text { bases teóricas y principios de } \\
\text { Big6, SCONUL, pero enfatiza } \\
\text { en los aspectos legales de } \\
\text { uso de la información. }\end{array}$ & $\begin{array}{l}2003 \\
2005\end{array}$ & $\begin{array}{l}\text { Reconocer una necesidad de información } \\
\text { Determinar el alcance de la información requerida } \\
\text { Acceder a ella con eficiencia } \\
\text { Evaluar la información y sus fuentes } \\
\text { Incorporar la información seleccionada a su propia base } \\
\text { de conocimientos } \\
\text { Utilizar la información de manera eficaz para acometer } \\
\text { tareas específicas } \\
\text { Comprender la problemática económica, legal y social }\end{array}$ \\
\hline
\end{tabular}

\footnotetext{
${ }^{70}$ Véase site de Big6: http://publications.drdo.gov.in/ojs/index.php/djlit/article/view/166/77.

${ }^{71}$ Véase http://oud.vvbad.be/files/200706_Vanouplines.pdf consultado 12 septiembre 2009.

${ }^{72}$ Ibíd. 8 Alejandro Uribe Tirado p.30-32.

${ }^{73}$ Descripción completa del modelo puede ser consultado en el documento de Philip Payne, y Angela Conyers, Angela (2005) y también http://www.sconul.ac.uk.
} 


\begin{tabular}{|c|c|c|}
\hline Nombre del modelo & Fecha & Habilidades involucradas \\
\hline & & $\begin{array}{l}\text { que rodea al uso de la información } \\
\text { Acceder a ella y utilizarla de forma ética y legal } \\
\text { Clasificar, almacenar, manipular y re-elaborar la } \\
\text { información reunida o generada } \\
\text { Reconocer la alfabetización en información como } \\
\text { prerrequisito para el aprendizaje a lo largo de la vida }\end{array}$ \\
\hline $\begin{array}{l}\text { Modelo de alfabetización } \\
\text { informática } \\
\text { Desarrollado por Shapiro, J. } \\
\text { J. Hughes, S. K.Hughes } \\
\text { Describe un programa o } \\
\text { propuesta de modelo de } \\
\text { alfabetización informática } \\
\text { basado en siete dimensiones, } \\
\text { que a su vez son otras } \\
\text { alfabetizaciones }\end{array}$ & 1996 - & $\begin{array}{l}\text { Alfabetización en herramientas - conocimiento y uso de } \\
\text { las herramientas } \\
\text { Alfabetización en recursos - conocimiento de las formas } \\
\text { y métodos } \\
\text { Alfabetización socio- estructural - comprensión de la } \\
\text { situación social, legal, política y coyuntura } \\
\text { socioeconómica y para la producción de la información } \\
\text { Alfabetización investigadora - uso de las herramientas } \\
\text { generar conocimientos y/o resultados del trabajo de } \\
\text { investigación y académico } \\
\text { Alfabetización para la publicación - habilidad para } \\
\text { difundir y publicar información } \\
\text { Alfabetización en las tecnologías incipientes - capacidad } \\
\text { de pensamiento crítico para tomar decisiones } \\
\text { inteligentes con respecto a las nuevas tecnologías, sus } \\
\text { beneficios y costos }\end{array}$ \\
\hline $\begin{array}{l}\text { 8Ws of Information Inquiry- } \\
\text { LAMB }^{75} \\
\text { Modelo desarrollado por } \\
\text { Annette Cordero en la } \\
\text { década de los 90's como } \\
\text { producto de un estudio } \\
\text { realizado por la Asociación } \\
\text { de Bibliotecas Escolares de } \\
\text { Ontario (OSLA) en Canadá y } \\
\text { referenciado en el } 2007 \text { por } \\
\text { Marti Lahera en el } 2007\end{array}$ & $\begin{array}{l}1990 \\
2007\end{array}$ & $\begin{array}{l}\text { Se orientan al desarrollo de habilidades para la } \\
\text { comprensión de conceptos, razonamiento, organización, } \\
\text { comunicación y aplicación del conocimiento. El modelo } \\
\text { propone el estímulo de } 8 \text { habilidades básicas: } \\
\text { Explorar } \\
\text { Indagar - investigar } \\
\text { Buscar de forma precisa } \\
\text { Evaluar con criterios concretos } \\
\text { Sintetizar en la diversidad } \\
\text { Crear e innovar } \\
\text { Comunicar } \\
\text { Evaluar integralmente todo el proceso de recuperación } \\
\text { de información }\end{array}$ \\
\hline $\begin{array}{l}\text { American Association of } \\
\text { School Librarians y la } \\
\text { Association for educational } \\
\text { Comunications and } \\
\text { Technology (AASL-AECT) }{ }^{76} \\
\text { El modelo surge en escuelas }\end{array}$ & 1998 & $\begin{array}{l}\text { Distingue nueve estándares agrupados en tres categorías } \\
\text { Categoría 1a Alfabetización en información: El estudiante } \\
\text { con alfabetización en información: } \\
\text { Estándar 1: Accede a la información con } \\
\text { eficiencia y efectividad } \\
\text { Estándar 2: Evalúa la información de forma }\end{array}$ \\
\hline
\end{tabular}

\footnotetext{
${ }^{74}$ Para detalles del modelo véase http://net.educause.edu/apps/er/review/reviewarticles/31231.html.

${ }^{75}$ Véase mayor información del modelo http://virtualinquiry.com/inquiry/ws.htm.

${ }^{76}$ Una guía completa para la aplicación del modelo esta disponible en http://www.sp.uconn.edu/ djleu/Handbook.html.
} 


\begin{tabular}{|c|c|c|}
\hline Nombre del modelo & Fecha & Habilidades involucradas \\
\hline $\begin{array}{l}\text { de secundaria y } \\
\text { posteriormente se extiende a } \\
\text { prácticas en las universidades }\end{array}$ & & $\begin{array}{l}\text { crítica y competente. } \\
\text { Estándar 3: Usa la información de forma correcta } \\
\text { y creativa. } \\
\text { Categoría 2a Aprendizaje independiente: } \\
\text { Estándar 4: Busca información referente a } \\
\text { intereses personales } \\
\text { Estándar 5: Aprecia y disfruta la literatura y otras } \\
\text { expresiones creativas de información } \\
\text { Estándar 6: Se esfuerza al máximo por la } \\
\text { excelencia en la búsqueda de información y } \\
\text { generación de conocimiento } \\
\text { Categoría 3a Responsabilidad social: El estudiante que } \\
\text { contribuye positivamente a la } \\
\text { comunidad de aprendizaje y a la sociedad está } \\
\text { alfabetizado en información } \\
\text { Estándar 7: Reconoce la importancia de la } \\
\text { información en una sociedad democrática } \\
\text { Estándar 8: Practica un comportamiento ético } \\
\text { respecto a la información y a la tecnología de la } \\
\text { información } \\
\text { Estándar 9: Participa efectivamente en grupos } \\
\text { para ubicar y generar información }\end{array}$ \\
\hline $\begin{array}{l}\text { Big Blue. Information Skills } \\
\text { Training } \\
\text { Modelo Big Blue fue } \\
\text { desarrollada en el marco } \\
\text { del proyecto liderado por las } \\
\text { bibliotecas universitarias de } \\
\text { Manchester y Leeds } \\
\text { (MMU 2002). El modelo se } \\
\text { centra en } 8 \text { competencias }\end{array}$ & 2002 & $\begin{array}{l}\text { Recocer su necesidad de información } \\
\text { Afronta de forma consciente su necesidad y toma } \\
\text { acciones concretas } \\
\text { Obtiene información } \\
\text { Evalúa críticamente la información obtenida } \\
\text { Adapta la información a sus necesidades } \\
\text { Organiza la información } \\
\text { Comunica la información } \\
\text { Revisa todo el proceso de forma integral }\end{array}$ \\
\hline $\begin{array}{l}\text { Declaratoria de Ciudad } \\
\text { Juárez } \\
\text { Esta propuesta es el } \\
\text { resultado del trabajo } \\
\text { conjunto realizado por los } \\
\text { asistentes en el Tercer } \\
\text { Encuentro sobre desarrollo } \\
\text { de Habilidades Informativas } \\
\text { (LAU y CORTÉS, 2004). } \\
\text { Sugiere la necesidad de } \\
\text { estimular siete habilidades }\end{array}$ & $\begin{array}{l}2002- \\
2005\end{array}$ & $\begin{array}{l}\text { Habilidad para determinar la naturaleza de una } \\
\text { necesidad informativa } \\
\text { Habilidad para buscar y encontrar información } \\
\text { Habilidad para recuperar información } \\
\text { Habilidad para evaluar información } \\
\text { Habilidad para asimilar y utilizar la información } \\
\text { Habilidad para presentar los resultados de la } \\
\text { información obtenida } \\
\text { Respeto a la propiedad intelectual y a los derechos de } \\
\text { autor }\end{array}$ \\
\hline
\end{tabular}

\footnotetext{
${ }^{77}$ Descripción completa del modelo se ubica en el sitio web http://www.library.mmu.ac.uk/bigblue.

${ }^{78}$ Véase mayor información sobre los acuerdos en: http://bivir.uacj.mx/dhi/PublicacionesUACJ/Default.htm.
} 


\begin{tabular}{|c|c|c|}
\hline Nombre del modelo & Fecha & Habilidades involucradas \\
\hline $\begin{array}{l}\text { informativas generales } \\
\text { orientadas a crear } \\
\text { conocimientos, habilidades y } \\
\text { técnicas para la búsqueda, } \\
\text { recuperación y uso de la } \\
\text { información. }\end{array}$ & & \\
\hline $\begin{array}{l}\text { ACRL-ALA }^{79} \\
\text { Es un modelo reconocido en } \\
\text { el contexto de la } \\
\text { alfabetización Informacional } \\
\text { a nivel universitario. } \\
\text { El modelo se subdivide en } \\
\text { cinco estándares (Normas) } \\
\text { cada uno de los cuales } \\
\text { implica diferentes } \\
\text { indicadores. }\end{array}$ & 2000 & $\begin{array}{l}\text { Norma } 1 \text {. Competencias relacionadas al acceso - El } \\
\text { estudiante es capaz de determinar la naturaleza y nivel } \\
\text { de la información que necesita } \\
\text { Norma } 2 \text {. El estudiante posee la capacidad de acceder y } \\
\text { hacer uso de la información, accede a la información } \\
\text { requerida de manera eficaz y eficiente } \\
\text { Norma 3. El estudiante evalúa la información y sus } \\
\text { fuentes de forma crítica e incorpora la información } \\
\text { seleccionada a su propia base de conocimientos y a su } \\
\text { sistema de valores } \\
\text { Norma } 4 \text {. El estudiante utiliza la información } \\
\text { eficazmente para cumplir un propósito específico } \\
\text { Norma } 5 \text {. El estudiante comprende muchos de los } \\
\text { problemas y cuestiones económicas, legales y sociales } \\
\text { que rodean al uso de la información, y accede y utiliza la } \\
\text { información de forma ética y legal }\end{array}$ \\
\hline $\begin{array}{l}\text { Modelo Gavilán } \\
\text { Desarrollado por la } \\
\text { Fundación Gabriel Piedrahita } \\
\text { Uribe (FGPU) - el modelo } \\
\text { tiene su base teórica de los } \\
\text { modelos "Big 6" y OSLA y } \\
\text { centra su atención al uso } \\
\text { efectivo de Internet como } \\
\text { principal fuente de } \\
\text { información }\end{array}$ & 2006 & $\begin{array}{l}\text { El modelo orienta el desarrollo de cuatro competencias } \\
\text { para que el estudiante puede se forma eficiente } \\
\text { Capacidad y habilidad para reconocer y definir el } \\
\text { problema de información } \\
\text { Habilidad para buscar y evaluar las diferentes fuentes y } \\
\text { soportes de información } \\
\text { Capacidad para analizar la información } \\
\text { Sintetizar y utilizar la información }\end{array}$ \\
\hline $\begin{array}{l}\text { Modelo Habilidades de } \\
\text { información en un mundo } \\
\text { electrónico } \\
\text { Christine A. Barry } \\
\text { (1997) autor de este modelo. } \\
\text { Especifica las pautas } \\
\text { generales de la ACRL/ALA en } \\
\text { relación a las experiencias y } \\
\text { usos de los medios y las }\end{array}$ & 1997 & $\begin{array}{l}\text { Formulación y análisis de necesidades } \\
\text { Identificación de posibles fuentes } \\
\text { Localización de fuentes individuales } \\
\text { Examen, selección y rechazo de fuentes } \\
\text { Interrogación a las fuentes } \\
\text { Registro y almacenamiento de información. } \\
\text { Interpretación, análisis, síntesis y evaluación de la } \\
\text { información recogida } \\
\text { Presentación y comunicación del trabajo resultante }\end{array}$ \\
\hline
\end{tabular}

\footnotetext{
${ }^{79}$ Mayor información del modelo en :http://www.ala.org/acrl/standards/informationliteracycompetency.

${ }^{80}$ Una descripción del modelo Gavilán está disponible en el sitio http://www.eduteka.org/pdfdir/ModeloGavilan.pdf.

${ }^{81}$ Véase http://revistas.um.es/analesdoc/article/view/2731.
} 


\begin{tabular}{|l|l|l|}
\hline Nombre del modelo & Fecha & Habilidades involucradas \\
\hline $\begin{array}{l}\text { competencias que los } \\
\text { estudiantes/usuarios deben } \\
\text { adquirir para ser } \\
\text { considerados alfabetizados } \\
\text { informacionalmente en la } \\
\text { actual sociedad de la } \\
\text { información }\end{array}$ & Evaluación de los logros conseguidos \\
\hline $\begin{array}{l}\text { IFLA } \\
\text { Completa y resume las } \\
\text { habilidades y orienta que las } \\
\text { actividades de los programas } \\
\text { de alfabetización } \\
\text { informacional deben ser } \\
\text { dirigidas a tres líneas de } \\
\text { acción: el acceso, la } \\
\text { evaluación y el uso. }\end{array}$ & 2006 & $\begin{array}{l}\text { Acceso. Buscar e identificar de forma efectiva y eficiente } \\
\text { a la información necesaria. } \\
\text { Evaluación. Revisión y valoración de la información } \\
\text { identificada. } \\
\text { Uso. Hacer posible el uso ético de la información y } \\
\text { conocimiento para transfórmalos y transferirlos a través } \\
\text { de medios de comunicación. }\end{array}$ \\
\hline
\end{tabular}

Tabla 17. Modelos de Alfabetización informacional.

Fuente: Elaboración propia.

\subsection{Repositorios para la educación}

El tercer ámbito de convergencia que se quiere plantear son los repositorios de datos y recursos para la educación. Las universidades, como centros de enseñanza superior, necesitan disponer de recursos de apoyo al aprendizaje. Para ello, las bibliotecas, como responsables de la selección, organización y difusión de los recursos de información, deben plantearse la creación y mantenimiento de repositorios desde los que se dé acceso a estos recursos y que a su vez puedan integrarse con el resto de los repositorios de acceso a la producción científica y docente y con las plataformas de enseñanza en línea que se utilicen en la universidad.

\subsubsection{Introducción al servicio de repositorios para la educación}

Actualmente la Internet es un medio donde se pueden encontrar respuestas a casi todo tipo de preguntas. De forma contradictoria la proliferación de información y el constante surgimiento de sitios web, ha generado desconocimiento de lo que está disponible en la red, o dudas de la autenticidad de lo recuperable o bien resultados que direccionan a enlaces de fuentes de información no disponible.

Ante esta situación la comunidad universitaria desarrolla mecanismos de flujos eficientes y rápidos capaces de responder a tres objetivos:

a) Facilitar el acceso a la información precisa, confiable y de contenidos específicos en relación a la demanda información académica y científica.

b) Facilitar el cumplimiento de los objetivos educacionales, es decir poder acceder a la información necesaria para el proceso de enseñanza aprendizaje.

\footnotetext{
${ }^{82}$ Véase http://archive.ifla.org/VII/s42/pub/IL-Guidelines2006.pdf.
} 
c) Contribuir de forma directa al desarrollo de investigaciones y difundir la información generada a nivel institucional.

Asimismo, la necesidad de disponer e intercambiar la información a nivel del mundo académico, ha motivado discusiones e iniciativas internacionales para lograr el acceso gratuito a la información científica $^{83}$ contenida en diferentes soportes, tales como libros, documentos, revistas, etc. Como resultado de estas iniciativas surgen los llamados repositorios para la educación. Se trata de colecciones especializadas de recursos electrónicos de texto completo, portales y directorios cuyo contenido resulta ser de gran apoyo a las tareas de educación e investigación.

La inclusión del estudio de los repositorios para la educación en esta tesis es considerada fundamental, dado que estos representan ser el tercer elemento básico en el diseño de un modelo de oferta de servicio ofrecido por la biblioteca académica como apoyo a procesos de enseñanza electrónica E-learning, que es en definitiva uno de los aportes de esta tesis doctoral.

En apartados anteriores se ha incluido al servicio de referencia como punto de partida a través del cual, el usuario se involucra de forma directa con los diferentes servicios y las fuentes de información. Asimismo la alfabetización informacional es el medio para la formación de habilidades, capacidades y destrezas en el individuo para buscar, recuperar y usar la información.

Sin embargo, estos dos servicios no son suficientes para generar una atractiva oferta de servicios de información para E-learning, debido a que no basta indicar dónde localizar la información y enseñar a buscar la información, es necesario ofrecerles los recursos debidamente organizados para que puedan ser utilizados. En este sentido, los repositorios para la educación representan las fuentes de información científica y especializada de gran importancia para cualquier actividad académica y científica.

\subsubsection{Conceptos relacionados}

Los recursos tecnológicos y las diferentes aplicaciones web facilitan en gran medida los procesos de comunicación en línea y transferencia de información escrita, visual, sonora. Estos recursos telemáticos son herramientas importantes para acceder a los contenidos. Sin embargo, en dependencia de los entornos, políticas, aplicaciones y normas de acceso en que están inmersos estos recursos, así es condicionado su uso. La elaboración de este apartado ha requerido de una revisión conceptual de algunos aspectos que influyen directamente en el funcionamiento y caracterización de estos. Los conceptos que a continuación se definen, en su conjunto representan ser el marco de referencia en el desarrollo de los repositorios y a la vez obtener una visión global de sus objetivos e importancia en la educación. Es importante describir, aunque sea de forma somera, ya que simplemente se quiere contextualizar la investigación los siguientes conceptos:

Acceso abierto
Colecciones digitales
Metadatos
Contenidos abiertos
Objetos de aprendizaje
Portales
Repositorios

${ }^{83}$ Conocido también como acceso abierto y Open Access en inglés. 


\subsubsection{Acceso abierto}

El tutorial realizado por SEDIC ${ }^{84}$ sobre acceso abierto hace referencia al aporte teórico de Peter Suber $(2006)^{85}$.para definir el acceso abierto como "el libre acceso a cualquier recurso electrónico derivado de la producción científica o académica sin barreras económicas o restricciones derivadas de los derechos de copyright sobre los mismos".

Ernest Abadal (2012, p.9) ${ }^{86}$ aporta un concepto simplificado e integral al referirse a este, como "un cambio en el funcionamiento de la comunicación científica que, en estos momentos, no es ni gratis ni libre, cuyo acceso está sujeto a el pago de licencias para su uso y, además, la mayor parte de sus contenidos están bajo derechos de explotación de las editoriales".

Abadal retoma la definición de Peter Suber $(2006)^{87}$ para destacar dos importantes condiciones que deben cumplir los contenidos científicos que sean de acceso abierto. Primero "tienen que ser gratuitos y segundo, libres de algunas restricciones de derechos de explotación". Es decir, que los usuarios tienen la posibilidad de consultar gratis el documento y además, descargarlos, copiarlos, imprimirlos, distribuirlos, etc."

En esta línea y completando el aporte de Abadal, el JISC (Joint Information Systems Committee) en su sitio web expone un documento oficial $(2010)^{88}$ donde define el concepto e importancia de acceso abierto a la información como un potencial para la prestación de servicios variados, la preservación y la difusión del conocimiento como estímulo a la producción científica y la investigación.

\subsubsection{Colecciones digitales}

Colección digital es un conjunto de recursos y objetos de información digital o digitalizados, debidamente seleccionados, sistematizados, organizados y almacenados en un depósito de almacenamiento y accesible a través de procesos de búsqueda en línea. Se distinguen dos tipos de colecciones:

a) Conjunto de datos descriptivos o referenciales de objetos o recursos. Estos son asociados a los términos metadatos.

b) Conjunto de recursos electrónicos como documentos, libros, revistas etc. que están acompañados de mecanismos de recuperación que involucra el uso de metadatos.

\subsubsection{Metadatos}

Eva Méndez y José A. Senso $(2004)^{89}$ en material de estudio sobre metadatos ofrece una unidad de formación ${ }^{90}$ definen metadatos como "datos estructurados sobre otros datos que incluyen datos

\footnotetext{
${ }^{84}$ Tutorial promovido por la Subdirección General de Coordinación Bibliotecaria.

${ }^{85}$ Véase documento "Open Access for UK Research - JISC's contributions" (2010) en el sitio web de

SEDIC.http://www.jisc.ac.uk/publications/programmerelated/2010/openaccessmainbrochure.aspx\#what. Consultado $07-$ 10-2012.

${ }^{86}$ Ernest Abadal (2012) Acceso abierto a la ciencia. Documento completo disponible en http://eprints.rclis.org/bitstream/10760/16863/1/2012-acceso-abierto-epi-uoc-vfinal-autor.pdf Consultado 30-10-2012.

87 "Open-access literature is digital, online, free of charge, and free of most copyright and licensing restrictions" (Suber, 2006).

${ }^{88}$ Mayor información sobre el enfoque de JISC se encuentra disponible en el siguiente enlace: http://www.sedic.es/autoformacion/acceso_abierto/presentacion.htm Consultado 30-10-2012.

${ }^{89}$ Véase material de curso: Introducción a los metadatos: estándares y aplicación. Unidad de autoformación.SEDIC. http://www.sedic.es/autoformacion/metadatos/tema1.htm Consultado 30-10-2012.
} 
asociados con un sistema de información o con un objeto de información particular con un propósito de descripción, administración, funciones técnicas, conservación, etc." Asimismo José Ángel Martínez y Pablo Lara (2006, p.3), agregan que los metadatos deben ser vistos como conjuntos de unidades de información debidamente descritas para facilitar su identificación, recuperación, gerencia, preservación y la interoperabilidad.

Clara López Guzmán; Francisco J. García Peñalvo (2003 p.99-107) caracterizan el concepto al señalar que el formato de descripción de los metadatos incluye 76 elementos extensibles, pero usualmente se reconoce la aplicación de nueve grupos organizados en forma jerárquica, listados a continuación.

a. Aspectos generales que describen el objeto de aprendizaje

- Ciclo de vida: Descripción de los antecedentes referencial del OA

- Metadata: Información sobre la plataforma en que se gestiona el metadato

b. Aspectos técnicos: Requerimientos y características técnicas del objeto de aprendizaje

- Educación: Condiciones específicas del uso educativo del OA

- Derechos de propiedad: Condiciones de uso para el aprovechamiento diverso del recurso

- Relación: Relación del recurso descrito con otros objetos de aprendizaje

- Anotación: Comentarios sobre el uso educativo del objeto de aprendizaje

- Clasificación: Descripción temática del recurso en algún sistema de clasificación

Claudia Lacombe Rocha (2007), en concordancia con los conceptos anteriores reconoce tres tipos de metadatos que seguidamente se describen.

\begin{tabular}{|l|l|}
\hline Tipo de metadatos & Tipo de recurso \\
\hline $\begin{array}{l}\text { 1. Administrativos. Su fin apunta a la gestión de } \\
\text { documentos y su preservación. }\end{array}$ & Documentos digitales \\
$\begin{array}{l}\text { La descripción ofrece información sobre la fecha de } \\
\text { recibimiento; acción de preservación, conversión, } \\
\text { actualización, derechos de acceso, confidencialidad, } \\
\text { propiedad intelectual. }\end{array}$ & $\begin{array}{l}\text { 2. Estructurales. Su fin es evidenciar las relaciones entre } \\
\text { documentos y estructura interna de documentos } \\
\text { complejos formados por diversos archivos relacionados. } \\
\text { Ejemplo de estos metadatos son las bases de datos, } \\
\text { páginas de la web, correos electrónicos con anexos. }\end{array}$ \\
\hline
\end{tabular}

${ }^{90}$ Remedios Melero Melero, Investigadora Titular del Instituto de Agroquímica y Tecnología de Alimentos (IATA). Consejo Superior de Investigaciones Científicas (CSIC); José Manuel Barrueco Cruz, Licenciado en Documentación. Biblioteca de Ciencias Sociales de la Universidad de Valencia. 


\begin{tabular}{|l|l|}
\hline $\begin{array}{l}\text { 3. Descriptivos. Su objetivo es facilitar la búsqueda y } \\
\text { localización de los documentos. Los datos descriptivos } \\
\text { que ofrece corresponde a los campos de autor, } \\
\text { destinatario, fecha de creación, institución productora, } \\
\text { clasificación, asunto; entre otros }\end{array}$ & Documentos tradicionales y \\
\hline
\end{tabular}

\subsubsection{Contenidos abiertos}

Núria Ferran Ferrer y Juliá Minguillón Alfonso (2007, p.4), señalan que los contenidos abiertos pueden ser analizados desde la perspectiva de los programas informáticos (Open Source Software OSS) y desde la filosofía de acceso abierto (Open Access OA) para generación y difusión de conocimiento. En este contexto y en el marco de esta tesis, los contenidos abiertos se entienden como aquellos contenidos de acceso gratuito y con la flexibilidad de ser usados libremente en Internet, para fines de copiar, distribuir, imprimir, buscar o enlazar los textos completos de los artículos, indizarlos, usarlos para diferentes propósitos sin barreras legales o técnicas a excepción del copyright.

Ferran Ferrer y Minguillón Alfonso (2007), destacan que el uso y reutilización de los contenidos abiertos para fines educativos ocurre en programas y tareas formativas. Esto puede ocurrir en uno o varios programas educativos simultáneamente, es decir en un curso completo, en módulos independientes. Estos contenidos pueden estar inmersos en un artículo, libro completo o en partes, videos, ilustraciones, fotos, material multimedia.

\section{Contenidos educativos abiertos}

Los contenidos educativos abiertos, se caracterizan por la actualización de sus datos, la presencia de un modelo pedagógico, uso de aplicaciones medias, su diseño, por su rápida navegación y sobre todo por la adecuada descripción del contenido basada en estándares.

Cabe destacar que existen contenidos educativos que cumplen con estas mismas características, pero son considerados cerrados. La diferencia entre ellos ocurre fundamentalmente porque su acceso está limitado al sector educación. Seguidamente se presentan las características de los contenidos educativos.

Los contenidos educativos se caracterizan

- Actualización de sus contenidos: Elemento pedagógico que ayuda a la compresión de los conceptos

- Amigables tributos de usabilidad, como fácil y rápida navegación, homogeneidad en el uso de fuentes, visibilidad, adecuada apariencia y uso de aplicaciones de media

- Adecuada descripción de los objetos de aprendizaje basada en estándares 


\section{Diferencias de acceso entre contenidos educacionales}

Contenido cerrado

Dublin Core, Marc, IMS, Learning Resource metadatos, LOM, entre otros

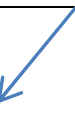

s

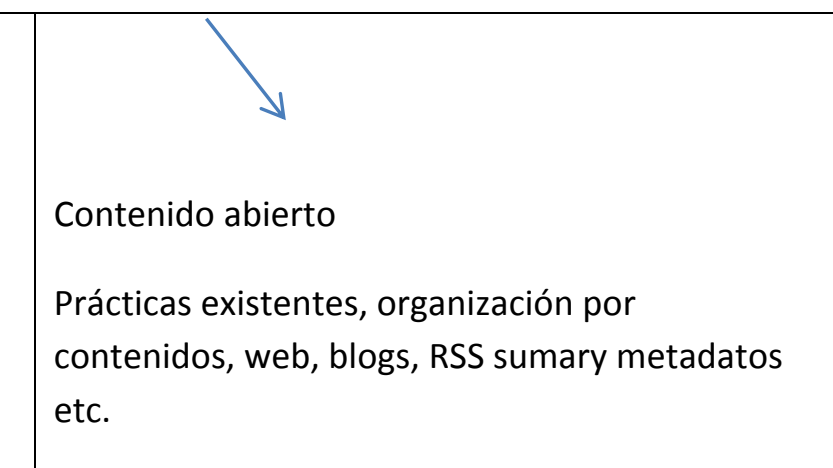

Figura 27. Caracterización de los contenidos educativos. Fuente: Elaboración propia.

\subsubsection{Objetos de aprendizaje}

En un intento de resumir los diferentes aportes conceptuales identificados en la revisión de literatura, se define como "objetos de aprendizajes" los diferentes recursos cuyos contenidos son elaborados para la instrucción y aprendizaje o enseñanza basada en computadora. En dependencia de su objetivo, éste pude ser una unidad educativa o formar parte de un conjunto. Su presentación puede variar desde imágenes, fotografías, textos, multimedios, software instruccional y cursos, html, pdf, txt, etc., hasta un conjunto complejo de entornos y herramientas que hacen posible la reutilización de estos.

López Guzmán y García Peñalvo (2006), señalan que los objetos de aprendizaje (OA) son "recursos flexibles y de gran valor en el proceso de formación electrónica". Se caracterizan por la composición de elementos digitales y por su capacidad de uso y re-usabilidad e una misma o diversas plataformas tecnológicas E-learning.

López Guzmán; y García Peñalvo agregan que la identificación, localización y uso de los OA requiere del acompañamiento de sus metadatos, que además le permitirán ser exportables hacia otras aplicaciones y diversos contextos.

La generación de OA para la educación que involucren la aplicación de estándares internacionales, le atribuyen a los $O A$ algunos atributos importante para su uso que seguidamente se listan.

- Interoperabilidad

- Interacción

- Comunicación entre sistemas

- Posibilidad de ser utilizados de forma simultánea en múltiples tareas

- Facilidades para la gestión de los contenidos y usuarios

- Accesibilidad y durabilidad de estos recursos. 


\subsubsection{Portales}

La definición del concepto "portal", adoptado en esta investigación corresponde a la puerta de entrada al internet o espacio virtual donde se localiza de forma organizada determinados contenidos. Es decir, un mecanismo que acorta caminos y permite llegar de forma más directa a la información, servicios y/o productos.

Con el objetivo de fundamentar la apropiación del concepto referido, seguidamente se presentan algunos aportes teóricos que definen el concepto portal.

Mike Ebbers y Armelle Creuzet (2001), de la empresa International Business Machines Corporation en su documento publicado en el $2001^{91}$, definen el término portales como las aplicaciones informáticas en sitios web para gestionar, analizar y distribuir información dentro y fuera de una empresa y ofrecidas a sus usuarios en la forma de pasarela única y personalizada para las tomas de decisiones de negocios.

Desde un punto vista técnico, Juan Carlos García Gómez (2001, p.6), funcionario del Servicio de Información de la Universidad de Murcia, retoma las características que atribuye David Morrison $(2000)^{92}$ quién hace un acrónimo del término PORTAL para diferenciarlo de la página web.

Personalización para usuarios finales

Organización del escritorio

Recursos informativos divididos y organizados

Trayectoria o seguimiento de las actividades de los usuarios (tracking)

Acceso a bases de datos

Localización de gente o de cosas importantes

Mike Ebbers y Armelle Creuzet (2001) distinguen dos tipos de portales:

1. Generales (mega portales o portales horizontales). Están orientados a todo tipo de público y ofrecen contenidos de carácter muy amplio. Suelen incorporar servicios de valor añadido como espacio web gratuito, personalización de la información, chat, e-mail gratuito, mensajes a teléfonos móviles, software de libre distribución, grupos de discusión, comercio electrónico o buscador.

2. Especializados. Superan el modelo de metadatos globales por cuanto responden a objetivos y clientela concreta. Se identifican dos subgrupos en esta categoría:

- Corporativos. Provee información de la empresa a los empleados, así como de acceso a una selección de webs públicos y de mercado.

- Verticales. Provee información y servicios a un sector o industria en particular.

\footnotetext{
${ }^{91}$ Documento disponible en pdf: http://www.redbooks.ibm.com/redbooks/pdfs/sg246231.pdf

92 Citación de Juan Carlos García Gómez (2001): MORRISON, David. Building successful portals. En: Group computing magazine, 2000, mayo-junio.
} 
- La cobertura de sus contenidos se centra en un tema o área concreta. A su vez es posible clasificarlos dentro de otros dos grupos fundamentales que son los "geográficos: centrados específicamente en una zona o área concreta" y los "temáticos: atienden a una línea temática".

\subsubsection{Repositorios}

El término repositorio es definido por la Real Academia Española ${ }^{93}$ "como lugar donde se guarda algo". Si retomamos esta definición literalmente, hace referencia a un punto o sitio centralizador de almacenamiento " La aplicación de este término en las ciencias de la información se asocia a la necesidad de organizar, identificar y preservar en un punto centralizado los archivos de información científicas de libre acceso. Por la diversidad de formatos y tipo de datos contenidos en los archivos, los repositorios se caracterizan por su flexibilidad y el manejo de metadatos para la descripción de los contenidos.

En la declaración de Budapest (Budapest Open Access Initiative, BOAI 2002) se define el open Access como el libre acceso a la literatura científica a través de internet, respetando las leyes de copyright existentes, Asimismo en la declaración de Bethesda (2003) se menciona las posibilidades que brinda internet en la difusión del conocimiento y se reconoce la importancia del acceso abierto (open Access.).

Salvador Sánchez García de las Bayonas y otros autores colaboradores (200? p.2-4), afirman que el surgimiento de los Repositorios responde a dos tendencias. Primero la "Ruta Oro" cuyo origen surge como respuesta a la problemas de constante subida de los precios de las suscripciones de publicaciones científicas y apunta a garantizar el acceso abierto de este tipo de publicaciones. Este proyecto "Ruta de Oro" fue centrado a la difusión de la investigación y el acceso abierto a los documentos electrónicos. La otra tendencia conocida como "Ruta verde" está centrada en el desarrollo de los "repositorios institucionales o depósitos institucionales". Enfatiza la necesidad de garantizar el depósito, como una alternativa para asegura la conservación, organización, difusión, aumento y el acceso del patrimonio institucional y la producción científica a la comunidad.

El proyecto 3R-Red de Repositorios Universitarios de Recursos Digitales de la Universidad Autónoma de México (2006 p.8) ${ }^{94}$ retoma el concepto de "Lynch (2003), un repositorio es una serie de recursos y servicios creados y administrados con el fin de que la comunidad académica pueda manejar y difundir materiales digitales. Su objetivo es capturar y administrar la producción intelectual de una o varias comunidades universitarias y maximizar la visibilidad e impacto en línea".

Ernest Abadal (2012 p. 23), define repositorio como "...un sitio web que recoge, preserva y difunde la producción académica o científica de una institución (o de una disciplina científica), permitiendo el acceso a los objetos digitales que contiene y a sus metadatos."

Clara López Guzmán y Francisco J. García Peñalvo (2003 p. 102), retoman el aporte hecho por Downes (2004) para definir a los repositorios OA como bases de datos que alojan recursos digitales

\footnotetext{
${ }^{93}$ Sitio del Diccionario de la Real Academia Española http://buscon.rae.es/drael/SrvltConsulta?TIPO_BUS=3\&LEMA=cultura Consultado 16-8-2011.

${ }^{94}$ 3R- Red de Repositorios Universitarios de Recursos Digitales Informe técnico Etapa I. Investigación. Disponible en http://eprints.rclis.org/bitstream/10760/12757/1/3R_primer_informe.pdf.
} 
y/o metadatos especializados en recursos educativos que pueden ser utilizados para el aprendizaje mediado y que son accesibles a través de Internet. Asimismo establecen una comparación entre los repositorios con bibliotecas digitales, debido a que en ambos casos se utilizan estándares de metadatos para inter-operar con otros repositorios y con otras aplicaciones de los entornos Elearning.

Retomando las aportaciones teóricas anteriores, seguidamente se definen y caracterizan los tipos de repositorios identificados durante el desarrollo de la presente investigación.

\section{Tipos de repositorios}

En la actualidad existen diferentes tipos de repositorios. Las diferencias entre ellos se originan en los objetivos y fines para lo que han sido creados, así como la tipología de usuarios a quien están dirigidos En la siguientes páginas se presenta una breve descripción de los tipos de repositorios identificados.

a.- Repositorios telemáticos

Conjunto de recursos de información disponibles en formato digital que pueden ser accesibles a través de mecanismos electrónicos ya sea desde una conexión a internet desde un computador o desde un teléfono móvil.

\section{b.- Repositorios temáticos}

Carolina De Volder (2008 p.1), aporta al concepto de repositorios temáticos como el conjunto de unidades de almacenamiento que recogen documentos científicos y/o académicos de una o varias disciplinas científicas específicas y son los investigadores de diversas instituciones quienes contribuyen autoarchivando sus trabajos. Generalmente, albergan artículos científicos en formato electrónicos (eprints), ya sea la versión previa a la publicación (preprint), la versión publicada o una versión posterior (post-print) ${ }^{95}$. Cabe destacar que en este grupo de repositorio se identifica los repositorios telemáticos para la educación que contienen información académica y científica.

c. Repositorio institucional (RI)

El Repositorio Institucional de la Universidad de Alicante (RUA), Define los repositorios institucionales como un "Sistema de información. Su objetivo es almacenar, preservar y difundir la producción intelectual de una determinada institución, normalmente de una comunidad universitaria. La creación de los RI surge a partir de la iniciativa de Open Access en $2002^{96 .}$

d. Repositorios de acceso abierto

Rachel Heery y Sheila Anderson (2006), consideran que los repositorios de acceso abierto son sistemas flexibles para interactuar con otras tecnologías y abiertos para el intercambio de

\footnotetext{
95 Ibid. 3R- Red de Repositorios Universitarios de Recursos Digitales Informe técnico Etapa I. Investigación.

${ }^{96}$ Declaración de Budapest 2002.
} 
herramientas y la realización del trabajo de desarrollo en colaboración, a menos que sean restricciones legales.

e. Repositorios de documentos electrónicos

Repositorios de documentos electrónicos tiene la preservación de los documentos institucionales en formato electrónico (e-documentos) y paralelamente facilitar el permanente acceso de estos. Para lograr este objetivo, se valen de motores de herramientas de búsquedas y uso de los recursos, así como de normas para protección de los derechos de autor de los investigadores de la institución, etc. Dentro de este grupo de repositorios se distinguen los siguientes tipos:

- e.1. Repositorios de revistas. Son repositorios que contienen colecciones de revistas electrónicas.

- e.2. Repositorios de libros electrónicos contienen colecciones de libros completos o partes en formato electrónico.

- e.3. Repositorios de mapas (GIS): que es una integración organizada de datos geográficos que permite capturar, almacenar, manipular, analizar y desplegar en todas sus formas la información geográficamente referenciada con el fin de resolver problemas complejos de planificación y gestión.

- e.4. Repositorios de objetos de aprendizajes: Unidad que contiene soportes electrónicos de materiales metodológicos y didácticos para la enseñanza. Puede presentar diferentes formatos, tamaño y requerimientos de uso.

f. Repositorios de Objetos de Aprendizaje (ROA)

Anteriormente se ha definido los repositorios como unidades de almacenamientos de recursos electrónicos que facilitan el acceso y uso de la información contenida en ellos. Asimismo se ha destacado también que los repositorios facilitan la organización, difusión, aumento y conservación de la producción científica institucional. En esta línea un repositorio de objetos de aprendizaje puede ser definido como un conjunto de recursos electrónicos, que se caracteriza y destaca de cualquier otro tipo de repositorio por el contenido selecto y diseñado para ser utilizados para fines formativos y educativos. Es decir un producto final que concentra información académica que pueden ser usables y reutilizables en plataformas comunes como, por ejemplo, los programas Eprints, Dspace y Bepress. El modelo ideal de ROA según López Guzmán y García Peñalvo, es aquel modelo que pueda interoperar entre sistemas de diferentes naturalezas, es decir que se dispone de una interfaz web, para facilitar el acceso al contenido (colecciones $\mathrm{OA}$ ) y la interacción directa e inmediata con la plataforma de aprendizaje, es decir el modulo del curso.

ROA externo al servidor es un tipo repositorio de objetos de aprendizaje, se encuentra en un servidor separado de los metadatos y de Internet. Es el modelo más usado. Funcionan de forma independiente (stand alone) a modo de interfaz web y mediante un mecanismo de búsqueda y listados con algún tipo de clasificación. Opera como módulo adicional a otros productos como las plataformas de aprendizaje o para gestión de contenidos (sin que el usuario tenga el acceso directo al repositorio). 


\subsubsection{Importancia de los repositorios para la educación}

Las entidades educativas en los últimos veinte años implementan el modelo de educación electrónico (E-learning) que confluye con el modelo presencial. Las prácticas de implementación de cursos completos o módulos parciales, ha demandado la creación de materiales de estudio especializados, conocidos como objetos de aprendizaje $(\mathrm{OA})^{97}$. Estos casi siempre son gestionados por los docentes en conjunto con el personal de la biblioteca. Cabe destacar que las prácticas actuales de generación y uso de objetos de aprendizaje y los ROA involucran la participación de la biblioteca. En algunos casos como facilitadora de los metadatos, en otras como diseñadora de tutoriales y como miembro del grupo responsable de los repositorios educacionales

De forma general es posible destacar la importancia de los repositorios en el sector educación en los siguientes cinco objetivos.

\section{Democratización del conocimiento}

Facilitan el acceso a los recursos de información, recursos pedagógicos y didácticos necesarios para motivar la construcción del conocimiento en el individuo. Asimismo propician el acceso libre a los resultados de investigación y de las publicaciones científicas y el incremento del uso e impacto de éstos.

\section{Disminución de costos}

Reducir costos para que el conocimiento pueda llegar a diverso sectores económicos, culturales y sociales.

\section{Producción y publicación de información científica}

Estimular la producción y publicación de información científica, a fin de generar un incremento cuantitativo y cualitativo en la generación de nuevos conocimientos.

\section{Intercambio de información}

Facilitar las condiciones para el intercambio de información y la comunicación científica y agiliza la transferencia de conocimiento y la interoperabilidad entre productos y sistemas.

\section{Reutilización de los recursos}

Generar la posibilidad de reutilizar los contenidos para que estos puedan ser utilizados de forma paralela para dos o más objetivos, es decir facilitar su consulta y el uso de estos para generar otros productos y servicios.

Ultimando sobre la importancia de los repositorios, se retoma lo expuesto en el apartado 4.2 en relación a los puntos de encuentro E-learning y la biblioteca. En este se ha concluido que las plataformas E-learning carecen de un servicio dinámico y especializado de apoyo a la enseñanza electrónica, hecho que atribuye a la biblioteca el espacio para participar como gestora de tutoriales y puente de acceso a los repositorios especializados para la educación. En esta línea el modelo de ROA, representa ser el tercer elemento del modelo de oferta de servicio propuesto en esta tesis, pensado para ser ofrecido por la biblioteca para E-learning. Cabe destacar que la integración de los ROA en el modelo complementa el ciclo de transferencia de conocimiento.

\footnotetext{
${ }^{97}$ Aprendizaje cegado ocurre como consecuencia de la falta de contacto físico o visual entre el profesor y el aprendiz.
} 
Visto de esta forma el servicio de referencia es el punto de orientación al usuario-cliente de donde localizar la información; el servicio ALFIN como medio que le permite adquirir capacidades y habilidades para buscar la información necesaria y, finalmente el servicio de acceso a los ROA como el mecanismo de acceso a la información necesaria cuyo valor agregado se caracteriza por su selectividad, autenticidad, precisión, interoperabilidad.

\subsubsection{Interoperabilidad de los repositorios educacionales en E-learning}

En el cuarto informe sobre vigilancia de metadatos (2002) del proyecto europeo Schemas ${ }^{98}$, destaca que el uso de los metadatos es esencial para la interoperabilidad de los contenidos educativos (objetos de aprendizaje) siempre y cuando, de forma paralela garanticen el respecto a la propiedad intelectual y el uso ético del contenido. Desde una perspectiva basada en el desarrollo del modelo de biblioteca digital y el E-learning sugieren Leonel Iriarte Navarra y otros et.al. (2004, p.1), dar atención a los siguientes aspectos:

- Uso de formatos semánticos como XML

- Uso de recursos de descripción referenciales RDF

- Arquitectura común de intermediarios CORBA (Common Object Request Broker Architecture)

- Protocolos para la diseminación del contenido de los metadatos (Barrueco 2003) como el Open Archieves Initiatieve - Iniciativa de archivos abiertos (OAI)

- Uso de protocolos para la diseminación de contenidos de los metadatos OAI Open archives Iniciative)

La principal característica de operatividad a los repositorios OA se centra en la posibilidad que ofrecen estos para reutilizar los materiales educativos en distintas plataformas y aplicarlos a diferentes niveles de usuarios, así como el poder intercambiarlos con otros programas y repositorios. Hecho que es posible dado el uso de estándares y que además, facilitan el proceso de búsqueda, recuperación y distribución.

La creciente práctica de uso de los ROA en programas de educación, demuestra que estos son de gran utilidad en el proceso de enseñanza- aprendizaje, no obstante, existen algunas limitaciones que seguidamente se enuncian:

- Los objetos de aprendizaje son recursos novedosos orientados hacia la docencia y procesos enseñanza- aprendizaje. Generalmente el o los autores (docente, pedagogo, etc.) no aplican ninguna normativa estándar como es el caso de otro tipo de recurso de investigación.

- La filosofía del movimiento Open Access aún no incluye este tipo de documentos.

\footnotetext{
${ }^{98}$ Refleja que las iniciativas de estandarización son DCMI-Education (Dublin Core Metadatos Initiative for Education), los LOM (Learning Object Metadatos - objetos de aprendizaje) y EML (Educational Modelling Language - Lenguaje de modelo Educativo) SCHEMAS (2002). Fourth Metadata Watch Report . [Fecha de consulta: 18 noviembre 2012].
} 
- Las plataformas desarrolladas y utilizadas para los "objetos de aprendizaje" aún no están normalizadas, asimismo existen limitaciones técnicas en el almacenamiento y recuperación de los mismos.

- La existencia de estas limitaciones representa una debilidad en el actual siglo XXI, no obstante, gracias al trabajo de cooperación internacional los especialistas analizan dicha problemática y buscan algunas alternativas en forma de proyectos locales, regionales e internacionales.

La consulta y análisis de artículos identificados sobre ROA, incluidos en la bibliografía anexa y retomando como referencia práctica la experiencia presentada por Leonel Iriarte Navarra; y otros et.al. (2004, p.6-7) y la experiencia española "Aula Virtual - AVE" (2003), es posible concluir que los elementos básicos que debe cumplir un objeto de aprendizaje, son los siguientes:

\section{Componentes básicos de un objeto de aprendizaje}

Plantilla LO

Estructura XML que contiene los elementos necesarios para documentar el objeto de aprendizaje (Plantilla LO) según el estándar al que se desea exportar

Los valores de los metadatos pueden contener un valor literal o hacer referencia al nombre de la función de la biblioteca

Conjunto de fichero físicos necesarios para obtener él LO de salida. Existen dos tipos: los ficheros asociados a una plantilla y los ficheros de datos.

a) ficheros físicos con archivos HTML que contiene llamadas a videos y objetos

b) ficheros físicos como imágenes, videos, documentos office, presentaciones Flash que están referenciados dentro de los LO

Plantilla para definir la estructura de un determinado contenido y se combina varios LO para lograr el objetivo docente

Biblioteca de funciones

Están presentes todas las funciones referenciales en las plantillas. Su implementación depende de la estructura y filosofía de programación definida

Procesos

Dependen de la descripción de materiales. Los procesos utilizan las facilidades XSLT para generar diferentes formatos de salida a partir de las plantillas XML originales y se vale de la biblioteca de funciones para sustituir las referencias de las plantillas de valores por los valores correspondientes 
Base de datos propias

Son base de datos que las plataformas utilizan para su desempeño y una importante herramienta para el componente "biblioteca de funciones"

Objetos de aprendizaje

Poseen una estructura de base de datos que contiene información sobre el proceso de administración docente, sesiones de clase, los materiales docentes y modelos de aprendizaje

Tabla 18. Repositorios de objetos de aprendizaje que cumple con las normativas SCORM y los OA organizados por temas. Fuente: Elaboración propia. 
La revisión teórica y práctica encaminada a identificar los puntos de encuentro entre la biblioteca y el E-learning permitió identificar el fundamento teórico en que se sustenta el modelo de oferta de servicio propuesto en esta tesis. La factibilidad de implementación práctica del servicio requiere ser demostrado. Para ello, en la presente Parte IV se ofrecen tres capítulos orientados a la demostración de la validez del modelo basado en la convergencia Biblioteca/E-learning a partir de los servicios de referencia, la alfabetización informacional y los repositorios educacionales.

El Capítulo 5 desarrolla los aspectos metodológicos y los estándares existentes para la evaluación de servicios en línea del E-learning y de la biblioteca. A continuación, el Capítulo 6 incluye una propuesta metodológica que retoma los puntos coincidentes de los estándares E-learning y de la biblioteca y que son integrados en una propuesta metodológica y específica para la evaluación de servicios en línea orientados procesos de enseñanza semipresencial y E-learning.

Por último, el Capítulo 7 refleja los resultados de la aplicación práctica de la propuesta metodológica contenido en el capítulo 6, en un estudio de caso realizado en cuatro países en seis bibliotecas académicas. Los resultados obtenidos permitieron demostrar la funcionalidad de la propuesta metodológica para la evaluación de servicios orientados a la modalidad educativa en línea y la factibilidad y viabilidad de implementar el modelo de oferta de servicio propuesto. 


\section{PARTE IV. ANÁLISIS DE SERVICIOS EN LINEA}

\section{Capítulo 5. Evaluación de servicios en línea E-learning y Biblioteca}

5.1 Introducción

5.2 Estándares para evaluar servicios E-learning

5.2.1 Las prácticas de evaluación de servicios E-learning

5.2.2 Parámetros e indicadores para la evaluación de servicios del E-learning

5.3 Parámetros e indicadores para la evaluación de servicios en línea de la biblioteca

\section{Capítulo 6 Propuesta metodológica para evaluar servicios en línea}

6.1 Introducción

6.2 Guía metodológica

6.2.1 Presentación de la guía

6.2.2 Metodología de trabajo

6.2.2.1 Delimitación de objetivos

6.2.2.2 Escenarios identificados

6.2.2.3 Definición de criterios

6.3 Modelo de oferta de servicio de la biblioteca para E-learning

6.3.1 Introducción

6.3.2 Propuesta de modelo de servicio de la biblioteca para E-learning

6.3.3 Estructura del modelo

6.3.4 Usuarios del modelo

6.3.5 Aplicación del modelo

\section{Capítulo 7. Estudio de casos}

7.1 Introducción

7.2 Ámbitos geográficos de la investigación

7.3 Fases y parámetros considerados para el estudio de casos

7.3.1 Fases definidas

7.4 Descripción de casos

7.4.1 Universidad de Wageningen

7.4.2 Universidad Tecnológica de Delft (TUDelft)

7.4.3 Universidad Metropolitana de Ciencias de la Educación (UMCE)

7.4.4 Universidad EARTH

7.4.5 Universidad de Sevilla

7.4.6 Universidad de Salamanca (USAL)

7.5 Revisión general de los estudios de casos

7.5.1 Perspectiva exterior de las bibliotecas

7.5.2 Diseños de sitio web y portales de las bibliotecas

7.5.2.1 Servicios de referencia digital

7.5.2.2 Servicios de alfabetización informacional

7.5.2.3 Repositorios para la educación

7.5.3 Puntos de atención: análisis DAFO/SWOT 


\section{Capítulo 5. Evaluación de servicios en línea E-learning y Biblioteca}

\subsection{Introducción}

En las páginas anteriores hemos reparado en algunas áreas de convergencia entre la biblioteca y el Elearning y hemos puntualizado que la biblioteca puede apoyar en el proceso enseñanza aprendizaje electrónico a través de la oferta de los siguientes tres servicios:

- la referencia digital visto como un proceso de comunicación entre el bibliotecario

- alfabetización informacional para la formación de habilidades y destrezas informacionales

- servicio de acceso a los repositorios para asegurar el acceso a los contenidos y por ende de desarrollo eficiente del ciclo de transferencia de la información y conocimiento.

En la búsqueda de las premisas claves para la integración de estos tres servicios antes mencionados en plataformas E-learning, se ha profundizado en las experiencias y metodología existentes para la evaluación de estos servicios, a fin de reparar la funcionalidad de los mismos y sus características informáticas.

Para este fin se realizó una revisión de los criterios y parámetros utilizados en la evaluación de servicios en línea tanto de E-learning como de la biblioteca. El resultado de este análisis se expone en el presente capítulo que trata de los elementos comunes identificados, y propone la integración de aquellos criterios y parámetros en una solo propuesta metodológica para la evaluación de servicios en línea.

Se parte del hecho que cada servicio en línea tiene características propias y objetivos concretos y diversos. En dependencia de su diseño y nivel de aplicación tecnológica estos pueden interactuar con otros sistemas de gestión de contenidos y en algunos caso con plataformas de gestión del aprendizaje basadas en normas estándares como SCORM $^{99}$ y AICC.

\subsection{Estándares para evaluar servicios E-learning}

Previo a introducirnos a los estándares para la evaluación del servicio y reparar específicamente en los referentes a E-learning y de la biblioteca, es necesario señalar los diferentes tipos de servicios en línea existentes, de manera que sea posible destacar las diferencias entre estos a partir del uso de las telecomunicaciones. Autores como Juan Carlos Barahona; René Zuleta y Olga Calderón (2008), Luis Bellido de la Universidad Politécnica de Madrid (2004) y Félix Murillo Alfaro (2000) del Instituto Nacional de Estadística e Informática de Perú, señalan los servicios en línea y los agrupan en los siguientes tres grupos:

1. Servicios que facilitan el proceso de democratización y participación ciudadana. Estos servicios se reconocen en el marco del llamado "gobierno digital y son ofrecidos por entidades públicas y gobiernos." ${ }^{100}$.

\footnotetext{
${ }^{99}$ Mayor información sobre SCORM véase http://scorm.com/scorm-solved/scorm-driver.

100 Juan Carlos Barahona; René Zuleta; Olga Calderón. (2008) En: http://es.scribd.com/doc/8630733/Herramienta-Para-La-

Evaluacion-de-La-Calidad-de-La-Prestacion-de-Servicios-Por-Medios-Digitales.
} 
2. Servicio de telecomunicación dirigido a facilitar medios de comunicación. Estos servicios consisten en la oferta de conexión permanente a teléfono, televisión, e Internet ${ }^{101}$.

3. Servicios de comercialización de productos y servicios en línea. Conocido también como comercialización electrónica (e-commerce), consiste en cualquier transacción comercial compra-venta de productos o servicios en la cual las partes involucradas interactúan de manera electrónica en lugar de hacerlo de la manera tradicional con intercambios físicos o trato físico directo. En la década de los año 90's este tipo de servicio se prolifera mediante el uso de Internet y tarjetas de crédito o débito bancarias. ${ }^{102}$

Considerando las agrupaciones de servicios antes referidas como un marco de referencia básico, se ha definido como servicios considerados relevantes en esta tesis, aquellos cuyo objetivo es facilitar el proceso de comunicación y transferir algún contenido. Es decir aquellos que además de facilitar el proceso de democratización del conocimiento y participación ciudadana, tiene como fin la formación integral del individuo. Cabe destacar que en ambos casos no se descarta la posibilidad, que estos impliquen el pago de una matrícula o inscripción al servicio.

Los servicios en línea orientados a la formación y capacitación tienen sus antecedentes en la educación a distancia. Los hechos históricos de esta modalidad de enseñanza evidencian que el servicio en línea inició con el uso de aparatos telemáticos que conforme el desarrollo tecnológico ha sido desplazado o usado de forma combinada.

Lorenzo García Aretio (1999), de la Universidad Nacional de Educación a Distancia, resume que la educación en línea inició con la comunicación asincrónica a través de correspondencia postal. Con el invento del teléfono se estableció la tutoría telefónica que posteriormente se masifica con el uso de la radio, la televisión y audio casetes. Con la introducción de los computadores, el servicio de formación integra los componentes de sonido e imagen mediante videos, hecho que facilitó el aprendizaje y fortaleció el sentimiento de tutoría o acompañamiento. En la década de los noventas con la masificación del uso del internet, los servicios en línea han ampliado sus facilidades y ofertas de servicios. Hoy día las prácticas de enseñanza y de aprendizaje verdaderamente puede ser una combinación de procesos sincrónicos y asincrónicos vía correo electrónico, sitios web y la videoconferencia por Internet.

Una vez claro la evolución que han tenido los servicios en líneas orientados a la educación, en las siguientes páginas se presentan algunos aportes teóricos sobre evaluación de estos servicios.

\subsubsection{Las prácticas de evaluación de servicios E-learning}

Los servicios orientados a la formación o capacitación, se caracterizan por la interacción dinámica y constante comunicación entre el docente - orientador y el individuo en proceso de formación o grupo meta.

De los resultados obtenidos de la revisión de estándares existentes utilizados para evaluar servicios E-learning, se constató que las empresas y universidades han centrado la evaluación hacia los siguientes tres aspectos.

\footnotetext{
101 Luis Bellido, et.al. . (200?) Universidad Politécnica de Madrid.

102 Félix Murillo Alfaro(2000).
} 
- Contenido de los materiales de estudio (objetos de estudio y objeto de aprendizaje)

- Aplicación tecnológica. Visto como el medio que facilita la gestión, el acceso al contenido y los procesos de comunicación.

- Uso - Usabilidad - Usuario. El servicio es evaluado a partir del uso del servicio, acceso a la información (administrativa, didáctica, técnica y científica, complementaria, productos concretos) y la orientación personalizada en línea.

El proceso de evaluación dirigido a estos tres aspectos intenta determinar y medir la relación entre los objetivos, las necesidades y la utilidad de los recursos, es decir la revisión de la prestación del servicio - producto en correspondencia con los resultados y el nivel de satisfacción logrado.

Marc J. Rosenberg $(2001)^{103}$ en su aporte teórico destacado en el capítulo 3.2.1 señala estos tres aspectos considerados en la evaluación, como elementos determinantes en el proceso de diseño, construcción e implementación de cualquier proyecto E-learning. Asimismo en el mismo capítulo Jorge A. Mendoza (2003) ha destacado que el concepto de E-learning debe ser aplicable como una unidad compuesta por estas tres dimensiones y por consiguiente deben ser consideradas como puntos centrales al momento que se va a evaluar. En una perspectiva más académica Toral Marín, (2006, p.99-113), recomienda desarrollar procesos de evaluación considerando los aspectos de orden metodológicos en relación con la perspectiva social, el usuario y las características del entorno.

En concordancia con lo anterior pero con un enfoque más global, Enrique Vílchez Quesada (2005 p. 5-8), agrega que la evaluación de los servicios E-learning puede ser realizada en forma sistémica o direccionada a aspectos específicos como la calidad técnica, la organización, creatividad y la comunicación. María José Rubio (2003, p.102), agrega que este enfoque sistémico debe dirigirse a la búsqueda de un balance entre la actividad formativa, los materiales de formación, la plataforma tecnológica, el usuario y la relación costo.

En síntesis, los autores anteriores recomiendan aplicar una dimensión sistémica en cada proceso de evaluación, sin perder de vista el "contenido-usuario-tecnología. Este enfoque sistémico debe estar dirigido a evaluar la actividad E-learning en sus tres dimensiones:

a) como proceso de enseñanza (curso) en cada una de sus partes

b) como un producto concreto (material de estudio o acceso a los contenidos)

c) como parte de un plan estratégico institucional

Con el fin de profundizar en estos aspectos, se ha realizado el cuadro 19 , que ilustra de forma descriptiva las relaciones explícitas e implícitas que se deben considerar en el momento de momento de delimitar qué se va a evaluar, partiendo de las diferentes perspectivas de la evaluación, de los resultados visibles y de los tipos de servicios.

\footnotetext{
${ }^{103}$ Véase mayor detalle en el apartado 3.2.1.
} 


\begin{tabular}{|c|c|c|}
\hline $\begin{array}{l}\text { Perspectiva de } \\
\text { evaluación del E-learning }\end{array}$ & Resultado visible & Tipos de servicios \\
\hline $\begin{array}{l}\text { E-learning como un } \\
\text { servicio de formación }\end{array}$ & $\begin{array}{l}\text { Instrucción, } \\
\text { enseñanza } \\
\text { Actualización }\end{array}$ & $\begin{array}{l}\text { Servicios de gestión administrativa } \\
\text { Dos niveles jerárquicos y que a } \\
\text { continuación se explican } \\
\text { Gestores del curso } \\
\text { Estudiantes }\end{array}$ \\
\hline $\begin{array}{l}\text { E-learning como un } \\
\text { producto concreto }\end{array}$ & $\begin{array}{l}\text { Comunicación } \\
\text { Material de estudio }\end{array}$ & $\begin{array}{l}\text { Servicios de comunicación y acceso a los } \\
\text { contenidos } \\
\text { Proceso lineal entre la información } \\
\text { (metadatos, repositorios, objetos de } \\
\text { aprendizajes, portales, etc.) } \\
\text { Acceso a los contenidos correspondientes y } \\
\text { obligatorios a la materia del curso; los } \\
\text { contenidos complementarios y de } \\
\text { referencias y los contenidos de acceso } \\
\text { abierto }\end{array}$ \\
\hline $\begin{array}{l}\text { E-learning como un } \\
\text { medio estratégico para } \\
\text { alcanzar determinadas } \\
\text { metas u objetivos }\end{array}$ & $\begin{array}{l}\text { Programa } \\
\text { consecuente }\end{array}$ & $\begin{array}{l}\text { Servicios de orientación, seguimiento y } \\
\text { evaluación } \\
\text { Recursos } \\
\text { Pruebas de espacios abiertos y pruebas de } \\
\text { respuesta cortas } \\
\text { Generación de herramienta para Autores y } \\
\text { la elaboración de reportes estadísticos }\end{array}$ \\
\hline
\end{tabular}

\subsubsection{Parámetros e indicadores para la evaluación de servicios del E-learning}

Los parámetros e indicadores utilizados para la evaluación de los servicios E-learning varían en correspondencia con los objetivos específicos que se percibe de la evaluación. En este sentido Félix Buendía García y Antonio Hervás Jorge (2006), afirman que la evaluación de servicios E-learning debe orientarse a los aspectos de contenido, comunicación y gestión del proceso de aprendizaje.

Claudia Tedesco (2008 p.3-5), en consecuencia de lo anterior, señala en su propuesta metodológica, que la evaluación debe aportar elementos cuantitativos por cuanto se hace necesario entender, valorar procesos y cuantificarlos, a fin de medir el logro de los objetivos. Tedesco propone para ello considerar los siguientes criterios y variables: 


\section{Criterios}

La eficacia

Eficiencia

Impacto

Pertinencia

Viabilidad o sostenibilidad

\section{Variables}

Compromiso institucional

Tecnología

Servicios de satisfacción del estudiante

Oferta educativa

La docencia

Materiales

La entrega y distribución

Finanzas

Cumplimiento legal de normas

Impacto en la sociedad / creación de conocimiento

Evaluación

Enrique Vílchez Quesada (2005 p. 6-8), agrega un enfoque más técnico y orienta ejecutar la evaluación a partir de la revisión de la infraestructura tecnológica; adecuación y organización de los contenidos y el acceso y navegación. Vílchez además propone la necesidad de definir algunos criterios para direccionar el proceso de evaluación y a continuación se resumen en la siguiente tabla.

\begin{tabular}{|c|c|c|c|}
\hline CRITERIOS & Calidad técnica & Organización y & Comunicación \\
\hline \multirow[t]{3}{*}{$\begin{array}{l}\text { Infraestructura } \\
\text { tecnológica. }\end{array}$} & $\begin{array}{l}\text { Aspectos de } \\
\text { accesibilidad y } \\
\text { complejidad }\end{array}$ & $\begin{array}{l}\text { Flexibilidad para } \\
\text { perfilar enfoques de } \\
\text { instrucción y } \\
\text { aprendizaje }\end{array}$ & $\begin{array}{l}\text { Posibilidad de crear foros de } \\
\text { discusión }\end{array}$ \\
\hline & $\begin{array}{l}\text { Costo y } \\
\text { mantenimiento }\end{array}$ & $\begin{array}{l}\text { Flexibilidad para } \\
\text { adaptación y uso de } \\
\text { otros ámbitos } \\
\text { educativos }\end{array}$ & $\begin{array}{l}\text { Calidad y versatilidad de } \\
\text { tabla de noticias }\end{array}$ \\
\hline & $\begin{array}{l}\text { Nivel de } \\
\text { conocimientos } \\
\text { técnicos para su } \\
\text { mantenimiento }\end{array}$ & $\begin{array}{l}\text { Versatilidad en } \\
\text { adaptación o } \\
\text { implementación de } \\
\text { sistemas de ayuda en } \\
\text { correspondencia a los } \\
\text { ritmos de aprendizajes } \\
\text { y diversidad curricular }\end{array}$ & $\begin{array}{l}\text { Eficiencia en los sistemas de } \\
\text { correo electrónicos internos } \\
\text { y externos }\end{array}$ \\
\hline
\end{tabular}




\begin{tabular}{|c|c|c|c|}
\hline $\begin{array}{l}\text { Contenido y } \\
\text { navegación }\end{array}$ & $\begin{array}{l}\text { Factibilidad de } \\
\text { navegación a } \\
\text { través de } \\
\text { interfaces }\end{array}$ & $\begin{array}{l}\text { Posibilidad para } \\
\text { organizar los } \\
\text { contenidos mediante } \\
\text { índices y mapas } \\
\text { conceptuales }\end{array}$ & $\begin{array}{l}\text { Eficiencia de calendarización } \\
\text { y personalización }\end{array}$ \\
\hline $\begin{array}{l}\text { Navegación y } \\
\text { acceso }\end{array}$ & $\begin{array}{l}\text { Calidad de los } \\
\text { sistemas de } \\
\text { control y } \\
\text { seguridad. Acceso } \\
\text { a los procesos de } \\
\text { enseñanza }\end{array}$ & $\begin{array}{l}\text { Posibilidad de creación } \\
\text { automática o manual } \\
\text { de glosarios de } \\
\text { términos relacionados } \\
\text { en unidades de } \\
\text { aprendizajes }\end{array}$ & $\begin{array}{l}\text { Posibilidad de organizar } \\
\text { sesiones Chat }\end{array}$ \\
\hline \multirow[t]{2}{*}{ Usabilidad } & \multirow[t]{2}{*}{$\begin{array}{l}\text { Versatilidad para } \\
\text { el seguimiento de } \\
\text { altas y bajos de los } \\
\text { alumnos }\end{array}$} & $\begin{array}{l}\text { Posibilidad de } \\
\text { integración de } \\
\text { multimedia }\end{array}$ & $\begin{array}{l}\text { Disponibilidad de espacios } \\
\text { virtuales para materializar } \\
\text { visiblemente los momentos } \\
\text { iniciales, ayudando al } \\
\text { establecimiento de } \\
\text { relaciones afectivas }\end{array}$ \\
\hline & & $\begin{array}{l}\text { Disponibilidad de } \\
\text { herramientas de } \\
\text { seguimiento }\end{array}$ & $\begin{array}{l}\text { Posibilidad de organizar } \\
\text { actividades de intercambio } \\
\text { cultural e intercultural }\end{array}$ \\
\hline
\end{tabular}

Tabla 20. Criterios básicos para evaluar servicios E-learning. Fuente: Elaboración propia.

Continuar ahondando en aspectos teórico sobre indicadores o criterios utilizados para evaluar servicios digitales E-learning, resulta redundante, debido a que casi todos los aportes teóricos identificados, coinciden significativamente. Por consiguiente como resultado de la consulta hecha, y en el contexto de los objetivos de la presente tesis, a continuación, se presenta un esquema que reúnen y resumen los aspectos considerados relevantes en prácticas de evaluación de servicios Elearning.

\section{CONTENIDO}

Materiales de formación en correspondencia con los objetivos planteados.
En este sentido son tomados en cuenta los siguientes aspectos:

- Las necesidades reales y potenciales

- Determinar las capacidades para la realización de materiales -Input

- Corregir y perfeccionar el proceso de elaboración y uso del material

- Juzgar la calidad y re-usabilidad

- Determinar el uso y funcionamiento del material en comparación con otros materiales

- Factibilidad de navegación y acceso a través de interfaces 


\section{TECNOLOGÍA}

Plataforma tecnológica de acuerdo a los entornos, recursos económicos y usuarios.

\section{INVERSIÓN - BENEFICIO}

Comportamiento de la y el retorno de la inversión hecha

$$
\left\{\begin{array}{l}
\text { Parámetros evaluables son: } \\
\text { - Estabilidad y Fiabilidad } \\
\text { - Tolerancia a fallos } \\
\text { - Aplicación de estándares } \\
\text { - Flexibilidad } \\
\text { - Velocidad } \\
\text { - Actualidad } \\
\text { - Diseño amigable y didáctico }
\end{array}\right.
$$

Aspectos de accesibilidad y complejidad

- Viabilidad (Es posible)

- Inversión (Cuánto cuesta)

- Rentabilidad ( Genera algún ingreso)

- Costos de mantenimiento (sostenibilidad)

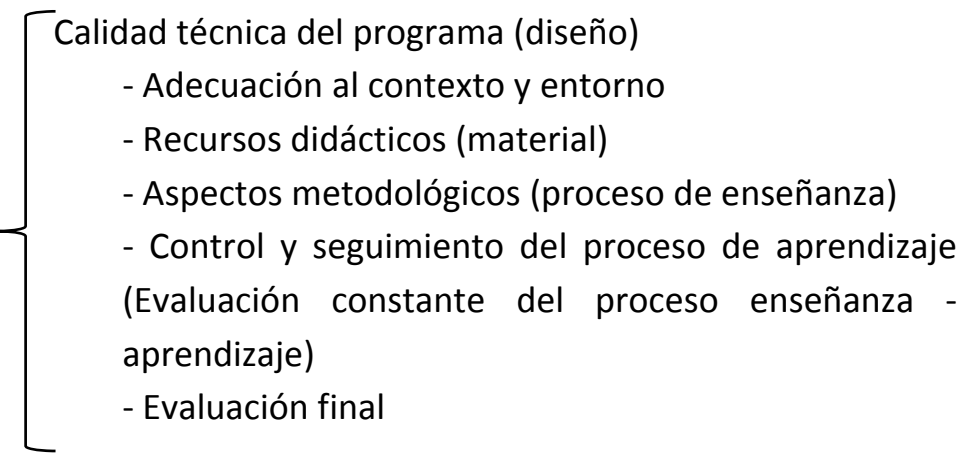

4. ACTIVIDAD FORMATIVA
Cumplimiento de los objetivos,
del proceso de enseñanza -
aprendizaje
Altas y bajas de los alumnos. $\quad\left\{\begin{array}{l}\text { - Recursos didácticos (material) } \\ \text { - Aspectos metodológicos (proceso de enseñanza) } \\ \text { - Control y seguimiento del proceso de aprendizaje } \\ \text { (Evaluación constante del proceso enseñanza - } \\ \text { aprendizaje) } \\ \text { - Evaluación final }\end{array}\right.$

En este mismo orden es importante señalar que, la evaluación como proceso de revisión y valoración exige la aplicación de un enfoque sistémico, por cuanto los resultados deben ser una radiografía real del estado actual de los servicios, vistos desde su funcionalidad y uso. Es decir, el proceso de evaluación exige el análisis de las relaciones existentes entre cada uno de los componentes básicos de E-learning.

En esta línea resulta relevante volver a destacar el aporte teórico de J. Rosenberg (2001) presentado en el apartado 3.2.2 sobre los componentes estándares E-learning, en el cual E-learning se define como el trinomio conformado por los usuarios - contenido - tecnología. En este contexto, podemos concluir que la evaluación de los servicios E-learning debe ser vista como una sola unidad conformada en partes. La siguiente figura establece la relación condicionada entre los contenidos tecnología y usuario, por cuanto no puede existir un servicio en línea sin tecnología, que su vez requiere la presencia obligatoria de contenidos para el cumplimiento de los objetivo educativos y estos dos componentes no tienen sentido sin la existencia de una demanda por parte de los usuarios o grupo meta del servicio. 


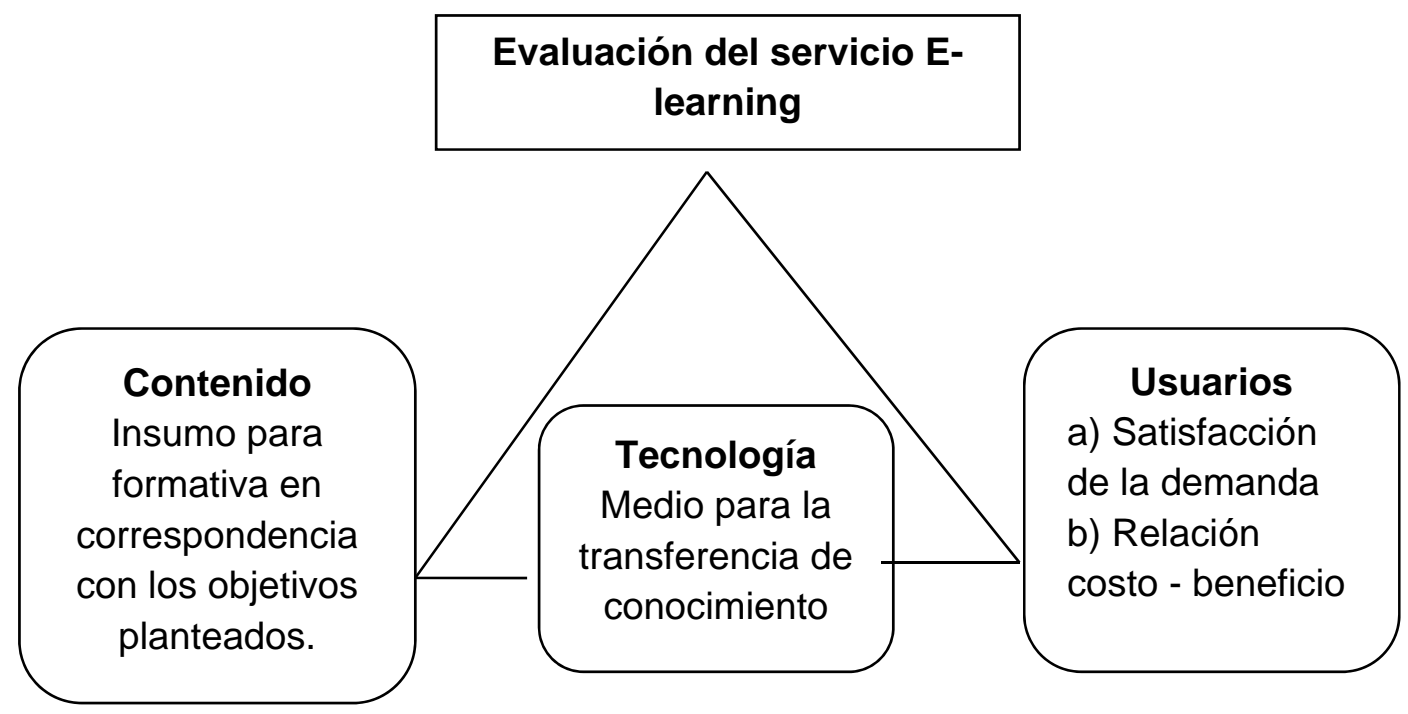

Figura 28. Vínculos de los componentes E-learning en la prestación de servicios. Fuente: Elaboración propia.

En consecuencia de los anterior cabe destacar que es posible que existan diferencias entre cada uno de estos componentes en relación al nivel de aplicación tecnológica y material educativo. En algunos casos es posible que los contenidos sean más interactivos que otros o bien que en algunos casos, las aplicaciones tecnológicas sean más avanzadas; sin embargo en el proceso de evaluación se deban considerar los tres puntos anteriores que forman parte del todo. Estas diferencias determinan las características de este como sistema y servicio.

\subsection{Parámetros e indicadores para la evaluación de servicios en línea de la biblioteca}

Las prácticas de evaluación de servicios en línea ofrecidos por la biblioteca, presenta similitudes con el proceso metodológico de evaluación de los servicios de la biblioteca tradicional y del modelo de biblioteca híbrida. Todos ellos están orientados a medir el nivel de correspondencia entre la oferta, la demanda y sobre todo medir el nivel de eficiencia y eficacia de éstos, es decir medir el nivel de satisfacción de los usuarios. Algunos criterios e indicadores tradicionales que hasta hoy en día continúan siendo incorporados para evaluar servicios de la biblioteca se destacan en la siguiente tabla.

\begin{tabular}{|l|l|}
\hline Criterios & Indicadores \\
\hline Referentes a la colección o recursos de & Objetivos \\
información: & Alcance \\
& Autoridad, audiencia \\
& Precisión de la información \\
& Seguridad y confiabilidad \\
& Presentación y organización \\
\hline
\end{tabular}




\begin{tabular}{|l|l|}
\hline Procedentes de la recuperación de & Relevancia \\
información: & Ponderación \\
& Enlace \\
& Usabilidad \\
Satisfacción con lo encontrado \\
\hline $\begin{array}{l}\text { Satisfacción del usuario con el uso del } \\
\text { sistema: }\end{array}$ & Facilidad del uso del sistema: \\
& Usabilidad y reusabilidad \\
Funcionalidad, tareas apropiadas, errores, \\
esfuerzos de interfaces.
\end{tabular}

Tabla 21. Indicadores tradicionales para evaluar servicios de la biblioteca. Fuente: Elaboración propia.

Aunque la lista de criterios e indicadores antes señalados resulta también válida para ser aplicados en procesos de evaluación de servicios en línea de la biblioteca, cabe destacar que el alcance y medición de los resultados varía en dependencia de las características de los servicios en línea. La aplicación de criterios e indicadores ocurre desde otra perspectiva y está en dependencia del alcance, objetivo, medios tecnológicos, usuario virtual y las condiciones socioculturales en que se ofrecen los servicios en línea. Asimismo cabe destacar que, el resultado de la evaluación en un mismo modelo puede presentar diferencias cuantitativas y cualitativas, así como mayor o menor impacto en dependencia a las posibilidades de los usuarios para hacer uso de este.

Con el fin de discernir en los criterios e indicadores utilizados para la evaluación de servicios en línea ofrecidos por la biblioteca, se presenta a algunos aportes de autores que nos introducen a los estándares más utilizados.

Mariela Ferrada Cubillos (2005) y Lluís María de Ferrer (2000), en diferentes documentos aseguran que actualmente "los usuarios virtuales y remotos tienen mayores niveles de exigencias y confían que la biblioteca les hará llegar la información necesaria hasta su casa u oficina vía email, y sobre esto plantean que el desafío no consiste en el diseño de nuevos servicios, sino en la búsqueda del engranaje de los hábitos, actitudes y experiencias de los usuarios para que ellos puedan sacar aprovechamiento de las interfaces virtuales."

La afirmación anterior de Cubillos y de Ferrer (2000) destaca la necesidad de ampliar la cobertura del proceso de evaluación de los servicios digitales, debido a que ahora no sólo se debe buscar medir el nivel cuantitativo, sino el nivel de eficiencia y eficacia del acceso al conocimiento organizado. Es necesario comprobar si la información está siendo utilizada, y si los usuarios están adquiriendo las habilidades necesarias para satisfacer sus necesidades de información en tiempo y forma.

Durante el proceso revisión de literatura sobre este tema, fue posible reconocer la existencia e iniciativas de evaluación de servicios en línea ofrecidos por la biblioteca, no obstante, no se identificó una metodología unánime para determinar los criterios e indicadores específicos para servicios en línea ofrecidos por la biblioteca. Las prácticas más comunes incluyen la aplicación de la metodología estándar para evaluar sitios y recursos web. Con el objetivo de ampliar la anterior aserción, a continuación se incluyen citaciones de autores, que por el contenido y actualización de sus aportes 
teóricos, han sido considerados como insumos relevantes para el diseño en la propuesta metodológica de evaluación de servicios en línea de ocho bibliotecas, cuyos resultados se detallan en el apartado referente al estudio de casos de esta tesis.

\section{Criterios y parámetros para el análisis de los servicios}

La creciente generación de servicios en Internet, motiva la necesidad de servicios más competitivos y por ende la urgencia de disponer de estándares para evaluar sitios web y recursos electrónicos. Rada (1991), señala que los criterios y parámetros requeridos para la evaluación de servicios en línea deben organizarse en dos líneas. Primero desde un enfoque general (nivel macro) y desde una perspectiva específica (nivel micro).

Lluís Codina profesor de la Universidad Pompeu Fabra, aporta elementos teóricos metodológicos que durante la revisión de artículos y documentos sobre evaluación de servicios en línea, son destacados repetidamente y notablemente utilizados como un estándar referencial. Codina (2003), establece una diferencia metodológica en procesos de evaluación de sitios web y objetos digitales. Señala que aunque algunos aspectos son estrictamente incluyentes como es el caso de la organización, presentación, acceso, ergonomía y adecuación al medio digital; el enfoque varía de acuerdo a los contextos y entornos que determinan los diferentes requerimientos y nivel de exhaustividad del proceso de evaluación. La siguiente tabla se presenta de forma resumida el enfoque sistémico y los ejes centrales propuesto por Lluis Codina que deben ser considerados en la evaluación de servicios en línea.

\begin{tabular}{|c|c|c|c|}
\hline Evaluación de la web & \multicolumn{2}{|c|}{ Evaluación de recursos digitales } & $\begin{array}{l}\text { Estructura de la propuesta } \\
\text { metodológica }\end{array}$ \\
\hline $\begin{array}{l}\text { 1. Contenido } \\
\text { 2. Autoría } \\
\text { 3. Ergonomía } \\
\text { 4. Representación de la } \\
\text { información }\end{array}$ & \multicolumn{2}{|c|}{$\begin{array}{l}\text { 1 Potencia } \\
\text { 2. Operatividad } \\
\text { 3. Capacidad didáctica } \\
\text { 4. Articulación } \\
\text { 5. Compatibilidad }\end{array}$} & $\begin{array}{l}\text { Conceptos - criterios } \\
\text { Parámetros } \\
\text { Indicadores }\end{array}$ \\
\hline $\begin{array}{l}\text { - Calidad y volumen de I } \\
\text { - Autoría (responsabilida } \\
\text { - Legibilidad y ergonomí } \\
\text { - Navegación y represen } \\
\text { - Capacidad de recupera } \\
\text { - Interactividad } \\
\text { - Compatibilidad } \\
\text { - Velocidad de descarga } \\
\text { - Servicios adicionales }\end{array}$ & $\begin{array}{l}\text { n } \\
\text { dentificación y } \\
\text { enido y cantidad de } \\
\text { egación, } \\
\text { rmación } \\
\text { Ivencia) } \\
\text { de la información } \\
\text { le datos }\end{array}$ & \multicolumn{2}{|c|}{$\begin{array}{l}\text { Parámetros- Macronavegación } \\
\text { Aspectos de luminosidad (citas emitidas o enlaces } \\
\text { que parten del hiperdocumento considerado hacia } \\
\text { otros Hiperdocumentos) y visibilidad: Citas recibidas } \\
\text { o enlaces de otros documentos hacia el } \\
\text { hiperdocumento = popularidad } \\
\text { - Luminosidad } \\
\text { - Calidad de los enlaces } \\
\text { - Actualización de los enlaces } \\
\text { - Descripción, selección y evaluación } \\
\text { - Visibilidad } \\
\text { - Autodescripción }\end{array}$} \\
\hline
\end{tabular}

Tabla 22. Diferencias en la evaluación de sitios web y los objetos digitales. Fuente: Basado en Lluis Codina. Metodología de análisis y evaluación de recursos digitales en línea (2003). 
María Dolores Ayuso García y Victoria Martínez Navarro (2006, p.17-22), retoman los aportes de Lluís Codina (2002 y 2003) y elaboran una guía para la evaluación de la calidad de fuentes y recursos digitales que integra los 11 los siguientes parámetros:

1. Identidad

2. Actualización

3. Accesibilidad

4. Arquitectura de la información (Micro y Macro navegación)

5. Servicios - Diversidad de servicios

6. Colecciones

7. Contenido

8. Diseño de interfaz

9. Posicionamiento

10. Sistema de búsquedas y recuperación

11. Usabilidad

Ampliando estos parámetros, Mari Carmen Marcos Mora y Cristòfol Rovira Fontanals (2006, p.3-6), establecen dos niveles en el proceso de evaluación en relación a la usabilidad y proponen el uso de las siguientes dos metodologías complementarias entre sí.

a). La evaluación experta que consiste en poner a prueba con un equipo de expertos el uso del servicio servido en la web.

b) La evaluación de usuarios que implica la observación de cómo utilizan los usuarios el sistema.

Zulia Ramírez Céspedes. (2006, p.5-7), amplia este enfoque y señala que la evaluación de los servicios digitales de la biblioteca deben orientarse a tres aspectos fundamentales que seguidamente se explican:

\begin{tabular}{|c|c|}
\hline Ejes de orientación & Criterios \\
\hline $\begin{array}{l}\text { Entornos virtuales - tecnología } \\
\text { Se refieren a las condiciones físicas en que se } \\
\text { edifica la infraestructura tecnológica, que hará } \\
\text { posible la creación de entornos virtuales para la } \\
\text { prestación de servicios y hacer accesible los } \\
\text { recursos de información. }\end{array}$ & $\begin{array}{l}\text { Criterios procedentes de la biblioteca } \\
\text { tradicional } \\
\text { Colección - objetivos, alcance, autoridad, } \\
\text { cubrimiento, circulación, audiencia, formato, } \\
\text { preservación, etcétera. } \\
\text { Información -precisión, representación y } \\
\text { organización, singularidad, enlaces, } \\
\text { presentación, etcétera. } \\
\text { Uso -accesibilidad, disponibilidad, facilidades } \\
\text { de búsqueda, usabilidad, etcétera. } \\
\text { Estándares para un número de elementos y } \\
\text { procesos. }\end{array}$ \\
\hline
\end{tabular}




\begin{tabular}{|c|c|}
\hline $\begin{array}{c}\text { Organización y presentación de los contenidos } \\
\text { ofrecidos }\end{array}$ & $\begin{array}{c}\text { Criterios procedentes de la recuperación de } \\
\text { información: }\end{array}$ \\
$\begin{array}{c}\text { La definición de políticas para la selección, } \\
\text { sistematización y organización de los } \\
\text { contenidos. La selección de estándares que } \\
\text { permitan el fácil acceso y manipulación de los } \\
\text { recursos informativos internos y externos. }\end{array}$ & -Relevancia, satisfacción, etc. \\
\hline $\begin{array}{c}\text { Interacción de los usuarios } \\
\text { Se refiere a todos los procesos de }\end{array}$ & Criterios procedentes de la interacción \\
comunicación que implica la prestación de \\
servicios. Aquí se presta atención a los hábitos, \\
actitudes y experiencias del usuario.
\end{tabular}

Tabla 23. Perspectiva de la evaluación de servicios digitales. Fuente: Basado en Zulia Ramírez Céspedes. (2006)

Sintetizando las aportaciones anteriores, es posible señalar que la evaluación de los servicios en línea ofrecidos por la biblioteca, debe ser una intersección de la base teórica de evaluación de los servicios tradicionales de la biblioteca y la metodología para evaluar servicios en línea ofrecidos a través de un sitio web.

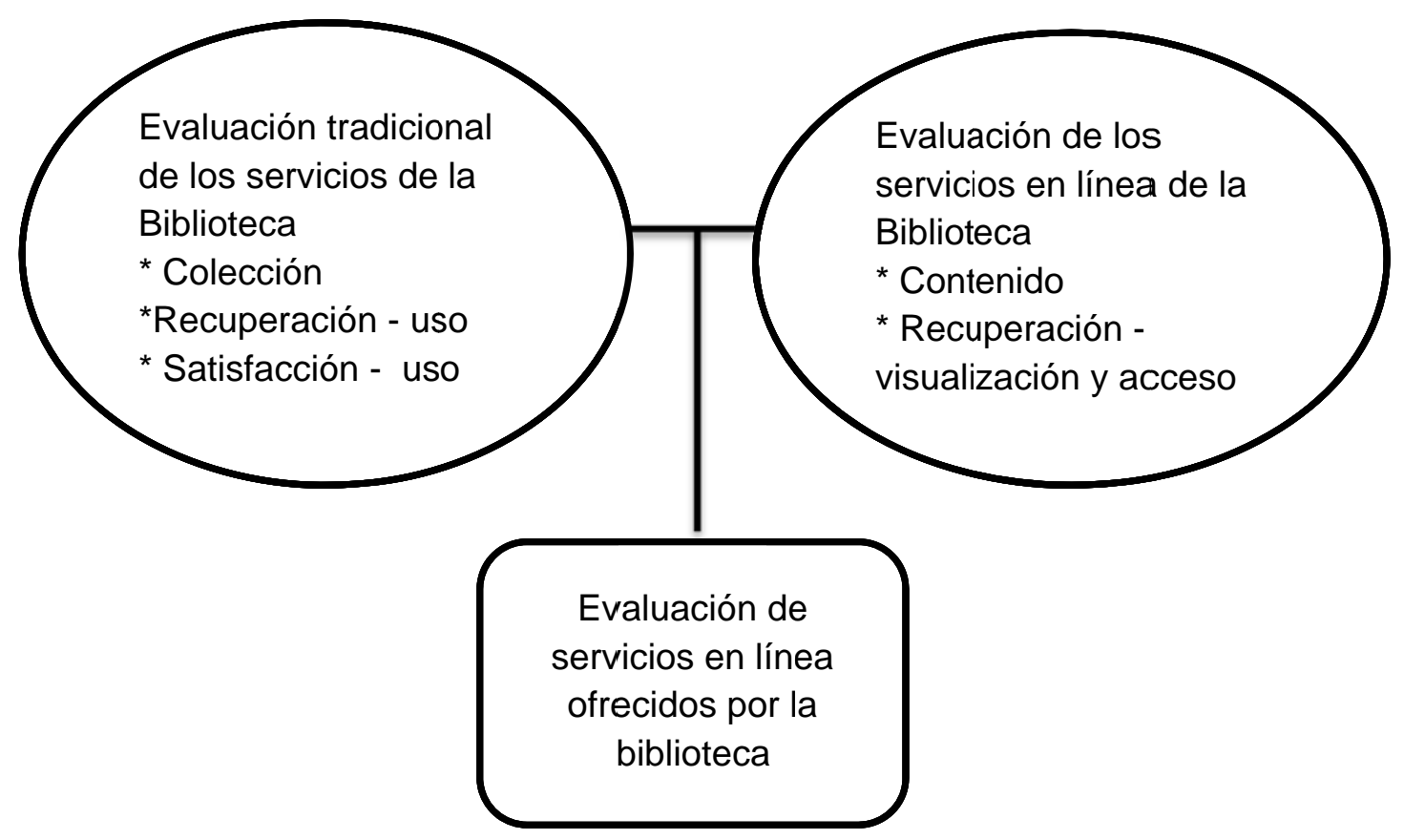

Figura 29. Fundamento para la evaluación de servicios en línea. Fuente: Elaboración propia. 
En el intento de unificar los elementos comunes en el proceso de evaluación de servicios E-learning y los servicios ofrecidos por la biblioteca, se retoma y aplica el enfoque de Marc J. Rosenberg (2001) sobre los ejes de evaluación para servicios E-learning a los servicios en línea ofrecidos por la biblioteca. El resultado de esta práctica presentado enla siguiente tabla evidencia que en ambas casos, la unión de los criterios, parámetros e indicadores para evaluar servicios es una herramienta coherente y tridimensional entre usuario-contenido- tecnología, que puede ser usada como marco de referencia para el análisis descriptivo y comparativo del funcionamiento de los servicios en línea. Asimismo demuestra que la biblioteca puede convergir con el E-learning para la prestación de servicio orientado a la educación.

\begin{tabular}{|l|l|l|}
\hline Ejes de evaluación & E-learning & Biblioteca \\
\hline Usuarios & Desde un enfoque docente & Desde un enfoque bibliotecológico \\
& $\begin{array}{l}\text { Lecesidades de } \\
\text { conocimientos }\end{array}$ & $\begin{array}{l}\text { La satisfacción de necesidades de } \\
\text { información }\end{array}$ \\
\hline Contenido & $\begin{array}{l}\text { Organizados y sistematizados } \\
\text { de acuerdo el nivel } \\
\text { profundidad }\end{array}$ & $\begin{array}{l}\text { Organización y sistematización de } \\
\text { la información }\end{array}$ \\
\hline Tecnología & $\begin{array}{l}\text { Unidades de aprendizajes } \\
\text { Software y hardware } \\
\text { Interfaces de interacción } \\
\text { entre contenido } \\
\text { y el sistema } \\
\text { accesibilidad y usabilidad }\end{array}$ & $\begin{array}{l}\text { Software y hardware } \\
\text { Interfaces de interacción entre los } \\
\text { recursos informativos (fuentes), } \\
\text { servicios y productos de la } \\
\text { biblioteca y el usuario }\end{array}$ \\
\hline
\end{tabular}

Tabla 24. Enfoque tridimensional de evaluación de servicios en línea. Fuente: Elaboración propia 


\section{Capítulo 6 Propuesta metodológica para evaluar servicios en línea}

\subsection{Introducción}

Las nuevas formas de enseñanza electrónica en las entidades educativas, han generado la necesidad de contar con fuentes de información electrónicas organizadas y disponibles en Intranet e Internet. Este hecho ha provocado que algunos servicios digitales ofrecidos por la biblioteca sean integrados como medio de apoyo a la docencia y la investigación en línea. Los bibliotecarios han tenido que auto capacitarse en el uso de la tecnología Web 2.0 para poder participar en la elaboración de los metadatos de los recursos electrónicos, intervenir en la gestión de los repositorios para la educación y en algunos casos crear y/o gestionar los tutoriales.

En el proceso de realización de esta investigación doctoral, fue posible identificar algunas iniciativas de servicios digitales en línea que habitualmente ofrecen las bibliotecas. Aunque estas iniciativas resultan ser buenas prácticas para la prestación del servicio, todavía no existe un instrumento metodológico para el diseño básico de servicios en línea, que pueda ser utilizado como marco de referencia para caracterizar y ajustar éstas nuevas formas de servicios en línea en diversos entornos tecnológicos, económicos y culturales.

Retomando el estudio teórico presentado en los capítulos anteriores y con el objetivo de contribuir al proceso de evaluación de los servicios en línea, en las siguientes páginas, se presenta algunos lineamientos metodológicos para la evaluación de servicios en línea. La importancia de la elaboración y aplicación de esta guía metodológica se concreta en su aplicación en el estudio de campo ejecutado en esta investigación, cuyos resultados expuestos en el capítulo siete, demuestran la funcionalidad del modelo de servicio propuesto en esta tesis. Asimismo cabe destacar que el conjunto de lineamientos que a continuación son expuestos, pueden ser utilizados como un instrumento de referencia metodológica, aplicable de tanto de forma individual o comparativa para la evaluación de uno o varios servicios y productos en línea, o bien en el diseño y planificación de nuevos servicios.

\section{Terminología}

Metodología. Término proveniente del griego ${ }^{104}$ (metá: más allá; odós: caminos; logos: razón, estudios) que se resume "a todos los caminos del estudio". Asimismo el diccionario de la Real Academia Española ${ }^{105}$ define literalmente el término como "Conjunto de métodos que se siguen en una investigación científica o en una exposición doctrinal".

Evaluación. Literalmente el término "evaluación" es definido por el diccionario de la Real Académica Española como la "acción de señalar, estimar, apreciar, calcular el valor de algo"106. En la práctica el término es aplicado como el punto de partida para la toma de decisiones, debido a que la evaluación es parte fundamental en el proceso de gestión y planificación estratégica. La evaluación como proceso se reconoce en las siguientes dos fases. En primer lugar en el análisis sistémico del todo en cada una de sus partes, y segundo lugar como un estudio de factibilidad que permitan identificar el balance entre costos y beneficios de posibles nuevos servicios.

\footnotetext{
${ }^{104}$ Definición extraída de la Wikipedia. Véase mayor información en http://es.wikipedia.org/wiki/Metodolog\%C3\%ADa.

${ }^{105}$ Sección de consulta del diccionario de la Real Académica Española http://buscon.rae.es/drael/SrvltConsulta?TIPO_BUS=3\&LEMA=metodología.

${ }^{106}$ Ibíd. http://buscon.rae.es/drael/SrvltConsulta?TIPO_BUS=3\&LEMA=evaluación.
} 
Metodología de la evaluación. Partiendo de los conceptos antes definidos, el concepto "metodología de la evaluación" deberá ser entendida como el conjunto de métodos y prácticas implementadas para evaluar y caracterizar la funcionalidad de los servicios en línea.

\subsection{Guía metodológica}

\subsubsection{Presentación de la guía}

En correspondencia con los objetivos propuestos en la presente tesis, fue necesario constatar la integración y organización de la modalidad de educación a distancia en las universidades y comprobar la participación de la biblioteca en las actividades E-learning.

Para esto fue necesaria la revisión de los sitios web de las universidades relevantes para este estudio, así como algunos servicios ofrecidos por la biblioteca que potencialmente sirven de apoyo a la enseñanza electrónica. Esto exigió contar con un instrumento para la evaluación de los servicios, razón por la que fue elaborada la presente tesis.

La presente guía metodológica representa ser un instrumento metodológico para el análisis de servicios ofrecidos desde sitios web. Para su elaboración se ha retomado información procedente de la revisión de artículos y sitios Web de evaluación de servicios E-learning y de la biblioteca.

La siguiente guía metodológica, representó ser un importante instrumento para el análisis de los elementos básicos que integran la propuesta de modelo de servicio dirigido a la modalidad de enseñanza E-learning incluyente en esta tesis. Hecho por el cual representa ser una herramienta aplicable en ambas áreas.

Los criterios y parámetros fueron aplicados en el estudio de casos de 8 bibliotecas, en las cuales se evaluó de forma individual el servicio de referencia, el servicio de alfabetización informacional y el acceso a repositorios. Posteriormente fue posible combinar la guía con la metodología de evaluación FODA/DAFO para el análisis global de los tres servicios en línea ofrecidos por la biblioteca.

\subsubsection{Metodología de trabajo}

\subsubsection{Delimitación de objetivos}

La aplicación de la presente guía de evaluación puede ser dirigida estratégicamente a dos objetivos concretos. Por un lado puede estar orientada en forma sistémica a la revisión completa de un todo en cada una de sus partes. El objetivo o los objetivos en este caso, pueden estar orientados a conocer la eficacia y eficiencia de un servicio; identificar los niveles de satisfacción, reconocer problemas con miras a mejorar el servicio. Por otro lado, la evaluación puede conocer el grado de factibilidad para iniciar un nuevo servicio e identificar el balance entre costos y beneficios previos a la implementación del mismo.

La definición clara del qué y para qué evaluar, permitirá definir objetivos lógicos y reales que delimiten el alcance de la evaluación y orienten el proceso mismo. En esta línea el proceso de evaluación reconoce dos tipos de objetivos. El objetivo general pretende contribuir a la búsqueda de soluciones, mediante una propuesta y/o acción y los objetivos específicos, que permiten definir de 
forma real, el alcance enfoque y resultados que se esperan lograr. Es decir permitirá delimitar qué exactamente se busca conocer, hacer y obtener.

\subsubsection{Escenarios identificados}

La evaluación debe ser desarrollada desde un enfoque sistémico, razón por la cual, identificar los posibles escenarios en que puede desarrollarse el proceso de evaluación resulta importante. Conocer la realidad y entornos en que se ofrece el servicio es importante para prever posibles situaciones que influyen directamente en los resultados de la evaluación. La visualización clara de los escenarios en que se ofrecen los servicios que se desea evaluar, facilitará identificar, delimitar y seleccionar el universo y muestra para el estudio. Ejemplos concretos de aspectos que deben ser tomados en consideración corresponden a los aspectos culturales, económicos, tecnológicos y recursos humanos. Con el objetivo de ejemplificar la influencia que pueden tener los escenarios en el desarrollo de la evaluación, en la siguiente tabla, se muestra situaciones identificadas durante la visitas a sitios Web de algunas universidades que no pudieron formar parte de la muestra en el estudio.

\begin{tabular}{|c|c|c|}
\hline Aspecto influyente & Situación encontrada & Limitación para la evaluación \\
\hline Cultural / político / social & $\begin{array}{l}\text { No existen políticas de } \\
\text { estímulos a nivel nacional para } \\
\text { proyectos de servicios en línea. }\end{array}$ & $\begin{array}{l}\text { Reducción del universo } \\
\text { debido a que no todos los } \\
\text { países cumplen con los } \\
\text { criterios definidos para el } \\
\text { estudio }\end{array}$ \\
\hline Económico & $\begin{array}{l}\text { Escasa inversión en proyectos } \\
\text { de servicios en línea. } \\
\text { - Algunas iniciativas quedan a } \\
\text { nivel de intranet y solo tienen } \\
\text { impacto institucional }\end{array}$ & $\begin{array}{l}\text { Acceso restringido. No es } \\
\text { posible acceder a las } \\
\text { experiencias }\end{array}$ \\
\hline Tecnológico & $\begin{array}{l}\text { Limitaciones en la } \\
\text { infraestructura tecnológica }\end{array}$ & $\begin{array}{l}\text { Las instituciones con servicios } \\
\text { presentan problemas de } \\
\text { conexión, acceso y } \\
\text { navegación, hecho que limita } \\
\text { evaluar los servicios }\end{array}$ \\
\hline Recursos humano & $\begin{array}{l}\text { Los profesionales están } \\
\text { inmersos en diferentes tareas } \\
\text { dentro de la biblioteca. } \\
\text { Carecen de conocimientos y } \\
\text { experiencias de servicios en } \\
\text { línea }\end{array}$ & $\begin{array}{l}\text { Limitaciones para disponer de } \\
\text { una persona contacto. }\end{array}$ \\
\hline
\end{tabular}

Tabla 25. Escenarios en el desarrollo de la evaluación. Fuente: Elaboración propia.

\subsubsection{Definición de criterios}

La evaluación requiere contar con normas y criterios por cuanto, estos representan ser la base lógica en que se desarrolla el análisis evaluativo. En dependencia del enfoque y alcance de la evolución del 
servicio en línea a evaluar, los criterios pueden ser tratados con diferentes niveles de profundidad. En general en las prácticas y consulta bibliográfica, se reconocen los siguientes nueve criterios fundamentales para la evaluación de servicios en línea y que posteriormente se explican.

Criterio 1. Aspectos conceptuales

Criterio 2. Límites de la evaluación

Criterio 3. Enfoque de la evaluación

Criterio 4. Parámetros para la evaluación

Criterio 5. Selección de la muestra para el estudio

Criterio 6. Selección de servicios digitales

Criterio 7. Técnicas e instrumentos de captación de información

Criterio 8. Ejecución del estudio casos

Criterio 9. Procesamiento de datos

\section{Criterio 1. Aspectos conceptuales}

Implica la necesidad de definir y esclarecer el significado y aplicación del concepto de servicio.

Criterio 2. Límites de la evaluación

Conlleva definir claramente el alcance y límite del estudio. Es decir que exactamente qué se va evaluar y a qué profundidad en correspondencia del objetivo planteado.

Criterio 3. Enfoque de la evaluación

Supone delimitar el enfoque del análisis que puede ser determinado a partir de las siguientes tres áreas de acción:
a) Usuario
b) Contenido
c) Web

Asimismo para la determinación del enfoque de la evaluación es recomendable aplicar el enfoque sistémico y considerar como elementos claves los siguientes aspectos:

- Caracterización del servicio

- Organización y propiedad de contenidos

- Acceso - Navegación

- Visibilidad

- Usabilidad

- Satisfacción de los usuarios

Criterio 4. Parámetros para la evaluación

Los parámetros entendidos como los factores que permiten analizar o valorar una situación, y obtener la información necesaria para el desarrollo de cada una de las actividades que 
supone la evaluación. En la presente guía, se propone el uso total o parcial de 10 parámetros para la evaluación de servicios en línea.

El origen de estos parámetros corresponde a los aportes metodológicos del profesor Lluís Codina (2000), para evaluar sitios web y objetos electrónicos. La selección e incorporación de estos parámetros en la guía, obedece al hecho que estos, son aplicables tanto para servicios E-learning como servicios en línea ofrecidos por la biblioteca.

La aplicación de los parámetros que a continuación se listan, no compromete el uso de indicadores fijos. Debido a que por las características, objetivo, alcance y enfoque de cada servicio pueden variar significativamente.

1. Identidad

2. Actualización

3. Accesibilidad

4. Servicios básicos de la web

5. Contenido

6. Arquitectura de la información

7. Diseño de la interfaz

8. Posicionamiento

9. Sistema de búsqueda y recuperación

10. Usabilidad

Criterio 5. Selección de la muestra para el estudio

La selección de la muestra en cualquier análisis evaluativo, debe contar con argumentos sólidos y válidos que justifiquen la muestra del estudio. Es importante considerar analizar las condiciones del entorno, realidad económica, sociocultural y tecnológica al momento de seleccionar la muestra, visto que una subestimación de estos factores, podrían generar problemas en la recopilación de datos.

Criterio 6. Selección de servicios digitales

Conlleva determinar qué servicios que serán evaluados. Es necesario reflexionar del porqué de la evaluación, es decir la revisión de los objetivos previamente definidos. Esto facilitará significativamente el proceso de selección de parámetros e indicadores.

Criterio 7. Técnicas e instrumentos de captación de información

Implica la selección de técnicas para la elaboración de los instrumentos de captación de información requerida durante la evaluación. La selección de estas herramientas tiene su punto de partida en los estándares existentes. Se recomienda mantener una visión integral de los objetivos de la evaluación en correspondencia el contenido, tecnología y los usuarios del servicio. 
Debido a que existen una tendencia a confundir el término de técnicas con instrumentos seguidamente se conceptualizan los dos términos, a fin de asegurar un manejo único en esta guía.

A. Definición de técnicas. La Real Academia Española ${ }^{107}$ técnica se refiere al "Conjunto de procedimientos y recursos de que se sirve una ciencia o un arte". En un proceso de investigación el término técnica se refiere a la forma o manera en que se llevará el proceso de captación de datos. Las técnicas más reconocidas en investigación científicas son: análisis descriptivo, estudio de satisfacción de necesidades, observación, pruebas de funcionamiento y entrevista.

B. Definición de instrumentos. Se refiere al conjunto de herramientas individuales o combinadas para el logro de un objetivo ${ }^{108}$. El uso de aplicaciones tecnológicas para el diseño de instrumentos de captación de información, ha permitido que estos adquieran un formato electrónico y que puedan ser aplicables en línea. Los instrumentos más destacables en prácticas de evaluación son:

b.1 Encuesta para usuarios. Centra la atención a los aspectos de visibilidad, acceso, navegación y usabilidad. Puede estar dirigida a uno o varios grupos de usuarios residentes en el país y en otro país o región.

b.2 Encuesta para gestores del servicio. Es orientada solamente a los líderes y/o gestores de los servicios digitales. Su objetivo se centra en conocer, caracterizar aspectos de gestión, organización y funcionamiento del servicio.

b.3 Matriz. Representa ser el marco de referencia para un análisis global y la base en la que se elaboran las específicas. El uso de una única matriz permite orientar el proceso de observación y prueba de funcionamiento de los servicios. La elaboración de la matriz implica el uso de los10 parámetros antes indicados en el criterio 4.

Es importante destacar que los instrumentos elaborados para el análisis de los servicios, deben ser debidamente sometidos a la consulta y revisión de los directores de las bibliotecas, a fin de integrar algún elemento de relevancia para ellos. Posteriormente es necesario realizar pruebas de los mismos, a fin de constatar el grado de correspondencia de la información recopilada y los objetivos planteados.

Criterio 8. Ejecución del estudio casos

El proceso de evaluación debe incluir un perfil descriptivo de la o las institución(es) consideradas muestras para el estudio de casos y de la unidad o departamento responsable del servicio.

\footnotetext{
${ }^{107}$ Véase definición en el diccionario en línea http://buscon.rae.es/drael/SrvltConsulta?TIPO_BUS=3\&LEMA=t\%E9cnica.

${ }^{108}$ Ibíd. Véase definición en el diccionario en línea

http://buscon.rae.es/drael/SrvltConsulta?TIPO_BUS=3\&LEMA=instrumento.
} 
Criterio 9. Procesamiento de datos.

Este criterio implica tener una visión clara de cómo organizaran, anallizaran los datos, los tipos de relaciones entre variables y posteriormente cómo se presentarán los resultados en el informe final.

\subsection{Modelo de oferta de servicio de la biblioteca para E-learning}

\subsubsection{Introducción}

El diseño de un modelo de servicio en línea propuesto en las siguientes páginas, requirió hacer una consulta a los académicos involucrados con actividades E-learning ${ }^{109}$. Para esto fue motivada la discusión en LinkedIn en diferentes grupos de E-learning sobre la presencia de los servicios de la biblioteca como medio de apoyo al proceso de enseñanza - aprendizaje en línea (semipresencial y totalmente virtual).

Las reacciones obtenidas se ilustran a continuación.

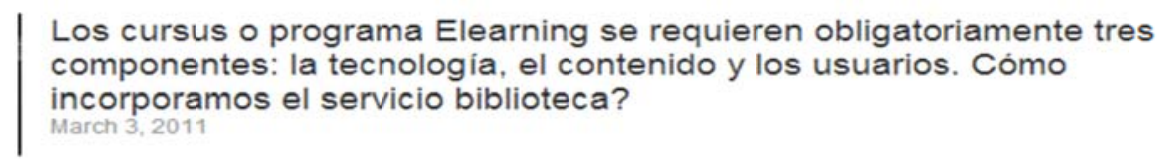

\begin{tabular}{|c|c|c|c|c|}
\hline Like & $\nabla$ Comment & $\sum$ Unfollow & Prlag & More \\
\hline
\end{tabular}

Jose A. Patraca Montiel - Considero que quizas una opcion viable para la incorporacion de bibliotecas para el Elearning, puede ser la contratacion de este servicio de manera virtual; actualmente existen empresas que por un pago anual dan acceso a una variedad de titulos especializados en diferentes areas.

March 8, 2011 • Like

Cristina Sierra Casanova - Me parace buena idea el contratar un servicio especializado de bibliografias de referencia como recursos complementarios a los contenidos e leraning pero no obstante habria siempre que hacer la selección más adecuada a la acción formativa que se imparte on line. No solo habria que incluir bibliografias, sino tambien vidotecas, articulos

March 10,2011 • Like $\cdot$ Reply privately $\cdot$ Flag as inappropriate

Francisco Lamamie de Clairac Palarea - Hola Karla,

Gracias a ti. El modelo de tres elementos: tecnología / contenido y pedagogia da mucho de si, no sólo como estructura para pensar el elearning. sino porque ayuda a entender que necesitamos un trabajo de equipo, de mentes conectadas en el fin educativo Sabiendo que podemos tener varias disciplinas y tareas tecnológicas, de contenido y pedagógicas se puede hacer más y mejor eleraning.

May 19, 2011 • Like • Reply privately • Flag as inappropriate

Figura 30. Grupo de Discusión Clay Construyendo eLearning. Linkedin. http://www.linkedin.com

Los resultados de las reacciones en los tres grupos de discusión, permitió identificar las siguientes tres grupos de reacciones:

\footnotetext{
${ }^{109}$ Discusión generada en los grupos de trabajos de Linkedin. Véase: e-Learning Latino; Latin Ameriica e-Learning Professionals Network (Educación a Distancia) y Work Literacy/E-Learning Guild: Web 2.0 for Learning Professionals.
} 
1. El primero grupo que considera la partición de la biblioteca es necesaria e importante para el proceso enseñanza aprendizaje electrónico. Este grupo destaca en rol de la biblioteca como apoyo a la actividad y formación docente y como facilitadora de información en todo el ciclo del proceso de aprendizaje.

2. Un segundo grupo manifestó que nunca antes habían pensado o supuesto que la biblioteca pudiera ejercer algún rol dentro de procesos E-learning

3. El tercer grupo expresa que la biblioteca debería tener un rol más activo en la educación en línea a través de sus servicios. Se destacan como ejemplo el manejo y gestión de los puntos de acceso a la información electrónica acorde a los programas educativos de las diferentes modalidades de educación. Aunque este grupo reconoce la importancia de la participación de la biblioteca en el E-learning, no comparte la idea que la biblioteca pueda participar como actora de procesos de enseñanzaaprendizaje (a nivel docencia). Para algunos "el del cómo utilizar la información" es un asunto que el docente debe enseñar a sus alumnos.

Las anteriores reacciones evidencian la existencia de poca claridad sobre la participación de la biblioteca en el proceso educativo, así como cierto temor a que la biblioteca asuma roles que les corresponde a los docentes. Aunque estos juicios pueden ser comprensibles, no son justificables, debido a que se trata de dos enfoques diferentes que seguidamente se exponen.

Biblioteca

Docente como formador
Promueve el aprendizaje por parte del estudiantes o usuarios de cómo buscar, recuperar y utilizar la información (formación de habilidades y competencias informacionales)

Orienta el aprendizaje del uso y aplicación del conocimiento contenido en las fuentes de información para generar o modificar el estado de conocimiento del individuo.

En definitiva la participación de la biblioteca en procesos E-learning pretende ser un medio de apoyo en los procesos de educación. Mediante la oferta y prestación de sus servicios de información persigue facilitar el proceso de generación y transferencia de conocimiento. En esta línea la propuesta de modelo de servicio resultante de esta tesis puede ser aplicada en los siguientes contextos:

a) Un puente entre los servicios de las bibliotecas y el E-learning, con el fin de incrementar la calidad y autenticidad de los contenidos de la educación E-learning.

b) Un servicio básico e integral de apoyo a proceso de enseñanza electrónica, que estimule el interés tanto del instructor como del estudiante E-learning a hacer uso de los servicios digitales de información disponible en la biblioteca como un medio para fomentar actitudes de investigación.

c) Una práctica simbiótica para instalar nuevas aplicaciones organizativas y tecnológicas entre las plataformas de E-learning que vincule a la biblioteca como entidad dinámica de apoyo para E-learning y punto de partida para el acercamiento al conjunto de experiencias de trabajo mixtos. 


\subsubsection{Propuesta de modelo de servicio de la biblioteca para E-learning}

El punto de partida para el diseño del modelo de oferta de servicio, corresponde a la ciencia sistémica y la ciencia de la información. La primera atribuye al modelo una función complementaria en el proceso de transferencia de información y conocimiento y por ende la posibilidad de establecer sinergias con el E-learning. En el mismo nivel de importancia, el modelo se vale de la ciencia de la información, para orientar la organización y difusión del conocimiento mediante servicios de información.

La viabilidad de integrar la propuesta del modelo de oferta de servicio para E-learning, también se justifica en el hecho que en la actualidad las bibliotecas participan en forma indirecta en actividades E-learning. Ejemplo concretos son los cursos de Alfabetización informacional, la gestión de tutoriales y el acceso a publicaciones electrónicas.

Asimismo, en la presencia de un módulo denominado "biblioteca" de las plataformas E-learning para para la gestión de materiales didácticos, que resulta no ser suficiente para completar la información necesaria. Generándose de esta manera la demanda por parte de E-learning del uso de los recursos información disponible en la biblioteca.

En esencia, el modelo propuesto en esta tesis es una oferta de servicio integradora que tiene como fin responder de forma efectiva y eficaz a la demanda de la instalación de tres actuales servicios de información ofrecidos por las bibliotecas académicas, para brindar apoyo a la docencia e investigación; de tal forma que estos sean accesibles desde las plataformas E-learning, ya sea como un módulo o como un enlace.

\subsubsection{Estructura del modelo}

La oferta del modelo de servicio propuesto es orientada a actividades de enseñanza electrónica, hecho por el cual, la estructura del modelo se constituye del concepto tridimensional basada en los componentes usuarios-contenido-tecnología del E-learning ${ }^{110}$, y que a su vez interactúan como estructura, proceso y medio. Es decir, el servicio debe ser visto como un medio de apoyo para la formación y conocimientos a distancia.

La estructura del modelo se constituye del servicio de referencia digital, el servicio de alfabetización informacional y el servicio de acceso a los repositorios para la educación. Desde un enfoque sistémico el servicio de referencia digital debe ser visto como la entrada al sistema donde el usuario aclara dudas e identificar el rumbo de búsqueda. Los cursos de formación de habilidades y destrezas (ALFIN) representan ser el medio del sistema que permite a los estudiantes entender y aprender el uso del sistema recursos y el servicio de acceso a los repositorios debe ser entendido como un componente de la salida y retroalimentación del sistema, por cuanto el acceso y uso de la información genera nuevos conocimientos. En la actualidad estos servicios ya existen y en algunos casos son ofrecidos por la biblioteca las 24 horas del día a través de internet o intranet.

\footnotetext{
${ }^{110}$ Marc J. Rosenberg (2001) Véase apartado 3.2 Definición de enseñanza electrónica (E-learning).
} 
En la siguiente ilustración es notable que cada servicio responda a determinados objetivos específicos, sin embargo, en la estructura del modelo ocupan un mismo nivel de importancia y posición jerárquica. Asimismo es importante señalar que la funcionalidad de los servicios como unidad, resulta ser suficiente para generar un único servicio de transferencia dle conocimiento para fines educativos.

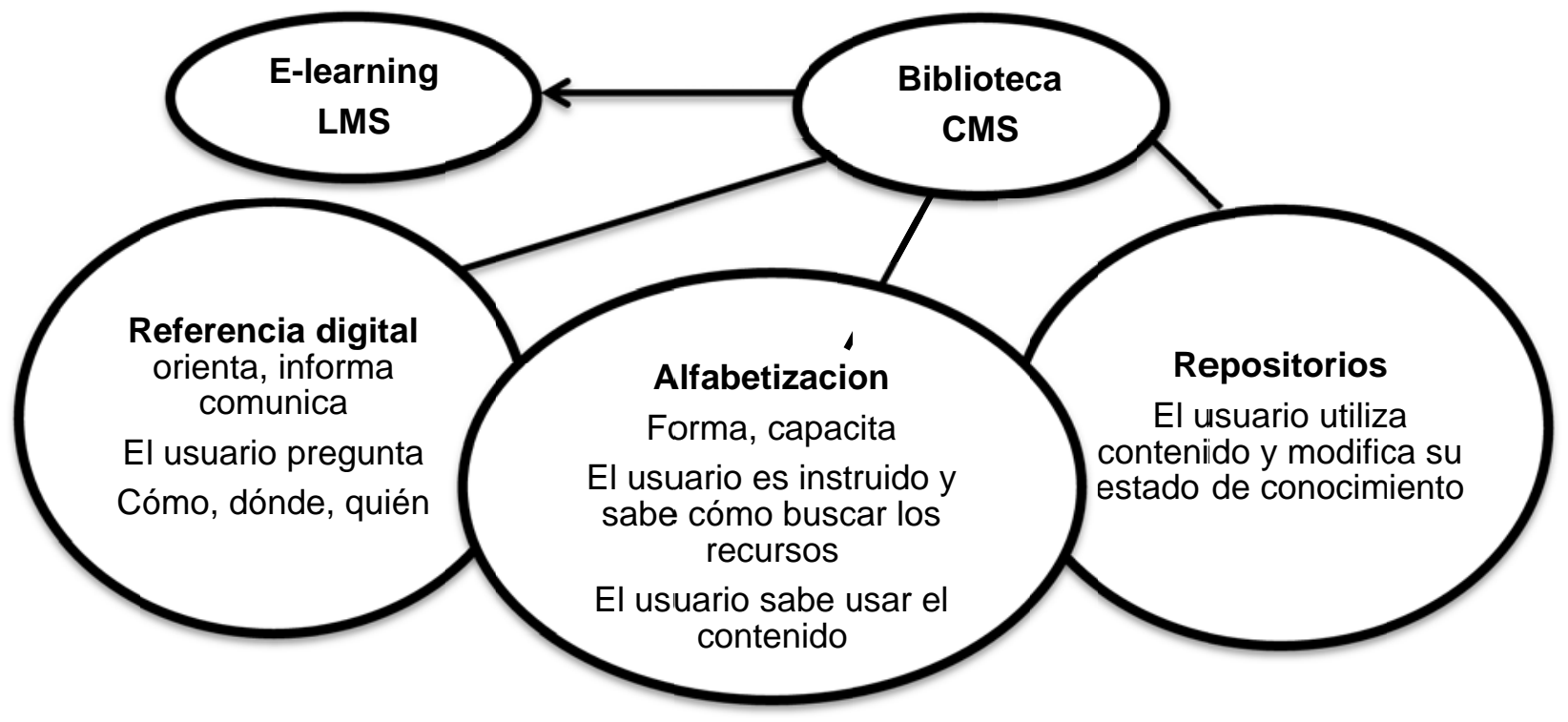

Figura 31. Representación de la estructura del modelo y cohesión con el E-learning. Fuente: Elaboración propia.

En la práctica la visualización de la oferta de "servicio de la biblioteca para E-learning" ocurre desde la plataforma E-learning (LMS / LCMS) ya sea en forma de un ícono, lema o término que permita el enlace directo al servicio. Es decir desde la plataforma E-learning, el enlace asegura el acceso al servidor donde se encuentra instalado el servicio. Esta sinergia como se ilustra a continuación ocurre sin problema técnicos, debido a que por la flexibilidad de las plataforma E-learning, estas pueden interoperar con el sistema de manejo de contenido de la biblioteca (CMS).

Sistema de gestión de datos de la Biblioteca (CMS) Oferta de servicio integrado y especializado

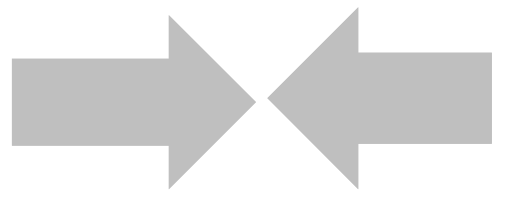

Plataforma E-learning (LMS/ LCMS)

Accede al servicio para la enseñanza y estimular generación de conocimiento 


\subsubsection{Usuarios del modelo}

El usuario o estudiantes a que está dirigido el modelo de servicio aquí descrito, corresponde en gran medida a estudiantes de las modalidades de enseñanza semipresencial y E-learning. Ellos determinan en gran medida, la estructura y característica de los contenidos educativos, las aplicaciones tecnológicas y métodos didácticos. En dependencia de la tipología de usuarios y sus necesidades.

En el contexto del modelo de servicio y tomando como referencia los grupos de usuarios caracterizados en el capítulo 2.2 y 3.2., es posible tipificar dos grupos potenciales de usuarios:

a) Usuarios físicos: aquellos que además de seguir un curso virtual, pueden hacer uso de las instalaciones de la biblioteca.

b) Usuarios virtuales: aquellos que hacen uso de los recursos y de los servicios de forma meramente virtual.

En esta línea Enric Mor, Muriel Garreta, Maria Galofré 2007,p. $3^{111}$ destacan el éxito de un servicio de formación en línea, está directamente relacionado con la experiencia de los usuarios o estudiante con la usabilidad de los módulos y servicios para la satisfacción de sus necesidades, así mismo los Enric Mor y Muriel Galofré destacan que en dependencia de las características de los usuarios, son delimitados los niveles de contenidos y las condiciones de acceso a la información (administrativa, didáctica, técnica y científica, complementaria, productos concretos) y la orientación personalizada en línea.

De lo anterior se destaca la necesidad de establecer una relación condicionada entre los usuarios, el contenido y las aplicaciones del E-learning en relación a los de la biblioteca. Es decir garantizar que los tres servicios que forman parte del modelo, puedan ser utilizadas por los usuarios para acceder a la información adecuada de acuerdo su nivel y necesidades. Dependiendo de la armonía o posible desconexión de los componentes (usuario-contenido- tecnología), y los elementos que conforman la oferta de servicio (referencia digital - Alfabetización informacional y el acceso a los repositorios), el impacto del modelo, puede presentar efectos positivos o negativos dentro del sistema E-learning y su entorno.

\subsubsection{Aplicación del modelo}

La interacción del sistema de contenido de la biblioteca (CMS) y el sistema de gestión de recursos para el aprendizaje ( LMS y LCMS) del E-learning puede estar orientada a incrementar la calidad y autenticidad de los contenidos de la educación.

Asimismo la presencia del modelo de servicio en la plataforma E-learning, ofrece al docente y estudiante las condiciones para acceder a la información necesaria, confiable, actualizada para el desarrollo de sus cursos. Desde un enfoque amplio la funcionalidad del modelo puede ser vista en dos líneas:

a) Primero como un recurso de apoyo a las actividades de enseñanza electrónica. En este sentido los servicios definidos como elementos básicos del sistema, se organizan alrededor de la temática del o

\footnotetext{
${ }^{111}$ Enric Mor, Muriel Garreta, Maria Galofré. Diseño Centrado en el Usuario en Entornos Virtuales de Aprendizaje, de la Usabilidad a la Experiencia del Estudiante. Disponible en http://spdece07.ehu.es/actas/Mor.pdf.
} 
de los cursos y en correspondencia de las características de los estudiantes o usuarios. Asimismo en dependencia de los contenidos y los usuarios se delimita el acceso a los recursos y aplicaciones tecnológicas. El objetivo principal de esta aplicación del servicio, se limita a facilitar, orientar e instruir sobre la disponibilidad de los recursos y garantizar el acceso a las fuentes de información. Ejemplos de las facilidades que ofrece esta aplicación son:

- Búsquedas especializadas (diseminación selectiva de información)

- Elaboración de bibliografías

- Elaboración tutoriales (también asesoría de cómo hacerlos)

- Acceso a metadatos

- Acceso a colecciones de revistas electrónicas

- Acceso a E-documentos

- Acceso a E-libros

b) La segunda aplicación que puede tener e modelo dentro del E-learning es la de una función proactiva. Es decir, la biblioteca a través del modelo puede dictar cursos desde las plataformas Elearning orientados a la instrucción de usuarios hacia el desarrollo de cursos de formación de habilidades y destrezas para los estudiantes del E-learning en sus diferentes categorías y necesidades. El beneficio de esta aplicación garantiza que estos estudiantes puedan alcanzar un nivel de conocimiento que les permita buscar la información necesaria, citar adecuadamente las fuentes, solicitar los servicios en línea dentro y fuera de la plataforma E-learning y la adquisición de valores éticos en relación al uso de la información. Ejemplos de estos son:

- Cursos de formación en el uso de los programas informáticos y el uso de los recursos telemáticos.

- Cursos de formación en el uso adecuado y ético de la información, que implica todo el proceso de transferencia de la información (buscar, localizar, recuperar, utilizar, citar y publicar).

Las dos posibles aplicaciones del modelo no exige la presencia obligatoria del modelo en la plataforma E-learning, sin embargo las practicas identificadas demuestran el servicio de ALFIN es ofrecido por algunas universidades desde programas LCMS y LMS como Moodle en Blackboard.

Finalmente para complementar lo antes referido, se presenta a continuación el capítulo 7 que contiene un análisis evaluativo de los tres servicios que integran el modelo en ocho entidades académicas ubicadas en Europa y Latinoamérica, que demuestra la viabilidad de la implementación del modelo a partir de las prácticas de servicios ya existentes. 


\section{Capítulo 7. Estudio de casos}

\subsection{Introducción}

En las páginas anteriores se han abordado aspectos teóricos de E-learning y presentado un análisis de los modelos de bibliotecas, señalando las nuevas capacidades tecnológicas de las bibliotecas para la prestación de servicios que permitan a los usuarios converger en un mundo físico virtual a fin de satisfacer sus necesidades de información. Del mismo modo, se han señalado algunos puntos de coincidencia entre los modelos de bibliotecas con los modelos de E-learning. Asimismo, se ha presentado una propuesta de modelo de oferta de servicio para E-learning.

Con el objetivo de sustentar el corpus teórico reflejado en los anteriores apartados y a fin de demostrar la validez de la propuesta del modelo de prestación de servicio en línea, el siguiente capítulo refleja un estudio de casos que recoge la experiencias prácticas de aplicaciones tecnológicas de seis bibliotecas universitarias, con repetitividad en los ranking web para universidades y para repositorios DOAR y ROAR. Las bibliotecas analizadas se ubican en los países de España, Países Bajos, Chile y Costa Rica. A partir de los resultados obtenidos del análisis de las instituciones, fue posible evidenciar la existencia de diferentes formas de participación de la biblioteca en procesos E-learning.

Para la ejecución del estudio de caso utilizó la metodología de análisis diseñada por Robert K. Yin (2009, p.20-81) que se ilustra a continuación y posteriormente se explica.

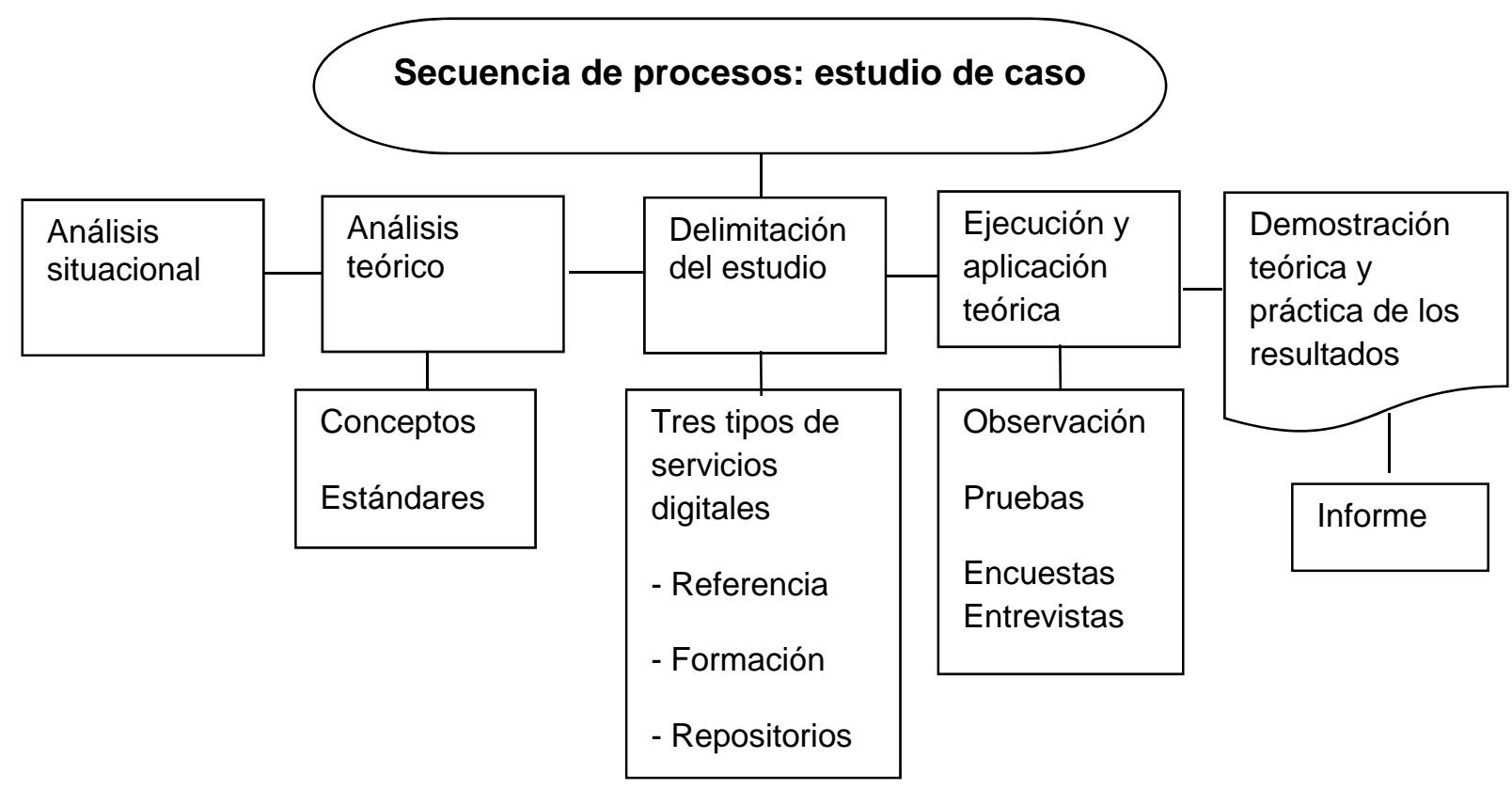

Figura 33. Esquema metodológico para estudios de casos. Fuente: Elaboración propia

Del esquema metodológico de Robert K. Yin, fue retomado el enfoque sistémico y lineal para la ejecución del estudio, el cual tiene su punto de partida en el análisis situacional, continúa con la delimitación del estudio, la aplicación teórica y el desarrollo y demostración de nuevos aportes teóricos. 
La aplicación de esta metodología para fines de esta tesis, implicó la siguiente secuencia lógica en el desarrollo del estudio de caso.

1. Análisis situacional. Fueron analizadas las capacidades y características de las posibles instituciones a considerar muestra en el estudio.

2. Análisis teórico. Los aspectos teóricos y metodológicos descritos en los capítulos anteriores a la tesis fueron retomados como marco de referencia para la ejecución del estudio de caso.

3. Delimitación del estudio. En correspondencia a los objetivos planteados, fue definido el alcance y nivel de aplicación de la guía metodológica diseñada para evaluación de servicios en línea de tres tipos de servicios digitales.

4. Ejecución y aplicación teórica. La descripción de cada uno de los servicios y el análisis de funcionamiento de estas prácticas implicaron el uso de la guía metodológica resultante en esta tesis para evaluar servicios en línea. Asimismo, fueron tomados en consideración los aportes teóricos referentes estándares como un marco de referencia para la selección y elaboración de técnicas e instrumentos para la recopilación de información. El estudio de casos se inició con un análisis descriptivo e individual de cada una de las universidades y de las bibliotecas involucradas. Posteriormente fue realizado el análisis comparativo de las seis bibliotecas estudiadas.

5. Demostración teórica y práctica de los resultados. Finalmente los datos obtenidos fueron analizados, organizados e incluidos en el presente capítulo.

\section{2 Ámbitos geográficos de la investigación}

En el periodo entre 1994 y $1995^{112}$ la doctoranda proveniente de Nicaragua efectuó estudios de tercer ciclo en la Universidad Autónoma de Madrid. La finalización de este periodo académico se materializó en un estudio comparativo de los sistemas de automatización de bibliotecas, casos específicos de universidades de españolas y Nicaragua. El estudio reflejó diferencias significativas en el diseño de los sistemas, por cuanto en España se utilizaba sistemas modulares y en Nicaragua mayormente la versión de Micro Isis que en ese entonces era incipiente. Otra diferencia era que en España (por no decir en toda Europa) la infraestructura tecnológica está mucho más avanzada, lo cual permitió desarrollar iniciativas de trabajo en redes y la conexión en línea.

Retomando como punto de referencia el antecedente anterior y considerando que la doctoranda desarrolla su actividad profesional con residencia en los Países Bajos se ha definido como universo para la investigación la región Europa y América Latina. La cercanía y vinculo establecidos por la doctoranda de las dos regiones facilitan en primer instancia la ejecución del estudio. Asimismo, la delimitación del estudio en estas dos regiones tiene como fin lograr un acercamiento a dos realidades marcadas por las diferencias económicas, tecnológicas y socioculturales.

Considerando la existencia de una gran cantidad de bibliotecas universitarias, tanto en la región de Europa y América Latina, para la selección de la muestra fueron aplicados una serie de criterios y

\footnotetext{
${ }^{112}$ Desarrollo de la automatización en las unidades de información: Estudios de casos de Nicaragua y España Bonilla, Karla Vanessa Bonilla En Revista AIBDA. Ene-jun 1995. V. 16(1) p. 35-48. Turrialba, Costa Rica. 1995.
} 
parámetros que permitieron orientar la formación de un muestra ejemplificativa para demostrar la funcionalidad del modelo.

Durante la revisión de las capacidades y disponibilidad de servicios de posibles instituciones a considerar en el estudio de caso, fue posible identificar diferentes escenarios en relación a la infraestructura tecnológica, disponibilidad y/o limitación económica para el desarrollo de proyectos, variedad de oferta de servicios digitales, disponibilidad de repositorios, y entorno sociocultural. La identificación de los escenarios también se sustenta en la revisión de documentos incluidos en literatura adjunta en el presente documento.

Un ejemplo concreto que conviene mencionar es el aporte de Silva Sunyer $(2006)^{113}$, quien apunta al diseño de servicios bibliotecarios en línea para una Europa basada en el conocimiento y el informe del congreso centroamericano $(2006)^{114}$ que ofrece una visión del estado de los servicios en la región.

\begin{tabular}{|c|c|c|}
\hline Escenarios & Europa & América latina \\
\hline $\begin{array}{l}\text { Servicios digitales } \\
\text { Los servicios digitales de las } \\
\text { bibliotecas en Europa y en } \\
\text { algunos países de América } \\
\text { Latina se desarrollan } \\
\text { significativamente de forma } \\
\text { eficiente y eficaz al punto que } \\
\text { se expanden a nuevos } \\
\text { mercados como E-learning. }\end{array}$ & $\begin{array}{l}\text { 1.Las bibliotecas académicas en } \\
\text { Europa ofrecen diferentes } \\
\text { servicios a través de Intranet e } \\
\text { Internet en las siguientes cinco } \\
\text { líneas: } \\
\text { * El acceso al catálogo } \\
\text { * Servicio de Referencia digital } \\
\text { sincrónica y asincrónica } \\
\text { * Servicios administrativos } \\
\text { (reservas, renovación, etc.) } \\
\text { * Acceso a los recursos y } \\
\text { fuentes de información } \\
\text { electrónicas } \\
\text { * Acceso a repositorios y } \\
\text { fuentes internas y externas } \\
\text { 2. Existe una fuerte demanda } \\
\text { de servicios digitales que } \\
\text { motiva a los gobiernos de la } \\
\text { región a invertir en proyectos } \\
\text { de innovación tecnológica. }\end{array}$ & $\begin{array}{l}\text { 1.En América latina existen } \\
\text { iniciativas de servicios a través } \\
\text { de Intranet e Internet en las } \\
\text { siguientes cinco líneas: } \\
\text { * El acceso al catálogo } \\
\text { * Servicio de Referencia digital } \\
\text { asincrónica } \\
\text { * Servicios administrativos } \\
\text { (reservas, renovación, etc.) en } \\
\text { horas laborables } \\
\text { * Acceso a los recursos y } \\
\text { fuentes de información } \\
\text { electrónicas } \\
\text { * Acceso a repositorios y } \\
\text { fuentes externas } \\
\text { 2. Los servicios digitales son } \\
\text { dependientes de recursos } \\
\text { electrónicos y repositorios } \\
\text { externos, debido a que las } \\
\text { iniciativas nacionales son } \\
\text { pocas. }\end{array}$ \\
\hline
\end{tabular}

\footnotetext{
${ }^{113}$ Centros de Recursos para el Aprendizaje y la Investigación (CRAI), y servicios bibliotecarios estratégicos para una Europa basada en el conocimiento. p. 327-337. Disponible en Pdf en: http://redalyc.uaemex.mx/pdf/549/54920401.pdf.

${ }^{114}$ Uso potencial de las nuevas tecnologías para la transferencia de información y comunicación (ICT) en el proceso de modernización de las bibliotecas Centroamericanas. Disponible: http://igitur-archive.library.uu.nl/DARLIN/2007-0301200927/memoria.pdf.
} 


\begin{tabular}{|c|c|c|}
\hline Escenarios & Europa & América latina \\
\hline $\begin{array}{l}\text { Repositorios } \\
\text { Existe una fuerte tendencia al } \\
\text { desarrollo de proyectos de } \\
\text { digitalización de los recursos } \\
\text { informativos de las bibliotecas, } \\
\text { a fin de ofrecer el acceso de } \\
\text { estos en formato digital. Estas } \\
\text { iniciativas ocurren mayormente } \\
\text { en entidades vinculadas con la } \\
\text { procesos educativos y de e } \\
\text { investigación. }\end{array}$ & $\begin{array}{l}\text { 1. Las universidades en Europa } \\
\text { se han organizado por país para } \\
\text { la creación de repositorios } \\
\text { académicos nacionales. } \\
\text { 2. Actualmente existe una } \\
\text { iniciativa regional a nivel de } \\
\text { Europa. }\end{array}$ & $\begin{array}{l}\text { 1. Algunos proyectos } \\
\text { institucionales, reconocidos a } \\
\text { nivel nacional no son } \\
\text { identificadas a nivel } \\
\text { internacional } \\
\text { 2. Existen algunas iniciativas de } \\
\text { redes de cooperación a nivel de } \\
\text { país y región para la creación } \\
\text { de un repositorio académico. }\end{array}$ \\
\hline $\begin{array}{l}\text { Aspectos económicos } \\
\text { La crisis económica mundial } \\
\text { impacta negativamente en las } \\
\text { iniciativas de desarrollo de } \\
\text { proyectos de transferencia de } \\
\text { información nacionales e } \\
\text { internacionales, hecho por la } \\
\text { cual el financiamiento a } \\
\text { iniciativas de servicios de } \\
\text { información digital se ven } \\
\text { limitados. }\end{array}$ & $\begin{array}{l}\text { 1. En Europa se han realizado } \\
\text { ajuste en los presupuestos de } \\
\text { las bibliotecas universitarias, no } \\
\text { obstante los proyectos de } \\
\text { servicios digitales continúan } \\
\text { siendo prioridad. } \\
\text { 2. El trabajo en cooperación a } \\
\text { nivel nacional y regional genera } \\
\text { oportunidades de acceso a los } \\
\text { recursos de información. }\end{array}$ & $\begin{array}{l}\text { 1. Se carece de presupuestos } \\
\text { para la implementación de } \\
\text { iniciativas de proyectos de } \\
\text { modernización } \\
\text { (mejoramiento) de la } \\
\text { infraestructura tecnológica y } \\
\text { por ende el desarrollo de } \\
\text { proyectos locales de } \\
\text { digitalización al acceso de } \\
\text { recursos externos. } \\
\text { 2. Las limitaciones económicas } \\
\text { para el acceso a repositorios } \\
\text { externos son resueltas en su } \\
\text { mayor parte, mediante } \\
\text { iniciativas nacionales y } \\
\text { regionales de proyectos de } \\
\text { cooperación para el acceso } \\
\text { libre de la información. }\end{array}$ \\
\hline $\begin{array}{l}\text { Aspectos tecnológicos } \\
\text { El desarrollo en la } \\
\text { infraestructura tecnológica en } \\
\text { América latina camina } \\
\text { aproximadamente cinco años } \\
\text { atrás en relación a Europa. } \\
\text { Estas diferencias están } \\
\text { marcadas por los factores } \\
\text { meramente económicos, } \\
\text { políticos y socioculturales. }\end{array}$ & $\begin{array}{l}\text { Los proyectos de } \\
\text { modernización y/o } \\
\text { mejoramiento de la } \\
\text { infraestructura tecnológica en } \\
\text { Europa es una inversión por } \\
\text { parte de todas las } \\
\text { Universidades, por cuanto } \\
\text { representa el soporte para los } \\
\text { procesos para la gestión } \\
\text { académicos, la comunicación, } \\
\text { transferencia de conocimiento } \\
\text { e información. }\end{array}$ & $\begin{array}{l}\text { Se carece de recursos } \\
\text { económicos y de una } \\
\text { adecuada infraestructura } \\
\text { tecnológica a nivel de la } \\
\text { región, que permita la } \\
\text { implementación de proyectos } \\
\text { de modernización y/o } \\
\text { mejoramiento de las } \\
\text { condiciones tecnológicas, el } \\
\text { desarrollo de servicios } \\
\text { digitales y el mejoramiento al } \\
\text { acceso a recursos externos. }\end{array}$ \\
\hline
\end{tabular}




\begin{tabular}{|c|c|c|}
\hline Escenarios & Europa & América latina \\
\hline Aspectos socioculturales & $\begin{array}{l}\text { El desarrollo sociocultural de } \\
\text { los países se ve estimulado a } \\
\text { través de las iniciativas de } \\
\text { acceso abierto (Open Access) a } \\
\text { los repositorios que hacen } \\
\text { posible la democratización de } \\
\text { la información. }\end{array}$ & $\begin{array}{l}\text { Las limitaciones en la } \\
\text { infraestructura tecnológica } \\
\text { limitan la participación total } \\
\text { de estos países en proyectos } \\
\text { de cooperación de Open } \\
\text { Access y por ende el } \\
\text { beneficiarse de ellos. }\end{array}$ \\
\hline
\end{tabular}

Tabla 26. Escenarios identificados previos al estudio de casos.

Fuente: Elaboración propia.

\subsection{Fases y parámetros considerados para el estudio de casos}

Las aplicaciones tecnológicas y el uso de social media en las bibliotecas académicas se desarrollan de forma diversa y en diferentes escalas. Aunque se identificaron aplicaciones con objetivos y grupos de usuarios comunes, estas se diferencian unas de otras en las formas y dinámica en que se presentan los servicios. Dada la diversidad de experiencias fue necesario delimitar el estudio de casos a una muestra compuesta por seis bibliotecas universitarias con servicios visibles y accesibles en Internet. Para la búsqueda e identificación de las instituciones, se definieron un conjunto de criterios que facilitaron la selección y el logro de los objetivos planteados.

\section{Fases definidas}

\section{Fase 1. Alcance conceptual}

El estudio no estableció diferencias conceptuales entre servicios de información virtuales, servicios en línea y los servicios digitales proporcionados a través de una conexión de Internet y/o intranet. Se parte de servicios telemáticos como servicios ofrecidos en línea, desde cualquier tipo de red. Las universidades ofrecen una serie de servicios a sus usuarios de forma no presencial, remota, a través de redes. El carácter telemático de los servicios ha sido el elemento tenido en cuenta para la selección y análisis de dichos servicios.

\section{Fase 2. Delimitación de grupos de servicios}

Se consideraron importantes todos aquellos servicios ofrecidos por la biblioteca a través de Internet e intranet y que son distinguidos de los servicios tradicionales, por la atribución de la denominación calificativa de virtuales, en línea y digitales, que por sus características pueden ser de apoyo en procesos E-learning. Los servicios considerados para el estudio de caso se describen a continuación:

\section{a. Referencia digital}

Entendido como el punto de partida, a través del cual el usuario se involucra de forma directa con los diferentes servicios de información en línea. En capítulos precedentes se delimitó el concepto de referencia digital, pero se parte de aquellos 
servicios en los que lo usuario puede realizar una consulta a la biblioteca de forma remota, empleando redes. Se destacaron dos tipos de servicios de referencia:

- Servicio de referencia sincrónico en tiempo real que implica procesos de comunicación cara a cara (face to face) y un acompañamiento virtual.

- Servicio de referencia asincrónico o meramente digital con un tiempo de respuesta variado. Dentro de esta tipología encontramos los siguientes modelos:

a.1 Respuestas automáticas

a.2 Respuestas monitorizadas

a.3 Respuestas automáticas y monitoreadas. En este tipo de servicio pueden ocurrir procesos combinados sincrónicosasincrónicos

\section{b. Alfabetización informacional}

Definido como el proceso de enseñanza que se dirige al desarrollo de habilidades en los usuarios, para que sean capacer de buscar, identificar, seleccionar y utilizar de forma crítica la información necesaria para satisfacer sus necesidades de información; se estructura preferentemente en los siguientes dos tipos:

b.1 Alfabetización informática o digital. Se orienta al uso de los medios tecnológicos en general, es decir programas, equipos informáticos (hardware y software). Su objetivo principal apunta al desarrollo de habilidades y capacidades en el individuo, específicamente en el uso de los equipos y programas informáticos.

b.2 Alfabetización informacional. Se engloba el aprendizaje de técnicas y métodos para el desarrollo de habilidades y capacidades que garantizan un uso eficiente de los recursos de información y el uso de la biblioteca misma para el logro de objetivos concretos.

\section{c. Repositorios para la educación}

La creación, mantenimiento y acceso a los repositorios para la educación debe ser entendido como la concentración de información especializada y diversa que se encuentra debidamente organizada que responde a objetivos educativos concretos. Desde un punto de vista conceptual, pero también operativo, se entenderán como repositorios educacionales, a los efectos de esta tipo, las colecciones de recursos informativos que las bibliotecas ofrecen a sus usuarios de forma telemática mediante plataformas normalizadas: acceso abierto, metadatos, estructura de contenidos, etc. 


\section{Fase 3. Límites de la evaluación}

El estudio se centró esencialmente en la caracterización de los servicios en línea y en la búsqueda de la correspondencia entre la relación oferta-demanda y no a la relación costo-beneficio. Se tienen en cuenta los parámetros que se explican en la fase cinco.

\section{Fase 4. Enfoque de la evaluación}

Para delimitar el enfoque del análisis se determinaron como ejes centrales o como áreas de acción los siguientes: el usuario, el contenido y el diseño de la web. Desde una perspectiva sistémica para cada una de las áreas analizadas, se prestó además atención a los siguientes aspectos:

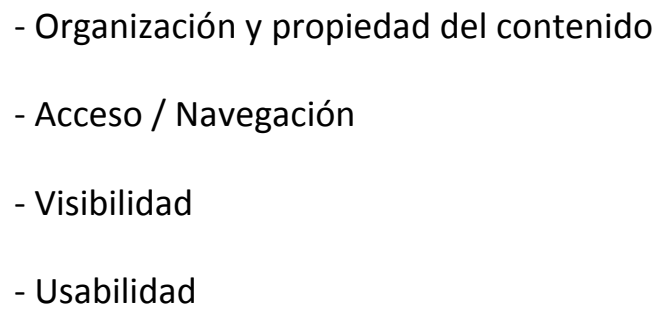

\section{Fase 5. Parámetros para la evaluación}

Fueron utilizados los diez parámetros anteriormente reflejados en la propuesta metodológica para la caracterización y organización de los servicios.

1. Identidad

2. Actualización

3. Accesibilidad

4. Servicios básicos de la web
Orienta la identificación oficial de la institución sujeta al estudio.

Permite medir la actualidad de los datos ofrecidos en el sitio web de la institución y vigencia de los enlaces

Implica la revisión de aspectos de conexión navegación, la facilidad de localización y acceso a los contenidos por personas sin ó con incapacidad visual, auditiva o física. Así el cumplimientos de normativa WAI.(Web Accesibility Initiative del consorcio Wide World Web (w3c)

Orienta la identificación de servicios estándares considerados básicos en la Web, tales como directorio de recursos, comunidades virtuales, espacios personalizados, novedades, recursos meta datos basados en el uso de la Web, portales, servicio de orientación y mecanismos de comunicación como correo electrónico, servicios de chat, video conferencias, etc. 
5. Contenido

\section{Arquitectura de la información}

\section{Diseño de la interfaz}

\section{Posicionamiento}

\section{Sistema de búsqueda y recuperación}

\section{Usabilidad}

Conlleva el análisis del contenido del sitio o servicio. Percibe la medición del grado de adecuación entre la autoría y la agenda temática; el reconocimiento y credibilidad de la fuente; la conexión entre los contenidos y las referencias bibliográficas a través de uso de estándar Digital Object Identifier $=\mathrm{DOI}$ usado por editoriales técnicas y científicas y la presencia de indicaciones que orienten al usuario dónde y en que sección se encuentra.

Sitúa la revisión de la jerarquización de los contenidos, es decir la indicación directa o indirecta de la importancia relativa de las secciones o la información contenido en la Web, la existencia de rutas de navegación, enlaces que facilitan y agilizan la búsqueda interna de información en el sitio.

Dirige la evolución a los aspectos físicos y ergonómicos del sitio desde donde es ofrecido el servicio. Aspectos del diseño de la interfaz son: consistencia y contraste en el uso de colores, homogeneidad de estilos, tipo de letras, tamaño de letras, líneas de texto, anchura de pantalla, márgenes, entre otros.

Se refieren a la identificación del servicio de la biblioteca en el sitio principal de la institución y su localización desde cualquier buscador en Internet.

Apunta a la verificación de la existencia de puntos de acceso y recuperación de datos y forma de presentación de los contenidos; en este parámetro se refiere al cuido de la semántica de los metadatos.

La aplicación del parámetro usabilidad, implica la revisión del grado de flexibilidad ofrecido por el servicio para copiar, pegar información; asimismo la medición del tiempo de inversión en búsqueda y uso; número de errores cometidos. Un aspecto fundamental en la medición de la usabilidad del servicio corresponde a la satisfacción el usuarios y la posibilidad de reutilizar la información

La aplicación de los anteriores parámetros en cada uno de los tres servicios experimentó variantes en dependencia de las características propias del servicio. En algunos casos no fueron aplicados todos los parámetros, ya que no era posible por el tipo de indicador en relación al tipo de servicio. Otra variante esencial correspondió al uso de diferentes indicadores, ajustables a cada situación. Caso concreto es el servicio de acceso a los repositorios educacionales. En este servicio no son aplicables 
los parámetros de arquitectura de la información y servicios básicos. En la siguiente tabla se muestra la aplicación de los parámetros de evaluación en los servicios analizados en el estudio de caso.

\begin{tabular}{|l|c|c|c|}
\hline \multicolumn{4}{|c|}{ Aplicación de parámetros en cada servicio evaluado } \\
\hline Parámetros & $\begin{array}{c}\text { Servicio de referencia } \\
\text { digital }\end{array}$ & $\begin{array}{c}\text { Alfabetización } \\
\text { informacional }\end{array}$ & $\begin{array}{c}\text { Repositorios } \\
\text { nacionales }\end{array}$ \\
\hline 1. Identidad & $\mathrm{X}$ & $\mathrm{X}$ & $\mathrm{X}$ \\
\hline 2. Actualización & $\mathrm{X}$ & $\mathrm{X}$ & $\mathrm{X}$ \\
\hline 3. Accesibilidad & $\mathrm{X}$ & $\mathrm{X}$ & $\mathrm{X}$ \\
\hline $\begin{array}{l}\text { 4. Servicios básicos de la } \\
\text { web }\end{array}$ & $\mathrm{X}$ & $\mathrm{X}$ & $\mathrm{NO}$ \\
\hline 5. Contenido & $\mathrm{X}$ & $\mathrm{X}$ & $\mathrm{X}$ \\
\hline $\begin{array}{l}\text { 6. Arquitectura de la } \\
\text { información }\end{array}$ & $\mathrm{X}$ & $\mathrm{X}$ & $\mathrm{X}$ \\
\hline 7. Diseño de la interfaz & $\mathrm{X}$ & $\mathrm{X}$ & $\mathrm{X}$ \\
\hline 8. Posicionamiento & $\mathrm{X}$ & $\mathrm{X}$ & $\mathrm{X}$ \\
\hline 9. Sistemas de búsqueda & $\mathrm{X}$ & $\mathrm{X}$ & $\mathrm{X}$ \\
\hline 10. Usabilidad & $\mathrm{X}$ & \\
\hline
\end{tabular}

Tabla 27. Aplicación de parámetros en los servicios evaluados.

Fuente: Elaboración propia

\section{Fase 6. Selección de servicios digitales}

La selección de los tres tipos de servicios anteriormente indicados en la Fase 2 ha sido intencionada, partiendo de bibliotecas que prestan los servicios que se querían evaluar y que disponen de plataformas de enseñanza en línea. Una de las razones corresponde al hecho que estos servicios representan ser los componentes básicos de la propuesta de modelo que aporta esta investigación. En segundo lugar, y teniendo en cuenta un enfoque sistémico, estos permiten generar de forma dinámica el proceso de transferencia de información y conocimiento.

\section{Fase 7. Selección de la muestra para el estudio}

La selección de una muestra representativa de bibliotecas universitarias para el estudio de caso se realizó en un proceso complejo, dada la existencia de un gran número de entidades académicas en Europa y Latinoamérica con diferentes niveles de desarrollo y características propias para la gestión de las actividades educativas. Asimismo, otro aspecto que limitó la formación de la muestra fue debido a que algunas iniciativas de servicios en línea no son de acceso abierto.

Consideradas estas limitaciones y la diversidad de opciones existentes, fueron definidos algunos requisitos para la selección, delimitación y caracterización de la muestra.

\section{Pautas:}

a) Sector. Las entidades seleccionadas corresponden al grupo de educación superior. Se necesitó la disponibilidad de los profesionales de las bibliotecas para participar en el proceso 
de evaluación, mediante la cumplimentación de formularios de la entrevista y las guías de evaluación.

b) Alcance geográfico. Las bibliotecas seleccionadas se ubican en la región de Europa y América Latina y ofrecen los tres tipos de servicios básicos involucrados en el modelo propuesta.

c) Conexión y acceso a los servicios y recursos. Las bibliotecas son visibles y sus servicios son accesibles a través de Internet e intranet.

El resultado de la revisión rigurosa de los diferentes sitios de bibliotecas y la comunicación vía correo electrónico sostenida con los empleados de algunas bibliotecas, fue posible caracterizar el universo los siguientes tres grupos:

Grupo 1. Bibliotecas visibles en Internet a través de un sitio web. pero no ofrecen el servicio de referencia digital y cursos de formación de habilidades en línea.

Grupo 2. Bibliotecas con rápida conexión, facilidades de navegación y acceso en todo sitio web. Este grupo dispone de una oferta de cursos de formación de habilidades con modalidad presencial Actualmente las bibliotecas no tienen participación en los cursos de formación electrónica.

Grupo 3. El sitio de la biblioteca ofrece información general y descriptiva tanto de la biblioteca como de sus servicios. Dispone de los tres servicios considerados para la evaluación, pero en algunos casos el acceso es restringido, para entrar es necesario hacer uso de una clave.

En consecuencia, se contactó con los directores y jefes de las bibliotecas del grupo que disponían sitios con estructuras dinámicas de conexión, navegación y que además ofrecían los tres servicios de interés, a fin de conseguir el acceso temporal a estos servicios. Los resultados de repetidas solicitudes evidenciaron poca apertura o interés de ser evaluados, hecho que forzó limitar la muestra a seis instituciones ubicadas en los Países Bajos, España Costa Rica y Chile, quienes ofrecieron las facilidades para la realización del estudio.

Es necesario dejar constancia de que se tiene conocimiento de que la muestra seleccionada no es estadísticamente significativa y que la evaluación contiene restricciones desde el punto de vista de una metología científica que parta de la representación proporcional de las entidades estudiadas, se considera que la evaluación realizada suficientemente ejemplificativa para la demostración del modelo, al tratarse de bibliotecas universitarias que representan a la comunidad objeto típica y que posibilitan la aplicación de todos los indicadores de evaluación propuestos.

Se han seleccionado seis universidades de cuatro países diferentes en las cuales se cumplían los criterios de partida: disponer de plataformas E-learning en uso, ofrecer los servicios bibliotecarios telemáticos objeto de esta investigación doctoral y confirmar la disponibilidad de personal responsable de estos servicios para el apoyo en la evaluación, mediante la cumplimentación de los diferentes tipos de encuestas necesarias (ver Anexos).

Las instituciones seleccionadas como muestra para el estudio de caso correspondieron a las siguientes entidades: 
1. Universidad de Wageningen

2. Universidad Tecnológica de Delft

3. Universidad EARTH

4. Universidad Metropolitana de Ciencias de la Educación

5. Universidad de Sevilla

6. Universidad de Salamanca
Países Bajos

Países Bajos

Costa Rica

Chile

España

España

\section{Fase 8. Técnicas e instrumentos de captación de información}

Las técnicas e instrumentos utilizados para la ejecución del estudio de caso se orientaron en dos direcciones:

a) La revisión general y descriptiva de universidad y de la biblioteca como entidad prestadora de servicios. El resultado final de este análisis permitió conocer el entorno organizativo en el que se desarrollan y prestan los servicios.

b) El análisis los servicios definidos como elementos básicos en el modelo propuesto fue ejecutado desde dos perspectivas con el fin de obtener una visión global del funcionamiento y funcionalidad por parte de los encargados de los servicios y los usuarios.

b.1) Evaluación de los servicios desde la perspectiva de los gestores del servicio. Permitió conocer a nivel interno de la biblioteca la organización de los servicios; las limitaciones técnicas y los mecanismos de seguimiento.

b.2) Evaluación de los servicios desde la perspectiva de su funcionalidad en la Web. Implicó la revisión de la página web desde dónde se ofrece el servicio. Se reparó en la organización del contenido, aplicación tecnológica y facilidades para interacción con los usuarios (comunicación).

\section{Técnicas aplicadas:}

La ejecución del análisis institucional y la evaluación de los sitios web de las instituciones se valió de las siguientes técnicas:

- Análisis descriptivo. Fue dirigido a identificar la existencia de información institucional, tales como misión, objetivos, visión, informes y planes de trabajo a corto y largo plazo, a fin de determinar el nivel de correspondencia con la oferta de servicios en línea ofrecidos por la biblioteca y la viabilidad de implementar el modelo propuesto en esta tesis.

- Observación y pruebas de funcionamiento. La orientación de la observación fue dirigida a la visibilidad, presentación, contenido, facilidades de acceso y uso del servicio en línea. De forma paralela a la observación fueron realizadas pruebas de 
funcionamiento del servicio a fin de conocer las facilidades, y características de los servicios.

- Entrevista. La entrevista fue utilizada como técnica complementaria para el análisis descriptivo y la observación, dada que mucha información referente a los servicios no está disponible en el sitio Web. Las entrevistas fueron dirigidas a los gestores de los servicios de las 6 bibliotecas analizadas y un grupo de 10 docentes, y de forma complementaria a 8 expertos de E-learning a través de la red Linkedln.

Para la aplicación de las técnicas antes citadas, fue necesario el diseño de un conjunto de instrumentos para la recopilación de información, los cuales se describen a continuación y se encuentra disponibles en el apartado de anexos de este documento.

a. Matriz. El estudio de caso implicó el diseño y utilización de una única matriz a partir de los diez parámetros referidos en el apartado 7.3.1. La matriz que incluye el apartado de anexos de esta tesis, fue considerada el marco de referencia para el desarrollo de procesos de observación y la ejecución de las pruebas de funcionamiento de los tres servicios.

b. Cuestionarios para entrevista. Fue necesario elaborar tres tipos de cuestionarios para la evaluación por cada uno de los tres servicios ofrecidos. El uso de estos cuestionarios facilitó complementar la información obtenida a través de la observación y pruebas de funcionamiento.

Desde un enfoque sistémico y con el fin de evaluar la funcionalidad de los servicios, fueron utilizadas de forma combinada las técnicas e instrumentos en cada uno de los procesos evaluativos de los servicios. La siguiente tabla muestra la aplicación de parámetros y uso de instrumentos en cada caso.

\begin{tabular}{|l|l|l|l|}
\hline Servicios & Técnica & Instrumentos & Parámetros \\
\hline $\begin{array}{l}\text { Servicio de } \\
\text { referencia digital }\end{array}$ & * Análisis descriptivo & Matriz & $1,2,3,4,5$ \\
& $\begin{array}{l}\text { * Observación } \\
\text { * Pruebas de funcionamiento } \\
\text { * Entrevista a gestores del } \\
\text { servicio }\end{array}$ & & $6,7,8,9,10$ \\
\hline $\begin{array}{l}\text { Alfabetización } \\
\text { informacional }\end{array}$ & * Análisis descriptivo & Matriz & \\
& * Observación & Cuestionario & $6,7,8,9,10$ \\
\hline $\begin{array}{l}\text { Repositorios para } \\
\text { la educación }\end{array}$ & * Entrevista & & \\
& * Análisis descriptivo & Matriz & $1,2,3$ \\
& * Pruebas de funcionamiento & Cuestionario & $6,7,8,9,10$ \\
& * Entrevista & & \\
\hline
\end{tabular}

Tabla 28. Aplicación de Técnicas e instrumentos en la revisión de servicios. Fuente: Elaboración propia.

Para finalizar la descripción de la Fase 8, cabe destacar que estos instrumentos diseñados y utilizados para el análisis de los servicios digitales fueron debidamente sometidos a consulta y revisión de los directores de las bibliotecas, a fin de integrar algún elemento de relevancia para ellos. 
Posteriormente se realizó una prueba de los mismos en la biblioteca de la Universidad de Wageningen, a fin de constatar el grado de correspondencia de la información recopilada y los objetivos planteados.

\section{Fase 9. Ejecución del estudio de casos}

El estudio de casos fue desarrollado gradualmente. Las instituciones recibieron de forma previa el documento metodológico que describe la intensión y organización del proceso de evaluación mediante correo electrónico. Esto permitió generar confianza o credibilidad profesional y garantizar la transparencia del proceso de evaluación.

Dadas las limitaciones de índole económica por parte de la doctoranda para desplazarse a las instituciones, así como para viajar hacia los 6 países, el proceso de recopilación de datos fue hecho en dos modalidades.

a. Evaluación del sitio web de cada una de las instituciones a través de una conexión Internet.

b. En algunos casos el contacto directo con personas en espacios físicos y en otros mediante el contacto virtual a través de medios de comunicación de la Internet.

\section{Fase 10. Procesamiento de datos}

La organización y análisis de los datos e información resultante del estudio de casos, se realizó tomando en consideración las normas metodológicas para la evaluación de los servicios ISO 11620, ISO 2789, NISO Z39, EQUINOX, E-metric, Framework, LIBQUAL. Asimismo para el análisis comparativo de los casos se retomó los aspectos relacionados con acceso, visibilidad, navegación y usabilidad como puntos de partidas para el establecimiento de relaciones de semejanzas y diferencias.

Los estudios de casos que se muestran a continuación describen de forma exhaustiva cada uno de los diez elementos sobre los que se basa el método empleado en esta investigación, así como los tres servicios bibliotecarios que se prestan de forma telemática y que se vinculan con el E-learning:

\section{Elementos de evaluación}

1. Identidad

2. Actualización

3. Accesibilidad

4. Servicios básicos de la web

5. Contenido

6. Arquitectura de la información

7. Diseño de la interfaz

8. Posicionamiento

9. Sistema de búsqueda y recuperación

10. Usabilidad

\section{Servicios bibliotecarios telemáticos}
A. Referencia digital
B. Alfabetización informacional
C. Repositorios educacionales 


\subsection{Descripción de casos}

\subsubsection{Universidad de Wageningen}

En 1876 la Escuela de Agricultura de Wageningen ${ }^{115}$ es reconocida como la entidad de Educación Superior para la región de Gelderland (Países Bajos). Un año después se construye la primera estación de experimentos que actualmente funciona como instituto de investigaciones. En 1988 nace el Instituto de Investigaciones de Pesca, conocido en la actualidad como MARES. Posteriormente en 1903 se constituye la Escuela Superior de Silvicultura actualmente Escuela Superior Larenstein. En 1918 inicia la universidad con las primeras carreras de educación superior en Jardines y Silvicultura. Entre el período de 1956 y 1968 se ejecuta un proceso de evaluación de la oferta académica, lo que da origen a la creación de nuevos estatutos y el fortalecimiento con otras entidades de educación superior. En 1986 ocurre a nivel nacional la revisión de la ley de estudios superiores y de esto, el reconocimiento oficial de esta como una universidad agrícola y posteriormente en 1997 se constituye como la primera Universidad y Centro de investigaciones (WUR) en el sector agrícola. Como consecuencia de este cambio se integran a la universidad nuevos centros de investigaciones y unidades de trabajo.

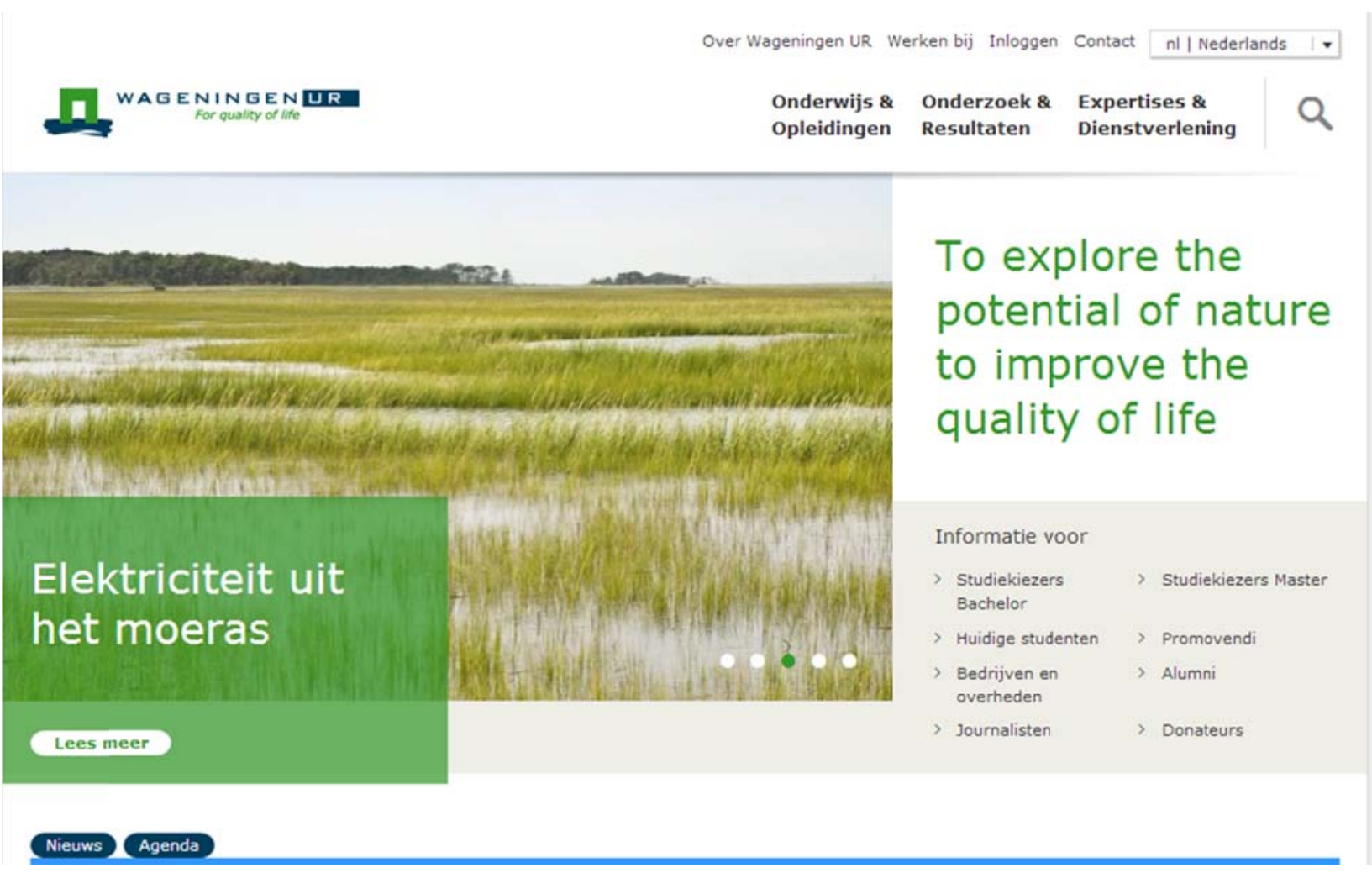

Figura 34. Página principal del sitio web de la WUR. ${ }^{116}$

La Universidad de Wageningen y Centro de investigación (WUR), tiene como misión "Explorar el potencial de la naturaleza para mejorar la calidad de vida", para esto realiza estudios con entidades gubernamentales y diversas empresas a fin de contribuir a garantizar alimentos saludables y mejores

\footnotetext{
${ }^{115}$ Los antecedes y descripción institucional han sido tomados de los documentos disponibles en el sitio web http://www.wageningenur.nl/nl/Over-Wageningen-UR.htm.

${ }^{116}$ Página vigente consultada 30-11-2012, sin embargo hubo cambio en el portal. http://www.wur.nl.
} 
condiciones de vida. Asimismo el plan estratégico de la WUR 2007-2010 establece tres líneas básicas de acción:
a) Europa como mercado interno
b) Próximos a la economías del conocimiento
c) Países en desarrollo

Un punto fuerte de la Universidad de Wageningen y su escuela superior Van Hall Larenstein, su integración temática en diferentes campos de las ciencias naturales y sociales. Esto le atribuye la capacidad de trabajar en todas las líneas de acción en alianzas con otros institutos de investigación especializados ${ }^{117}$ Del mismo modo resulta importante destacar que los programas de investigación de la WUR se constituyen y ejecutan en coordinación con el gobierno, la comunidad empresarial, los grupos de intereses especiales, y de otras Universidades e Institutos de Investigación en los Países Bajos. Este hecho que le permite tener un impacto real en la sociedad en su conjunto.

En la actualidad la WUR es reconocida internacionalmente. En sus programas de académicos de master y doctorado participan estudiantes provenientes de más de 100 países.

\subsubsection{Biblioteca de la Universidad de Wageningen}
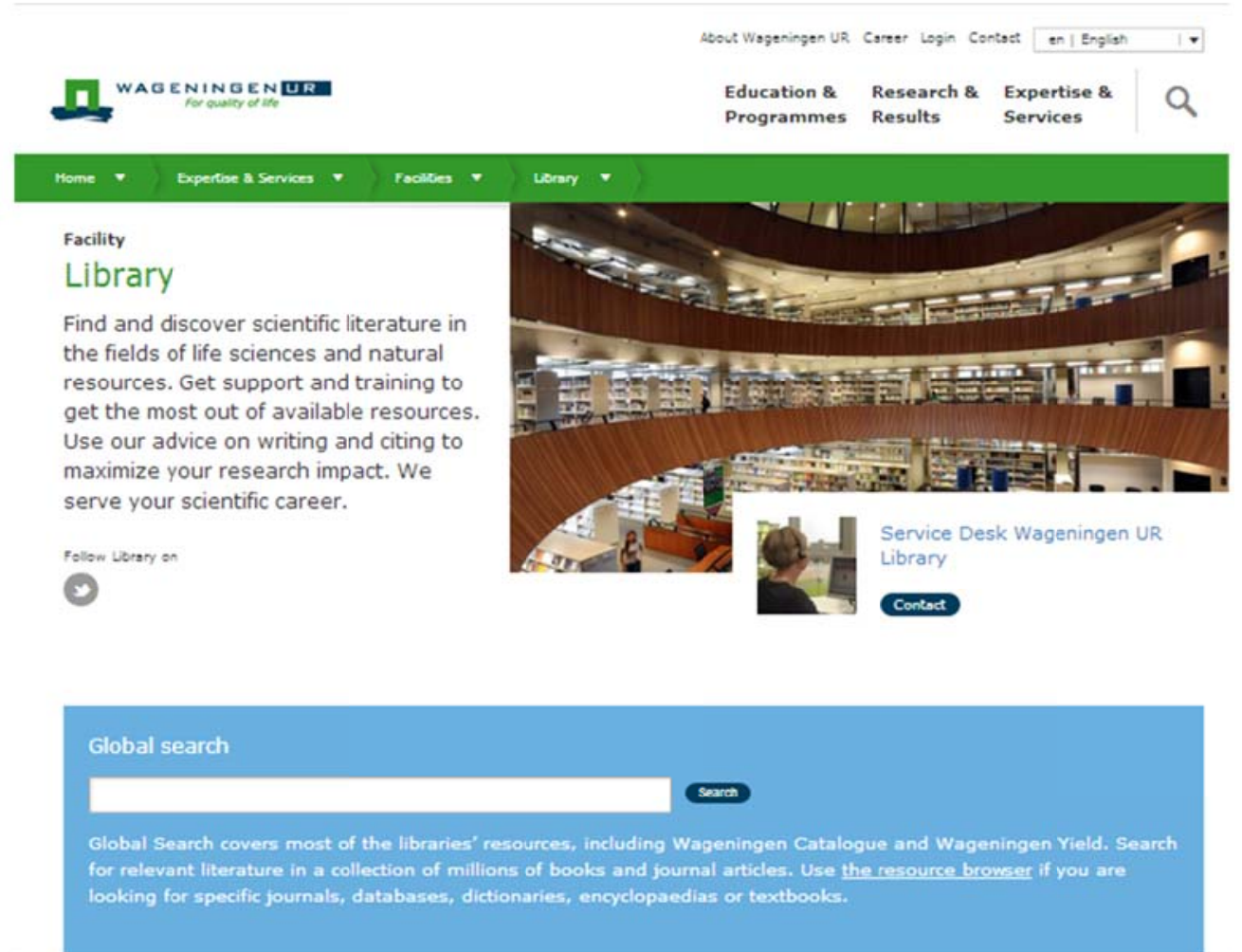

Figura 35. Biblioteca de la Universidad de Wageningen. Visualización desde el Portal die la WUR118.

\footnotetext{
117 Escuela superior Van Hall Larenstein que trabaja de forma conjunta con la Universidad de Wageningen http://www.vanhall-larenstein.nl.

${ }^{118}$ Pagina vigente consultada 30-11-2012 http: http://www.wageningenur.nl/en/Expertise-Services/Facilities/Library.htm
} 
La Biblioteca ${ }^{119}$ se originó con la primera colección de libros que fueron ofrecidos por la Escuela Agrícola establecida en 1873 como un departamento de la escuela secundaria local. En sus primeros años el desarrollo de la colección de la biblioteca correspondió a un presupuesto limitado para la compra y de generosas donaciones recibidas. Según datos registrados en los archivos de la Universidad, el auge de crecimiento de la colección ocurrió entre los años 1917 y 1923.

En 1873 la Biblioteca se ubica dentro de la escuela secundaria local. En 1922 se trasladó a Duivendaal, un suburbio de Wageningen. En los años posteriores a la segunda guerra mundial, la colección se distribuye entre la biblioteca central (en ese momento situada detrás del auditorio) y en las bibliotecas pertenecientes a los diversos Departamentos Universitarios. En 1981 la Biblioteca Central fue trasladada al edificio Kopshuis, situadas en la calle General Foulkesweg en Wageningen. Desde julio de 2007 la biblioteca se ubica como un "Sistema" y en dos grandes lugares en Wageningen: la Biblioteca central, ubicada en el edificio del Fórum y la Biblioteca Leeuwenborch.

\section{Servicios de información del Sistema de Biblioteca de la WUR}

Los servicios de información se agrupan en dos categorías: el acceso a los recursos y servicios generales de la biblioteca y el servicio de apoyo a la docencia e investigación.

\section{Acceso a los recursos y servicios generales}

- Servicio de referencia

- Recursos de información

- Portales, guías de literatura

- Acceso a portales, catálogos y bases de datos bibliográficas

- Acceso a fuentes de información tradicional y electrónica

- Solicitud de artículos electrónicos

- Préstamo de recursos de información

- Préstamos de libros y revistas

- Colección especial

- Revistas electrónicas

- Libros electrónicos

- Acceso a catálogos, portales

- Uso de la biblioteca

- Servicios de atención a los usuarios

- Mi biblioteca - Espacio personal

- Solicitud de materiales en línea

\section{Servicios de apoyo a la docencia e investigación}

- Servicio de Alertas y diseminación selectiva de la información DSI

- Nuevas adquisiciones

- Acceso a bases de datos y repositorios académicos

- Programa de gestión de citas

- Cursos de formación de habilidades:

- Asignación de ISBN

- Derecho de autor

\footnotetext{
${ }^{119}$ Las fuentes de información para la descripción de la biblioteca de la Universidad de Wageningen ha sido tomados del sitio Web:http://www.wur.nl/UK/about/organisation/facilities/Wageningen+UR+Library.
} 
- Orientación personalizada en diferentes ámbitos temáticos por parte de bibliotecarios especialistas

- Adiestramiento básico autodidáctico mediante el uso de videos cortos y demostrativos sobre determinados temas referentes al uso de la biblioteca

\section{Servicio de E-learning dentro de la WUR ${ }^{120}$}

Las facilidades que dispone la Universidad de Wageningen para el desarrollo de cursos de formación presencial semipresencial, a distancia y E-learning son responsabilidades del departamento de apoyo a la docencia. El departamento trabaja de forma coordinada con otros departamentos de la universidad para el desarrollo de aplicaciones y servicios para la ejecución de los programas de estudios. Para este fin la WUR se apoya de una plataforma denominada EDUWeb Support que integra un sistema LMS que permite organizar y gestionar los contenidos y procesos enseñanza aprendizaje y los procesos de comunicación de los cursos. En pocas palabras se define EDUWeb Support ${ }^{121}$ como un portal de acceso hacia una serie de servicios, facilidades y opciones que se categorizan en dos grupos: docente y estudiantes.

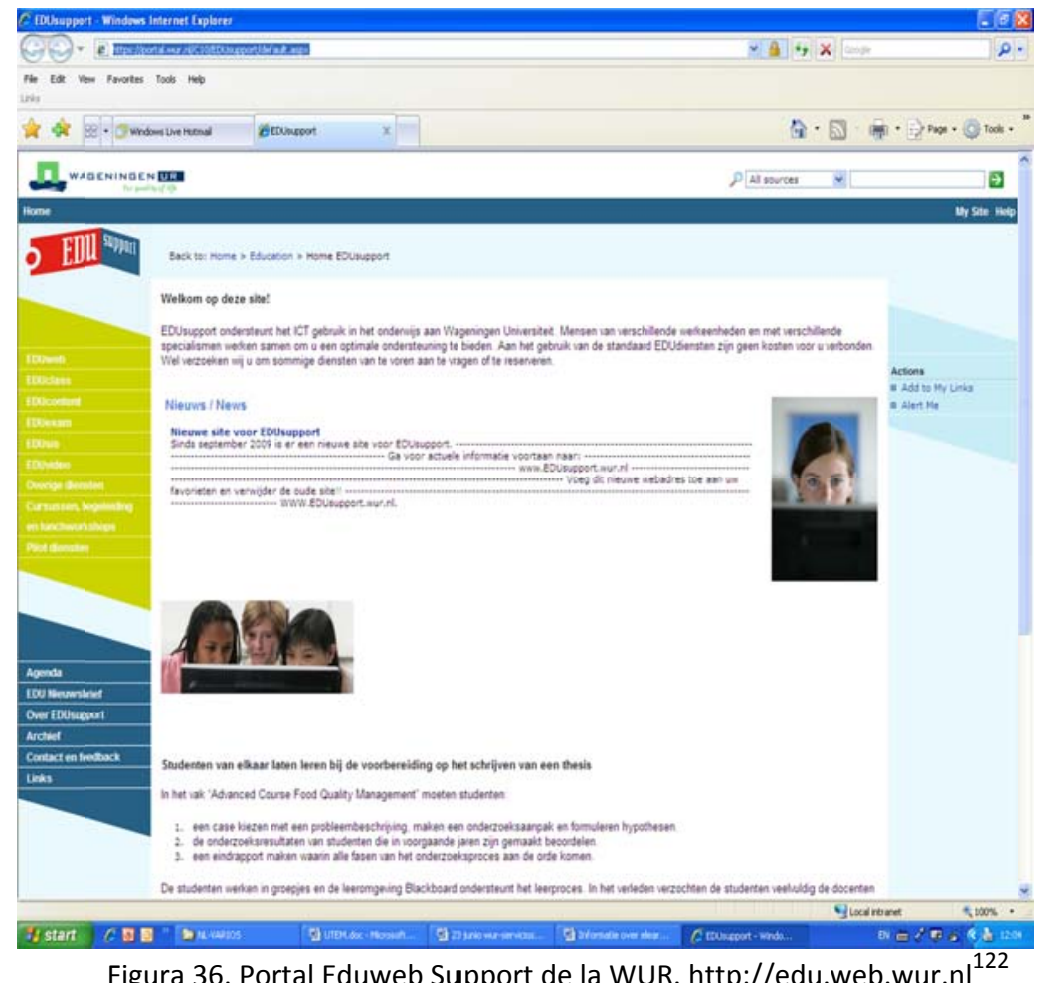

En la entrevista sostenida con Chris Blom ${ }^{123}$, Coordinador de Educación y Tecnologías de Información y comunicación explica en forma general el funcionamiento del portal y señala que en esencia los servicios funcionan a partir de los siguientes dos componentes básicos:

\footnotetext{
${ }^{120}$ Mayor descripción sobre la organización y servicios E-learning de la Universidad de Wageningen se encuentra disponible en el sitio Web: http://edu.webweb.wur.nl.

${ }^{121}$ Portal de acceso hacia una serie de servicios para la educación en línea https://portal2.wur.nl/SITES/EDUSUPPORT/NLNL/EDUCLASS/Pages/default.aspx.

${ }^{122}$ Actualmente sustituido por un nuevo estilo. Véase https://edu6.wur.nl/webapps/portal/frameset.jsp
} 
- Los estudiantes desde EDUWeb pueden acceder a la información sobre los módulos de estudios, cursos, contenidos de las materias y horarios.

- EDUclass entorno de aprendizaje electrónico. para el trabajo docente. Permite al docente subir al sitio, contenidos diversos y materiales necesarios para el desarrollo del curso, tales como textos, videos, figuras, organizar foros de discusiones, trabajos de grupos, creación de espacios virtuales para que los estudiantes puedan comunicarse, intercambiar materiales y comentarios. Ofrece además la posibilidad que cada docente puede personalizar el curso y dar un estilo propio. Desde el portal principal EDUclass ese posible utilizar una serie de recursos de apoyo a la docencia, tales como Blackboard, SharePoint, sitios de cursos (Courses sites), Questionmark perception y los cursos de la biblioteca (course library).

Según datos registrados en la evaluación de tres periodos académicos 2003-04, 2004-05 y 2005-06, un $75 \%$ de los servicios de apoyo a la docencia ocurre en el sistema Blackboard para el manejo de contenido ${ }^{124}$ y de incipiente manera para procesos asincrónicos y sincrónicos de comunicación, no obstante algunos docentes han organizados discusiones abiertas (en tiempos definidos) con especialistas de diversas instituciones en las cuales los estudiantes pueden hacer sus preguntas. Otro aspecto que se destaca en el mismo documento citado es el hecho que actualmente el mayor uso de los recursos ofrecidos por EDUWeb se concentra en aquellos que permiten la organización de los contenidos en una estructura de menú.

\section{EDUWEB y la Biblioteca}

La presencia de la biblioteca en EDUWEB se reconoce en el portal bajo el lema "Course Libraries" que consisten en cursos impartidos por los especialistas en información la formación de habilidades, competencias y destrezas en estudiantes, profesores y personal de la universidad ${ }^{125}$.

Durante la entrevista sostenida con Marianne Renkema, especialista en información de la biblioteca de la Universidad de Wageningen, se constató que actualmente se identifican cuatro cursos importantes:

a. El curso ECS-52901 es un valor de crédito introducido como parte de materias de programas de maestrías y licenciaturas

b. El curso ECS- 65100 para estudiantes de programas de doctorados que incluye la formación de habilidades, competencias, y destrezas y el uso de programas para la gestión de citas

c. Instrucción en búsquedas y uso de los materiales de información

d. Construcción de bibliografías y manejo de referencias bibliográficas mediante aplicaciones de programas especializados como Endnote y diseño de documentos con Adobe InDesign

123 Entrevista con Chris Blom, Coordinador de Educación y Tecnologías de Información y comunicación (Chris.blom@wur.nl).

124 Blackboard evaluates: reportage (200?) 23 p. WUR.

125 Entrevista con Marianne Renkema (marianne.renkema@wur.nl). 
Otras formas de participación de la biblioteca en procesos de formación académica en general y potencialmente de gran utilidad para E-learning, corresponde a la formación de colecciones electrónicas y la sistematización y gestión del material de estudio virtual o digital ubicado físicamente en la biblioteca y que puede ser recuperable desde el catálogo y utilizado por el usuario desde su espacio personalizado de estudio virtual. Desde acá el usuario puede acceder a partes o documentos completos y solicitar estos en formato pdf. Ejemplo de lo anterior, es el servicio de apoyo al proceso de enseñanza aprendizaje agraria a nivel técnico y superior, es la plataforma de información "Groen Kennisnet". La biblioteca ofrece el servicio de formación de colecciones especiallizadas y orientadas a temas concretos a la red Groen Kennisnet. Los usuarios del servicio expresan sus necesidades y la biblioteca a través de un especialista en información recopila los recursos de información en los diferentes medios y la hace disponible para el desarrollo del curso.

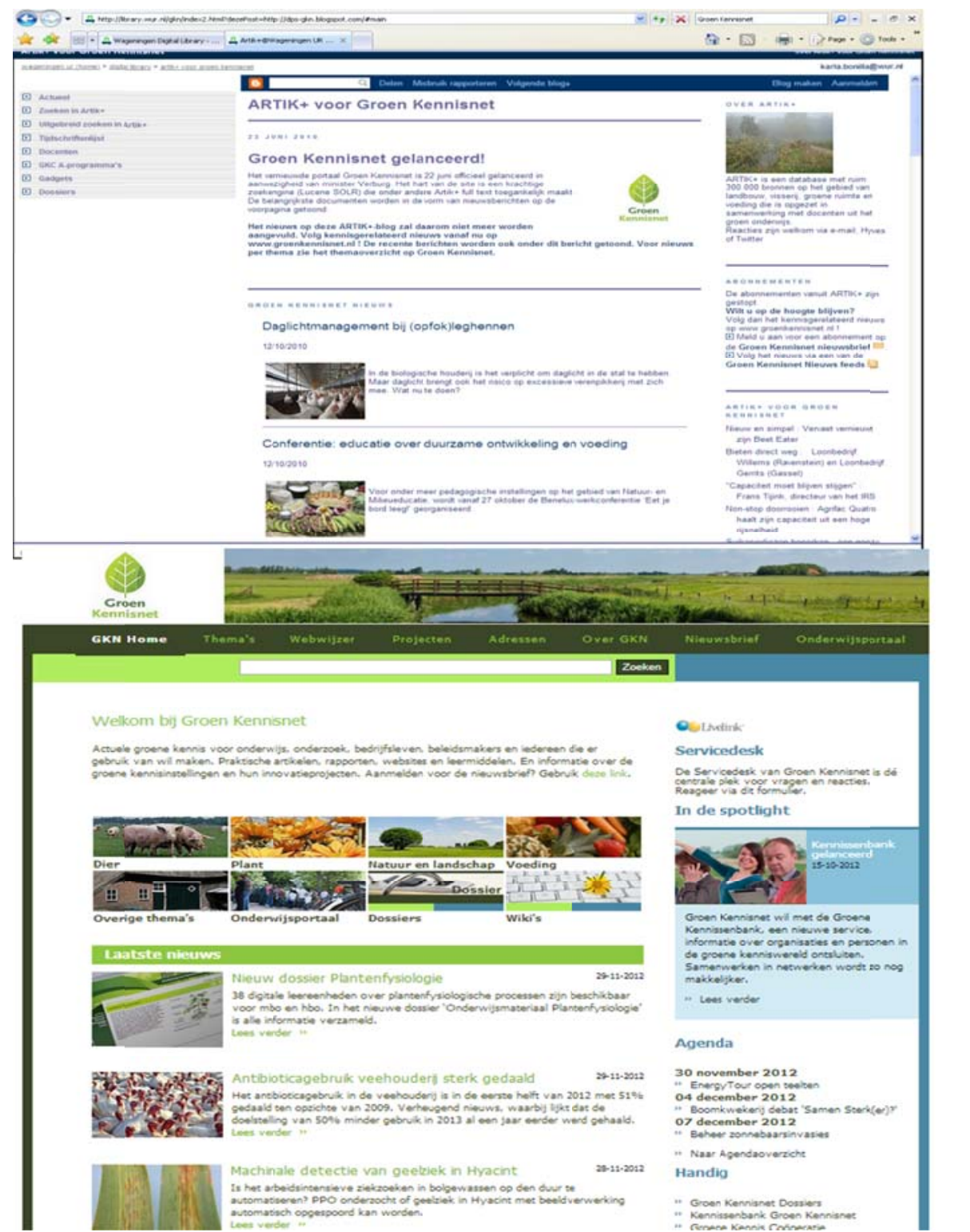

Figura 37. Groen Kennisnet. Servicio de apoyo a la educación e investigación agropecuaria ${ }^{126}$

\footnotetext{
${ }^{126}$ Sitio http://www.groenkennisnet.nl consultado 30-11-2012
} 


\subsubsection{Evaluación de la web de la Biblioteca de la WUR}

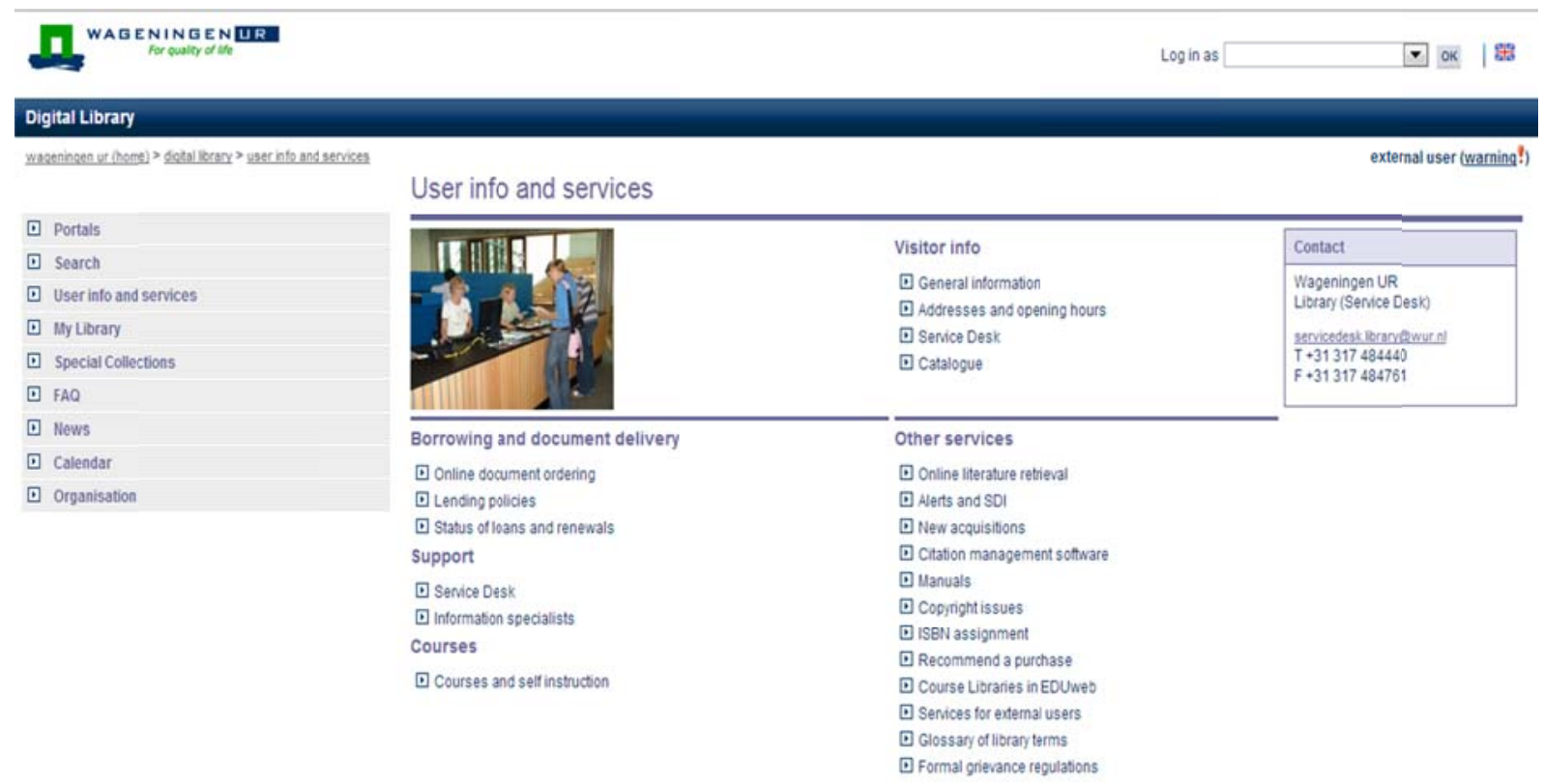

Figura 38. Oferta de servicios de la biblioteca de la WUR.

\section{Presentación de resultados}

\section{Parámetro 1. Identidad}

Dentro de la biblioteca de la Universidad de Wageningen es posible ubicar los sitios web de la Universidad bajo diferentes términos. En la página principal http://www.wur.nl/NL/ se reconoce un enlace reconocido con el término "publicaciones". Este se identifica en dos idiomas: en inglés bajo el término "Publications" y en holandés "publicaties". El enlace direcciona a un sitio donde se concentran los siguientes servicios:

- Servicios de publicaciones de la universidad con conexión a la biblioteca

- Servicios propios de la biblioteca

- Boletines informativos de la Universidad.

Partiendo de la observación y de los datos obtenidos en entrevistas con docentes, se constató que la biblioteca no es fácilmente localizable en la intranet. Para llegar al sitio de la biblioteca se hace necesario abrir una nueva pantalla o cambiar de página URL.

Ejemplos concretos se esquematizan a continuación, donde se han recogido los principales portales y direcciones web que se pueden encontrar en esta universidad en relación a los elementos que son objeto de estudio en la presente tesis doctoral: 


\begin{tabular}{l} 
Situación \\
\hline Desde la página principal de Intranet no es \\
clara su ubicación de la biblioteca. Es \\
necesario buscar en sección de servicios y \\
posteriormente en el menú de opciones.
\end{tabular}

\section{Situación}

En el sitio LEl (Landbouw Economisch Instituut = Instituto de Agricultura $\mathrm{y}$ Economía) Es un servicio de acceso al catálogo de la biblioteca se localizó dentro del sitio destinado para el Centro de información de publicaciones, no obstante su localización es poco clara.

\section{Situación}

En el portal EDUWEB de la biblioteca sólo es posible localizar en el espacio personalizado de cada usuario de esta plataforma.

EDUWEB ofrece la posibilidad de acceso a la biblioteca mediante la opción de un enlace hacia "My Library" y por ende al catálogo. No obstante desde la página principal de EduWeb la biblioteca no localizable.

\section{Sitio concreto}

http://www.intranet.wur.nl/nl/home/Pages/FB-

home.aspx

Grupos en intranet:

- Agrotechnology \& Food Sciences Group Animal Sciences Group

- Concernstaf+

- Environmental Sciences Group

- Facilitair Bedrijf

- IMARES

- Plant Sciences Group

- RIKILT-Instituut voor Voedselveiligheid

- Social Sciences Group

- Hall Larenstein

- Wageningen International

- Kameleon

\section{Sitio concreto}

http://www.lei.wur.nl/NL/publicaties+en+producten/Inf ormatiecentrum/

\section{Sitio concreto}

https://eduweb.wur.nl/Pages/default.aspx 


\section{Parámetro 2. Actualización}

A través del uso del indicador estándar de fecha y derechos de autor (Alle content (C) 2010 Wageningen UR. Alle rechten voorbehouden) se evidencia la actualización del sitio de la WUR.

\section{Parámetro 3. Accesibilidad}

La biblioteca utiliza un sistema de LMC desarrollado por la biblioteca para la organización y gestión de contenidos que cumple con los estándares internacionales como Scorm. De forma paralela se utilizan otros programas como Blackboard y otras aplicaciones que interactúan con este LCM a lo interno y externo de la biblioteca. En general, se puede afirmar que el acceso a los servicios de la biblioteca no presenta ningún problema, sin embargo se identificó que no existe ninguna opción para conexiones lentas. De la consulta realizada a docentes de la universidad se identificó que la conexión desde casa o desde el exterior del país resulta lenta y ciertas limitaciones en el acceso a ciertas revistas.

La visibilidad del sitio resulta agradable y amigable. El sitio no se encuentra cargado de información y ofrece un buen contraste entre fondo y texto. No obstante no se observó ningún servicio extra para personas con discapacidades físicas, visuales y auditivas. Aunque el sitio tiene esta debilidad, si fue posible comprobar la posibilidad de usar la opción estándar de Windows para ampliar el ancho de pantalla.

El proceso de navegación en cada una de las pantallas del sitio web de la biblioteca se considera excelente en cuanto a tiempo entre enlace a enlace, búsqueda y cambio de pantallas. Los usuarios externos a la universidad pueden navegar en el sitio de la biblioteca pero no utilizar los servicios que ofrece la biblioteca, por cuanto se requiere el registro previo.

El diseño del sitio web de la biblioteca se presenta a modo de menú de enlaces que direccionan hacia los diferentes servicios que ofrece. Se observa la presencia de íconos para indicar algunos servicios como es el caso de tutoriales, no obstante, se observó la ausencia de mapa del sitio que oriente la jerarquía del mismo y por ende la orientación del usuario dentro del sitio. En este mismo contexto es importante señalar que durante el proceso de exploración de los contenidos, fue posible identificar la existencia de diversas rutas para llegar a los contenidos de la biblioteca. Esto es posible a través de las opciones en el motor de búsqueda, portales de bases de datos y Google scholar. Una vez que el usuario se ha registrado en el sistema es posible bajar documentos, guardar parte o documentos completos.

\section{Parámetro 4. Servicios básicos de la web}

Los servicios en línea ofrecidos por la biblioteca son de respuesta inmediata, aunque se dispone de un margen de respuesta entre 12 y 24 horas según sea la demanda. Los servicios que mayormente se destacan en el sitio de la biblioteca son:

- Espacios personalizados: My library

- Portales 
- Servicio de Referencia

- Servicio de cursos de orientación al estudiante

- Email

- Blogs, Wikis, Flickr, RSS

- Acceso a diversos Metadatos

- Acceso a directorio de recursos Web,

- Acceso a objetos de aprendizaje multimedia, glosarios, manuales

- Diversos (noticias, variedades, entretenimientos, etc.)

\section{Parámetros 5 y 6 Contenido y Arquitectura de la información}

Las prácticas de búsqueda realizadas en el catálogo, bases de datos y repositorios, demuestran el cumplimiento de los siguientes parámetros de calidad en la presentación de los contenidos de los recursos de información: autoridad de autores reconocida; adecuación entre la autoría y la agenda temática; adscripción del autor a la organización que pertenece; factibilidad de contacto entre el autor-usuario de la fuente; reconocimiento y credibilidad de la fuente así como la identificación básica de las diferentes secciones de la publicación (autor, título y fechas).

\section{Parámetro 7. Diseño de interfaz}

Los sitios web de la WUR y de la biblioteca cuentan con un adecuado y flexible diseño. Partiendo de los criterios estándares para el diseño de sitios web, es posible señalar que ambos cumplen con los siguientes aspectos: consistencia y contraste en el uso de colores, tipo de letras, tamaño de letras, líneas de texto, anchura de pantalla, márgenes, legibilidad, claridad o contraste adecuado entre el texto y el fondo, velocidad o tiempo de descarga de la publicación, considerándose el tiempo promedio de descarga por página de 25 segundos y la posibilidad de manifestar opiniones sobre el contenido de la web a responsable o administrador

\section{Parámetro 8. Posicionamiento}

Los servicios y los contenidos ofrecidos por la biblioteca son identificables y recuperables a través de una búsqueda desde cualquier buscador en Internet e entranet.

\section{Parámetro 9. Sistema de búsqueda y recuperación}

Los mecanismos de búsquedas ofrecidos desde la web de la biblioteca, permiten la identificación de recursos por su descripción, el uso de lenguaje controlado y por aproximación y ponderación en todo el contenido, así como el uso de operadores boléanos. 
Dado que la biblioteca dispone de diferentes bases de datos, se proyecta mejorar el sistema de búsqueda, mediante la creación de un meta buscador que permita realizar búsquedas integradas en todos las bases de datos y catálogo de la biblioteca. Los recursos de información están disponibles en formato pdf, doc, HTML, dot y otros.

\section{Parámetro 10. Usabilidad}

No es claro o visible si el sitio cuenta con la flexibilidad para realizar una acción de diferentes maneras. Tampoco fue posible identificar niveles de aplicación en el uso de imágenes o sonido en el recurso completando la información textual. Otra limitante en la usabilidad de los servicios, se presenta el uso de mensajes de ayuda. Estos no son claramente visibles y algunos de ellos son demasiado largos.

Cabe destacar que aunque la biblioteca ofrece una serie de servicios, la existencia y posible uso de estos resulta ser desconocido por gran parte de la comunidad universitaria. De las entrevistas aleatorias sostenidas con docentes se identificaron las siguientes razones:

- Desconocimiento del potencial que ofrecen estos servicios y por ende la poca proyección de estos.

- La oferta de los repositorios y servicios es presentada mediante siglas y/o nombres de los repositorios y bases de datos que en la mayoría de los casos no reflejan el objetivo del producto y la importancia del contenido. Un ejemplo concreto se observa en la siguiente figura.

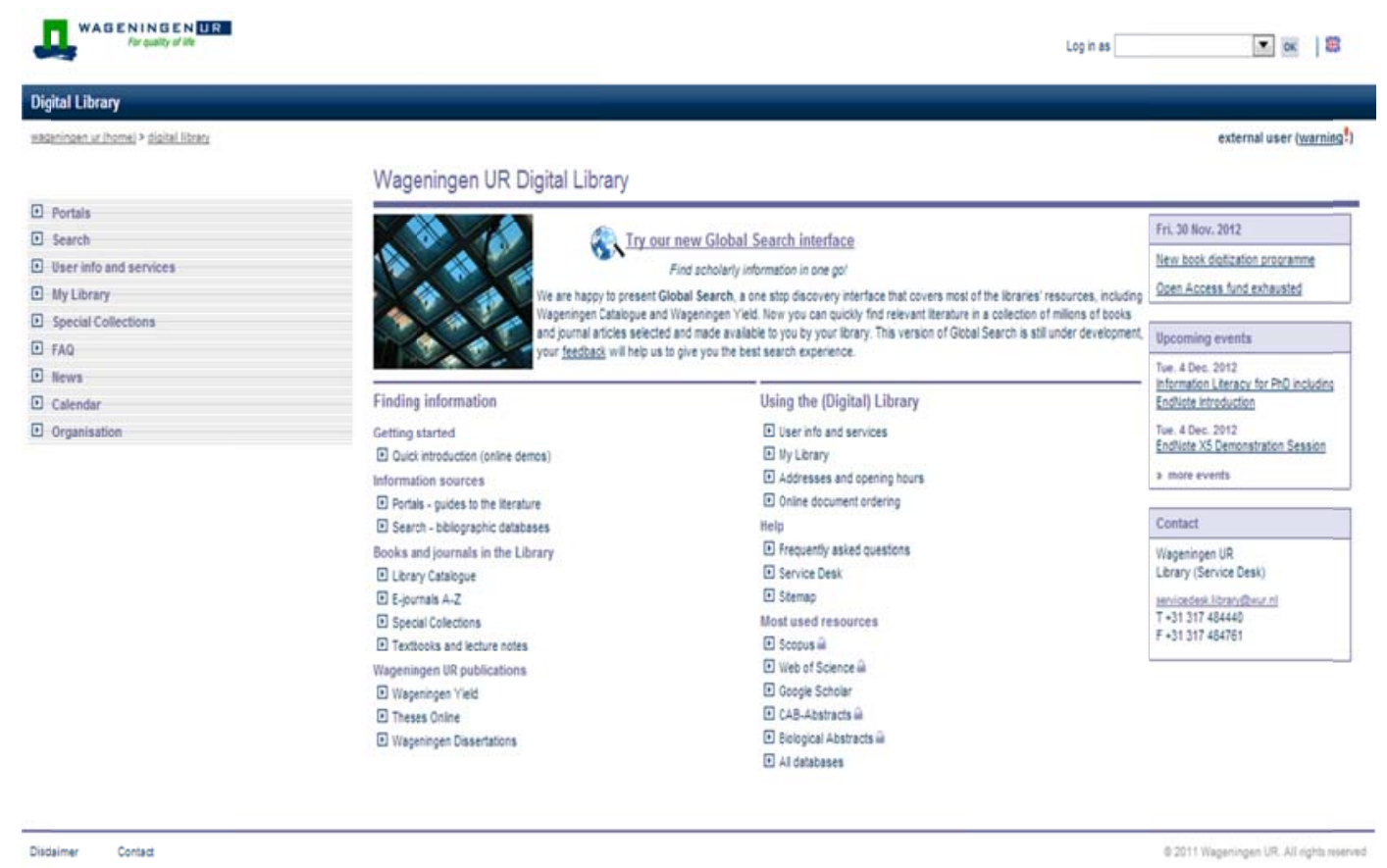

Figura 39. Oferta de repositorios y bases de datos de la biblioteca de la WUR ${ }^{127}$

\footnotetext{
${ }^{127}$ Pagina vigente consultada 30-11-2012 http://library.wur.nl.
} 


\subsubsection{Evaluación del servicio de cursos de formación de usuarios}

Los cursos de formación de habilidades, competencias y destrezas ofrecidas por la biblioteca se dividen en tres niveles:

a) Los cursos de introducción al uso de la biblioteca que incluyen visitas guiadas, prácticas y charlas sobre el uso de los servicios y recursos de la misma. Aunque estos cursos son presenciales tienen un componente virtual.

b) Instrucciones de auto formación a través del uso herramientas multimedia de autoaprendizaje. En los últimos años la biblioteca ha desarrollado una guía virtual, tutoriales y demostrativos.

c) Cursos ALFIN orientados a la formación de habilidades, competencias y destrezas propiamente dicho dirigidos a estudiantes de la universidad. Actualmente se identifican cuatro importantes cursos:

1. Cursos obligatorios (créditos) introducidos dentro de materias de programas. La oferta de cursos se reconoce como: "Information Literacy courses"

ECS-52901 dirigido a estudiantes de maestrías y licenciaturas ECS-65100 PhD Course Information Literacy, including Introduction to Endnote (PhD Education Programme)

2. Instrucción en búsquedas y uso de los materiales de información

3. Construcción de bibliografías y manejo de referencias bibliográficas mediante aplicaciones de programas especializados como Endnote

4.- Diseño de documentos con Adobe InDesign

Con el objetivo de ilustrar dichas prácticas, en las siguientes figuras extraídas del sitio Web de la biblioteca se observa la oferta a los tres tipos de programas de formación antes mencionados.

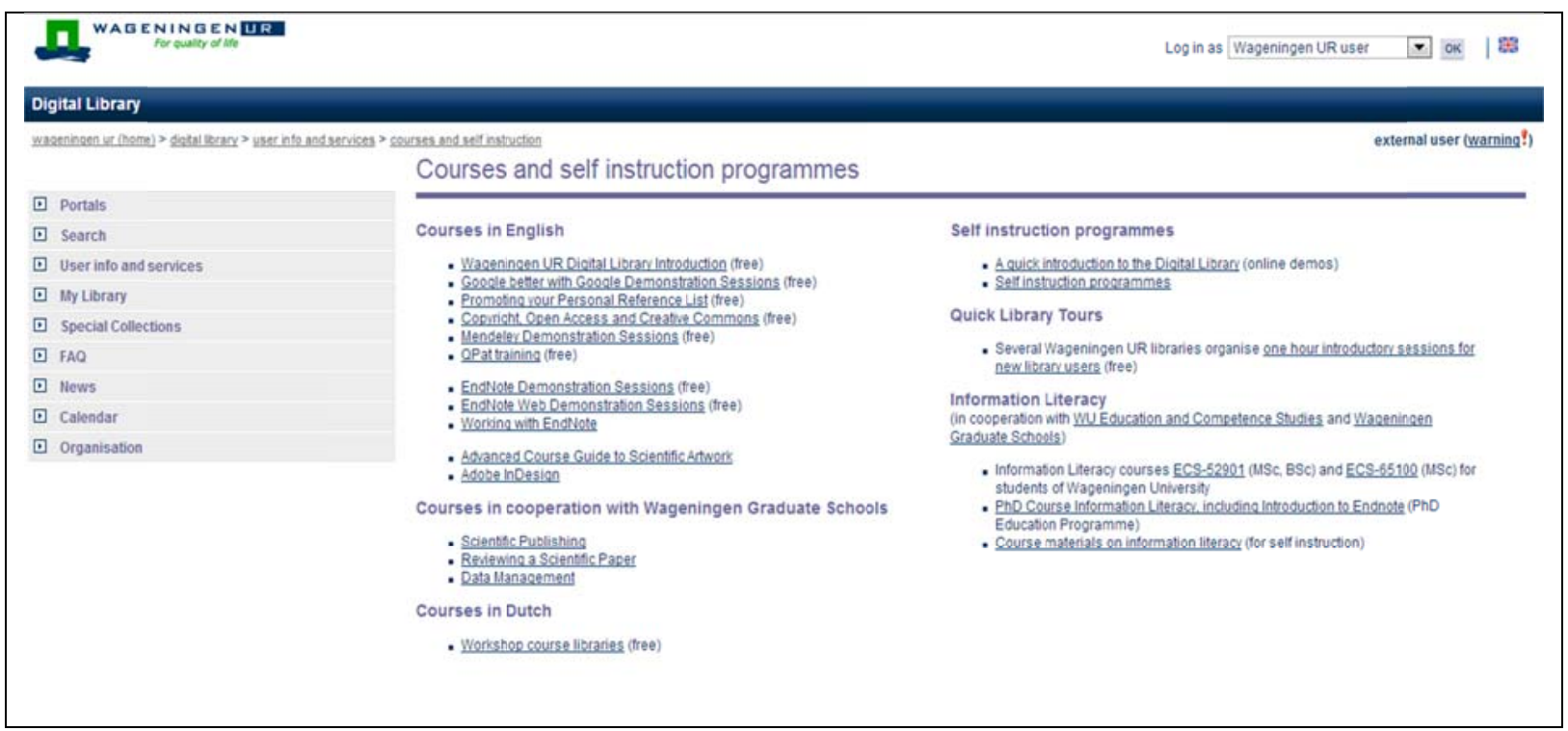




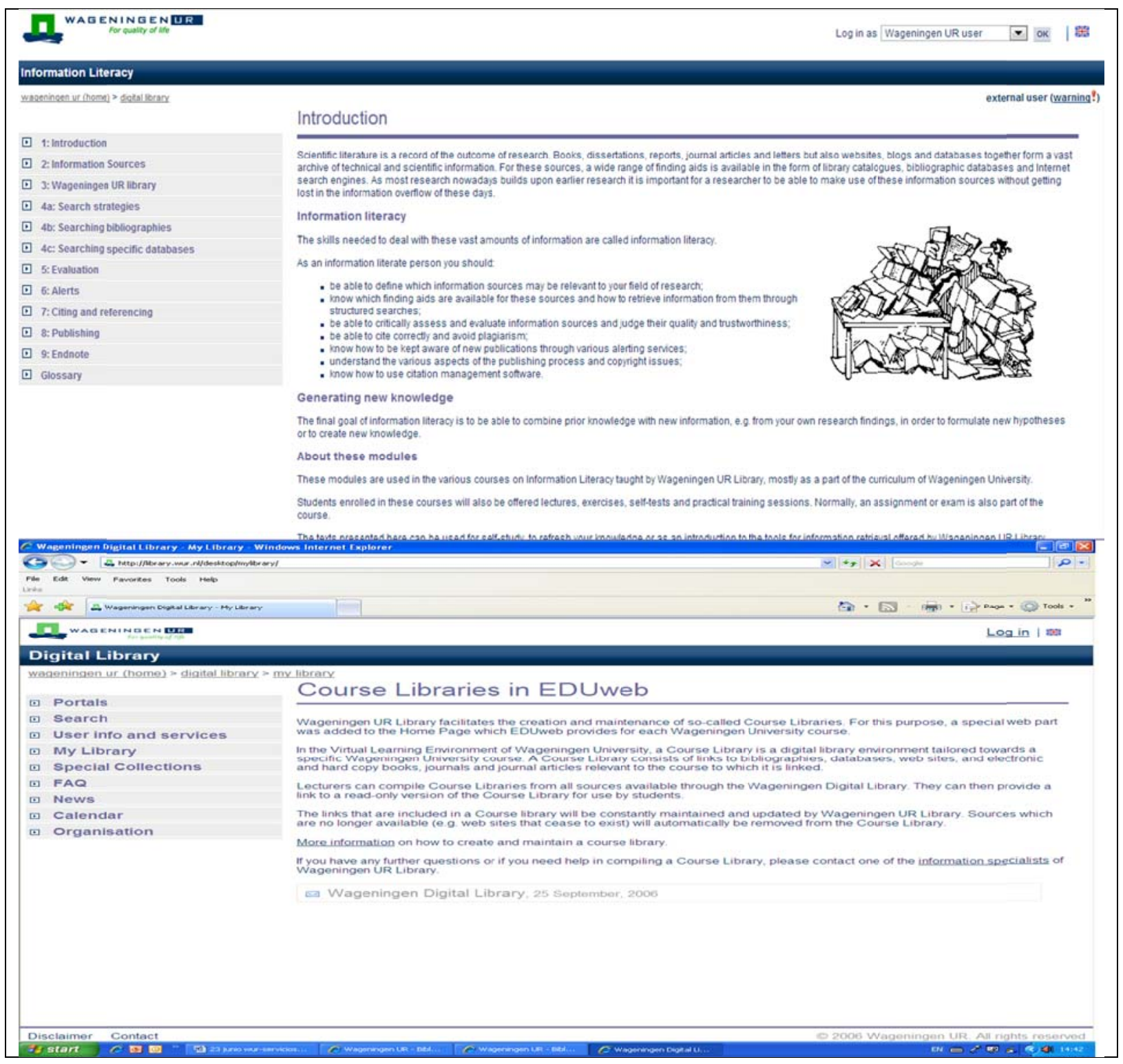

Figura 40. Oferta de recursos y cursos para la formación de usuario de la Biblioteca de la WUR.

Los cursos de formación de habilidades, competencias y destrezas ofrecidos por la biblioteca se organizan y ejecutan de forma semipresencial desde la plataforma Eduweb. El sistema de gestión de contenido LMS utilizado es Blackboard. Actualmente la oferta consiste en tres cursos, uno a nivel universitario, otro dirigido a máster y el tercero a estudiantes de doctorado. 
La descripción y organización del curso es en módulos y se visualizan a modo de pantalla mediante opciones de menú de enlaces a los contenidos.

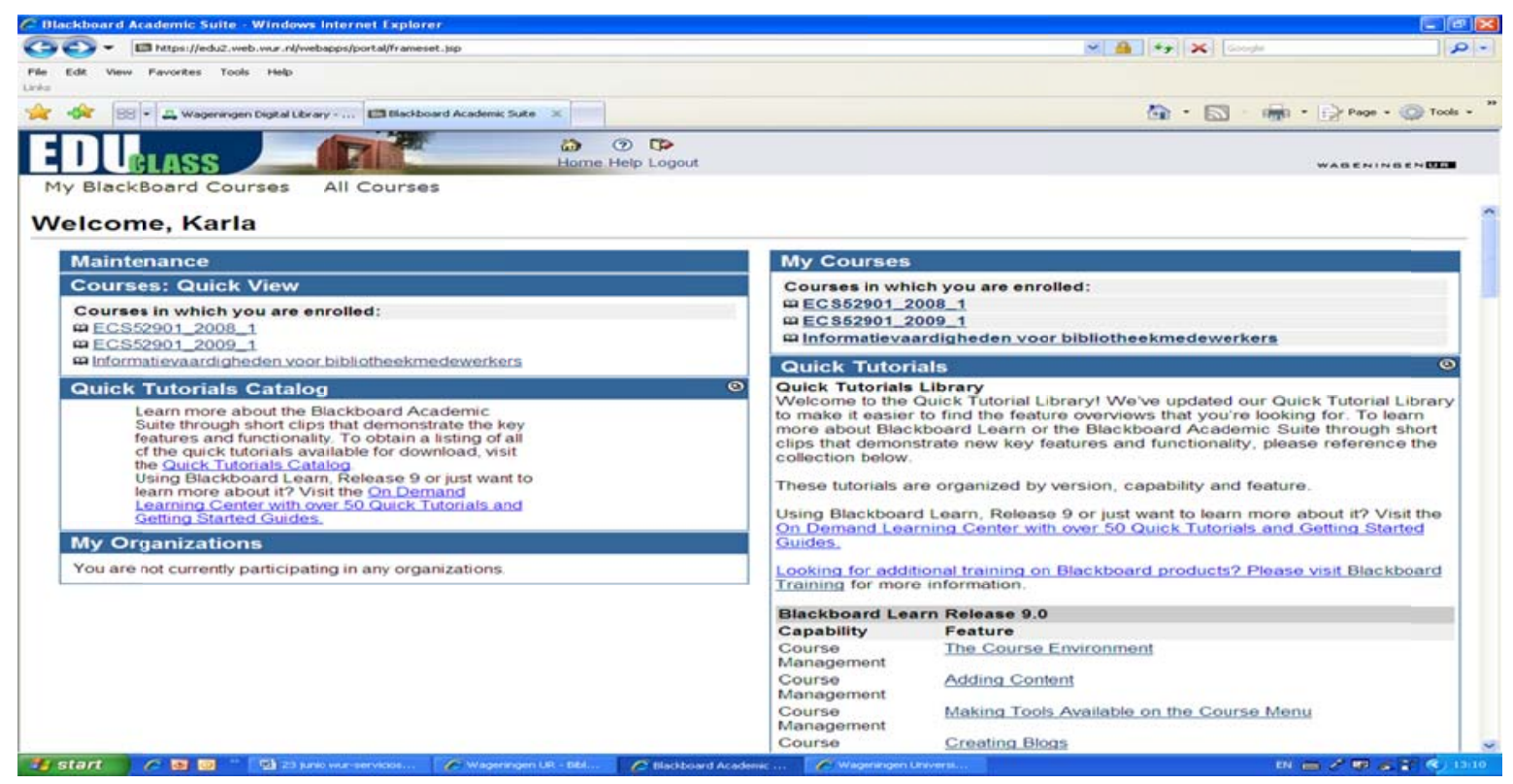

Figura 41. Visualización de cursos ofrecidos en Blackboard.

Los contenidos de los cursos son colocados en el sistema en forma de archivos independientemente del programa. Blackboard al igual que otros LCMS permiten el uso interactivo de diferentes gestores de contenidos, tales como Microsoft office (Word, Power Point, Excel), gestores de videos y el uso de enlaces a sitios URL externos. Un ejemplo concreto en esta línea es el enlace a un traductor o bien al catálogo de la biblioteca. Los contenidos de los cursos ofrecidos por la biblioteca se componen básicamente de cuatro partes:

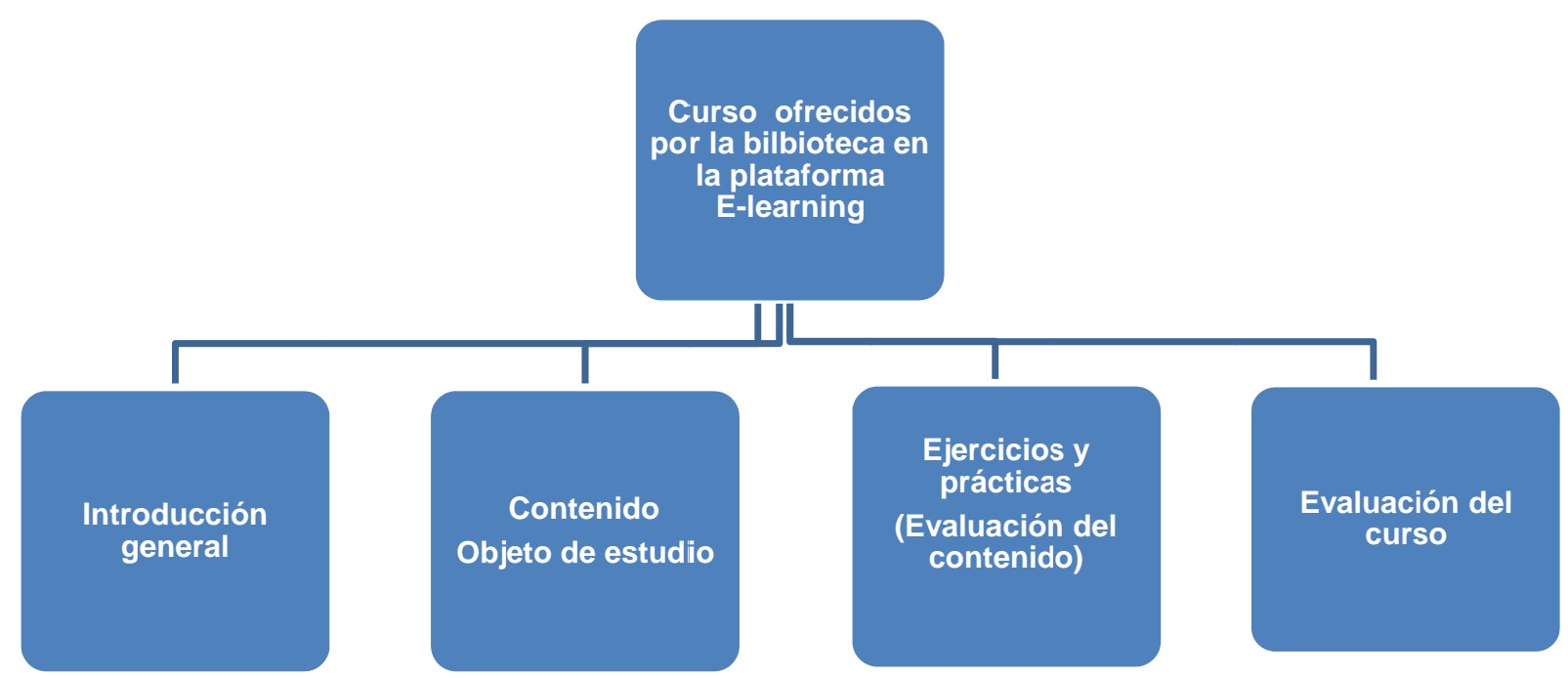

Figura 42. Componentes de los cursos ofrecidos en Blackboard. Fuente: Elaboración propia. 
a. La introducción general del objetivo contiene una presentación de los objetivos, fines y metodología del curso.

b. El contenido - objeto de estudio. Se hacen accesibles todos los materiales de estudios y recursos necesarios para el cumplimiento de los objetivos.

c. Ejercicios y prácticas. Se facilitan una serie de instrucciones y guías para la realización de prácticas que permitan evaluar la asimilación de los contenidos. En esta fase el proceso evaluativo del aprendizaje ocurre de forma indirecta a través de los resultados de las prácticas, exámenes o bien de forma indirecta a través de discusiones de grupo.

d. Evaluación. Se realiza de forma interactiva o individual y se realiza la evaluación general del curso.

Con el objetivo de profundizar la organización de los cursos ofrecidos por la biblioteca de la universidad de Wageningen, se muestra a continuación una serie de figuras que reflejan la presentación de la oferta antes referida.

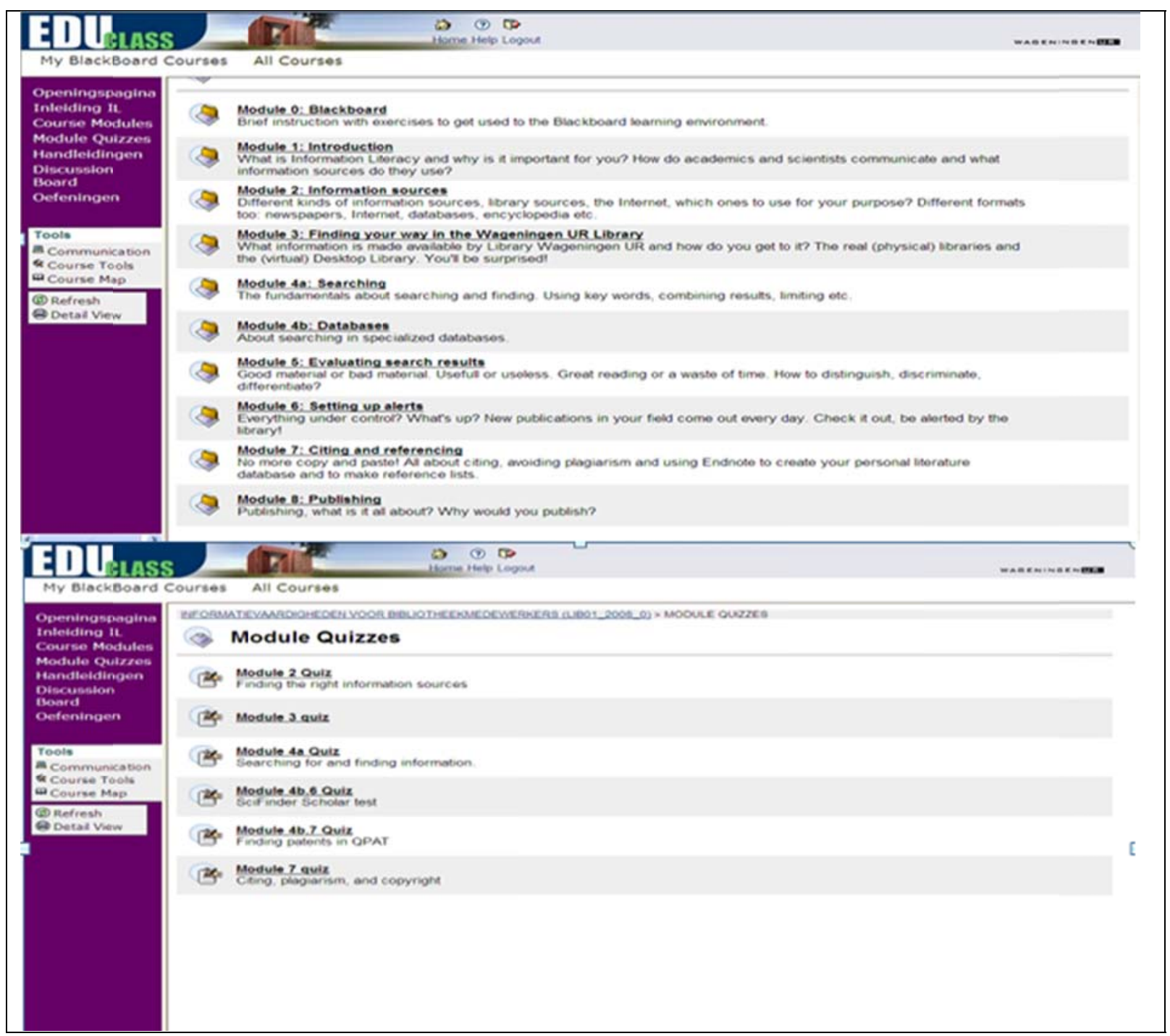

Figura 43. Estructura modular de los cursos. 


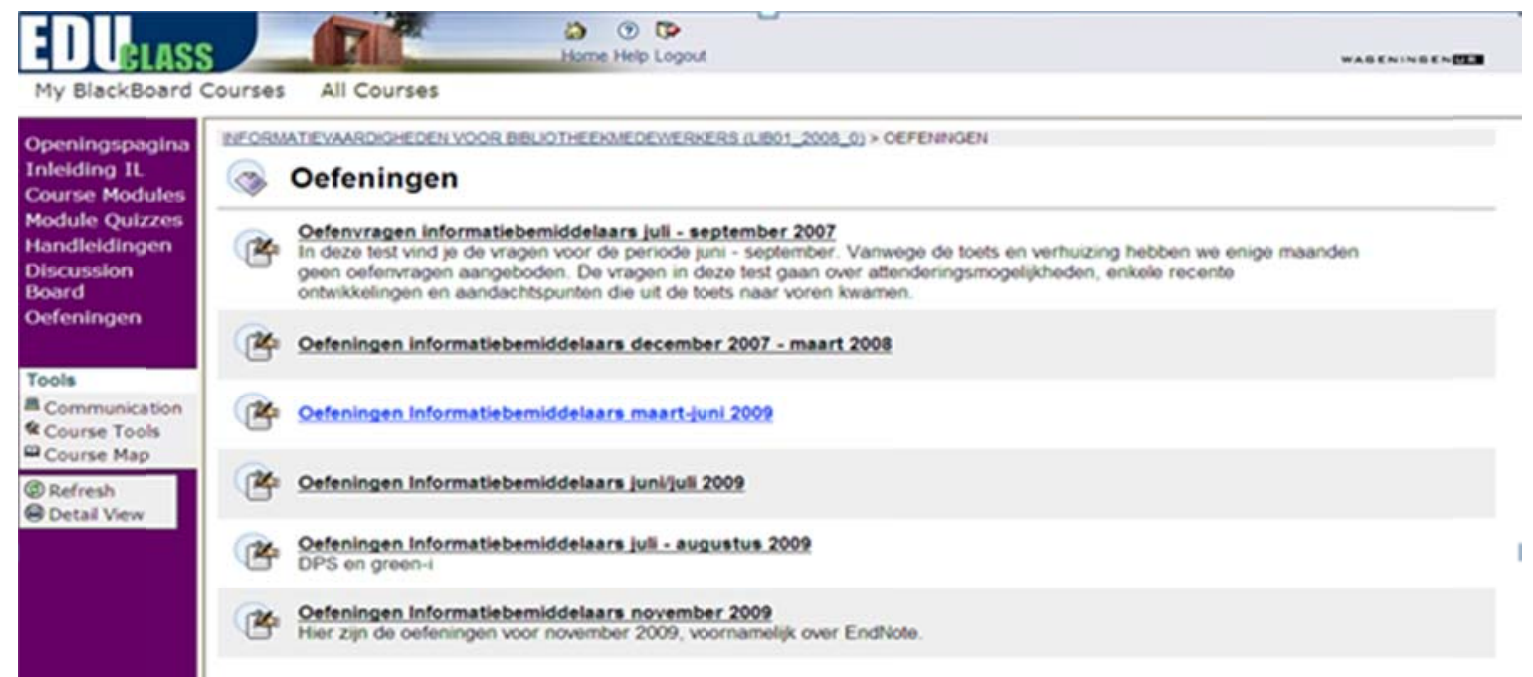

Figura 44. Formas de seguimiento y evaluación del aprendizaje.

Al momento de la observación de los cursos de formación de habilidades ofrecidos desde la plataforma EDUWEB, se observó cierta dificultad para la localización de estos. Primero porque la oferta es limitada a un grupo determinado, segundo porque se requiere conocimiento de la existencia de la plataforma. Sin embargo una vez contando la autorización para el acceso a los cursos (clave de acceso para navegar dentro de la plataforma y curso), se reconocen las siguientes dos rutas para llegar a ellos.

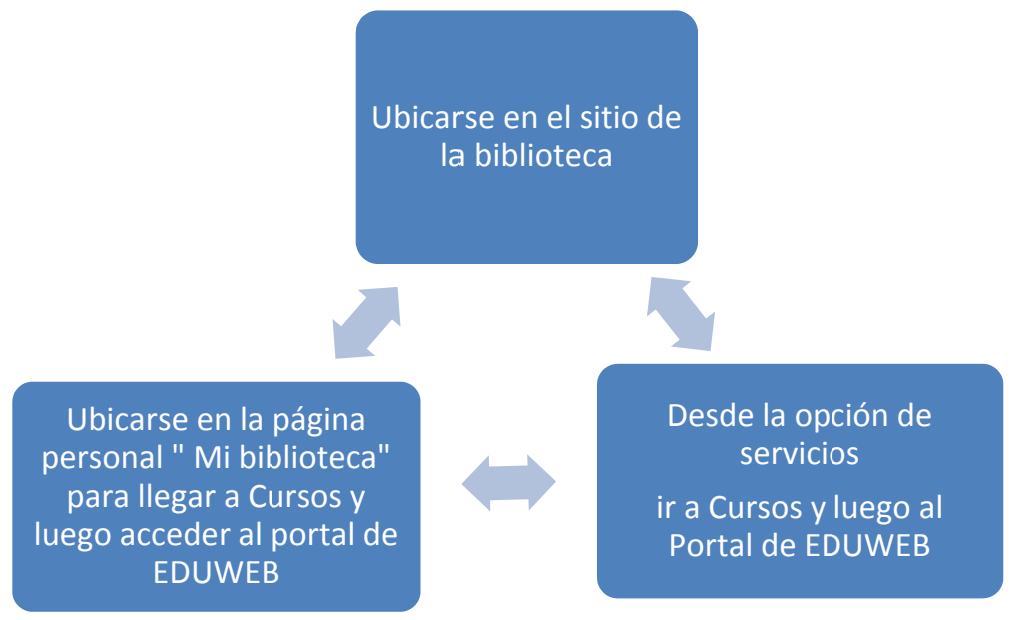

Figura 45. Vías de localización de cursos ofrecidos en Eduweb. Fuente: Elaboración propia.

Opción 1. Para llegar al servicio "Cursos", primero se debe llegar al sitio de la biblioteca, luego hacer una lectura del menú de servicios e ir a My Library. 
Opción 2. Llegar al sitio de la biblioteca y seleccionar la opción Información y usuarios (User info and services), seguidamente seleccionar Cursos (Courses and self instruction programmes) y finalmente llegar a My course libraries in EDUWEB.

\subsubsection{Evaluación del servicio de referencia}

El servicio de referencia es frecuentemente utilizado y considerado la entrada principal a los servicios de la biblioteca. En la biblioteca de la WUR este servicio se reconoce en casi todo los sitios de la biblioteca en diferentes formas y bajo diferentes términos. Principalmente el servicio de referencia se organiza en dos grupos. El servicio de ayuda y acceso a los materiales de referencia como libro de dirección, reportes anuales, programas especiales para hacer cálculos, citas, conversiones, diccionarios, directorios, información gubernamental, etc. En la consulta realizada al sitio se destacan los siguientes servicios como parte del servicio de referencia:

- Servicio de información general (General information). Ofrece información básica sobre horarios, direcciones, acceso al catálogo y un enlace al servicio de pregunte al bibliotecario.

- Portales (Portals). Dentro de este servicio se reconoce el enlace a la colección de recursos o fuentes de referencias. (diccionarios, enciclopedias, etc.).

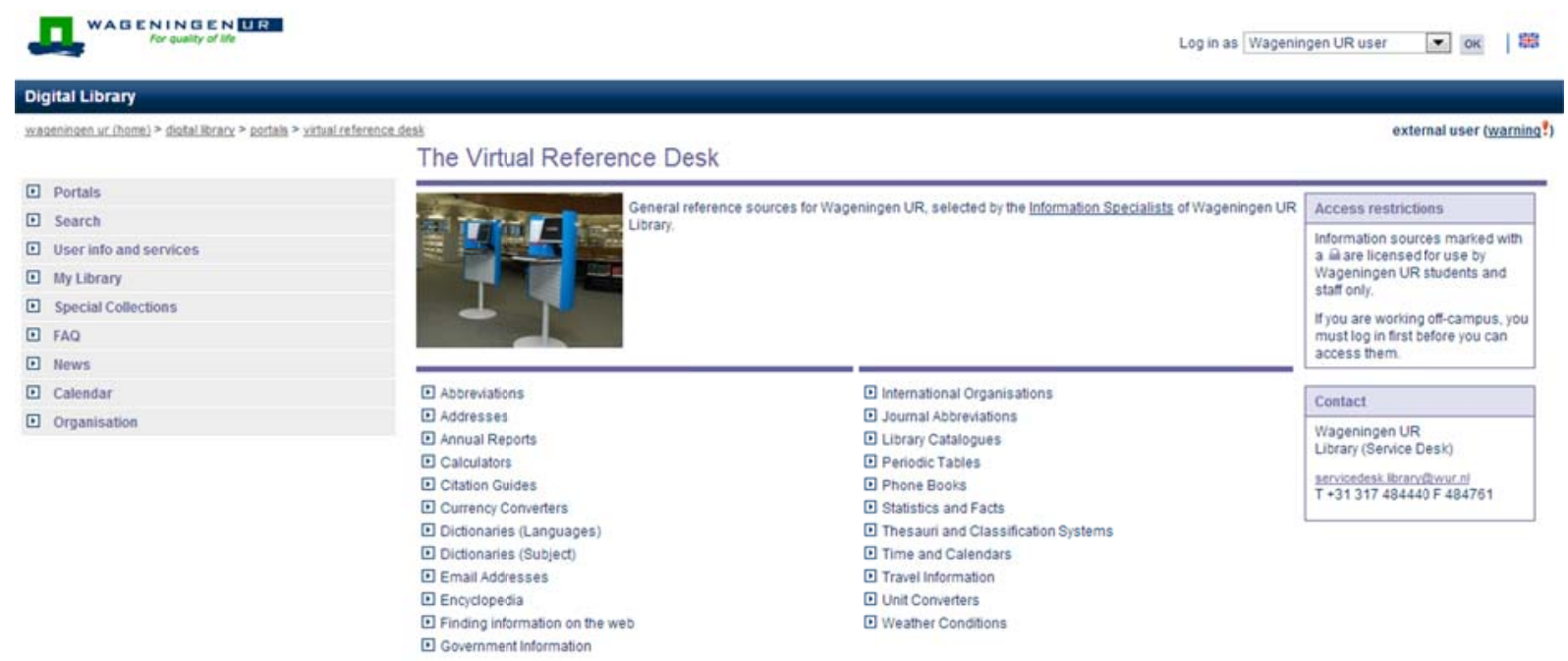

Figura 46. Servicio de referencia virtual de la Biblioteca WUR.

Una segunda forma del servicio de referencia se dirige a procesos de comunicación para la orientación del usuario dentro de la biblioteca física y virtual para acceder a los servicios y recursos existentes. Se reconocen los siguientes servicios dentro de esta categoría:

Servicio de ayuda y acceso a los materiales de referencia:

- Servicio de contestación automática (Preguntas frecuentes)

- Servicio de comunicación chat, email

- Preguntas frecuentes

- Atención en línea 
- Mapa de la web

- Diccionarios

- Gestión administrativa personalizada

- Adiestramiento básico para el uso de los servicios, recursos de la a biblioteca mediante uso de programas informáticos (Demo)

- FAQ. Preguntas frecuentes. Se trata de un listado de preguntas predefinidas con respuestas concretas

En la siguiente figura se muestran tres sitios concretos que forman parte del servicio de Referencia. En la primera opción se ilustra el servicio de preguntas frecuentes, en la segunda la opción de pregunte al bibliotecario a través del servicio de correo electrónico, y en la última se muestra la opción de videos demostrativos sobre el uso de los recursos informativos de la biblioteca.
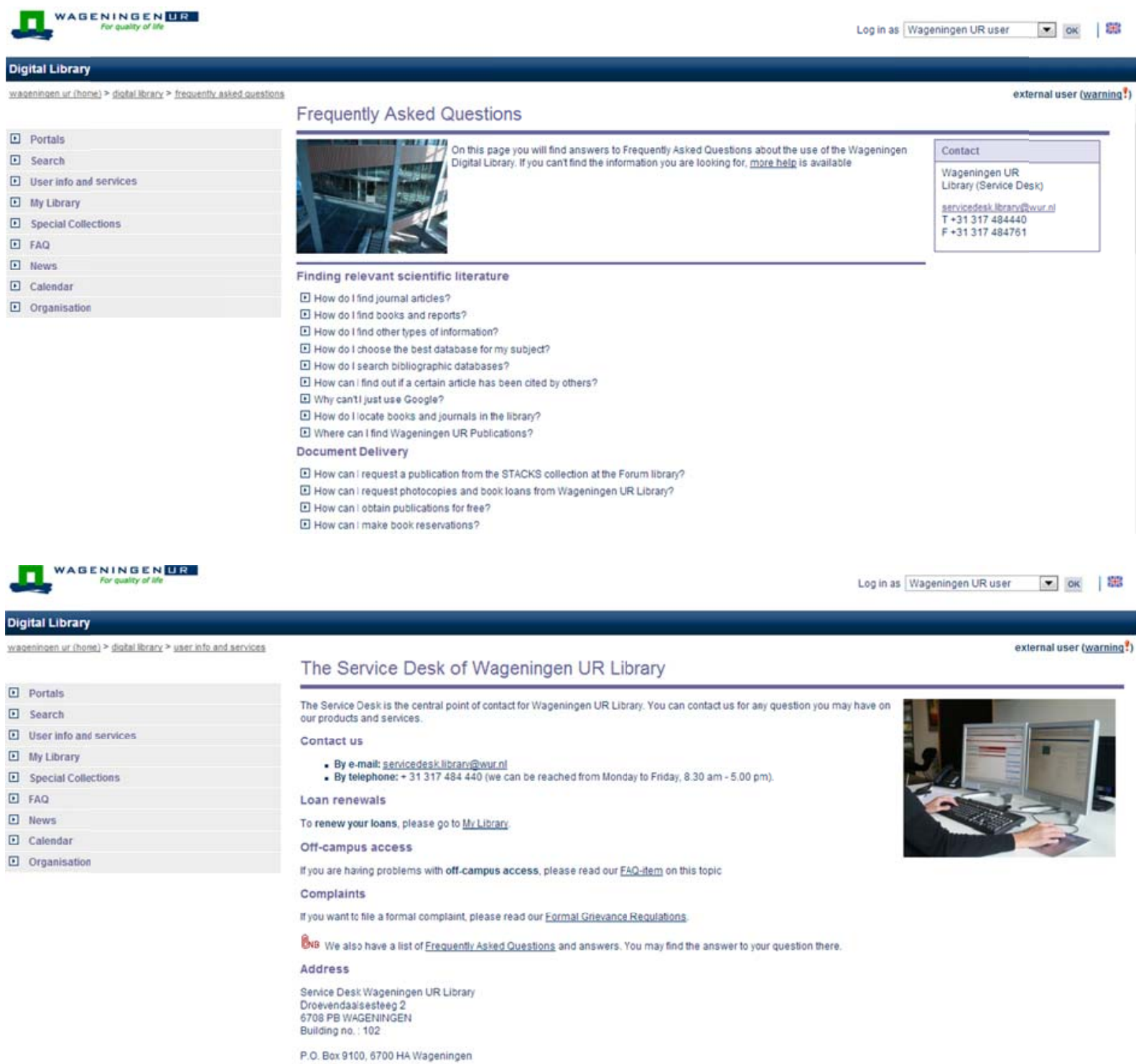


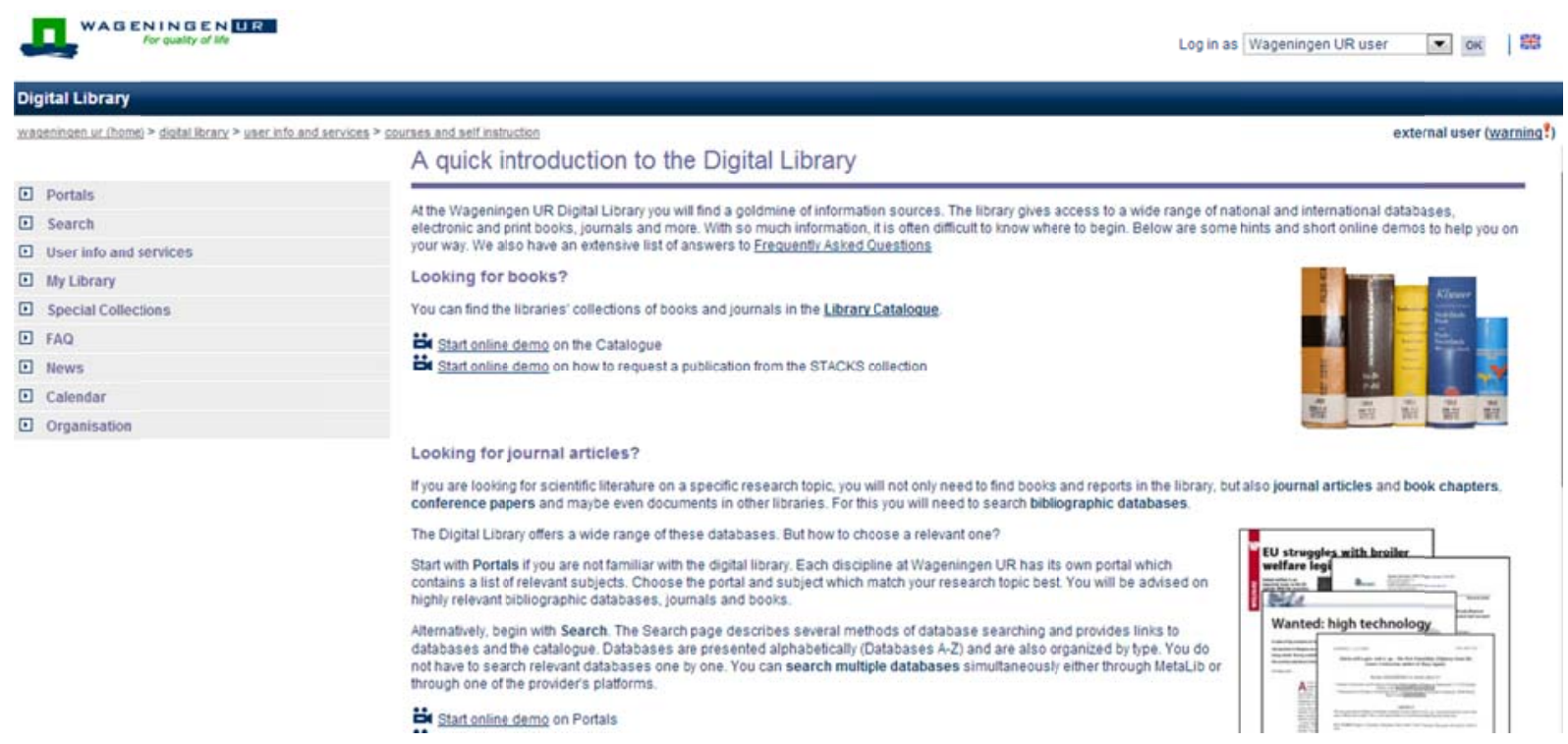

Figura 47. Opciones del servicio de referencia de la Biblioteca WUR.

- Servicio de soporte (Support) que incluye dos servicios Buro Servicio al cliente (Service Desk) y el apoyo de especialista en información (Information specialist)

- Demostraciones cortas (Quick Introduction Sesion) Consiste de una intraducción rápida a los servicios

- Vídeos cortos (Online Demos) con videos que demuestran el uso de los servicios de la biblioteca e instrucciones de uso

En general el servicio de la biblioteca de la WUR responde a los estándares, no obstante siendo el servicio de referencia un pilar importante en el direccionamiento de las demandas, se requiere el manejo de un único e integral concepto del servicio que a su vez vincule e incorpore las dos categorías de servicios anteriormente señaladas. Actualmente no es claro el vínculo (si existe) entre el servicio de Mostrador de la Biblioteca (Library Service Desk) y la opción de Preguntas más frecuentes (Frequently Asked questions).

\subsubsection{Evaluación visual del acceso a los repositorios}

Tal como se indicó anteriormente el acceso a los recursos electrónicos de la biblioteca se realiza a través de la opción catálogo y desde cada uno de los portales que ofrece el acceso a los repositorios. La oferta de estos corresponde a la misión y objetivos institucionales. Asimismo, cumple con las normativas de estandarización, ética internacionales para el acceso y transferencia de información ${ }^{128}$.

\footnotetext{
${ }^{128}$ Estándares internacionales para la descripción de información. Derecho de autor, etc.
} 


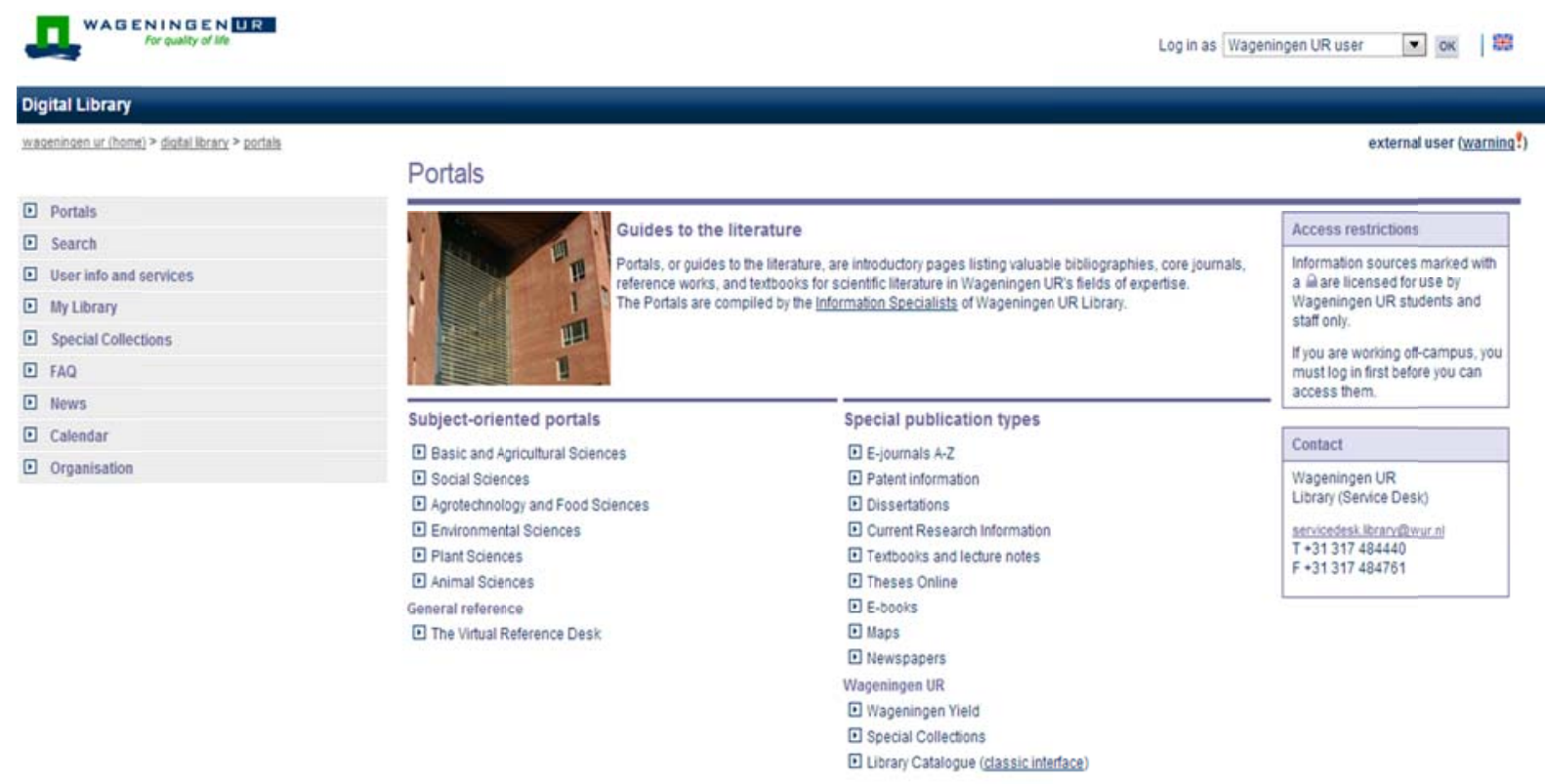

Figura 48. Portal de acceso a los repositorios.

Los resultados de la observación de los repositorios y de consulta realizada con docentes, se identifica algunas limitantes en el diseño de la interfaz y la usabilidad de los recursos.

Como resultado de las pruebas realizadas, se constataron las siguientes limitaciones para el acceso a la información:

- Algunos enlaces de ayuda no son claramente visibles

- Poca visibilidad de los recursos de los repositorios dentro del sitio

- En algunos casos una inadecuada rotulación de repositorios, debido a que se les ha asignado nombres que no proporcionan ninguna información sobre el contenido. Un ejemplo a citar es el caso de Wageningen Yield. Para alguien que recién tiene un vínculo con la universidad el término no resulta suficiente para saber que este enlace nos lleva a las publicaciones propias de la universidad.

Los recursos de los repositorios externos son localizables desde el menú de Búsqueda múltiple en bases de datos. Aunque la opción resulta atractiva para el usuario, el nombre del meta buscador no dice mucho sobre la materia del contenido. Asimismo se carece de opciones de ayuda que orienten el contenido.

En esta misma página se lista a modo de enlaces, los recursos de mayor consulta, que igual que el buscador en bases de datos, se identifica con términos siglas o nombres que no dicen mucho de que se tratan. Solamente los últimos 5 de la lista repositorios disponen de opción de ayuda. 


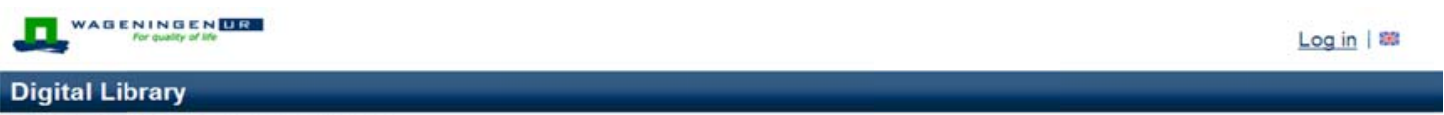

\begin{tabular}{|c|c|c|c|c|}
\hline [] & Portals & \multicolumn{3}{|l|}{ Search } \\
\hline ๑ & Search & \multirow{4}{*}{\multicolumn{2}{|c|}{$\begin{array}{l}\text { Mibliographic databases } \\
\text { Through this page, you can access a wide range of national and } \\
\text { international databases - which you can use to search for journal } \\
\text { articles, books and other publications. Some are large and }\end{array}$}} & Wed. 13 Oct. 2010 \\
\hline ๑ & User info and services & & & Current access problems \\
\hline ๑ & My Library & & & with journals and \\
\hline ๑ & Special Collections & & & \\
\hline & FAQ & \multirow{2}{*}{\multicolumn{2}{|c|}{$\begin{array}{l}\text { The Search multiple databases options are meant for broad searches and in case you don't } \\
\text { know where to start The lists of Frequently used resources will lead you to the native } \\
\text { interface of the databases, with more advanced features for searching. }\end{array}$}} & Current trials \\
\hline ๑ & News & & & OECD iLibrary \\
\hline ๑ & Calendar & \multirow{5}{*}{$\begin{array}{l}\text { Search multiple databases } \\
\square \text { MetaSearch by subject launch a } \\
\text { cross-database search in one of } 21 \text { broad } \\
\text { subject areas } \\
\square \text { MetaLib QuickSearch "quick and } \\
\text { dirty search actions in pre-defined sets of } \\
\text { databases }\end{array}$} & \multirow{8}{*}{$\begin{array}{l}\text { Frequently used resources } \\
\square \text { Databases A-Z } \\
\square \text { Databases by type } \\
\square \text { E-journals A-Z } \\
\square \text { Scopus } \\
\square \text { Web of Sciences } \\
\varpi \text { Google Scholar } \\
\square \text { OvidSP } \\
\square \text { EBSCOhost } 2\end{array}$} & Genes \& cancer \\
\hline & Organisation & & & " all trials \\
\hline & & & & \\
\hline & & & & Contact \\
\hline & & & & $\begin{array}{l}\text { Wageningen UR Library } \\
\text { (Service Desk) }\end{array}$ \\
\hline & & ๑) Provider's platforms: search mutiple & & servicedesk.library@wur.nl \\
\hline & & $\begin{array}{l}\text { databases hosted by OVD, CSA or } \\
\text { EBSCO }\end{array}$ & & $T+31317484440$ \\
\hline & & Books in Wageningen UR & & $F+31317484761$ \\
\hline & & Library & & \\
\hline & & $\square$ Library Catalogue & & \\
\hline
\end{tabular}

Disclaimer Contact

2006 Wageningen UR. All rights reserved

Figura 49. Motores de búsqueda de la Biblioteca WUR.

\subsubsection{Análisis SWOT de los servicios}

Con el objetivo de ofrecer un análisis global y sistémico de los servicios de la biblioteca de la universidad de Wageningen, se ha hecho la aplicación de la metodología SWOT Strengths, Weaknesses, Opportunities, Threats (Fortalezas, Debilidades, Oportunidades y Amenazas) conocido también en el habla hispana como FODA o DAFO en España, siendo el resultado final un conjunto de directrices que pueden ser consideradas estratégicamente para la transformación o diseño de una nueva oferta de servicio de apoyo a actividades E-learning.

\section{Fortalezas}

- Participación en el plan de acción de la Universidad (nuevas líneas de acción) - La moderna capacidad tecnológica de la Universidad

- Fortalecimiento de relaciones de cooperación

- La revisión constante de los servicios e implementación de otros nuevos servicios

Debilidades
- Poca presencia de la biblioteca dentro de nuevos
proyectos de docencia con modalidad E-learning
- Carencia de aplicaciones más atractivas de apoyo a
los docentes
- Poca apertura docente para expresar sus
necesidades de servicios de información y por ende
poco interés de incorporar los servicios de la
biblioteca en sus plataformas de estudio
- Se requiere un mayor posicionamiento de la
biblioteca a nivel interno y externo de la
Universidad
- Desconocimiento la demanda real




\section{Oportunidades}

- El entorno de cambios a nivel de toda la universidad

- La recién apertura a programas de estudios con modalidades E-learning

- Las nuevas oportunidades de cooperación que ofrece el convenio de la Unión Europea - El cambio de líderes dentro de la biblioteca y el proceso re organización interno

- La revisión constante de los servicios

\section{Amenazas}

- Problemas de comunicación a lo interno de la universidad

- Poco involucramiento de la biblioteca en proyectos

E-learning

- El poco aprovechamiento de la cooperación internacional

- Problemas de motivación a lo interno para asumir los retos

- La falta de visión sistémica, (conceptual y práctica) por parte de los líderes en procesos de evaluación de servicios. Se requiere la consulta de docentes, estudiantes y líderes.

\section{Conclusión- Caso WUR}

La biblioteca juega un rol importante dentro del proceso educativo de la Universidad de Wageningen, no obstante, el uso de los servicios ofrecidos por la biblioteca por parte de docentes y estudiantes no es $100 \%$ aprovechable a consecuencia del desconocimiento de la oferta. En esta línea se requiere un mayor posicionamiento de la biblioteca y de sus servicios de forma direccionada hacia cada una de las áreas de trabajo dentro de la universidad. Casos concretos:

- Agrotecnología y grupo de ciencias de alimentos y ciencia animal

- Desarrollo científico

- Ciencias de las plantas

- Seguridad alimentaria

- Ciencias sociales

- Proyección internacional

Del análisis descriptivo y funcional de los servicios de la biblioteca, se refleja que el uso de los servicios de apoyo a procesos de enseñanza - aprendizaje y formación continua, centran su mayor demanda en los siguientes tres grandes ejes: Qué y Cómo encontrar y el Uso mismo de la información para cumplir determinados objetivos.

En esta línea se recomienda la incorporación elaborar una oferta de servicio que presentada en forma de enlace oriente por lo menos a los siguientes tres servicios básicos.

- Servicio de referencia electrónico que permite identificar las rutas de la búsqueda de los recursos

- Cursos de la biblioteca que forme al usuario en el uso de la información para la transformación del estado conocimiento

- Opciones de búsqueda para el acceso a las fuentes de información

La revisión del diseño del sitio web relacionadas con aspectos de visibilidad y acceso para orientar mejor al usuario acerca del contenido de los enlaces, así como la integración de facilidades para personas con discapacidades, resultan oportunos para el mejor uso y aprovechamiento de los recursos que dispone la biblioteca. 


\subsubsection{Universidad Tecnológica de Delft (TUDelft)}

La Universidad Tecnológica de Delft ${ }^{129}$ (TUDelft) tiene alrededor de 165 años de existencia y desde 1986 es conocida con tal denominación "Universidad Tecnológica de Delft".

La universidad surge en primera instancia como una academia del reinado especializada en Ingeniería civil. El 8 de enero de 1842 se constituye la academia por el Rey Pillen II, siendo dirigida por ingenieros y especialistas de la industria de Reino Unido de los Países Bajos y la India.

Después de 22 años la academia recibe el estatus de Escuela Superior, ampliando su oferta de estudios hacia arquitectura, ingeniería de caminos, ingeniería mecánica, contracción de barcos y minería. El 10 de julio de 1905, la Escuela es inaugurada por la Reina Wihelmina como Escuela Técnica Superior, alcanzando un mayor nivel académico.

Posteriormente, en 1985 surgen nuevas leyes para el sistema educativo superior que producen el cambio de nombres de Escuela Superior a Universidad, y es en este momento en el que surge la Universidad Tecnológica de Delft. La estrategia de trabajo de la TUDelft se centra en la filosofía de trabajo cooperativo entre cada uno de los elementos que componen su estructura organizativa.
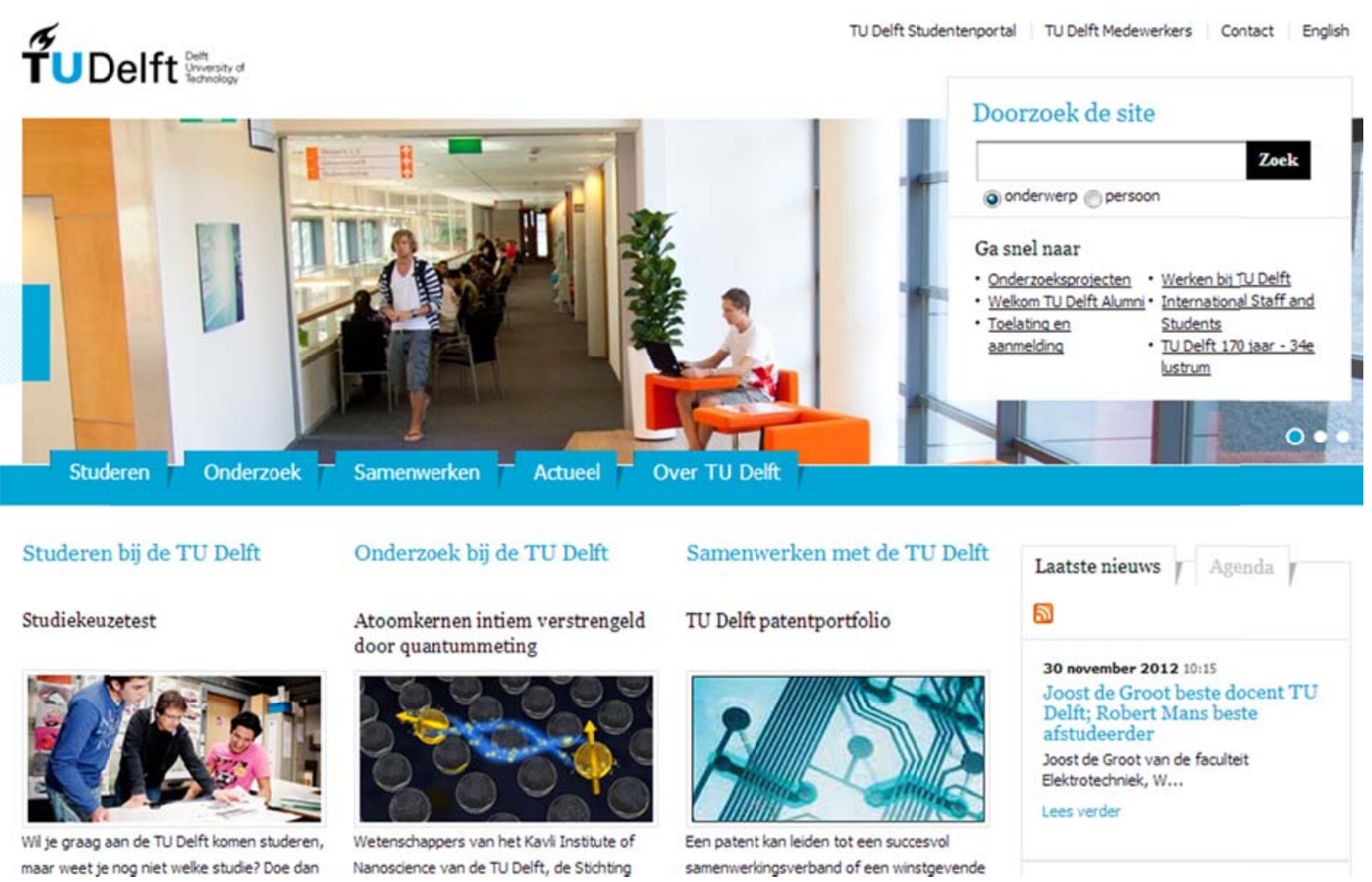

ธิ

30 november 2012 10:15

Joost de Groot beste docent TU Delft; Robert Mans beste

afstudeerder

joost de Groot van de faoulteit

Elektrotechniek, w...

Lees verder

Een patent kan leiden tot een succesvol

samenwerkingsverband of een winstgevende

Figura 50. Página principal de la Universidad Tecnológica de Delft ${ }^{130}$

TUDelft ofrece carreras universitarias, programa de master y doctorados, para ellos dispone de las siguientes nueve Facultades: Arquitectura; Ingeniería Civil y Geografía; Electrónica, Matemática e

\footnotetext{
${ }^{129}$ Antecedentes institucionales han sido retomados y traducidos del sitio Web de la Universidad. http://www.tudelft.nl/live/pagina.jsp?id=300c4edd-74f6-4f4d-a5cd-42a70682cb98\&lang=nl.

130 Portal vigente. Consultado 30-11-2012.
} 
Informática; Diseño Industrial; Aeronáutica y Navegación Espacial; Técnica y Ciencia de la Naturaleza; Técnica, Dirección y Manejo; Ingeniería Mecánica, Marítima y Tecnología de Materiales.

Los diferentes servicios de la universidad tienen como misión facilitar la ejecución de los procesos organizativos y directivos, facilitando así la preparación, modificación e implementación de la agenda de trabajo. En su conjunto los servicios universitarios apuntan a facilitar y hacer transparente las funciones de las siguientes unidades de servicios: Dirección, manejo y apoyo; Carreras y estudiantes; Mercado y comunicación; Control y finanzas; Organización de personal; Facilidades y manejo de bienes; Información, comunicación y tecnología; Electrónica y mecanismos de apoyo; Biblioteca TUDelft (BTUD).

\subsubsection{Biblioteca Técnica de Delft (BTUD)}

La Biblioteca Técnica de Delft ${ }^{131}$ es un componente importante de apoyo prara el desarrollo de procesos de enseñanza e investigación dentro y fuera de la Universidad. Ella provee servicios de información científica y técnica. Como sistema de biblioteca se constituye en una red de seis bibliotecas correspondiente a cada una de las Facultades. La Biblioteca central coordina dicha red desde el Campus universitario Prometheuspleim, donde se encuentra ubicada. Cuenta con una moderna y sólida infraestructura tecnológica que desde cualquier punto facilita el acceso a todos los recursos informativos internos y externos de la biblioteca. El acceso a toda su colección es posible vía Internet e intranet, del mismo modo, los estudiantes y trabajadores pueden acceder a través de un enlace a las revistas electrónicas de texto completo disponibles en línea ${ }^{132}$.
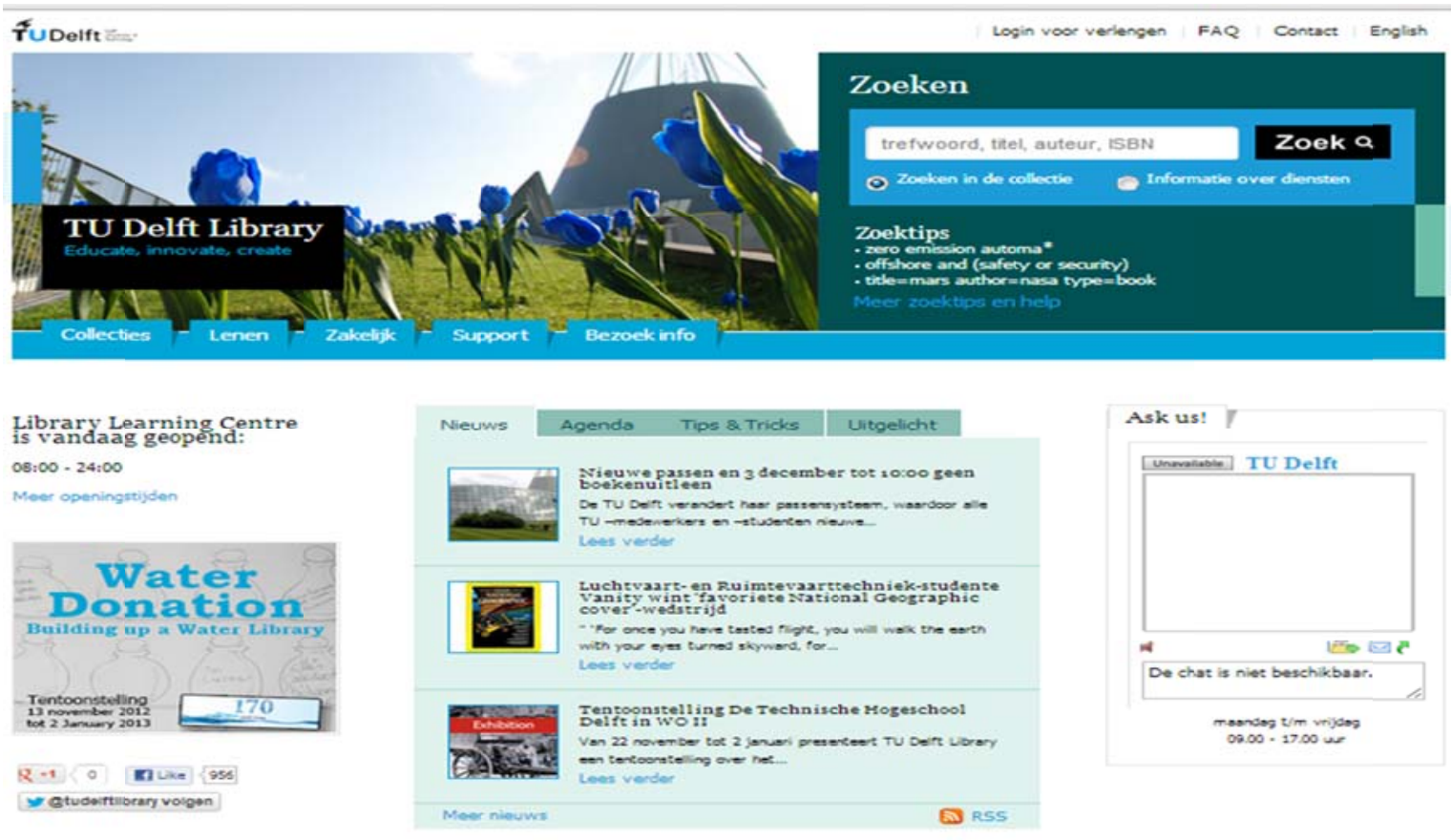

Figura 51. Visualización de la biblioteca desde el portal principal de la TUDelft.

\footnotetext{
${ }^{131}$ Los datos de este apartado han sido tomados del documento de estudio "De strategie stroomversnelling van de Bibliotheek De Technische Universiteit Delft, 004" y otras fuentes actuales disponibles en Internet que se citan correspondientemente en la bibliografía.

${ }^{132}$ La visualización de menú de oferta de servicios ofrecido por la biblioteca de la Universidad de Delft es posible en la siguiente dirección www.library.tudelft.nl
} 


\section{Recursos informativos de la BTUD}

Los recursos informativos corresponden al material de información científico técnico (libros, revistas, bases de datos, patentes, y material de referencia); recursos de información de relevancia temática disponible en Internet, tales como enlaces a sitios web; información sobre congresos, agendas nacionales e internacionales, artículos, documentos, etc., archivos especializados para el desarrollo de actividades y procesos de educación e investigación; medios de comunicación para la interacción con la comunidad académica (eventuales entrevistas y/o consultas de investigación con expertos), y recientes publicaciones de la Universidad.

El proceso de búsqueda y recuperación de información en las diferentes fuentes de información de la BTUD es facilitado a través de un servicio de referencia "Pregunta al bibliotecario" traducido del inglés: Reference desk - ASK a librarian. El sitio URL funciona como un escritorio virtual en el cual el usuario puede interactuar con el bibliotecario y ser guiado por un especialista de información en sus procesos de búsqueda de información. Asimismo recientemente han desarrollado un motor de búsqueda (meta buscador) denominando Discovery con capacidad de buscar información en todas las bases de datos internas y externas.
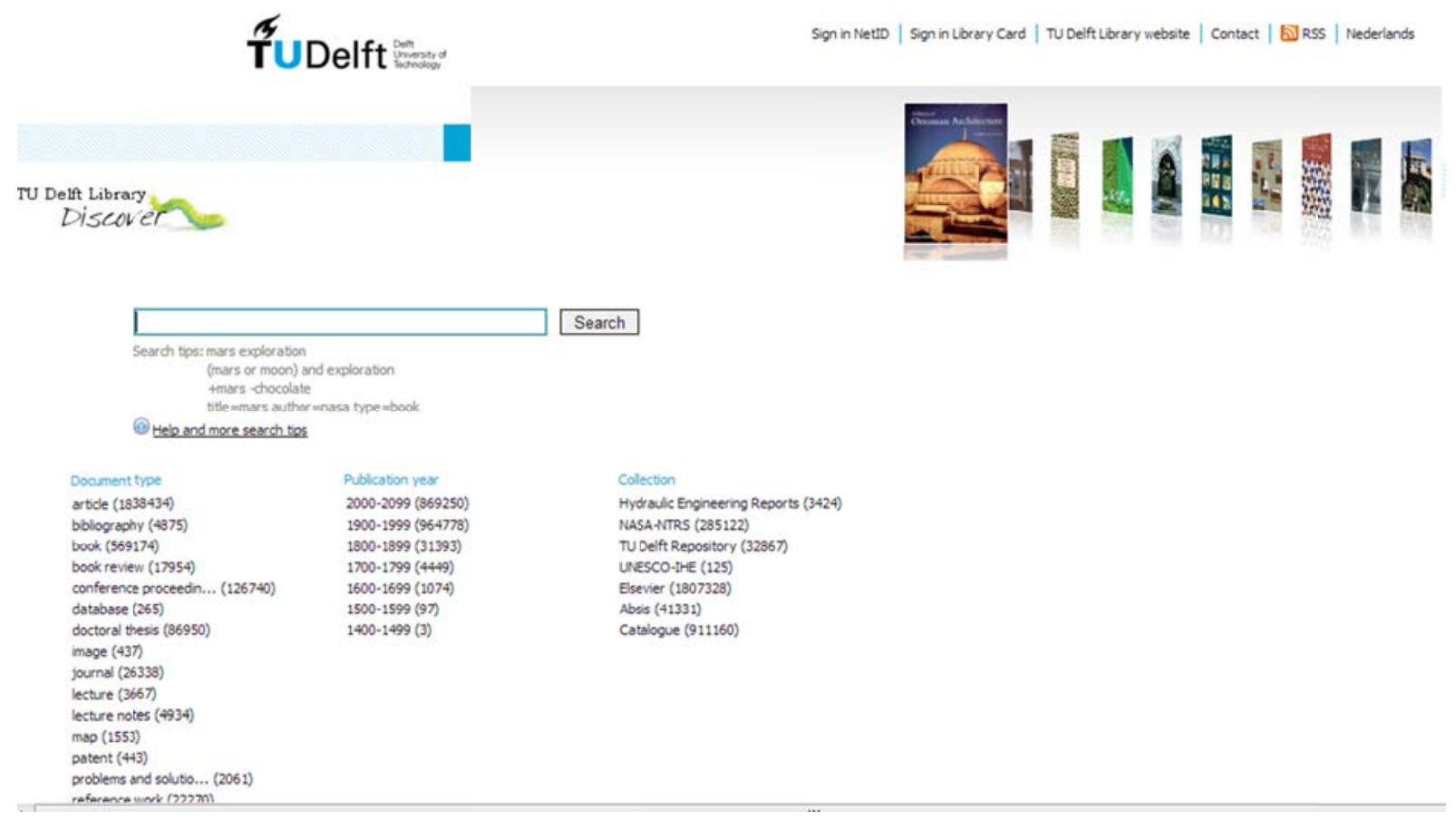

Figura 52. Meta buscador "Discover" de TUDelft.

\section{Servicios generales de información}

- Acceso a los recursos de información disponibles en la intranet e Internet

- Oferta de información digital contenida o referida en soportes electrónicos

- Disponibilidad en línea de documentos textos completos (escaneados a solicitud previa)

- Acceso a los archivos personales de registros

- Facilidad de comunicarse e interactuar vía email o Chat

- Servicios de formación de usuarios

- Servicio de referencia online 


\subsubsection{Evaluación general del sitio web de la BTUD}

\section{Parámetro1. Identidad}

El sitio de la Universidad es identificable desde cualquier buscador en Internet. A simple vista se observa homogeneidad de estilos. El acceso a los contenidos en cada una de las secciones del sitio web de la Universidad es posible en el idioma Inglés y Holandés. Desde la web principal de la universidad, la biblioteca se identifica como una opción en el menú horizontal ubicado en la parte inferior desde la página principal mediante un enlace de palabra TU Delft Library.

\section{Parámetro 2 Actualización}

En general la biblioteca se actualiza periódicamente y esto es posible constatar mediante el indicador estándar de fecha y derechos de autor (02010TU Delft reflejado en la parte inferior de la página del sitio de la Universidad.

\section{Parámetro 3 Accesibilidad}

La conexión y el acceso al sitio resultan rápidos y fáciles dentro y fuera de la ciudad de Delft. A simple vista no fue posible identificar en el sitio facilidades de uso de los servicios para personas con alguna incapacidad física, auditiva o visual, pero durante el análisis exhaustivo del servicio de cursos de formación de habilidades se constató la opción para personas con limitaciones visuales. En general el acceso a los servicios, productos de la biblioteca es siempre posible gracias a la permanencia de un buscador (Search) representado por una ventanilla en casi todas las secciones del sitio de la biblioteca.

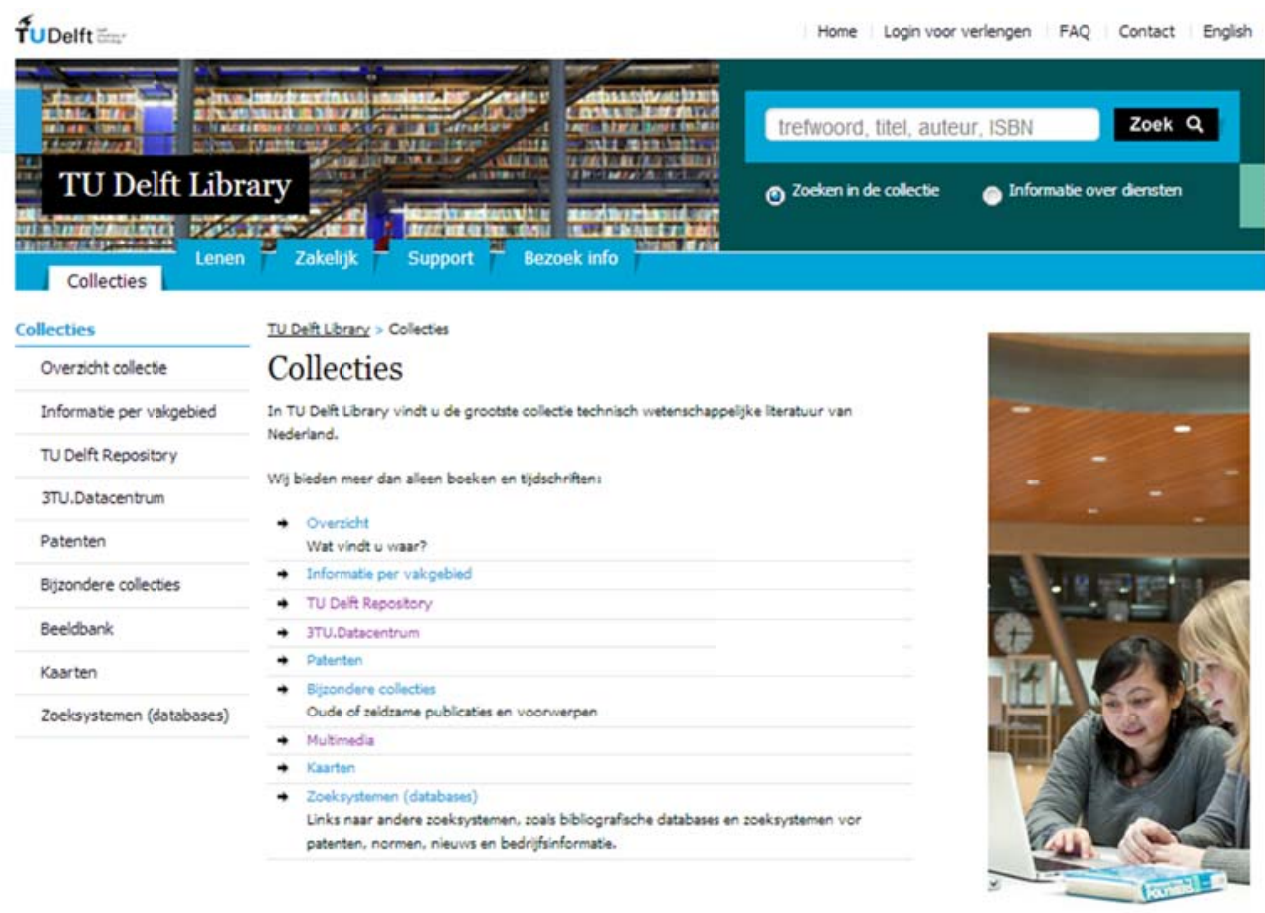

Figura 53. Oferta de acceso a las bases de datos y repositorios de la BTUD 


\section{Parámetro 4. Servicios básicos de la web}

Los servicios básicos que a continuación se listan son ofrecidos por el sitio de la biblioteca en casi todas sus secciones. Los sitios más populares son:

- Grupo / comunidades virtuales vía Twitter

- Acceso a diversos Metadatos

- Recursos Metadatos

- Portales, Correo electrónico, Chat, RSS

- Diversos (noticias, variedades, entretenimientos, etc.)

Según datos obtenidos de los empleados, se calcula que el tiempo aproximado de respuesta entre la demanda y la respuesta varia en dependencia del servicio. Generalmente el rango dura entre 12 y 24 horas. Según datos de estudios de usuarios registrados el rango de satisfacción promedio es entre el 80 y $90 \%$.

\section{Parámetros 5. Contenidos}

La organización de los contenidos se encuentra bien estructurada y los temas de contenidos son visibles. En general la biblioteca y el sistema de Centros Virtuales de Información y Conocimiento (VKC) se valen de todos los recursos informativos analógicos y electrónicos disponibles en formatos HTML, pdf, ascci, dot, etc. Entre ellos se destacan las colecciones especiales, recursos multimedia, material académico de programas virtuales, los repositorios de resultados de investigaciones, bases de datos externas de ámbito nacional e internacional.

\section{Parámetro 6. Arquitectura de la información}

El proceso de navegación dentro del sitio de la biblioteca se considera apropiado, por cuanto el enlace entre página y paga es de segundo. Las rutas definidas para el acceso a los contenidos son enlaces ordenados en forma de menú y claramente visibles como opciones. El sitio web de la biblioteca se apoya en sistemas de menú, donde cada opción representa un enlace a un servicio específico. Un ejemplo es el servicio TULIB se visualiza en el siguiente conjunto de Figura $s$ las diferentes opciones ofrecidas al usuario para acceder a los contenidos de diferentes formas. En la primera la búsqueda en través de enlaces o términos ofrecidos por TULIB; en la segunda ilustración desde el catalogo, mediante un sistema de menú que incluye iconos. En ambos caso se observa la presencia permanente de una ventana para formulaciones de búsquedas libres. 


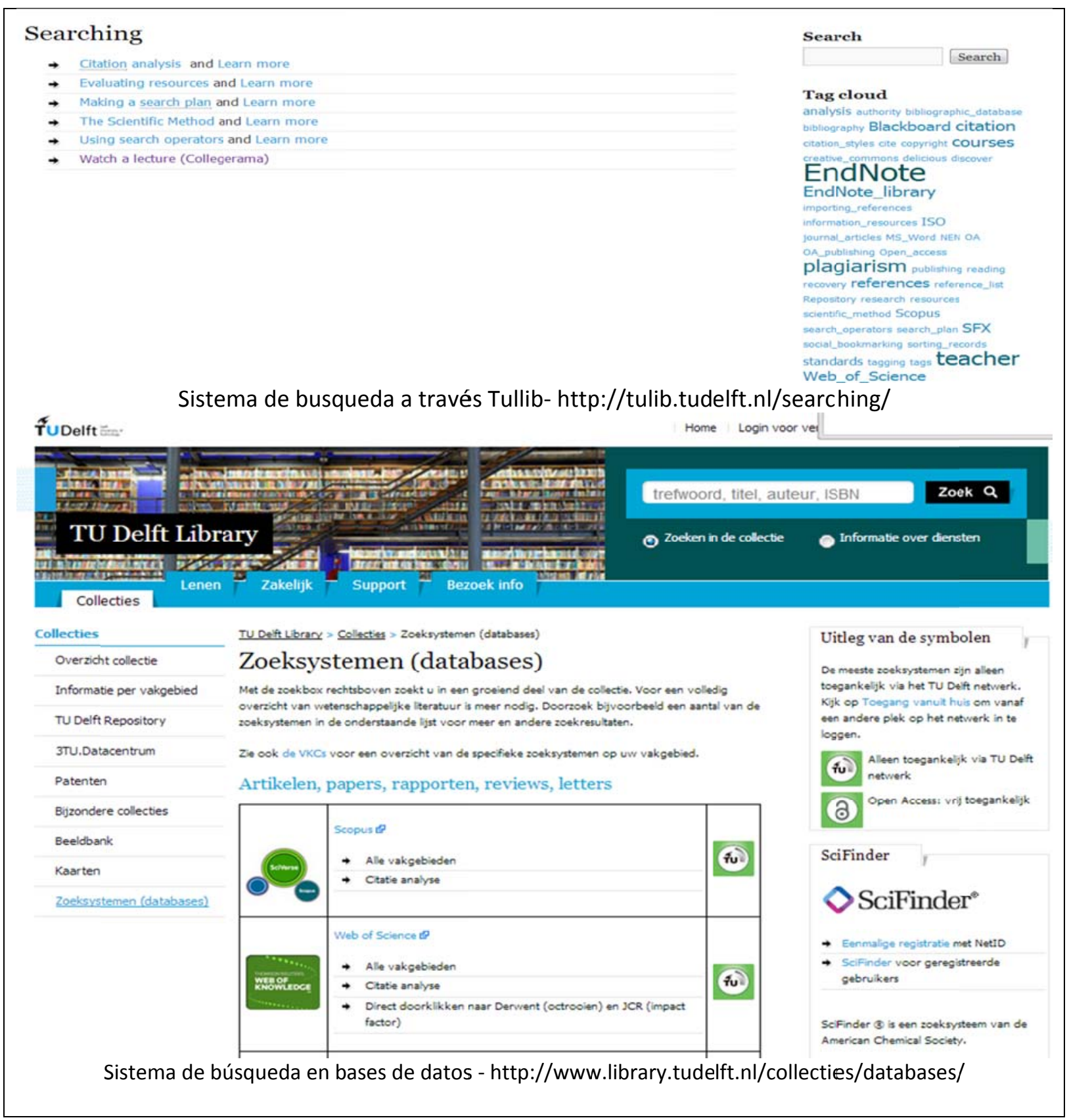

Figura 54. Buscadores general de la Biblioteca TUDelft.

Como se observa en la figura anterior, el sistema de búsqueda ofrece la posibilidad de ubicarse dentro del sitio y enlazar con otra sección a través de la opción de "mapa del sitio" que se presenta al igual que la opción de búsqueda y casi en todas las secciones de forma permanente. En caso de documentos o publicaciones electrónicas disponibles en formatos pdf en HTML se identificó que es posible la lectura secuencial en el contenido, es decir existe la posibilidad de seguir un contenido de forma total, parcial o de forma secuencial. La velocidad o tiempo de descarga de los documentos o publicaciones se considera rápida tomando en cuenta que el tiempo promedio de descarga por página es de 25 segundos.

Partiendo de las pruebas realizadas, es posible señalar que tanto la búsqueda, la identificación y descarga de los documentos no presenta ningún tipo de problema en cuanto a conexión, 
visualización y uso de la información. Asimismo se comprobó el cumplimiento de los siguientes parámetros de calidad en la presentación de los contenidos de los recursos de información.

- Autoridad de autores reconocida

- Adecuación entre la autoría y la agenda temática.

- Adscripción del autor a la organización que pertenece

- Factibilidad de contacto entre el autor-usuario de la fuente

- Reconocimiento y credibilidad de la fuente

- Identificación básica de las diferentes secciones de la publicación (autor, título y fechas)

Los usuarios de la BTUDELFT tiene la posibilidad de copiar y transferir archivos sin ningún problema, no obstante es evidente el cuido a la propiedad intelectual, por cuanto los documentos en su mayoría tienen formato PDF. Sin embargo una limitante identificada fue que el uso de algunos tutoriales, el sistema demanda la instalación de determinados programas o capacidades en el computador como se presenta de forma concreta en la siguiente figura ${ }^{133}$.

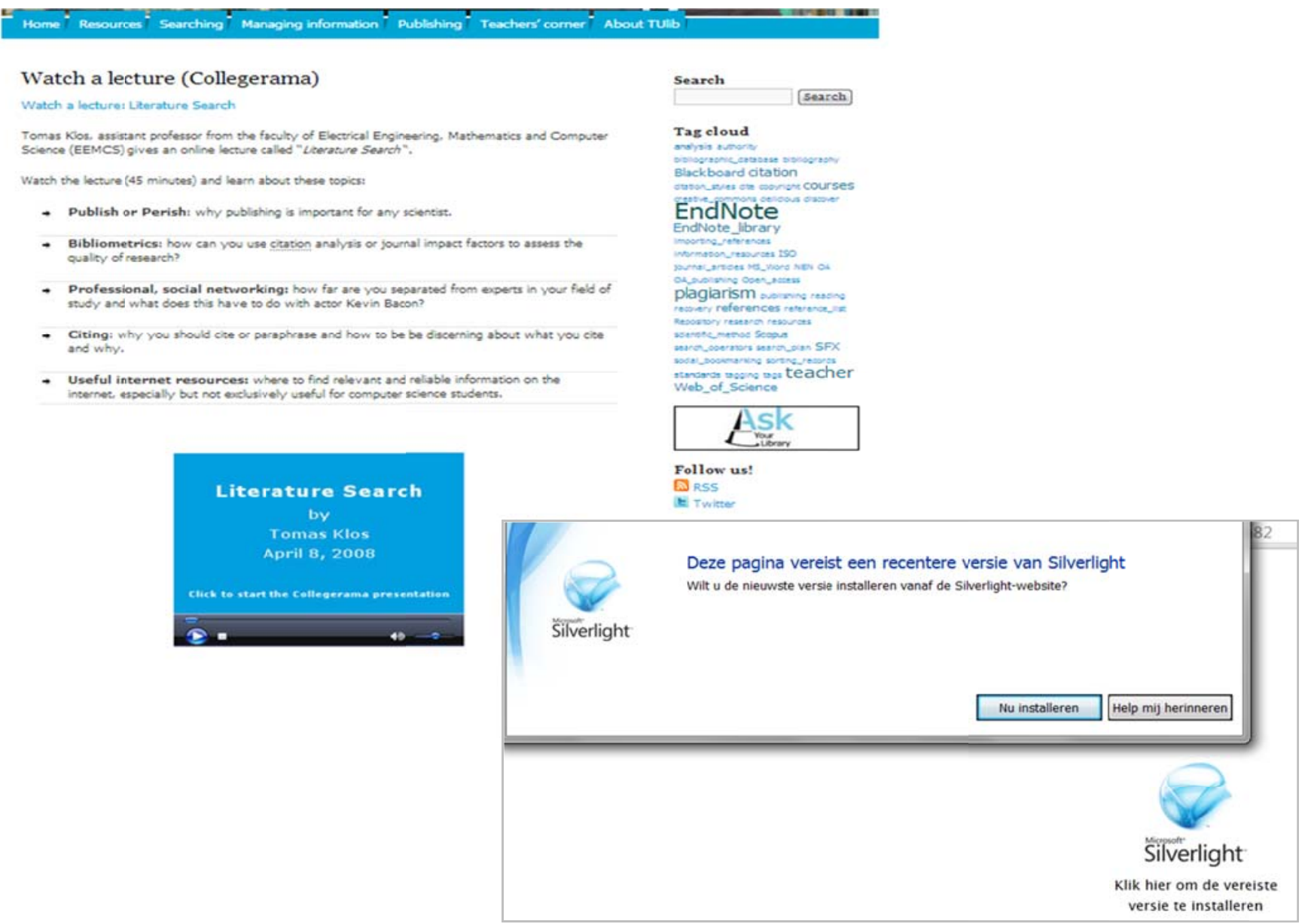

Figura 55. Ejemplo de petición de descarga de programa

\footnotetext{
${ }^{133}$ La descarga de programas es realizado desde el sitio de la biblioteca http://tulib.tudelft.nl/. Sujeto a prueba 30-11-2012
} 


\section{Parámetro 6. Diseño de la interfaz}

En general el diseño del sitio web de la Universidad de Delft como el de la biblioteca, resulta ser coherente y se caracterizan por la consistencia y consecuencia en su aspecto físico y detalles ergonómicos agradable a la vista que facilitan la navegación y uso de los recursos disponibles. Los aspectos físicos y ergonómicos que son notables en el diseño del sitio web son:

- Consistencia y contraste en el uso de colores

- Consecuencia en el uso de tipo, tamaño de letras, aunque resulta pequeña

- Consistencia en el uso de líneas de texto, márgenes y anchura de pantalla

- Consistencia entre la claridad o contraste adecuado entre el texto y el fondo que facilitan la legibilidad

- Flexibilidad para realizar búsquedas desde las diferentes secciones del sitio.

Es importante destacar que en cada una de las secciones de la web existe la opción de preguntas mediante el servicio de referencia o las opciones Chat, Twitter, RSS, etc. Se observó además que el uso adecuado de imágenes o sonido como complementos a la información textual. Ejemplo de ello son los archivos utilizados para orientar el uso de los servicios de la biblioteca en los cuales se combina la descripción de algo acompañada de un demostrativo visual o video.

\section{Parámetro 8. Posicionamiento}

La identificación del sitio de la biblioteca de la Universidad de Delft es posible mediante el acceso directo a la dirección URL o bien mediante la búsqueda del término cualquier buscador como Google, Yahoo y otros.

\section{Parámetro 9. Sistema de búsqueda y recuperación}

Tal como se ha mencionado en el análisis del parámetro 5, lo interno de la biblioteca se ha desarrollado diferentes aplicaciones para realizar búsquedas dentro del sitio web de la biblioteca. Estos facilitan el despliegue de resultados en diferentes formas y facilita el enlace hacia las publicaciones en formatos electrónicos.

Los resultados de búsquedas realizadas durante las pruebas en el sitio web de la biblioteca reflejaron que existe una mayor aproximación en los resultados obtenidos del catálogo, que en los meta buscadores. Este hecho responde al hecho que en el catálogo existe mayor cuido en la semántica al momento de las descripciones de los recursos.

Una de las facilidades que ofrecen los buscadores como Discovery son los mensajes de ayuda que orientan al usuario como formular la búsqueda misma valiéndose de operadores auxiliares. Sin duda, es un instrumento útil para la recuperación de la información. 


\section{Parámetro 10. Usabilidad}

El parámetro usabilidad fue evaluado mediante la consulta al sitio fuera de Delft y dentro de los Países Bajos. No se observó problemas de conexión, tampoco de velocidad en procesos de navegación. En general el proceso de evaluación de servicios se realiza de forma irregular y generalmente a través de un estudio de satisfacción de necesidades de los usuarios del servicio.

La única limitante identificada fue el acceso a las secciones de préstamo y cursos de formación de usuarios que requieren de una autorización IP, es decir clave de acceso. Sin embargo es posible tener acceso a algunas publicaciones disponibles a través del convenio de acceso abierto. Se comprobó la posibilidad de copiar, guardar y citar. Ejemplo de esto se ilustra a continuación en una búsqueda hecha en el meta buscador Discovery.

Paso No.1 Formulación de la búsqueda

TU Delt Library

Discover

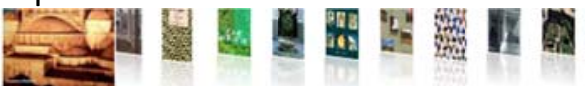

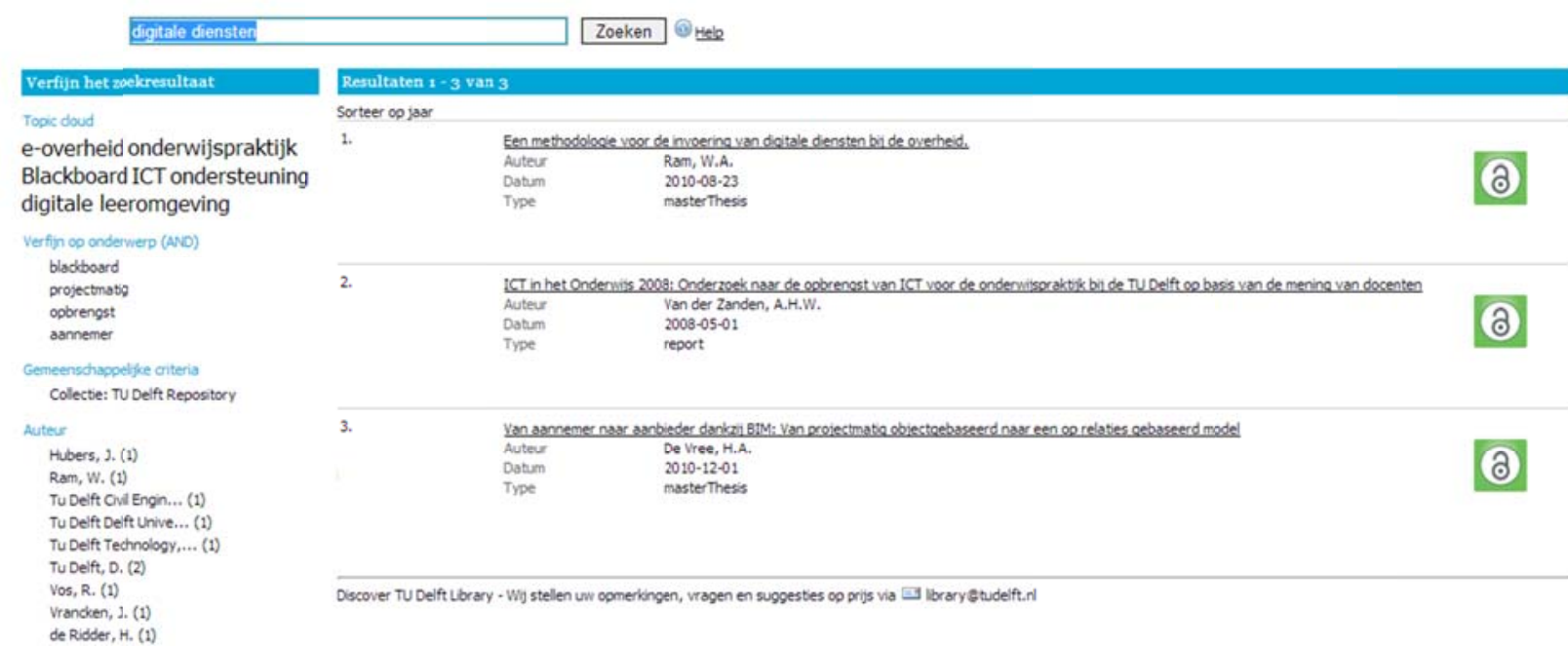

Paso No.2 Selección del documento deseado

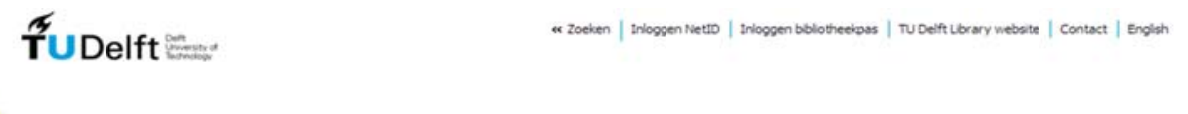

TU Deift Library

Discove

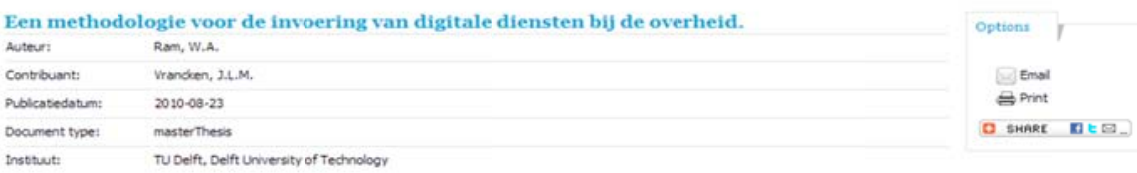

(2) ander apen accees 
Paso No.3 Resultado final: el documento no esta disponible en libre: acceso.

\section{TUDelft . . Institutional Repository}

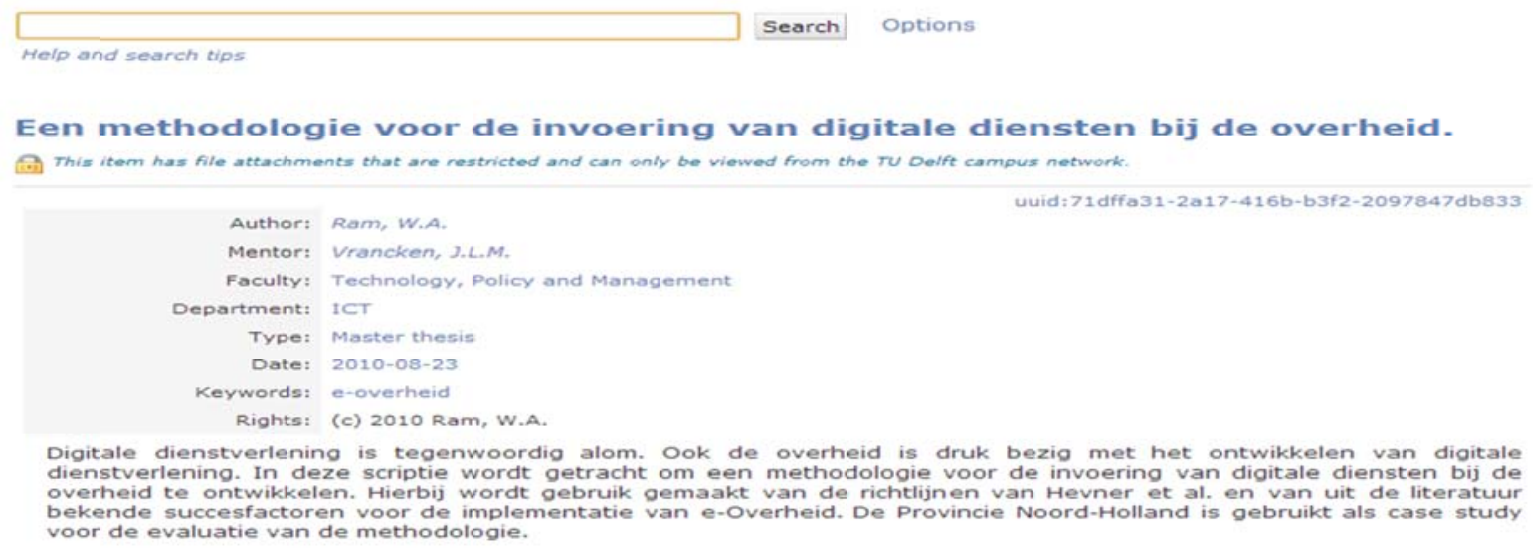

Figura 56. Proceso de búsqueda en Discover.

\subsubsection{Evaluación del servicio de referencia}

El servicio de referencia que ofrece la biblioteca de la universidad Tecnológica de Delft (BTUDELFT) se considera excelente. El concepto del servicio esta presente en de cada uno de los servicios ofrecidos por la biblioteca (secciones y contenido de la web) generando el sentimiento de "acompañamiento" en los usuarios. Por las características del servicio, el contenido del servicio, experimenta una constante actualización.

En relación al diseño de la interfaz se reconoce coherencia entre concepto y práctica, un dinamismo y claridad en los mensajes, por lo cual está en correspondencia con los objetivos perseguidos. El diseño del servicio de referencia se destaca en general dentro del sitio web de la biblioteca por el uso de cuatro íconos que aunque son para diferentes funciones, es claro que pertenecen al servicio de referencia.

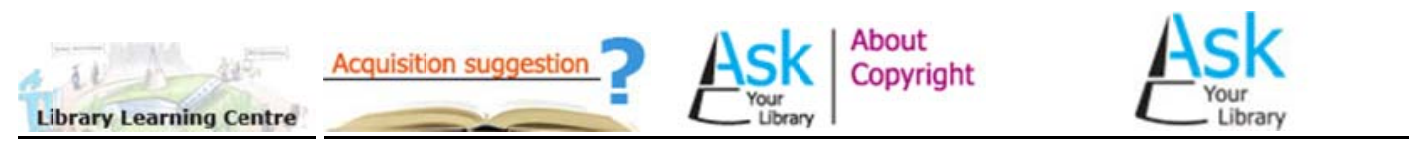

La orientación del servicio ocurre a dos niveles. Primero como un servicio que orienta y facilita el acceso a obras y recursos generales y segundo como punto de información referencial que filtra las preguntas y solicitudes que posteriormente son remitidas hacia la fuente, persona que hace disponible recurso de información o dar una respuesta a la pregunta.

Los componentes básicos del servicio de referencia son:

a) Comunicación con el usuario

Pregunte a la biblioteca - ASK your library. Consiste en un sistema de comunicación dinámico que se vale de diferentes medios de comunicación interactivos, sincrónicos y asincrónicos en los que se destaca el correo electrónico (email) y el diálogo interactivos como chat que incluye las posibilidades de Messenger, Yahoo, talk, AIM y Twitter reconocidos con los íconos que a continuación se ilustran: 


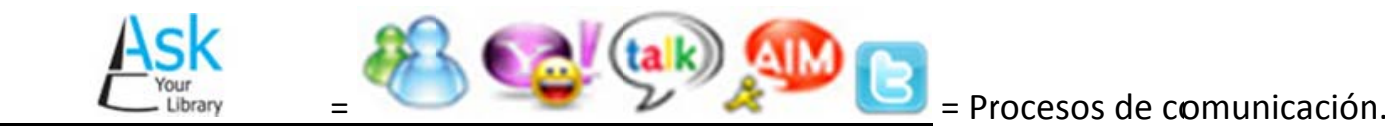

Asimismo desde este componente del servicio, es posible acceder a un menú de enlaces directos con opciones de renovación de préstamos, la lista de precios, solicitudes de envío de artículos electrónicos o fotocopias, solicitud de reservaciones y la opción de "envíe una sugerencia"

b) Acceso a obras de referencia

Se considera como un repositorio de materiales de información científicos. Su de acceso limitado a usuarios suscriptos a la universidad. Otros recursos de Internet que posibles son materiales de acceso libre, son RSS, Blogs, Wikis, etc.

Los objetivos a que apunta el Servicio de Referencia son:

- Responde a necesidades concretas de información

- Facilitar de forma eficiente y eficaz las respuestas a preguntas concretas

-Actuar como intermediario y direccionar adecuadamente las demandas de información entrantes dentro de la biblioteca.

Resulta importante destacar que el recorrido y navegación en cada una de las secciones se ve facilitado a través de la presencia de enlaces en forma de íconos o términos localizados en cada una de las secciones. Asimismo la presencia de mapa contenido del sitio permite por un lado ubicar tanto los contenidos como la ubicación misma del usuario dentro del web site, sin embargo no resulta visible si este servicio ofrece facilidades para usuarios con incapacidades físicas, auditivas o visuales.

\subsubsection{Evaluación del servicio de cursos de formación de usuarios (ALFIN)}

El servicio de formación de habilidades, destrezas y competencias en el manejo de información, conocido popularmente como alfabetización informacional (ALFIN) de la BTUDEFLT se estructura en tres partes:

1. El servicio de referencia dirigido a proceso de búsquedas identificable en el sitio como el TUlib.

2. La formación de estudiantes como usuarios de la biblioteca, que involucra del desarrollo de talleres y cursos basado en estándares internacionales de ALFIN ${ }^{134}$ incluye actividades de aprendizaje sobre el uso de los servicios de la biblioteca.

3. Cursos de formación especializada sobre técnicas de búsquedas avanzadas, citación y peticiones concretas de los miembros de la comunidad científica y académica.

\footnotetext{
${ }^{134}$ Véase http://www.ala.org/ala/mgrps/divs/acrl/issues/infolit/index.cfm y http://www.ala.org/ala/mgrps/divs/acr//issues/infolit/standards/standardstoolkit.cfm.
} 
Del análisis realizado del servicio se destacan dos niveles de prácticas de formación de usuarios. La primera forma de servicio se identifica como Talleres (Workshop) y la segunda orientada a formación de habilidades y destrezas en el manejo de información científica (ALFIN). Esta oferta está orientada a usuarios expertos que desean profundizar sobre mecanismos de búsquedas avanzadas, técnicas de citaciones, procedimientos para publicar, derechos de autor entre otros temas.

\section{Talleres de formación de usuarios}

Los Talleres de formación de usuarios están dirigidos a estudiantes, docentes y empleados involucrados en actividades de la universidad. El objetivo y práctica estos son cursos talleres se orienta proporcionar un nivel básico de conocimientos en los usuarios, a fin de generar en ellos capacidades para realizar búsquedas que garanticen resultados acordes a la necesidad de información. Los recursos utilizados en el desarrollo de los talleres corresponden al servicio de referencia, los archivos demostrativos, videos y la guía virtual ofrecida por la biblioteca.

\section{Cursos de formación en procesos de investigación científica}

Los cursos de formación de habilidades y competencias en el manejo de información en procesos de investigación científica (ALFIN) son de acceso limitado. Estos se ofrecen como créditos dentro de materias de curso.

Hacer una evaluación del servicio fue un complejo, debido a que el acceso requiere una clave de acceso, sin embargo a través de la entrevista sostenida con Nicoleta Nastase, especialista en información de la Biblioteca de la Universidad de Delft ${ }^{135}$ fue posible acceder a los contenidos y por ende obtener una visión clara de la estructura organizativa.

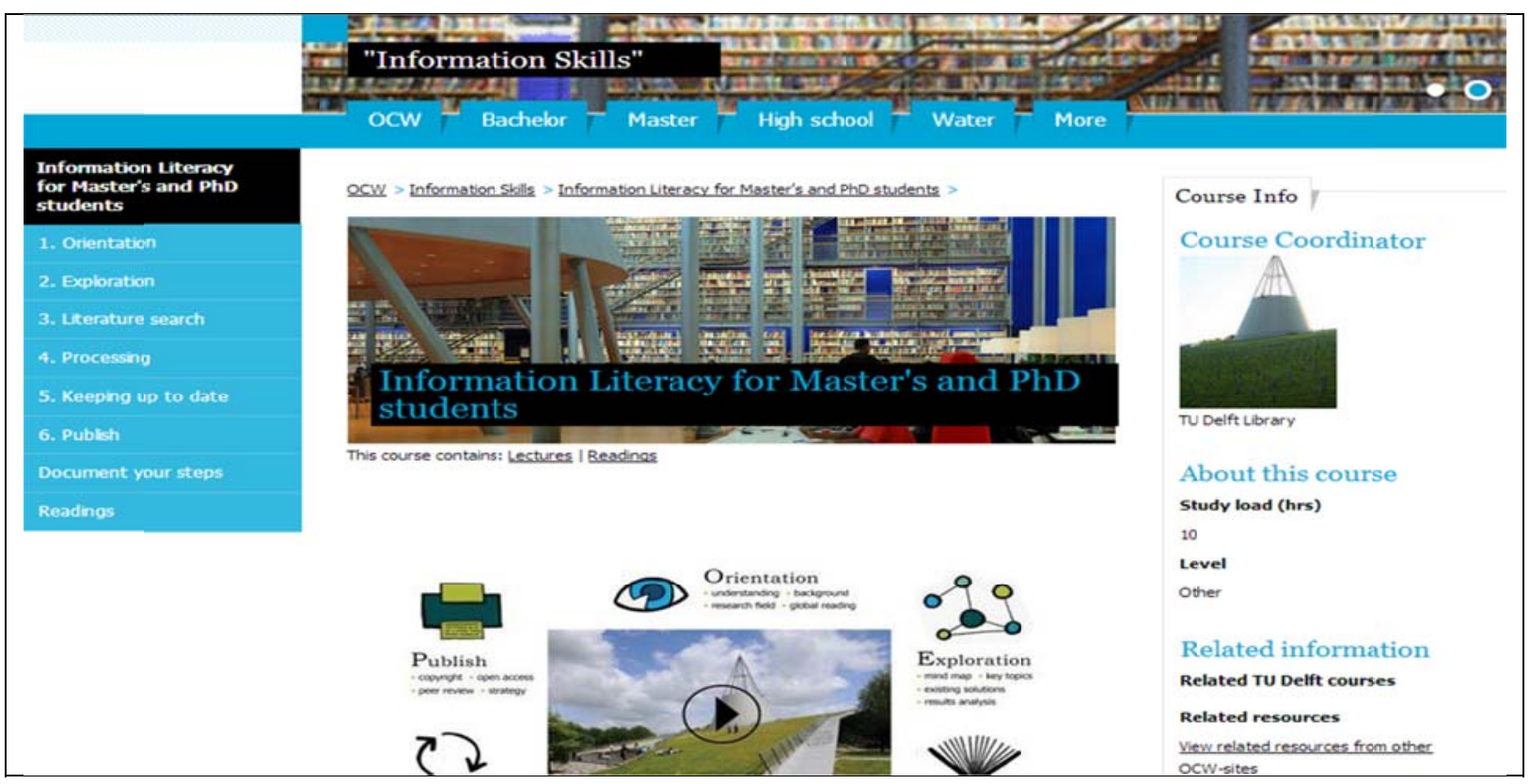

\footnotetext{
${ }^{135}$ Nicoleta Nastase. Especialista en información de la Biblioteca de la Universidad de Delft Véase perfil profesional en http://www.linkedin.com/profile/view?id=20632106\&authType=name\&authToken=LuWF.
} 


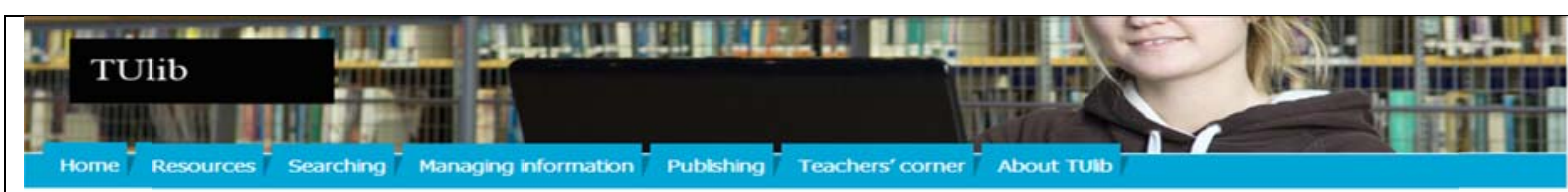

Teachers' corner - Instructions Information Literacy

Instructions:

- Information Literacy

- Information Literacy for Master's and PhD students

Information Literacy 1

After following the instruction information literacy 1 , which is built in and available in Blackboard, the students should be able to select the relevant information sources, search these sources in the right way, and report properly about the results, i.e. make correct references in the report, make a correct and consistent bibliography, paraphrase and cite correctly, and know how to avoid plagiarism.

\section{Checklist for teachers}

Also a role has been granted to the teachers, in whose course the information literacy instruction is incorporated. For these teachers a checklist has been composed. This will help them to organize the information literacy instruction sessions.

Directions for the Information Literacy instruction 1

As mentioned before, the first year's information literacy instruction is built in and available in Blackboard. The students follow the instruction during sessions at the faculty, but can access the instruction afterwards and anywhere for reference purposes. A document has been prepared explaining how the students can enrol for and start the instruction.

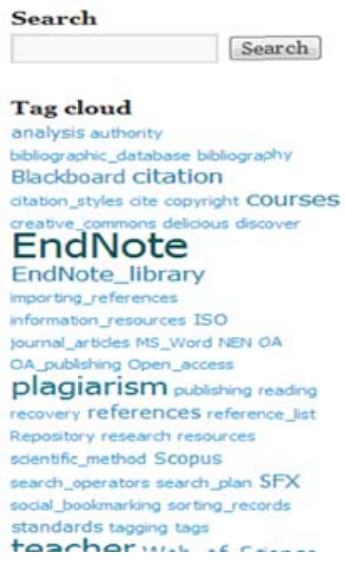

Figura 57. Oferta de ALFIN.

Los contenidos de los cursos de ALFIN considerados "créditos" se encuentra organizados y accesibles a través del sistema de manejo de contenidos y plataforma E-learning conocida como Blackboard ${ }^{136} \mathrm{y}$ reconocido por la flexibilidad para uso de diferentes procesadores de datos y gramas (software) interactivos. La universidad en general utiliza para todos sus cursos un estándar de color, tipo y tamaño de letra, y determinados logos, no obstante los profesores a nivel interno pueden personalizar el contenido de los cursos. Es importante señalar que aunque la biblioteca es usuaria de este sistema, la gestión y mantenimiento del LCMS es responsabilidad de la oficina encargada del Servicio de apoyo a aprendizaje, identificable en el sitio web de la universidad como "e-learning support" ${ }^{\prime 137}$. En la siguiente figura se ilustra la estructura del Blackboard TUTDELF y algunos cursos ofertados.

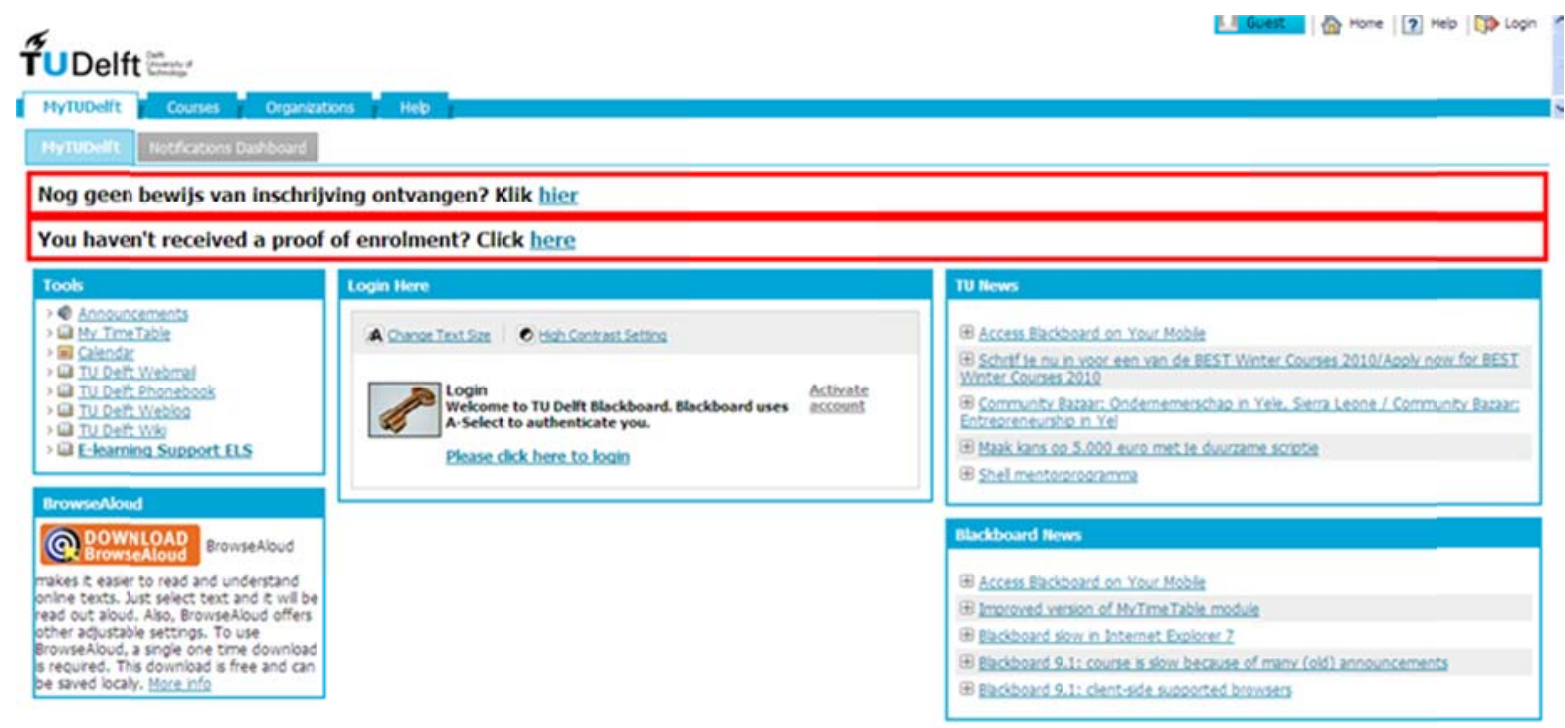

Figura 58. Aplicación de Blackboard de Biblioteca TUDelft.

\footnotetext{
${ }^{136}$ Es un programa de Blackboard para administrar aprendizaje en línea (e-learning), y manejo de comunidades en línea. Blackboard ha anunciado recientemente su «Blackboard Beyond Initiative», con la que pretende llevar el e-learning a una nueva fase (e-Learning 2.0) de la mano de la filosofía del Web 2.0. Véase http://cent.uji.es/octeto/node/1943

${ }^{137}$ https://blackboard.tudelft.nl/webwebapps/portal/frameset.jsp?tab_tab_group_id=_3_1
} 
Durante la revisión del sitio E-learning de la biblioteca en el sistema Blackboard, se identificó tres cursos ofrecidos por la biblioteca que están insertos como parte de una materia dentro de un programa de estudios. Especialistas en información son responsables de la organización, diseño y desarrollo de los cursos, quienes en estrecha coordinación con los docentes de la materia logran el cumplimiento del objetivo. Los cursos identificados al momento de estudio de caso se reconocen con el nombre de "information literacy" y seguidamente se listan.

- IOS Information Literacy

- Information Literacy 2 Aerospace Engineering (2010-2011)

- Information literacy Aerospace Engineering (2010-2011)

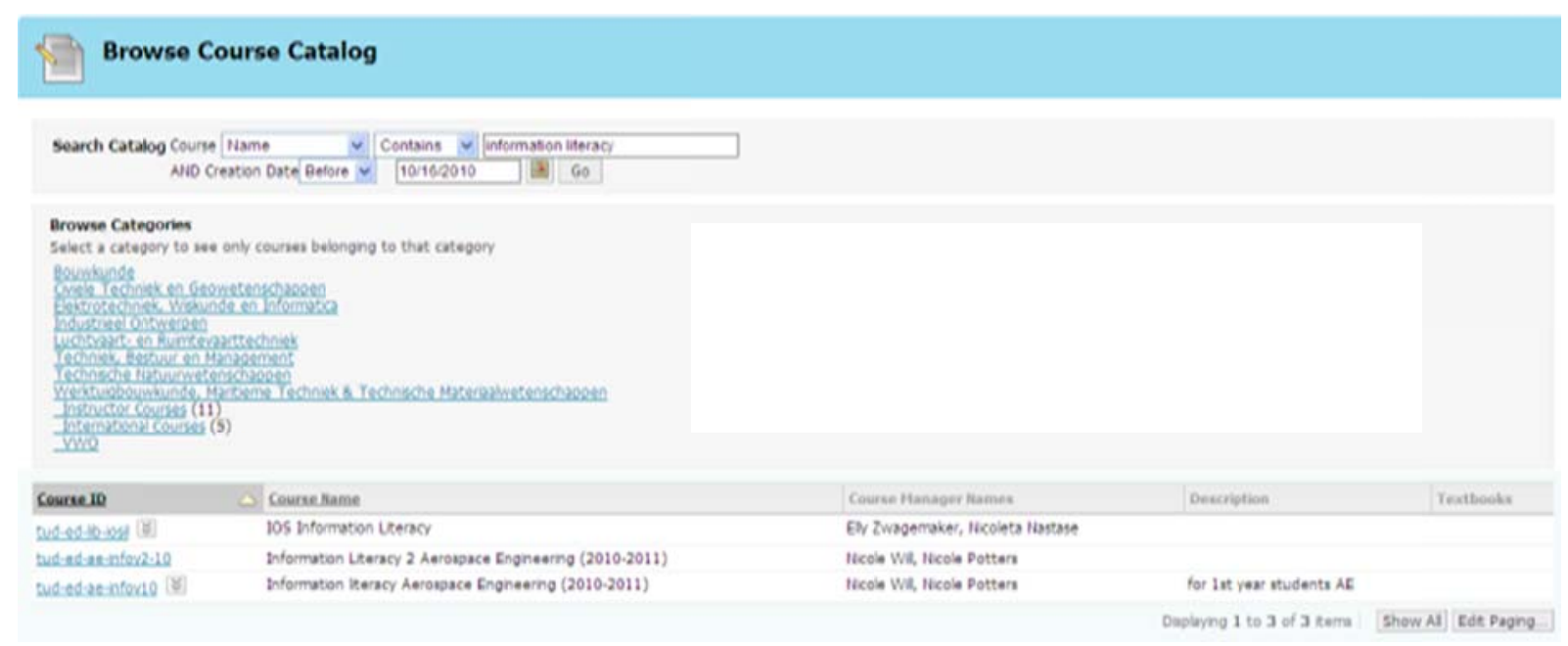

Figura 59. Oferta de cursos de la Biblioteca en Blackboard.

\subsubsection{Evaluación visual del acceso a los repositorios educacionales BTUDELFT}

La BTUDELFT es responsable de la organización y manejo de todos los repositorios propios de la Universidad Tecnológica de Delft, lo que representa una importante contribución en las áreas de trabajo, tanto a nivel nacional e internacional. Estos repositorios son una iniciativa desarrollada en conjunto con el programa DARE ${ }^{138}$ Se trata de un proyecto que involucra todas las universidades del Reino Unido de los Países Bajos, la Organización Holandesa para la Investigación Científica ${ }^{139}$ y la Academia Real de Arte y Ciencia ${ }^{140}$

Los repositorios de la BTUD son reconocidos nacional e internacionalmente por su nivel científico, especificidad, y actualidad. Una copia de cada uno de los documentos se encuentra depositada en la Biblioteca Nacional. Las publicaciones son accesibles por todo el mundo a través de Internet, Google Scholar, Yahoo y Scirus.

Además; las publicaciones de la Universidad Tecnológica de Delft también se encuentran registradas en un sistema de información de investigación, conformado por universidades, organizaciones de

\footnotetext{
${ }^{138}$ Digital Academic Repository www.darenet.nl. Su objetivo es estimular las redes nacionales de repositorios científicos. DARE actualmente ofrece el acceso a 100,000 publicaciones científicas.

${ }^{139}$ Detalles de la organización NWO están disponible en http://www.nwo.nl/

${ }^{140}$ Detalles de la organización KNAW http://www.knaw.nl/
} 
investigación e investigadores denominado $\mathrm{METIS}^{141}$. Este sistema de información aglutina en una base de datos los trabajos de investigación y facilita el acceso a través de portales. Cabe destacar que no existe restricción alguna al acceso a las publicaciones científicas de la Universidad en DARE y METIS. La protección de los derechos de autoría y originalidad de contenidos están legalizados por las leyes; razón por la cual existe una normativa sobre el manejo de los repositorios y las prácticas de acceso abierto ${ }^{142}$.

Otro repositorio de gran valor informativo es la colección de libros, revistas y mapas antes de 1850 conocida como TRESOR. Dispone de una colección original de la biblioteca de la Universidad Franeker, desaparecido en 1811. Por su valioso contenido técnico en el área de ingeniería, ésta es preservada y utilizada como material de referencia. La colección se compone de 40,000 volúmenes. El uso de esta colección está dirigido a la investigaciones o estudios históricos técnicos científicos, la investigaciones en industria arqueológica y a la investigaciones de procedencia e interés personal. En general se puede afirmar que la BTUDELF posee una riqueza de recursos de información de gran valor para el proceso de enseñanza - aprendizaje, independiente de las modalidades del proceso educativo. La actual apertura de acceso a los recursos científicos Open Access representa un mecanismo complementario a la oferta actual.

\subsubsection{Análisis SWOT de los servicios}

Los resultados del análisis del sitio web y de los servicios digitales ofrecidos por la biblioteca de la Universidad Tecnológico de Delft, han generado una serie de insumos que vertidos y organizados en la metodología SWOT ${ }^{143}$, hacen posible proporcionar en una visión sistémica y global los puntos fuertes y débiles a considerar en posibles futuros proyectos de servicios vinculados a E-learning.

\section{Fortalezas}

- Los cambios a favor de la modernización en las modalidades de educación representan un principio de TUDELFT. Este hecho motiva la constante revisión, mejoramiento de la oferta sus programas de estudios, cursos y servicios. En esta línea la biblioteca hace la revisión constante de su oferta, transformándolos y generando nuevos servicios y productos digitales acordes a la coyuntura y cambios institucionales.

- La presencia y posicionamiento de la biblioteca en todo el sitio web institucional es claro dentro y fuera de la universidad.

\footnotetext{
${ }^{141}$ El sistema METIS es una iniciativa de la Académica real de arte y ciencia (KNAW)

142 Información sobre el acceso abierto en los Países Bajos puede ser consultada en el sitio www.surf.nl/openacces; www.surf.nl/openarchief; www.surf.nl/copyrighttoolbox

143 SWOT Strengths, Weaknesses, Opportunities, Threats (Fortalezas, Debilidades, Oportunidades y Amenazas) conocido también en el habla hispana como DAFO o FODA.
}

\section{Debilidades}

- Se evidencia poca participación y/ presencia de la biblioteca dentro de plataforma E-learning y por ende dentro de los proyectos de educación a distancia semipresencial y E-learning.

- El acceso hacia algunos servicios ofrecidos a través de la web de la biblioteca está limitado a personas con incapacidades físicas, auditivas y/o visuales. 


\section{Oportunidades}

- El actual desarrollo de nueva ofertas de cursos y carreras a distancia genera la necesidad de nuevos servicios de apoyo a la práctica a E-learning

- Las nuevas oportunidades de cooperación que ofrece el convenio de la Unión Europea facilitan desarrollar acciones para el fortalecimiento de alianzas para el desarrollo de proyectos regionales.

\section{Amenazas}

- La posible poca atención a los cambios ocurridos en los entornos, podría generar una actitud menos proactiva por parte de la biblioteca.

- Poca atención a las iniciativas externas relacionadas con la gestión de servicios digitales de información, y las políticas de acceso abierto pueden influir en la disminución de la calidad de los actuales servicios y productos ofrecidos.

\section{Conclusión - Caso TUDELFT}

El sistema de bibliotecas de la universidad Tecnológica de Delft se caracteriza por su sólida estructura organizativa, el aprovechamiento máximo de las tecnologías de la información y comunicación para la prestación de servicios. Su constante actividad de innovación en el uso de tecnologías le permite desarrollar aplicaciones amigables y coherentes a las necesidades de los usuarios.

Un ejemplo concreto a esto son los Centros Virtuales de Información y Conocimientos (VKC) pensados y desarrollados como medio de apoyo a procesos de enseñanza - aprendizaje e investigación en entornos virtuales. Asimismo el desarrollo de sistemas de búsquedas (meta buscadores) con filtros y parámetros adecuados garantiza la recuperación de una mayor aproximación a la información requerida. Casos concretos citables son "Discovery", TUlib y el catálogo mismo.

La actual utilización de una plataforma E-learning dentro de la universidad para el desarrollo de programas de estudios a nivel de grado, máster y doctorado, resulta oportuno para el involucramiento de la biblioteca en esta modalidad. En este contexto la biblioteca no tendría problema alguno para la implementación del modelo de servicio propuesto en esta tesis, que representa una nueva oferta de servicios digitales especializados de acuerdo al tema de los cursos. 


\subsubsection{Universidad Metropolitana de Ciencias de la Educación (UMCE)}

La Universidad Metropolitana de Ciencias de la Educación (UMCE) ${ }^{144}$ se ubica en la Comuna de Ñuñoa, Santiago, Chile. Su creación obedece a la re-estructuración de las Universidades Públicas de Chile en virtud de la Ley Orgánica de Enseñanza (LOCE) y sus decretos derivados.

El origen de la UMCE se remonta al Instituto Pedagógico de la Universidad de Chile creado como dependencia de la Universidad de Chile, durante el rectorado de Don José Joaquín Aguirre en 1889 con el objetivo de formar profesionalmente al profesorado de la educación secundaria. En 1931 se incorpora a ésta el Instituto de Educación Física y Técnica (creado en 1906). En 1948 se crea su sede en Valparaíso. Las labores del Instituto Pedagógico fueron tan importantes que cerca del $80 \%$ de los docentes chilenos eran formados en estas aulas, llegando a considerarse como uno de los más prestigiosos centros de formación docente en América. Numerosas Misiones Pedagógicas fueron destinadas a formar nuevos Centros Pedagógicos en otros países como Venezuela y Costa Rica.

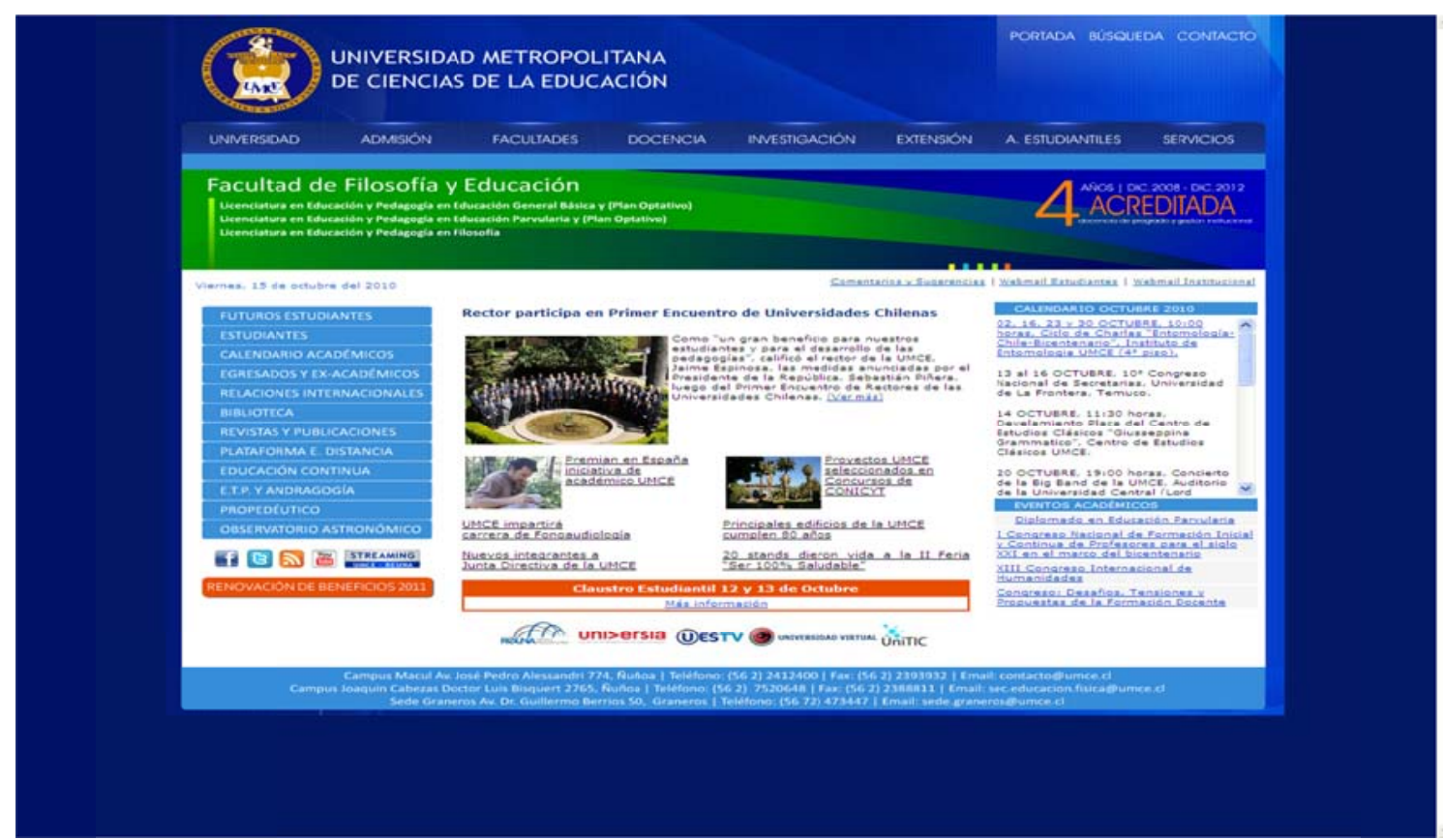

Figura 60. Portal de la Universidad Metropolitana (UMCE).

En el siglo XX se inició en Chile la Psicología Experimental. Lo Pedagógico se transformó en centro en el que confluían poetas, literatos, científicos, políticos y trabajadores, siendo un importante foco cultural y social desde donde se desarrolló un espíritu crítico y se fomentó el arte y la cultura. En 1981 la junta de gobierno promulgó el DFL número 7 (17-02-1981) publicada en el diario oficial por el gobierno de Pinochet, quedando separado de la Universidad de Chile y se transforma en la Academia Superior de Ciencias Pedagógicas de Santiago. Otra inesperada decisión del gobierno nuevamente cambió el nombre pasando a llamarse Universidad Metropolitana de Ciencias de la Educación por la Ley número 18433 de 1985, denominación que no ha sufrido cambios hasta hoy, tanto en su estructura como en su administración conservando el mismo estatuto y organización que la fijada por el gobierno de entonces.

\footnotetext{
${ }^{144}$ Información extraída de la Wikipedia. Véase amplio texto en los sitios Web: http://es.wikipedia.org/wiki/Universidad_Metropolitana_de_Ciencias_de_la_Educaci\%C3\%B3n y http://es.wikipedia.org/wiki/Instituto_Pedag\%C3\%B3gico_de_la_Universidad_de_Chile.
} 
La separación de esta universidad de la Universidad de Chile tuvo negativas consecuencias para el ex Instituto Pedagógico, tales como las mermas económicas originadas de la disminución de los aportes estatales y la mala administración. Después de una crisis de más de tres meses la Ministra de Educación, Mariana Aylwin, informó a la prensa el 8 de septiembre de 2001 que la UMCE sería traspasada a la Universidad de Chile. Esta medida ampliamente apoyada (en un 95\%) por los estudiantes de la UMCE no prosperó ya que fue resistida por el anterior rector Raúl Navarro que dejó su cargo en el 2009, pero además fue rechazada en el Congreso Nacional después de la negación de los parlamentarios.

\subsubsection{Biblioteca de la Universidad Metropolitana de Ciencias de la Educación (UMCE) ${ }^{145}$}

El Sistema de Bibliotecas de la Universidad Metropolitana de Ciencias de la Educación se compone de una Biblioteca Central, cinco bibliotecas periféricas y 2 colecciones especiales. El sistema es definido como un centro de recursos para el aprendizaje, la docencia, la investigación y las actividades relacionadas con el funcionamiento y la gestión de la Universidad / Institución en su conjunto.

El Sistema de Bibliotecas de la UMCE tiene como misión facilitar el acceso y la difusión de los recursos de información y colaborar en los procesos de creación del conocimiento, a fin de contribuir a la consecución de los objetivos de la Universidad como Institución.

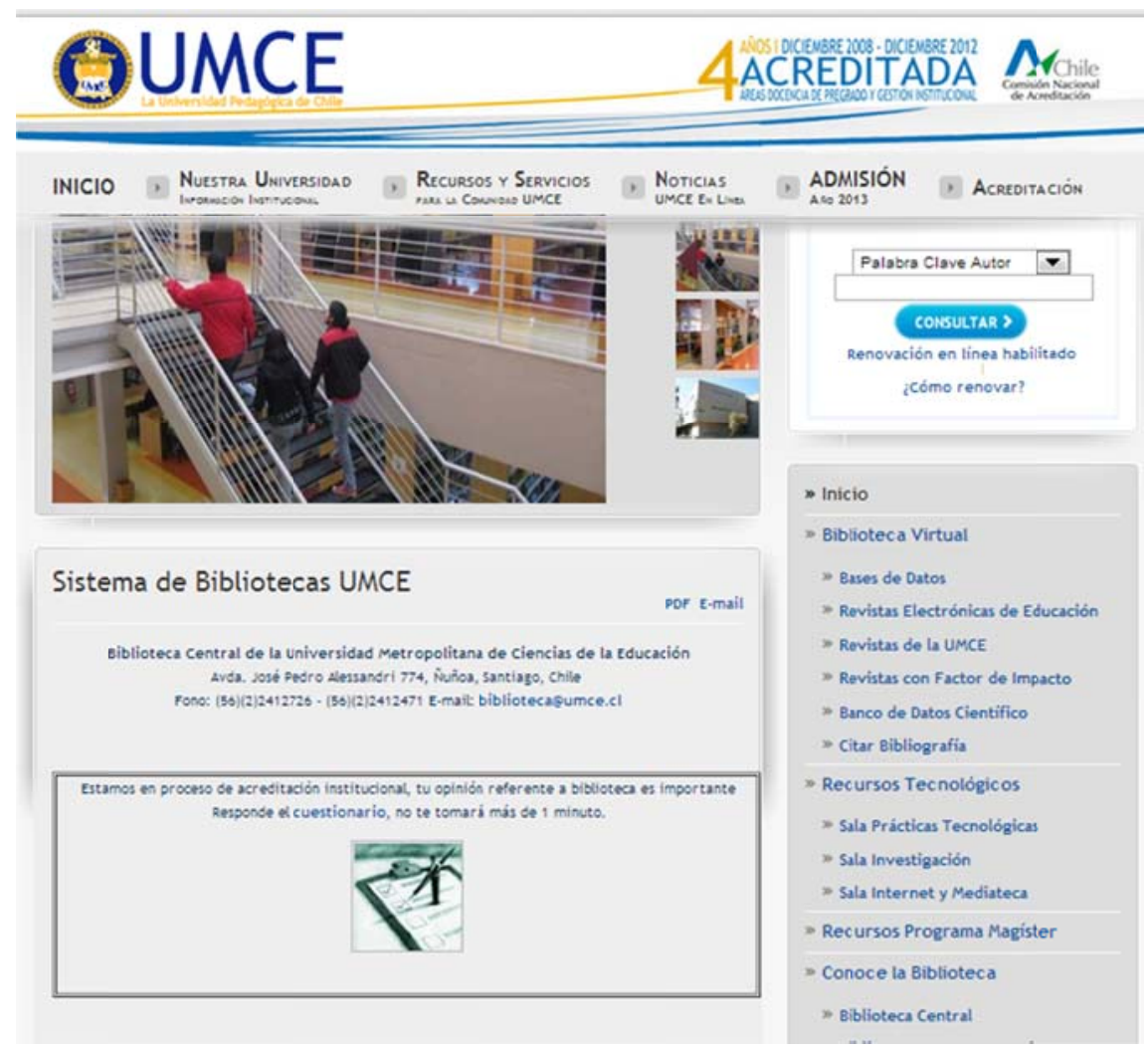

Figura 61. Entrada principal del sitio web del sistema de Bibliotecas de la UMCE.

\footnotetext{
${ }^{145}$ Datos tomados literalmente del sitio Web del Sistema de Biblioteca de la UMCE (2010). http://www.umce.cl/biblioteca/ Enlace consultado en octubre de 2010. Sin embargo a fines del año 2011 el sitio Web experimento una modificación en la que fue considerada la evaluación reflejada en esta tesis en el $2010 \mathrm{El}$ actual URL de la biblioteca es: http://www.umce.cl/2011/item-inicio-biblioteca.html La ilustración presentada es visible a noviembre 2012
} 
La biblioteca central fue creada a fines de 1983 con una colección inicial de 9 mil volúmenes recibidos de la anterior Biblioteca Central "Eugenio Pereira Salas" de la Universidad de Chile y de las colecciones existentes en 13 departamentos de la Academia Superior de Ciencias Pedagógicas considerado como un aporte significativo por la cantidad y calidad del material bibliográfico recibido. Según datos disponible en el sito de la biblioteca a febrero del 2011, la colección dispone de aproximadamente 74.000 volúmenes de libros, 7.051 tesis, 1.300 materiales audiovisuales y suscribe 105 títulos de revistas.

En 1990, luego de asumir como directora la Sra. Nancy Torres, se realizan algunos trabajos de readecuación del edificio y la ampliación de la Sala de Lectura. En el siguiente año se realiza un "Estudio de la estructura interna del Sistema de Bibliotecas de la Universidad Metropolitana de Ciencias de la Educación", basado en la metodología del curso "Planificación Estratégica" ejecutado por las bibliotecarias, Patricia Ortíz, Patricia Riquelme y Marcela Vidal. Sobre esta base, se realiza un nuevo diagnóstico y una reformulación de los objetivos que dio lugar a los siguientes logros:

-. Firma del Convenio entre la UMCE y la Dirección Nacional de Bibliotecas, Archivos y Museos, convirtiéndose en miembros activos de la Red Nacional de Información Bibliográfica (RENIB).

-. Préstamo automatizado: Diseño del programa, colocación de los códigos de barra y el uso de la credencial universitaria, para acreditación de los alumnos en su calidad de usuarios.

-.Cursos de capacitación para el manejo del sistema computacional al personal de biblioteca.

En 1995 bajo la dirección Patricia Riquelme Klare se incorporan nuevas tecnologías para impulsar el nuevo modelo del Sistema Integrado de Biblioteca, basado en los conceptos de biblioteca convencional y biblioteca virtual, con el fin de ofrecer el acceso a una colección bibliográfica permanente y actualizada, publicaciones periódicas especializadas, una nueva oferta de recursos tecnológicos para procesos de comunicación que faciliten de forma eficiente para localizar y capturar la información disponible a nivel nacional e internacional. Otros avances significativos ocurridos en el proceso de modernización de la biblioteca ocurren y se presentan a continuación:

En 1999 la biblioteca inicia la oferta de recursos electrónicos (media) para procesos de instrucción y de auto-instrucción, con el fin de formar usuarios autónomos en el manejo de nuevas tecnologías. Esta unidad además facilita el acceso a Internet, base de datos, revistas electrónicas, vídeos, películas y CD ROM educativos. En el 2000 se establece una clara forma de trabajo en cooperación entre la Dirección del Sistema de Bibliotecas desarrolla actividades y los departamentos académicos, con el objetivo de introducir cursos, talleres grupales, a fin de apoyar a los alumnos y docentes mediante cursos de formación de usuarios en el uso de nuevas herramientas electrónicas de información.

El año 2002 se inicia el estudio y análisis de la estructura y funciones de las unidades de información existentes en la UMCE, a fin de establecer, reglamentariamente, su funcionamiento y dependencia administrativa como Sistema de Bibliotecas. En el año 2003 el Ministro de Educación Señor Sergio Bitar, comunicó a la UMCE la adjudicación del proyecto Mejoramiento de la Formación Inicial Docente a Través de la Optimización de los Recursos y Servicios del Sistema de Bibliotecas, a través del cual se financia este proyecto. En los últimos década del 2010, la biblioteca ha continuado desarrollando proyectos de modernización de la infraestructura tecnológica, a fin de mejorar la prestación de servicios de información. 


\subsubsection{Evaluación general del sitio web de la Biblioteca UMCE}

La evaluación del sitio web de la Biblioteca de la UMCE fue realizada en dos fases. Primero una evaluación descriptiva y de funcionamiento desde la óptica de los gestores de los servicios. La consulta a los especialistas fue vía correo electrónico y se utilizaron 3 tipos de cuestionarios, cada uno de ellos para determinado servicio. La elaboración de los mismos correspondió a los parámetros y criterios propuestos en la metodología de este documento para evaluación de servicios digitales.

La segunda fase implicó un proceso de revisión del sitio web de la biblioteca y de cada una sus secciones donde se ubicaron los servicios y objetos de este estudio (Referencia digital, Cursos de formación de habilidades, destrezas y competencias - ALFIN) y la oferta de repositorios. Posteriormente los resultados obtenidos de ambos procesos de evaluación fueron el punto de partida para realizar el análisis de las fortalezas, debilidades, oportunidades, amenazas y aciertos. La organización de los resultados se presenta seguidamente partiendo de una evaluación general del sitio y posteriormente la evaluación de los servicios.

\section{Parámetro1. Identidad}

El acceso a la Universidad Metropolitana de Ciencias de la Educación (UMCE) es posible a través de una búsqueda en cualquier buscador en Internet, ya sea introduciendo el nombre propio de la Universidad o bien mediante la dirección URL. En general la página principal de la UMCE y el sitio del Sistema de Bibliotecas se visualiza como un sitio dinámico de acceso rápido. Su estructura jerárquica es transparente, el uso de colores, tipo y tamaños de letras, anchura de pantalla, márgenes son consecuentes. Se observa un adecuado contraste entre texto y fondo que hacen posible que el contenido sea claramente legible.

La existencia y presencia del Sistema de Bibliotecas de la Universidad Metropolitana de Ciencias de la Educación (en adelante SBUMCE) se visualiza desde el sitio web de la Universidad dentro de una franja horizontal que ofrece en forma de menú con presencia fija en casi todas las secciones sitios y portales de las facultades, departamentos y entidades Universitarias. Las opciones que presenta se ilustran seguidamente.

\begin{tabular}{|l|l|l|l|l|l|l|l|}
\hline Investigación & Extensión & Universidad & Admisión & Facultades & Docencia & Estudiantes & Servicios \\
\hline
\end{tabular}

Una vez seleccionada la opción de "Servicios" se despliega una franja horizontal que a su vez presenta una serie de opciones a modo de menú, en la que se identifica la presencia de la biblioteca con un mismo nivel jerárquico entre otras opciones. Sin embargo esta presencia no es homogénea.

\begin{tabular}{|l|l|l|l|l|}
\hline Biblioteca & Medios Educativos & Revistas y publicaciones & Centro de informaciones pedagógicas & Plataformas \\
\hline
\end{tabular}

En algunos casos la biblioteca se identifica dentro de la franja de "Servicios" y otras veces de forma directa bajo el término BIBLIOTECA. Los sitios donde se observó dificultad para localizar la biblioteca fueron:

- Medios educativos. (No resultó ser clara la existencia de la oferta)

- Videoteca: (no se refleja directamente, pero si se ofrece la franja de menú de la página principal en donde la biblioteca se ubica dentro de "Servicios Revistas y Publicaciones. 


\section{Parámetro 2: Actualización}

La actualización de la información contenidos en el sitio no es clara tanto en la página principal de la UMCE como en el de la biblioteca, debido a que se carece del indicador de fecha y propiedad de autoridad (C2010), no obstante en la página principal se reconoce un alcance de la validez del sitio identificada en la parte superior derecha. En este sentido, si se constató la presencia en algunos sitios de recursos que orientan las fecha tales como agendas.

\section{Parámetro 3: Accesibilidad}

El acceso a los servicios de la SBUMCE no presenta ningún problema en cuanto a conexión lenta y acceso a los servicios. El proceso de entrada al sitio es rápido desde el exterior del país, no obstante se observó que el acceso si es limitado para personas con incapacidades auditivas o visuales.

\section{Parámetro 4. Servicios básicos de la web}

La oferta de recursos es diversa pero selectiva de acuerdos a los objetivos de las instituciones Desde el portal principal de la biblioteca se visualiza en la columna izquierda un menú a las siguientes opciones de servicios:

- Acceso a 6,100 títulos de revistas electrónicas a través del convenio Conicyt

- Acceso a Dialnet en convenio con la Universidad de la Rioja

- Acceso a guías temáticas y materiales de estudios e investigación

- Acceso a diversos recursos electrónicos

- Acceso al servicio de mensajería

Desde la página principal de la biblioteca se identifica en posición horizontal en la parte superior del sitio un menú con la opción de servicios en la que se identifica claramente la división en la organización y caracterización de los servicios en dos grupos:

a) Servicios de la biblioteca convencional que ofrece los servicios tradicionales ofertados físicamente dentro del edificio

b) Servicios de la biblioteca virtual en los que se destacan el servicio de referencia digital, directorio de recursos web descriptos e indicadores, acceso a repositorios de recursos electrónicos, servicio de alerta y medios interactivos de comunicación como Skype, Videoconferencias, Messenger y Facebook.

\section{Parámetro 5. Contenido}

Durante la consulta realizada en el catálogo y según datos obtenidos en los cuestionarios, se constató que el contenido de los recursos está en correspondencia con la misión, visión y objetivos de la institución y sus usuarios. Del mismo modo fue posible comprobar el reconocimiento de autoridad y validez de la fuente y la precisión en las referencias bibliográficas ofrecidas en el catálogo. 


\section{Parámetro 6. Arquitectura de la información}

La navegación dentro del sitio es posible mediante diferentes tipos de navegadores tales como Explore, Avant, Mozilla, Opera. Esta puede ocurrir de forma secuencial pero no dentro de las diferentes secciones del sitio. Desde la página principal se emplea una ruta de navegación que se vale de enlaces que facilitan la navegación y que intenta cumplir una regla de tres Click para ubicar y facilitar al usuario llegar al contenido deseado. Para facilitar el acceso a los contenidos, el sitio se vale de tablas de contenidos, siendo visibles las relaciones de jerarquización entre temas.

Al momento de navegación resulta posible identificar la jerarquización entre las secciones y contenidos de la web gracias al uso de etiquetas, tablas y colores. El sistema en que se organizan los servicios es en forma de menú con opciones que enlazan a los servicios tanto de la biblioteca tradicional como a la biblioteca digital. Habiendo hecho una revisión de los servicios ofrecidos en la biblioteca digital, se constató que aunque este sistema de menú de servicios resulta fácil, sencillo y rápido, no se visualiza la opción de retorno. En general es rápido entre página y página, asimismo el tiempo de descarga de documento cumple el estándar de 25 segundos por página.

\section{Parámetro 7. Diseño de la interfaz}

El diseño del sitio toma en consideración estándares definidos para el diseño de sitios web. Se observa en todo el sitio la consistencia y contraste en el uso de colores, pero se consideran demasiados oscuros; homogeneidad de estilos, tipo, tamaño de letras, líneas de texto, anchura de pantalla y márgenes. Las limitaciones identificadas en el diseño corresponden a:

- Carencia de facilidades para personas con incapacidades físicas, auditivas y visuales.

- Inadecuado contraste entre texto y fondo, debido a que los colores oscuros dificultan la lectura del contenido

- Poca flexibilidad para realizar una acción de diferentes maneras y enlaces que faciliten la navegación.

\section{Parámetro 8. Posicionamiento}

La identificación del sitio web de la biblioteca se realiza mediante el acceso directo a la dirección URL de la biblioteca o bien mediante la búsqueda del término en cualquier buscador como Google, Yahoo y otros.

\section{Parámetro 9: Sistema de búsqueda y recuperación}

El sistema de búsqueda que dispone la biblioteca permite identificar recursos por su descripción, uso de operadores boléanos, lenguajes controlados y por aproximaciones. Durante el proceso de pruebas de evaluación del funcionamiento del sistema, se realizó una búsqueda que permitió constatar la eficacia y eficiencia, la rapidez del sistema de recuperación de información, así como las diferentes opciones y alternativa para el acceso a los documentos y los diferentes formatos de presentación de 
resultados. Otro ejercicio realizado que a continuación se ilustra es el despliegue de pantalla de una búsqueda sobre "educación virtual" en la que se aprecia la presentación de los resultados, la oferta de opciones para guardar los mismos, ya sean en el sitio personalizado (mi biblioteca) o por correo electrónico.

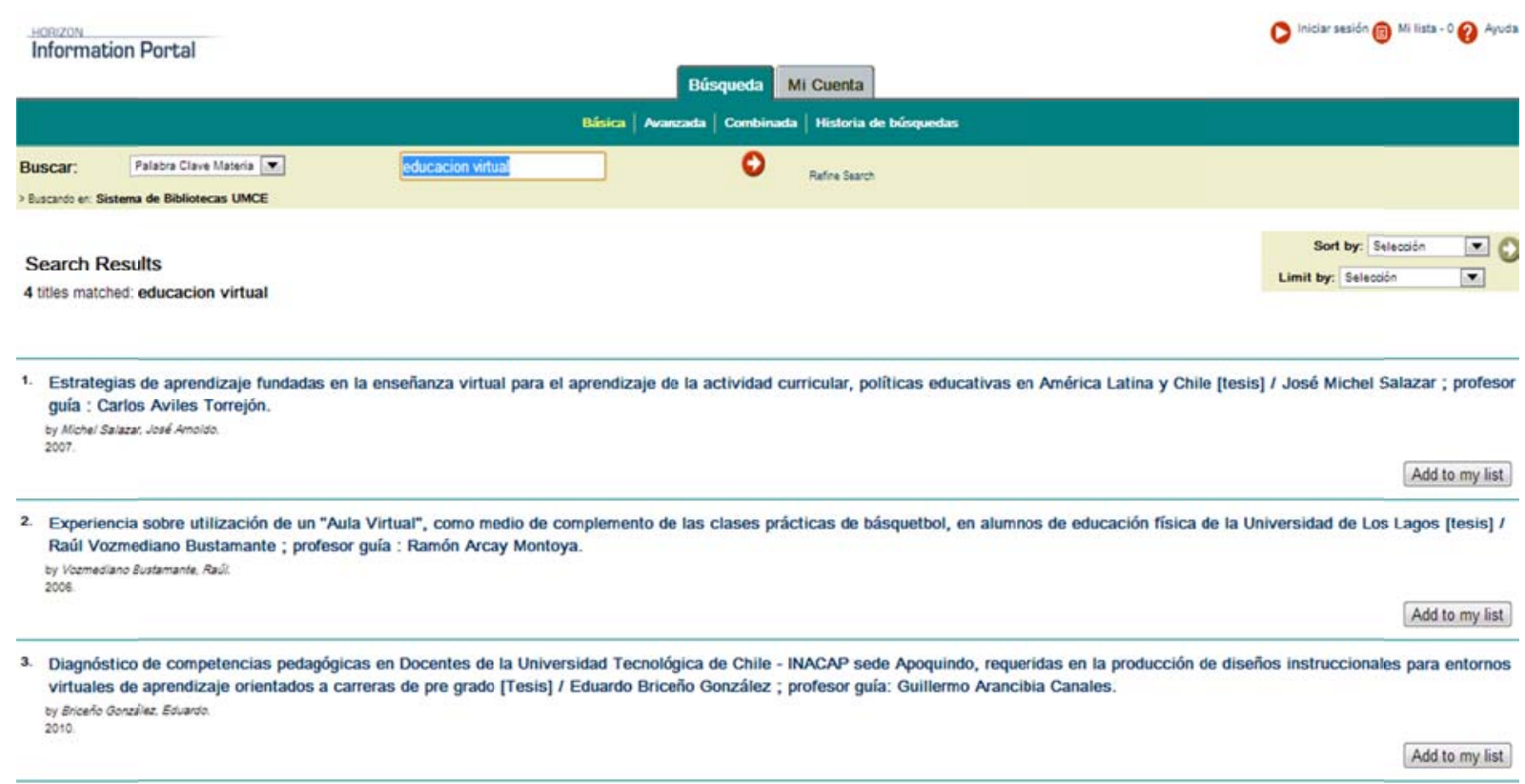

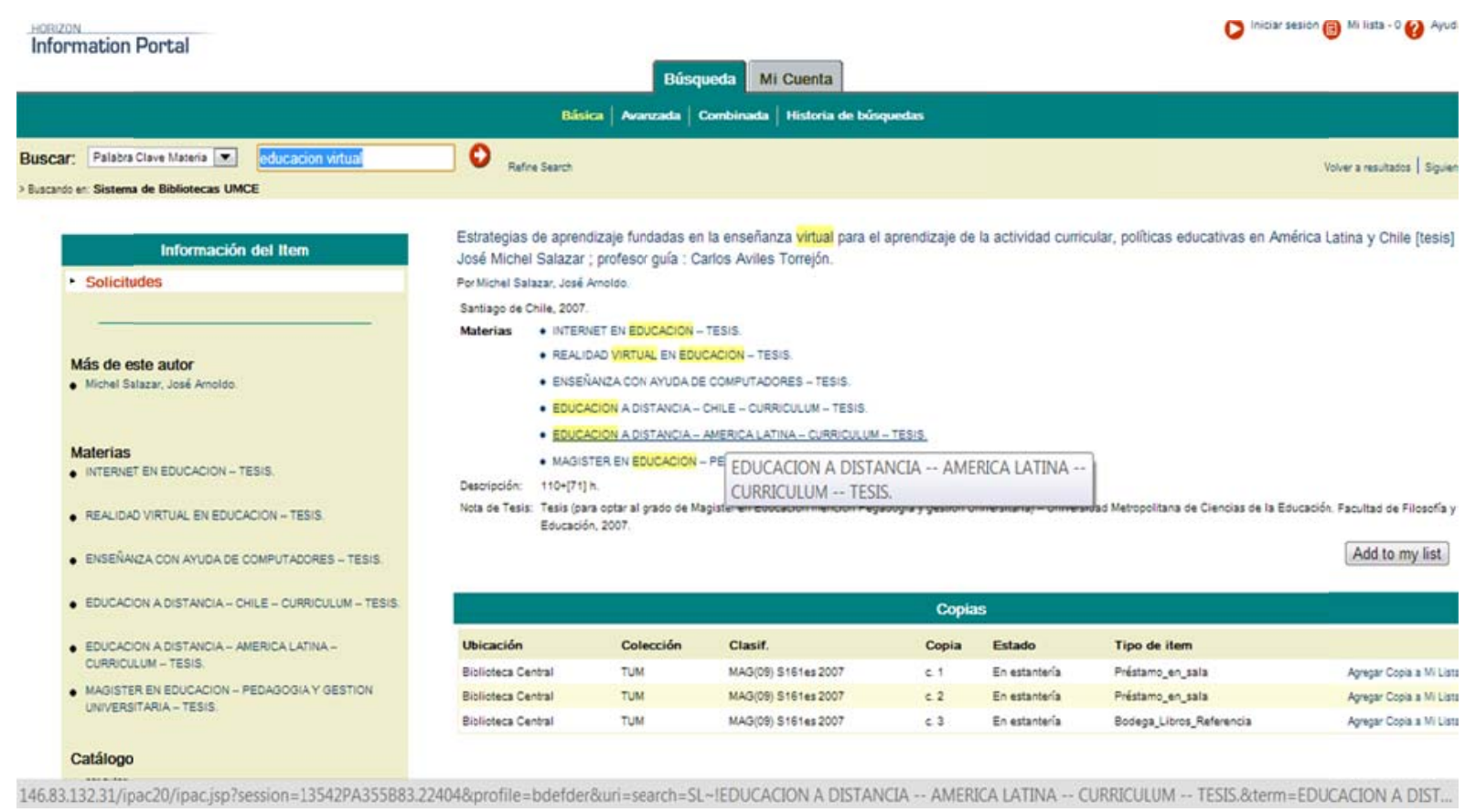

Figura 62. Práctica realizada en el sistema de búsqueda de la UMCE.

\section{Parámetro 10: Usabilidad}

No fue posible valorar la usabilidad de los servicios desde una óptica dirigida a la satisfacción de usuarios. Sin embargo a través de la consulta a los servicios de catálogo, servicio de referencia y acceso a algunos repositorios, fue posible constatar que el acceso a los recursos de información es 
rápido y eficiente. Se comprobó la disponibilidad de documentos en formato pdf, HTML y doc. Asimismo la posibilidad de guardar archivos completos y copiar y pegar partes de los documentos. A la fecha de las pruebas realizadas, no se identificó mecanismos para la medición del tiempo que el usuario invierte en las búsquedas y uso del material, así como del número de errores cometidos.

\subsubsection{Evaluación del servicio de referencia}

La identificación de los servicios de referencia en el sitio web de la biblioteca se realiza mediante el término "Servicio de Referencia" y responde a los siguientes objetivos:

- Responder a necesidades concretas de información.

- Direccionar adecuadamente las demandas de información.

- Orientar de forma eficiente y eficaz a los usuarios sobre la forma y medio para localizar la información.

El servicio Service desk ofrecido desde una plataforma web que permite la consulta sobre los diferentes servicios y productos de la biblioteca. Asimismo existen puntos de referencia para solicitar información general sobre temas especializados. La interacción entre el usuario y el bibliotecario ocurre de forma dinámica mediante el uso de email, chat, sistema de mensajería, teléfono y formularios predefinidos.

Los recursos informativos del que se vale el servicio de referencia de la universidad son:

- Biblioteca científica

- Cooperación Internacional

- Guías temáticas

- Otros recursos electrónicos

- Comunicación

+ Sistema de correo electrónico a través de un formulario

+ Blogs y Facebook

Los usuarios que hacen uso de este servicio se categorizan en los siguientes grupos: empleados administrativos, docentes, estudiantes internos y externos a la universidad.

Durante el proceso de evaluación del servicio, se observó que el proceso de navegación en este servicio al igual que en todo el sitio no presenta problemas de descarga, el tiempo de cambio de sección a sección tiene una duración de uno a dos segundos.

De acuerdo a los parámetros de adecuación y calidad, se observa que el sitio del servicio cumple con los siguientes criterios:

- Adecuación entre la consulta y agenda temática

- Facilidades de contacto entre el usuario y la fuente de información 
- Posibilidad de opinar sobre el contenido del sitio

- Presencia de indicadores que orienten la ubicación del usuario dentro del sitio

En general el servicio se organiza dentro del sitio web de la biblioteca en dos niveles. a) El acceso a los repositorios y b) el acceso al contacto con el referencista o especialista en información. El primer grupo se identifica bajo el término "Servicio de Referencia" reflejado a modo de título de menú de opciones. La consistencia entre letra y fondo no es muy clara a la vista por cuanto el fondo es demasiado oscuro, sin embargo es legible.

Desde el menú ofrecido por el servicio de referencia se direcciona a diferentes repositorios organizados en cinco grupos que a continuación se analizan.

\section{Biblioteca científica ${ }^{146}$}

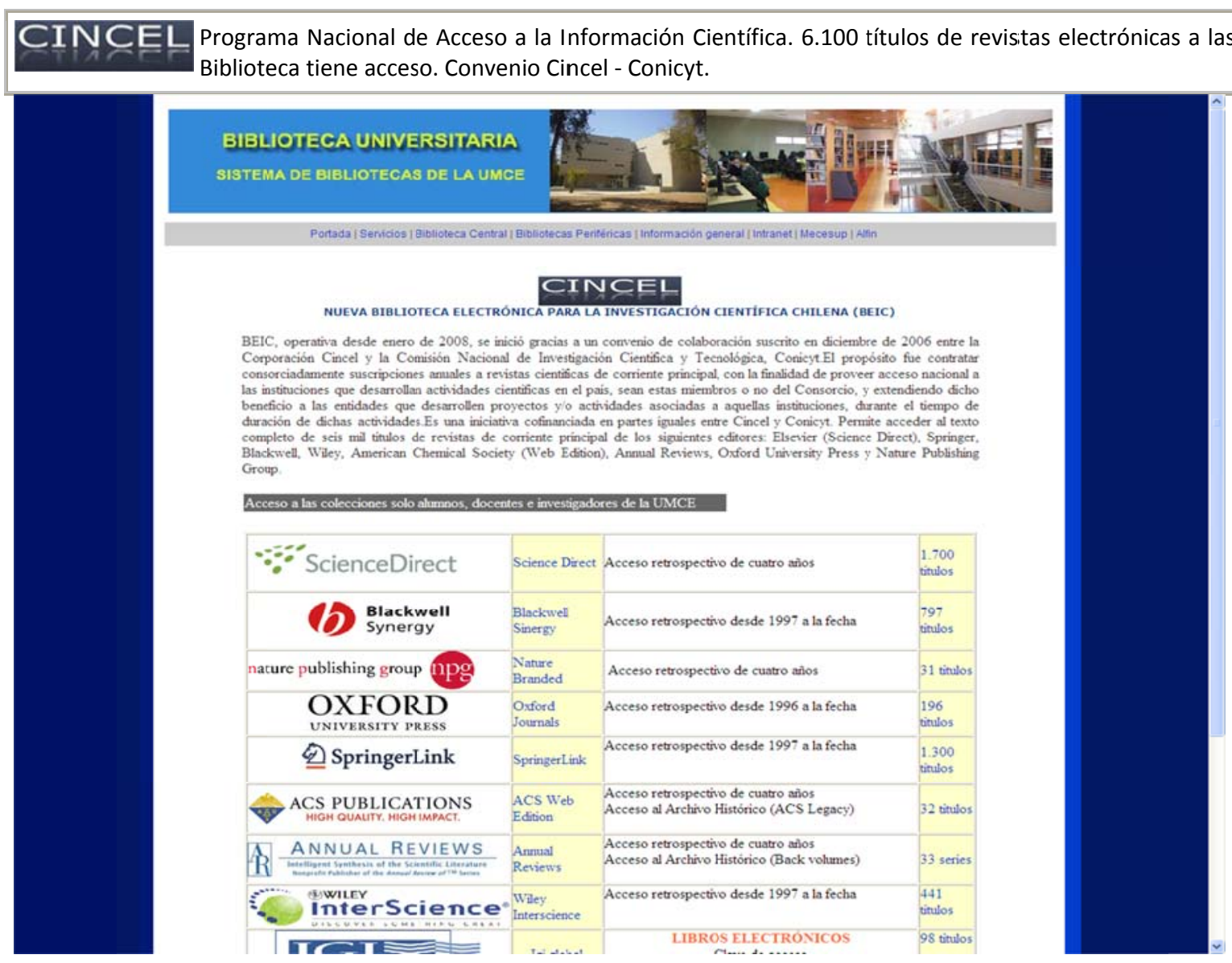

Figura 63. Portal de acceso a repositorio de revistas científicas (UCME).

La opción de Biblioteca Científica, ofrece el servicio de acceso al repositorio de revistas científicas de reconocimiento mundial y de contenido relevante para el trabajo de formación e investigación que desarrolla la UMCE.

\footnotetext{
${ }^{146}$ Servicio analizado en el 2011. Actualmente ha cambiado de nombre y se reconoce al noviembre del 2012 bajo el término "Revistas electrónicas para la educación" Los contenidos se mantienen. La variante corresponde en su totalidad a la presentación de la oferta en el sitio web.
} 


\section{Cooperación Internacional}

- Dialnet Portal de revistas científicas. La Biblioteca de la UMCE en convenio con la Universidad de la Rioja pone a disposición de alumnos y docentes el acceso a la base de datos bibliográfica Dialnet.

\section{BIBLIOTECA UNIVERSITARIA \\ SISTEMA DE BIBLIOTECAS DE LA UMCE

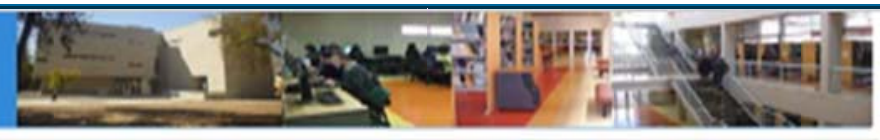

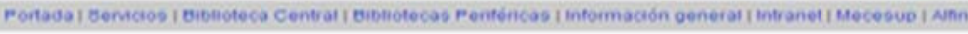

IALEEY

pntal of nevigtas oe wegrigacion en espapol

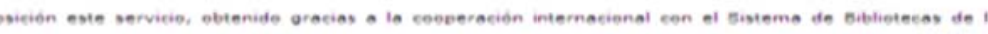

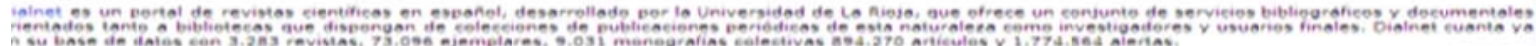

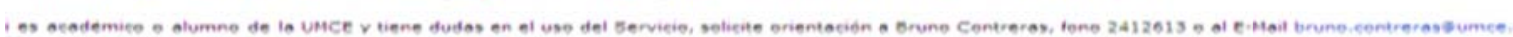

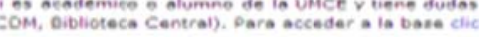

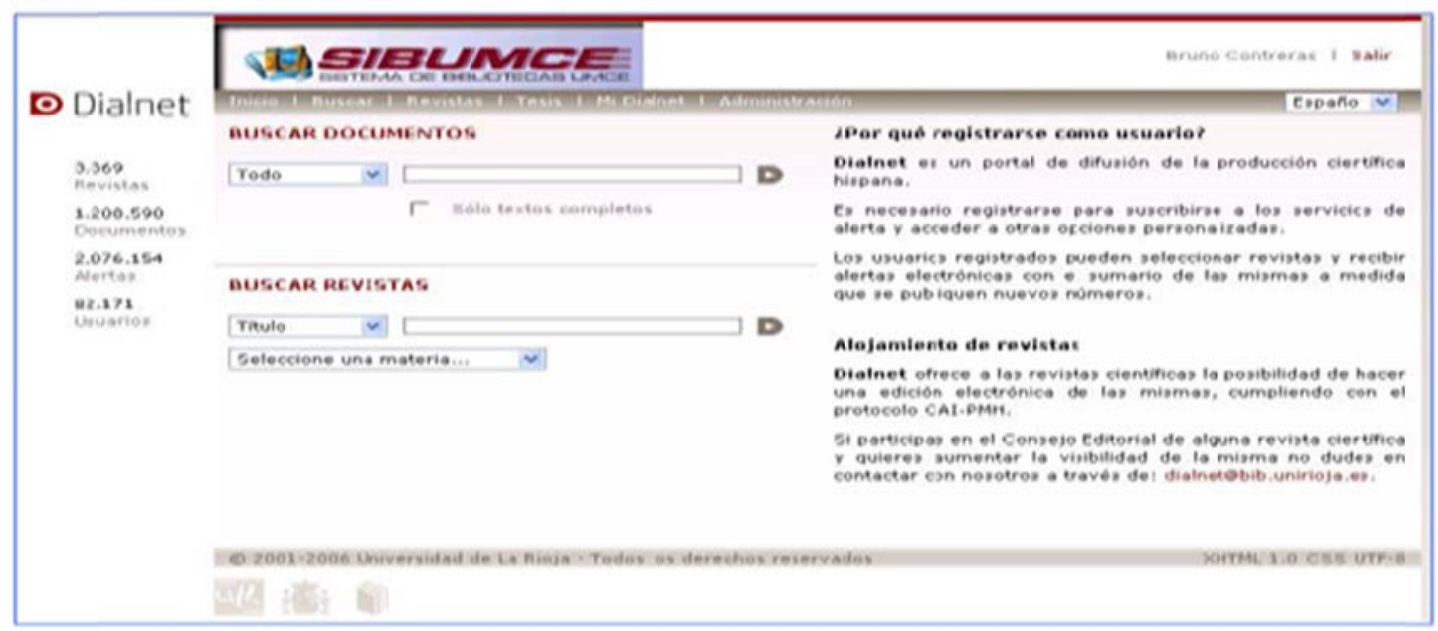

Figura 64. Portal de acceso a bases de datos bibliográficos internacionales (Dialent) UCME.

El servicio de acceso a la opción Cooperación internacional, representa un enlace a Dialnet, como sistema de búsqueda del portal del repositorio de revistas y recursos científicos de España.

\section{Guías temáticas}

Selección y análisis de Recursos de Información publicados en el web de Biblioteca en relación con las distintas materias de docencia e investigación de la UMCE. Acceso

Figura 65. Oferta de servicio Guía Temática de la UMCE.

La opción de guías temáticas carece de un claro concepto y objetivo. La información ofrecida no deja claro si se trata de un servicio de diseminación selectiva de información o el acceso de los materiales de estudios (objetos de estudios) generados para las diferentes actividades de docencia e investigación de la UMCE. El direccionamiento del enlace deja en evidencia que se trata de un espacio limitado a un grupo específico de usuarios con disponibilidad de clave de acceso. 


\section{Otros recursos electrónicos}

El servicio de "Otros recursos electrónicos" carece de concepto, no obstante es claro que se trata de punto de acceso a una agrupación de recursos electrónicos

- Bases de Datos (de acceso abierto)

- Revistas Electrónicas (texto completo)

- Vídeos para la educación

- Sitios web recomendados

- Citas bibliográficas (normas)

- Decretos, Indicadores, Estadísticas

- SCIRUS Buscador científico especializado

\section{Recursos disponibles a partir de la colaboración Internacional}
a) Recursos Electrónicos de Información
b) CDC Colección Digital Complutense

\section{Comunicación}

Consiste en un servicio de mensajería a través de correo electrónico. Paralelamente a esta opción de mensajería, el servicio de referencia se apoya en el menú servicios de "Web 0.2" que ofrece un mecanismo de comunicación con la biblioteca a través de Blog y Facebook. La limitación identificada en la consulta a las opciones de la Web 0.2 , es el abandono que ocurre del sitio de la biblioteca al momento de activar el enlace (link) en vez de abrirse una nueva pantalla.

En su conjunto el servicio de referencia de la biblioteca de la UMCE se encuentra disponible las 24 horas y es ofrecido y monitoreado por 3 profesionales que también realizan otras funciones dentro del Centro de Documentación Multimedia ${ }^{147}$. Según datos obtenidos en la entrevista con uno de los encargados del servicio; el tiempo aproximado de respuesta que se estable entre la consulta del usuario y el referencista es de minutos, siendo el rango de exactitud en las respuestas de un $100 \%$.

Las facilidades que dispone la biblioteca para interactuar con los usuarios le permite realizar evaluaciones generales sobre la biblioteca, hecho que ocurre posterior a la consulta. El referencista generalmente a cargo del servicio, luego de que le usuario es atendido, entra en contacto directo con él ya sea por teléfono o mediante correo electrónico para identificar el nivel de satisfacción para lo cual se vale de un estándar de preguntas.

Entre los servicios que se destacan están:

- Directorio

- Formulario de correo electrónico

\footnotetext{
${ }^{147}$ El Centro de Documentación Multimedia es la unidad que ofrece las facilidades físicas y tecnológicas para que los usuarios puedan hacer uso de los recursos de información disponibles en el sistema. Sus componentes son Sala Internet, Mediateca, Sala Prácticas Tecnológicas, Oficina de Desarrollo Virtual. Actual URL http://www.umce.cl/2011/universidad/bibliotecas-umce/informacion-general.html.
} 
- Blog de la biblioteca

- Facebook de la biblioteca

- Encuesta sobre la biblioteca

\subsubsection{Evaluación del servicio de cursos de formación de usuarios (ALFIN)}

Los cursos de formación de usuarios al igual que ocurre en las mayorías de las bibliotecas universitarias se presenta en dos niveles y es dirigido a todos los usuarios, y el segundo nivel se trata del servicio de formación de habilidades, destrezas y competencias (ALFIN).

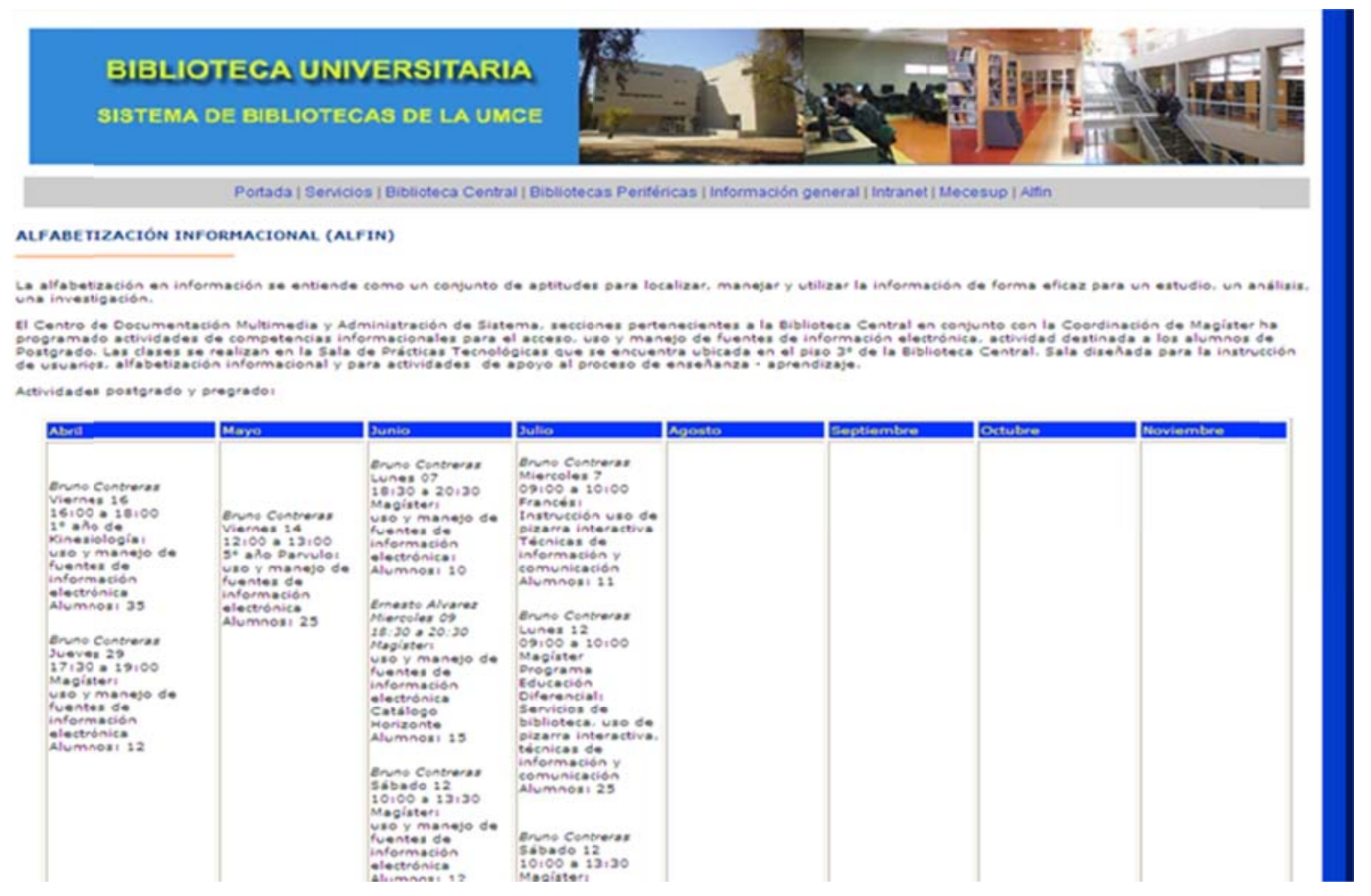

Figura 66. Oferta de cursos de formación de usuarios de UMCE.

La oferta actual de cursos por tanto se dividen y caracteriza en los siguientes dos grupos:

\section{a) Formación básica:}

Cursos presenciales organizados dentro de la biblioteca dirigida a usuarios en general. En este grupo se destacan dos ofertas de cursos:

- Curso de orientación e introducción a la biblioteca

- Curso de técnicas de búsquedas eficientes en el sistema de la biblioteca

\section{b) Formación especializada}

Los cursos de formación especializada son impartidos con la modalidad semipresencial. Para ello la biblioteca se vale de la plataforma E-learning Moodle. Actualmente la Biblioteca de la UMC trabaja en coordinación con el Departamento de Educación a Distancia a fin de diseñar cursos y actividades involucradas con ALFIN de acuerdo los temas de los cursos impartidos a través de la plataforma 
Moodle. Es importante destacar que una de las características de estos cursos es que estos se acoplan de la cobertura temática de estos cursos con los contenidos de las carreras que imparte la universidad. Los cursos concretos que se ofrecen actualmente se orientan hacia tres ejes:

- El aprendizaje de técnicas de búsquedas eficientes en el sistema información de la biblioteca

- La formación de habilidades, destrezas y competencias

- El manejo y uso ético de los recursos informativos

Tal como se ha indicado anteriormente los cursos ALFIN son dirigidos a grupos metas, razón por la cual sus contenidos están orientados a temas específicos que son ofrecidos en forma de crédito en materias dentro de algún plan de estudio presencial y semipresencial de formación universitaria, post universitaria, hecho por la cual son impartidos por especialistas en información del Centro de Documentación de Multimedia.

La planificación, organización, visualización gestión de los contenidos y datos administrativos son hechas desde la plataforma Moodle y de acceso cerrado. Estos están limitados al grupo de estudiantes previamente inscritos en el registro académico d la universidad. Gracias al apoyo recibido por parte de miembros de la biblioteca de la UMCE fue posible el análisis general de la estructura organizativa de los mismos. La actual oferta es diversa y bien orientada. En la siguiente figura se presentan los nombres de los cursos que enlazan a la descripción y contenidos de los mismos.

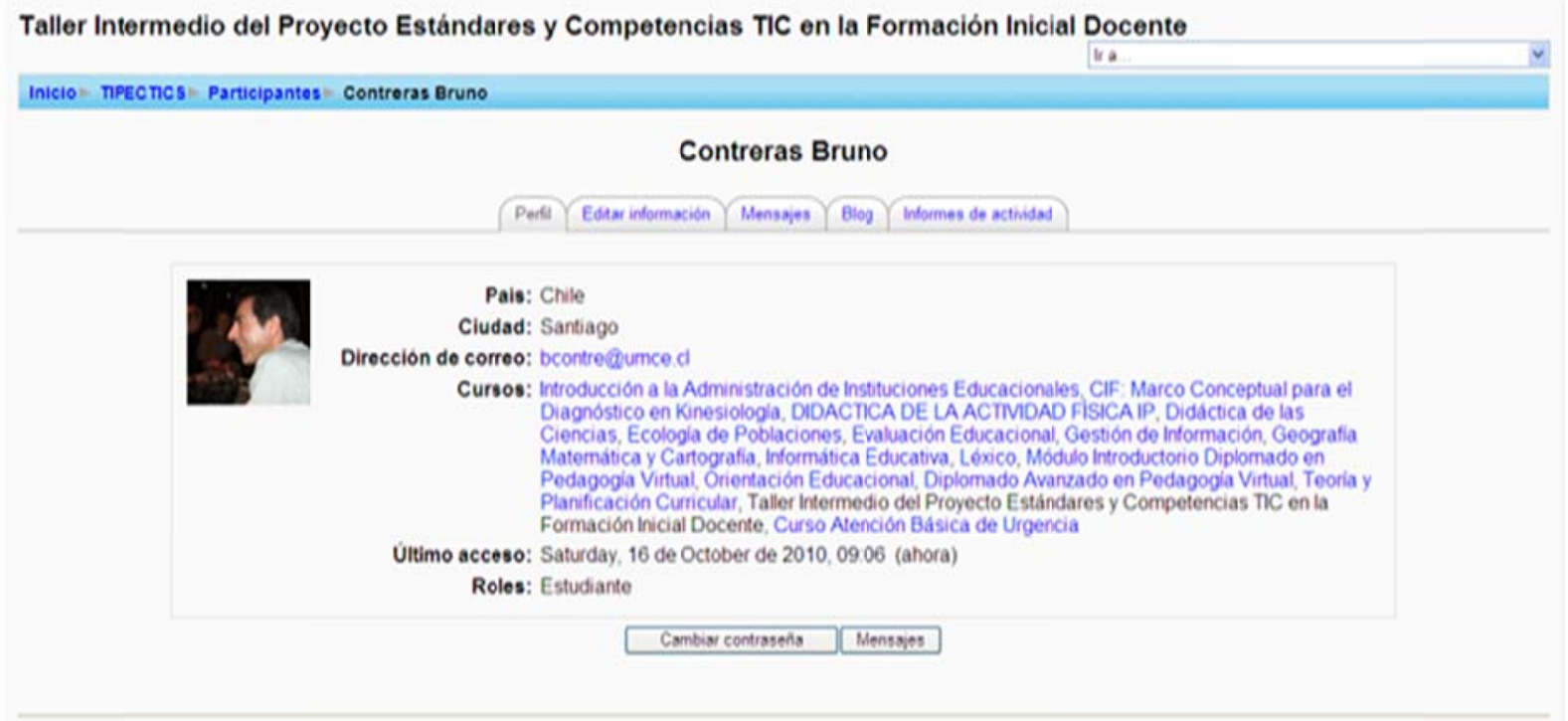

Figura 67. Ejemplo de curso taller ofrecido por la Biblioteca como crédito académico.

Los recursos de que se vale la biblioteca para desarrollar los cursos ALFIN son las colecciones analógicas y electrónicas de libros y revistas, bases de datos internas y externas, objeto y material de estudio de los cursos académicos, blogs entre otros.

Cabe destacar que los contenidos son posibles de visualizar de diferentes formas ya sea a través de tablas de contenidos y/o iconos. Seguidamente se presenta un ejemplo de curso que ilustra la 
estructura organizativa de los contenidos, los formatos de archivos utilizados (pdf, enlaces, archivos compactados, etc.) para la presentación de los contenidos.

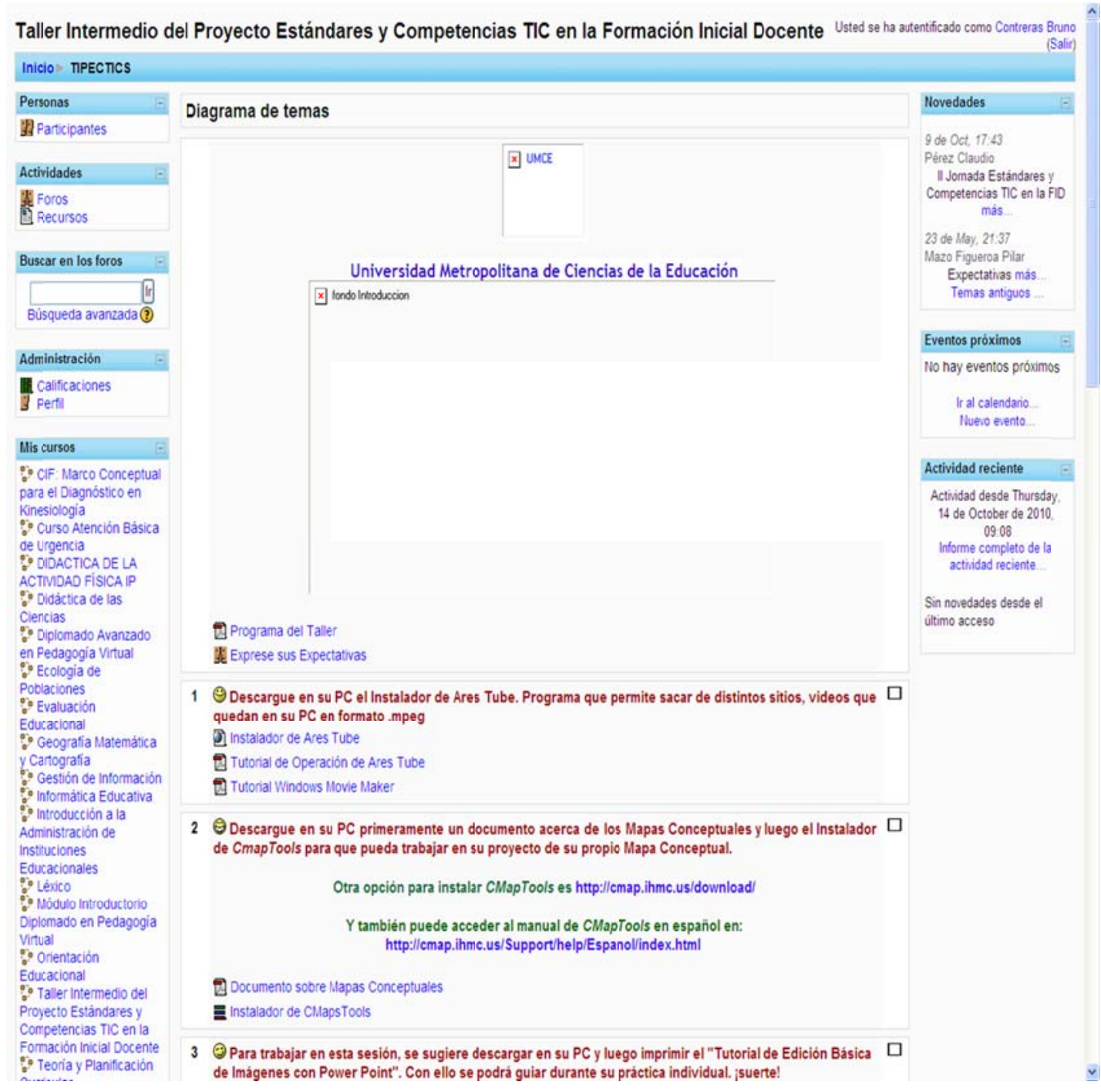

Figura 68. Estructura y organización de contenido de curso en Moodle.

Dada la flexibilidad del sistema Moodle, es posible realizar desplazamientos secuenciales y no secuenciales dentro de los materiales de estudio. La actualización de los contenidos propios de la asignaturas corresponden a los docentes, así como el proceso de evaluación de los cursos, que en general se realiza a través de las prácticas y un cuestionario estándar.

\subsubsection{Análisis SWOT de los servicios}

El análisis global realizado del sitio web de la biblioteca y de los servicios de referencia y de formación de habilidades, han generado una serie de insumos que en su conjunto hacen posible visualizar de forma sistémica algunos puntos de fortalezas, debilidades, oportunidades y amenazas actuales y futuras que podrían ser tomadas en consideración para el mejoramiento o fortalecimiento de los mismos. 


\section{Fortalezas}

- Los cambios institucionales y la actualización tecnológica permiten mejorar las actuales ofertas de profesionalización al mismo tiempo que se reconoce el rol de la biblioteca como fundamental como componente de apoyo en la transferencia de información de apoyo al proceso enseñanza aprendizaje - La actual posición de apertura, y disposición hacia cambios encaminados a la búsqueda de elevar los actuales niveles de eficiencia y eficacia en los servicios y productos ofrecidos por el Sistema de Bibliotecas de la UMCE motiva la constante revisión de su oferta, hecho que le atribuye a la biblioteca valores agregados de credibilidad y dinamismo a nivel interno y externo de la universidad. - La participación y trabajo conjunto de la biblioteca con el Departamento de Educación a distancia, puede ser aprovechable para la implementación de futuros proyectos de elaboración y utilización de servicios y materiales multimedia de apoyo a la docencia dentro de la plataforma E-learning (Moodle)

\section{Oportunidades}

El entorno de cambios a nivel de toda la universidad

- Existen proyectos e iniciativas regionales y aun ámbito internacional relacionados con el Acceso abierto que resultan oportuno para el fortalecimiento de la oferta de contenido y servicios de la biblioteca

- El aprendizaje de las prácticas nacionales e internacionales de aplicaciones tecnológicas para el desarrollo de cursos ALFIN

\section{Debilidades}

- No se identificaron debilidades de orden gerencial y organizativo. En general las debilidades identificadas se ubican en el diseño del sitio web: - El sitio web de la MCE presenta una estructura consecuente en su diseño, no obstante se identifican las siguientes limitantes:

- Diseño. Se desconoce si el diseño servicio de referencia cumple con las normativas WAI. - Visibilidad. En correspondencia con el contraste de colores entre letra y fondo dificultad la visualización del texto. Asimismo el tamaño de la letra resulta pequeño y dificulta la lectura de la información.

- Ausencia de mecanismo de ayuda y/o para regresar a la página anterior.

- Control semántico. Se observa poca atención al cuido de la semántica de los metadatos.

- Limitaciones idiomáticas. El sitio se encuentra en español y no ofrece la posibilidad del acceso a los contenidos en otros idiomas.

- Acceso. El sitio de la biblioteca no dispone de facilidades para el uso de los servicios por parte de personas con incapacidades físicas, auditivas y/o visuales. No obstante según datos obtenidos de la entrevista, la biblioteca dispone de computadores con hardware y software y periféricos especializados

\section{Amenazas}

Se reconocen las siguientes posibles amenazas para el debilitamiento de la actual oferta de servicios:

- Limitaciones económicas producto de la crisis mundial

- La falta de visión sistémica, (conceptual y práctica) por parte de los líderes de cada una de las secciones de la universidad y de la biblioteca en procesos de evaluación de servicios y necesidades

- Se requiere la consulta de docentes, estudiantes y líderes

- Poca presencia y participación en discusiones a nivel de gestores

\section{Conclusión- caso UMCE}


Los resultados del análisis realizado del sitio del sistema de biblioteca de la Universidad Metropolitana de Ciencias de la Educación (UMCE), permiten concluir que la biblioteca dispone de un sitio web con diseñado apropiado, cuyo contenido y organización corresponde a los objetivos, misión y visión institucional.

Las diferentes aplicaciones identificadas en el sitio, permite a los usuarios interactuar de forma dinámica en las diferentes secciones y de esta manera acceder fácilmente a los servicios y recursos de información.

La vinculación existente entre las actividades de capacitación de ALFIN y los cursos académicos, resultan ser estratégico en la proyección de las capacidades de la biblioteca tanto en la modalidades presenciales como en línea. El actual posicionamiento de la biblioteca dentro de la universidad resulta ser oportuno para negociar la incorporación de un enlace permanente en cada uno de los sitios de la web institucional que direccione a la oferta del servicio de referencia electrónica, los cursos de formación de la biblioteca y el servicio de acceso a los recursos. 


\subsubsection{Universidad EARTH ${ }^{148}$}

EARTH es una universidad privada, sin fines de lucro, dedicada a la educación en ciencias agrícolas y recursos naturales. Su objetivo principal es contribuir al desarrollo de los trópicos mediante la conciliación de la producción agrícola y la preservación del medio ambiente. Se ubica geográficamente en Guácimo de Limón, Costa Rica. Su misión responde a la formación de líderes con valores éticos para contribuir al desarrollo sostenible del trópico húmedo y construir una sociedad próspera y justa. El proyecto de creación de EARTH fue presentado por la Comisión de Asuntos Agropecuarios a la Asamblea Legislativa de Costa Rica el 2 de abril de 1986. Después de varios meses de análisis, en octubre de ese año es aprobada su creación. El 2 de abril de 1989 fue colocada la primera piedra del campus universitario, en un terreno de 3.300 hectáreas que alberga una pequeña ciudad de $\mathbf{5 3 . 0 0 0}$ metros cuadrados con aulas, laboratorios, oficinas académicas y administrativas, áreas deportivas, servicios y residencias para estudiantes, profesores y funcionarios.

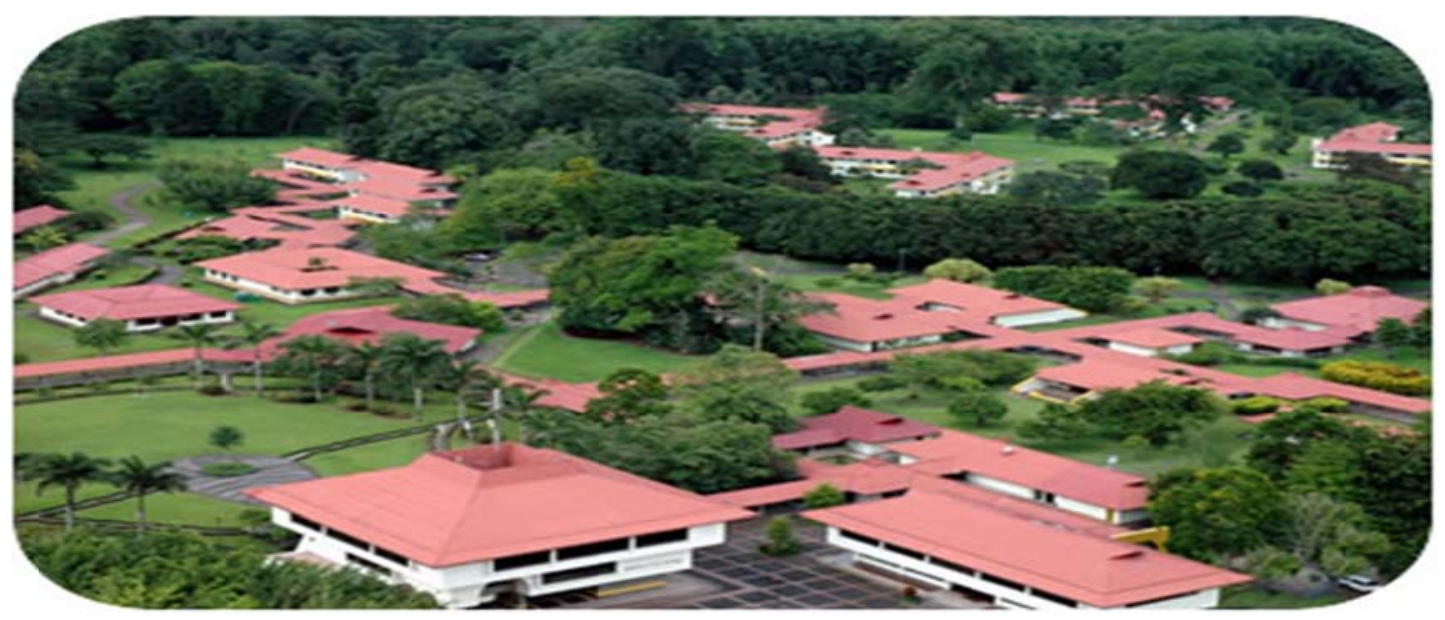

Figura 69. Campus de la Universidad Earth.

El 26 de marzo de 1990 se inaugura el primer curso lectivo y el campus de la EARTH. Actualmente su programa académico de licenciatura se concentra en las ciencias agropecuarias y el manejo racional de los recursos naturales enfocados a la generación de proceso académicos y de investigación, generadores de nuevos conocimientos y técnicas que contribuyan al desarrollo de eficientes $y$ eficaces formas de sistemas de producción, mejor uso y conservación de los recursos naturales y la constitución de un buen sistema de comercialización agropecuario.

\subsubsection{Biblioteca de la Universidad EARTH ${ }^{149}$}

Biblioteca "Will Keith Kellogg" de la Universidad EARTH es el centro de información especializado en los recursos naturales, agricultura y temas pecuarios, con énfasis en la región tropical húmeda del planeta. La misión de la biblioteca es la prestación de servicios y productos de información que puedan resultar útil y oportunos a las necesidades y demandas de información necesaria para el desarrollo de proceso de enseñanza-aprendizaje, la capacitación, la investigación, la toma de decisiones dentro de EARTH y para el desarrollo mismo de su entorno.

\footnotetext{
${ }^{148}$ Información extraída del sitio Web de la Universidad http://www.earth.ac.cr/index.php. Enlace consultado el 17 de octubre de 2010. Recientemente el sitio se ha modificado pero conserva la misma dirección URL.

149 Información descriptiva tomada textualmente del sitio de biblioteca consultado 17 de octubre de 2010 (http://www.earth.ac.cr/biblioteca.php). En 2012 la biblioteca dispone de una nueva dirección url: http://www.earth.ac.cr/about-earth/library/
} 


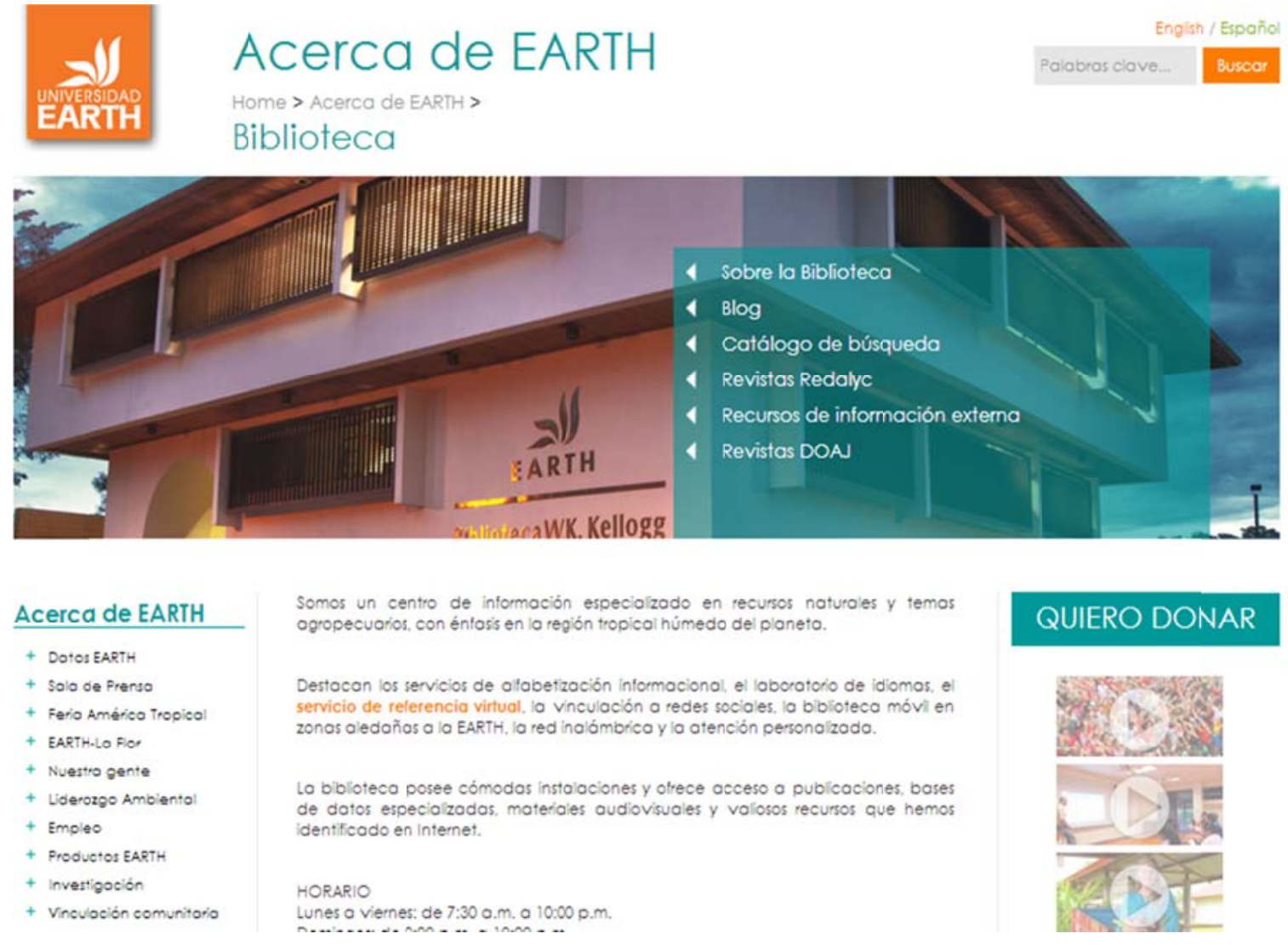

Figura 70. Sitio web de la Biblioteca de la Universidad Earth.

Los usuarios de la biblioteca reconocen y agrupan los siguientes tipos de usuarios:

- Estudiantes y miembros de la comunidad EARTH

- Donantes

- Egresados

- Instituciones afines

- Visitantes y bibliotecas con vínculos de cooperación

\section{Servicios de Información}

La biblioteca ofrece una variedad de servicios que se organizan en dos grupos. Los servicios de información general y los servicios de apoyo a la docencia.

\section{A) Servicios de Información general}

- Servicio de Referencia virtual

- Servicio de búsquedas de información

- Acceso al catálogo y bases de datos de la Biblioteca de la EARTH

- Servicio de préstamo de recursos de información (libros, revistas, mapas, películas, artículos, documentos de graduación y las publicaciones de la EARTH, etc.)

- Acceso a bases de datos externas de texto completo 
- Acceso a la colección de videos

- Acceso a revistas y libros electrónicos

\section{B) Servicios de apoyo al aprendizaje a la investigación:}

- Servicio de búsquedas especializadas

- Acceso a recursos internos y convenios de préstamos inter bibliotecarios

- Servicios de información sobre nuevas adquisiciones

- DSI - diseminación selectiva de información

- Programa de formación de usuarios y desarrollo de habilidades

- Documentos en línea

- Secciones o áreas de estudio individual y grupal

\subsubsection{Evaluación general del sitio web de la biblioteca}

El proceso de evaluación del sitio web de la biblioteca fue realizado en dos fases. Primeramente se realizó una consulta a los especialistas con responsabilidades en la prestación de los tres servicios y objetivos de estudios (referencia, formación de usuarios y acceso a los repositorios) a través de correo electrónico. La recopilación de datos fue realizada mediante el llenado de cuestionarios evaluativos de los servicios. La segunda fase implicó un proceso de revisión del sitio web de la biblioteca. Ambos procesos de evaluación fueron realizados mediante la metodología propuesta en este documento que incluye la aplicación de 10 parámetros estándares y la metodología SWOT para un análisis sistémico.

Los resultados de la evaluación del sitio de la Earth se presentan seguidamente partiendo de una evaluación general del sitio y posteriormente la evaluación de cada uno de los tres servicios y objeto de estudio.

\section{Parámetro 1. Identidad}

El sitio de la universidad Earth se encuentra disponible en inglés y español. La consulta a ambas versiones permitió verificar que no se trata de una traducción literal de los contenidos. Un ejemplo concreto a citar es que el servicio de referencia virtual no está disponible en el sitio de idioma inglés. La biblioteca como un componente básico de la universidad se identifica desde la página principal de la biblioteca con el término "Biblioteca" que funciona a modo de enlace al sitio de la biblioteca.

De la observación hecha es posible afirmar que la presencia de la biblioteca es evidente, permanente y homogéneo en cada una de las secciones del sitio de la universidad, mediante la presencia de un menú de opciones estándar que se ubica en la columna izquierda. 


\section{Parámetro 2: Actualización}

La existencia de indicadores de actualización y derechos de propiedad del contenido fue identificable en la parte inferior de cada una de las secciones del sitio, lográndose comprobar que la última actualización fue realizada en el 2009 como se ilustra textualmente a continuación.

Derechos Reservados c 2009. Teléfono: (506) 2713-0000 / Fax: (506) 2713-0001

\section{Parámetro 3. Accesibilidad}

El acceso a la biblioteca es abierto a cualquier persona que navega en Internet. El sitio es recuperable sin problema desde cualquier buscador, pero el acceso a algunos servicios y productos específicos está limitado solamente a estudiantes y personal de la universidad, ya que se requiere de una clave de acceso. Asimismo se comprobó que existen limitaciones de acceso a personas con discapacidades físicas, visuales y auditivas. En general, se puede afirmar que el proceso de navegación hacia cada una de sus secciones resulta rápido. Se identifica el uso de enlaces para direccionar a los usuarios al uso de los servicios yl agiliza el proceso de navegación. Sin embargo, cabe destacar que durante las pruebas de valoración del proceso de navegación se observó la carencia de opciones que faciliten la navegación, opciones de regreso a página anterior, continuación, inicio etc.

\section{Parámetro 4. Servicios básicos de la web}

Los servicios y productos que se visualizan en el sitio de la web por la biblioteca desde el sitio web se dividen en los servicios propios de la biblioteca y los servicios de la universidad. El primer grupo se presenta en formato de menú donde cada opción direcciona secciones específicas de servicios. Las opciones que se destacan corresponden a los siguientes servicios y puntos de acceso.

- Búsquedas de información

- Revistas

- Servicios

- Referencia virtual

- Otras bibliotecas

- Biblioteca comunitaria

- Colección virtual

- Nuevas adquisiciones

- Diarios de Costa Rica

El segundo grupo se presenta en forma dispersa (parte superior, inferior, y derecha) dentro de toda la página e incluye las siguientes opciones:

- Ventana de buscador

- Enlace a portales

- Noticias 


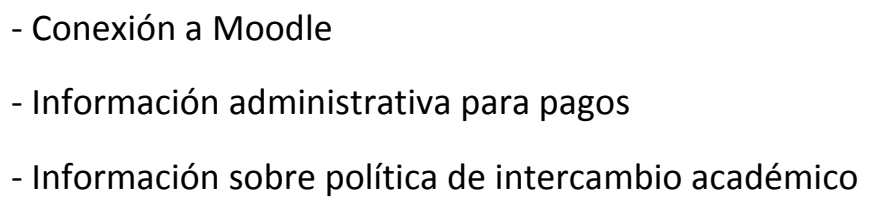

\section{Parámetro 5 Contenido}

Los contenidos identificables en el sitio de la biblioteca corresponden a la temática de trabajo de la universidad. El acceso a ellos es posible a través de los diferentes servicios y productos de información posibles.

En general todos los recursos son accesibles desde Internet e intranet. Otro mecanismo de acceso a estos servicios y recursos informativos es posible a través de recursos como RSS, blog y listas. Aunque estas aplicaciones no están integradas como un sistema único de búsqueda, son utilizadas a modo de enlaces.

Un aspecto identificable durante las prácticas de búsquedas, es el cumplimiento de los siguientes estándares establecidos para la presentación de los contenidos de los recursos de información.

- Reconocimiento de autoridad

- Adecuación entre la autoría y la agenda temática

- Adscripción del autor a la organización que pertenece

- Factibilidad de contacto entre el autor-usuario de la fuente

- Reconocimiento y credibilidad de la fuente

- Identificación básica de las diferentes secciones de la publicación (autor, título y fechas)

\section{Parámetro 6. Diseño de la interfaz}

El sitio de la Earth como el de la sección de la biblioteca cumplen con los estándares internacionales para diseño de sitio web, hecho por el cual se caracteriza por su estructura consecuente, un adecuado contraste entre el texto y fondo, homogeneidad de estilos, tipo, tamaño de letras, líneas de texto, anchura de pantalla y márgenes.

Además se constata de un aceptable tiempo de descarga de páginas, considerándose el tiempo promedio de descarga por página de 25 segundos.

Las limitaciones en el diseño encontradas son:

- El sitio cuenta con poca la flexibilidad para realizar una acción de diferentes maneras

- Se observó la carencia de opciones para desplazamiento de retorno a página anterior o próxima página

- No identifica la presencia de archivos multimedia y por ende no se constata la adecuación de uso de imágenes o sonido como complemento de la información textual 


\section{Parámetro 8. Posicionamiento}

El posicionamiento del sitio dentro de la Internet resulta evidente debido a que tanto el sitio como los servicios son recuperables a través de una búsqueda sencilla desde cualquier buscador en Internet.

\section{Parámetro 9. Sistema de búsqueda y recuperación}

La búsqueda e identificación de los recursos de información de la biblioteca son recuperables a través de intranet desde tres puntos básicos de acceso que direccionan a diferentes colecciones: a) el catálogo de la biblioteca - Búsquedas de información; b) directamente desde cada una de las bases de datos y repositorios de revistas científicas, informes de investigación y tesis y c) consulta externas en otras bibliotecas. Es importante señalar que cada uno de estos enlaces direcciona hacia una descripción del servicio que orienta al usuario sobre el contenido mismo.

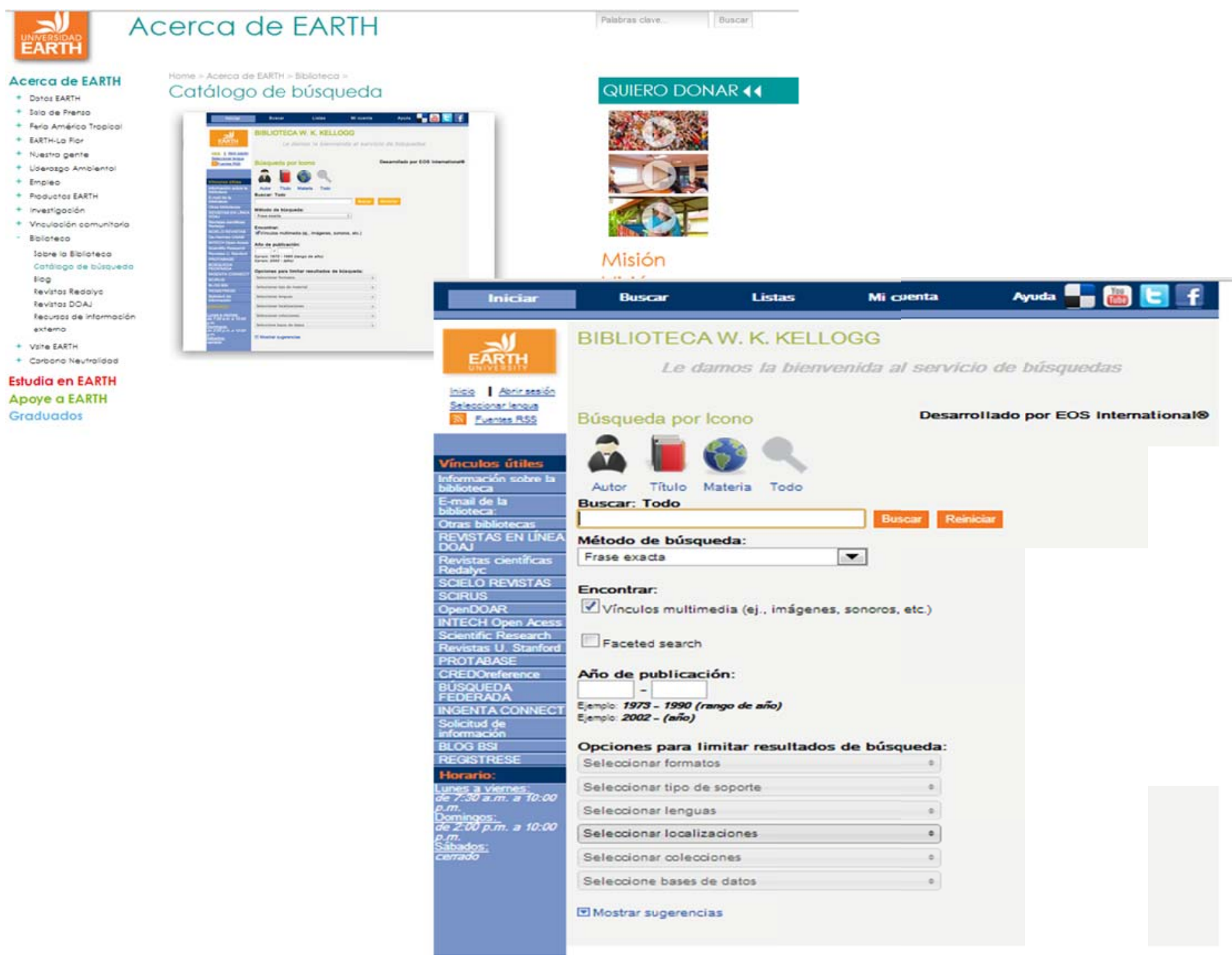

Figura 71. Puntos de acceso a los recursos e información de la Biblioteca de la Universidad Earth. 
La prueba de búsqueda realizada en el catálogo demuestra la proyección de resultados de forma inmediata. Permite formular búsquedas sencillas y avanzadas mediante la combinación de términos mediante operadores booleanos.

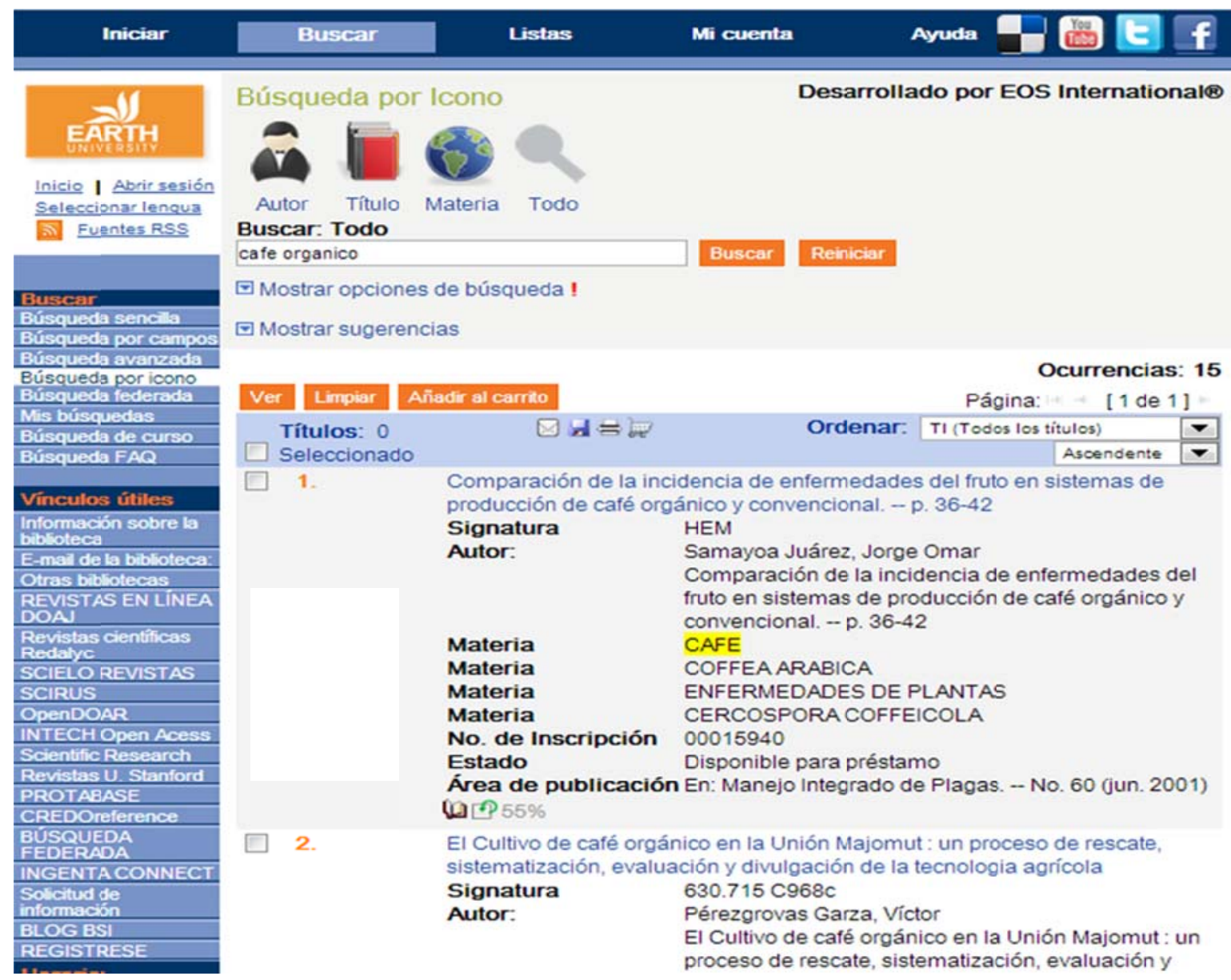

Figura 72. Visualización del sistema de búsqueda en el catálogo de la Biblioteca de la Universidad Earth.

El despliegue de los resultados de cualquier búsqueda se presenta en forma de lista, indicando la referencia básica del recurso, por ejemplo el título de un libro con enlace a la descripción completa que incluye además la descripción del contenido a través de uso de términos controlados.

Asimismo se observa en la parte superior izquierda la lista y opción "seleccionar" que ofrece la facilidad de indicar en que formato se desea visualizar la organización de los resultados (autor, título, etc.).

Otra opción de búsqueda que ofrece el catálogo corresponde a la posibilidad de realizar búsquedas avanzadas. Un ejemplo ilustrativo se muestra en las siguientes figuras donde se visualizan las opciones alternativas ofrecidas por el catálogo. 


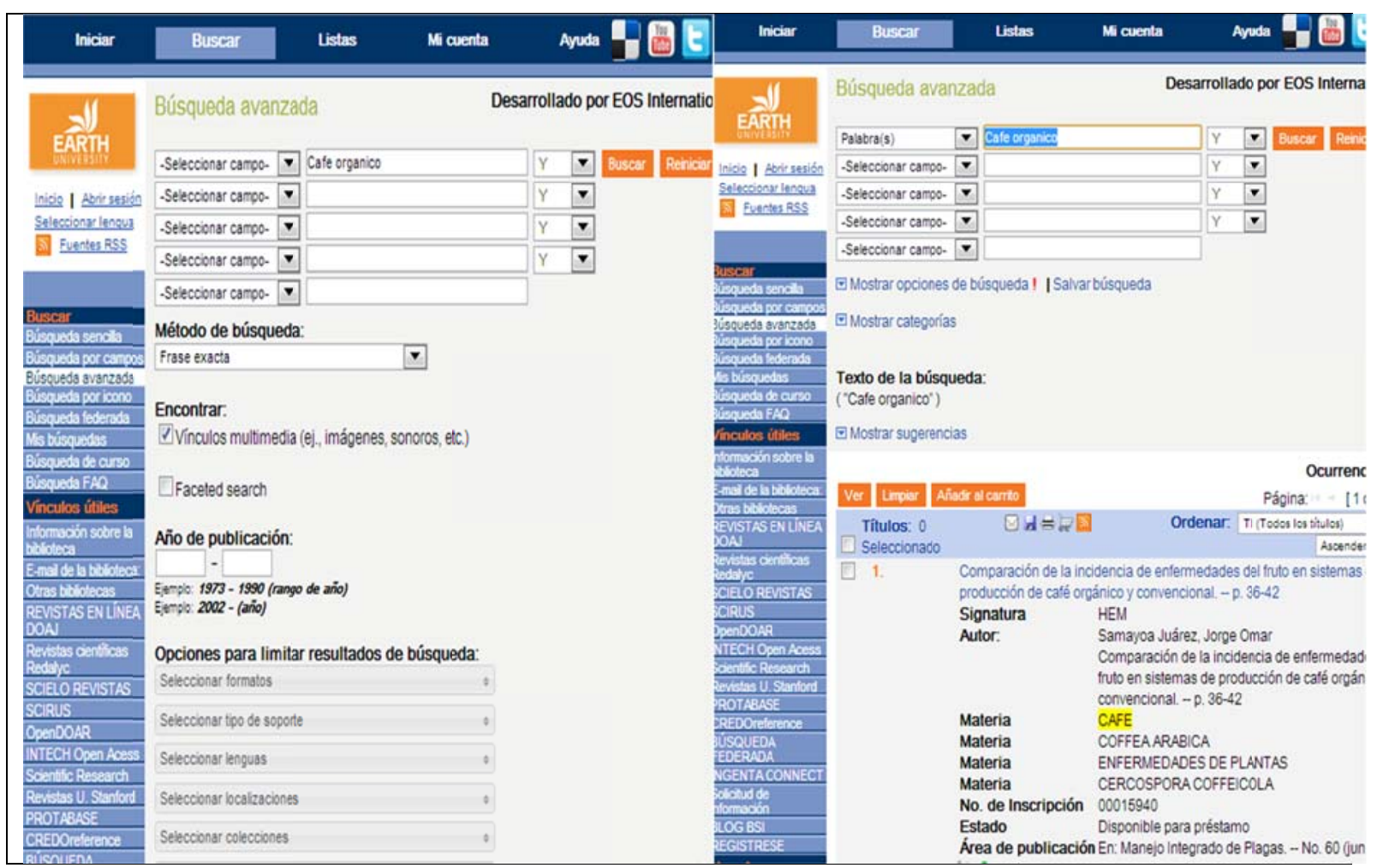

Figura 73. Práctica de búsqueda avanzada en el catálogo.

De la consulta realizada a funcionarios de la biblioteca, se evidencia el deseo de ampliar la oferta de servicios actual mediante la incorporación de los siguientes recursos: directorio de recursos web; objetos de aprendizaje multimedia; comunidades virtuales, y aplicaciones social medias como Wikis, Flickr, etc.

\section{Parámetro 10: Usabilidad}

El uso de los recursos del sitio fue imposible de verificar a través de un estudio de satisfacción de usuarios, debido a las limitaciones geográficas y económicas, no obstante se realizó a través de correo electrónico con personal de la biblioteca a cargo de los servicios y mediante la consulta y pruebas operacionales. Como en el resto de las evalauciones de los estudios de caso, fue esencial la aportación del personal implicado, que respondió a las preguntas relacionadas con los datos que se necesitaban para evaluar este parámetro. El resultado permite concluir lo siguiente:

- No experimentó problemas de acceso a los recursos de información electrónico

- El acceso a documentos electrónicos en formato pdf, HTML y doc resulta rápido y en algunos casos es posible guardar archivos completos y copiar y pegar partes los documentos.

- No existe control o medición del tiempo que el usuario invierte en la realización de procesos de búsquedas, uso del material y tampoco el número de errores cometidos.

- El nivel de satisfacción se constata de forma general en procesos de evaluación que la biblioteca ejecuta. 


\subsubsection{Evaluación del servicio de referencia virtual}

El servicio de referencia digital se identifica dentro del sitio de la biblioteca mediante el término Servicio de Referencia Virtual, que es atendido por dos profesionales. Aunque su nombre resulta ser amplio, de lo que se trata es del servicio de diseminación selectiva de información o elaboración de búsquedas bibliográficas que se materializan en listados de recursos sobre temas especializados. La fortaleza del servicio corresponde al uso de los recursos de información internos y las alianzas con otras bibliotecas que hace posible el uso de recursos externos.

El servicio de referencia virtual se visualiza como una opción del menú en la columna izquierda en el sitio web de la biblioteca. El usuario que accede a este enlace, es transferido a una pantalla donde se ubica un formulario de solicitud del servicio, disponible solo en español que a continuación se ilustra.

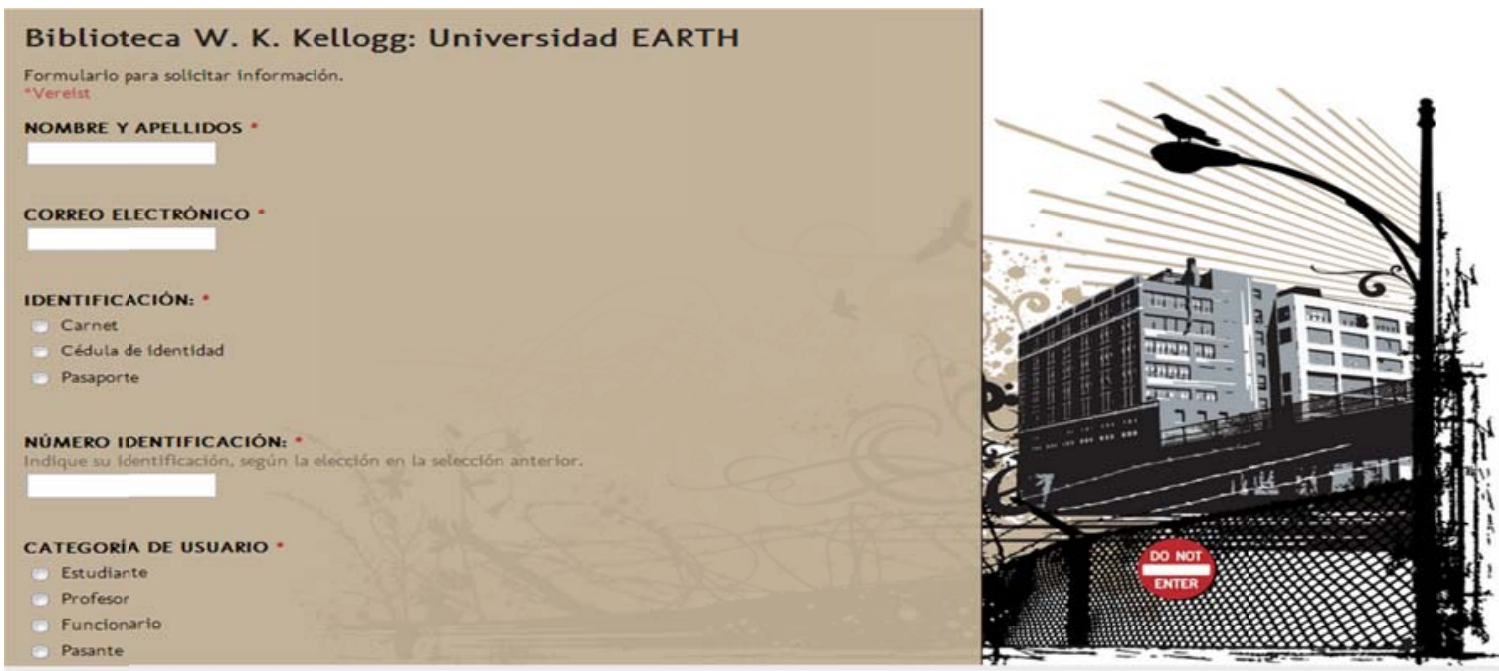

\section{Biblioteca W. K. Kellogg: Universidad EARTH}

Hemos registrado su solicitud; pronto nos comunicaremos para informarle sobre los resultados de su petición o coordinar algún detalle que sea necesario.

Nog een reactie verzenden I Uw eigen formulier maken

\section{Google docs}

Figura 74. Visualización y despliegue del servicio de referencia virtual de búsqueda del catálogo de la Biblioteca de la Universidad Earth.

Una vez hecha la consulta o expresada la demanda, el usuario recibe una respuesta de confirmación de su solicitud, en la cual se especifica que la duración aproximada es de 48 horas.

Del mismo modo y paralelamente a las solicitudes registradas mediante este formulario, la biblioteca recibe solicitudes por correo electrónico y teléfono, logrando así direccionar la demanda y dar respuestas eficientes y eficaces. En esta línea resulta importante destacar que según datos proporcionados por el personal a cargo del servicio el rango de satisfacción entre la consulta y la respuesta se ubica entre 80 y 100\%. La evaluación del servicio se realiza de forma directa mediante un formulario estándar, pero de forma indirecta e inmediata mediante la comunicación de doble vía entre el usuario y el referencista. 
Por las características del servicio, el parámetro de actualización y navegación no fueron posible de aplicar, por cuanto este servicio tiene dependencia directa al acceso de todos los recursos, y servicios de la biblioteca; aspecto que anteriormente ha sido revisado en la evaluación general del sitio.

\subsubsection{Evaluación del servicio de cursos de formación de usuarios (ALFIN)}

Actualmente la Universidad Earth no ofrece la modalidad de educación a distancia total o E-learning, sin embargo la universidad imparte algunos cursos de "Formación Estratégica y de Capacitación Empresarial" con una modalidad semipresencial. Para el desarrollo de programa de estudio, la universidad utiliza el programa Moodle como sistema de gestión de contenidos.

En aprovechamiento de las facilidades y características de esta plataforma, la universidad oferta y desarrolla cursos en partes o en forma completa logrando cumplir con los objetivos propuestos. Aunque Moodle es un programa que trabaja con patrones o plantillas predefinidos, permite realizar cambios en el estilo y apariencia del sitio Con el objetivo de ilustrar la adaptación hecha por la Universidad Earth en el sistema, se presente la siguiente figura con la oferta de programas educativos de la Earth del 2010.

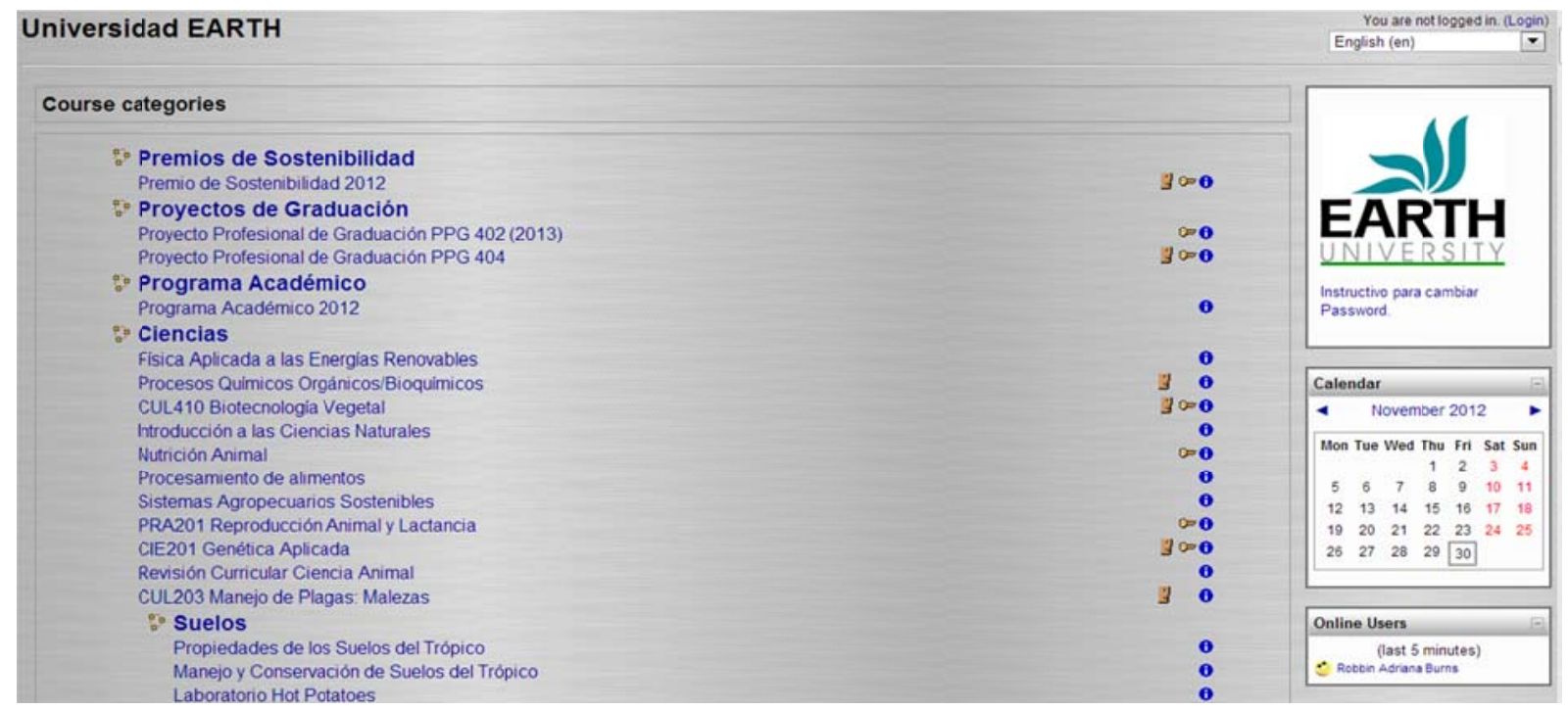

Figura 75. Programas de formación de la Biblioteca de la Universidad Earth.

\section{Participación de la biblioteca en cursos a distancia}

Los cursos de formación de usuario de la biblioteca no son visibles en la biblioteca como una oferta abierta, razón por la cual el análisis de estos fue posible gracias al acceso temporal al entorno virtual de aprendizaje de la Earth facilitado por la biblioteca ${ }^{150}$.

El trabajo de formación de habilidades es un servicio ofrecido a grupos involucrados con actividades académicas, ya sea como estudiante, docente, investigador que se encuentran físicamente o no dentro de Costa Rica. La participación de estudiantes generalmente ocurre dentro de la materia "Proyecto de formación profesional de graduación" conocido como PPG 404.

\footnotetext{
${ }^{150}$ Agradecimiento por la confianza y apoyo brindado por Carlos Granados, referencista/bibliotecario e instructor cegranad@earth.ac.cr.
} 
El curso ALFIN ocurre como un taller ofrecido a los estudiantes como requisito de materia. El curso se reconoce con el nombre curricularmente como taller INFO101-10: "Preparatorio de computación".

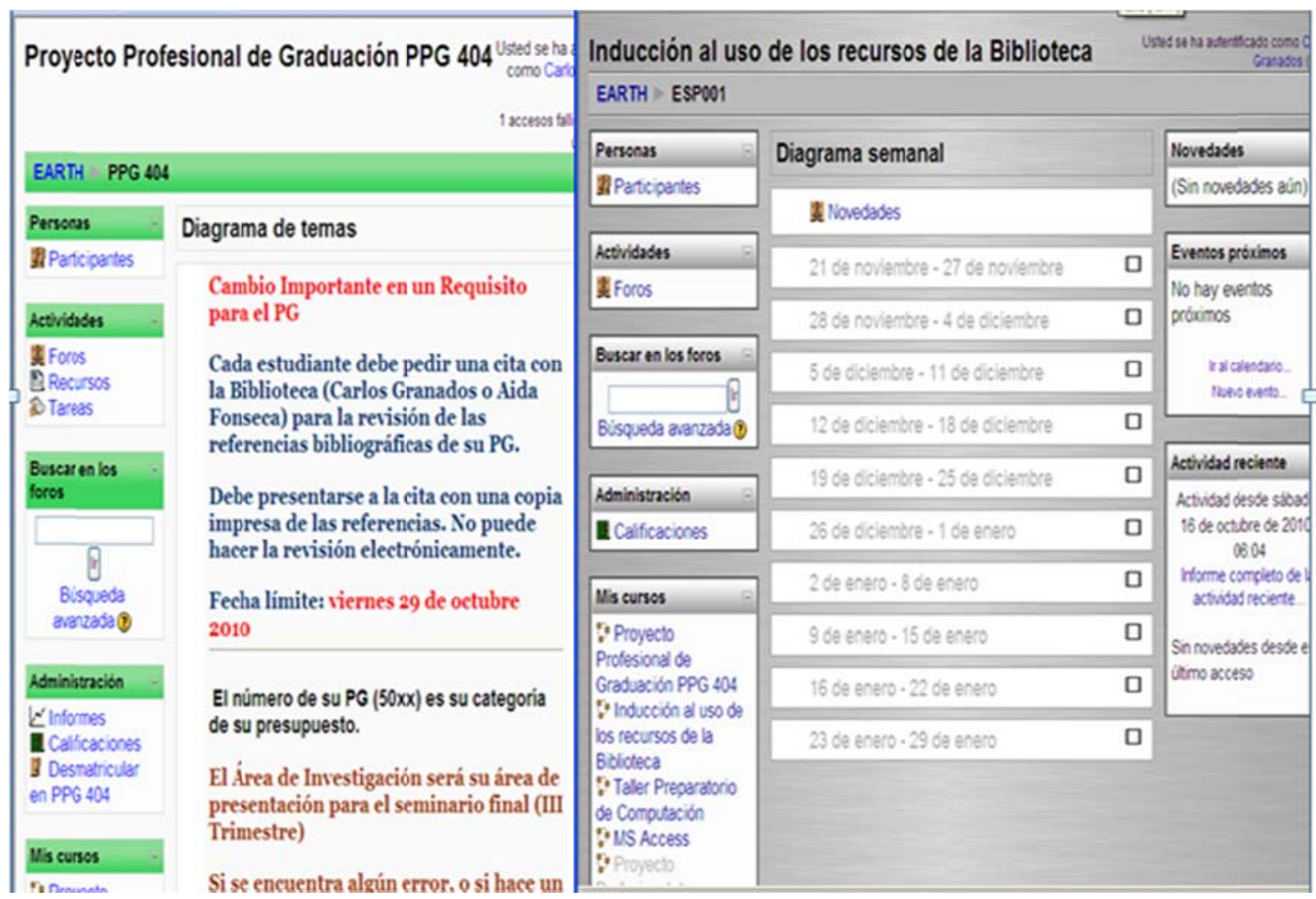

Figura 76. Participación de la Biblioteca en el curso Taller INF 101-10 preparatorio de computación Earth.

\section{Definición de la práctica}

Una vez introducidos en el curso del taller formación profesional de graduación PPG 404, se constató que se trata de un programa completo de alfabetización informática e informacional; hecho que seguidamente se ilustra con una combinación de dos despliegues de pantallas que evidencia que los contenidos están dirigidos a dos niveles:

- Técnicas para el uso de programas computacionales

- Formación, habilidades y competencias para búsqueda y uso de la información precisa, oportuna y confiable

Cabe destacar que los contenidos desarrollados por la biblioteca se encuentran incluidos como crédito o materia dentro de un plan de estudios de la universidad, pero poseen un reconocimiento de su importancia a nivel institucional. 


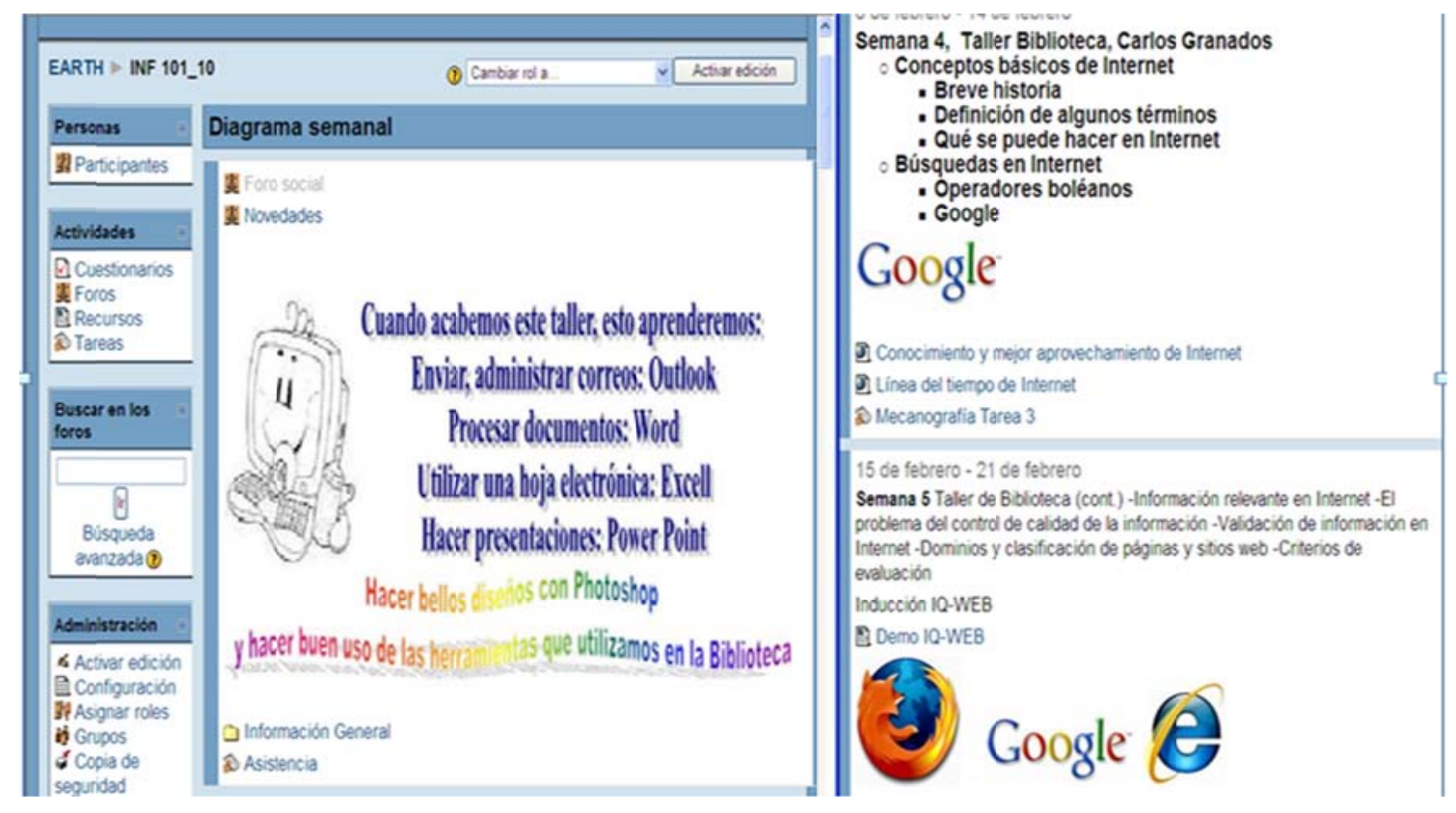

Figura 77. Despliegue de contenido del curso taller INF 101-10 (Alfabetización informática) de la Biblioteca de la Universidad Earth.

\section{Organización}

La organización y preparación de los contenidos son debidamente elaboradas por el personal de la biblioteca, que una vez sujeto a revisión y pruebas son colgados en forma de archivo pdf, ppt, xls, HTML entre otros en la plataforma Moodle. En esta misma línea, es importante señalar que en algunos contenidos se hace uso de foros de discusión y enlaces organizados como "recursos" alternativos, ejemplo de estos se presentan en la siguiente figura.
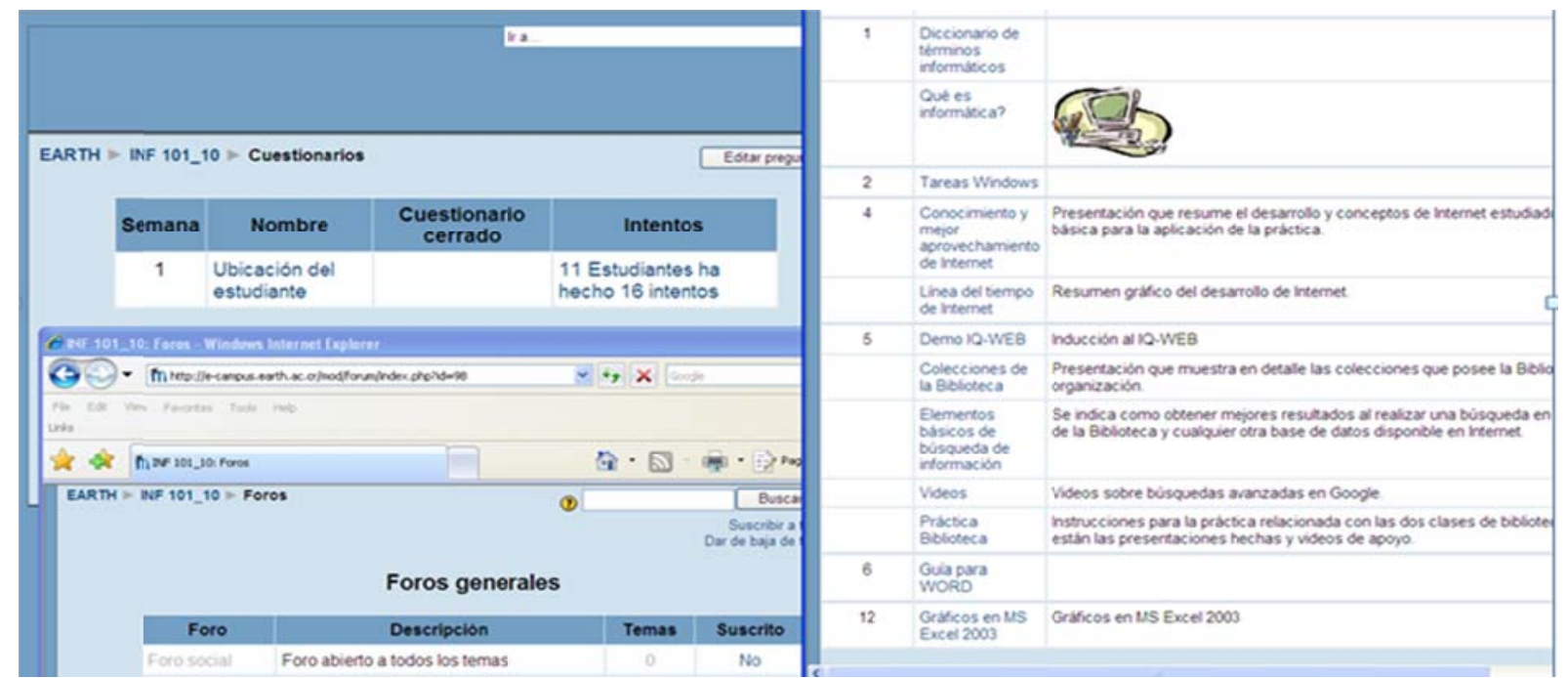

Figura 78. Organización de contenidos del curso INF 101-10 Earth.

\section{Evaluación}

El seguimiento del proceso enseñanza-aprendizaje se efectúa mediante los ejercicios individuales específicos para objeto de estudio y mediante la realización de prácticas (tareas) y los foros de discusión que son organizados en el mismo espacio virtual. 
Algunos recursos y fuentes de información disponibles en la biblioteca que son utilizados para el desarrollo de prácticas y ejercicios son:

- Colección en papel (primaria y secundaria)

- Colecciones especiales en papel

- Colecciones especiales (formato digital)

- Bases de datos internas de referencias (documentos digitalizados)

- Bases de datos externas de documentos digitalizados

- Recursos multimedia

- Información gris

- Google académico

Finalmente de forma general se constató un buen nivel de uso tanto de la plataforma E-learning y de los recursos de información para el desarrollo de los cursos. Lamentablemente fue evidente la ausencia de opciones especiales para personas con discapacidades físicas, visuales y auditivas.

\subsubsection{Evaluación del servicio de acceso a los repositorios}

El servicio se reconoce bajo el término repositorio y tiene como objetivo facilitar el acceso organizado y oportuno a las fuentes de información especializada en los temas de ciencias agropecuarias y recursos naturales con énfasis en trópico húmedo requeridas para el desarrollo de las actividades académicas y de investigación.

La oferta de repositorios cumple con las normativas de estandarización y ética internacionales para el acceso y transferencia de información ${ }^{151}$.

La consulta a estos repositorios es posible mediante tres puntos de acceso que a continuación se listan:

\section{- Catálogo}

- Bases de datos de publicaciones electrónicas subscritas y recuperables a través de intranet

- Bases de datos de publicaciones de acceso libre recuperables a través de internet.

En la siguiente figura se presentan los puntos de acceso ofrecidos por la Biblioteca de la Universidad Earth para el acceso a los repositorios.

\footnotetext{
${ }^{151}$ Estándares internacionales para la descripción de información. Derecho de autor, etc.
} 


\begin{tabular}{l} 
Vínculos útiles \\
Información sobre la \\
biblioteca \\
\hline E-mail de la biblioteca: \\
\hline Otras bibliotecas \\
\hline REVISTAS EN LINEA \\
DOAJ \\
\hline Revistas cientilicas \\
Redabyc \\
\hline SCIELO REVISTAS \\
\hline SCIRUS \\
\hline OpenDOAR \\
\hline INTECH Open Acess \\
\hline Scientilic Research \\
\hline Revistas U. Stanford \\
\hline PROTABASE \\
\hline CREDOreference \\
\hline BUSQUEDA \\
FEDERADA \\
\hline INGENTA CONNECT \\
\hline SOICitud de \\
información \\
\hline BLOG BSI \\
\hline REGISTRESE \\
\hline
\end{tabular}

\section{Home > Acerco de EARTH > Bibioteco $>$ Recussos de información extema}

OAsster: Lo red líder mundial mós grande de contenido con mós de 23 millones I documentos electrónicos en líneo.

SCIRUS: Instumento de investigoción cienfifico, posee mós de 410 millones de arficulos.

INTECH Open: Es un sitio multidisciplinario que ofrece occesso o publicaciones de occe libre.

Proyecio Gütemberg: Es un colección freedom, esto significo que usted puede hocer que usted desee con los publicaciones ofrecidos en este sitio.

Tesis electrónicos en línea: Cybertesis.NEI permite reolizar búsquedos simultóneos a trov de uno sola interfoz web, y recuperar los tesis electrónicos olmocenodos en los repositori universitorios.

PROTABASE: Reune informoción sobre 7,000 plantos útiles de Átrico Tropical

Biblioteco Digital Mundial: Pone o disposición importantes materioles fundomentoles I culturos de todo el mundo.

\section{El librototal (30 mil obros literarios a texio completo)}

Figura 79. Puntos de acceso a repositorios

Considerando los resultados de la pruebas de consulta a estos tres punto de acceso a los repositorios, es posible afirmar que la oferta y acceso es adecuada y accesible, no obstante la Earth podría considerar las posibilidades de acceso abierto internacional de las publicaciones científicas para ampliar su oferta.

\subsubsection{Análisis SWOT para introducir el modelo de servicios en programas E-learning}

El análisis de los servicios de la biblioteca de la Earth y la aplicación general de la metodología SWOT Strengths, Weaknesses, Opportunities, Threats ${ }^{152}$ ha permitido identificar una serie de insumos que a continuación se presentan y que de ser tomadas en cuenta podría facilitar la orientación del mejoramiento de actuales servicios ofrecidos por la biblioteca.

\footnotetext{
152 Metodología SWOT: Strengths, Weaknesses, Opportunities, Threats (Fortalezas, Debilidades, Oportunidades y Amenazas) conocido también en el habla hispana como "FODA".
} 


\section{Fortalezas}

- Las actuales iniciativas de cursos en la plataforma Moodle pueden significar una oportunidad para el posicionamiento y estructura de una oferta de cursos ALFIN basado en normativas estándares.

- Los cambios en las formas y modalidades de educación, representa una razón para la constante revisión, mejoramiento de la actual oferta de contenido dentro PPG 404, así como el análisis de repetir dichas prácticas dentro de otros programas formativos en Moodle.

\section{Debilidades}

-.En general las debilidades identificadas se ubican en el diseño del sitio web.

- Poca presencia y participación de la biblioteca en discusiones gerenciales a lo interno Earth.

- La limitada inversión en la plataforma tecnológica limita el desarrollo de servicios de información en línea más dinámicos y eficientes.

- El servicio de formación de usuarios, todavía no cumple con los parámetros estándares para actividades ALFIN.

\section{Oportunidades}

-. El entorno de cambios a nivel de toda la universidad.

-. Los proyectos e iniciativas regionales e internaciones relacionados con el Acceso abierto y ALFIN.

-. El potencial de la biblioteca para participar en la elaboración y utilización de materiales multimedia de apoyo a la docencia.

\section{Amenazas}

-. Limitaciones económicas producto de la crisis mundial.

-.Carencia de visión sistémica, (conceptual y práctica) por parte de los líderes de la en procesos de evaluación de servicios y necesidades a los interno la Earth

-. Limitada consulta a los usuarios docentes, estudiantes y líderes relacionadas con la mejora o ampliación de servicios

\section{Conclusión-caso Universidad Earth}

El sistema de biblioteca Earth participa de forma directa en actividades E-learning a través del desarrollo de contenidos parciales dentro de programas de formación de competencias informáticas e informacionales. La incorporación oficialmente y estructural de un curso ALFIN o como parte de un curso académico en Moodle, posicionaría a la biblioteca como un componente de apoyo al proceso mismo de enseñanza aprendizaje electrónica.

Aunque el sitio web de la biblioteca de la Universidad Earth se considera adecuado y cumple con los estándares establecidos, se recomienda prestar atención a los tres servicios analizados, específicamente en los siguientes aspectos:

- Desde la opción de pantalla no se puede regresar al menú de servicios virtuales de la biblioteca digital.

- Actualmente no se ha prestado mucha atención al cuido de la semántica de los metadatos.

- Se desconoce el diseño del servicio de referencia que cumpla con las normativas WAI. 
- El acceso al sitio web de la biblioteca está limitado a personas con incapacidades físicas, auditivas $\mathrm{y} / \mathrm{o}$ visuales.

- La biblioteca no ofrece dentro de sus opciones el servicio a índices de gráficos, personajes, lugares, etc.

- Las bases de datos que componen en su conjunto el repositorio de la biblioteca se encuentran en sistemas diferentes y se carece de un buscador que pueda integrar la búsqueda en todas ella, razón por la cual el usuario tiene que invertir mucho tiempo para realizar sus búsquedas.

- Durante el proceso de revisión de los servicios de referencia y acceso al catálogo, no fue posible comprobar el uso de imágenes y sonidos como material complementario a textos. 


\subsubsection{Universidad de Sevilla}

\subsubsection{Antecedentes de la Universidad de Sevilla}

La creación de la Universidad de Sevilla ${ }^{153}$ inicia en 1256 cuando el Rey Alfonso X autorizó a la ciudad de Sevilla crear el centro de estudio y escuelas generales de Latin i Arabigo. Posteriormente en 22 febrero 1502, los Reyes Católicos Conceden al Ayuntamiento de Sevilla la Real Cédula que le permitió fundar un programa de estudio general de cátedras de teología, cánones, leyes, medicina y artes liberales práctica que inicia en el Colegio Santa María de Jesús.

Un antecedente significativo de la Universidad se Sevilla ocurre en 1772 - 1845 (finales del siglo XVIII) con la independización de la Universidad se independiza del Colegio de Maese Rodrigo y cambia jurídicamente y físicamente su sede y nace la Universidad de Sevilla como organismo público. La verdadera transformación de la universidad ocurre bajo el reinado Carlos III cuando se toman medida para la remodelación de la enseñanza y solventar el problema generado con la expulsión de los Jesuitas (1767). En este mismo año Pablo de Olavide analiza la coyuntura y problemática y elabora un informe que marco una auténtica reforma universitaria. El documento fue el marco de referencia para ordenar y orientar la constitución de la Universidad de Sevilla, por cuanto sugirió los siguientes puntos:

Misión y objetivo. "La educación superior debe ser considerada como un servicio público exclusivo de la universidad, siendo el principal papel de ésta proporcionar servidores a estado".

Ubicación física al momento que él afirma que "las casa de los jesuitas podrían ser utilizadas con fines docentes".

Autonomía. Pablo de Olavide apela a la reforma universitaria al momento que señala como cuestión fundamental "la separación total y definitiva de la Universidad y del Colegio de Santa María de Jesús".

Materiales para la educación. El informe recomienda la elaboración de nuevos estatutos y la publicación de nuevos textos para la enseñanza incluyendo como nuevo curso las matemáticas en las distintas facultades de Artes-Filosofía, Teología, Cánones y Leyes y medicina.

Con la Ley de Reforma Universitaria (L.R.U.) aprobada en 1983, se consagra la autonomía universitaria pero está el año 2003 que la Universidad de Sevilla elaboró su estatuto que fue aprobado ese mismo año. Desde 1999 con la declaración de Bolonia se sientan las bases para la construcción de un "Espacio Europeo de Educación Superior", hecho por el cual todas las titulaciones de la Universidad de Sevilla están adaptadas al Espacio Europeo de Educación Superior.

En la actualidad la Universidad de Sevilla se destaca por su misión de prestar servicios públicos y la competencia de sus catedráticos y profesores, manteniendo como lema el respecto a la "Igualdad, Libertad, Justicia y Pluralismo ${ }^{154}$. La visión de la Universidad de Sevilla, en coherencia con su misión, se formula en base a dos importantes ejes:

\footnotetext{
${ }^{153}$ Los antecedentes históricos de la Universidad presentados a continuación se basan en la información oficial y públicamente disponibles en el sitio Web de la Universidad de Sevilla http://www.us.es/acerca/index.html Consultado: 29 agosto de 2011 y 30 noviembre 2012.

${ }^{154}$ Mayor información sobre los antecedentes históricos véase los siguientes sitios: http://personal.us.es/alporu/historia/index.htm; http://www.topuniversities.com/institution/universidad-de-sevilla
} 
1. Reconocimiento institucional por su excelencia académica y de investigación en todo el ámbito nacional e internacional.

2. Aportación a la transformación y al progreso de la sociedad mediante los resultados de su investigación y la calidad en la formación de sus titulados en correspondencia al Espacio Europeo de Educación Superior.

La Universidad de Sevilla implanta su misión y visión desarrollando una estrategia centrada en la comunidad universitaria y las instituciones sociales del sector universitario basada en las siguientes seis líneas estratégicas:

- Una universidad excelente para aprender y enseñar.

- Una universidad innovadora y punta de lanza en docencia e investigación.

- Una universidad comprometida con las aspiraciones de sus estudiantes.

- Una universidad moderna y renovada.

- Una universidad integrada en su entorno.

- Una universidad solidaria y comprometida con el medio ambiente

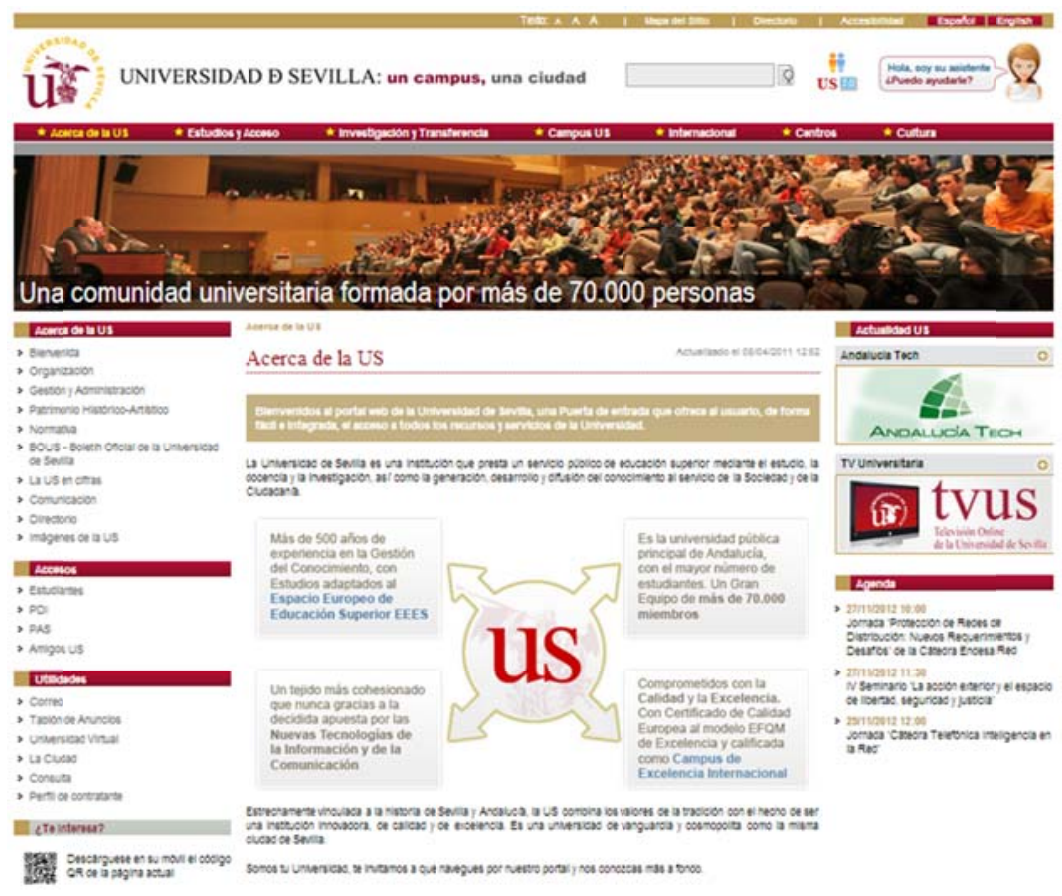

Figura 80. Página principal del sitio web de la Universidad de Sevilla.

\section{La educación electrónica en la Universidad de Sevilla}

La Enseñanza Virtual ${ }^{155}$ es el proyecto de la Universidad de Sevilla diseñado para apoyar la docencia presencial por medio de recursos tecnológicos propios de la formación online. Estos medios facilitan el acceso de los estudiantes a los contenidos y materiales formativos de las distintas enseñanzas en cualquier momento e independientemente del lugar en que se encuentren. Para ello la Universidad de Sevilla dispone para la formación virtual de varias herramientas que tienen como objetivo facilitar el contacto entre los docentes y los estudiantes, así como potenciar la participación y el intercambio de conocimiento:

\footnotetext{
${ }^{155}$ Véase http://www.us.es/campus/univirtual/index.html.
} 
- Educlick - Plataforma e-learning que representa ser la herramienta para el desarrollo de evaluaciones rápidas, sencillas y seguras en el aula

- Elgg - Aplicación de software libre asociado a una aplicación blog, una carpeta personal, una red de contactos, feeds, RSS y un perfil personal. Permite crear comunidades de usuarios, perfiles, usar un disco duro virtual, calendarios, etc.

- MediaWiki es un software wiki libre escrito originalmente para Wikipedia. Dispone de herramientas básicas para la creación de contenidos en forma colaborativa. Soporta múltiples usuarios y diferentes niveles de acceso, así como capacidad para manejar varios formatos de imagen.

- Live Classroom. Es una herramienta de comunicación integrada en WebCT (plataforma Elearning) para impartir clases en línea en tiempo real y la comunicación asíncrona entre el docente y los estudiantes.

- Wimba Podcaster. Es un recurso que permite añadir archivos de audio a los cursos en línea para que los estudiantes puedan suscribirse y recibirlos como podcasts.

- Voice Tools. Conjunto de herramientas que permite integrar archivos de voz como parte del contenido de la asignatura, siendo necesario tener un micrófono y los altavoces activados. Facilita enormemente la enseñanza de idiomas de manera sencilla, acentuando el discurso o la pronunciación.

- Aulas de Informática (Aulas TIC) implantadas en los distintos Campus de la Universidad de Sevilla es servir de soporte tanto a la docencia de los distintos planes de estudio y el autoaprendizaje y la alfabetización digital de la comunidad universitaria, ayudándose para ello de las Tecnologías de la Información y las comunicaciones (Internet, ofimática, servicios en red, bases de datos, etc.).

\subsubsection{Análisis general del sitio web de la Universidad de Sevilla}

La Universidad de Sevilla puede accederse en la Internet mediante cualquier meta buscador como Gloogle o Yahoo. Basta teclear el sitio Web para identificar la universidad. También es posible realizar una búsqueda truncada para ser remitidos al sitio web de la biblioteca.

La página principal de la Universidad de Sevilla cumple con las normativas básicas para diseño de sitios Web. Su diseño se constituye básicamente de bloques, cinco horizontales en la parte superior, uno en la parte inferior y tres verticales, todos ellos contienen enlaces que direccionan al contenido de las ofertas de servicios de la Universidad disponible en Español e Inglés y corresponde a los objetivos y fines institucionales.

En el primer bloque horizontal superior las opciones para personas con incapacidades visuales (aumento de letras), el acceso al mapa del sitio; opción para resolver problemas de acceso y la opción de cambio de idioma. En el segundo bloque horizontal el logo e identificación oficial de la universidad ofrece la opción (Ventana) para búsquedas rápidas, y un enlace a la Universidad virtual "Universidad de Sevilla 2.0". En el tercer bloque se visualizan por medio de enlaces que facilitan el recorrido por toda la estructura organizativa de la universidad. 
El contenido está disponible en español e Inglés y corresponde a los objetivos y fines institucionales. Los bloques verticales (columnas) refieren a enlaces de información general sobre la gestión de la Universidad. En cada una de ellos se observa la presencia de opciones para impresión y agregar a favoritos. La actualización de la página no cuenta con un indicador de fecha de la última actualización, sin embargo por el campo de información de agenda, es posible constatar que la actualización se realiza de forma regular.

Los enlaces ubicados en todo el sitio web no presentaron ningún problema técnico o de funcionalidad de los enlaces. Tampoco se observó ningún problema de acceso y navegación dentro de cada sección y fue posible verificar que la Web puede ser accesible desde diferentes navegadores de Internet Explore, Firefox, Mozilla y Netscape (Windows), Safari, Omniweb (Mac Osx) y Konqueror (Linux). En relación a este punto es posible identificar mayor información en el último bloque inferior horizontal que contiene los enlaces relacionados con el acceso RSS, aviso legal, condiciones de uso, derechos de autor, normativas W3C. En relación a los aspectos ergonómicos del sitio web de la Universidad de Sevilla se observó bastante consistencia en uso de colores, combinación de texto, figura y fondo.

Desde la página principal del sitio Web de la Universidad de Sevilla, se identifican tres tipos de información:
a) los referentes a la universidad
b) la oferta de estudios
c) las actividades coyunturales en el campus.

\subsubsection{Biblioteca de la Universidad de Sevilla}

\section{Antecedentes históricos}

Los antecedentes históricos de la biblioteca de la Universidad de Sevilla (BUS) inician en correspondencia a la creación de la universidad en el siglo XVI en el contexto ya antes mencionado del Colegio de Sta. María de Jesús, fundado en 1505 por Arcediano Maese Rodrigo Fernández de Santaella.

La formación de la colección de la biblioteca inicia con la donación de libros hecha por Fernández de Santaella otras donaciones y otras adquisiciones hechas con ayudas económicas de colegiales distinguidos. Al producirse la separación del Colegio y la Universidad la mayoría de estos libros formaron el fondo de la biblioteca de la Universidad y posteriormente fueron sumándose otros fondos bibliográficos pertenecientes a los jesuitas y otras órdenes religiosas establecidas en Sevilla y su provincia. Estas se vieron afectadas por la Desamortización de Mendizábal; así mismos otras donaciones posteriores de Bibliotecas Públicas o de particulares continuaron enriqueciendo los fondos bibliográficos de la Biblioteca, hasta nuestros días.

El prestigio histórico de la BUS en gran parte responde a que en su colección alberga, conserva y custodia el Archivo Histórico Universitario concedido a la biblioteca por Real orden de 7 de Agosto de 1895, el cual está siendo digitalizado para ampliar su difusión y óptima conservación. En la actualidad la biblioteca de la Universidad de Sevilla es concebida como un sistema conformado por 25 bibliotecas pertenecientes a los 25 centros propios universitarios que se ubican geográficamente 
dispersos por toda la ciudad de Sevilla. El uso de herramientas Web permite ofrecer un punto único de acceso a los diferentes servicios y productos ofrecidos por cada una de las bibliotecas desde un Portal Web

\section{Misión y Visión de la Biblioteca de la Universidad}

La misión de la Biblioteca de la Universidad de Sevilla es gestionar los recursos de información, facilitar su acceso y llevar a cabo su difusión, así como colaborar en los procesos de creación del conocimiento, a fin de contribuir a la consecución de los objetivos de la Universidad y asegurar un servicio de excelencia a la sociedad.

Para el cumplimiento de su misión la biblioteca desarrollan un sin número de actividades y servicios que parten de los siguientes valores éticos y profesionales:

- Profesionalidad: que se manifiesta en su orientación al cliente, sentido de responsabilidad y eficacia

- Compromiso: a) compromiso con la institución, entendido como lealtad y compromiso con la consecución de los resultados y b) compromiso social, que engloba respeto, tolerancia y cortesía

- Comunicación: que implica cooperación, saber escuchar y trabajo en equipo.

- Mejora continua: para ello se necesita innovación, creatividad, capacidad de aprendizaje y adaptación al cambio

\section{Estructura organizativa}

La biblioteca de la Universidad de Sevilla está constituida como un sistema ${ }^{156}$ de servicio central que actúa como una unidad administrativa de gestión con una sola dirección, razón por la que cuenta con un solo presupuesto. La Comisión General de la biblioteca aprueba los objetivos anuales que rigen de forma centralizada las actividades y servicios que ofrecen las 25 bibliotecas del sistema. Asimismo el sistema diseña los procedimientos, normas y gestiona el presupuesto.

El trabajo de gestión de la biblioteca de la Universidad de Sevilla se caracteriza por cuido rigoroso en eficiencia - eficacia en la prestación de servicios, hecho que le atribuyó el haber recibido el certificado de calidad en el 2006 por parte de la Secretaría de Estado de Universidades e Investigación (ANECA ${ }^{157}$ ) y cuatro años después en abril de 2010 el reconocimiento del Sello de Excelencia Europea 300+ que concede el Club de Excelencia en Gestión.

\section{Fondo informativo}

Los recursos electrónicos suscritos por la Biblioteca se encuentran en el catálogo constituido por todas las colecciones existente en el sistema denominado "FAMA" Este catálogo permite realizar búsquedas concretas y la utilización de filtros para obtener los resultados específicos y por biblioteca.

\footnotetext{
${ }^{156}$ Datos extraídos del sitio Web del BUS. http://bib.us.es/sobre_la_biblioteca/carta_servicios/mision/estructura-idesidwebweb.html.

${ }^{157}$ Agencia Nacional de Evaluación de la Calidad y Acreditación (ANECA) Su objetivo contribuir a la mejora de la calidad del sistema de educación superior mediante la evaluación, certificación y acreditación de enseñanzas, profesorado e instituciones.
} 
El fondo de la biblioteca se encuentra conformado por una serie de recursos que brevemente se describen:

- Bases de datos: Desde el sitio Web de la BUS los usuarios pueden acceder a 260 bases de datos cuya contenido esta en correspondencia con los objetivos de la Universidad de Sevilla. La bases de datos permiten realizar búsquedas sencillas y avanzadas por materia (Arte, Derecho, Química, etc.) y tipo de tipo de material (prensa, factor de impacto, tesis, etc.)

- Revistas electrónicas. Actualmente la biblioteca ofrece el acceso a un número aproximado de 60,000 revistas a través del acceso remoto a la plataforma "Serial Solutions" clasificadas de forma temática según las normas de la biblioteca del Congreso de los Estados Unidos. Asimismo se suman 73 revistas españolas disponibles en el SCl y 48 en el SSCI (factor de impacto 2010)

- Colección de libros electrónicos Desde el catálogo FAMA la biblioteca permite localizar y acceder a 350.000 libros electrónicos por autor, título, palabra clave o materia en español (en el caso de libros modernos) suscritos por la Biblioteca. Según los reportes estadísticos se considera la sección más consultada por la comunidad universitaria. Además se suman los 610 libros electrónicos de Springer a texto completo correspondiente a la colecciones de Biomedicina, Informática, Ingeniería, Matemáticas, Humanidades, Ciencias Sociales y Derecho

- Colección fondo antiguo: Dispone de un valiosísimo fondo antiguo constituido por 917 volúmenes manuscritos, 330 incunables, 8.000 del siglo XVI y una amplísima colección de los siglos XVII y XVIII. Este fondo forma parte del Portal de Fondos Digitales de la Universidad de Sevilla y contiene más de 1900 obras con un total de 18.960 grabados en continuo crecimiento ${ }^{158} \mathrm{El}$ acceso a estas obras se realiza desde el Catálogo FAMA que direcciona al catálogo de Fondo Antiguo Digital)

- Colección de recursos Dialnet. A través del portal de la biblioteca de la Universidad de Sevilla es posible acceder al portar Dialnet que permite el acceso a diferentes recursos y servicios documentales:

- Servicio de alertas bibliográficas

- Hemeroteca virtual hispana

- Base de datos de contenidos científicos hispanos

- Depósito o repositorio de texto completo de acceso libre

- Colección de tesis doctorales. Es un repositorio de tesis y la colección de proyectos de fin de carrera en formato electrónico defendidos desde 2001 (e-REdING)

- Colección de un fondo jurídico antiguo. Conformado con un fondo aproximado de 6.000 volúmenes (PixeLEGIS), aunque el proyecto se centra en el siglo XIX, también recoge obras de otros siglos y obras no jurídicas contenidas en su fondo

- Colección de fotos (Fototeca). Constituida por piezas con valor histórico y artístico con alcance geográfico local, nacional e hispano-americano

\footnotetext{
${ }^{158}$ Datos reflejados en el informe presentado por las autoridades de la Universidad en el 2008. http://bib.us.es/nuestras_colecciones/fondo_antiguo/fondo_antiguo_digital-ides-idwebweb.html
} 
Colección de material de referencia electrónica. Incluye obras de referencia como diccionarios, patentes, etc. en formato electrónico.

\section{Servicios de apoyo a la docencia e investigación}

- Servicio de alertas y diseminación selectiva de la información (DSI)

- Acceso a bases de datos y repositorios académicos

- Programa de gestión de citas

- Orientación personalizada en diferentes ámbitos temáticos por parte de bibliotecarios especialistas

- Compra de materiales para la biblioteca

- Visitas guiadas

- Cursos de formación de habilidades y competencias informáticas e informacionales

Con el objetivo de orientar la localización y uso de bases de datos, libros y revistas (electrónicos o impresos), de cada disciplina, la biblioteca dispone de una serie de guías por materias que están relacionados con los ámbitos temáticos de la docencia y la investigación y que han desarrolladas con aplicaciones Web 2.0. Estas guías de apoyo para la docencia son periódicamente actualizadas.

\subsubsection{Evaluación de la web de la Biblioteca de la Universidad de Sevilla}

\section{Parámetro 1. Identidad}

El acceso a la biblioteca de la Universidad de Sevilla (en adelante US) es posible a través de un enlace desde la Web de la Universidad, no obstante este no se realiza a primera vista. Es necesario introducirse al sitio de la universidad, ya sea en la sección de Investigación y Transferencia o en la sección de Campus para acceder al enlace que direcciona al portal de la biblioteca.

Desde el sitio principal de la Universidad de Sevilla, la biblioteca puede ser localizada dentro de dos secciones
Investigación y Transferencia

Se identifican en dos sitios dentro de la sección. En la primera columna la palabra "biblioteca" se presenta como parte de la sección de Investigación y Transferencia. http://www.us.es/investigacion/biblioteca/index.html

El término "Biblioteca" se identifica por segunda vez en la página en la parte inferior y central de la sección como parte del grupo de "Enlaces relacionados". Desplegando el sitio Web de la biblioteca http://bib.us.es/

\section{Campus US}

Se identifica como parte del Campus y se ubica como enlace en el menú de opciones del primer bloque vertical 
Desde Google, se localiza la biblioteca con solo teclear "biblioteca universidad de Sevilla". Las opciones de acceso resultantes van desde el acceso a la índice como a las partes del sitio.

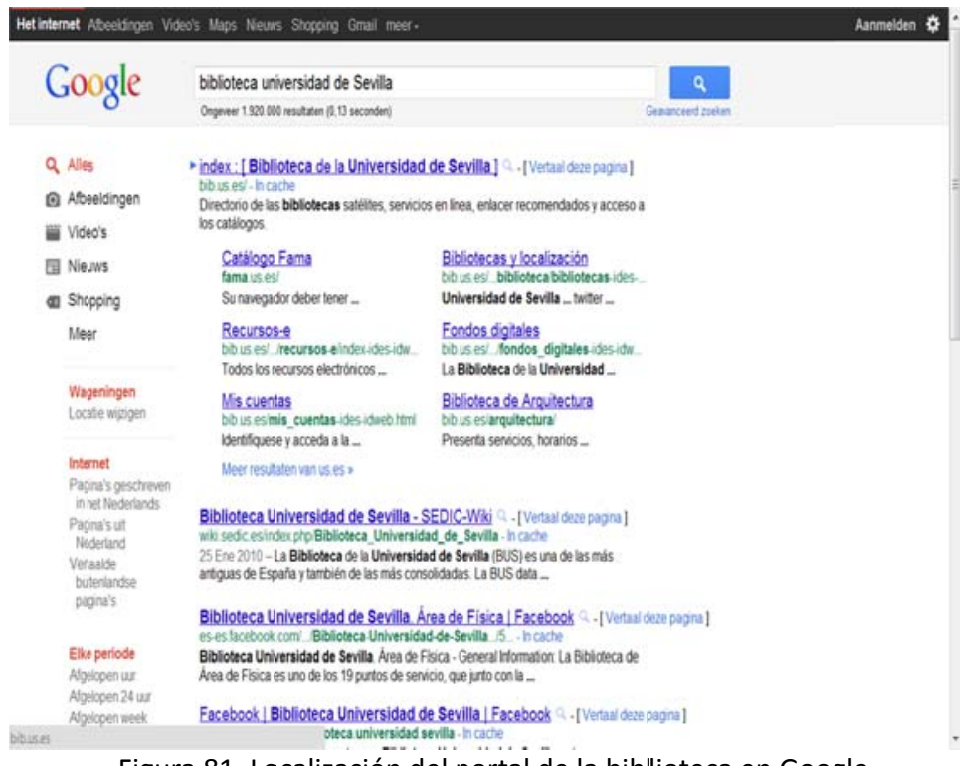

Figura 81. Localización del portal de la bibllioteca en Google

El primer sitio Web de la biblioteca www.us.es/investigacion/biblioteca/index.html forma parte del sitio institucional, hecho por lo cual conserva la misma estructura de tres columnas, consistencia de letras y colores. La construcción de la dirección URL deja en evidencia que se trata de índice a los servicios y recursos. El diseño se constituye de franjas horizontales y columnas. En las franjas superiores se identifican los mismos datos que en la página inicial de la Universidad de Sevilla. Es decir, la identificación institucional, su logo, el acceso a la universidad virtual y un motor de búsquedas para el sitio. En la primera columna se destacan los enlaces a los servicios, las formas de acceso y algunos recursos de utilidad para los interesados en la sección de Investigación y Transferencia. La columna izquierda presenta información sobre las actividades y agenda de la sección. En la columna central se presenta el contenido relacionado con la biblioteca que en definitiva es el menú de servicios.

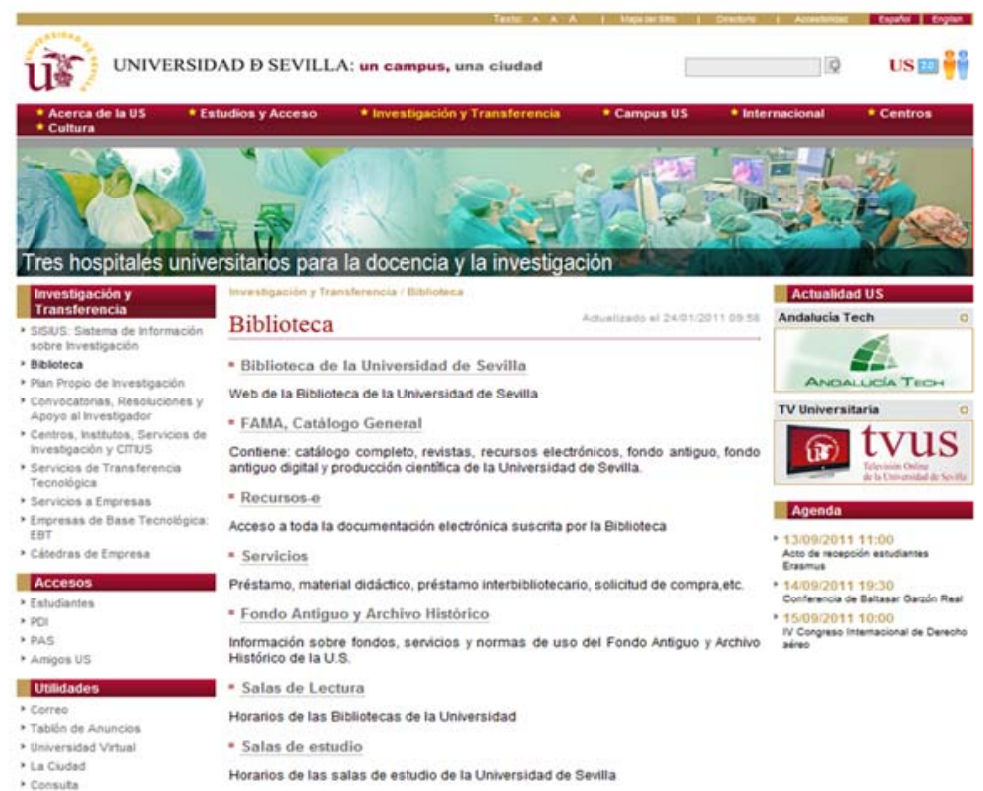

Figura 82. Portal inicial para llegar a los servicios de la biblioteca.

El segundo direccionamiento de la biblioteca se trata un enlace al portal propio de la biblioteca. Es decir no es una página dependiente de la dirección URL sino un enlace al portal http://bib.us.es/. El diseño del portal es consecuente con la lógica institucional y se constituye en columnas y franjas. 


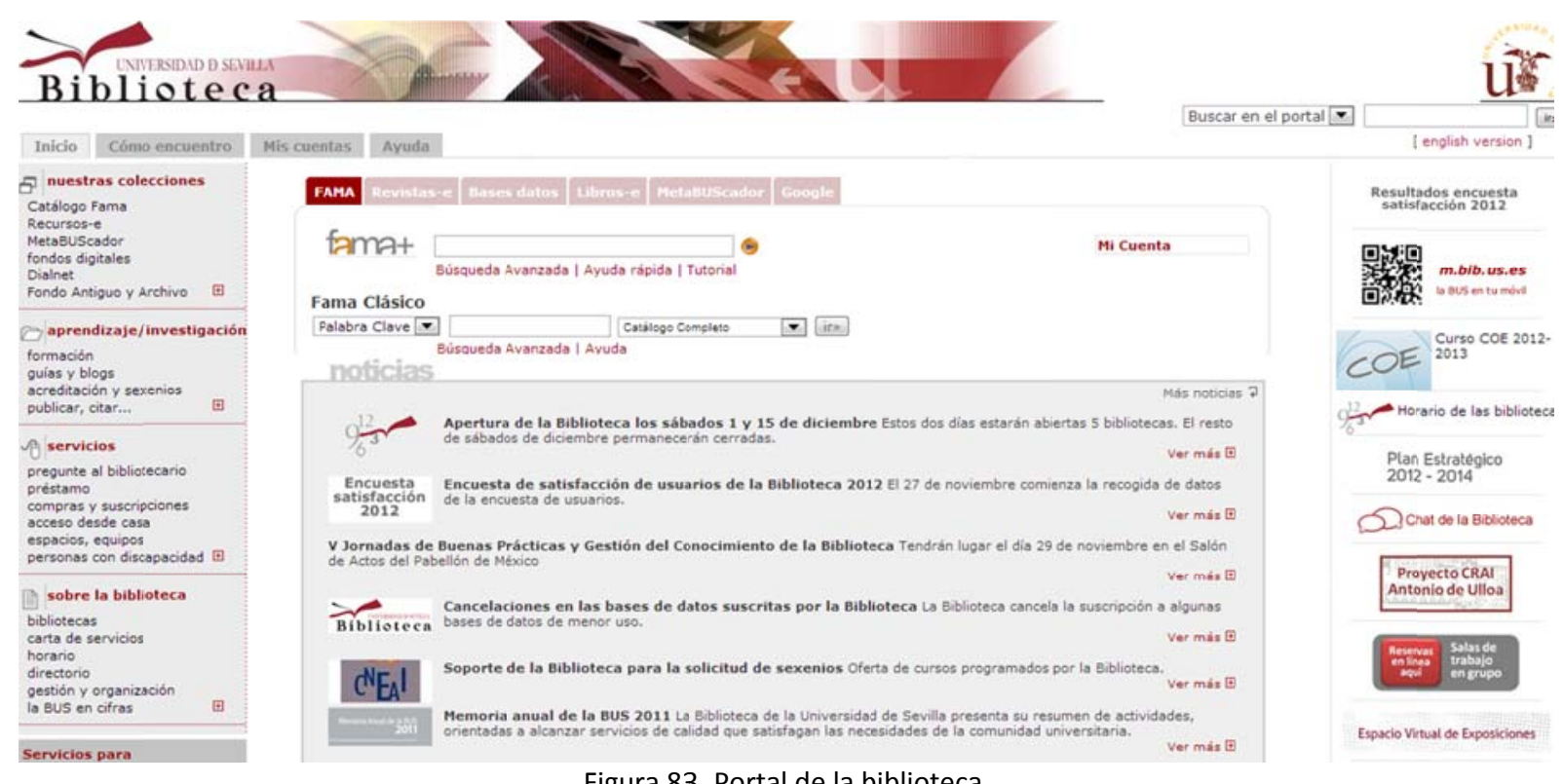

La primera franja superior horizontal destaca el nombre la universidad con su respectivo logo y de la biblioteca. La segunda ubicada a lado derecho superior es una opción de búsqueda dentro del portal y una opción para cambio de idioma. La tercera franja se estructura en forma de etiquetas y se ubican en la parte superior entre el primer y central bloques verticales. Las columnas de izquierda y derecha ofrecen en forma de menú los servicios y recursos de la biblioteca. La columna central ofrece información general acompañada de enlaces.

En su parte superior ubica la opción para localizar recursos en los diferentes puntos de acceso, tales como el catálogo central "Fama", e-revistas, bases de datos, libros. Asimismo se ofrece la posibilidad de realizar búsquedas en Google o en un meta buscador. Igualmente se ofrece un menú de gestión de préstamo rápido. Cabe destacar que el servicio de referencia, el servicio de formación de usuarios y el acceso a los recursos de apoyo a la enseñanza se ubica en la columna derecha como un enlace inmediato.

\section{Parámetro 2. Actualización}

En el sitio web de la biblioteca no fue posible encontrar ningún elemento para identificar la última fecha de actualización del contenido. Aunque el sitio dispone en la columna derecha de un enlace "Recursos del mes", al momento de acceder se identificó que se trata de un servicio ofrecido por una base de datos de tesis y tesinas ProQuest.

\section{Parámetro 3. Accesibilidad}

Durante la conexión al sitio de la universidad y biblioteca no se experimentó ningún problema de acceso o navegación. 


\section{Parámetro 4. Servicios básicos de la web}

La biblioteca ofrece desde la Web de la US y del portal un menú de servicios que pueden ser iniciados en línea que requieren posteriormente la visita al edificio de la biblioteca. Las solicitudes de servicios en línea ofrecidos por la biblioteca no son de respuesta inmediata, a diferencia de los servicios de acceso a textos que pueden ser recuperados por los usuarios y el servicio de Referencia (Chat). Sin embargo, el margen de respuesta a toda solicitud que no es inmediata es entre 12 y 24 .

Los servicios de la biblioteca que se destacan en el sitio de la Universidad de Sevilla (índex de la biblioteca) se listan a continuación:

- Acceso al catálogo completo, revistas, recursos electrónicos, fondo antiguo, fondo antiguo digital y producción científica de la Universidad de Sevilla. (Catálogo general - FAMA)

- Acceso a toda la documentación electrónica suscrita por la Biblioteca (Recursos-e)

- Servicios de préstamo, material didáctico, préstamo interbibliotecario, solicitud de compra, etc.

- Acceso a la información sobre fondos antiguos y archivo histórico

Información sobre Horarios de las Bibliotecas de la Universidad

- Noticias y Novedades de la Biblioteca

Desde el portal de la biblioteca la oferta es mucho más amplia. Los servicios que se destacan son los siguientes:

Acceso:

- Espacio personalizado y domiciliar

- Directorio

- Objetos de aprendizaje multimedia

- Acceso a diversos recursos de información

- Catálogo Fama

- Recursos-e

- Meta buscador

- Fondos digitales

- Dialnet

- Fondo Antiguo y Archivo

- Enlaces de interés

Servicios:

- Préstamo o reserva de materiales

- Recepción y gestión de solicitudes de compras y suscripciones de recursos de información

- Servicio de referencia (en la forma de "pregunte al bibliotecario")

- Servicio de apoyo a la enseñanza y docencia

- Cursos de orientación al estudiante

- Guías y blogs, Wikis

- Acreditación y sexenios

- Cursos de cómo publicar, citar, entre otros

- Instalaciones físicas

- Atención especial para personas con discapacidades físicas

- Servicio informativo (noticias, variedades, entretenimientos, etc.) 


\section{Parámetros 5 y 6. Contenido y Arquitectura de la información}

El contenido de la información desplegable en el sitio y portal de la biblioteca corresponde a los objetivos y fines institucionales. La revisión del catálogo FAMA, permitió constatar el cumplimiento de los siguientes parámetros estándares definidos para la presentación de los contenidos de información en línea.

- Autoridad de autores reconocida

- Adecuación entre la autoría y la agenda temática

- Reconocimiento y credibilidad de la fuente

- Identificación básica de las diferentes secciones de la publicación (autor, título y fechas)

\section{Parámetro 7. Diseño de interfaz}

El sitio URL de la biblioteca y su portal disponen de un adecuado, sencillo y flexible diseño basado en las normas establecidas para diseño de sitios Web. Se destacan el cumplimiento de los siguientes aspectos: consistencia y contraste en el uso de colores; tipo de letras; líneas de texto; anchura de pantalla; márgenes; legibilidad; claridad o contraste adecuado entre el texto y el fondo; velocidad de cambio de pantalla a pantalla y tiempo de descarga de documentos; posibilidad de dar seguimiento al contenido y entrar en contacto con el gestor de la Web a través de correo, Facebook, RSS, Flickr.

\section{Parámetro 8. Posicionamiento}

El posicionamiento del sitio dentro de la Internet resulta evidente debido a que tanto el sitio como los servicios y contenidos son recuperables a través de una búsqueda desde cualquier buscador en Internet. Sin embargo por la importancia y rol de la biblioteca dentro de la Universidad de Sevilla, se considera que el enlace a la biblioteca debería ubicarse en la página inicial de Web de la Universidad.

\section{Parámetro 9. Sistema de búsqueda}

La biblioteca dispone de diferentes y flexibles mecanismos o búsquedas. Se destacan dos tipos de buscadores. Un mecanismo de recuperación dentro del portal y el buscador dentro de contenidos de las colecciones.

Los contenidos ofrecidos por la biblioteca son posibles de identificar mediante mecanismos de búsquedas que permiten la identificación de recursos por su descripción (autor, título, ISBN, lenguaje controlado). Las formulaciones de búsqueda admiten el uso de operadores boléanos. 


\section{\begin{tabular}{|l|l|l|l|l|l|} 
FAMA & Revistas-e & Bases datos & Libros-e & Metabuscador & Coogle \\
\hline
\end{tabular}}

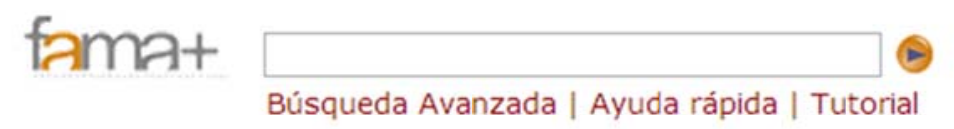

Mi Cuenta

\section{Fama Clásico}

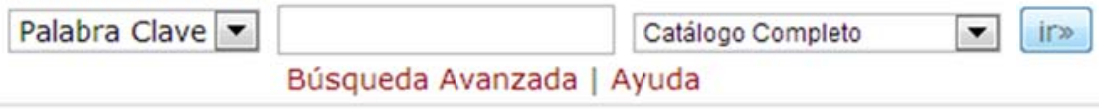

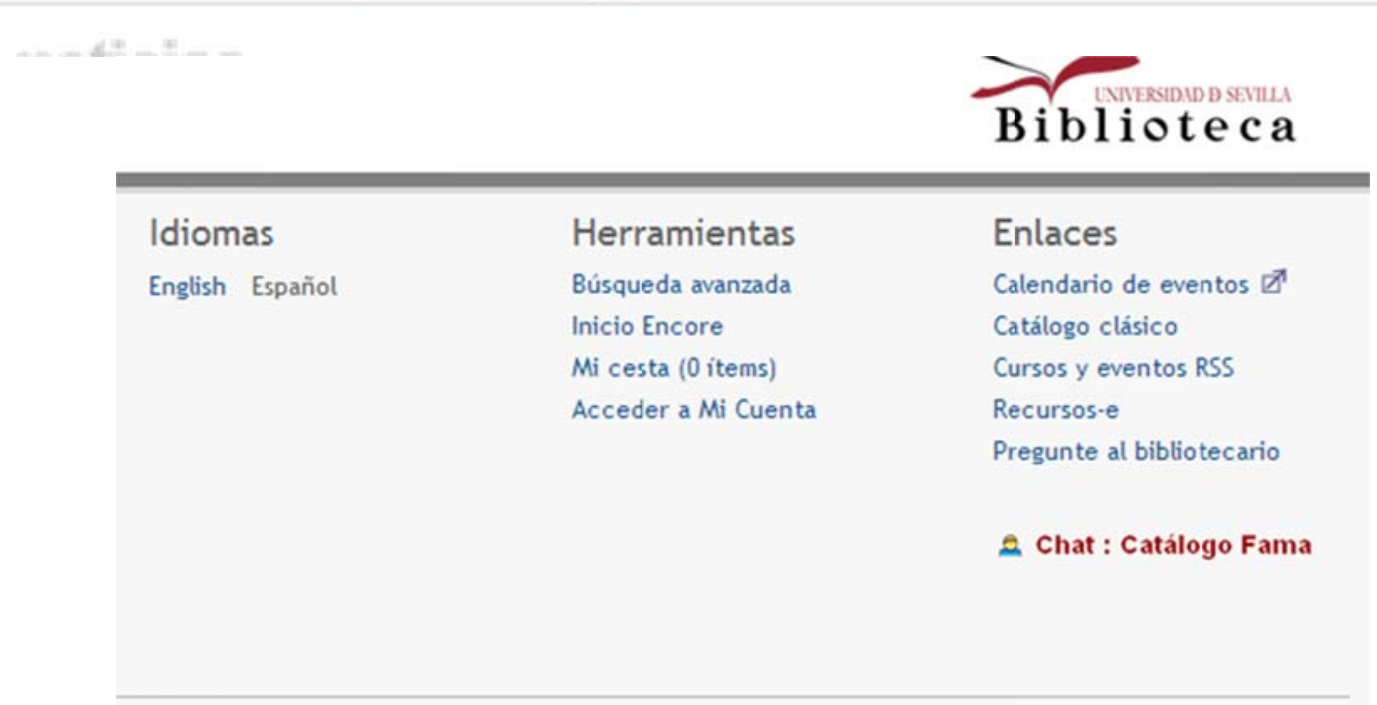

Figura 84. Catálogo Fama.

\section{Parámetro 10. Usabilidad}

No fue posible verificar la usabilidad de los contenidos. En el caso de la Universidad de Sevilla por limitaciones de acceso a los usuarios no fue posible realizar consultas a ellos.

\subsubsection{Evaluación del servicio de referencia}

El servicio de referencia se localiza en el grupo de servicios en línea. Su objetivo es proporcionar asistencia a cualquier persona que demande el servicio. No obstante para usuarios externos a la Universidad existen limitaciones de acceso a los recursos electrónicos. Los usuarios reales del servicio corresponden principalmente a la comunidad docente y los estudiantes de la Universidad de Sevilla.

El servicio dispone de una "política de privacidad, hecho por el cual no se requiere dar ningún tipo de registro personal durante una comunicación en línea, las transcripciones son manejadas por el personal a cargo del servicio y posteriormente eliminadas. El tiempo determinado para dar respuesta a las solicitudes se enmarca en un promedio de minutos y una hora, en dependencia del tipo de demanda o pregunta. En algunas ocasiones no puede ser inmediata y se responde vía correo electrónico, para lo cual existe una dirección específica.

El servicio de referencia virtual tiene como fin responder adecuadamente a las consultas sobre el funcionamiento y quehacer de la biblioteca. En esta línea se distinguen los siguientes objetivos específicos: 
- Responder acertadamente a las necesidades concretas de servicios y productos

- Facilitar de forma eficiente y eficaz respuestas a preguntas concretas

- Actuar como intermediario y direccionar adecuadamente las demandas de información dentro de la biblioteca y ayudar a la búsqueda y localización de información electrónica.

Los componente básicos del seque se utilizan para la gestión del servicio son ordenadores, programa LibraryH3lp, teléfono, correo electrónico, Chat, RSS, Blogs cooperativos y wiki's.

Según información publicada en la página del servicio y datos proporcionados por el profesional de la biblioteca, la funcionalidad del servicio está sujeta a una revisión constante, para esto se realizan estadísticas diarias con fines evaluativos y mejoras del servicio. Según datos recibidos la última evaluación del servicio fue realizada en mayo del 2011.

\section{Identificación del servicio}

El servicio de referencia Virtual propiamente dicho no se identifica fácilmente, debido a que este se ofrece con dos fines concretos. Por un lado el ofrecer las facilidades de comunicación entre el usuario - bibliotecario y en segundo lugar como un medio de apoyo para la identificación de los recursos y servicios que ofrece la biblioteca y en tercer lugar facilitar el acceso a las obras de referencias propiamente dichas. La identificación del servicio fue posible dentro del portal de la biblioteca y mediante pruebas de búsqueda en Google. El resulta en ambos casos direcciona al enlace a la siguiente figura que ilustra la oferta del servicio.

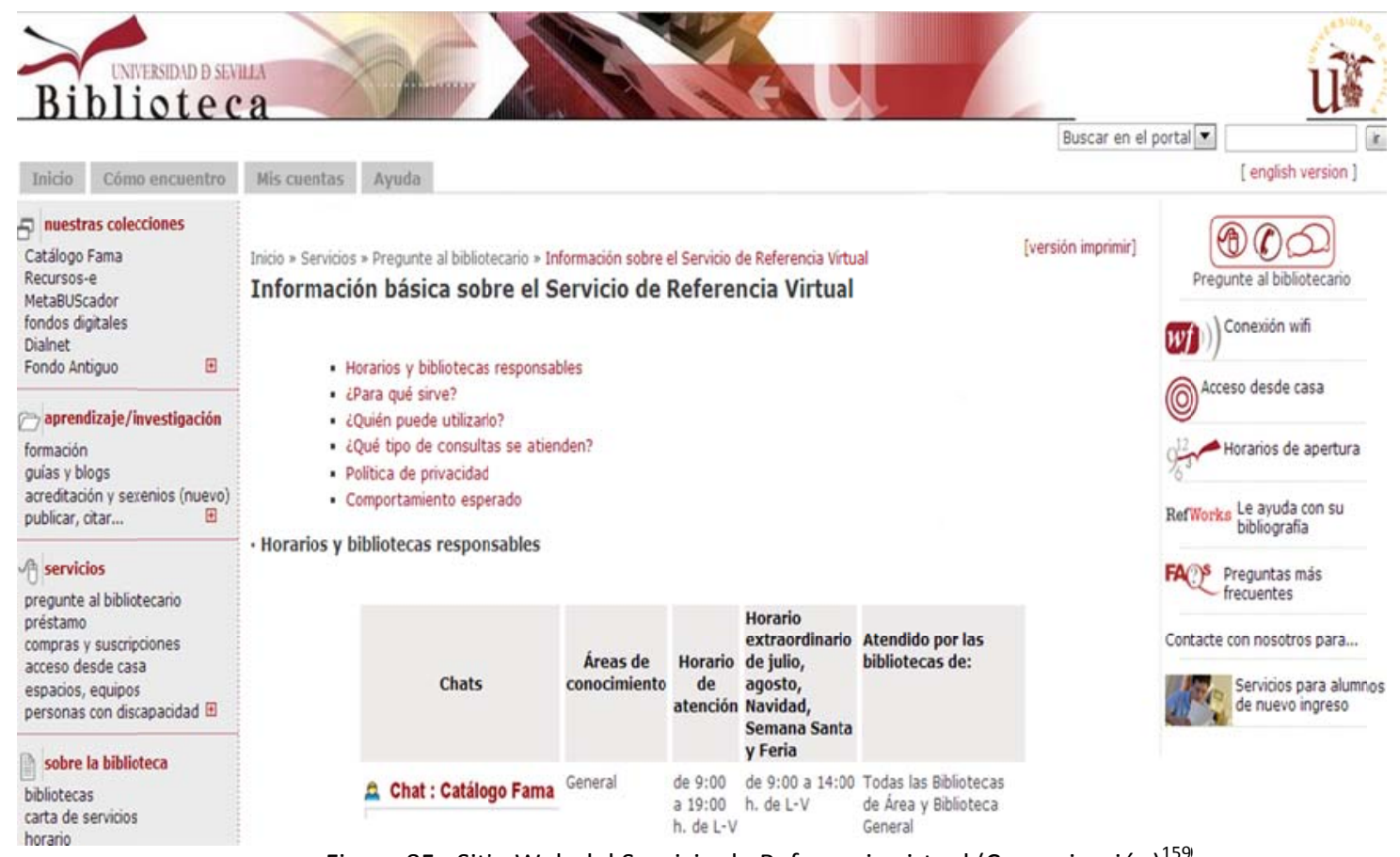

Figura 85. Sitio Web del Servicio de Referencia virtual (Comunicación) ${ }^{1591}$

En la figura anterior se observa en la parte superior izquierda la presencia de íconos que orientan la posibilidad de hacer uso de las diferentes posibilidades de comunicación sincrónica y asincrónica. Asimismo en el centro de la pantalla, se presentan preguntas en forma de enlaces, que estimulan la

\footnotetext{
${ }^{159}$ Véase http://bib.us.es/servicios/pregunte/ayuda_chat-ides-idwebweb.html.
} 
curiosidad de saber sobre el servicio. Seguidamente se ilustra en la siguiente figura, la oferta de la opción Chat.

El servicio de comunicación de la referencia virtual (chat) se reconoce con el nombre de Pregunte al bibliotecario. Éste se localiza desde el sitio general de la biblioteca en la columna izquierda superior y en la segunda columna derecha, el nombre acompañado de un ícono.

El proceso de comunicación sincrónica se realiza a través de conversaciones en línea vía Chat o teléfono. El servicio está disponible en 19 las bibliotecas y dispone de 31 especialistas de información para ayudar a los usuarios a identificar los recursos de información y usar los recursos adecuadamente para el cumplimiento de sus objetivos. Asimismo ayudar a resolver problemas de acceso a los recursos electrónicos. En la siguiente Figura se hace visible la disponibilidad de los bibliotecarios especialistas. El servicio se vale también de un formulario predefinido para la recepción de preguntas, aunque la comunicación resulta asincrónica, la respuesta ocurre en un plazo máximo de 24 horas.

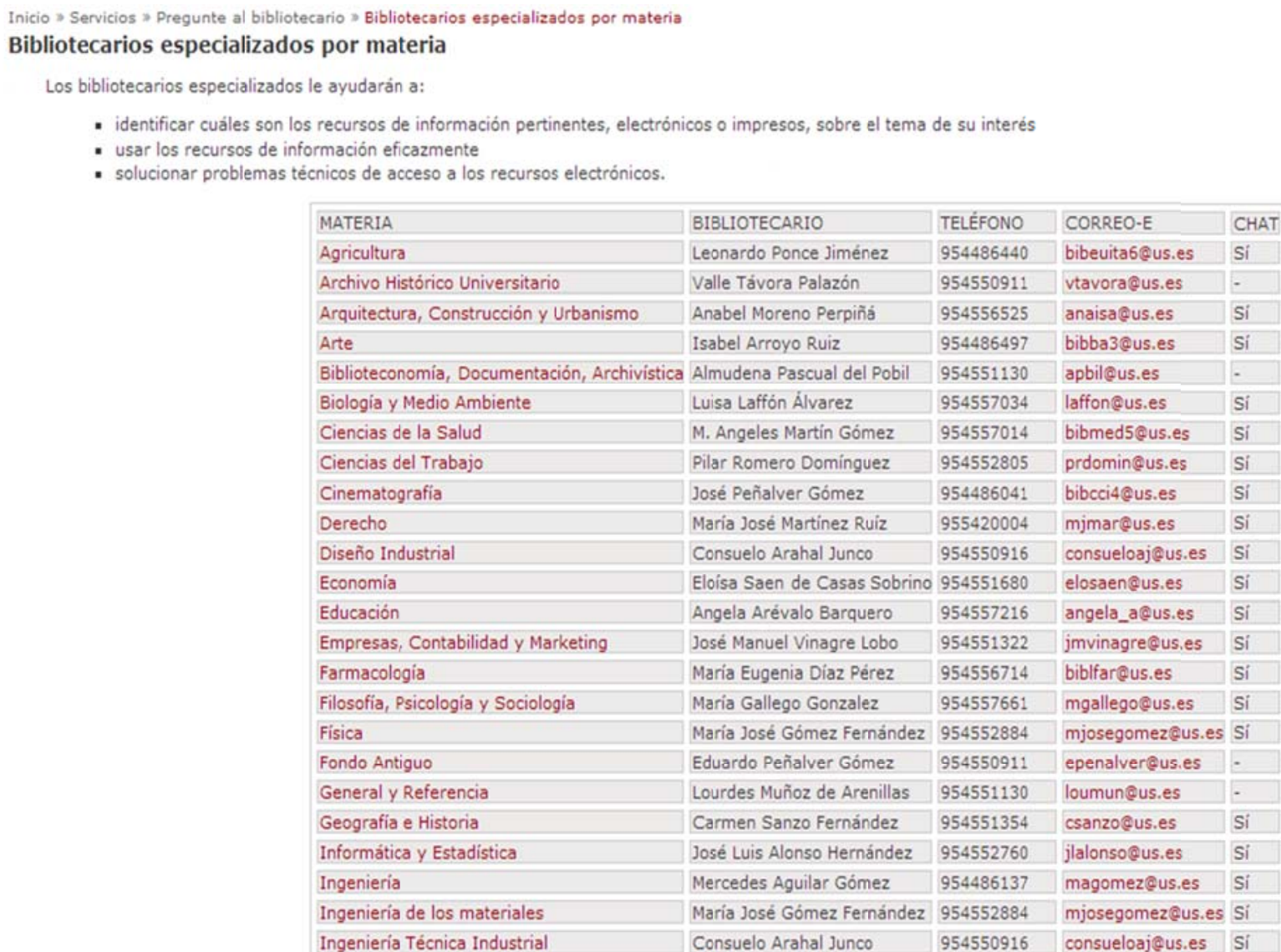

Figura 86. Disponibilidad de referencistas en línea. ${ }^{160}$

Durante el análisis del servicio se realizaron algunas conversaciones vía chat con algunas bibliotecas. No se observó ningún problema de acceso y técnico. La consulta fue inmediata y se destacó la disposición de los bibliotecarios para ayudar y las respuestas fueron acertadas e inmediatas. Aunque si bien existe un LOGO estándar y un mismo uso de sistema de ventanilla para el chat, la ubicación de

\footnotetext{
${ }^{160}$ Acceso: http://bib.us.es/servicios/pregunte/bibliotecarios_especializados-ides-idwebweb.html.
} 
éste en las páginas de las bibliotecas varia, no obstante la dinámica y eficiencia del servicio no se alterna.

Con el objetivo de ilustrar lo anterior, se adjuntan dos fragmentos de consulta chat con desde dos bibliotecas. La primera figura muestra la conversación sostenida el 13 de septiembre 2011, sostenida con un bibliotecario de la Biblioteca de Psicología y Filosofía realizada. El segundo fragmento que corresponde a una charla con el referencista a cargo del chat ubicado en el sitio correspondiente al catálogo FAMA. Aunque el servicio es inmediato y eficiente, la pantalla "Chat" resulta poco visible.

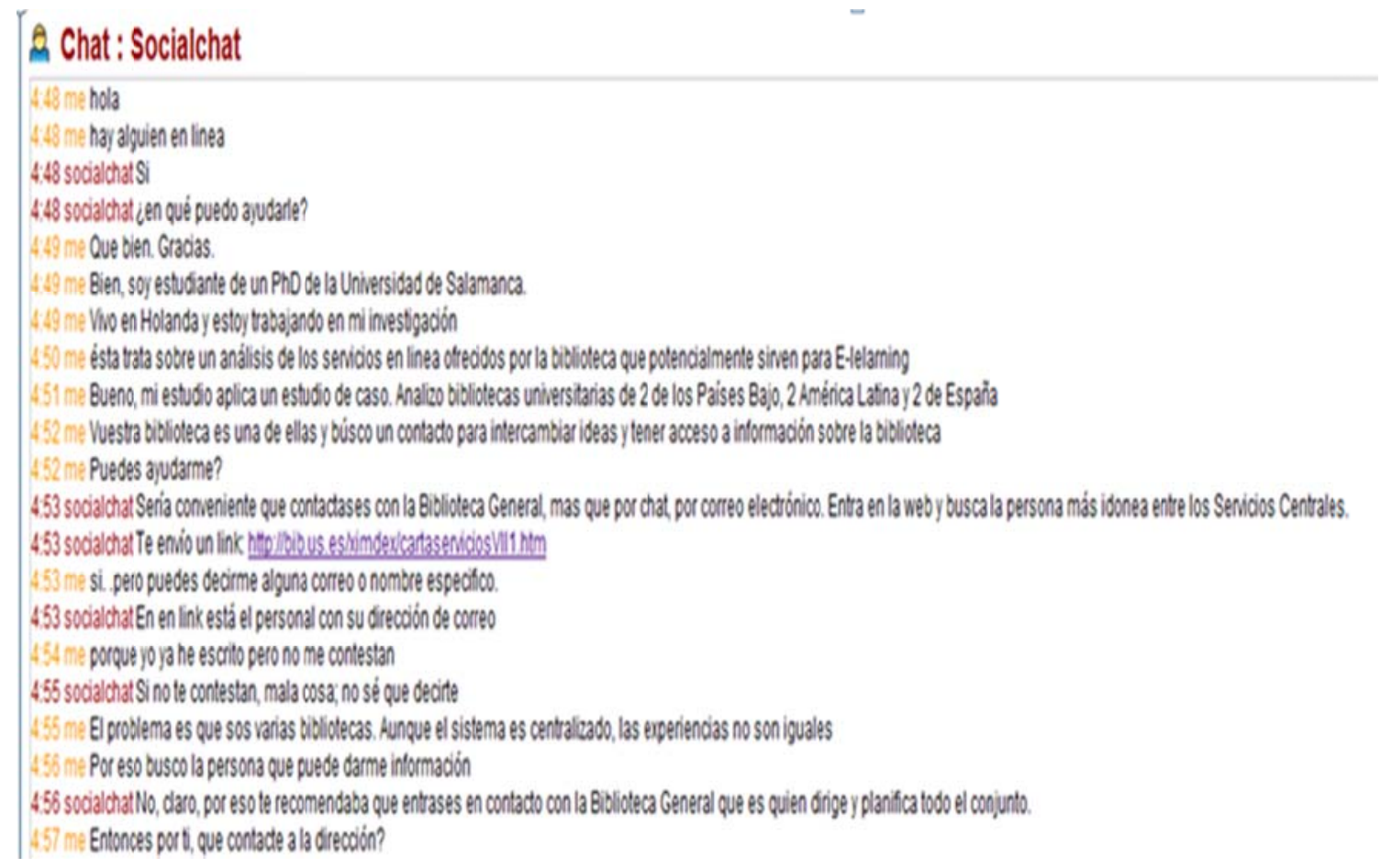

Figura 87. Prueba de diálogo sincrónico.

La segunda forma de comunicación del servicio de "Pregunte al bibliotecario" corresponde a la modalidad asincrónica a través de correo electrónico. Este medio utiliza un sistema de formulario que además de recibir preguntas, permite caracterizar la demanda y el demandante. Se trata del modelo convencional de la referencia digital, que permite que el usuario realice preguntas a través de un correo o de un formulario, para que el personal referencista le envíe la respuesta al correo electrónico que el usuario haya indicado.

En la figura siguiente se muestra el modelo de formulario empleado en la Biblioteca de la Universidad de Sevilla para la recepción de preguntas, debiendo indicarse previamente qué tipo de usuario es el que realiza la consulta: docente, alumno, doctorando, PAS, otros. 


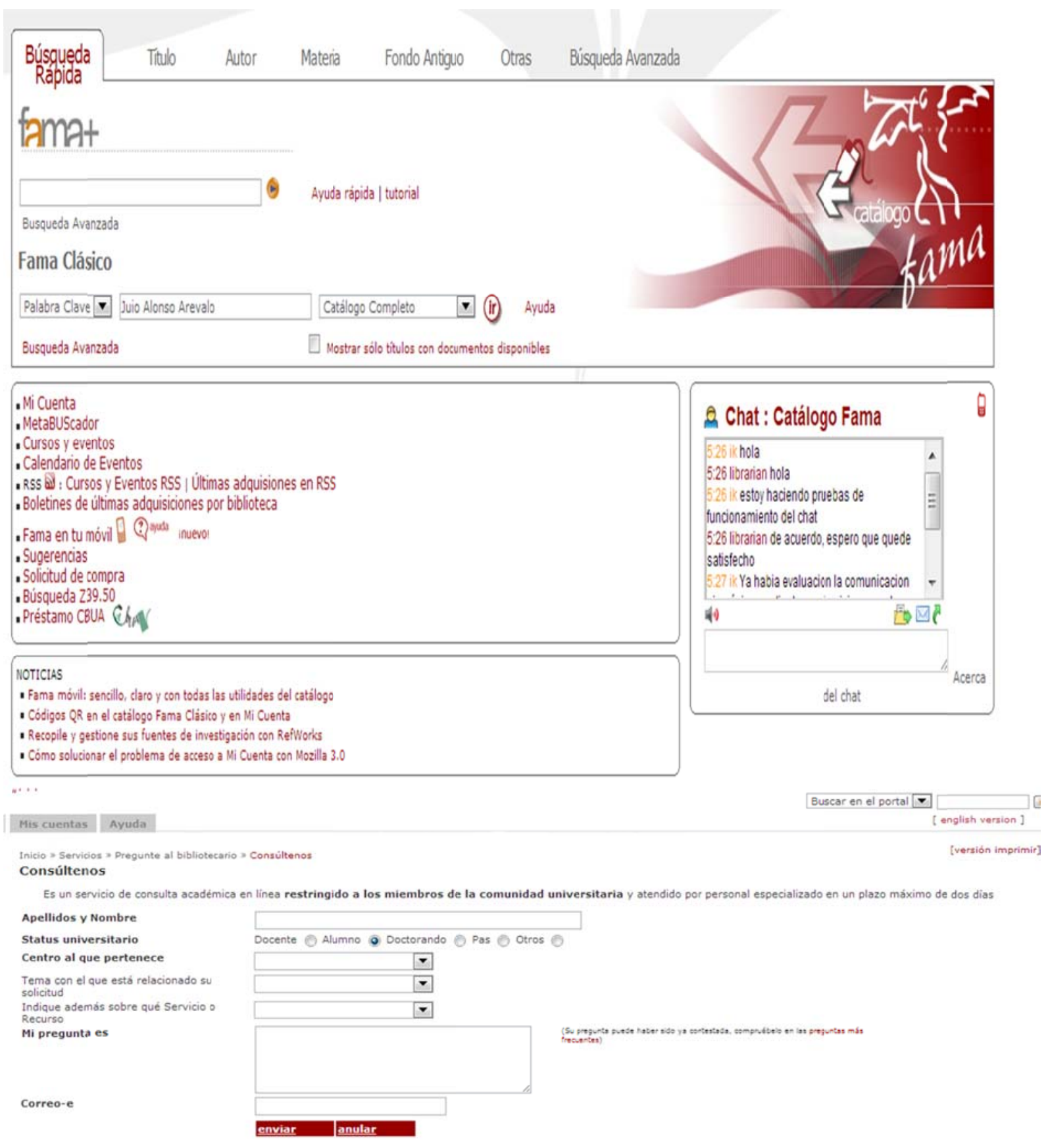

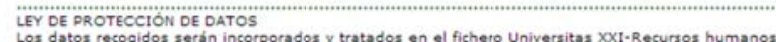

Figura 88. Servicio de mensajería de correo electrónico del Servicio de Referencia161

Servicios de acceso a las colecciones de obras de referencia propiamente dicha que se listan a continuación y seguidamente se ilustra con una figura extraída del sitio la oferta de recursos virtuales para la referencia digital:

\footnotetext{
${ }^{161}$ Véase http://bib.us.es/servicios/pregunte/consultenos-ides-idwebweb.html.
} 
- Información básica sobre el Servicio de Referencia Virtual

- Tesis

- Enciclopedias

- Buscadores

- Prensa

- Viajes

- Diccionarios y traductores

- Enciclopedias

- Estadísticas

- Patentes

- Atlas y callejeros

- Biografías

Inicio » Aprendizaje e Investigación » Más » Colección referencia virtual

\section{Colección referencia virtual}

\begin{tabular}{|l|l|l|}
\hline Administración & Diccionarios y traductores & Tesis \\
\hline Atlas y Callejeros & Enciclopedias & Tiempo \\
\hline Becas & Estadísticas & Universidades \\
\hline Biografias & Normas & Viajes \\
\hline Buscadores & Patentes & \\
Conversores & Prensa & \\
\hline
\end{tabular}

Figura 89. Oferta de colección de referencia virtual.

Durante el proceso de análisis del servicio, se identificó que éste se constituye de cuatro páginas. En la primera página describe el servicio y facilita enlaces al chat, la base de datos de preguntas más frecuentes y el menú de servicios de la biblioteca, cuya presencia es permanente en todas las páginas del sitio. En la siguiente Figura es posible observar en la parte central de la página la orientación del chat por biblioteca y en parte inferior central la posibilidad de contactar al bibliotecario vía telefónica, correo electrónico, diálogo sincrónico con el bibliotecario o con el especialista.

\section{Actualización del contenido}

No fue posible constatar la actualización del sitio y de los enlaces. Se carece de indicativos de fechas de actualización de la página y del contenido del mismo.

\section{Facilidades para personas con incapacidades}

El servicio de referencia virtual, como todos los sitios de la Universidad de Sevilla, dispone de aplicaciones para personas con limitaciones auditivas, visuales, y físicas.

Los servicios especiales que se destacan son:

- Explicaciones sonoras sobre la biblioteca y sus servicios

- Servicio de sala con 14 espacios especiales adaptados para personas con incapacidades visuales, otros para personas con discapacidad motora 
- Extensión del período de préstamo de los recursos y ampliación del número de recursos que pueden prestarse

- Personas con discapacidad motora grave o estancia hospitalaria pueden realizar préstamos, solicitar reservas o renovaciones de materiales vía telefónica o electrónica, mediante su cuenta

- Solicitar elaboración de bibliografías especializadas

- Acceder a los cursos de formación ofrecidos por la biblioteca

Los sistemas de búsqueda del que se vale el servicio de Referencia Virtual corresponde al catálogo Fama, el motor de búsqueda "Meta buscador", aplicaciones de Google book, Google scholar beta y enlaces a los sistemas de búsqueda de la Enciclopedia Británica y otras bibliotecas.

Los enlaces que facilitan y agilizan la navegación son en su mayoría términos acompañados en algunos casos con íconos. No se observa la presencia de índices, mapas del sitio, tablas de contenido en la página que amplíen la oferta de servicios. Lo que prevalece son opciones en forma de menú con enlaces a los servicios y recursos. En el caso específico de "Pregunte al bibliotecario" se ofrece enlaces a cada uno de los servicios que ofrece la biblioteca. Esto es posible mediante el uso de una franja horizontal en la parte superior de la página donde se ofrece el servicio "Chat."

Recursos | Aprendizaje e Investigación | Servicios | Sobre la Biblioteca Inicio» Biblioteca de Psicología y Filosofía» Servicios» Pregunte al bibliotecario

\section{Contenido}

El análisis detallado de los contenidos de los recursos no fue posible, debido a que no se logró tener acceso a todos los contenidos. Se careció de clave de acceso que solamente disponen los miembros de la comunidad universitaria.

\section{Aspectos físicos y ergonómicos}

El diseño y presentación del servicio es consecuente al portal y sitio Web de la universidad. Se observa consistencia y contraste en el uso de colores, homogeneidad de estilos, consistencia en tipo y tamaño de letras, líneas de texto, ancho de pantalla, márgenes, contraste adecuado entre el texto y el fondo, flexibilidad para realizar una acción de diferentes maneras, adecuación del uso de imágenes o sonido en el recurso completando la información textual

\subsubsection{Evaluación del servicio de cursos de formación de usuarios (ALFIN)}

En este apartado se ofrece un análisis descriptivo y de funcionamiento del servicio ofrecido por la biblioteca de la Universidad de Sevilla para la formación de los usuarios en habilidades y destrezas informacionales (ALFIN), a fin de identificar la viabilidad de este servicio para ser integrado como parte o módulo en los programas de estudios E-learning. La biblioteca utiliza la plataforma E-learning de la Universidad Virtual para desarrollar los cursos de formación en línea ${ }^{162}$ y gran parte de los cursos están integrados en el aula virtual de la Universidad de Sevilla. Los estudiantes introduciendo sus claves pueden acceder a los contenidos y llevar el curso según su propia organización de tiempo.

\footnotetext{
${ }^{162}$ Ver presentación de curso 2011-2012 disponible en: http://prezi.com/ft5rvhfs1nf9/coe-201112.
} 
En el sitio web del sistema de Biblioteca de la Universidad de Sevilla, el servicio ALFIN se identifica en dos campos. Primero dentro del menú de servicios ofrecidos a la biblioteca en la primera columna ubicada a mano derecha. Este se reconoce como un submenú con el título "aprendizaje/ investigación" que permite el acceso a la oferta de cursos, guías y blogs, acceso a la acreditación y sexenio e información de cómo publicar y citar. En la columna derecha se visualiza un ícono acompañado del acrónimo COE que corresponde a los Cursos de Orientación a Estudiantes de nuevo ingreso. Los cursos suelen estar realizados con CourseGenie que es un programa que convierte los contenidos en páginas navegables html, lo que facilita el desplazamiento a los contenidos. De acuerdo a la temática y nivel de desarrollo de los contenidos en los cursos estos se dividen en tres grupos:

a) Formación básica y de actividades introductorias.

b) Formación especializada que implica la participación de la biblioteca como parte de sesiones en las asignaturas, sesiones de postgrado y máster.

c) Formación en competencias transversales presentes en los cursos introductorios de la biblioteca, en las diferentes titulaciones de grados, en postgrados y máster. En este contexto fue posible observar que la oferta de algunos cursos de la biblioteca también se desarrollan en algunos programas de máster en idioma inglés.

Nieves González Fernández-Villavicencio (2009) en una presentación oficial sobre las actividades ALFIN en la Universidad de Sevilla, ofrece una clasificación de los cursos en dos grandes grupos. a) Cursos propios de la biblioteca que no tienen participación curricular y b) curso que forman parte de una materia o programa de estudio. Ambas clasificaciones son descripta por la autora en la siguiente figura.

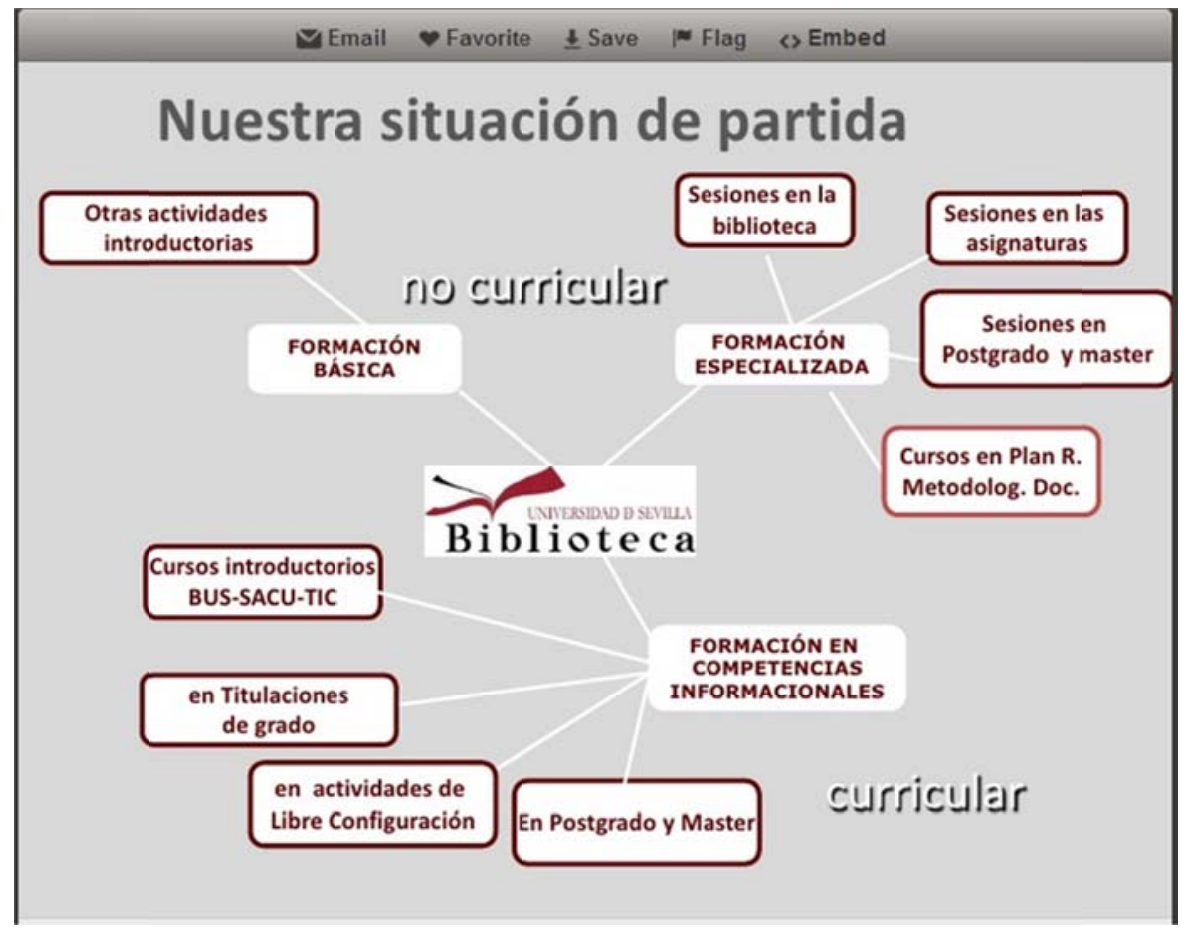

Figura 90. Servicio ALFIN. Universidad Sevilla. Elaborada por Nieves González Fernández.-Villaivicencio. 2009 p. $7^{163}$

\footnotetext{
${ }^{163}$ Figura elaborada por Nieves González Fernández-Villavicencio http://www.slideshare.net/nievesglez/programas-alfinen-la-biblioteca-de-la-universidad-de-sevilla.
} 
En la Figura 90 se aprecia la agrupación de dos categorías de usuarios: los usuarios reales que recurren a la biblioteca (docentes y estudiantes) y los usuarios de nuevo ingreso, y los estudiantes de los cursos de enseñanza de grado, postgrado, masters y doctorados que llevan cursos de la biblioteca como parte de su formación curricular. Independiente de estas dos categorías de usuarios, los cursos de formación de habilidades ofrecidos por la biblioteca perciben generar conocimientos habilidades y destrezas. La variante ocurre en el nivel de desarrollo de los contenidos y en correspondencia de las siguientes capacidades y habilidades transversales:

- Reconocer una necesidad de información

- Determinar el alcance de la información requerida

- Acceder a ella con eficiencia

- Evaluar la información y sus fuentes

- Incorporar la información seleccionada a su propia base de conocimientos

- Utilizar la información de manera eficaz para acometer tareas específicas

- Comprender la problemática económica, legal y social que rodea al uso de la información

- Acceder a ella y utilizarla de forma ética y legal

- Clasificar, almacenar, manipular y re-elaborar la información reunida o generada

- Reconocer la alfabetización en información como prerrequisito para el aprendizaje a lo largo de la vida.

Un ejemplo de la oferta de cursos ofrecidos por la biblioteca de la Universidad de Sevilla se presenta en esta otra figura extraída del mismo documento de Nieves González Fernández.-Villavicencio (2009) que resumen la organización de los cursos en los cuatro niveles en que son desarrollados los contenidos.

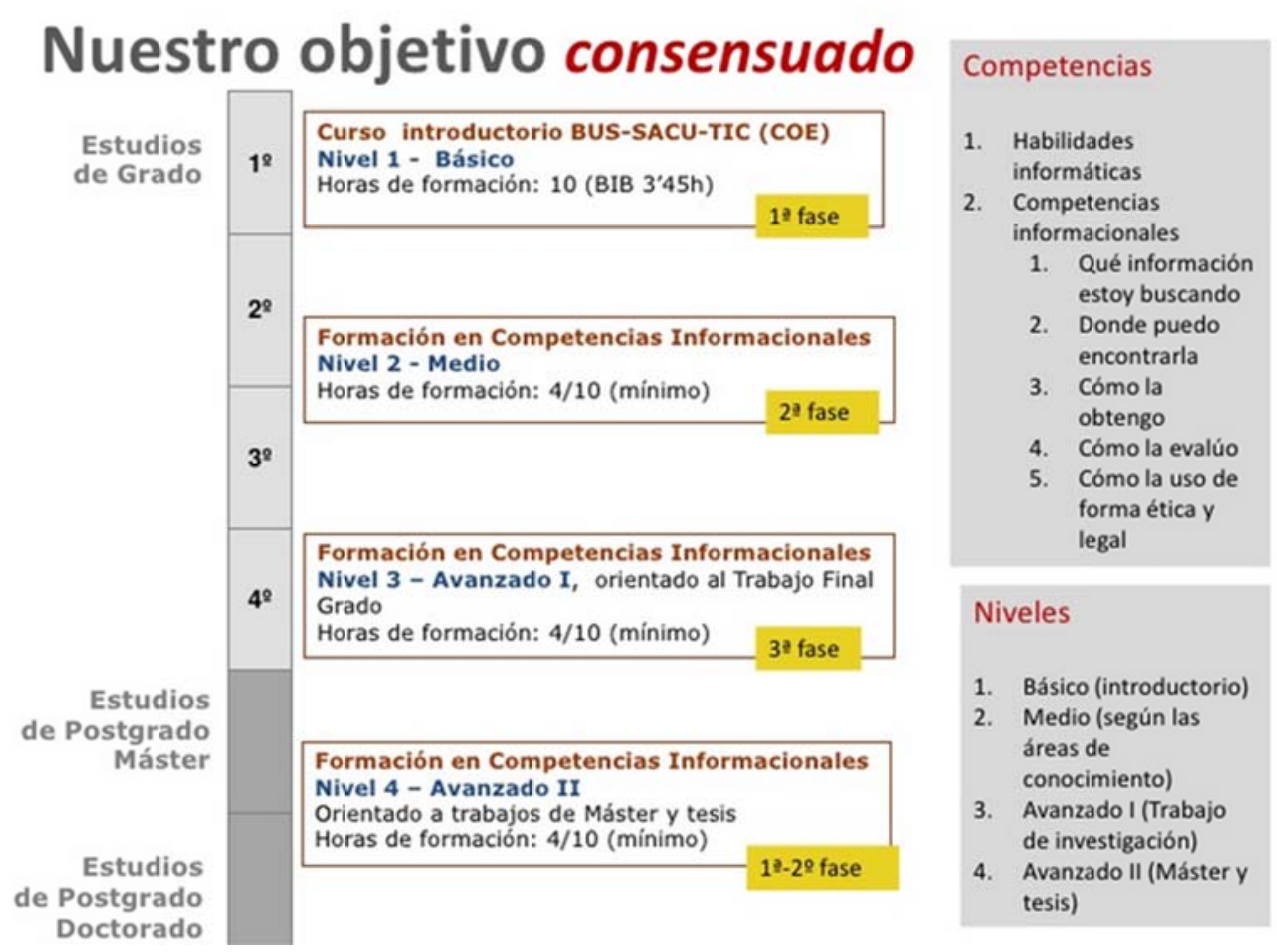

Figura 91. Organización de cursos ALFIN en la Universidad de Sevilla. Fuente: Elaborada por Nieves González Fernández.-Villavicencio. 2009 p.11 ${ }^{164}$

\footnotetext{
${ }^{164}$ Ibíd. http://www.slideshare.net/nievesglez/programas-alfin-en-la-biblioteca-de-la-universidad-de-sevilla.
} 
Para la organización y desarrollo del servicio de formación, la biblioteca se apoya de un grupo de profesionales (especialistas en temas concretos), su infraestructura tecnológica (systeem and software for digital service), los sistemas de información de la biblioteca (todos los recursos de información analógicos y electrónicos), los medios de comunicación y social media 2.0 (Portales, RSS, Google académicos, Blogs colaborativos, Wikis, Flickr, RSS) y el servicio de "Pregunte al bibliotecario (pregunta - respuesta, sus políticas y estándares para el trabajo en red (network) y de procesos de evaluación de los cursos a fin de mejorarlas.

La oferta de los cursos se difunde mensualmente en el portal de la biblioteca. El portal se vale de otras aplicaciones Web social 2.0 (Facebook, Twitter, RSS) para la difusión de la oferta de cursos, a fin de que toda la comunidad universitaria pueda seguir la agenda de la biblioteca. Asimismo la presencia y consulta del recurso "Agenda" permite constatar la actualización del sitio.

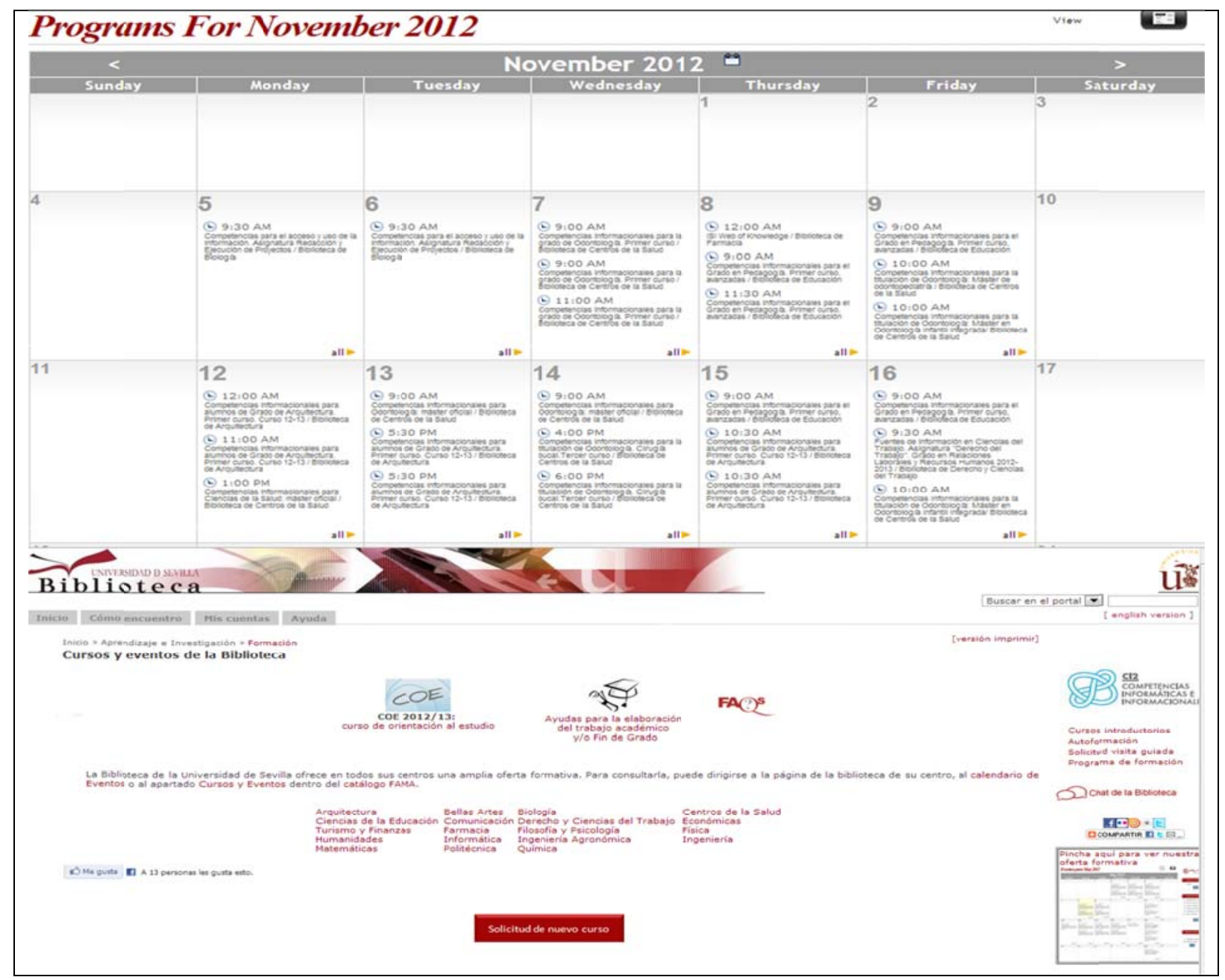

Figura 92. Agenda y Oferta mensual de cursos ALFIN. Biblioteca de la Universidad de Sevilla ${ }^{165}$

Los cursos que se desarrollan de forma presencial se organizan y realizan en las instalaciones de las diferentes bibliotecas del Sistema de Biblioteca de la Universidad de Sevilla. Con el fin de introducir de manera general esta oferta, se listan de forma descriptiva estos cursos:

\footnotetext{
${ }^{165}$ Acceso: http://bib.us.es/aprendizaje_investigacion/formacion/index-ides-idwebweb.html
} 


\section{Cursos introductorios}

Son cursos de orientación sobre el funcionamiento de la biblioteca. Estos se orientan en dos líneas:

a) Información general: Recursos de información orientado a docentes / Biblioteca de Centros de la Salud

b) Competencias informacionales

\section{Autoformación}

Se trata de una oferta de recursos y materiales diseñados profesionalmente para el autoaprendizaje con el objetivo de orientar el adecuado uso de los recursos de información.

La colección de estos materiales se constituye en tres grupos:

- Tutoriales interactivos, vídeos, etc., elaborados por la Biblioteca

- Tutorial Fama. Duración aproximada de 2 meses. Destinado a miembros de la Comunidad Universitaria

- Tutorial: Mi cuenta es el espacio personal en Fama donde podrá realizar reservas de libros, renovaciones, guardar búsquedas. Duración aproximada de 2 meses y está dirigido a miembros de la Comunidad Universitaria

- Tutoriales de ayuda al aprendizaje, enseñanza e investigación

* Descripción de las competencias y habilidades. Duración aproximada de 10 meses y está dirigido a alumnos y profesores

* Habilidades y técnicas de búsqueda de información para la realización de trabajos de clase. Duración aproximada de 20 meses. Destinado a los alumnos de 10 y 20 ciclo

* Orientación sobre los servicios y recursos de información del sistema de bibliotecas. Destinados a alumnos.

\section{Recursos de autoaprendizaje}

La biblioteca se vale de aplicaciones Wiki's y blog's para crear y organizar diferentes recursos de información de apoyo a la docencia y la investigación. La edición de los contenidos está bajo la responsabilidad de los bibliotecarios especializados en las distintas áreas temáticas.

En esta línea los Wiki's que se destacan corresponden a la Wiki Taller Web 2.0 Innovación docente (Biblioteca de Ingeniería) y la Wiki Cine y Medicina (Biblioteca de Centros de la Salud).

En la siguiente figura se presenta la oferta temática de las guías y blogs de este servicio ${ }^{166}$.

\footnotetext{
${ }^{166}$ Véase http://bib.us.es/aprendizaje_investigacion/guias_tutoriales/index-ides-idwebweb.html.
} 


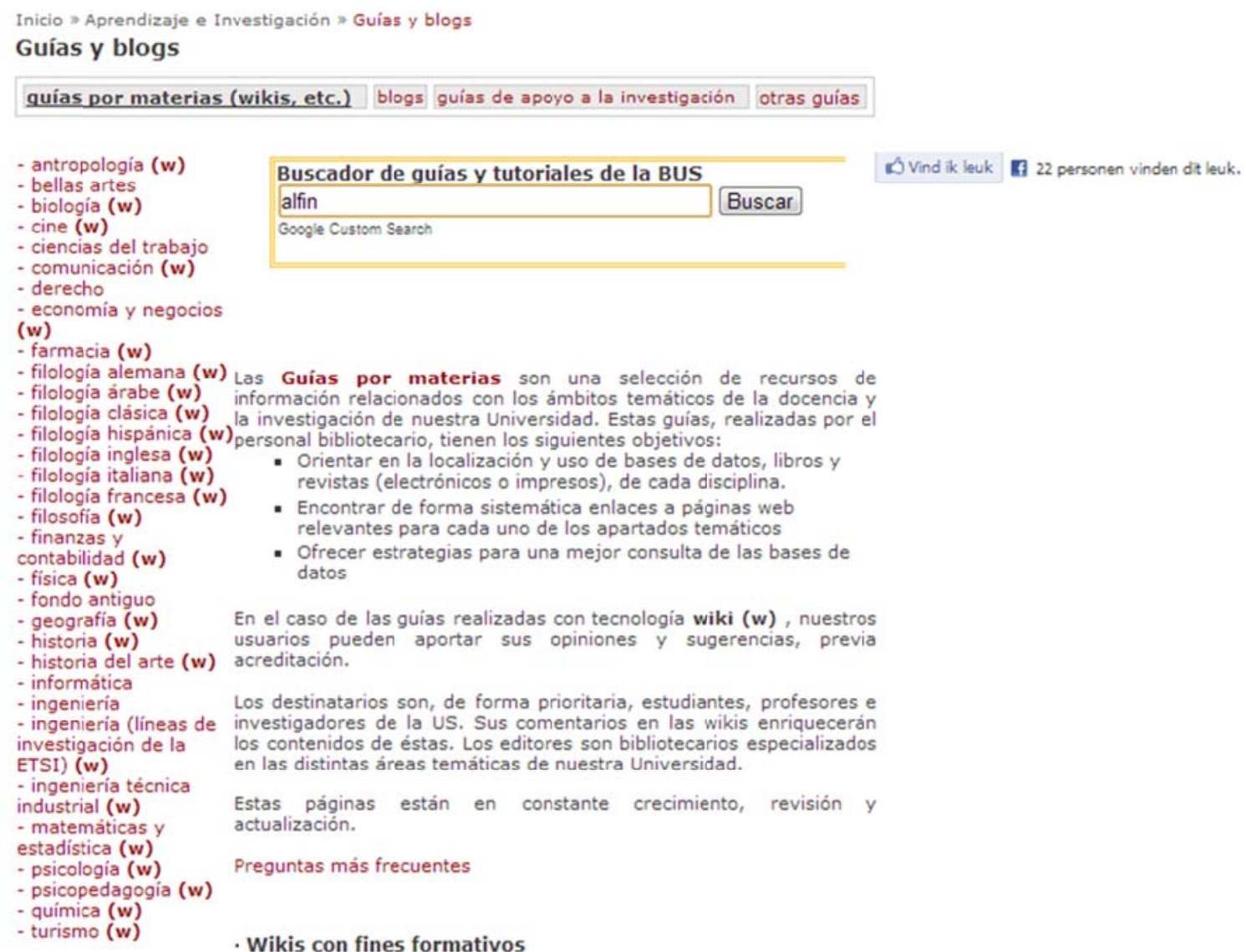

Figura 93. Recursos para el aprendizaje e investigación.

\section{Seminarios en línea ofrecidos por los editores.}

Es un conjunto de recursos en línea provenientes de los proveedores y editores de los recursos electrónicos, puesto a disposición para la y el aprovechamiento más eficiente de los recursos electrónicos disponibles en la Biblioteca.

\section{Curso de gestión de bibliografía -“Refworks"}

Otros cursos ofrecidos en línea y dirigidos a estimular la investigación y orientar el buen uso de los recursos es la formación pero no incluidos en la curricula de la universidad es el curso de "Formación en línea de Refworks". Refworks es un programa al que la universidad está suscrita, que permite la gestión de referencias bibliográficas que permite manipular e importar referencias, formateándolas en el estilo que necesite. Este sistema ofrece además otras facilidades y tutoriales para el intercambio o uso colectivo de las referencias entre varias personas, facilitando así la gestión correctamente de los derechos de autor de las publicaciones científicas.

\section{Curso de impacto curricular (Competencias informáticas e informacionales)}

Este curso se destaca en diferentes puntos del portal de la biblioteca. Se ubica dentro de los programas de estudios de la Universidad de Sevilla. Consiste en un "Curso de Orientación al Estudio para alumnos de nuevo ingreso (COE)". El curso pretende de forma sistémica orientar a los estudiantes en manejo de técnicas de estudio y a la vez estimular el uso de las diferentes facilidades y servicios informáticos de la red de la Universidad de Sevilla. Para este fin el curso se centra en la 
formación de habilidades y destrezas de cómo buscar, localizar, evaluar y utilizar la información necesaria para los trabajos de clase, citando las fuentes.

\section{Escribir, publicar, citar}

Otros cursos que se destacan desde el sitio Web de la universidad de gran apoyo a la docencia e investigación corresponden a las aplicaciones de cómo publicar. Se trata de un conjunto de recursos (tutoriales, acceso a fuentes, enlaces, etc.) que permiten orientar sobre las normas y lugares para publicar.

Los recursos y servicios que se ofrecen dentro del programa de Formación de Habilidades y destrezas son acceso a objetos de aprendizaje multimedia; espacios personalizados; recursos Metadatos; servicio de orientación al estudiante; comunicación sincrónica y asincrónica, Facebook, Blogs colaborativos, Wikis, Flickr, RSS, asi como noticias, variedades, entretenimientos, etc.

\section{Organización de los contenidos}

Los contenidos de los cursos se organizan jerárquicamente dentro de temas y estos son accesibles a través de enlaces que en su mayoría están acompañados de íconos.

\section{Aspectos ergonómicos}

De manera general se observa el cuido de aspectos físicos y ergonómicos considerados estándar en el diseño de sitios y contenidos en línea. Se destacan la consistencia y contraste en el uso de colores, homogeneidad de estilos, tipo de letras, tamaño de letras, líneas de texto, ancho de pantalla, legibilidad. Claridad o contraste adecuado entre el texto y el fondo, flexibilidad para realizar una acción de diferentes maneras, adecuación del uso de imágenes o sonido en el recurso completando la información textual y posibilidad de manifestar opiniones sobre el contenido de la Web a responsable o administrador.

\section{Actualización}

Apoyado en los datos recibidos del personal a cargo del servicio, fue posible identificar que la actualización y vigencia de los enlaces a los contenidos es revisada cada seis meses.

\subsubsection{Evaluación del servicio de repositorios para la educación}

La oferta de acceso a los recursos electrónicos ofrecida por la biblioteca de la Universidad de Sevilla se ubica en sus colecciones digitales, anteriormente indicados en el apartado referente a la descripción de la biblioteca. Sin embargo, al referirnos a repositorios para la educación se distinguen tres grupos repositorios importantes de apoyo a la docencia e investigación. a) Los repositorios institucionales, b) los portales de acceso abierto y c) repositorios de objetos de aprendizaje propio de la Universidad de Sevilla.

a) Repositorios institucionales externos:

- UPCommons (Universidad Politécnica de Cataluña)

- Archivo institucional E-Prints Complutense

- Digital.CSIC: repositorio institucional del Consejo Superior de Investigaciones Científicas 
b) Portales de acceso abierto

- arXiv.org: Portal de acceso a 400.000 artículos y recursos sobre temas de física, matemáticas, informática y biología cuantitativa (US National Science Foundation, US Department of Energy)

- BioMed Central: Portal editorial independiente de acceso a más de un centenar de revistas sobre Biomedicina en "Open Access" y evaluados peer-review

- DOAJ: Proyecto internacional y multidisciplinario promovido por la Universidad de Lund que pone a disposición de la comunidad científica más de 100.000 artículos en formato "Open Access"

- e-ciencia: Plataforma digital de acceso libre a la producción científica, generada por las Universidades públicas radicadas en la región madrileña

- PubMed: Archivo digital de publicaciones de biomedicina auspiciado por la US Nacional Library of Medicine, con su consulta integrada en PubMed

- Recolecta: Es considerado un punto de acceso único a los repositorios de ciencia y tecnología españoles Repositorio Español que almacenan trabajos de los científicos e investigadores depositados en repositorios institucionales abiertos (plataformas de libre acceso).

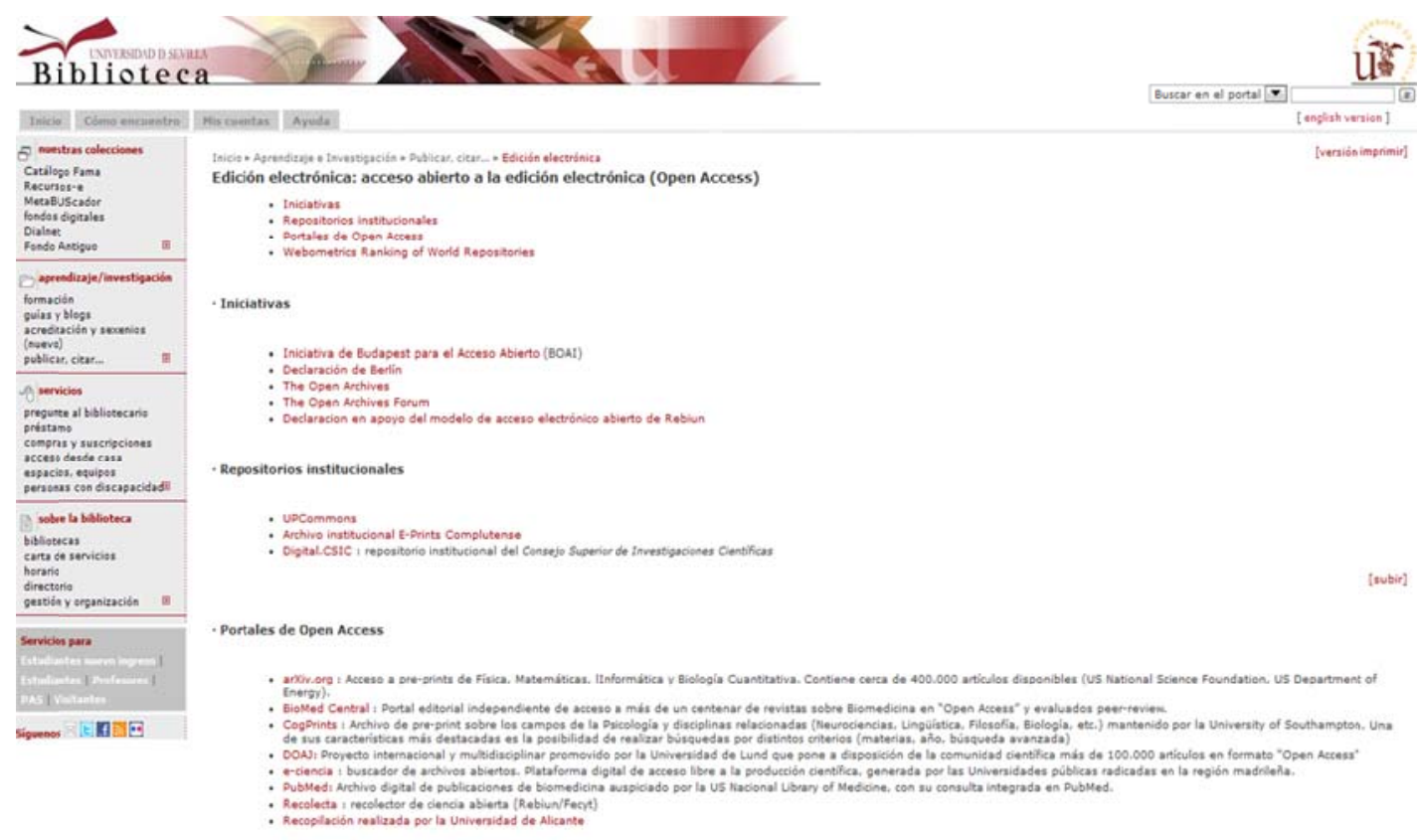

Figura 94. Oferta de acceso a repositorios para la Educación.

c) Repositorio de objetos de aprendizaje propio de la Universidad de Sevilla (RODAS)

El repositorio se localiza dentro del portal de la biblioteca y se identifica como término RODAS $^{167}$ a partir de una búsqueda dentro del portal. RODAS ${ }^{168}$ surge por la necesidad de gestionar la gran

167 La US ofrece un repositorio de más de 15.000 objetos digitales de aprendizaje. Texto oficial de presentación del Repositorio RODAS. Dirección de Comunicación. Universidad de Sevilla. Disponible:

http://www.comunicacion.us.es/?q=node/6547Consultado:18 sep. 2011

168 Véase http://rodas.us.es/access/home.do. 
cantidad de contenidos generados para la Enseñanza Virtual de la Universidad de Sevilla. Es un banco de datos que dispone de un catálogo de recursos educativos estructurados, organizados y sistematizados disponibles a través de su escenario de Enseñanza Virtual. En la siguiente Figura se presenta la página de inicio de repositorio.

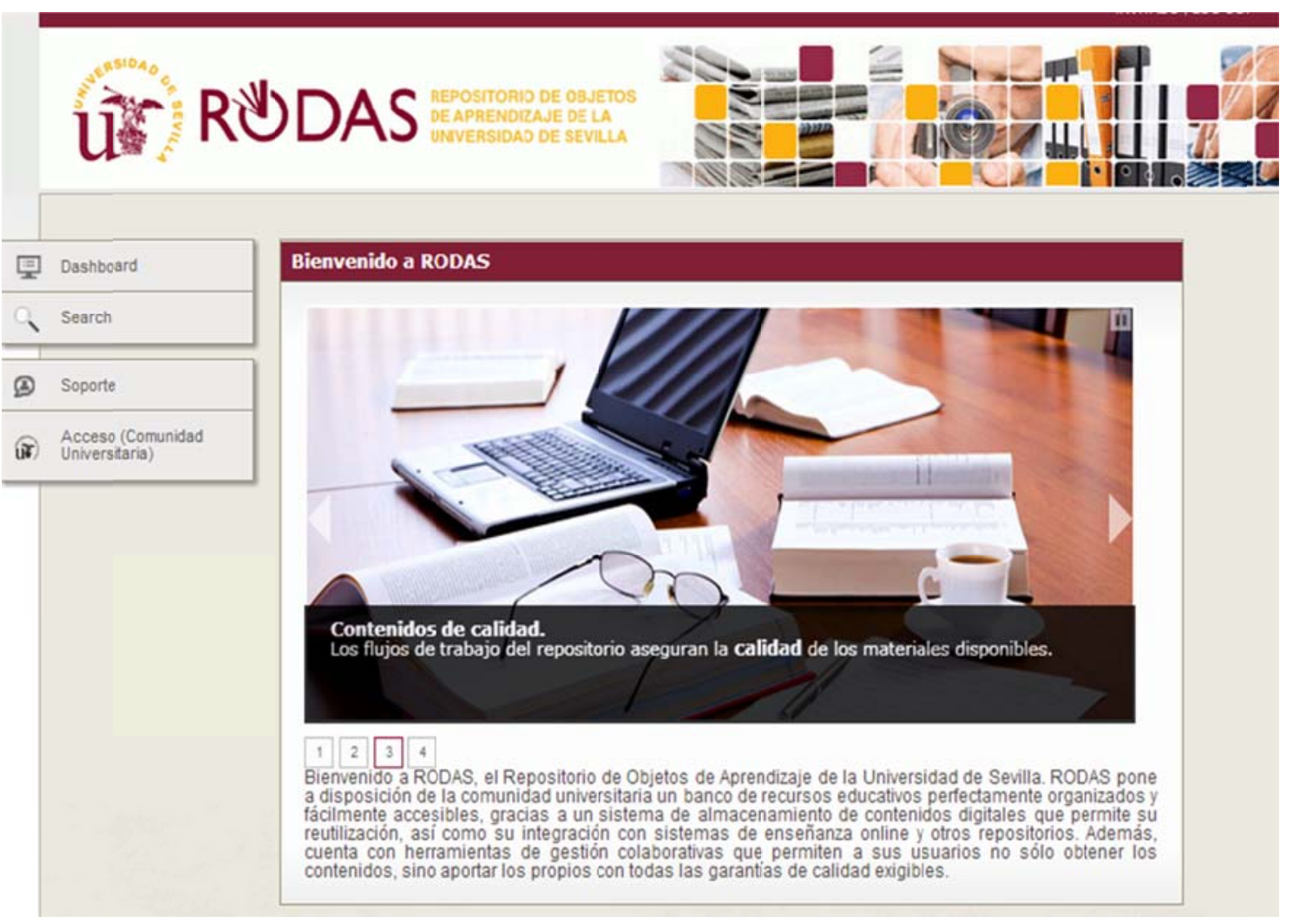

Figura 95. Repositorios ROA de la Universidad de Sevilla.

A simple vista el repositorio se ubica dentro del sitio Web de la Universidad de Sevilla. Se visualiza claramente en una franja horizontal con una Figura y el acrónimo del Repositorio Objetos de Aprendizaje como se presenta en la Figura siguiente. Desde el portal de la biblioteca no es identificable el término "Repositorio o RODAS" sin embargo es posible recuperar y acceder a una variedad de recursos externos como parte de iniciativas nacionales (portales y repositorios) para la educación ${ }^{169}$.

La flexibilidad del sistema de almacenamiento de contenidos LCM contiene recursos de diferentes formatos que pueden ser reutilizables en diversos cursos simultáneos. Se caracterizan por su interoperabilidad en otras plataformas E-Learning y con otros repositorios. Cabe además destacar que el sistema de RODAS dispone de herramientas de gestión colaborativas que permiten a sus usuarios no sólo obtener los contenidos, sino aportar los propios con todas las garantías de calidad exigibles.

El sitio de los repositorios RODAS pude ser localizable mediante una búsqueda desde el portal de la biblioteca, la que genera una serie de resultados con enlaces al sistema LCM del repositorio. El sistema de gestión de repositorio es sencillo, claro y se vale de enlaces para guiar el uso de los

\footnotetext{
${ }^{169}$ Véase información detallada en el siguiente sitio Web: http://bib.us.es/aprendizaje_investigacion/publicar_citar/edicion_electronica-ides-idwebweb.html.
} 
recursos. RODAS ofrece además cinco posibilidades de búsquedas. La primera opción facilita la navegación por todo el repositorio, las segunda la posibilidad de realizar una búsqueda guiada, la tercera una búsqueda avanzada y la cuarta una búsqueda referida. La figura que se presenta a continuación demuestra la estructura del sitio del repositorio.

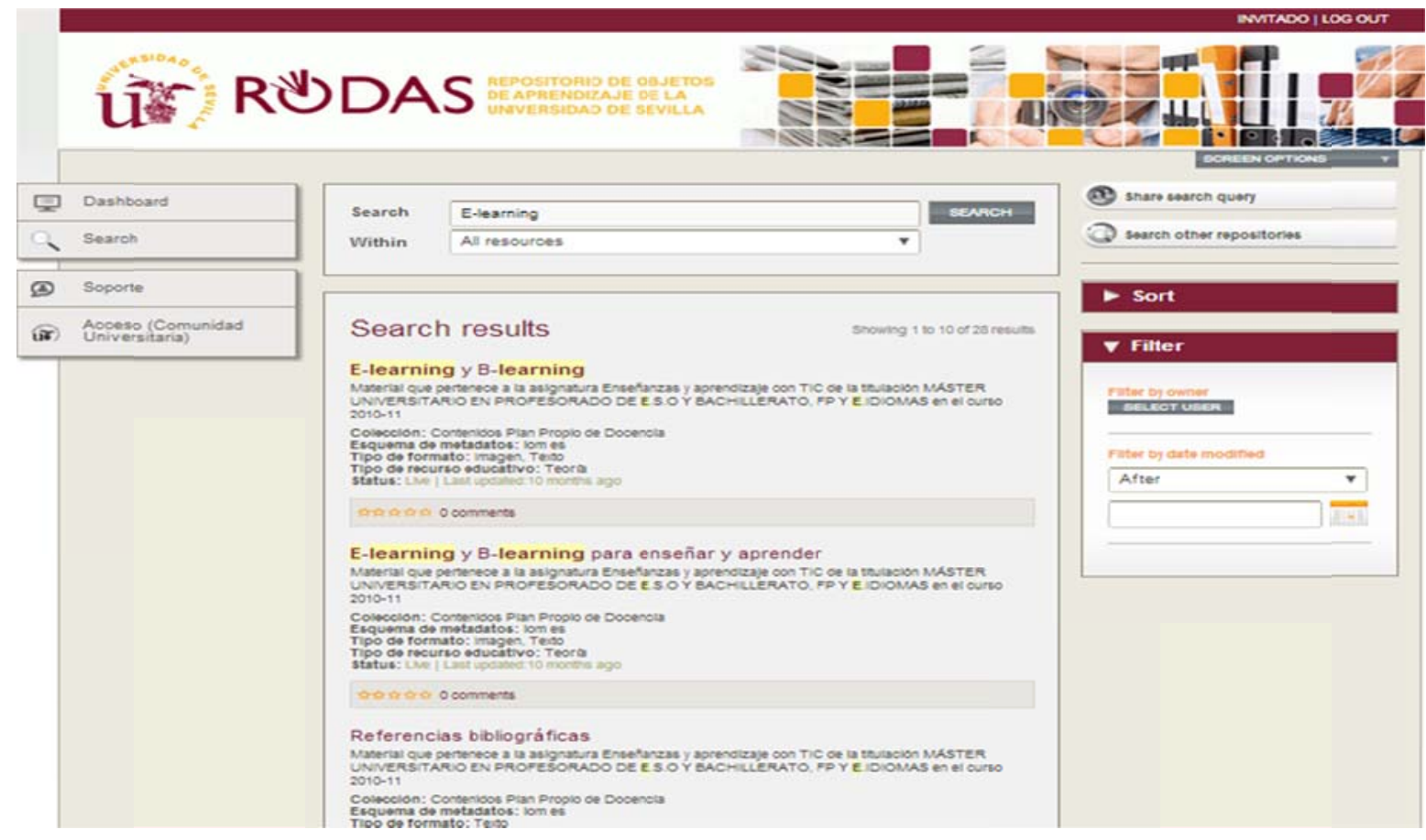

Figura 96. Estructura de Repositorio RODAS.

El portal no presenta ninguna indicación de fecha de actualización, no obstante los contenidos son presentados en agrupación por temas y divididos en dos partes, los más consultados y los más recientes como es posible observar en la Figura de introducción al RODAS. La revisión de los contenidos más actuales permitió constatar que existen objetos de aprendizajes del período académico 2010-2011.

La navegación dentro de repositorio no experimentó ningún problema. El proceso es rápido y claro, aunque en dependencia de su formato difieren entre recurso y recurso. El uso de imagen, sonido, íconos resulta común en los Objetos de Aprendizajes, debido a que su elaboración se apoya en diferentes recursos web 2.0, programas y aplicaciones informáticas para facilitar el proceso de transferencia de conocimiento. Sin embargo no fue posible identificar en el sitio del repositorio facilidades de uso para personas con incapacidades visuales, auditivas o de otra índole.

Siendo el objetivo del repositorio RODAS compartir recursos, éstos pueden ser utilizados con libertad, de tal forma que es posible descargar, copiar, limpiar, transferir recursos completos o en partes. Cada recurso dispone de un una descripción completa basada en normas internacionales.

Además de estar organizados en forma jerárquica y cumplen con los parámetros estándar de calidad. Algunos parámetros identificables corresponden a la adecuación entre la autoría y la agenda temática, identificación básica de las diferentes secciones de la publicación (autor, título y fechas), factibilidad de contacto entre el autor-usuario de la fuente, posibilidad de manifestar opiniones sobre el contenido, entre otros. 


\subsubsection{Análisis SWOT (FODA) ${ }^{170}$ de la Universidad de Sevilla}

El actual estado de funcionalidad de los servicios del Sistema de Biblioteca, representa ser un momento oportuno para la biblioteca del a Universidad de Sevilla implemente el modelo de oferta de servicio propuesto en esta tesis como una oferta de apoyo a los procesos de enseñanza aprendizaje en línea. El siguiente esquema de análisis FODA, pretende ser una premisa para estimular el ensamblaje del modelo propuesto en esta tesis doctoral.

\section{Fortalezas}

- La moderna capacidad e innovaciones tecnológicas de la Universidad y dentro de la biblioteca para la prestación de servicios, es un ejemplo de buenas prácticas y le atribuye un buen prestigio dentro y fuera de la Universidad

- La colaboración directa de la biblioteca en la aula virtual de la Universidad de Sevilla, le asigna un espacio de participación modalidad de educación electrónica (Elearning), que genera la posibilidad de nuevos proyectos conjuntos, experiencia y un nuevo mercado para los servicios

- La estructura, organización y funcionamiento de la oferta de los servicios de la biblioteca resulta excelente

\section{Debilidades}

En general el diseño requiere ser fortalecido en las siguientes líneas:

- Carencia de aplicaciones y/o facilidades de uso para personas con incapacidades visuales, auditivas o de otra índole - El sitio Web de la Universidad de Sevilla no ofrece opciones en otros idiomas. Para el acceso y difusión de los contenidos.

- Ausencia de un identificador que destaque la última renovación del contenido en el sitio, por lo que se desconoce la fecha de actualización de la información del sitio Web

- Ausencia de opciones de ayuda que oriente a docentes o alumnos la localización de los contenidos y de los cursos ALFIN desde cualquier sitio de la Web de la biblioteca.

\section{Oportunidades}

Alto desarrollo y posicionamiento alcanzado de la oferta de servicios en línea a nivel institucional y nacional por parte del Sistema de Bibliotecas de Sevilla, resulta oportuno y estratégico para introducir una nueva oferta de servicio a los usuarios de la comunidad Elearning

Resulta viable y estratégico en el contexto de fortalecer la presencia de la biblioteca en espacios virtuales de enseñanza, el filtrar recursos electrónicos de los repositorios en forma temática y ofertar su acceso en los cursos E-learning.

\section{Amenazas}

- La falta de visión sistémica, (conceptual y práctica) por parte de los líderes en proceso de evaluación de servicios y necesidades. Se requiere la consulta de docentes, estudiantes y líderes

- Problemas de comunicación a lo interno de la universidad

- Poco involucramiento de la biblioteca en proyectos E-learning

- Poco aprovechamiento de la cooperación internacional

\footnotetext{
${ }^{170}$ Metodología SWOT Strengths, Weaknesses, Opportunities, Threats (Fortalezas, Debilidades, Oportunidades y Amenazas) conocido también en el habla hispana como DAFO o FODA.
} 


\section{Conclusión-caso Universidad - Universidad de Sevilla}

De forma general, es posible concluir que el resultado del análisis crítico del diseño y funcionamiento del sitio web del Sistema de Bibliotecas de la Universidad de Sevilla evidencia un alto profesionalismo en el diseño y cumplimiento de normativas internacionales estándares. Asimismo el análisis destaca el desarrollo creativo e innovador de aplicaciones tecnológicas que hacen del sitio un lugar amigable y fácil para buscar información.

Las aplicaciones (web social Flickr, Facebook, RSS y Twitter) estimulan el posicionamiento de los servicios de la biblioteca en agendas en espacios personalizados de los usuarios. Sin embargo, la inserción de archivos interactivos resultan ser un recurso aún no orientado para para personas con problemas de lectura largas o limitaciones visuales y auditivas.

El servicio de Referencia Virtual de la Universidad de Sevilla dispone de componente comunicación sincrónica "Pregunte al bibliotecario" que lo destaca como un sistema dinámico y sin límites de espacios, eficiente y rápido. Asimismo el componente de comunicación sincrónica "Chat" atribuye al servicio la característica de sistema dinámico y sin límites de espacios, eficiente y rápido.

La oferta de servicio de acceso a los repositorios para la educación se centran básicamente en tres grupos: a) Los repositorios institucionales externos a la US, b) Los portales de acceso abierto o de Open Access y c) El Repositorio de Objetos de Aprendizaje de la Universidad de Sevilla. La posibilidad de filtrar información de los repositorios en forma temática y ofertar el acceso éstos recursos electrónicos en los cursos E-learning, resulta viable y estratégico en el contexto de fortalecer la presencia de la biblioteca en espacios virtuales de enseñanza. Las actividades de ALFIN presentan una oferta atractiva de formación de habilidades y competencias transversales, tanto en la modalidad presencial como en línea. 


\subsubsection{Universidad de Salamanca (USAL)}

\subsubsection{Antecedentes generales}

Como consta en la sede web $^{171}$ de la Universidad de Salamanca (USAL) ${ }^{172}$ : "La Universidad de Salamanca en latín Universitas Studii Salmanticensis se encuentra emplazada en la ciudad de Salamanca, en la comunidad autónoma de Castilla y León. Dispone de 9 campus docentes y administrativos ubicados en Ávila, Zamora, Béjar y Salamanca. En Salamanca misma se ubican el Campus Histórico, Campus de Ciencias, Campus de Canalejas, Campus Miguel de Unamuno (Campus Biosanitario y Campus FES-Derecho), Campus Ciudad Jardín y Campus Villamayor. Según datos registrados en el sitio oficial de la Universidad de Salamanca, la oferta de estudios académicos se compone de 81 titulaciones oficiales de primer y segundo ciclo pertenecientes a las cinco ramas de conocimiento en las Ciencias Sociales y Jurídicas, Humanidades y Experimentales.
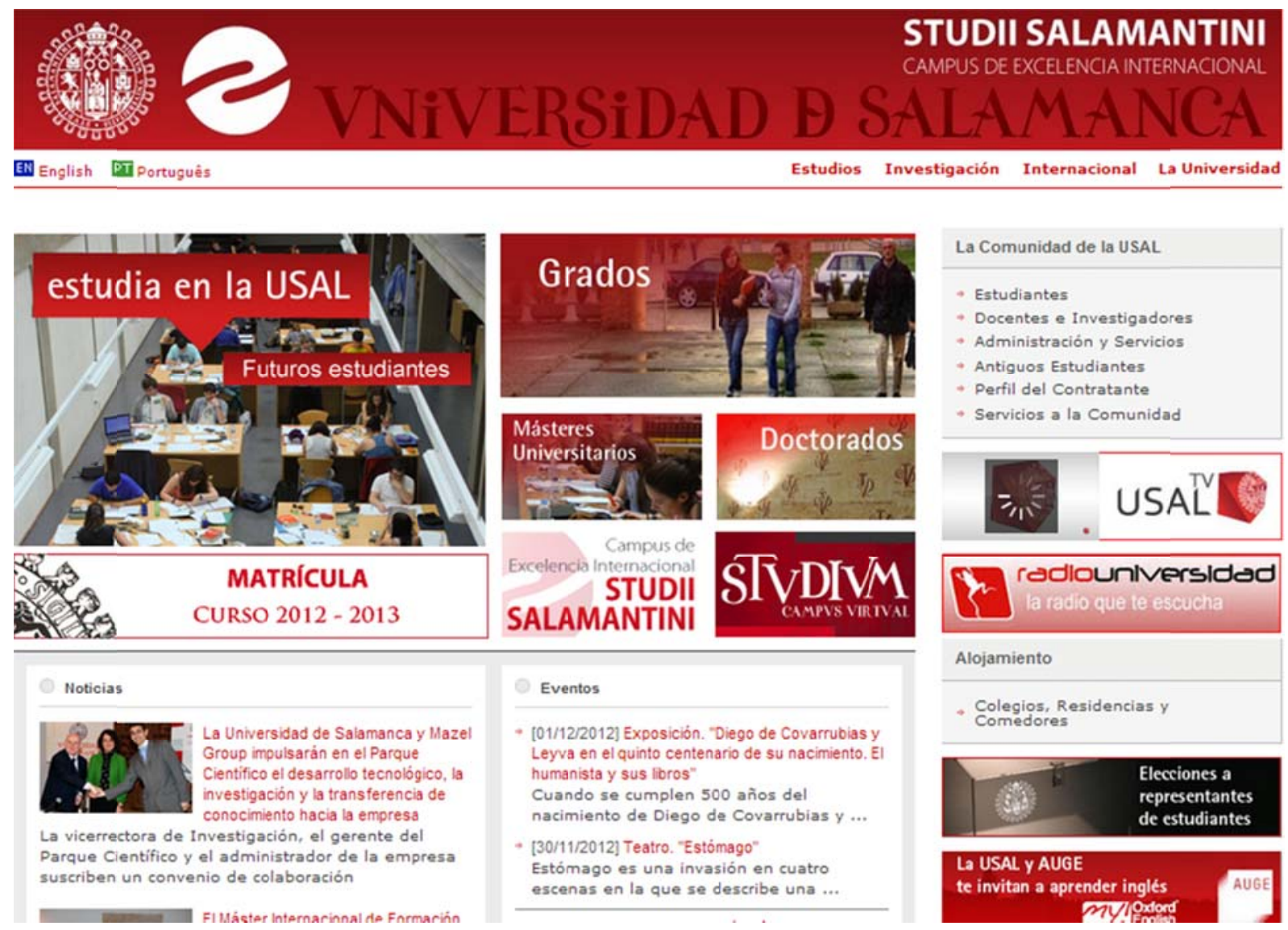

Figura 97. Portal de la Universidad de Salamanca

Su estructura funcional y organizativa se constituye de un equipo de Gobierno que está constituido por el Rector, la Secretaría General, los Vicerrectorados que a su vez incluye las áreas de Docencia, Economía y Gestión, Estudiantes e Inserción Profesional, Innovación e Infraestructuras, Investigación, Planificación Estratégica y Evaluación, Profesorado, Relaciones Internacionales e Institucionales, Gerencia, Oficina del VIII Centenario y los Órganos Colegiados conformador por el Consejo de Gobierno, el Consejo Social, el Claustro Universitario y el Claustro de Doctores.

\footnotetext{
${ }^{171}$ Véase http://www.usal.es/webusal/.

${ }^{172}$ Texto extraído de la reseña histórica de la USAL disponible al público en el sitio web http://www.usal.es/webwebusal/node/941?bcp=conocenos.
} 
Su fundación ${ }^{173}$ obedece al periodo de reinado del Rey Alfonso IX de León en el año 1218. Es reconocida como la más antigua de las universidades de España y la cuarta a nivel de Europa. En el año 1230 los reinados de León y Castilla son integrados a la corona de Fernando III de Castilla hecho que eliminó la competencia y daba mayor crédito a la oferta de estudio salmantino. Sin embargo fue en el reinado de Alfonso $X$ que el estudio general se transforma en Universidad y surgen las primeras cátedras y el cargo de bibliotecario, y conformando la primer biblioteca pública de Europa (1255) ${ }^{174 .}$

La legislación fundacional la destaca como la primera institución educativa española y europea que obtuvo el título de Universidad. Hecho que se registra en la carta del rey Alfonso $X$, con fecha del 8 de mayo de 1254 en la que se establecen las normativas de organización y dotaciones financieras; y las bulas pontificas de Alejandro IV, expedidas en el año 1255 le concede el uso de un sello propio y validez a los grados otorgados.

Entre los siglos XV y XVI la USAL se introduce a nuevas corrientes humanistas, en las que abundaron los manuscritos científicos en algunos colegios, como el Mayor de San Bartolomé, vinculados a las cátedras de Filosofía Natural, Matemáticas y Astronomía. Por los años centrales del siglo XVI, la confluencia del Derecho, la Teología tomista, las nuevas lógicas y las lenguas clásicas cristalizan en la Ilamada "Escuela de Salamanca", representada en la Figura de Francisco de Vitoria. Entre sus aportaciones destaca la reflexión práctica sobre ciertos problemas derivados de la expansión europea y colonización y transculturación americana.

En el año 1904, en el que, durante el rectorado de Miguel de Unamuno, se consigue su financiación estatal. Posteriormente en julio de 1943 en el marco de una nueva ordenación política, se promulga la Ley de Ordenación Universitaria para toda España, la Universidad quedó vinculada a las ideologías dominantes del nacional-catolicismo tradicionalista y posteriormente con las aceleradas transformaciones sociales de los años sesenta (Ley Villar Palasí 1970), se logra cierta autonomía a las universidades en materia de docencia e investigación. La aprobación publicación de la Ley Orgánica de Reforma Universitaria que marca acontecimientos importantes en la USAL como es la aprobación de los Estatutos de la Universidad de Salamanca en 1985 y posteriormente hasta su última modificación en el año 2003 y naturalmente en 2001 la aplicación de la Ley Orgánica de Universidades".

\section{Actividades E-learning en la Universidad de Salamanca}

La Universidad de Salamanca en la última década ha desarrollado algunas inversiones y acciones concretas para generar las condiciones necesarias para generar e integrar de una oferta de cursos de formación electrónica (e-learning) dentro de sus programas formativos como medio para dinamizar el proceso enseñanza - aprendizaje. Esta modalidad todavía no alcanza en su totalidad las características de la modalidad de formación a distancia, se trata de un modelo híbrido conocido como E-learning en B-learning, en el cual se hace uso del modelo de educación presencial con un fuerte componente de seguimiento del curso en espacio virtual.

Para este fin la Universidad de Salamanca cuenta con tres importantes iniciativas en uso a la fecha de realización de este estudio (2010-2011). La comunidad universitaria puede acceder a ellas a través de la clave de acceso que se le distingue como miembro activo para todos los servicios.

\footnotetext{
${ }^{173}$ Texto extraído del sitio Web de la USAL http://campus.usal.es/webweb-usal/Universidad/Historia/Historia.shtml y el Centro de Historia Universitaria Alfonso IX http://www.usal.es/webwebusal/node/1347.

${ }^{174}$ Las Universidades más antiguas en Europa son Bolonia, Oxford y Paris
} 
Studium (Moodle) se reconoce como el Campus Virtual de la Universidad. Stadium es un espacio virtual desarrollado en la plataforma Moodle ${ }^{175}$ En este espacio se localizan todos los cursos que pueden ser seguidos por Internet. La página principal de Stadium dispone de información e instrucciones para familiarizarte con el entorno. El estudiante que sigue un curso con la modalidad presencial y electrónica (B-learning) o totalmente en línea (Elearning) puede acceder a los cursos matriculados introduciendo su clave de estudiante.

OpenCourseWare (OCW). Otro recurso que dispone la USAL para sus prácticas de educación a distancia es el recurso OpenCourseWare, es una iniciativa de Massachussets Institute of Techonology (MIT). El proyecto fue iniciado en el 2001 y oficialmente anunciado en el 2002. Es de carácter público y no comercial. Este proyecto se vale de licencias de acceso libre "Creative Commons" y tiene como base la filosofía de compartir. OpenCourse. A la fecha de este estudio se reconoce como un consorcio de universidades con el fin de generar una red de acceso libre con fines educativos con el objetivo de promover el uso e intercambio de materiales docentes, ya sean cursos completos o asignaturas.

Grupo de Investigación en interacción y E-learning (GRIAL). El Grupo de Investigación en Interacción y E-learning (GRIAL) trabaja de forma colaborativa, siendo Grupo de Excelencia de reconocido por la Junta de Castilla y León. Está constituido por investigadores de diferentes ámbitos de conocimiento y perfiles técnicos y pedagógicos, expertos en gestión de proyectos de E-learning en el ámbito de las Humanidades, Ciencias Experimentales, etc. GRIAL desarrolla acciones concretas en aspectos tecnológicos de aplicaciones informáticas para el desarrollo de métodos y modelos didácticos de referencia para el aprendizaje en línea. Utiliza además herramientas Web 2.0 para interactuar con la comunidad de miembros y dispone de otros recursos como el portal Drupal, WordPress (Ágora), Moodle (Pólis), DSpace, etc. que son utilizados bajo licencias respectivas de la Creative Commons para la generación e intercambio de conocimientos.

\subsubsection{Servicio de Bibliotecas de la Universidad de Salamanca (SABUS)}

\section{Descripción general}

La Biblioteca ${ }^{176}$ de la Universidad de Salamanca se constituye como un sistema integral de bibliotecas y archivos ubicados en diferentes sitios y campus de la Universidad. "La función principal del Servicio de Bibliotecas es la provisión de recursos documentales y servicios de información para estudiantes, docentes e investigadores de la Universidad de Salamanca" ${ }^{177}$. Dado que estatutariamente este servicio se encuentra junto al Servicio de Archivos, aunque funcionalmente trabajen como dos unidades distintas, es común que se les denomine conjuntamente como Servicio de Archivos y Bibliotecas de la Universidad de Salamanca (SABUS). No obstante, Archivos y Bibliotecas tienen una estructura separada y dependen de direcciones y órganos superiores diferentes.

\footnotetext{
${ }^{175}$ Véase mayor información en apartado 3.7 Inventario de plataformas E-elarning.

${ }^{176}$ Hernández Vicente, Severiano. "La Experiencia De La Biblioteca De La Universidad de Salamanca (1997-2002). Xornadas de Xerencia 2002 - Logroño (La Lou en marcha ¿Marcha la LOU?) (2002).http://www.ti.usc.es/webwebxer/Xornadas/2002/0303.pdf

177 Memoria 2010/2011 - Bibliotecas Universidad de Salamanca http://bibliotecas.usal.es/docs/memorias/Memoria_curso_2010-2011.pdf
} 


\section{Servicios de información del Servicio de Bibliotecas de la Universidad de Salamanca}

Servicios estándares:

- Préstamo de fondos bibliográficos

- Préstamo inter bibliotecario

- Préstamo inter-campus

- Préstamo de lectores de libros electrónicos

- Préstamo de portátiles y lectores de libros electrónicos

- Suministro de documentos

- Servicio de Referencia - Pregunte al bibliotecario

- Asesoría para publicación y factor de impacto

- Asesoría en gestores bibliográficos

- Alertas informativas de nuevas adquisiciones o recursos

- Búsquedas bibliográficas

Información y difusión de noticias: Portal de bibliotecas, Blogs, Listas y boletines

- Servicio de formación y tutoriales formativos

- Acceso a recursos propios

- Acceso a recursos cooperativos: Dialnet, Catálogos colectivos, Patrimonio documental, Web of Knowledge, Scopus

En el universo de usuarios del SABUS se distinguen grupos con y sin experiencia, así como con experiencia avanzada y/o conocimiento de los recursos y servicios que se ofrecen. Dentro de estos grupos se reconocen los siguientes usuarios reales:

\section{Usuarios internos}

- Estudiantes de Grados y Titulaciones

- Estudiantes de Postgrado

- Estudiantes de Títulos Propios

- Estudiantes con discapacidad

- Personal Docente e Investigador

- Personal de Administración y Servicios

\section{Usuarios externos}

- Personas externas y antiguos alumnos

\section{Servicios para la formación de usuarios}

El sistema de Bibliotecas de la Universidad de Salamanca ofrece a toda la comunidad universitaria cursos presenciales sobre el uso de los recursos disponibles en las bibliotecas a fin de crear las capacidades en los usuarios para identificar necesidades de información, localización y uso de los recursos apropiados, evaluación de los resultados obtenidos y reutilización de la información. Entre la oferta de cursos se destacan:

- Cursos de orientación e introducción a la biblioteca

- Cursos de técnicas de búsquedas en el sistema de la biblioteca y en bases de datos externas

- Curso sobre manejo y uso de recursos informativos y sobre técnicas de citaciones

- Curso para bibliotecarios del sistema sobre el uso de herramientas Web 2

- Cursos de formación sobre el uso de servicios del SABUS y la gestión de información en 15 áreas de estudios de másteres oficiales de la Universidad de Salamanca

- Talleres exprés o cursos de cortar duración abiertos a toda la comunidad universitaria 


\section{Servicio de apoyo a la docencia e investigación}

A través de convenios establecidos con los departamentos de la Universidad de Salamanca, el SABUS participa a través de cursos sobre el manejo y uso de recursos informativos y sobre técnicas de citaciones en la formación de los estudiantes de titulaciones de grados en máster. Los cursos adquieren un valor de créditos que los estudiantes pueden utilizar en su perfil académico.

La participación del SABUS en el plan de formación docente del profesorado universitario, se realiza a través de cursos concretos sobre técnicas de búsqueda de textos científicos y recursos bibliográficos y recursos electrónicos para la investigación y la docencia, elaboración de índices de citas, factor de impacto e indicios de calidad y gestión de la información bibliográfica, entre otros.

\section{Recursos informativos involucrados en los servicios}

- Recursos impresos: colección en papel (primaria y secundaria) y colecciones especiales en papel

- Recursos electrónicos: blogs, portales, 400 portátiles, lectores de libros electrónicos

- Colecciones en formato electrónico: bases de datos internas, catálogos SABUS, repositorios para la educación, bases de datos externas de documentos digitalizados. Dispone de bases de datos, revistas electrónicas y libros electrónicos.

- Otros recursos: Directorios, enciclopedias internacionales en línea, diccionarios, y recursos externos especializados en las diferentes disciplinas de interés para la oferta de formación de la Universidad.

\section{Medios de difusión de servicios e información a la comunidad}

El sistema de difusión y comunicación que utiliza el SABUS para promover y hacer accesible los servicios corresponden principalmente a listas de distribución, Blogs, Netvibes, Facebook, Twitter. RSS. Se trata de una de las universidades cuyo servicio bibliotecario está apostando más fuertemente por el uso de herramientas 2.0 para la comunicación con los usuarios y la difusión de la información.

\subsubsection{Análisis del portal del Servicio de Bibliotecas de la USAL}

El presente análisis descriptivo y de funcionamiento del portal(es) del Sistema de Bibliotecas de la Universidad de Salamanca, ha sido realizado a partir de 10 parámetros para la evaluación de sitios y recursos web. La selección de estos responde al hecho que permiten analizar adecuación del diseño, la organización y caracterización de sitio y sus servicios. En este apartado se ofrece una revisión del mismo.

\section{Parámetros 1 y 2. Identidad y Actualización}

El Servicio de Bibliotecas de la Universidad de Salamanca se identifica fácilmente desde cualquier buscador en Internet. El portal principal al momento de este estudio estaba modificándose, por lo que disponía de dos sedes web ${ }^{178}$. Los dos portales convivieron desde junio de 2011 en que se lanzó el actual portal, hasta diciembre de 2012, mes en el que se eliminó definitivamente el sitio antiguo.

\footnotetext{
178 La revisión y evaluación de los dos sitos web del Sistema de bibliotecas se efectuó en octubre 2011, la información obtenida de los cuestionarios se procesó en noviembre-diciembre del mismo año.
} 
Debido a que ambos portales estaban disponibles en Internet en el momento de la aplicación de esta investigación, se decidió evaluar ambos sitios. Cabe destacar que la principal variante entre el antiguo y el nuevo portal corresponde a la apariencia visual y la organización y presentación de la oferta de servicios. De igual forma, el nuevo portal emplea las herramientas tecnológicas propias del momento de su creación, basándose en Drupal como gestor de contenidos, mientras que el portal anterior respondía a los tradiciones diseños web, realizados mediante conjuntos de páginas. Además, el nuevo portal es consecuente con el diseño general de la web de la Universidad de Salamanca.

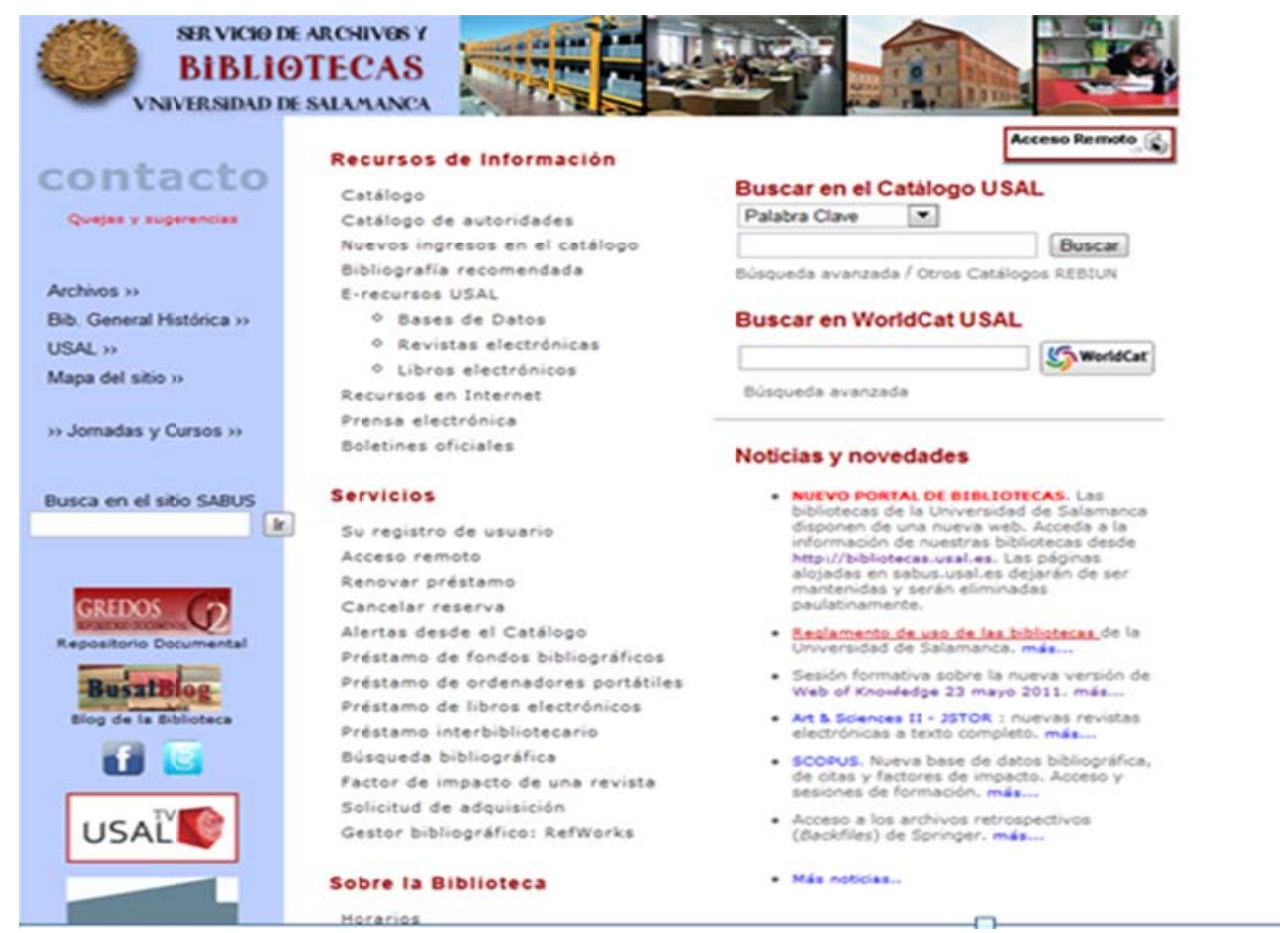

Figura 98. Portal de la biblioteca en sustitución: http://sabus.usal.es
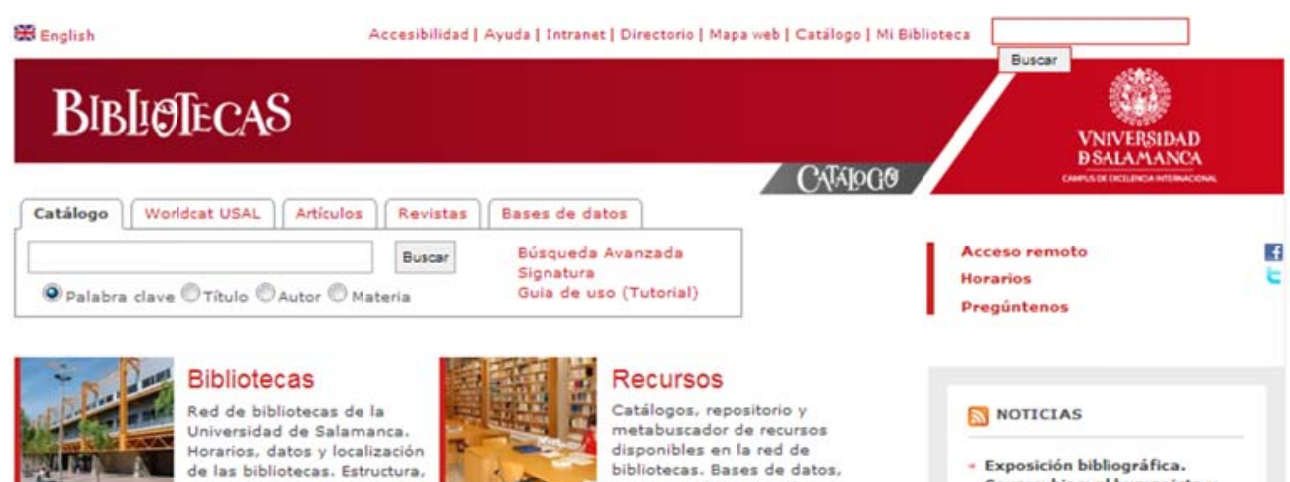

Bibliotecas

Red de bibliotecas de la

Universidad de Salamanca.

de las bibliotecas. Estructura

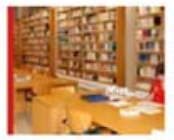

Recursos

arta de servicios y directorip.

Catálogons, repositorio y

metabuscador de recursos

disponibles en la red de

hevistas y libros electrónicos.

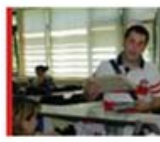

Servicios

Servicios al usuario.

réstamo de documentos

Parivivos. Información y

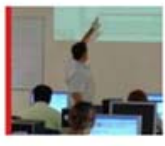

Formación

Guias de uso de recursos y

investigación. Servicios de

alerta e informativos.
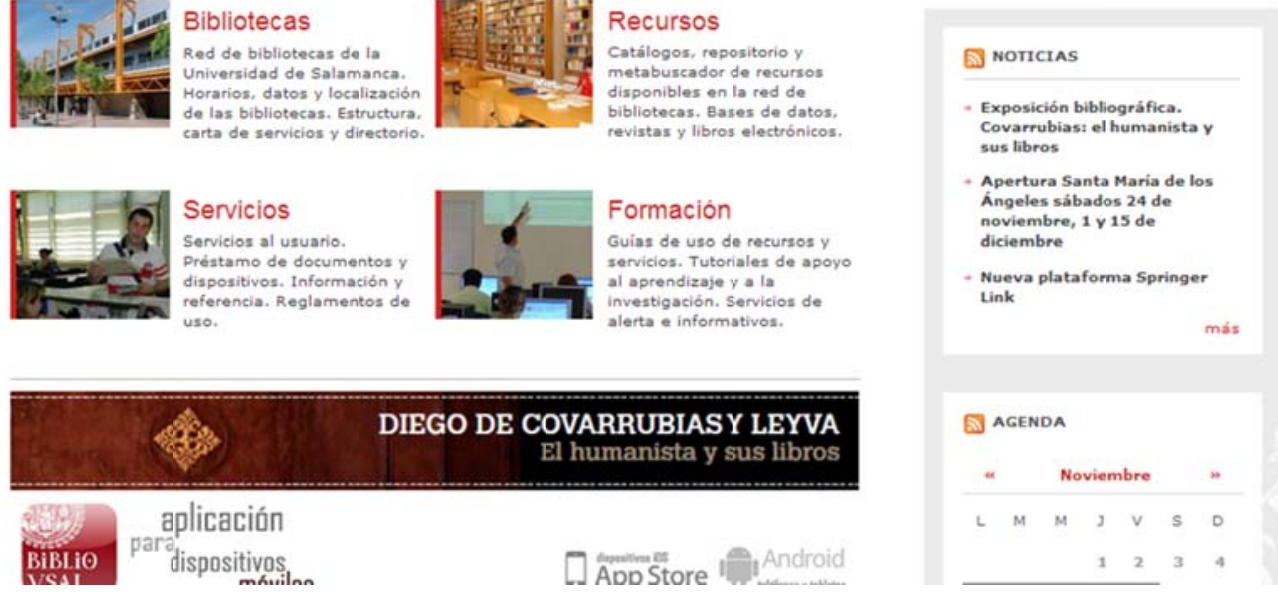

Figura 99. Nuevo portal http://bibliotecas.usal.es 
La localización de la biblioteca desde el sitio web de la Universidad de Salamanca, no es inmediata, no obstante el enlace al portal se ubica en el menú de servicios a la comunidad. A lo interno del Sistema de bibliotecas de la USAL se identifican otros sitios Webs y recursos Web 2.0 como blogs, Facebook, etc. ${ }^{179}$ que complementan y amplían la oferta de servicio del SABUS. La funcionalidad de los enlaces que seguidamente se presentan ha sido debidamente controlada:

- Servicio de Bibliotecas: http://bibliotecas.usal.es

- Catálogo: http://brumario.usal.es

- Catálogo móvil: http://usal.worldcat.org/m

- Meta buscador BUCLE: http://usal.worldcat.org

- Repositorio: http://gredos.usal.es

- Blog El astronauta: http://diarium.usal.es/bibliotecas

- Blog de Gredos: http://diarium.usal.es/gredos

- Facebook: http://www.Facebook.com/bibliotecasusal

- Twitter: http://Twitter.com/bibliotecasusal

\section{Parámetro 3. Accesibilidad}

Las diferentes pruebas realizadas evidencian la posibilidad de acceder a cada una de las aplicaciones antes listadas.

\section{Parámetro 4. Servicios básicos de la web}

Los servicios visibles y disponibles desde el portal corresponden al acceso a directorio de recursos Web, Servicio de orientación al estudiante (tutoriales), acceso a diversos recursos, bases de datos y repositorios, espacios personalizados, blogs, portales. RSS (agenda, noticias, variedades, entretenimientos, etc.), Twitter y Facebook.

\section{Colecciones digitales}

Las colecciones de recursos de información de SABUS corresponden a un fondo especializado para fines académicos y de investigación científica. En consecuencia se destacan las siguientes características en la presentación de los metadatos (descripción y enlace del recurso) del fondo informativo.

- Identificación básica de las diferentes secciones de la publicación (autor, título y fechas)

- Los contenidos de los diferentes recursos de la biblioteca se caracterizan por cumplir con los siguientes parámetros de calidad

- Autoridad de autores reconocida

- Adecuación entre la autoría y la agenda temática

- Adscripción del autor a la organización que pertenece

- Reconocimiento y credibilidad de la fuente

- Posibilidad de recorrido secuencial en forma total y parcial de forma secuencial

\footnotetext{
179 Memoria 2010/2011 - Bibliotecas Universidad de Salamanca http://bibliotecas.usal.es/docs/memorias/Memoria_curso_2010-2011.pdf
} 


\section{Parámetros 5 y 6 . Contenido y Arquitectura de la información}

El proceso de navegación dentro de los portales y aplicaciones Web 2.0 es excelente. Existe la presencia de enlaces (encabezados e Figura es) para agilizar el traslado de una página a otra. También la presencia de un mapa del sitio facilita la ubicación del usuario dentro de portal.

La organización de los contenidos en el antiguo y nuevo portal ocurre de forma diferente. El primer portal ofrecía tres ventanas de búsqueda, la primera en el catálogo USAL, la segunda en el WorldCat USAL y la tercera en todo el sitio SABUS. El nuevo portal ofrece una sola ventana de búsqueda en la que se puede seleccionar donde buscar el recurso, es decir en el catálogo, el Worldcat USAL, en base de datos de artículos, revistas, bases de datos y Gredos. Una vez que el usuario ha introducido su clave de acceso puede acceder al enlace de texto completo y utilizarlo con libertad e independencia (descargar, copiar, limpiar, transferir, etc.). Asimismo si se dispone de la dirección URL del archivo puede ser accesible desde internet. Cabe destacar que el nuevo portal del Sistema de bibliotecas de la USAL a diferencia del anterior dispone una versión en inglés.

\section{Parámetro 7. Diseño de la interfaz}

El diseño de la interfaz en este punto corresponde a los aspectos físicos y ergonómicos que son notables en el sito portal o Web del servicio. La revisión de estos aspectos en ambos portales del SABUS permite concluir que se observa una mejora en el diseño en cuanto al cumplimiento de aspectos físicos y ergonómicos. En la siguiente tabla se muestran a modo de resumen las nuevas aplicaciones en el sitio.

\begin{tabular}{|l|l|l|}
\hline $\begin{array}{l}\text { Aspectos físicos y } \\
\text { ergonómicos }\end{array}$ & Portal antiguo & Portal nuevo \\
\hline Tipo de letras & $\begin{array}{l}\text { No. se observa uso de diferentes tipos } \\
\text { de letras }\end{array}$ & Sí \\
\hline Colores de letras & $\begin{array}{l}\text { No. } \\
\text { Se identifican 4 diversos colores } \\
\text { utilizados sin consistencia }\end{array}$ & $\begin{array}{l}\text { Sí. Se observa consecuencia en } \\
\text { el uso de los mismos colores } \\
\text { dentro de todos los sitios del } \\
\text { portal y del sitio Web de la } \\
\text { Universidad }\end{array}$ \\
\hline Tamaño de letras & $\begin{array}{l}\text { Parcialmente, se identifica el uso de } \\
\text { tres tipos de tamaños y apariencia de } \\
\text { letras }\end{array}$ & Sí \\
\hline $\begin{array}{l}\text { Líneas de texto y } \\
\text { márgenes }\end{array}$ & $\begin{array}{l}\text { No. Se observa entre página y página } \\
\text { variedad en el uso de líneas de textos } \\
\text { y márgenes. Ejemplo página principal } \\
\text { y los apartados de servicios y recursos }\end{array}$ & Sí \\
\hline Anchura de pantalla & $\begin{array}{l}\text { El despliegue de la información en la } \\
\text { página inicial del portal y la página } \\
\text { "biblioteca" se concentra } \\
\text { prácticamente al lado derecho de la } \\
\text { pantalla. Hay mucho margen en } \\
\text { blanco al lado derecho }\end{array}$ & Sí \\
\hline Legibilidad. Claridad o & $\begin{array}{l}\text { No. El diseño del portal no presenta } \\
\text { Márgenes proporcionados }\end{array}$ \\
\hline
\end{tabular}




\begin{tabular}{|l|l|l|}
\hline $\begin{array}{l}\text { contraste adecuado } \\
\text { entre el texto y el fondo }\end{array}$ & $\begin{array}{l}\text { un buen contraste de colores. El fondo } \\
\text { blanco y la combinación de letras } \\
\text { pequeñas y de color gris dificulta su } \\
\text { visibilidad y lectura }\end{array}$ & Sín relación a las búsquedas \\
\hline $\begin{array}{l}\text { una acción de diferentes } \\
\text { maneras }\end{array}$ & $\begin{array}{l}\text { Sí. En relación a las búsquedas } \\
\text { Hay que ubicarse dentro del portal } \\
\text { y ubicarse dentro del portal }\end{array}$ \\
\hline $\begin{array}{l}\text { Adecuación del uso de } \\
\text { imágenes o sonido } \\
\text { complementando la } \\
\text { información textual }\end{array}$ & $\begin{array}{l}\text { No se observó presencia de media } \\
\text { como parte del diseño }\end{array}$ & $\begin{array}{l}\text { No se observó presencia de } \\
\text { media como parte del diseño }\end{array}$ \\
\hline $\begin{array}{l}\text { Velocidad o tiempo de } \\
\text { descarga }\end{array}$ & $\begin{array}{l}\text { Sí. Existe buena velocidad en el } \\
\text { desplazamiento de una página a otra y y } \\
\text { apertura de archivos }\end{array}$ & $\begin{array}{l}\text { Sí. Existe buena velocidad en el } \\
\text { desplazamiento de una página } \\
\text { a otra y apertura de archivos }\end{array}$ \\
\hline $\begin{array}{l}\text { Posibilidad de manifestar } \\
\text { opiniones sobre el } \\
\text { contenido de la web }\end{array}$ & $\begin{array}{l}\text { Sí. Presencia de un enlace para } \\
\text { “Contacto y sugerencias" }\end{array}$ & $\begin{array}{l}\text { Sí. Existe la presencia de un } \\
\text { enlace: “Sugerencias y quejas" }\end{array}$ \\
\hline
\end{tabular}

Tabla 29. Aspectos físicos y ergonómicos mejorados en el sitio web del SABUS Fuente: Elaboración propia.

\section{Parámetro 8. Posicionamiento}

Los portales y las diferentes aplicaciones Web 2.0 del SABUS son identificables en el internet de la Universidad y en el internet desde cualquier buscador en línea. El sistema de búsqueda y recuperación se encuentra mejorado en el nuevo portal del Sistema de Bibliotecas de la USAL. La nueva opción (en forma de ventana) que ofrece permite delimitar la búsqueda por tipo de recurso, autor, materia, palabra clave, signatura, y además definir el nivel de búsqueda, es decir de forma sencilla o avanzada y el posible acompañamiento de tutoriales para la ejecución eficiente de la misma.

El portal SABUS ofrece en la parte superior derecha una pequeña ventada para realizar búsquedas generales en todo los sitio web, blogs pertenecientes a cada una de las bibliotecas adscritas al SABUS. Las características que presenta el nuevo sistema de búsqueda del portal del Sistema de Bibliotecas de la Universidad de Salamanca son las siguientes:

- Amplia cobertura de búsqueda en todos los recursos

- Adecuada descripción del recurso basada en normas internacionales

- Uso de lenguajes controlados

-.Posibilidad de localización mediante el uso de términos semejantes por aproximación

- Uso de operadores boléanos

- Cuido de la semántica de los Metadatos

\section{Parámetro 9. Sistema de búsqueda y recuperación}

El sistema de búsqueda del sistema de bibliotecas de la USAL, permite realizar búsquedas libremente, obtener resultados y ampliar la búsqueda en otros buscadores externos. No obstante el acceso y uso del contenido requiere contar con un identificativo como usuario de la biblioteca. En la siguiente dos 
figuras se ilustra el catalogo en dos versiones. La fallada del catálogo identificado como Brumario (2008) y la actual versión en línea (2012).

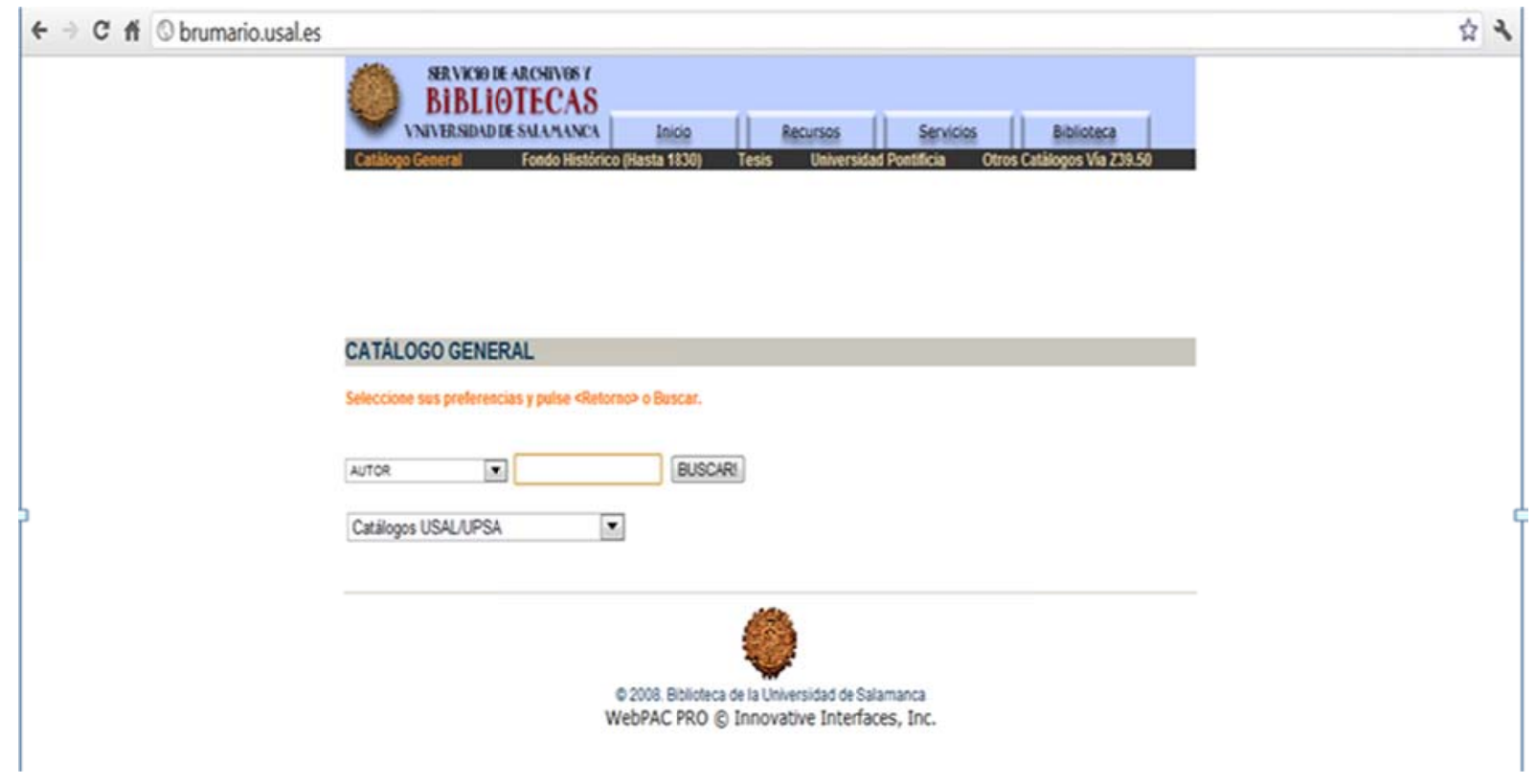

Figura 100.Catálogo general de Servicio de Bibliotecas de la USAL ${ }^{180}$ (antigua interfaz)
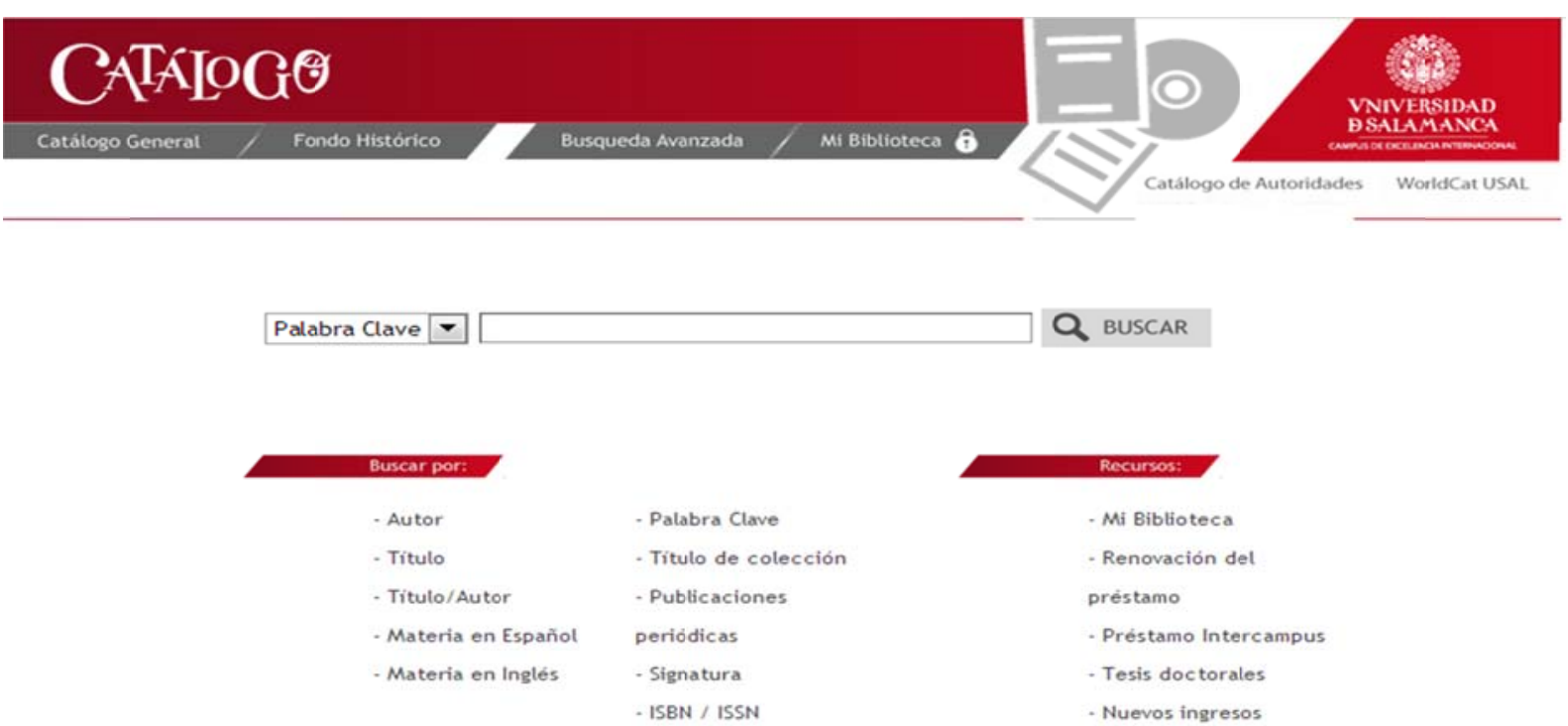

Figura 101. Portada del catálogo del Sistema de bibliotecas de la USAL ${ }^{181}$ (nueva interfaz)

Otro recurso ofrecido por el Servicio de Bibliotecas de la Universidad de Salamanca corresponde a la presencia del catálogo de la USAL en Worldcat bajo el identificativo BUCLE, consorcio regional con quien comparte catálogo, como catálogo colectivo del Consorcio de Bibliotecas Universitarias de Castilla y León (BUCLE). Las ventajas de este catálogo se pueden describir como:

\footnotetext{
${ }^{180}$ Acceso al catálogo desde: http://brumario.usal.es/

181 lbid
} 
a) Su capacidad y flexibilidad multilingüe. El buscador puede ser utilizado en diferentes idiomas, según la terminal (pc o portátil) utilizada.

b) La cobertura de búsqueda puede ser significativamente ampliada tanto en área geográfica como contenido

c) Limitaciones definidas por los participantes de Worldcat

Con el fin de ilustrar la funcionalidad del catálogo del sistema de la biblioteca, seguidamente se presenta un ejercicio realizado

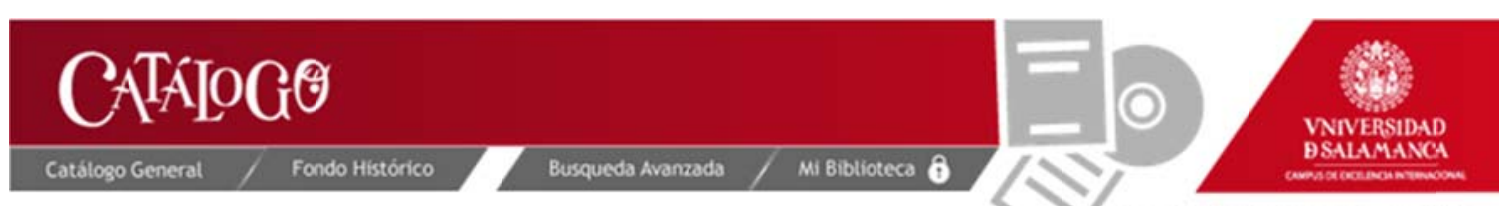

Catallogo de Autoridades WorldCat USAL.

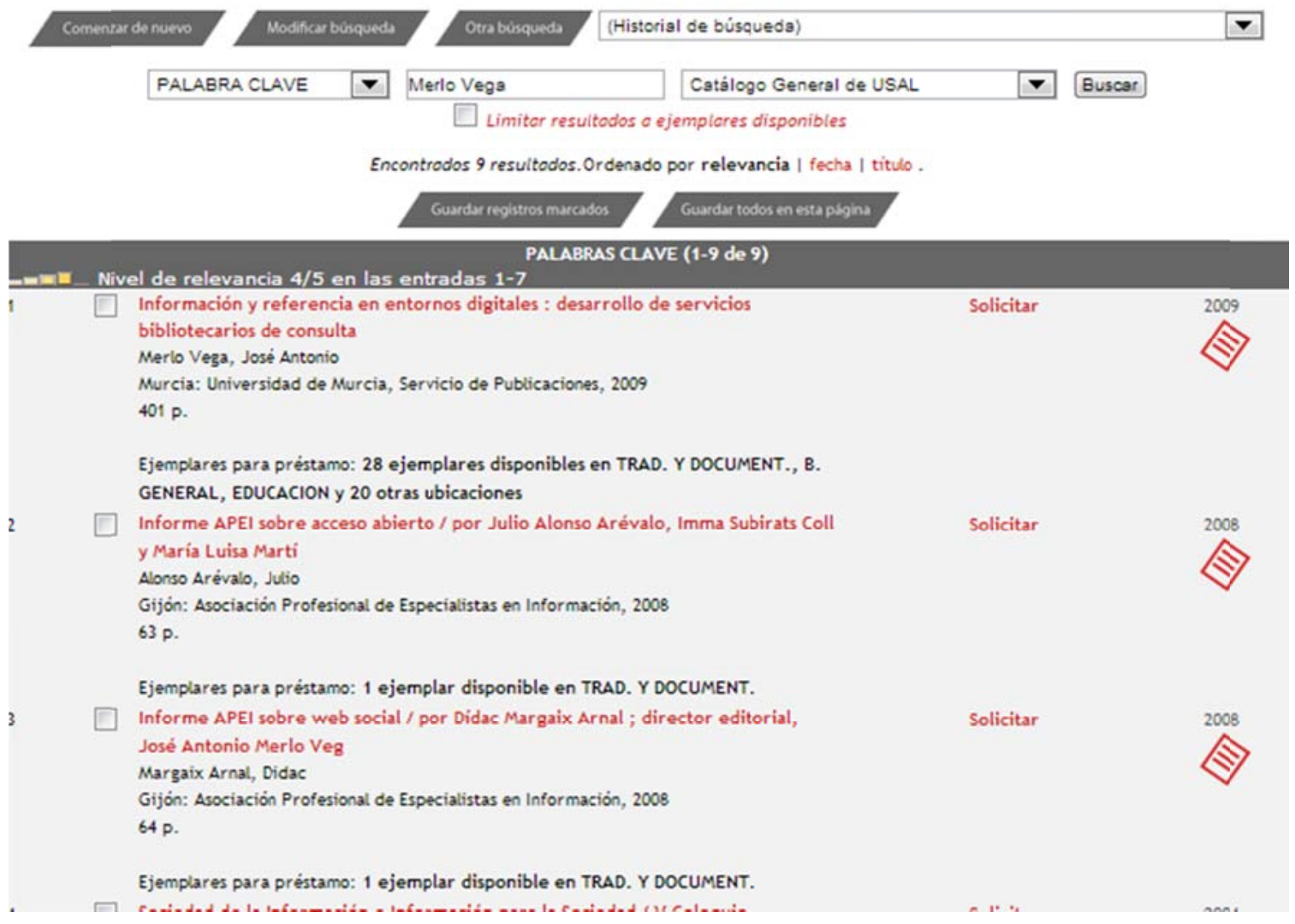

Figura 102.Ejercicio de búsqueda en el catálogo del Sistema de bibliotecas de la USAL ${ }^{182}$

\footnotetext{
${ }^{182}$ Acceso al catalogo vía http://brumario.usal.es/
} 


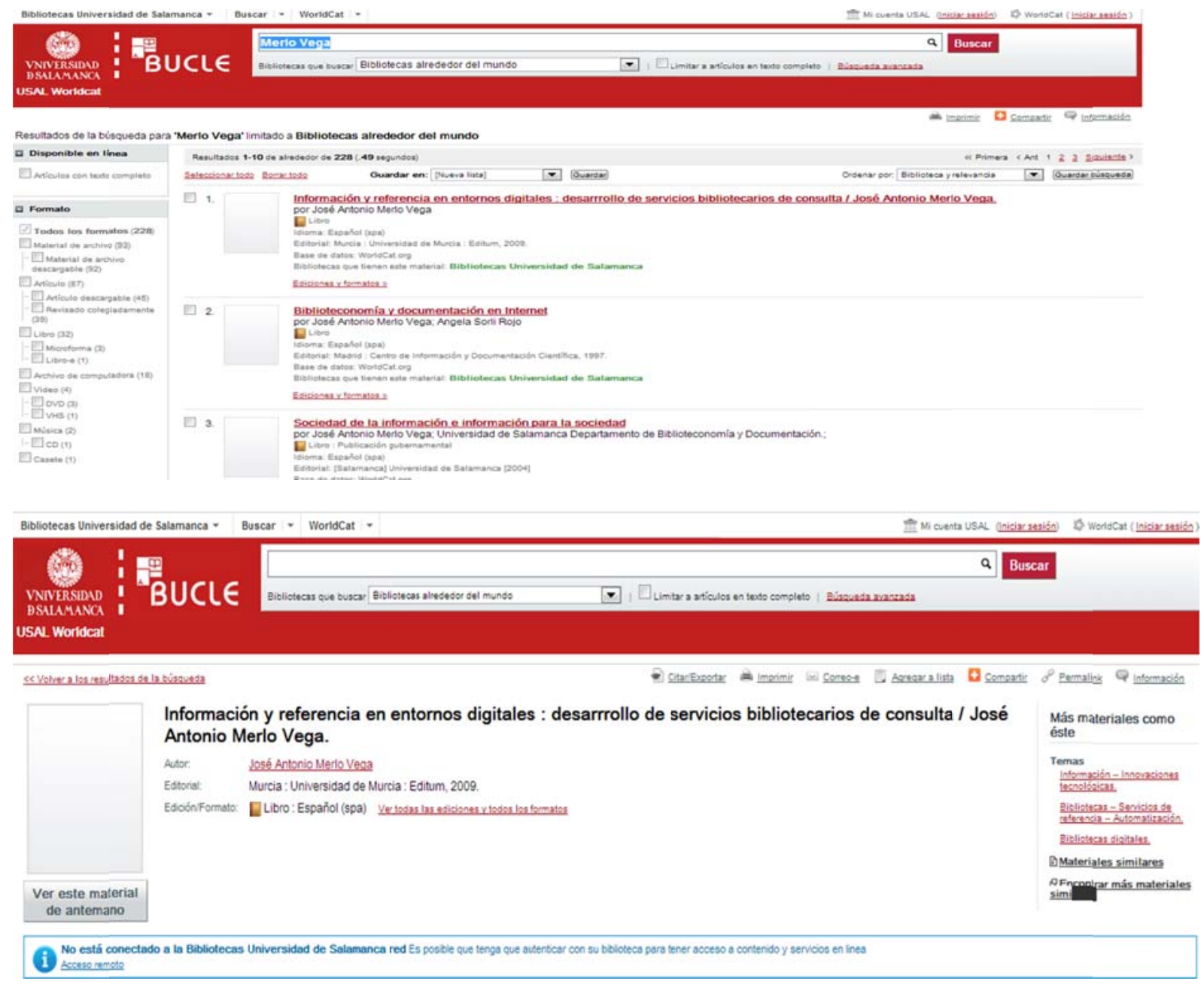

Figura 103. Sistema de búsqueda BUCLE asociado a Wordcat.org ${ }^{183}$

\section{Parámetro 10. Usabilidad}

Durante el proceso de pruebas de acceso a los portales y aplicaciones Web 2.0 desde el exterior de España, no se experimentó problema alguno. Fue posible acceder al catálogo y acceder a archivos pdf con la flexibilidad de copiar, pegar; ampliar o disminuir la visibilidad de lectura entre otros. Asimismo el portal del SABUS en sus diferentes partes que lo constituyen no ofrece funciones específicas de ayuda en cada campo, es decir de enlaces a textos explicativos que ofrezcan más información del servicio al usuario.

Cabe destacar que según información disponible en el sitio web del SABUS, fue posible constatar la biblioteca se vale de aplicaciones en línea en el sistema y de evaluaciones directas para analizar el comportamiento del servicio en relación de la demanda y medir el nivel la satisfacción de los usuarios. También es destacable que en los diferentes portales sitios y aplicaciones Web 2.0 del Sistema de Bibliotecas no ofrece facilidades extras para el uso por parte de personas con alguna incapacidad física, auditiva o visual. La única opción identificada corresponde al enlace de ayuda para cambios en el tamaño de la letra.

\footnotetext{
${ }^{183}$ Acceso al catálogo Worldcat de la USAL vía http://usal.worldcat.org.
} 


\subsubsection{Evaluación del servicio de referencia}

En correspondencia con la definición ofrecida de Servicio de referencia digital conceptualizado en el apartado 5.2, la practica ejercida por parte del Sistema de biblioteca de la USAL se materializa en un servicio de comunicación, a través del cual, los usuarios pueden realizar su consulta y ser referidos a los diferentes servicios y/o puntos de acceso a la información disponibles en la biblioteca.

\section{Identidad del servicio}

La identificación del servicio de referencia digital en los dos sitios web analizados refleja que el nuevo diseño de portal, supera la oferta de servicio ofrecida en el portal precedente. En la siguiente tabla se resume las ofertas ofrecidas por ambos portales.

\begin{tabular}{|l|l|}
\hline Portal antiguo http://sabus.usal.es & Portal actual http://bibliotecas.usal.es \\
\hline $\begin{array}{l}\text { Los servicios localizan de forma diversa y sin } \\
\text { responder a una jerarquización } \\
\text { determinada }\end{array}$ & Los siguientes servicios encuentran \\
Los servicios que se identifican como parte & jerárquicamente organizados. Se dispone de un \\
mapa del sitio & Los servicios que se desprenden de la referencia \\
- Peticiones bibliográficas - Solicitud de & digital corresponde a: \\
adquisición & - Pregúntenos. Responden consultas de información \\
-Préstamo y consulta & general o bibliográfica. \\
- Preguntas/Sugerencias & - Consultas especializadas \\
& - Quejas y sugerencias \\
& - Mantenerse informado \\
& - Formularios diversos \\
\hline
\end{tabular}

El servicio de referencia digital ofrecido por el Sistema de bibliotecas de la USAL acontece como un proceso de comunicación de doble vía entre el usuario y el bibliotecario. No fue posible identificar una forma de comunicación sincrónica, por cuanto el servicio utiliza un sistema de formularios predefinidos.

Desde el menú principal del sitio de la biblioteca se visualiza en la parte derecha superior, el término: "pregúntenos". Este direcciona al servicio de referencia. El enlace direcciona a dos posibilidades de acceder al bibliotecario referencista:

- Consultas de tipo general: Contacte con el Servicio de Bibliotecas

- Consultas especializadas: Contacte con la Biblioteca más afín 


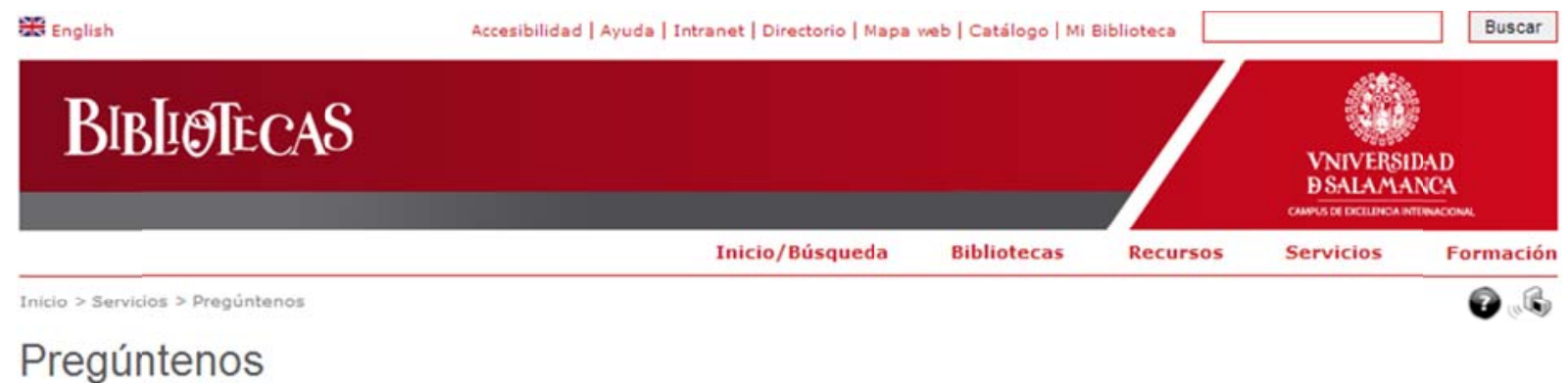

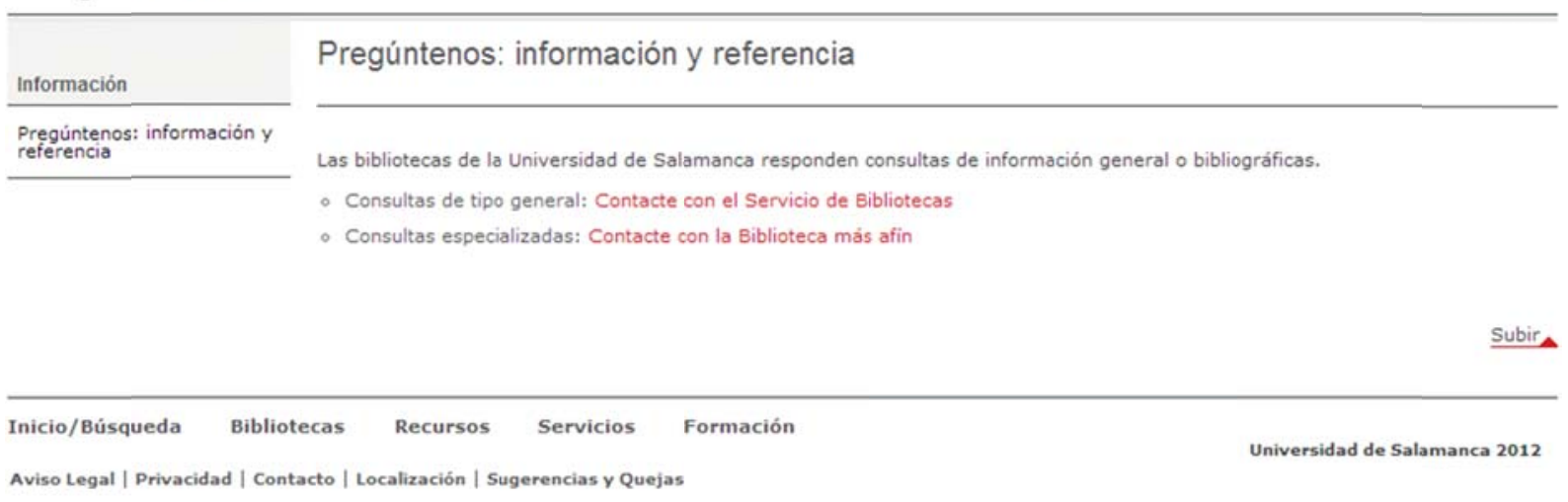

Figura 104. Servicio de Referencia de la USAL.

Otros servicios vinculados a la práctica de la referencia son localizables desde la página principal del sistema de bibliotecas de la Universidad de Salamanca, mediante los siguientes enlaces que a continuación se describen.

- Característica del servicio: medio de comunicación para expresar opinión

Localización: Parte inferior central de la página principal del Sistema de biblioteca

Identificador: Término: Sugerencias y quejas

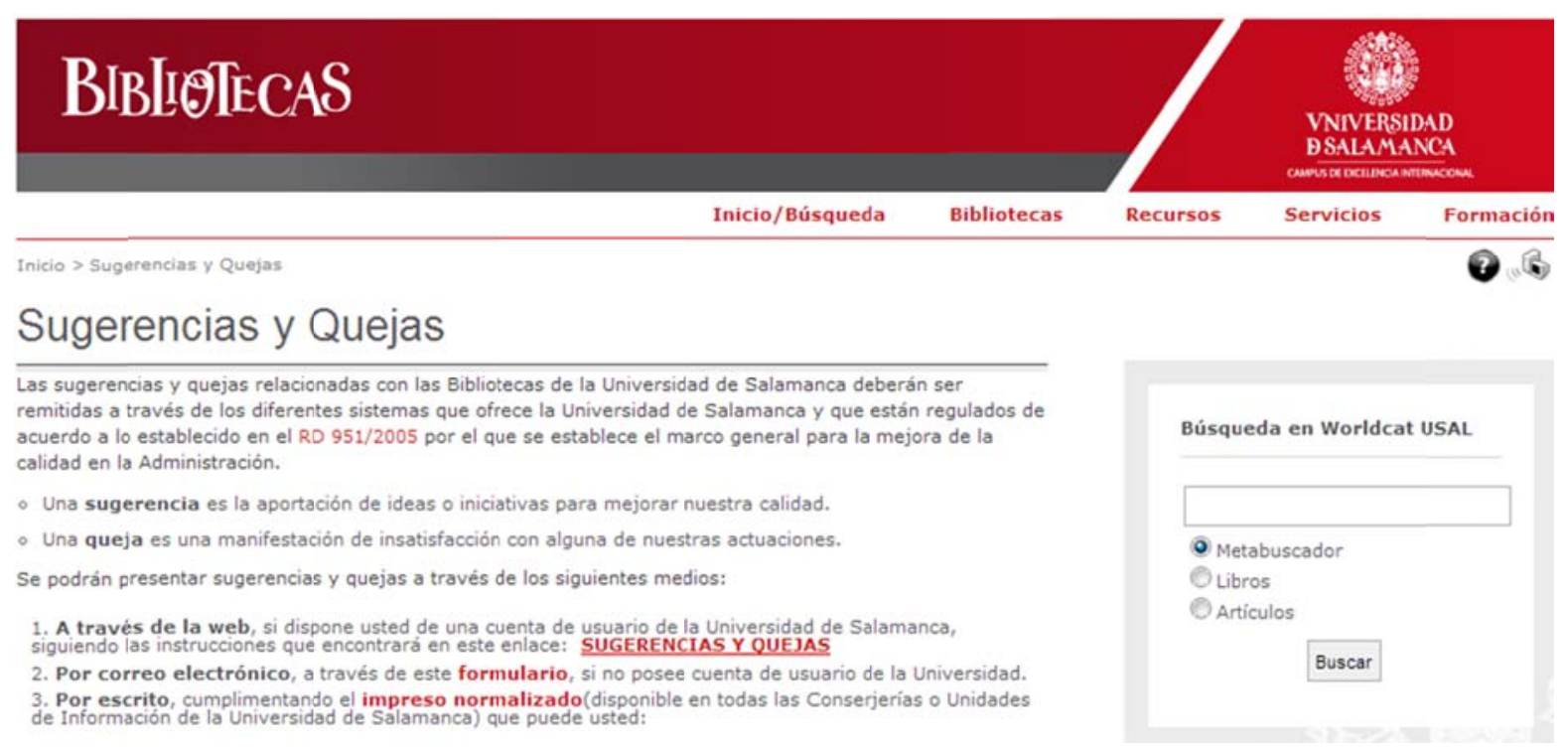

Figura 105. Servicio de sugerencia y quejas del sitio del Sistema de bibliotecas de la USAL. 
- Característica del servicio: medio de comunicación general

Localización: Parte inferior central de la página principal del Sistema de biblioteca Identificador: Término: Contacto

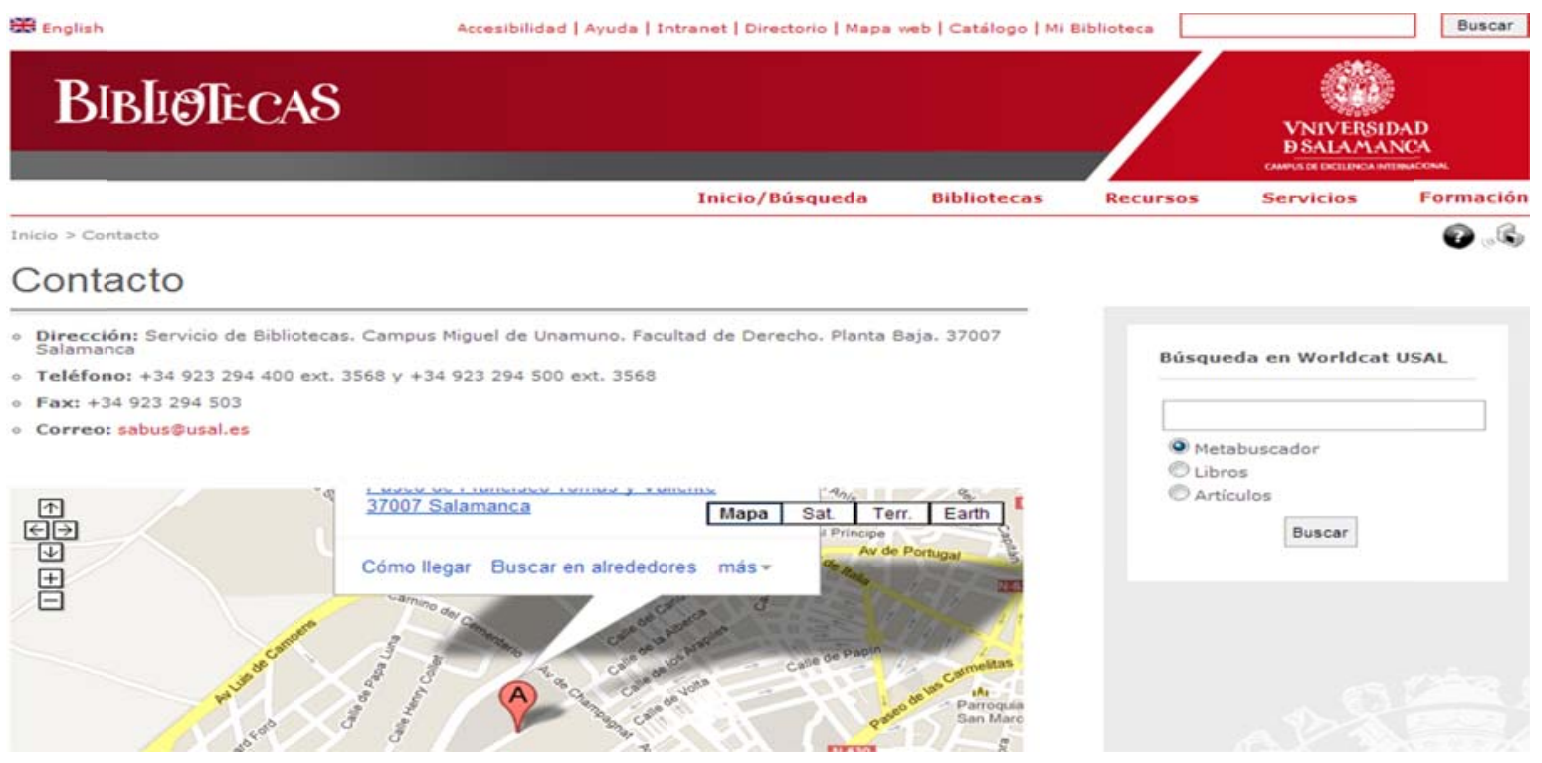

Figura 106. Servicio de comunicación para establecer contacto con los referencistas.

- Característica del servicio: medio de comunicación general

Localización: Desde la página principal y desde el enlace SERVICIO, se direcciona a otra página donde se ofrece el servicio Identificado con el término: Mantenerse informado.

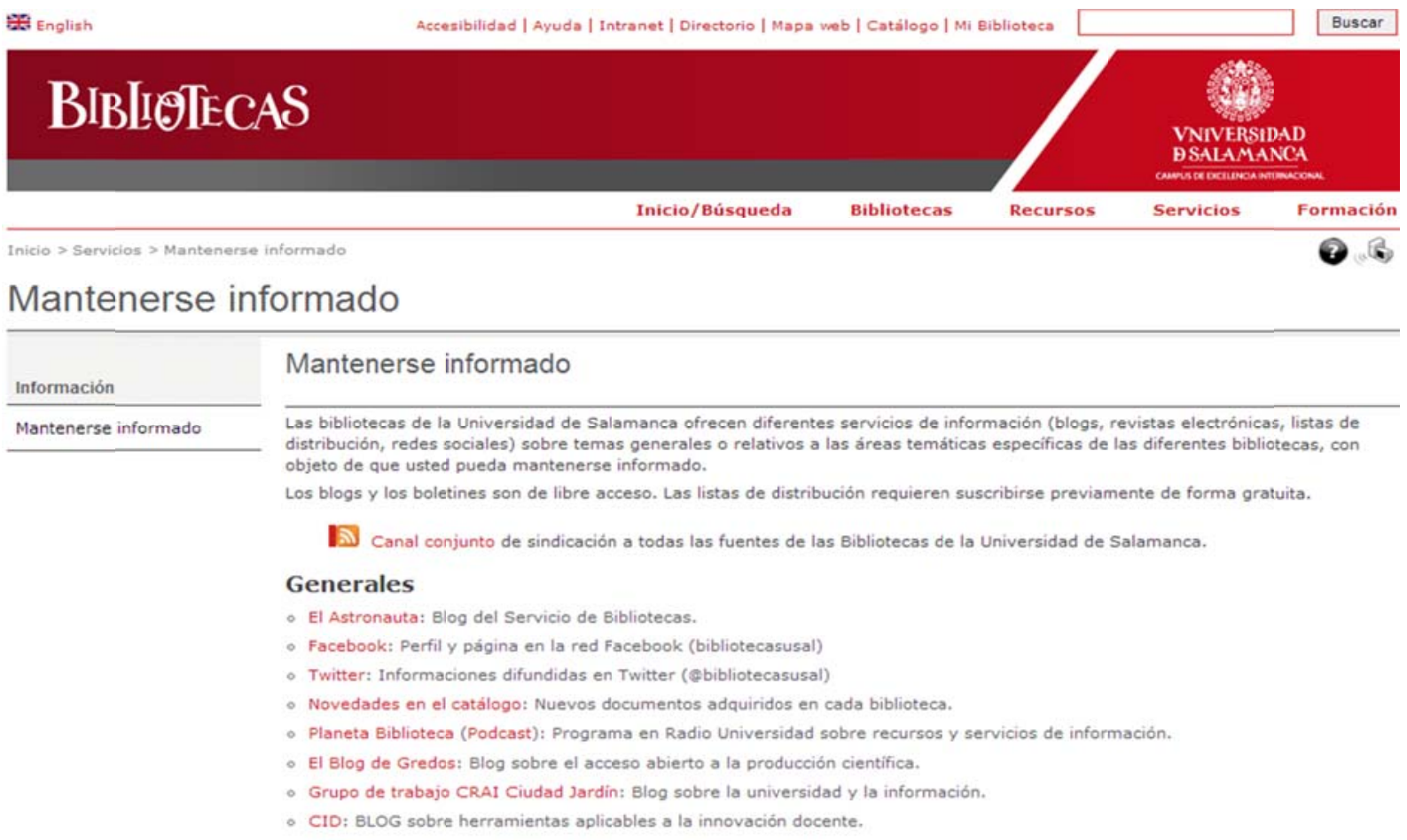

Figura 107. Servicio de comunicación con carácter informativo. 
Los servicios antes referidos no se encuentran centralizados jerárquicamente en un punto, pero en todos ellos el proceso de comunicación e interacción con el bibliotecario y el usuario ocurre a través de correo electrónico y/o formularios predefinidos.

\section{Actualización}

Tal como se muestra anteriormente sitio web no refleja ninguna señal de actualización, aspecto que, relativamente es incorporado en el nuevo sitio, dado que son visibles dos aplicaciones que permiten ubicar cronológicamente al usuario-lector en mes y el año de la web. Esto es posible gracias a la aplicación del calendario-agenda ubicada en la parte derecha inferior que despliega por mes las diferentes actividades programadas. Asimismo se identifica el derecho a la autoridad de la información con la respectiva indicación del año. El propio sistema empleado en el diseño de la web informa de la fecha de creación de cada contenido, que se actualiza de forma periódica.

\section{Accesibilidad}

El acceso al servicio no presenta ningún problema, la única limitante es la ausencia de facilidades para personas con incapacidades físicas, auditivas o visuales.

\section{Servicios básicos de la Web}

Los servicios que se integran en el sitio Web son básicamente los siguientes:

- Opción de ayuda

- Opción de búsqueda en catálogos

- Directorio

- Acceso a diversos metadatos

- Espacios personalizados

- Recursos meta

- Servicio de orientación al estudiante (formación)

- Comunicación

\section{Contenido}

El contenido reflejado en el portal se adecua a los objetivos y agenda del Servicio de Bibliotecas de la Universidad de Salamanca. Los contenidos están agrupados jerárquicamente en forma de menú de enlaces que direccionan a opciones e informaciones específicas. Los contenidos están organizados en cuatro grandes bloques (Bibliotecas, Servicios, Recursos, Formación), a los que se añaden páginas especiales (Acceso remoto, Pregúntenos, Horarios), más Noticias y Agenda. Existe un Mapa web que ofrece enlaces directos a cada página, además de un buscador específico. En todos los casos, se mostrará una guía que indica la ruta de la página que se está visitando.

Asimismo dispone de enlaces direccionales para subir de nivel o página y enlaces opcionales para llegar a determinados servicios. Cabe destacar que el sitio web del Servicio de Referencia a octubre 2011 sólo estaba disponible en idioma español. 


\section{Diseño de interfaz}

El diseño de la página del servicio está en correspondencia con todo el sitio de SABUS y cumple con los siguientes aspectos físicos y ergonómicos:

- Consistencia y contraste en el uso de colores

- Homogeneidad de estilos

- Tipo de letras

- Tamaño de letras

- Líneas de texto

- Ancho de pantalla

- Márgenes

- Contraste adecuado entre el texto y el fondo

- Posibilidad de manifestar opiniones al responsable o administrador

\section{Posicionamiento}

El posicionamiento del servicio de referencia de SABUS ocurre a lo interno y externo de la universidad. Este se destaca visiblemente desde la página principal del sistema de bibliotecas mediante los enlaces "Pregúntenos: información y referencia"; contacto; que direcciona al sitio del servicio que seguidamente se ilustra.

\section{Sistema de búsqueda y recuperación de los recursos}

El nuevo sitio web del SABUS ofrece un nuevo sistema de búsqueda que permite agilizar el proceso de búsqueda - recuperación y el contacto entre el usuario y la fuente. Desde la página Servicios y en cada uno de los sitios que aquí se desprenden, se despliegan en forma permanente, el menú superior horizontal que seguidamente se muestra:

\section{Inicio/Búsqueda - Bibliotecas - Recursos - Servicios - Formación}

El punto más fuerte del servicio anteriormente se ha dicho es la comunicación para fines de orientación y capacitación sobre el uso de los recursos, hecho por el cual resulta estratégico su incorporación como un medio de apoyo en el proceso enseñanza-aprendizaje, por cuanto puede orientar el proceso de búsqueda de información necesaria para el cumplimiento de los objetivos educacionales. En esta línea, cabe destacar que el servicio de referencia digital en conjunto con el Servicio de formación de usuarios garantizan, la posibilidad que los estudiantes puedan hacer mejor uso de los recursos de información ya que adquiere las habilidades y técnicas para el uso adecuado de la información.

Es destacable que el enlace Pregúntenos está presente en todas las páginas del portal de bibliotecas, siendo especialmente visible en la página principal, aunque también se mostrará en los diferentes niveles en los que se estructuran los contenidos de este portal, mediante un logotipo específico. 


\section{Usabilidad}

La opción permanente Sugerencias y Quejas estimula la posibilidad de establecer el contacto entre el usuario y la biblioteca y la posibilidad de manifestar opiniones sobre el contenido de la web a responsable o administrador. Aunque existen estadísticas anuales sobre los servicios del Sistema de bibliotecas, se desconoce la existencia de un estudio orientado específicamente al servicio de referencia.

\subsubsection{Evaluación del servicio de repositorios para la educación}

El concepto de Repositorios Académicos aplicado en este estudio se refiere al recursos o soporte de fuentes de información digital asociados a un propósito educativo que ha sido reunida, organizada, sistematizada y accesible para su uso a través de Internet.

El análisis de los repositorios del Servicio de Bibliotecas de la USAL ha sido revisado también desde dos perspectivas, debido a la existencia de dos sitios web en el momento del análisis, como ya se ha explicadol. El antiguo portal carece de una estructura clara de oferta de repositorio y pone en duda la posibilidad de acceder a los recursos. En las siguientes dos figuras se evidencia la poca información de la oferta de servicios y la presencia del término En prueba en la opción de E-recursos genera inseguridad sobre la funcionalidad del servicio, aunque se refiere a los recursos cuya suscripción estaba estudiando la Universidad de Salamanca.

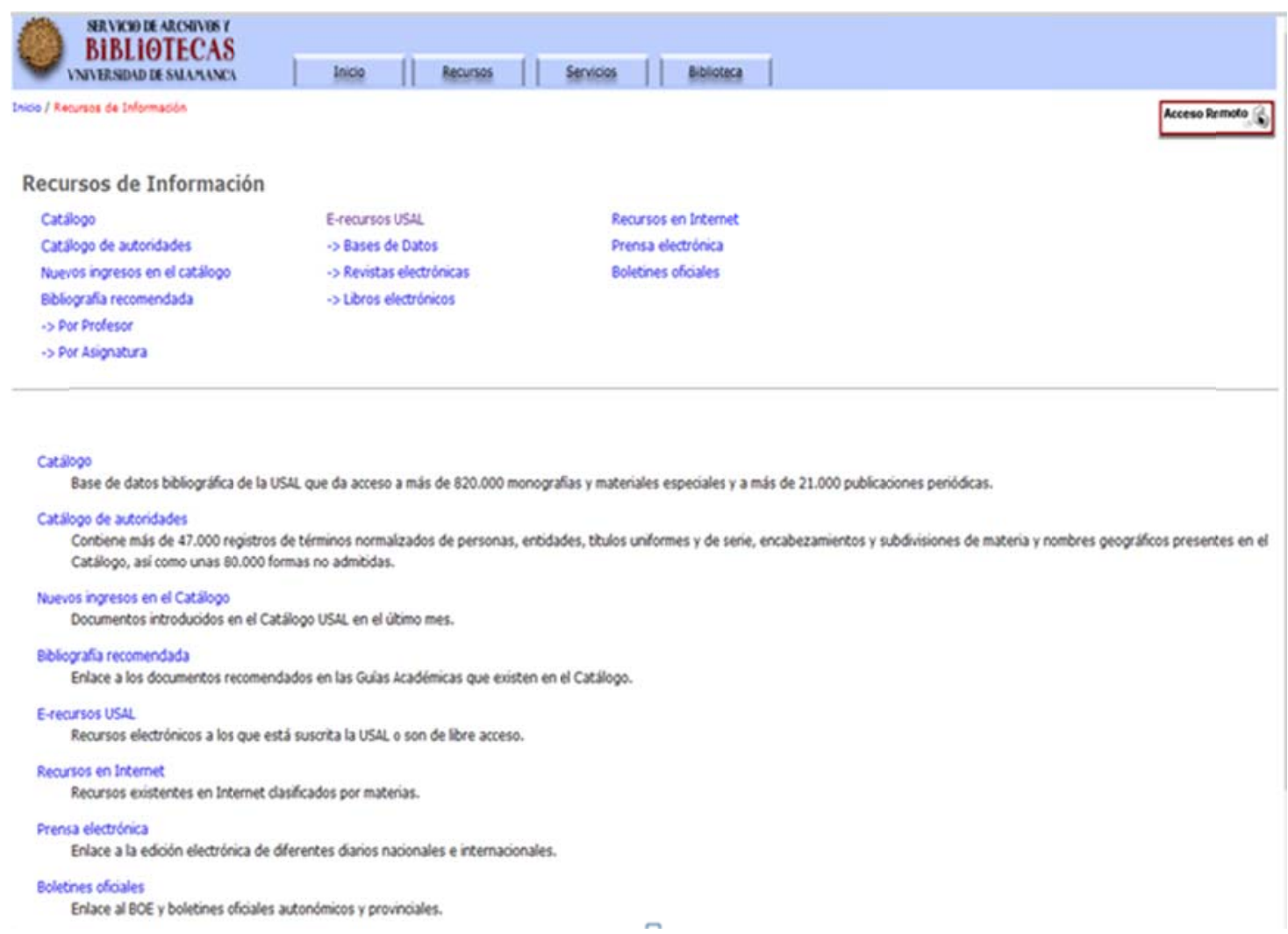




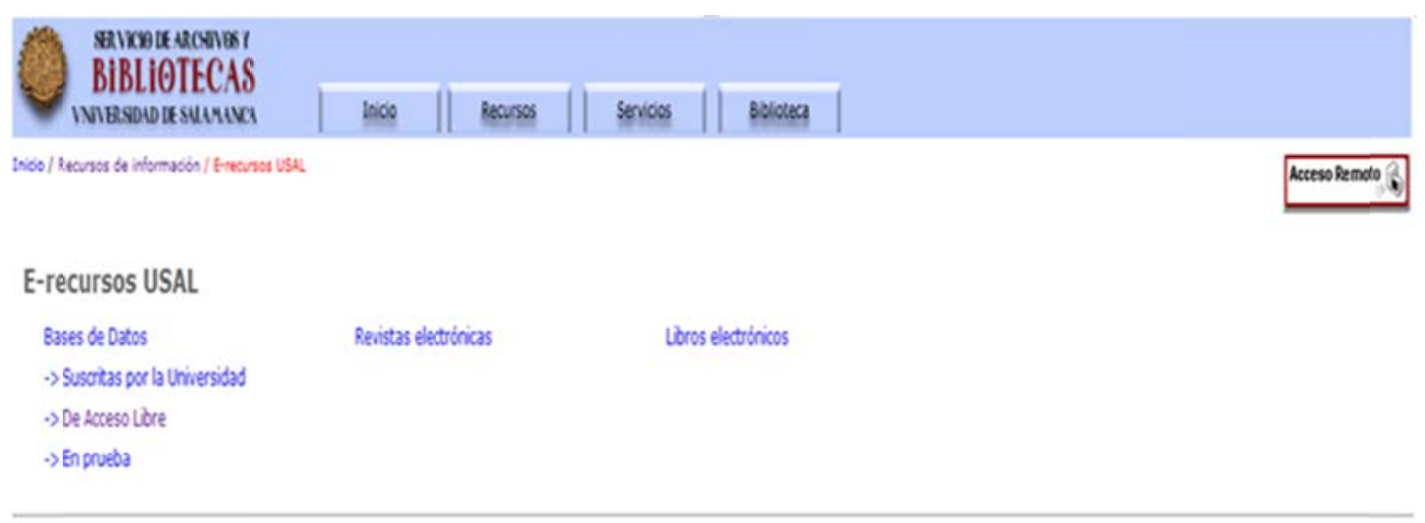

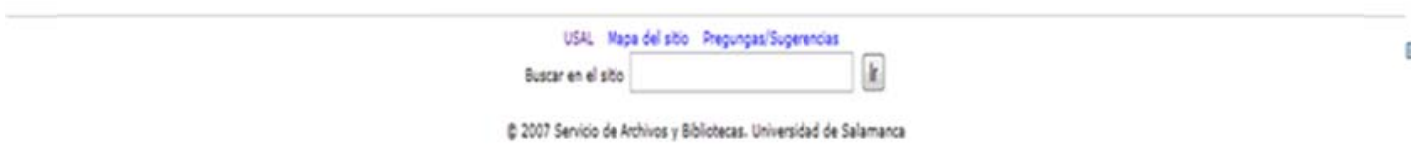

\begin{tabular}{|c|c|c|c|}
\hline 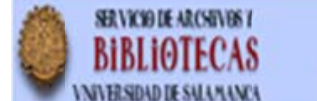 & & & \\
\hline 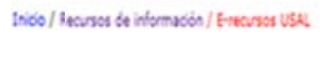 & & & Acteso Remento of \\
\hline E-recursos USAL & & & \\
\hline $\begin{array}{l}\text { Bases de Datos } \\
\rightarrow \text { Suscrtas oxc la universidad } \\
\rightarrow \text { De kcteso Lobe } \\
\rightarrow \text { En proveba }\end{array}$ & Renistas electrinicas & Lotros electricicos & \\
\hline
\end{tabular}

En cambio el nuevo sitio portal de SABUS, destina un sitio para Recursos que supera las debilidades del sitio anterior, ofreciendo de forma sistematizada un conjunto de opciones en forma de enlaces para llegar a las fuentes de información técnica y científica relevante, tanto por su contenido como en actualidad para el desarrollo de los programas educativos.

Desde la sección Recursos se organizan todos las posibilidades de acceso a la información, ya sea a través de catálogos o bases de datos o bien desde sistemas de localización de textos completos. Se observan recursos catalográficos, bases de datos y otros recursos electrónicos, así como enlaces externos, sobre todos en aquellos servicios en los que participa la Universidad de Salamanca. 


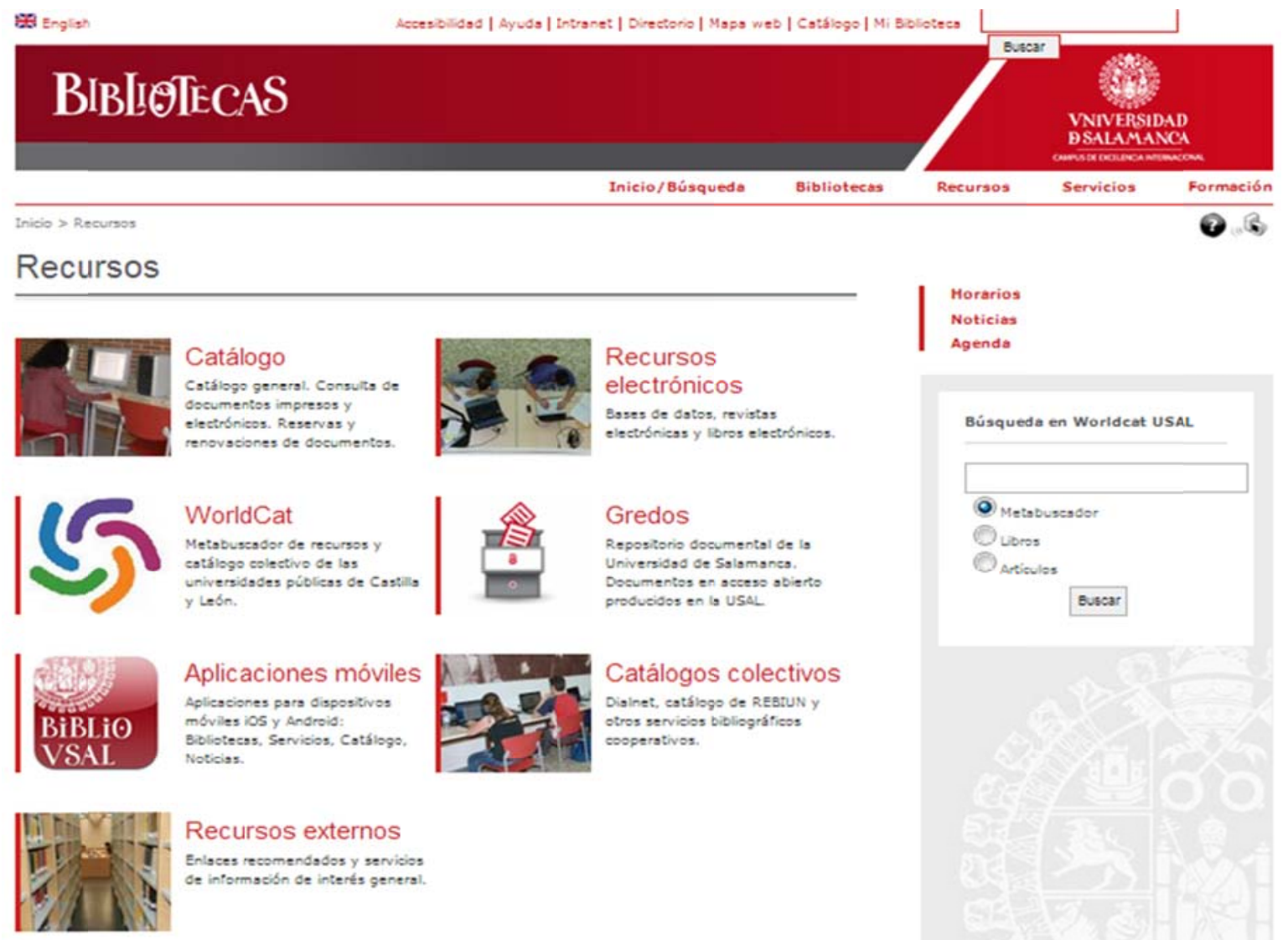

Figura 109. Repositorios para la educación- SABUS Nuevo portal.

Esta opción de "Recursos" concentra diferentes opciones de acceso a repositorios institucionales, nacionales y externos que se organizan de la siguiente manera:

\begin{tabular}{|c|c|c|c|}
\hline Recursos & Institucionales USAL & \multicolumn{2}{|c|}{ Colectivos y/o externos } \\
\hline $\begin{array}{l}\text { Los recursos de información de carácter o } \\
\text { valor científico generados de los resultados } \\
\text { de investigaciones académicas. (Artículos, } \\
\text { tesis, tesinas, etc. }\end{array}$ & Catálogo & \multicolumn{2}{|c|}{$\begin{array}{l}\text { BUCLE Worldcat } \\
\text { Dialnet } \\
\text { Otros }\end{array}$} \\
\hline $\begin{array}{l}\text { Recursos didácticos y pedagógicos para el } \\
\text { desarrollo de uno o varios contenidos } \\
\text { educativos }{ }^{184} \text {. } \\
\text { Los documentos están disponibles sin } \\
\text { restricciones. }\end{array}$ & $\begin{array}{l}\text { Repositorio Gredos } \\
\text { Revistas USAL } \\
\text { OCW }\end{array}$ & \multicolumn{2}{|c|}{$\begin{array}{l}\text { Recolecta } \\
\text { Hispana } \\
\text { OAISter y recolectores } \\
\text { Europeana }\end{array}$} \\
\hline $\begin{array}{l}\text { Bases de datos, revistas y libros electrónicos } \\
\text { Proyectos cooperativos. }\end{array}$ & Catálogos Colectivos & $\begin{array}{l}\text { REBIUN } \\
\text { Worldcat }\end{array}$ & $\begin{array}{l}\text { Dialnet } \\
\text { M. Cultura }\end{array}$ \\
\hline
\end{tabular}

Tabla 30.Organización de los recursos de apoyo a la enseñanza. Fuente: Elaboración propia.

\footnotetext{
${ }^{184}$ Nuevamente resulta relevante volver a mencionar que la Universidad dispone de aplicaciones OpenCourseWare en las que también están disponible materiales de aprendizaje (objetos de aprendizajes $\mathrm{OA}$ ).
} 
Dada la existencia de una diferencia entre ambos portales del SABUS; el análisis se limitó a la oferta del repositorio GREDOS ofrecido desde el nuevo Portal y que corresponde a los objetivos específicos planteados. El repositorio GREDOS dispone de servidor propio (http://gredos.usal.es) y se encuentra accesible desde la página principal, tanto de la propia Universidad de Salamanca, como desde el portal del Servicio de Bibliotecas, ya que es un recurso coordinado por este Servicio. Es importante destacar que GREDOS es el repositorio universitario de mayor volumen en España y el de este tipo que más aporta a Europeana. Además, la Universidad de Salamanca dispone de otro repositorio educativo OCW, que sigue las directrices internacionales para ofrecer materiales de asignaturas oficiales en acceso abierto. Los repositorios GREDOS y OCW están integrados, para que todos los materiales del repositorio OCW, de carácter docente, esté accesibles también desde GREDOS. EI repositorio de la USAL tiene una sección específica denominada Repositorio Docente desde la que da acceso a recursos de carácter didáctico.

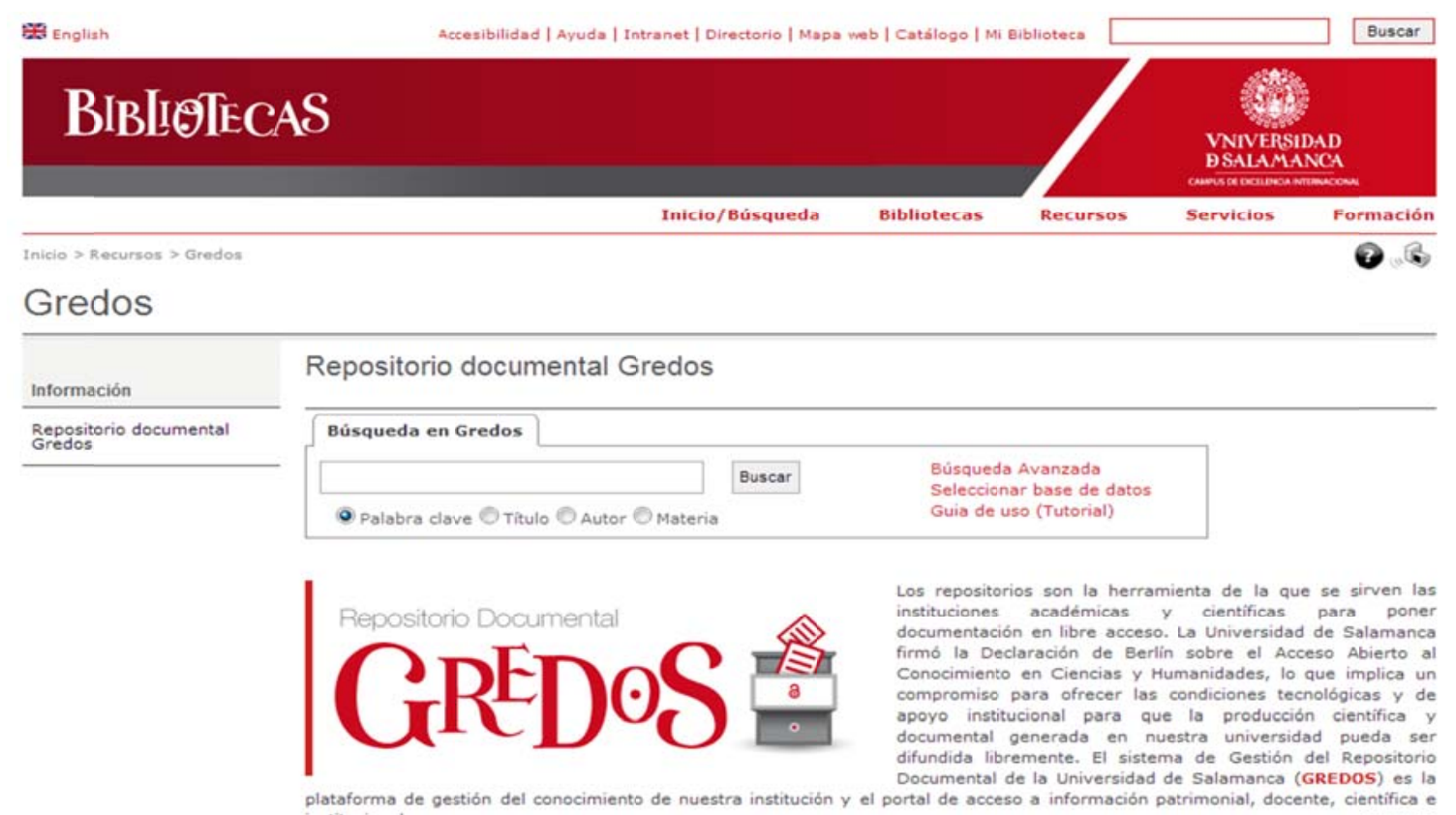

Figura 110. Visualización de la página de acceso al repositorio Gredos.

El repositorio GREDOS ${ }^{185}$ surge como una forma de participación al acceso abierto al conocimiento. El proyecto universitario es liderado por el Sistema de Bibliotecas de la Universidad y participan en él, los vicerrectorados, centros y los departamentos de la USAL. GREDOS se materializa como una plataforma para la gestión de contenidos - conocimiento y como un portal de acceso libre a la información institucional de alto contenido científico.

\section{Identidad del servicio}

El repositorio GREDOS es localizable desde el sitio oficial de la Universidad de Salamanca mediante el enlace "Repositorio Documental GREDOS", dentro del portal de SABUS y en Google bajo el termino GREDOS. En teoría los usuarios del servicio corresponden a la misma tipología del sistema de biblioteca, por las características del contenido, el servicio es mayormente demandado por parte de los docentes y estudiantes.

\footnotetext{
${ }^{185}$ Información extraída del sitio http://gredos.usal.es/jspui/. Consultada 30 noviembre 2012.
} 


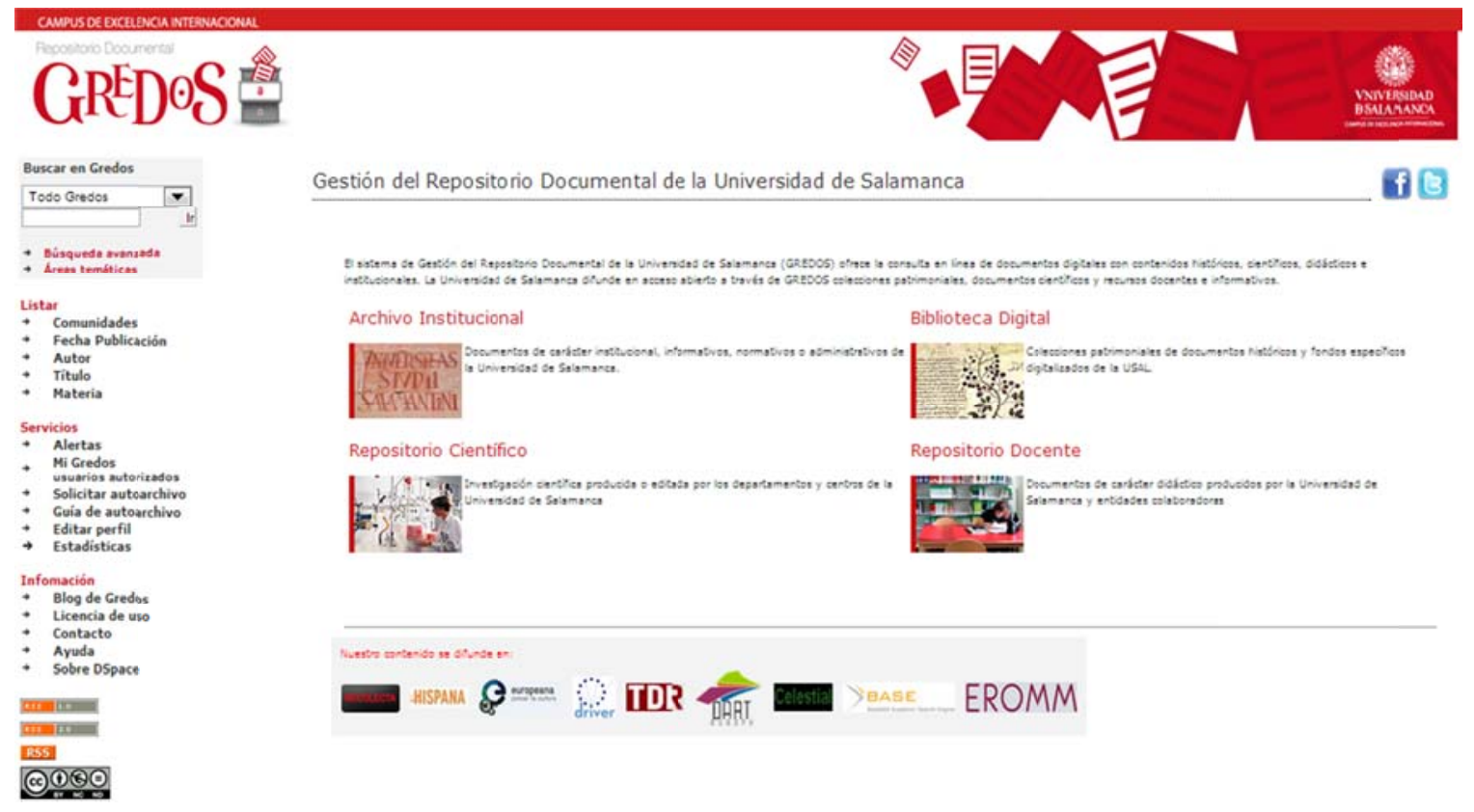

Figura 111. Repositorio Documental GREDOS.

\section{Actualización}

El sitio web no dispone de identificador de fecha de actualización, sin embargo partiendo de los resultados de una búsqueda en la que se introduce el año 2012 se constató que el repositorio se encuentra en constante actualización. Cada documento informa de la fecha en la que fue introducido y cada colección, además, ofrece enlaces destacados a las últimas aportaciones incluidas en cada uno de ellas.

\section{Accesibilidad}

No se observó ningún tipo de problemas de acceso y navegación durante las pruebas realizadas en repositorio GREDOS. El despliegue de los archivos generalmente ocurre en pdf que es un programa fácil de manejar y con altas facilidades para el desplazamiento dentro del contenido. El repositorio emplea la tecnología DSpace, que cumple estándares de accesibilidad.

\section{Servicios básicos del sitio}

El sitio posee una estructura lógica, amigable y de fácil uso. Los servicios básicos que se visualizan a lo inmediato son: directorio de recursos Web, objetos de aprendizaje, acceso a diversos metadatos, espacios personalizados, mapa del sitio, servicio de alerta, servicio de contacto y orientación al estudiante, sistema de ayuda, correo electrónico, aplicaciones RSS y blogs GREDOS.

\section{Contenido}

Los contenidos del repositorio están en correspondencia con los fines y objetivos educativos de la Universidad de Salamanca. Una prueba de búsqueda aleatoria realizada reflejó que los resultados obtenidos correspondieron en un $100 \%$ a la formulación. Las referencias despliegan suficiente información sobre la fuente y el contenido. Cada recurso de información se organiza con sus respectivos metadatos. En la siguiente figura se presenta un ejemplo de resultado de búsqueda, que 
muestra el cumplimiento de normativas estándares para la presentación de dlatos. En el siguiente ejemplo se evidencia el despliegue de las fuentes de ingreso y autoridad proveniente de los recursos.

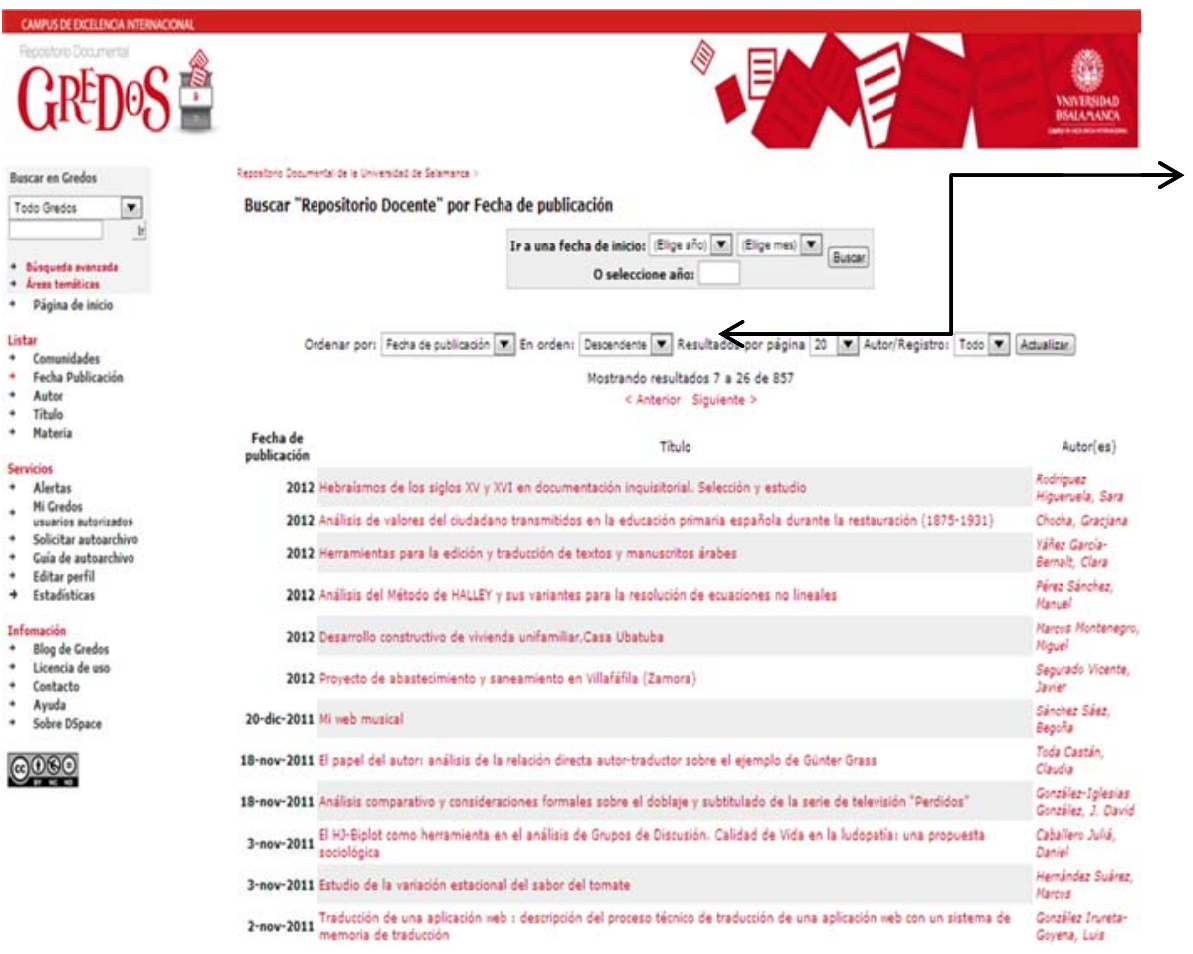

Delimitación de la búsqueda por fecha: año 2012 en orden descendente

Figura 112. Ejemplo de búsqueda por fecha
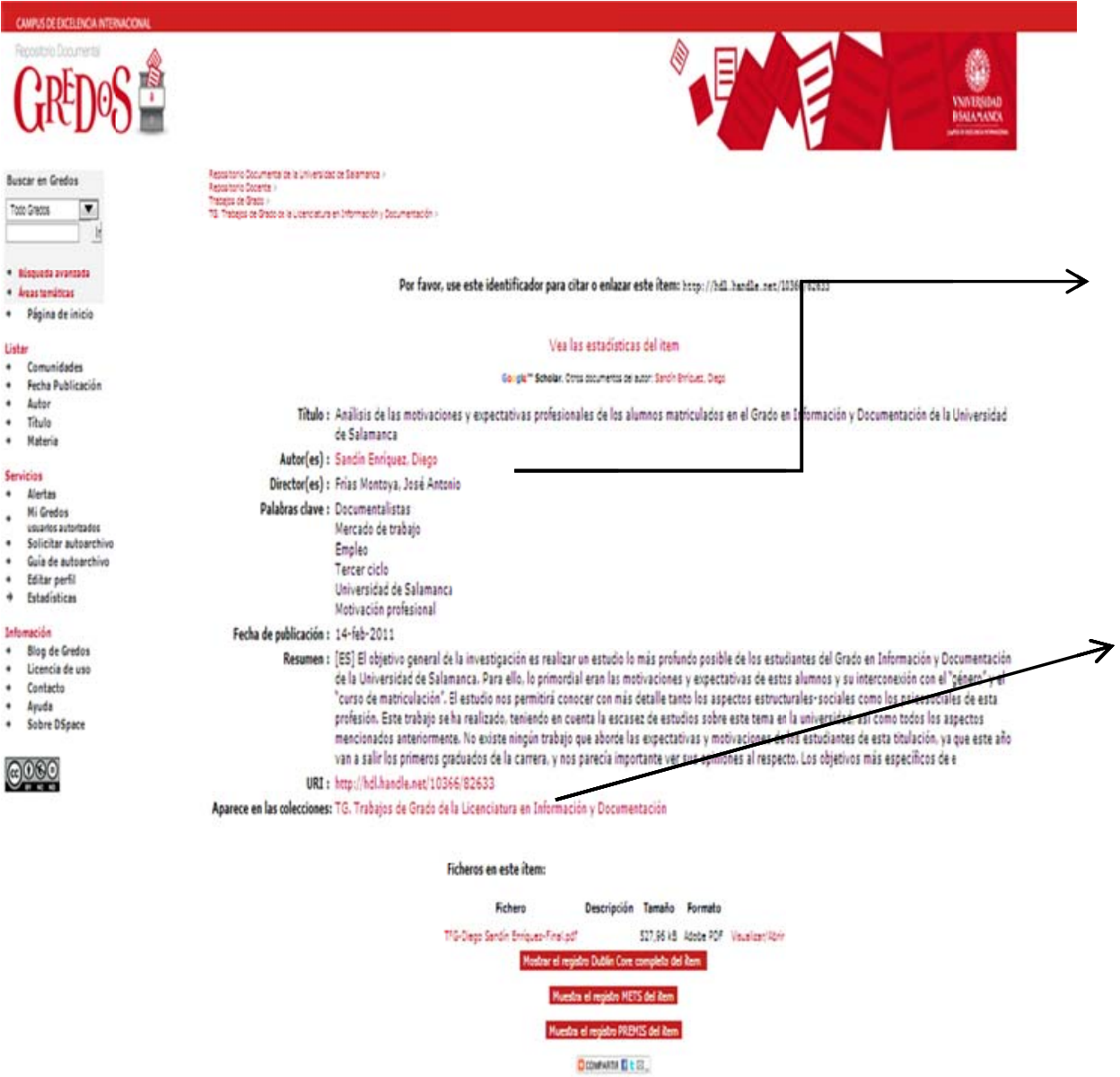

El metadato ofrece la posibilidad de acceder a más documentos del autor.

Se visualiza la posibilidad de recuperar el documento desde el fichero donde se encuentra.

Figura 113. Enlaces direccionales a otras fuentes y opción de formato de acceso al dlocumento. 


\section{Diseño de la interfaz}

La estructura básica del portal se organiza en cuatro áreas, cada una de las cuales aglutina diferentes tipos de contenidos y recursos:

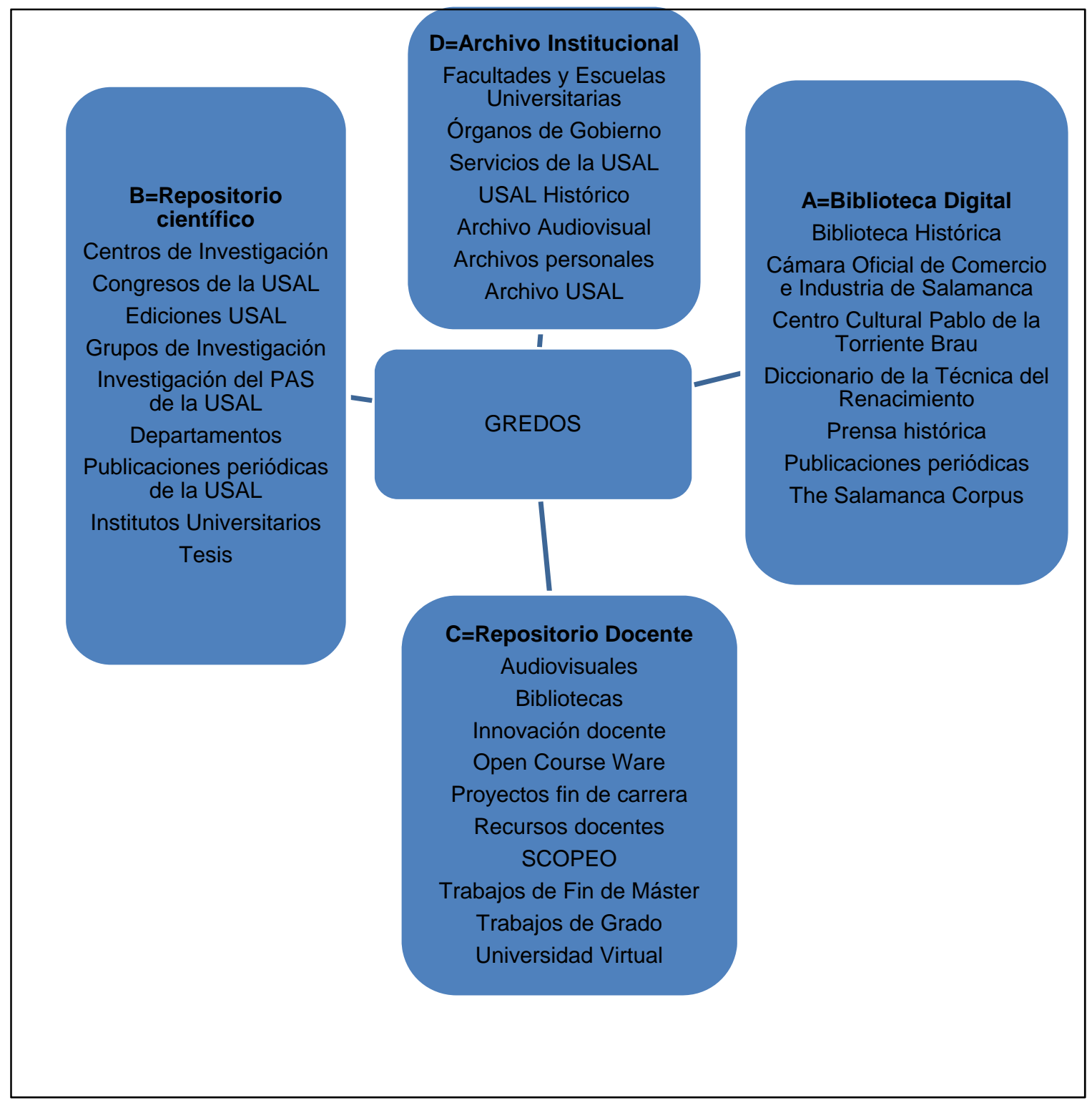

Figura 114. Recursos de GREDOS

Fuente: Elaboración propia.

A. Biblioteca digital Colecciones históricas y documentos de carácter patrimonial

B. Repositorio científico Tesis doctorales, o proyectos de fin de carrera, artículos editados en revistas científicas, publicaciones de Ediciones de la Universidad de Salamanca

C. Repositorio docente. Recursos de carácter didáctico - Objetos de aprendizajes

D. Archivo institucional. Documentos internos de la Universidad de Salamanca, generalmente de tipo administrativo

La consistencia entre colores, claridad o contraste adecuado entre el texto y el fondo, líneas de texto, tamaños y tipo de letras, anchura de pantalla, márgenes, legibilidad son elementos importantes en el diseño, así como la presencia de un medio para manifestar opiniones sobre el contenido de la Web a responsable o administrador. 


\section{Posicionamiento}

El servicio de repositorio del Servicio de Bibliotecas de la Universidad de Salamanca se proyecta como uno de los más importantes, por cuanto este ha sido conceptualizado como un proyecto universitario y no estrictamente de la Biblioteca, aunque sea ésta quien lo coordine. Este razonamiento se evidencia en el posicionamiento del servicio en la página principal del sitio Web de la Universidad. Asimismo una búsqueda formulada "repositorio universidad de Salamanca" proyectó en los diez primeros resultados enlaces relacionados con el URL del sitio de GREDOS. En la siguiente Figura se reflejan algunos de los resultados obtenidos.

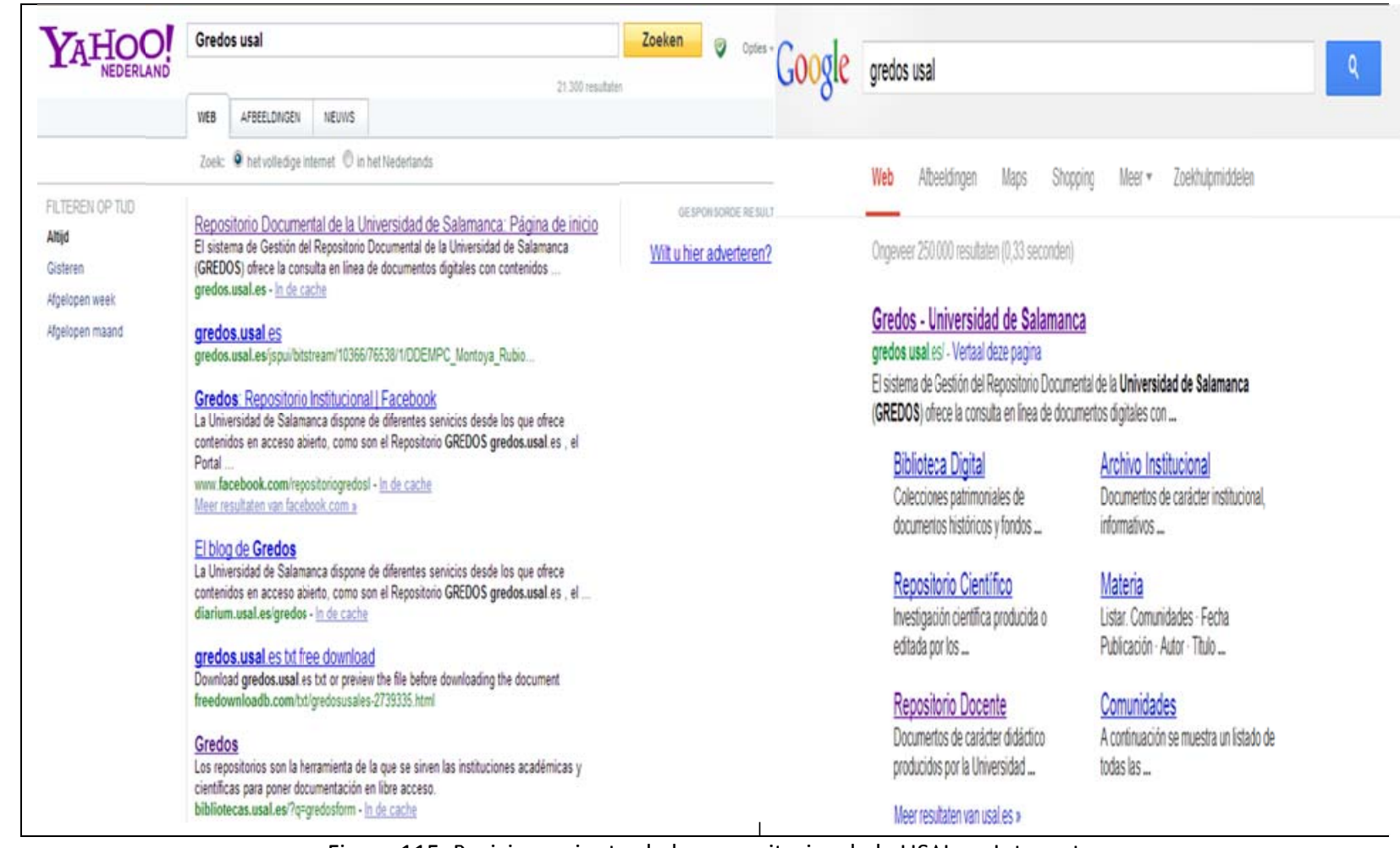

Figura 115. Posicionamiento de los repositorios de la USAL en Internet

\section{Sistema de búsqueda y recuperación}

El sitio GREDOS dispone de forma permanente de una opción de búsqueda. Se trata de una ventana permanente en el lado izquierdo superior que facilita realizar búsquedas sencillas por tipo de repositorio, tema y formular búsquedas más específicas (avanzadas). De forma complementaria a este motor de búsqueda se acompaña de un menú de enlaces que permiten selleccionar el orden en que se desea sean listados los resultados o desplazados a otro servicio dentro del sitio GREDOS.

Con el fin de ilustrar el funcionamiento del sistema, se presenta a continuación un ejemplo de búsqueda.

Repositorio específico: "repositorio científico"

Formulación de búsqueda: Término: educación electrónica

Listado deseado: Fecha de publicación

Orden: Descendente 


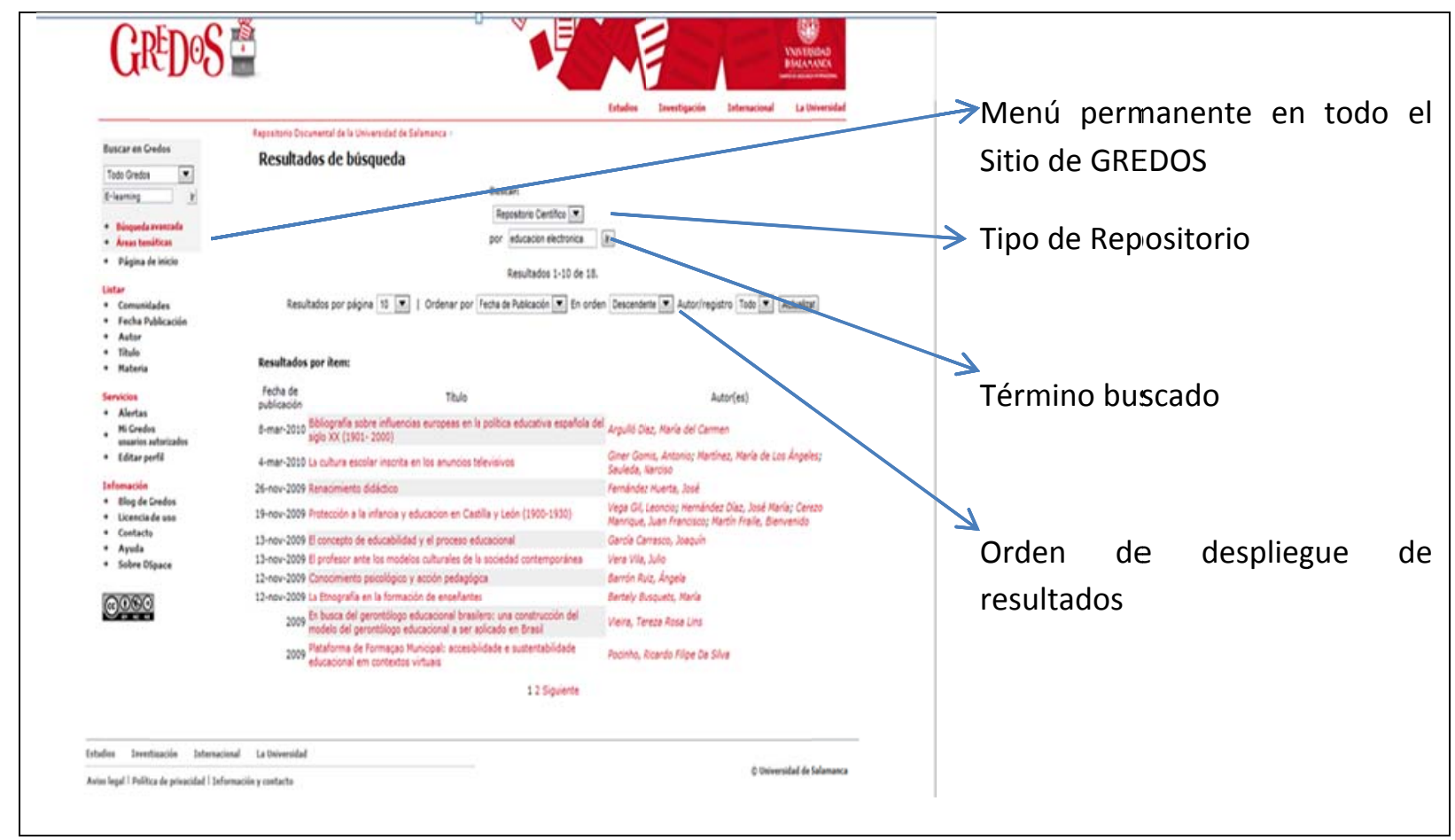

Figura 116. Sistema de búsqueda y recuperación de GREDOS.

El motor de búsqueda de GREDOS es capaz de localizar la información en todos los repositorios integrados en el sitio. El sistema identifica el término (controlado o no) en los contenidos de los recursos, descripción del recurso, términos controlados y libre por aproximación y permite el uso de operadores boléanos en búsquedas avanzadas. Los resultados siempre reflejan la descripción metadato de los recursos y la disponibilidad del formato.

\section{Usabilidad}

El uso del Servicio ofrecido por GREDOS es posible desde cualquier punto del interior o exterior de la entidad.

\section{Observación sobre las debilidades del sitio}

La web no ofrece funciones de ayuda al usuario. No se identificó facilidades para personas con limitaciones visuales y/o auditivas y el despliegue de dos ventanas de búsquedas puede generar confusiones al momento de navegar en la página Web del repositorio.

\subsubsection{Evaluación del servicio cursos de formación de usuarios (ALFIN)}

El presente análisis descriptivo y de funcionamiento, tiene como objetivo evidenciar el potencial que ofrece el "servicio de formación de habilidades y destrezas" ofrecido por la biblioteca como medio de apoyo a las actividades de formación con componentes E-learning.

\section{Identificación}

El Servicio de Bibliotecas de la Universidad de Salamanca ofrece estos servicios desde su página principal mediante el término enlace Formación, así como desde su Agenda de actividades. 


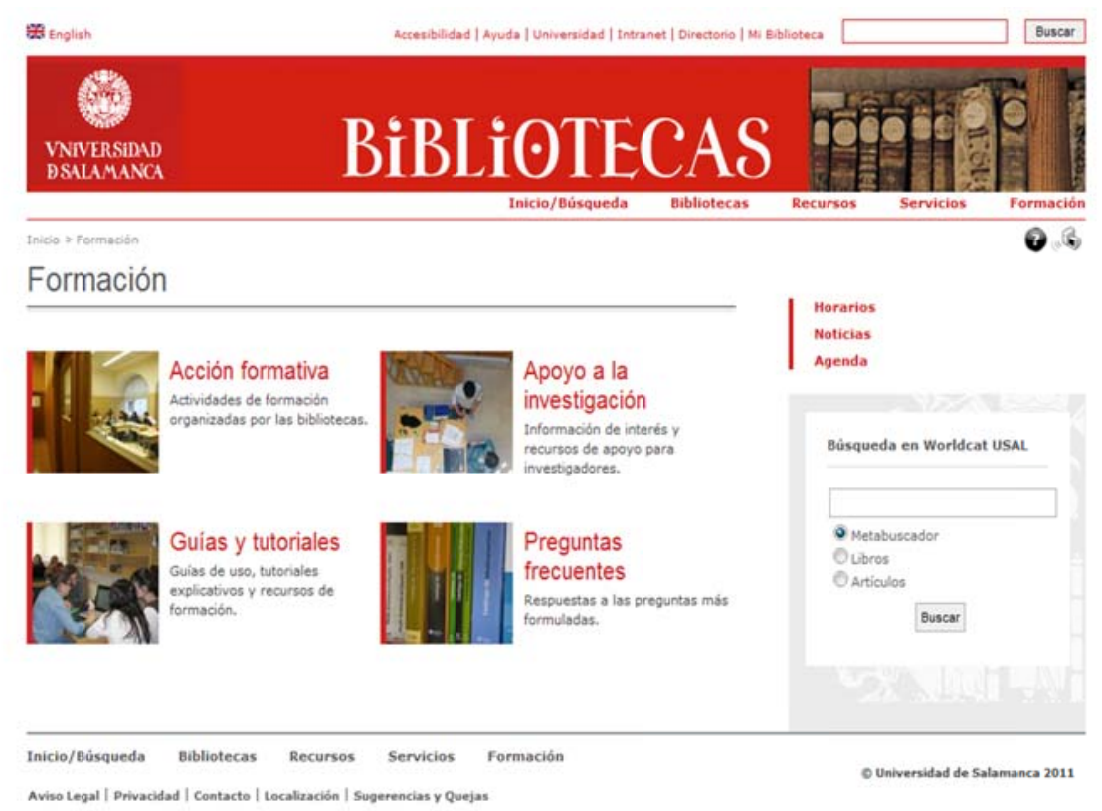

Figura 117. Servicio de Formación del Sistema de Bibliotecas de la Universidad de Salamanca

El servicio se presenta como una opción importante dentro del sub menú de Servicios, hecho por el cual dispone de un sitio web organizado en cuatro grandes grupos:

Grupo A. Corresponde a las actividades de formación general organizadas en forma de cursos presenciales sobre el uso de los recursos y servicios ofrecidos por la biblioteca. La oferta de este servicio se hace disponible en el sistema de "agenda", no obstante los usuarios pueden solicitar la organización de una sesión fuera de agenda.

Grupo B. Reúne la oferta de guías de uso, tutoriales, explicaciones y recursos de formación.

Grupo C. Corresponde a un servicio de respuesta predefinidas en correspondencia a preguntas formuladas de forma frecuente.

Grupo D. Oferta de servicios de información que por su contenido puede ser de apoyo en el desarrollo de actividades de investigación. Los servicios tienen como objetivo orientar el uso adecuado de los recursos de información, las técnicas de producción y publicación de información científica de acuerdo a los requerimientos estándares. En este contexto los contenidos del servicio se orientan a los siguientes temas:

- Factor de impacto - Instrumento utilizado para comparar y evaluar la importancia de las revistas dentro de un determinado campo científico.

- Acceso abierto - (open Access) Corresponde al servicio de orientación profesional sobre los diferentes recursos de información científicos disponibles de forma gratuita a texto completo 
- Acreditación - Ofrece información sobre herramientas y recursos estándares para la evaluación de las publicaciones científicas ${ }^{186}$.

- Propiedad intelectual - La información contenida en esta parte del servicio orienta sobre las normativas legales sobre la propiedad intelectual, derechos de autor, licencias entre otros aspectos específicos de la propiedad intelectual

- Elaboración de elaboración de trabajos científicos - Ofrece una completa guía organizada en partes que instruye y facilita la elaboración de trabajos académicos y de investigación. El contenido ofrecido desde esta página constituye un conjunto de materiales y recursos elaborados por entidades académicas de reconocimiento internacional. Las áreas centrales corresponden a los temas:

a. Búsqueda y localización de información

b. Evaluación de la información

c. Redacción

d. Remisión de fuentes de interés

- Citación y elaboración de bibliografías - Es una sesión que ofrece una serie de recursos elaborados por diferentes universidades españolas para el trabajo de citación y elaboración de bibliografías

- Técnicas de uso de programas (software) para citar información y/o fuentes (Endnote, Refworks) - Se trata de dos sitios diferentes para cada uno de los gestores de bibliografías en línea. Ambos sitios ofrecen una serie de recursos y documentos para el uso y manejo de estos programas.

Los usuarios del servicio de formación corresponden a toda la comunidad universitaria en la que se perfilan usuarios expertos y novatos, por tanto los contenidos de los cursos se organizan y adaptan en dependencia de la tipología de los usuarios.

\section{Actualidad}

Fue posible constatar la fecha de actualización del sitio mediante la presencia del indicador fecha del sitio, localizado en la parte inferior derecha: "2012". De igual forma, se aprecia la constante actualización en la agenda de actividades donde se oferta los de cursos.

\section{Accesibilidad}

No se experimentó ningún problema de acceso a la información sobre las actividades de ALFIN. EI acceso y navegación a los as sitio desde donde se ofrece los cursos ocurre de forma rápida entre enlaces, páginas, y texto resulta.

No obstante y como se ha indicado los cursos están orientados a un determinado grupo meta de usuarios. Estos grupos forman parte de la comunidad universitaria.

\footnotetext{
${ }^{186}$ Agencia de Evaluación de la Calidad y Acreditación (ANECA) y la Comisión Nacional Evaluadora de la Actividad Investigadora (CNEAI)
} 


\section{Servicios}

Los recursos informativos de los cuales se vale este servicio para el cumplimiento de su objetivo de formación corresponden a las guías, manuales, tutoriales, material académico de programas externos de otras entidades, Portales, RSS, Blogs colaborativos, y archivos. Otros servicios complementarios son las opciones de agenda, horarios de servicio, y noticias.

El servicio de formación ofrecido por el Sistema de Bibliotecas de la USAL ofrece básicamente los siguientes cursos:

- Cursos de orientación general a los servicios ofrecidos por el Servicio de Bibliotecas

- Cursos sobre técnicas de la realización de búsquedas en el catálogo de la biblioteca y otras en bases de datos externas

- Curso sobre manejo y uso de recursos informativos con propiedad y ética

- Curso sobre técnicas de citaciones

La actualización de los contenidos no fue posible de constatar, no obstante en el existe vigencia en la programación de los cursos en la opción Agenda.

\section{Contenido}

Algunos contenidos del sitio existe la posibilidad de acceder al contenido de la página en inglés. Los recursos de información ofrecidos son accesibles mediante enlaces que direcciona a la fuente que puede ser un documento en pdf, word, ppt, etc.

\section{Diseño de la interfaz}

A manera general y en correspondencia al análisis global del sitio Web portal del SABUS, el diseño resulta homogéneo al sitio principal de la Universidad de Salamanca. Se observa homogeneidad de estilos en cada una de las opciones de servicios, en el uso de márgenes, tipo y tamaño de letras, líneas de texto y ancho de pantalla. Se observa además un adecuado contraste entre el texto y el fondo, velocidad o tiempo de descarga de la publicación, y posibilidad de comunicarse con responsable o administrador del sitio.

El sitio web del servicio ALFIN cumplen con parámetros estándares de calidad, que facilitan el uso y re-uso de los recursos. Entre estos se destacan:

- Autoridad de autores reconocida

- Adscripción del autor a la organización que pertenece

- Correspondencia de objetivos

- Reconocimiento y credibilidad de la fuente

- Interconexión de los contenidos y las referencias bibliográficas, artículos.

- Navegación estructural. Es la posibilidad de realizar desplazamientos no secuenciales 


\section{Posicionamiento}

El servicio de "formación" no resulta fácil de recuperar en Internet. El término resulta general. En una búsqueda formulada y realizada en Google "ALFIN USAL", se obtuvo como resultados tres enlaces de sitios, que no forman parte o están presente en la página del servicio Formación.

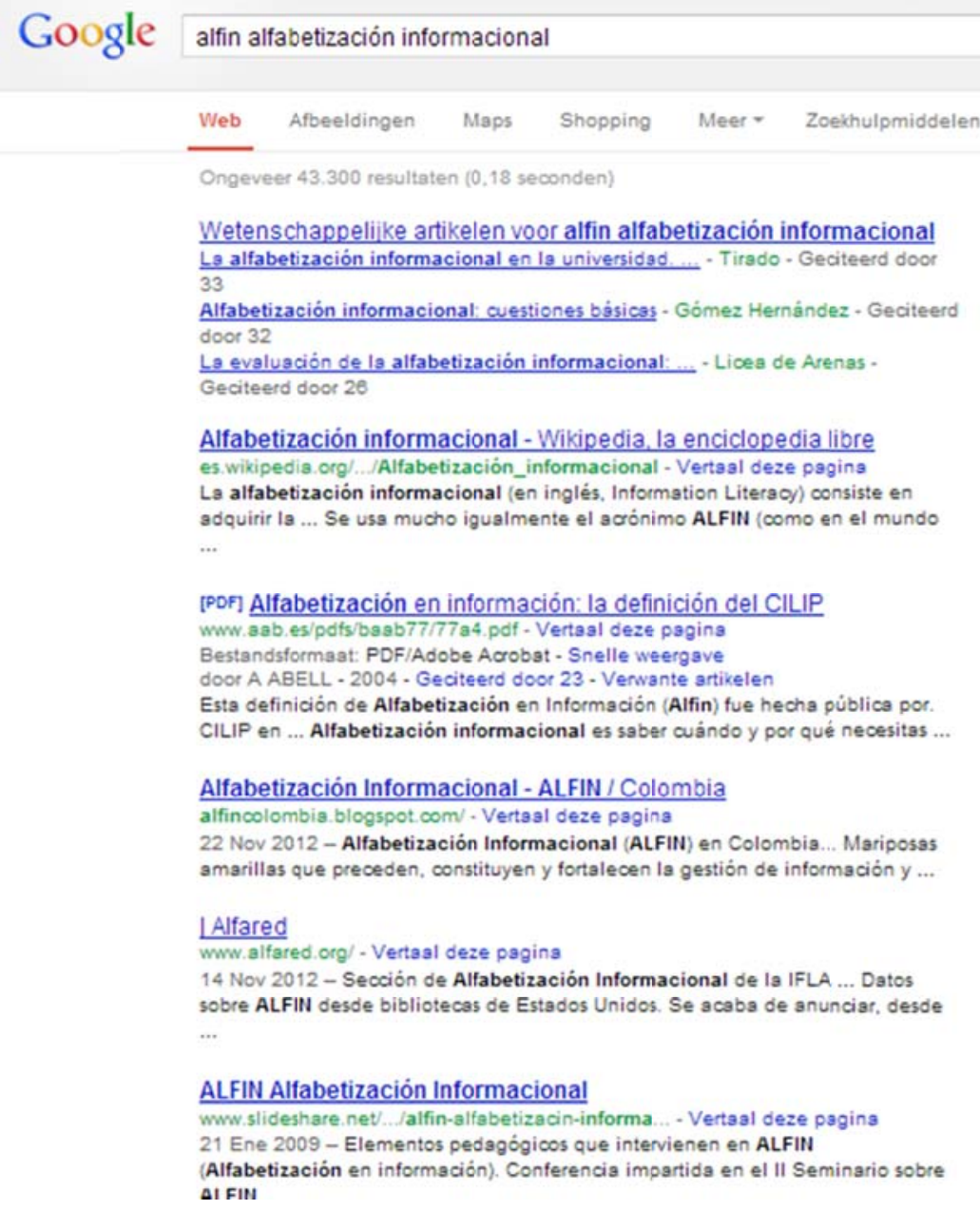

Figura 118. Resultado de búsqueda en Google (noviembre 2012)

\section{Sistema de búsqueda y recuperación}

El objetivo del servicio de formación es la capacitación del usuario en habilidades y destrezas transversales, no obstante, el sitio del servicio dispone de un sistema (ventana) de búsqueda es posible hacer consultas en el catálogo Worldcat de la USAL.

La presencia de este buscador permite vincular los recursos con la actividad de formación, facilitando y acortando procesos de búsquedas.

\section{Usabilidad}

No fue posible acceder a ninguno de los cursos desde el exterior de la entidad. Tampoco se identificó en el sitio la presencia de funciones de ayuda al usuario en el sitio de los cursos. 


\subsubsection{Análisis SWOT de la Universidad de Salamanca}

Los resultados de la evaluación del diseño y funcionamiento del Portal del SABUS reflejan la necesidad de un mejoramiento y/o ajuste de la oferta de los servicios hacia las nuevas demandas generadas en los en entornos virtuales de los cursos académicos en línea. Con el propósito de aportar a la delimitación de las áreas que requieren ser atendidas, a continuación ofrece una visión general de las fortalezas y debilidades de la actual oferta de servicios analizados en este estudio de $\operatorname{casos}^{187}$.

\section{Fortalezas}

El SABUS se distingue a lo interno de la Universidad, regional y nacional como un sistema de bibliotecas con valiosos recursos históricos, académicos. Asimismo su participación activa en tareas formativas dentro de la Red de Bibliotecas Universitarias de España, le atribuyen un estatus de credibilidad y profesionalismo.

La introducción de la modalidad E-learning dentro de la Universidad de Salamanca genera una nueva demanda de servicios en línea que puede ser aprovechada por el SABUS para ampliar su oferta de servicios.

La ubicación del repositorio "Gredos" como proyecto universitario representa ser un antecedente de credibilidad del potencial de la biblioteca para la prestación de servicios en línea.

El actual momento de constitución y transición hacia un nuevo diseño del portal del SABUS, consecuente con el diseño del sitio Web de la Universidad, representa ser un momento oportuno para integrar nuevas aplicaciones Web 2.0.

\section{Oportunidades}

La implementación de un sistema de educación europeo que propicia las posibilidades de cambios en las ofertas de servicios.

La participación de la Universidad y del Sistema de Bibliotecas en proyectos de trabajo colaborativo a lo interno de país, Europa e

\section{Debilidades}

- La participación del Sistema de Bibliotecas en procesos de formativos a través de sus servicios en línea en su totalidad no es aprovechada.

- Todavía no se han explorado las posibilidades de constituir una sinergia entre el E-learning y el SABUS.

- El diseño del sitio Portal antiguo y nuevo del Sistema de Bibliotecas se encuentra en fase evolutiva y podría incorporar aplicación dinámicas como:

- Es necesario la introducción de elementos de comunicación sincrónica y asincrónicas

- Integración de opciones (pestañas de ayuda) que ofrezcan mayor información sobre los enlaces

- Incorporación de facilidades para personas con incapacidades físicas

Incremento de posibilidades de recuperación de los servicios en Internet

\section{Amenazas}

- La carencia de una visión sistémica (conceptual y práctica) podría ser un limitante para el reconocimiento de las fortalezas $y$ oportunidades existentes, para el desarrollo y/o mejoramiento de la actual oferta de servicios ofrecidos en línea.

\footnotetext{
${ }^{187}$ Metodología SWOT Strengths, Weaknesses, Opportunities, Threats (Fortalezas, Debilidades, Oportunidades y Amenazas) conocido también en el habla hispana como "FODA"
} 
internacional, le permite un aprendizaje permanente de las diferentes experiencias de modelos de servicios en línea introducidas en plataformas E-learning. Esta coyuntura puede ser aprovechada para el desarrollo de una nueva forma de organización y oferta de servicios para los programas y proyectos Eelearning de USAL.

Las actuales experiencias de participación en la elaboración de materiales didácticos, tutoriales y cursos resultan una premisa para edificar relaciones de cooperación formal con las facultades y sus departamentos.
- Poco o nula presencia y participación del Sistema de Bibliotecas en discusiones y/o en iniciativas o proyectos E-learning, pueden ser causa de una clara exclusión de su participación. - La poca anticipación y pro actividad de la biblioteca en el proceso cambio institucional, reduce la posibilidad de posicionarse como una unidad de apoyo en los nuevos proyectos universitarios.

- El desconocimiento de la demanda ( y sus variantes) de los usuarios virtuales, representa un peligro para la generación de servicios con contenidos acordes a las necesidades actuales

\section{Conclusiones - SABUS}

El nuevo sitio del SABUS se caracteriza por su sólida estructura organizativa, la consistencia con el modelo institucional y el cumplimiento de estándares. La fusión de estos tres servicios analizados en una sola oferta de servicios orientada a la modalidad E-learning en la Web del SABUS es una oportunidad para generar una viable sinergia entre la biblioteca y el E-learning. Con el objetivo de aportar a la revisión de los actuales puntos débiles en el diseño del sitio, se sugiere dar atención a los siguientes aspectos:

\begin{tabular}{|l|l|l|}
\hline $\begin{array}{l}\text { Servicio de } \\
\text { referencia }\end{array}$ & $\begin{array}{l}\text { Proyección de servicio } \\
\text { - Se carece de visión clara y sistémica } \\
\text { del servicio. }\end{array}$ & $\begin{array}{l}\text { - Se carece de un sistema dinámico } \\
\text { de comunicación sincrónica. (Eje. } \\
\text { Chat) }\end{array}$ \\
& $\begin{array}{l}\text { - Se requiere establecer vínculos } \\
\text { dentro del sitio con las otras } \\
\text { opciones vinculadas al servicio de } \\
\text { referencia. }\end{array}$ & $\begin{array}{l}\text { - Ausencia de opciones de ayuda } \\
\text { (pestañas con mensajes con } \\
\text { información complementaria sobre } \\
\text { los enlaces. }\end{array}$ \\
& $\begin{array}{l}\text { - La oferta del servicio de referencia } \\
\text { servicio de la biblioteca de la USAL. }\end{array}$ & $\begin{array}{l}\text {-Inexistencia de facilidades para } \\
\text { personas con incapacidades visuales } \\
\text { y auditivas }\end{array}$ \\
\hline $\begin{array}{l}\text { Servicio de } \\
\text { formación }\end{array}$ & $\begin{array}{l}\text { Proyección de servicio } \\
\text { - La información sobre oferta no } \\
\text { resulta atractiva y/o novedosa. }\end{array}$ & $\begin{array}{l}\text { Aplicaciones tecnológicas } \\
\text { - Insuficiencia de información sobre } \\
\text { las aplicaciones tecnológicas } \\
\text { disponibles para la práctica de este } \\
\text { servicio }\end{array}$ \\
\hline - Se requiere fortalecer la estrategia \\
de mercado
\end{tabular}




\begin{tabular}{|l|l|l|}
\hline & $\begin{array}{l}\text { - No es visible la oferta de cursos } \\
\text { básicos estructurados en forma de } \\
\text { tutoriales }\end{array}$ & $\begin{array}{l}\text { usuario (pestañas con mensajes } \\
\text { cortos y rápidos) que orienten o } \\
\text { complemente información sobre los } \\
\text { contenidos de los enlaces }\end{array}$ \\
& $\begin{array}{l}\text { - Se desconoce la oferta incluida } \\
\text { como parte de créditos } \\
\text { - La oferta de “formación" no } \\
\text { alcanza posicionamiento como } \\
\text { servicio de la USAL y/o SABUS en la } \\
\text { Internet }\end{array}$ & $\begin{array}{l}\text { - Ausencia de facilidades para } \\
\text { personas con incapacidades visuales } \\
\text { y auditivas }\end{array}$ \\
\hline $\begin{array}{l}\text { Repositorios } \\
\text { educación }\end{array}$ & $\begin{array}{l}\text {-La oferta del servicio se presenta en } \\
\text { el sitio de la USAL y del SABUS bien } \\
\text { estructurado y desarrollado. }\end{array}$ & $\begin{array}{l}\text { Las aplicaciones tecnológicas se } \\
\text { consideran adecuadas y acordes a la } \\
\text { oferta. }\end{array}$ \\
\hline
\end{tabular}




\subsection{Revisión general de los estudios de casos}

\subsubsection{Perspectiva exterior de las bibliotecas}

La evaluación de los tres servicios propuestos en el modelo, tuvo como punto de partida el análisis de sitio de las bibliotecas consideradas muestras en el estudio de caso. El resultado de este análisis permitió constatar que las seis instituciones disponen de adecuados diseños con servicios básicos.

Las variantes significativas ocurren en la atención prestada a los aspectos de visibilidad e identidad de la biblioteca dentro del sitio, uso de indicadores para indicar la actualización del sitio y la liberta para acceder o no a todos los lugares del sitio. Con el objetivo de ilustrar lo antes referido, en la siguiente tabla se ofrece un resumen general del estado actual de los sitios-portales de las bibliotecas analizadas.

\begin{tabular}{|c|c|c|c|c|c|c|}
\hline Parámetros & BWUR & BTUD & BEARTH & BUMCE & BUS & SABUS \\
\hline Identidad & $\begin{array}{l}\text { No visible } \\
\text { desde la } \\
\text { página } \\
\text { principal de } \\
\text { la } \\
\text { universidad }\end{array}$ & $\begin{array}{l}\text { Claramente } \\
\text { visible en la } \\
\text { página } \\
\text { principal de } \\
\text { la } \\
\text { universidad }\end{array}$ & $\begin{array}{l}\text { Claramente } \\
\text { visible en la } \\
\text { página } \\
\text { principal de } \\
\text { la universidad }\end{array}$ & $\begin{array}{l}\text { No visible } \\
\text { desde la } \\
\text { página } \\
\text { principal de la } \\
\text { universidad }\end{array}$ & $\begin{array}{l}\text { No visible } \\
\text { desde la } \\
\text { página } \\
\text { principal de } \\
\text { la } \\
\text { universidad }\end{array}$ & $\begin{array}{l}\text { Visible desde } \\
\text { la página } \\
\text { principal de } \\
\text { la } \\
\text { universidad }\end{array}$ \\
\hline Actualización & $\begin{array}{l}\text { Indicador } \\
\text { visible }\end{array}$ & $\begin{array}{l}\text { Indicador } \\
\text { visible }\end{array}$ & $\begin{array}{l}\text { Indicador } \\
\text { visible }\end{array}$ & $\begin{array}{l}\text { Indicador } \\
\text { visible }\end{array}$ & $\begin{array}{l}\text { No es visible } \\
\text { el indicador } \\
\text { de fecha }\end{array}$ & $\begin{array}{l}\text { Indicador } \\
\text { visible }\end{array}$ \\
\hline Posicionamiento & $\begin{array}{l}\text { Se requiere } \\
\text { dar atención }\end{array}$ & $\begin{array}{l}\text { Reconocimie } \\
\text { nto } \\
\text { institucional }\end{array}$ & $\begin{array}{l}\text { Se requiere } \\
\text { dar atención }\end{array}$ & $\begin{array}{l}\text { Reconocimien } \\
\text { to } \\
\text { institucional }\end{array}$ & $\begin{array}{l}\text { Reconocimie } \\
\text { nto } \\
\text { institucional }\end{array}$ & $\begin{array}{l}\text { Reconocimie } \\
\text { nto } \\
\text { institucional }\end{array}$ \\
\hline Navegación & $\begin{array}{l}\text { Sin } \\
\text { problemas }\end{array}$ & $\begin{array}{l}\text { Sin } \\
\text { problemas }\end{array}$ & $\begin{array}{l}\text { Sin } \\
\text { problemas }\end{array}$ & Sin problemas & $\begin{array}{l}\text { Sin } \\
\text { problemas }\end{array}$ & $\begin{array}{l}\text { Sin } \\
\text { problemas }\end{array}$ \\
\hline Acceso & Restringido & $\begin{array}{l}\text { Abierto pero } \\
\text { con } \\
\text { restricción a } \\
\text { los de ALFIN }\end{array}$ & Restringido. & $\begin{array}{l}\text { Abierto pero } \\
\text { con restricción } \\
\text { a los de ALFIN }\end{array}$ & $\begin{array}{l}\text { Abierto pero } \\
\text { con } \\
\text { restricción a } \\
\text { los de ALFIN }\end{array}$ & Restringido \\
\hline Servicios básicos & Excelente & Excelente & Excelente & Excelente & Excelente & Excelente \\
\hline $\begin{array}{l}\text { Contenido } \\
\text { (general) }\end{array}$ & $\begin{array}{l}\text { Acorde a los } \\
\text { objetivos }\end{array}$ & $\begin{array}{l}\text { Acorde a los } \\
\text { objetivos }\end{array}$ & $\begin{array}{l}\text { Acorde a los } \\
\text { objetivos }\end{array}$ & $\begin{array}{l}\text { Acorde a los } \\
\text { objetivos }\end{array}$ & $\begin{array}{l}\text { Acorde a los } \\
\text { objetivos }\end{array}$ & $\begin{array}{l}\text { Acorde a los } \\
\text { objetivos }\end{array}$ \\
\hline
\end{tabular}

Tabla 32. Estado de los sitios de las bibliotecas - Estudio de casos. Fuente: Elaboración propia.

La realización del estudio de caso ha permitido constatar que los servicios se han desarrollo de una manera paralela a los cambios tecnológicos, y nuevas demandas de formatos y formas de transmisión de información.

Asimismo es posible constatar que existe un mayor desarrollo en la prestación del servicio de ALFIN y el Servicio de Referencia digital en relación con el servicio de Repositorios para la educación (OA). Hecho que ocurre ya que la idea de los repositorios $\mathrm{OA}$ es una iniciativa reciente y resultante de los últimos avances tecnológicos y aplicaciones de social media. 


\subsubsection{Diseños de sitio web y portales de las bibliotecas}

Los resultados del estudio de casos han demostrado que las experiencias de servicios en línea de las dos bibliotecas universitarias ubicadas en los Países Bajos (BTUD) y España (BUS) presentan un excelente diseño del sitio y mayor experiencia en las aplicaciones de las plataformas E-learning. Se evidencia mayor uso de recursos tecnológicos para comunicación sincrónica y uso de aplicaciones diversas para presentación de contenidos. Se reconoce además una mayor oferta de repositorios para la educación. La biblioteca de la Universidad de Sevilla (BUS) se destaca por su dinámica plataforma de comunicación para la prestación del servicio de referencia y por el alto desarrollo de programas ALFIN.

El sistema de bibliotecas de la Universidad de Salamanca (SABUS) en su nuevo portal dispone de nuevas facilidades para el proceso de comunicación, la prestación de servicios y el uso de la información misma. El portal de repositorios (GREDOS) es un recurso dinámico y de contenido valioso para la educación e investigación que puede servir de referencia para iniciativas como esta en otras universidades.

La biblioteca de la Universidad Metropolitana de Ciencias de la Educación (BUMCE) se dispone de una desarrollada infraestructura tecnológica que es utilizada para la prestación de servicios de formación de usuarios, la gestión de recursos electrónicos internos y externos sobre el tema de educación y el servicio de referencia.

La biblioteca de la Universidad EARTH (BEARTH) experimenta un menor desarrollo en los tres servicios analizados y esto ocurre debido a las limitaciones económicas institucionales, que impactan en la capacidad adquisitiva de recursos tecnológicos con mayores capacidades para la gestión de contenidos. Sin embargo los servicios son ofertados y utilizados por los estudiantes. Una alternativa de los gestores de estos servicios ha sido el uso de los recursos social media gratuitos para y facilitar procesos de comunicación dinámicos con los usuarios y difundir los servicios y recursos existentes en la biblioteca.

De forma general el diseño de los servicios de las bibliotecas es considerado adecuado y con tendencia a mejorar dadas las coyunturas de cambios en el desarrollo de los recursos tecnológicos (programas y equipos) y de las nuevas facilidades para el desarrollo de procesos de comunicación y prestación de servicios en línea.

Durante la evaluación de los servicios se observó que algunos sitios no cumplen en su totalidad con la aplicación del estándar, motivo por el cual hay carencia de indicadores de fecha, derechos de autoría, problemas de visibilidad causado por el inadecuado uso colores, fondos, etc. Asimismo se observa la tendencia al uso de meta-buscadores para integrar acciones de búsquedas en todas las bases de datos existentes. Seguidamente se presenta una tabla sinóptica del estado de los diseños de los sitios - portal de las seis bibliotecas analizada en el estudio de casos.

\begin{tabular}{|c|c|c|c|c|c|c|}
\hline Parámetros & BWUR & BTUD & BEARTH & BUMCE & BUS & SABUS \\
\hline $\begin{array}{l}\text { Diseño del } \\
\text { sitio }\end{array}$ & $\begin{array}{l}\text { Adecuado } \\
\text { pero puede } \\
\text { ser mejorado: } \\
\text { Carece de }\end{array}$ & $\begin{array}{l}\text { Excelente } \\
\text { Incorpora } \\
\text { elementos } \\
\text { ergonómicos, }\end{array}$ & $\begin{array}{l}\text { Adecuado } \\
\text { pero puede } \\
\text { ser mejorado } \\
\text { Carece de }\end{array}$ & $\begin{array}{l}\text { Adecuado } \\
\text { pero carece } \\
\text { de algunos } \\
\text { componentes } \\
\text { para personas }\end{array}$ & $\begin{array}{l}\text { Excelente. } \\
\text { Cumplimiento } \\
\text { de } \\
\text { estándares. }\end{array}$ & $\begin{array}{l}\text { Excelente. } \\
\text { El nuevo sito } \\
\text { del sistema } \\
\text { de bibliotecas }\end{array}$ \\
\hline
\end{tabular}




\begin{tabular}{|c|c|c|c|c|c|c|}
\hline & $\begin{array}{l}\text { componentes } \\
\text { para personas } \\
\text { con } \\
\text { limitaciones } \\
\text { físicas } \\
\text { Carece de } \\
\text { elementos de } \\
\text { comunicación } \\
\text { sincrónico }\end{array}$ & $\begin{array}{l}\text { uso de } \\
\text { recursos } \\
\text { social media } \\
\text { tanto para la } \\
\text { presentación } \\
\text { de contenidos } \\
\text { como para } \\
\text { procesos de } \\
\text { comunicación } \\
\text { sincrónica }\end{array}$ & $\begin{array}{l}\text { algunos } \\
\text { componentes } \\
\text { para personas } \\
\text { con } \\
\text { limitaciones } \\
\text { físicas } \\
\text { Carece de } \\
\text { elementos de } \\
\text { comunicación } \\
\text { sincrónico } \\
\text { Carece de } \\
\text { opciones para } \\
\text { agilizar el } \\
\text { desplazamien } \\
\text { to dentro de } \\
\text { la Web }\end{array}$ & $\begin{array}{l}\text { con } \\
\text { limitaciones } \\
\text { físicas } \\
\text { Poco flexible } \\
\text { para realizar } \\
\text { acciones en } \\
\text { diferentes } \\
\text { maneras } \\
\text { Carece de } \\
\text { elementos de } \\
\text { comunicación } \\
\text { sincrónico }\end{array}$ & $\begin{array}{l}\text { Se caracteriza } \\
\text { como un sitio, } \\
\text { dinámico, } \\
\text { flexible y } \\
\text { sencillo. }\end{array}$ & $\begin{array}{l}\text { supera las } \\
\text { limitaciones } \\
\text { del sitio } \\
\text { anterior, no } \\
\text { obstante } \\
\text { carece de } \\
\text { medios para } \\
\text { la } \\
\text { comunicación } \\
\text { sincrónica. }\end{array}$ \\
\hline $\begin{array}{l}\text { Sistema de } \\
\text { búsqueda }\end{array}$ & $\begin{array}{l}\text { Se requiere } \\
\text { contar con un } \\
\text { solo meta } \\
\text { buscador }\end{array}$ & $\begin{array}{l}\text { Dispone de } \\
\text { un sistema } \\
\text { integrador de } \\
\text { búsqueda }\end{array}$ & $\begin{array}{l}\text { No existe un } \\
\text { sistema de } \\
\text { búsqueda } \\
\text { integrado. El } \\
\text { usuario debe } \\
\text { realizar } \\
\text { búsquedas en } \\
\text { cada base de } \\
\text { datos y / o } \\
\text { catálogo }\end{array}$ & Excelente & Excelente & Excelente \\
\hline $\begin{array}{l}\text { Usabilidad de } \\
\text { los recursos }\end{array}$ & $\begin{array}{l}\text { Limitado solo } \\
\text { a miembros } \\
\text { de la } \\
\text { comunidad } \\
\text { Universitaria } \\
\text { Las } \\
\text { entrevistas } \\
\text { con los } \\
\text { docentes } \\
\text { destacan } \\
\text { cierto nivel de } \\
\text { desconocimie } \\
\text { nto de la } \\
\text { oferta por } \\
\text { parte de los } \\
\text { usuarios }\end{array}$ & $\begin{array}{l}\text { Limitado solo } \\
\text { a miembros } \\
\text { de la } \\
\text { comunidad } \\
\text { Universitaria } \\
\text { No fue } \\
\text { posible } \\
\text { evaluar la } \\
\text { comportamie } \\
\text { nto y } \\
\text { satisfacción } \\
\text { de los } \\
\text { usuarios }\end{array}$ & $\begin{array}{l}\text { Limitado solo } \\
\text { a miembros } \\
\text { de la } \\
\text { comunidad } \\
\text { Universitaria } \\
\text { No fue } \\
\text { posible } \\
\text { evaluar la } \\
\text { comportamie } \\
\text { nto y } \\
\text { satisfacción } \\
\text { de los } \\
\text { usuarios }\end{array}$ & $\begin{array}{l}\text { Limitado solo } \\
\text { a miembros } \\
\text { de la } \\
\text { comunidad } \\
\text { Universitaria } \\
\text { No fue } \\
\text { posible } \\
\text { evaluar la } \\
\text { comportamie } \\
\text { nto y } \\
\text { satisfacción } \\
\text { de los } \\
\text { usuarios }\end{array}$ & $\begin{array}{l}\text { Limitado solo } \\
\text { a miembros } \\
\text { de la } \\
\text { comunidad } \\
\text { Universitaria } \\
\text { No fue } \\
\text { posible } \\
\text { evaluar la } \\
\text { comportamie } \\
\text { nto y } \\
\text { satisfacción } \\
\text { de los } \\
\text { usuarios }\end{array}$ & $\begin{array}{l}\text { No fue } \\
\text { posible } \\
\text { evaluar la } \\
\text { comportamie } \\
\text { nto y } \\
\text { satisfacción } \\
\text { de los } \\
\text { usuarios }\end{array}$ \\
\hline
\end{tabular}




\subsubsection{Servicios de referencia digital}

El servicio de referencia digital o virtual orientado a proceso de enseñanza electrónica exige un servicio básico para el desarrollo de procesos de comunicación sincrónica. Sin embargo durante el estudio se observa que la oferta se limita a mecanismos asincrónicos a través de correo electrónico, servicio de mensajería y preguntas frecuentes.

De las seis bibliotecas universitarias solamente la biblioteca de la Universidad de Sevilla y la Universidad Tecnológica de Delft disponían del servicio sincrónico en forma de chat. Como resultado de pruebas realizadas se constató que en ambas casos resulta ser un servicio dinámico y eficiente.

En la siguiente tabla se presente un los recursos más utilizados para procesos de comunicación en la oferta del Servicio de Referencia.

\begin{tabular}{|l|l|l|l|l|l|l|}
\hline $\begin{array}{l}\text { Recursos para la } \\
\text { comunicación }\end{array}$ & \multicolumn{1}{|c|}{ BWUR } & BTUD & BEARTH & BUMCE & BUS & SABUS \\
\hline Email & $\mathrm{SI}$ & $\mathrm{SI}$ & $\mathrm{SI}$ & $\mathrm{SI}$ & $\mathrm{SI}$ & $\mathrm{SI}$ \\
\hline Chat & $\mathrm{NO}$ & $\mathrm{SI}$ & $\mathrm{NO}$ & $\mathrm{NO}$ & $\mathrm{SI}$ & $\mathrm{NO}$ \\
\hline $\begin{array}{l}\text { Formulario de } \\
\text { preguntas }\end{array}$ & $\mathrm{SI}$ & $\mathrm{SI}$ & $\mathrm{SI}$ & $\mathrm{SI}$ & $\mathrm{SI}$ & $\mathrm{SI}$ \\
\hline $\begin{array}{l}\text { Preguntas } \\
\text { frecuentes }\end{array}$ & $\mathrm{SI}$ & $\mathrm{SI}$ & $?$ & $\mathrm{SI}$ & $\mathrm{SI}$ & $\mathrm{SI}$ \\
\hline
\end{tabular}

Tabla 34. Recursos mayormente utilizados para procesos de Comunicación Estudio de casos. Fuente: Elaboración propia

Los programas utilizados por las bibliotecas para desarrollar servicios en línea corresponden a generalmente a iniciativas ocurridas a lo interno de departamentos o bibliotecas facultativas. Cabe destacar que el impacto positivo de estas prácticas ha permitido que estas sean incorporadas a nivel del y Sistema de Bibliotecas.

Las aplicaciones identificadas en el estudio de caso han sido desarrolladas mayormente en los siguientes programas: Facebook, LCM y multimedia para gestión de Objetos de Aprendizaje, Blog, Portales, Flickr, Twitter, Wikis, RSS, Google académico, Linkedin y teléfonos. Las diferencias entre aplicaciones a nivel de cada institución obedecen a limitaciones de orden económico que limitan la adquisición de equipo, programas o contratación de personal, así como el pago por el acceso a publicaciones en línea.

En el caso específico de las Universidad Metropolitana de Ciencias de la Educación (UMCE) de Chile y La Universidad Earth de Costa Rica han logrado un significativo avance en lo relacionado con el uso de plataformas E-learning. Ellos han iniciado a trabajar con el programa Moodle que es gratuito, para el desarrollo de actividades ALFIN. Asimismo, estos, superan la limitación presupuestaria para acceder a los repositorios de revistas científicas, mediante el establecimiento de relaciones de cooperación regional e internacional. 


\subsubsection{Servicios de alfabetización informacional}

El servicio de formación de usuario en el ámbito de las universidades resulta necesario a fin de estimular destrezas y adquirir competencias transversales de información para que los individuos en formación puedan acceder a la información adecuada y hacerla útil. Durante el desarrollo de esta investigación se constató que el uso de los servicios de apoyo a procesos de enseñanza - aprendizaje e investigación centraron su mayor atención al ¿qué?, ¿cómo encontrar? y el uso mismo de la información.

En este contexto los servicios básicos en línea que actualmente presenta la biblioteca son el servicio de referencia digital, la formación de habilidades, destrezas y competencias (ALFIN) y el acceso a los repositorios. En la siguiente tabla se describe a manera general a estructura y recursos tecnológicos utilizados para la prestación de este servicio.

\begin{tabular}{|c|c|c|c|c|c|c|}
\hline $\begin{array}{l}\text { Recursos para el } \\
\text { desarrollo de los } \\
\text { cursos }\end{array}$ & BWUR & BTUD & BEARTH & BUMCE & BUS & SABUS \\
\hline \multicolumn{7}{|c|}{ Plataforma y/o programa para E-learning } \\
\hline $\begin{array}{l}\text { Plataforma E- } \\
\text { learning }\end{array}$ & Blackboard & Blackboard & Moodle & Moodle & Moodle & Moodle \\
\hline Foros de discusión & $\mathrm{SI}$ & $\mathrm{SI}$ & $\mathrm{SI}$ & SI & SI & SI \\
\hline Videos conferencias & NO & NO & NO & NO & NO & NO \\
\hline \multicolumn{7}{|c|}{ Recursos para la gestión y seguimiento } \\
\hline Chat & $\mathrm{SI}$ & $\mathrm{SI}$ & $\mathrm{SI}$ & $\mathrm{SI}$ & $\mathrm{SI}$ & $\mathrm{SI}$ \\
\hline Correo electrónico & $\mathrm{SI}$ & $\mathrm{SI}$ & $\mathrm{SI}$ & $\mathrm{SI}$ & $\mathrm{SI}$ & $\mathrm{SI}$ \\
\hline Lista de discusión & $\mathrm{SI}$ & SI & $\mathrm{SI}$ & $\mathrm{SI}$ & $\mathrm{SI}$ & $\mathrm{SI}$ \\
\hline \multicolumn{7}{|c|}{ Recursos para la enseñanza - aprendizaje } \\
\hline Tutoriales & $\mathrm{SI}$ & $\mathrm{SI}$ & $\mathrm{SI}$ & $\mathrm{SI}$ & $\mathrm{SI}$ & $\mathrm{SI}$ \\
\hline $\begin{array}{l}\text { Videos } \\
\text { demostrativos }\end{array}$ & $\mathrm{SI}$ & $\mathrm{SI}$ & NO & NO & $\mathrm{SI}$ & $\mathrm{SI}$ \\
\hline $\begin{array}{l}\text { Objetos (recursos) } \\
\text { de aprendizajes }\end{array}$ & $\mathrm{SI}$ & $\mathrm{SI}$ & $\mathrm{SI}$ & $\mathrm{SI}$ & $\mathrm{SI}$ & $\mathrm{SI}$ \\
\hline \multicolumn{7}{|c|}{ Sistema de búsqueda } \\
\hline $\begin{array}{l}\text { Sistema meta } \\
\text { buscador en } \\
\text { diferentes bases de } \\
\text { datos }\end{array}$ & $\mathrm{SI}$ & $\mathrm{SI}$ & NO & NO & $\mathrm{SI}$ & $\mathrm{SI}$ \\
\hline $\begin{array}{l}\text { Catálogo de la } \\
\text { biblioteca }\end{array}$ & $\mathrm{SI}$ & $\mathrm{SI}$ & $\mathrm{SI}$ & $\mathrm{SI}$ & $\mathrm{SI}$ & $\mathrm{SI}$ \\
\hline Otras bases de datos & $\mathrm{SI}$ & $\mathrm{SI}$ & SI & $\mathrm{SI}$ & $\mathrm{SI}$ & $\mathrm{SI}$ \\
\hline $\begin{array}{l}\text { Repositorios en } \\
\text { temáticas } \\
\text { especializadas }\end{array}$ & $\mathrm{SI}$ & $\mathrm{SI}$ & NO & NO & $\mathrm{SI}$ & $\mathrm{SI}$ \\
\hline
\end{tabular}

Tabla 35. Estructura y recursos tecnológicos del de ALFIN - Estudio de casos. 


\subsubsection{Repositorios para la educación}

El desarrollo de repositorios orientados hacia fines educativos y de investigación surge en primer instancia como una alternativa al problema de acceso a recursos académicos causados por la baja en los presupuestos universitarios para acceder a recurso científicos y en posteriormente ante la necesidad de recursos didácticos (objetos de aprendizajes, $O A$ )) en formato electrónico disponibles en línea. Aunque la iniciativa de los repositorios OA es relativamente nueva, fue posible constatar iniciativas de proyectos universitarios a nivel nacional en España y los Países Bajos.

En el caso de Chile existen iniciativas locales ${ }^{188}$ pero todavía no involucra la participación de todas las universidades chilenas. Durante el análisis de caso se identificó que la BUMCE no oferta este servicio de forma directa. Este se ubica como parte del servicio de Referencia. En el caso específico de la BEARTH los repositorios se son conceptualizados como el conjunto compuesto por el catálogo, base de datos internos y suscritos.

\begin{tabular}{|c|c|c|c|c|c|c|}
\hline $\begin{array}{l}\text { Estado de los } \\
\text { Repositorios }\end{array}$ & BWUR & BTUD & BEARTH & BUMCE & BUS & SABUS \\
\hline $\begin{array}{l}\text { Reconocimiento } \\
\text { en la web }\end{array}$ & $\begin{array}{l}\text { No } \\
\text { directamen } \\
\text { te. } \\
\text { Los } \\
\text { repositorios } \\
\text { se ubican } \\
\text { dentro la } \\
\text { opción de } \\
\text { servicio } \\
\text { "portales" }\end{array}$ & SI & $\begin{array}{l}\text { SI/NO } \\
\text { El termino se } \\
\text { destaca pero } \\
\text { no } \\
\text { corresponden } \\
\text { a concepto } \\
\text { manejado en } \\
\text { la } \\
\text { investigación }\end{array}$ & $\begin{array}{l}\text { NO } \\
\text { Directamente. Se } \\
\text { oferta recursos } \\
\text { para la educación } \\
\text { que se localizan } \\
\text { en servicio de } \\
\text { acceso a "Bases } \\
\text { de datos" } \\
\text { termino no } \\
\text { corresponden a } \\
\text { concepto } \\
\text { manejado en la } \\
\text { investigación }\end{array}$ & $\mathrm{SI}$ & $\mathrm{SI}$ \\
\hline $\begin{array}{l}\text { Repositorio } \\
\text { institucionales } \\
\text { (proyectos } \\
\text { nacionales) }\end{array}$ & $\mathrm{SI}$ & $\mathrm{SI}$ & & $\begin{array}{l}\text { SI } \\
\text { En el momento } \\
\text { del estudio no } \\
\text { tenía } \\
\text { participación }\end{array}$ & $\mathrm{SI}$ & $\mathrm{SI}$ \\
\hline $\begin{array}{l}\text { Portales Open } \\
\text { Access }\end{array}$ & $\mathrm{SI}$ & $\mathrm{SI}$ & $\mathrm{SI}$ & $\mathrm{SI}$ & $\mathrm{SI}$ & $\mathrm{SI}$ \\
\hline $\begin{array}{l}\text { Repositorio de } \\
\text { Objetos de } \\
\text { Aprendizaje }\end{array}$ & $\mathrm{SI}$ & $\mathrm{SI}$ & NO & NO & $\mathrm{SI}$ & $\mathrm{SI}$ \\
\hline Tutoriales & $\mathrm{SI}$ & $\mathrm{SI}$ & NO & $\mathrm{SI}$ & $\mathrm{SI}$ & $\mathrm{SI}$ \\
\hline $\begin{array}{l}\text { Suscripción a } \\
\text { repositorios } \\
\text { externos }\end{array}$ & $\mathrm{SI}$ & $\mathrm{SI}$ & $\mathrm{SI}$ & $\mathrm{SI}$ & $\mathrm{SI}$ & $\mathrm{SI}$ \\
\hline
\end{tabular}

${ }^{188}$ Véase http://ticedu.fondef.cl/documentos/pdf/Informe_Final_APROA.pdf. 


\subsubsection{Puntos de atención: análisis DAFO/SWOT}

El análisis DAFO/SWOT permitió identificar algunos aspectos que permiten afirmar que el modelo propuesto en esta tesis, puede ser implementado en la actual coyuntura de cambios a nivel de las universidades europeas (tratado de Bolonia), así como parte del proceso de modernización de las universidades latinoamericanas.

Con el objetivo de fundamentar esta afirmación, a continuación se presentan las fortalezas, debilidades, oportunidades y amenazas identificadas a nivel general durante el análisis evaluativo de la muestra de este estudio.

\section{Fortalezas}

- Las entidades educativas están dispuesta a invertir en la mejora de sus ofertas educativas y en la búsqueda de un mejor posicionamiento a nivel nacional e internacional de su actividad formativa e investigación.

- Las transformaciones ocurridas en las formas de gestión de las Universidades de Europa y América Latina se concentran en el fortalecimiento de infraestructura tecnológica y relaciones de cooperación, a fin de ampliar la oferta de modalidades de formación académico. Hecho que obliga a las autoridades la revisión y mejora de los servicios ofrecidos por parte de las universidades, así como el desarrollo de nuevos servicios y productos digitales acordes.

- La existencia actual de los servicios en línea ofrecidos por la biblioteca facilita la implementación del modelo propuesto en la presente tesis en los programas de formación semipresencial y E-learning. Esto resulta ser viable, dadas las capacidades existentes de la biblioteca para la elaboración y gestión de materiales multimedia que pueden ser utilizados como recursos de apoyo en el proceso de enseñanza aprendizaje, y actividades docentes e investigación.

\section{Oportunidades}

- El aprovechamiento de las prácticas de proyectos e iniciativas regionales e internacionales relacionados con el acceso abierto y la alfabetización informacional puede ser considerado el punto de partida para la implementación del modelo propuesto en esta tesis doctoral.

- La biblioteca asume nuevas funciones en la formación en el uso de colecciones electrónicas, digitalización de recursos existentes y la generación de nuevos servicios en línea acordes a los nuevos programas educativos y flexibles modalidades de enseñanza ofrecidas por la universidad. En este contexto, la existencia de estos recursos electrónicos representa ser la materia prima para el diseño e implementación de nuevos servicios en línea.

- La incorporación de programas de educación a distancia semipresencial y la modalidad Elearning en las universidades, permitió constatar, la demanda por parte de los docentes de contar con recursos de información electrónicos con contenidos acordes a los cursos académicos. Esta nueva demanda representa ser otro argumento justificativo para el 
replanteamiento de la organización de los servicios hacia una nueva forma de ofertar la gestión de contenidos especializados.

- La apropiación de la credibilidad y experiencias ganadas con los cursos y prácticas orientados a la formación de usuarios, desarrollados por la biblioteca como materias o partes dentro de determinados programas de estudios, resulta ser el antecedente estratégico para la implementación del modelo sugerido en esta tesis.

\section{Debilidades}

- Se requiere un mayor posicionamiento de la biblioteca dentro de la Universidad. Debe darse mayor aprovechamiento de las aplicaciones de los social media para generar nuevos medios para la difusión y proyección de los servicios (tareas de marketing).

- Se evidencia poca presencia de la biblioteca dentro de nuevos proyectos de docencia con modalidad E-learning. Es necesario generar ofertas concretas de participación y/o cooperación en las tareas educativas. En esta línea el modelo propuesto podría ser una alternativa para fortalecer o generar la sinergia entre la biblioteca y las actividades semipresenciales y Elearning.

- No se establace un patrón de diseño específico. En todas las instituciones analizadas, se desconoce si el diseño del servicio de referencia cumple con las normativas WAI.

- La visibilidad no es la deseable. En algunos casos, se identifican poca o nula presencia de mecanismos de ayuda para los usuarios, tales como uso de pestañas que indiquen información descriptiva sobre los enlaces mismos. Asimismo, destaca poca presencia de mecanismo para indicar al usuario como regresar a la página anterior.

-Existe una carencia de sistemas atractivos de apoyo a los docentes. Un ejemplo es el servicio de comunicación directa entre el docente y el bibliotecario para que éste pueda expresar sus necesidades de información y a la vez estimular su interés para incorporar los servicios de la biblioteca en sus plataformas de estudio.

- El acceso al sitio web de algunas bibliotecas analizadas ${ }^{189}$ no incluye aplicaciones para ser utilizado por personas con incapacidades físicas, auditivas y/o visuales; no obstante la información obtenida a partir de la entrevista se evidenció la existencia de computadores con hardware en software y periféricos especializados.

\section{Amenazas}

- Los riesgos y amenazas se centran en la necesidad de fortalecer el involucramiento directo de la biblioteca en las actividades de educativas de la universidad. Para esto es necesario superar las limitaciones identificadas, que en definitiva, representan ser significabas amenazas para el

\footnotetext{
${ }^{189}$ Este aspecto es superado significamente por las bibliotecas de la Universidad de Sevilla, Universidad Tecnológica de Delft.
} 
funcionamiento eficiente y eficaz de cualquier nueva o ya existente propuesta de servicio por parte de la biblioteca. Los tipo de amenazadas detectados son los siguientes:

a.- Problemas internos de comunicación dentros de la universidad.

b. - Poco involucramiento de la biblioteca en proyectos E-learning.

c. - Escaso aprovechamiento de la cooperación internacional.

d. - Problemas internos de motivación para asumir los retos.

e. - Falta de visión sistémica (conceptual y práctica) por parte de los líderes en proceso de evaluación de servicios y necesidades. Se requiere mayor consulta de docentes, estudiantes y líderes.

f.- Escasa atención a los cambios ocurridos en los entornos, que podría generar una actitud menos proactiva por parte de la biblioteca.

g.- Poca atención a las iniciativas externas relacionadas con nuevas ofertas y gestión de servicios digitales, políticas nacionales e internacional de acceso abierto entre otros, influyentes en el aumento o disminución de la calidad de servicios y productos ofrecidos por la biblioteca.

h- Crisis económica a nivel mundial, que podría influir en la reducción de presupuesto para la generación y sostenibilidad de los servicios de información.

i- Poca presencia y participación de las bibliotecas en discusiones a nivel de gestores, podría ocasionar un distanciamiento de la biblioteca de las actividades educativas. Asimismo podría generar desconocimiento de la demanda real. Se requiere mayor consulta a docentes, estudiantes y líderes sobre sus necesidades y demandas de información y servicios. 


\section{PARTE V APLICACIÓN PRÁCTICA, CONCLUSIONES Y RECOMENDACIONES}

Una vez analizada la viabilidad teórica y práctica de implementar la propuesta de modelo de oferta de servicio presentada en esta tesis doctoral, en las siguientes páginas de la Parte $\mathbf{V}$ se establece la aplicación práctica de la relación entre servicios bibliotecarios y enseñanza telemáticos. El Capítulo 8 ofrece una guía básica y práctica para el diseño y aplicación flexible del modelo de oferta de servicio en línea orientado a las modalidades de educación semipresencial y E-learning. El objetivo de la inclusión de la guía en esta tesis es establecer un marco de referencia que sirva para contribuir al redireccionamiento de las actuales iniciativas de servicios ofrecidos en línea como apoyo a las actividades docentes en una única oferta, que garantice el siglo de transferencia de información y conocimiento de los participantes de los programas de estudios impartidos mediante plataformas Elearning.

En correspondencia a los objetivos planteados en este estudio académico, el Capítulo 9 incluye las conclusiones y recomendaciones generales que corresponden al enfoque crítico y perspectiva personal de la doctoranda, la que es sustentada en el análisis teórico-conceptual realizado y en el trabajo práctico ejecutado, que fueron orientados a la identificación de las relaciones simbióticas entre la biblioteca y el E-learning. Las conclusiones se han elaborado a partir de los resultados presentados en los capítulos precedentes, derivados tanto de las metodologías teóricas como de sus aplicaciones prácticas.

Finalmente se concluye con un conjunto de Anexos que incluye la bibliografía consultada durante el proceso de investigación y los cuestionarios utilizados para la recopilación de información necesaria. 


\section{PARTE V. APLICACIÓN PRÁCTICA, CONCLUSIONES Y RECOMENDACIONES}

\section{Capítulo 8. Guía para el diseño de servicios de información para E-learning}

8.1 Introducción

8.2 Organización de la guía

8.2.1 Objetivo de la guía

8.2.2 Elementos que deben considerarse en el diseño del servicio en línea para E-learning

8.2.2.1 Misión del servicio

8.2.2.2 Paradigma de la oferta de servicio

8.2.2.3 Estructura básica

8.2.2.4 Funciones del modelo

8.2.2.5 Funciones del (los) gestor(es) del servicio

8.3 Organización y gestión del servicio

8.3.1 Responsabilidad

8.3.2 Política del servicio

8.3.2.1 Procedimientos para el acceso

8.3.2.2 Controles estadísticos

8.3.3 Planificación

8.3.3.1 Actividades

8.3.3.2 Recursos

8.3.3.3 Personal

8.3.4 Diseño de la interfaz

8.3.5 Aspectos legales

8.3.5.1 Contenido ilegal

8.3.5.2 Derechos de autor y de copia

8.3.6 Colaboración

8.3.7 Promoción y publicidad

8.4 Práctica del servicio

8.5. Directrices generales

8.5.1 Directrices básicas para el componente de la referencia digital

8.5.2 Directrices básicas para el componente de la alfabetización informacional

8.5.3 Directrices básicas para el componente de los repositorios para la educación

\section{Capítulo 9 Conclusiones y recomendaciones generales}

9.1 Introducción

9.2 Conclusiones

9.2.1 Evaluación del modelo de biblioteca

9.2.2 E-learning

9.2.3 Puntos de encuentros entre la biblioteca y E-learning

9.2.4 Implementación del modelo

9.3 Recomendaciones generales 


\section{Capítulo 8. Guía para el diseño de servicios de información para E- learning}

\subsection{Introducción}

La diversidad de la bibliotecología como profesión permite que los gestores de las bibliotecas puedan participar como líderes y promotores en los cambios sociales, culturales, económicos y tecnológicos, mediante la prestación de servicios en línea orientados a determinados fines educativos e informacionales, siendo capaces de responder de forma eficiente y eficaz a la demanda de la comunidad de usuarios.

El proceso de transformación en la prestación de servicios dentro de las bibliotecas se realiza frecuentemente de forma relacionada con los cambios institucionales; sin embargo, la práctica diaria demuestra que las variantes esenciales acontecen en la administración de la biblioteca, dado que es aquí donde se identifican las necesidades, se definen las prioridades y se orientan los cambios en las formas de trabajo.

Las teorías revisadas sobre gestión de servicios afirman que, independientemente del epicentro que motive la revisión, transformación o generación de un servicio, es indispensable ordenarlo y encaminarlo estratégicamente. Por este motivo, resulta ineludible tener que anticiparse a la demanda y estar listo con una oferta puntual, creativa y eficiente donde los conceptos de calidad total y competitividad representen ser los pilares en los que gira la demanda de cualquier servicio.

De resultados del análisis DAFO es posible señalar que las actuales capacidades técnicas y organizativas de la biblioteca académica son oportunas para generar una nueva oferta de servicio integral que incluya la orientación del estudiante, la instrucción y formación de los estudiantes en competencias transversales para el uso eficiente de la misma. En este contexto, la presente guía aporta una serie de directrices básicas y ejemplos de buenas prácticas para la implementación de un modelo de servicio integral en línea orientado tanto para programas educativas semipresenciales como E-learning.

\subsection{Organización de la guía}

\subsubsection{Objetivo de la guía}

La presente guía para el desarrollo de prácticas pretende ser un instrumento de referencia para el diseño e implementación de un modelo de organización y oferta de servicios en línea ofrecidos la biblioteca como medio de apoyo al aprendizaje electrónico. 
La presentación del contenido se basa en aportaciones elaboradas por la IFLA (2006) ${ }^{190}$; MIT Institute; el manual LEADIRS II (2005) y autores como Arturo Martín Vega (2008), además de la propia observación y conclusiones derivadas de este trabajo doctoral. Los documentos anteriores permitieron dirigir la organización eficiente de los contenidos de la presente guía. La primera sección contiene una serie de directrices básicas para el diseño y organización del servicio en línea. Posteriormente se presentan algunos ejemplos concretos de prácticas de aplicaciones web 2.0 dentro de bibliotecas, como evidencia de la factibilidad de la aplicación del uso de estas herramientas en los servicios de referencia digital, el servicio de formación de habilidades y destrezas (ALFIN) y el acceso a repositorios en una sola oferta orientada a Elearning.

\subsubsection{Elementos que deben considerarse en el diseño del servicio en línea para E-learning}

\subsubsection{Misión del Servicio}

La oferta de servicios ofrecidos por la biblioteca para E-learning debe tener como misión el participar activamente en los diferentes programas de educación electrónica organizados por la entidad académica. Para este fin, la biblioteca debe diseñar o reorientar la oferta a servicios de contenidos especializados accesibles a través de mecanismos telemáticos, a fin de generar estímulos para el aprendizaje, el desarrollo de capacidades y habilidades para el adecuado uso de la información por parte de la comunidad académica.

Se parte, por tanto, de la necesidad de elaborar una herramienta que permita planificar de forma estructurada servicios bibliotecarios de información y herramientas de enseñanza en línea, para que ambos puedan integrarse y ofrecerse de forma conjunta y complementaria, indendientemente de cómo se presten estos servicios.

\subsubsection{Paradigma de la oferta de servicio}

La propuesta del modelo de oferta de servicio para modalidad de educación semipresencial y el E-learning propone una nueva forma de organización y prestación de servicio dirigida los usuarios involucrados en procesos de educación electrónica. El servicio se caracteriza por su contenido especializado y sistematizado en correspondencia a la temática de los cursos Elearning.

El modelo opera desde el sistema de gestión de contenidos de la biblioteca (CMS) que ser reconocido mediante una palabra o un icono que funcionará como enlace al directo con el sistema de gestión de E-learning (plataforma E-learning) ${ }^{191}$. La estructura de diseño del CMS para la web de la Biblioteca y el LMS-LCMS para la enseñanza telemática debe partir de un esquema que permita la integración, como se muestra en la figura siguiente:

\footnotetext{
${ }^{190}$ Véase http://archive.ifla.org/VII/s36/pubs/drg03-s.htm Consultado 28 -9-2011.

191 Generalmente CMS o LCMS y en algunos casos sistemas desarrollados por los especialistas informáticos de la institución.
} 


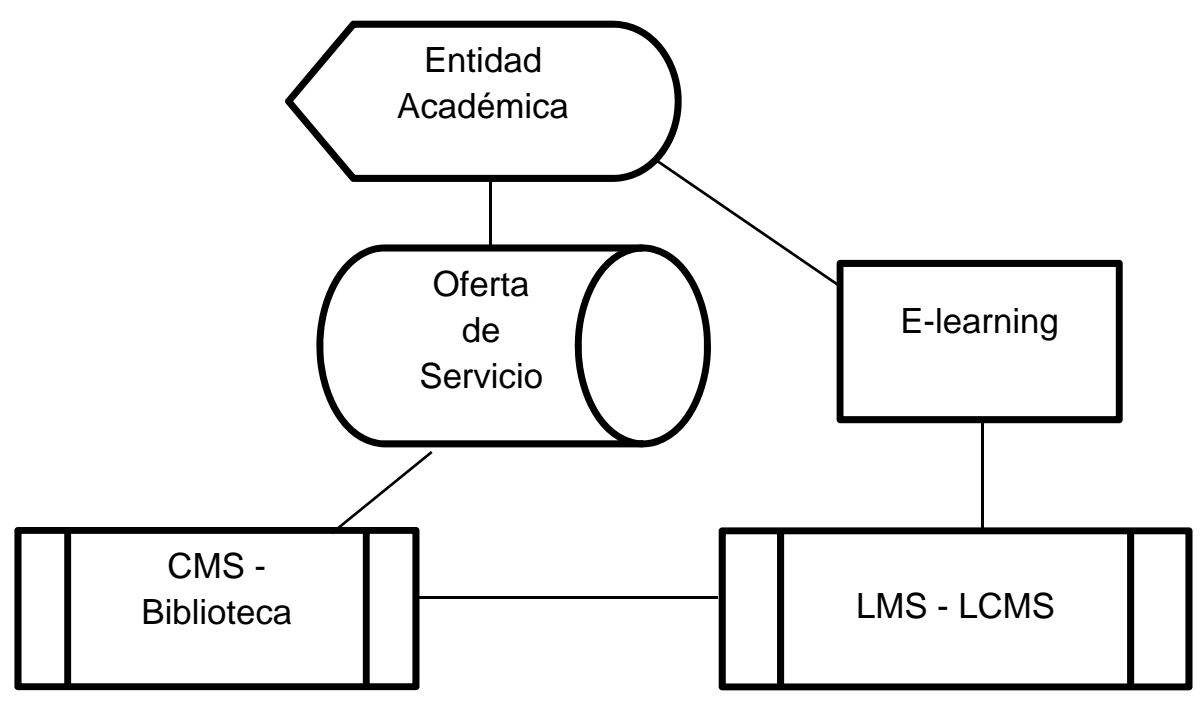

Figura 119. Lógica del funcionamiento del modelo de oferta de servicio. Fuente: Elaboración propia

En la figura 119 se pretente representar de forma gráfica la relación entre los dos agentes de las universidades que intervienen en el proceso de apoyo informacional a la enseñanza. Las universidades (Entidad Académica) ofrecen de forma telemática determinados servicios (Oferta de Servicio), de los que se encargan las bibliotecas. De igual forma, las universidades disponen de plataformas de enseñanza en línea (E-learning) con las que bien complementan su enseñanza presencial o bien la ofrecen de forma independiente. Desde el punto de vista tecnológico, los servicios se muestran a través de sistemas web de contenidos (CMS-Biblioteca) y las plataformas de enseñanza en línea se basan en aplicaciones específicas (LMS-LCMS). Ambos sistemas pueden relacionarse, a fin de que se retroalimenten y ambos obtengan beneficios mutuos.

\subsubsection{Estructura básica}

La estructura del modelo se constituye y caracteriza de igual forma que el E-learning, como un trinomio compuesto por los usuarios, los contenidos y la tecnología. Además, la oferta del servicio está compuesta por tres servicios que se reconocen como elementos básicos del modelo. Estos servicios son, como se viene mostrando a lo largo de esta tesis doctoral: la referencia digital, la alfabetización informacional (ALFIN) y el acceso a los repositorios para la educación.

El modelo incluye la presencia de estos tres servicios como una oferta única instalada en el sistema de gestión de contenido de la biblioteca (CMS) debido a que en la práctica estos servicios ya existen de forma independiente y están incorporados dentro de la infraestructura tecnológica de la biblioteca. Los especialistas en información, en conjunto con los docentes, definen los contenidos y niveles temáticos en correspondencia al o los 
cursos. Posteriormente de forma conjunta además con el personal informático, se diseña la aplicación del modelo y la lógica de interacción o interoperabilidad con el sistema de gestión del aprendizaje (LMS/LCMS=plataforma E-learning). En la siguiente figura se ilustra de forma gráfica el funcionamiento del modelo.

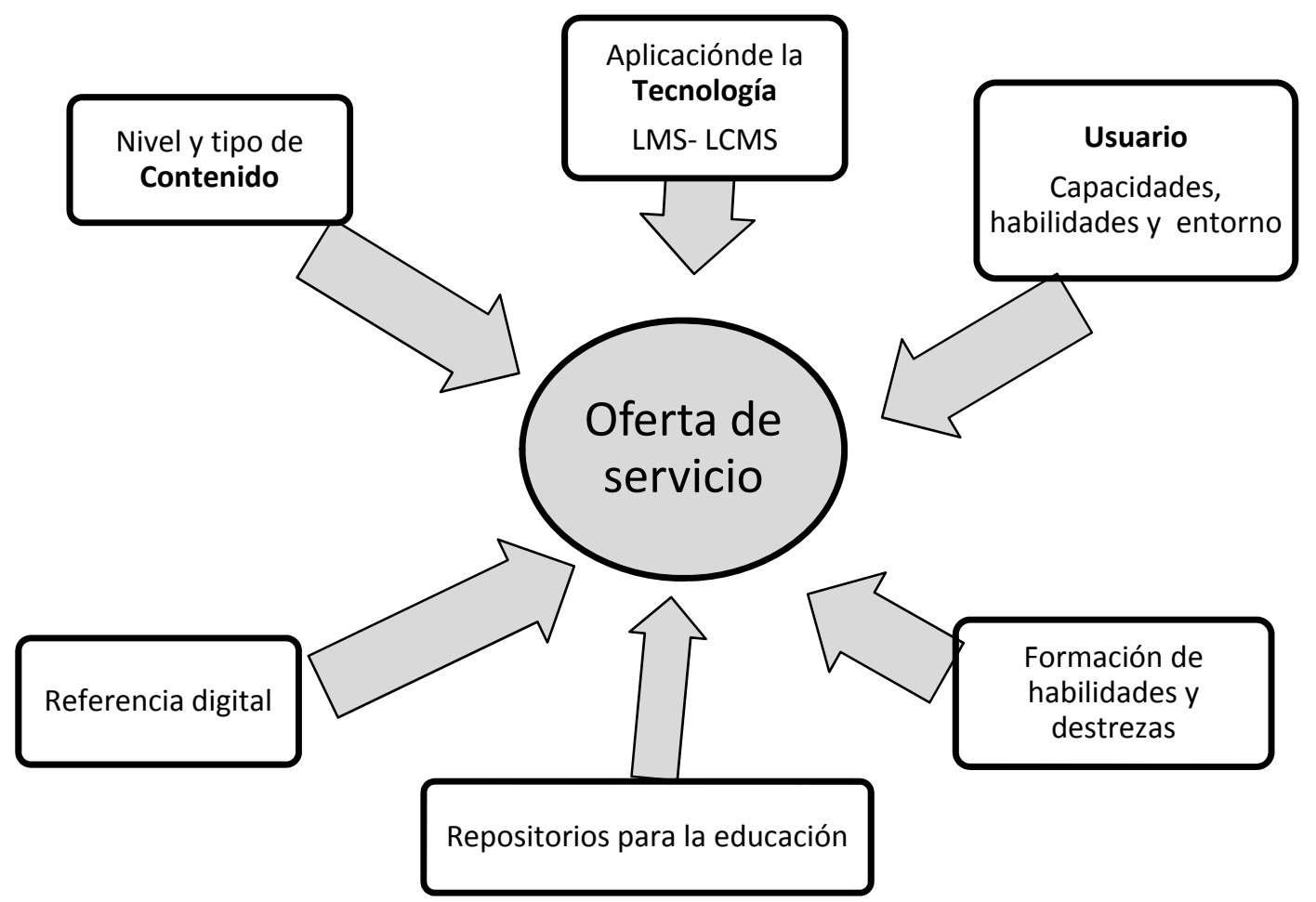

Figura 120. Estructura del modelo de oferta de servicio.

Fuente: Elaboración propia.

Se está empleado el concepto de modelo para designar a este conjunto de agentes y servicios que interactúan en los entornos de los servicios bibliotecarios digitales y la enseñanza ofrecida en línea, apoyada en plataformas específicamente concebidas para el aprendizaje formal telemático. Como se observa en la síntesis gráfica de la figura 120 , se parte de un núcleo central: la oferta de servicio. Alrededor de este centro se organizan, por una parte los tres elementos que forman el sistema de la educación telemática (E-learning) y por otra p,arte, los tres servicios que se ofrecen en línea como apoyo a la enseñanza electrónica:

a) Sistema de la educación telemática

Contenidos

Tecnología

Usuarios b) Servicios bibliotecarios telemáticos

Referencia digital

Alfabetización informacional

Repositorios educacionales 


\subsubsection{Funciones del modelo}

La convergencia Servicios bibliotecarios / E-learning se basa en una serie de aspectos que hay que tener presente para la planificación y desarrollo de este tipo de servicios integrados bibliotecarios y educativos. La universidad, como entidad superior, y la biblioteca, como responsable del apoyo al aprendizaje y a la investigación, deben partir de un modelo híbrido con el que se conseguirán importantes retos y mejoras, que se pueden sintetizar de forma amplia en los siguientes aspectos:

- Motiva nuevas formas de visión y actuación en el manejo de la información

- Fomenta la creatividad profesional

- Invita a la búsqueda de soluciones

- Facilita la accesibilidad de sus productos y servicios

\subsubsection{Funciones del (los) gestor(es) del Servicio}

Los gestores del servicio generalmente son los especialistas en información, bibliotecarios gestores de servicios. De igual forma, este tipo de personal debe trabajar de forma estrecha con los informáticos y responsables de redes. Dadas las características del servicio, se requiriere que este profesional biblioteacrio sea capaz de:

a.- Ser promotor del cambio

b.- Actuar de forma activa y creativa

c.- Disponer de capacidad para gestionar servicios

d.- Reconocer y anticiparse a las necesidades de los usuarios

e.- Investigar y presentar alternativas de cambio

f.- Generar o modificar la oferta de servicio según los entornos y demanda

g.- Tener capacidad para comunicarse con los diferentes tipos de usuarios

h.- Actuar de forma competitiva

i.- Permanecer en constante actualización profesional

\subsection{Organización y gestión del servicio}

\subsubsection{Responsabilidad}

La implementación y gestión del modelo es una tarea esencial de los gestores de las bibliotecas (directores o coordinadores de servicios, secciones o unidades); no obstante, el 
funcionamiento y responsabilidad exige la participación del profesional bibliotecario especialista en contenidos antes descritos, así como del docente responsable del o los cursos y el informático o gestor de la plataforma E-E-learning. De esta forma, en el modelo intervienen los agentes responsables de tipo académico, tecnológico y bibliotecario:

A/ Gestores académicos

1. Responsables de las políticas de enseñanza presencial, semipresencial y en línea, normalmente órganos rectores de la universidad y de los departamentos.

2. Reponsables de la coordinación docente, profesores y tutores de los cursos en línea, quienes ofrecen la formación telemática para los estudiantes.

B/ Gestores tecnológicos

3. Responsables de servidores y redes de telecomunicación, quienes mantienen la estructura tecnológica de la universidad relativa a equipamiento y redes.

4. Responsables de plataformas de enseñanza en línea, encargados de crear y manterner técnicamente las plataformas E-learning.

\section{C/ Gestores bibliotecarios}

5. Responsables de la gestión bibliotecaria, a través de los órganos de planificación, dirección y administración de la biblioteca: espacios, recursos y servicios.

6. Responsables de los servicios bibliotecarios telemáticos, encargados de la referencia digital, la alfabetización informacional y repositorios educacionales.

Estos seis tipos de gestores responsables deben trabajar de forma interconectada, como un equipo de trabajo, ya que la relación entre ellos debe ser estrecha para conseguir la convergencia pretendida entre enseñanza y servicios de información. Por una parte, existe un perfil de gestión global, más basado en la planificación y en la coordinación y, por otra lado, entre estos responsables hay perfiles ejecutivos, correspondiente a quienes, por ejemplo, diseñan los contenidos de los cursos, implementan dichos cursos en las plataforma E-learning o prestan de forma directa los servicios bibliotecarios telemáticos: atención a las consultas de referencia, acciones de formación de usuarios y conexión entre repositorios de recursos para el aprendizaje y contenidos educativos. El modelo de convergencia planteado requiere la interdiciplinariedad de los conocimientos y los perfiles y que se cumplan requisitos como los siguientes:

- conocer la oferta docente, los planes de estudios y las metodologías docente

- conocer las posibilidades tecnológicas aplicadas a la educación

- crear y mantener cursos en la plataforma E-learning de la institución

- integrar recursos y servicios de información en la plataforma E-learning 


\subsubsection{Política del servicio}

La definición de la política de servicio tiene como fin el orientar la actuación y/o normalizar la oferta democrática del modelo. Su definición debe estar en correspondencia con la política del sistema de la biblioteca. Su distinción corresponde a la orientación y modalidad semipresencial y al de acceso a recursos electrónicos.

La política debe ser que los servicios bibliotecarios y la oferta de enseñanza en línea puedan prestarse de forma coordinanda, apoyándose la educación en la biblioteca e integrando la actividad de la biblioteca en la docente. Se parte de la plataforma E-learning como espacio de aprendizaje y de que la biblioteca trabaja en ese espacio integrando sus servicios telemáticos: referencia, formación, recursos. La política del servicio por tanto es:

Plataforma E-learning $=$ Contenidos docentes + Recursos y servicios bibliotecarios

Los aspectos en que se enmarca la política del servicio corresponden a los siguientes cuatro aspectos que se deben tener en cuenta para la prestación óptima de los servicios y la mejor orientación de la integración y convergencia de la enseñanza E-learning y los servicios bibliotecarios telemáticos. Los aspectos que se deben tener en cuenta son los siguientes:

- Tipología de usuario (características, entornos y capacidades)

- Contenido de la demanda (en correspondencia de los programas E-learning)

- Tipo de recurso electrónico (multimedia, archivos, videos, tutoriales, metadatos, etc.)

- Personalización de los servicios de información (tratamiento personalizado)

Además, se debe normalizar una serie de cuestiones que también permitirán establecer servicios de éxito. Estas cuestiones están relacionas con el tipo de usuario y el acceso a los contenidos, es decir, quién puede acceder a los recursos/servicios y en qué condiciones puede hacerlo. En resumen, los cuestionamientos a que debe responder la política corresponden a los siguientes aspectos:

- ¿Quién puede solicitar los servicios?

- ¿Qué limitaciones tendrá el acceso a los materiales?

- ¿Cuál es la cantidad de límite para el acceso a los recursos?

- ¿Qué límites de tiempo para el acceso se definen?

En síntesis, la política debe establecerse a partir de dos grandes ámbitos: usuarios a los que se va a atender y tipo de atención que se le prestará, entiendo como tales al tipo de recursos, límites de contenidos, tanto en su volumen como en el tiempo de disfrute de los recursos. Esto es importante en los recursos y servicios universitarios, ya que es necesario restringir los accesos a la comunidad universitaria, tanto por ser la destinataria exclusiva de la oferta formativa, como porque la adquisición y suscripción de los recursos comerciales de apoyo a la docencia y a la investigación suelen conllevar licencias de uso que obligan a controlar los accesos a los mismos. 


\subsubsection{Procedimientos para el acceso}

El control de acceso al servicio deberá enlazar con el sistema central de la biblioteca, esto permitirá elaborar estadísticas sobre los préstamos, el acceso, usuarios y temas. Las plataformas de enseñanza E-learning requieren identificación para acceder a las mismas, ya que se basan en la creación de cursos a los que se incorporan alumnos, ya sea de forma manual o automatizada. Es frecuente que las universidades integren sus sistemas de gestión académica (matrículas) con los de enseñanza en línea (E-learning) de forma que cuando un profesor cree un curso pueda emplear el código asignado a la materia, en caso de asignaturas y planes de estudios oficiales, para que automáticamente se incorporen al curso creado los alumnos matriculados.

Los accesos a los cursos generan logs, que servirían como indicador numérico para conocer el número de entradas al curso. Además, los sistemas de identificación de la comunidad universitaria, ya sea mediante carnet y códigos y barras o bien a través de los correos electrónicos, permiten realizar la identificación previa de las personas que acceden a los cursos.

Los sistemas más comunes para la identificación de los usuarios de cara a su acceso a las plataformas E-learning son los siguientes:

a) Usuario y contraseña de E-learning, creados por el administrador del curso y específicos para entrar bien a toda la plataforma bien a cursos específicos.

b) Tarjeta de identificación, con código de barras o idenficación de usuario similar, que se emplea para el uso de servicios universitarios, como es el préstamo bibliotecario.

c) Usuario y contraseña de servicios académicos, asignados a cada miembro de la comunidad universitaria y útiles para todos los servicios, como es el correo electrónico o el acceso remoto a los recursos electrónicos suscritos por la biblioteca.

Teniendo en cuenta las apreciaciones anteriores, es necesario tener que se contemplen estos elementos en la política del servicio. Por ejemplo, un sistema de control debe registrar obligatoriamente la siguiente información:

- Identificación del demandante del préstamo en el sistema

- Tipo de material concedido en acceso o préstamo

- Limite de tempo o plazos de acceso a los recursos

- Numero de veces que el archivo puede ser bajado en línea

- Reservas de recursos

Se parte de la necesidad de identificar a la persona que accede a los cursos, servicios y recursos como miembro de la comunidad específica para la que se elaboran los cursos y se destinan los servicios de información. Los elementos que hay que controlar son la pertenencia al colectivo, pero también las condiciones específicas aparejadas a la categoría de usuario correspondiente, así como los límites en los accesos y las posibilidades de reserva o renovación de recursos. 


\subsubsection{Controles estadísticos}

Los controles estadísticos son de gran importancia para la cuantificación y cualificación de los servicios. La realización de controles periódicos permite conocer y evaluar la funcionalidad del servicio, ya que a través de la evaluación es posible analizar el proceso de demanda-satisfacción por tipos de usuarios, áreas temáticas, tipo de material y servicios mayormente demandados. En esta línea y en correspondencia a los objetivos planteados, resulta importante la correcta formulación de preguntas y el adecuado instrumento para la captación de información, ya que éstos determinarán el acierto de las respuestas.

La estadística se debe aplicar de forma diferente a cada uno de los elementos que intervienen en la convergencia de los servicios formativos e informativos, aunque se trata de aspectos muy estudiados por la investigación específica en pedagogía y bibliotecología y que no se considera conveniente reflejar de forma desarrollada en esta guía-síntesis. No obstante, sí es útil describir los bloques de datos estadísticos que se deben tener en cuenta:

a) Información estadística de las plataformas E-learning: debe incluir número de accesos a cada cursos, accesos a las secciones y servicios de cada curso (páginas, foros, documentos, etc.), contenidos más visitados y contenidos más descargados, al menos. Este tipo de datos se obtienen de forma automática, gracias a las propias herramientas de las aplicaciones informáticas de enseñanza en línea. La recogida de estos datos puede apoyarse en las huellas o logs que los usos dejan en los servicios informáticos así como en la integración de herramientas externas de análiticas web.

b) Información estadística de servicios de referencia digital: se basa en el control del número de preguntas, tipo de consultas realizadas, temática de las mismas, tiempo de respuesta o medio por el que se realiza la consulta (sincrónicos, asóncronos, etc.). En este aspecto, es esencial medir la satisfacción del usuario, lo cual se realiza a través de metodologías cualitativas, como encuestas, a las que se incluyen sistemas cuantitativos de medición de la satisfacción, a fin de tener datos medibles. Como se avanzó en la parte correspondiente de esta tesis doctoral, existen diferentes normas y métodos para la evaluación de los servicios digitales de referencia bibliotecaria ${ }^{192}$.

c) Información estadística de las actividades de alfabetización informacional: pretende medir el alcance de los programas de formación en información y del impacto de los productos y servicios ofrecidos en este sentido. De igual forma, se trató este tema en el apartado correspondiente de esta investigación ${ }^{193}$, aunque conviene al menos mencionar algunos de los datos que conviene obtener, como son: número de cursos ofrecidos, distinguiendo los que se dirigen a la educación formal y los que lo hacen a la no reglada, número de estudiantes que los han seguido y temática de los cursos ofrecidos, distinguiendo entre generales y específicos y los que se dirigen a técnicas, recursos o servicios concretos. También en este apartado es esencial recoger el grado de satisfacción de los estudiantes que han seguido los cursos de alfabetización informacional. En el caso de materiales didácticos, como guías y tutoriales, los datos se basan en el número de acceso y descargas.

\footnotetext{
192 Véase apartado 4.4 y Lankes (et al.), 2002.

${ }^{193}$ La métrica de la alfabetización informacional se encuentra en el apartado 4.5.
} 
d) Información estadística de los repositorios de materiales de apoyo al aprendizaje: se quiere medir el grado de adecuación de los recursos ofrecidos y del valor de los mismos. La biblioteca debe asegurarse de que está ofreciendo los recursos que son necesarios para cada cursos y de que estos tienen utilidad dentro de su finalidad de ser recursos de apoyo al aprendizaje. La métrica de este tipo de servicio es híbrida, entre los técnica de extracción de datos de forma automática (accesos y descargas) y los que se deben tomar de forma manual, como los relativos a la satisfacción del usuario. Independientemente de la forma de tomar la información estadística, ésta debe ser procesada con criterios de análisis de datos, que permitan conocer qué recursos son los más tipos, tanto en contenidos (materias) como en tipos (páginas, tutoriales, $F A Q$, etc.).

Los controles estadísticos deben formar parte del modelo integrador Biblioteca/E-learning, estableciendo además nuevos parámetros de evaluación, que relacionen datos hasta ahora independientes, como pueden ser los que se obtengan de los cuatro tipos de información estadística que han presentado en los párrafos anteriores. Se trata de obtener información conjunta que permita disponer de indicadores para valorar el rendimiento y el alcance de los servicios bibliotecarios telemáticos dentro de los procesos de enseñanza en línea.

\subsubsection{Planificación}

La planificación es el proceso estratégico que permite definir normas y organizar todas las actividades esenciales para el cumplimiento de los objetivos en las diferentes áreas de acción del modelo de servicio. A su vez, la correcta planificación de la oferta de servicio, hace posible describir fase por fase las actividades y la visualización clara de resultados en el orden secuencial en relación al tiempo programado para cada actividad.

La integración de servicios bibliotecarios en la oferta formativa telemática conlleva una ampliación de la concepción tradicional de la planificación en las bibliotecas, ya que se trata de plantear planes transversales, en los que intervienen docentes y tecnólogos. El carácter interdisciplinar requiere que se realice una planificación global de la entidad, pero también los específicos de cada servicio implicado y, además, con la planificación de la integración de los diferentes servicios que se están relacionando: docencia, tecnología, información. Se trata de tener en cuenta que la planificación debe tener un marco genérico institucional, varios específicos de los servicios y otro integrador, como se detalla en las siguientes líneas:

Marco global institucional Plan estratégico de la universidad

Cartas de servicios y herramientas de calidad generales

Marcos específicos

Plan estratégico de la enseñanza en línea

Plan estratégico de redes y servicios informáticos

Plan estratégico de la biblioteca

Planes estratégicos de servicios bibliotecarios telemáticos

Cartas de servicios y herramientas de calidad específicas

Marco integrador

Planificación de la convergencia Biblioteca/E-learning 


\subsubsection{Actividades}

En el proceso de planificación y organización de actividades se reconocen habitualmente los siguientes tres tipos actividades:

a. Actividades de iniciación. Corresponde a las actividades vinculadas a la organización e implementación del modelo de servicio. Es una fase primaria en la que se delimitan el qué hacer, cómo y para quién hacerlo. Se valoran y definen las necesidades para la implementación del modelo basado en el trinomio usuario-contenido-tecnología. Es decir, en esta fase es necesario definir el sistema de gestión de información, tipo y nivel de contenido de los recursos informativos, niveles de aplicación tecnología de acuerdo a las características y necesidades potenciales de los usuarios. En esta misma fase de planificación se define el mecanismo de evaluación del servicio mismo.

b. Actividades que contribuyen directamente en la satisfacción de las necesidades de los usuarios. Estas actividades involucran un grupo de acciones vinculadas con procesos de comunicación y acompañamiento virtual del usuario mediante el servicio chat, por ejemplo. La recogida de datos cualitativos y cuantitativos de satisfacción de usuarios permiten que se planifique los servicios en función de las necesidades y que se modifiquen aquellos que ofrecen peores resultados de satisfacción.

c. Actividades de formación y orientación de usuarios sobre el uso de los recursos y manejo ético de la información. Corresponde a todas las actividades de capacitación y formación directa o indirecta orientadas a estimular el uso correcto de los recursos y servicios de información. Un ejemplo que claramente se enmarca corresponde a la difusión de cursos ofrecidos por la biblioteca sobre cómo usar la biblioteca desde casa o cualquier lugar físicamente distante de la biblioteca, el cómo realizar búsquedas, recuperar y utilizar adecuadamente la información.

La revisión y seguimiento integral de la planificación y organización de las actividades antes descritas, tanto al inicio como durante la implementación del modelo, permite delimitar el alcance e impacto del servicio en la comunidad de usuarios.

\subsubsection{Recursos}

Los recursos necesarios para la prestación del servicio integrador necesario para la convergencia de Biblioteca y E-learning corresponden a los diferentes contenidos instalados en diferentes soportes o recursos telemáticos. Estos recursos son organizados y adecuados a los medios tecnológicos y aplicaciones web 2.0 de acuerdo a los objetivos educacionales y la tipología de los usuarios finales. En dependencia de las características de la infraestructura tecnológica y el nivel de inversión institucional, los recursos considerados básicos y fijos varían de una aplicación y otra del modelo de servicio.

\subsubsection{Personal}

El "personal profesional" involucrado en la prestación de este servicio corresponde a un grupo de profesionales que interactúan entre sí, con el fin de dar cumplimiento a un mismo objetivo. En este grupo de trabajo se destacan: 
- Docente responsable de o los cursos. Define los temas y nivel del contenido del servicio.

- Bibliotecario. Responsable de la organización de los recursos de información en que se albergan los contenidos.

- Profesional informático a cargo de la interfaz. Cabe destacar que en algunos de los casos, la actualización de los contenidos es asumida por el docente y/o bibliotecario.

Aunque cada de uno de los profesionales involucrados tiene responsabilidades concretas en el proceso de generación del servicio, ellos participan como un equipo de trabajo durante el proceso de planificación y gestión del modelo de servicio. El trabajo en equipo de estos profesionales, requiere mantener una comunicación continua y transparente, tanto durante el seguimiento del servicio, como para dar respuesta inmediata a situaciones inesperadas.

\subsubsection{Diseño de la interfaz}

El diseño de la interfaz del servicio requiere del uso de aplicaciones informáticas y sistemas combinados para generar procesos sencillos de comunicación simultánea, a fin de facilitar la gestión de contenidos y el proceso de enseñanza aprendizaje de forma interactiva y dinámica. La apropiación de las buenas prácticas ya existentes, facilita la creatividad, genera experiencia y reduce la posibilidad de cometer errores.

Los diseños de las interfaces varían desde el punto de vista tecnológico a medida que lo hacen los estándares de programación y las aplicaciones de diseño web. A menudo, los sistemas de gestión de contenidos para su publicación en la web limitan las posibilidades de integración con recursos externos. De igual forma, las plataformas de enseñanza en línea presentan limitaciones en sus interfaces y sólo permiten pequeñas adecuaciones en las hojas de estilo. Las herramientas más empleadas, como es el caso de Moodle, presentan interfaces compuestas por módulos que se combinan a partir de las necesides de los cursos concretos. Estos módulos incluyen contenidos tipo web y otros como foros, formularios o glosarios. Las bibliotecas deben emplear este tipo de módulos para integrarlos en los cursos específicos, lo cual implica tanto un conocimiento de la programación o diseño de los contenidos para ser integrados en cada sección, como la concepción de partida de que se está diseñando para un espacio específico dentro de un conjunto de módulo.

Con el objetivo de ilustrar en esta guía el resultado de un inventario que reúna las aplicaciones mayormente utilizadas a nivel mundial para la socialización interactiva (inventario es realizado y difundido en el 2010 por la Red de bibliotecas de Brabant y la fundación UBISS publicado en $2010^{194}$ ), se presenta la siguiente tabla donde se estable una comparación entre las aplicaciones utilizadas para el desarrollo de procesos educativos y para la prestación de servicios por parte de la biblioteca. Esta demuestra la compatibilidad en el uso de herramientas para la transferencia de información y conocimiento. 


\begin{tabular}{|l|l|}
\hline Aplicaciones más usadas para la educación & Aplicaciones más usadas en la biblioteca \\
\hline - RSS & - RSS \\
- Social bookmarking & - Social bookmarking \\
- LibraryThing & - LibraryThing \\
- Wiki's & - Wiki's \\
- Blogger & - Blogger \\
- Web traductores & - Web traductores \\
- Twitter & - Twitter \\
- Podcasting & - Podcasting \\
- Podcasts -radio & - Podcasts -radio \\
- Vodcasting & - Mensajería Instantánea (chat) \\
- Screencasting & - Flickr \\
- Mensajería Instantánea (chat) & - Delicious \\
- Flickr & - YouTube-video \\
- Delicious & - LibraryThing - Catalogar libros y recursos \\
- YouTube-video & - Geolocatie \\
- Aplicaciones de teléfono portátil & - Hyves \\
- Facebook & para actividades educativas y prestación de servicios. \\
- Hyves & Fuente: Elaboración propia \\
- Geolocatie & - Aplicaciones de teléfono portátil \\
- Podcasts & - Aplicaciones de Google en iGoogle apps \\
& - Facebook \\
& - Netvibes \\
\hline & - Podcasts \\
\hline & - Poken Presentaties \\
\hline & - Social bookmarking \\
\hline
\end{tabular}

\subsubsection{Aspectos legales}

El documento Manifiesto sobre Internet de la IFLA ${ }^{195}$ aprobado en el año 2002 atribuye a la biblioteca de forma textual la responsabilidad de facilitar el acceso a la información y comunicación mediante sus servicios, que deben ser ofrecidos en un entorno virtual debidamente estructurado, en el cual los usuarios puedan usar libremente y de forma confidencial los servicios y los recursos de información necesarios para el cumplimiento de su objetivos o satisfacción de necesidades.

El manifiesto destaca además que los servicios de información en línea que ofrecidos por las bibliotecas a través de internet e intranet, representan ser un medio para superar las barreras creadas por las distancias, limitaciones económicas y lograr reducir los posibles obstáculos para las transferencias de información y conocimiento.

El seguimiento y puesta en práctica de la anterior directriz, requiere la revisión de una serie de aspectos legales estrechamente ligados a los límites y formas de acceso a los contenidos, a fin de garantizar la protección de la autoridad, propiedad de la información, calidad y seriedad de 
contenidos y la democratización de los recursos ofrecidos `en línea. Siguiendo este escenario y en el contexto del modelo de oferta de servicio en línea propuesto en este documento, la presente guía sugiere prestar atención a los siguientes aspectos jurídicos y legales.

\subsubsection{Contenido ilegal}

Las leyes internacionales prohíben la puesta en línea de contenidos que directa o indirectamente impliquen o estimulen comportamientos de obscenidad, amenazas a la seguridad pública, a la privacidad o a la confidencialidad. Es una obviedad que las plataformas de enseñanza en línea y los servicios bibliotecarios nunca deben incluir contenidos sobre los que no tengan derechos.

\subsubsection{Derechos de autor y de copia}

\section{Derechos de autor - Propiedad intelectual}

Emilio Suñé Llinás (2008) ${ }^{196}$, profesor de la Universidad Complutense de Madrid, explica que la propiedad intelectual es un recurso legal, concebido para compensar a los creadores y promover la innovación; no obstante todavía existe una tensión entre los poseedores de derechos de autor y la necesidad de un dominio público saludable.

En presente siglo XXI, los derechos de autor todavía limitan el acceso, uso y navegación de algunos recursos en línea. La práctica demuestra, un cierto nivel de limitación para el acceso de publicaciones científicas y técnicas ofrecidas a través de los servicios de la biblioteca. Los casos específicos más sobresalientes se agrupan en los dos grupos siguientes:

a. Acceso limitado a documentos científicos o técnicos a los cuáles el autor mismo ha limitado el acceso a solamente partes de la obra.

b. Acceso limitado a resúmenes de documentos con valor académico, cuyo archivo de texto completo está condicionado a un pago. Esto ocurre porque la propiedad de la publicación y uso de la obra es de los editores, quienes exigen ofrecer el servicio de acceso a través de suscripciones al acceso de revistas.

En consecuencia a lo anterior Javier Bustamante Donas (2001), recomienda el trabajo de cooperación a fin de promover alternativas legítimas de los derechos de autor y de copia, como las licencias del tipo Creative Commons para la gestión de documentos electrónicos, logrando así disminuir las restricciones de acceso a la información, mediante iniciativas de cooperación.

\section{Privacidad}

Los usuarios deben ser informados acerca de las políticas de la biblioteca en relación con la privacidad, y el derecho al anonimato. Los usuarios deben disponer de la libertad necesaria para realizar sus búsquedas, sin que éstos sean examinados por otras personas. Es decir el modelo de oferta de servicio, debe ofrecer un espacio neutral en el que sea posible mantener la individualidad. 


\section{Posibles barreras}

La prestación de los servicios en línea debe restringir los límites de uso del servicio. Esto implica una restricción en el uso de las aplicaciones tecnológicas y la información misma. Se recomienda para esto tomar en consideración las siguientes acciones:

a. Uso de filtros. Es recomendable la utilización de un programa o software de filtrado en las terminales del servicio. Los usuarios deben estar debidamente informados sobre la presencia de los filtros

b. Aplicar políticas sobre uso del servicio ${ }^{197}$. La implementación de esta política debe estar sujeta a la revisión regular, con el objetivo de asegurar su vigencia en correspondencia a las metas y objetivos del servicio en relación a los entornos cambiantes.

\subsubsection{Colaboración}

La colaboración es un mecanismo indispensable para el intercambio de experiencias y como una alternativa para superar los problemas económicos. En el actual siglo XXI y debido a la crisis económica globalizada, las iniciativas de cualquier producto o servicio aislado, tiene garantizados un éxito sosegado. El modelo de oferta de servicio propuesto en esta guía, integra una filosofía de trabajo colaborativo. La cooperación se concibe como parte de un proceso directo o indirecto en cada una de las fases del servicio es decir, desde su diseño e implementación, promoción - difusión, hasta la evaluación y mejora del servicio.

El proceso de cooperación resulta importante en el diseño e implementación del modelo, la definición de normativas para el uso del servicio y la evaluación y seguimiento de la funcionalidad del mismo. Una ventaja de esta colaboración, es que permite incluir las diferentes perspectivas (desde el enfoque del docente, informático y bibliotecario) en el diseño e implementación, promoción difusión, evaluación y mejora del modelo de servicio. Asimismo el trabajo en equipo a lo interno de la institución permite mantener una visión sistémica al momento de delimitar los derechos y las obligaciones de la biblioteca como gestora del servicio y de los usuarios como grupo meta.

En este contexto, es recomendable iniciar la creación de alianzas en el interiro de la institución, con los profesores, personal administrativo e investigadores. Para esto resulta estratégico participar de forma directa o indirecta en discusiones con ellos, a fin de crear sinergias de cooperación de doble vía. Algunos ejemplos de iniciativas concretas son:

- Desarrollar iniciativas de colaboración con los diferentes departamentos y facultades del campus interesadas en disponer contenidos en línea para cursos E-learning.

- Presentar la oferta del servicio (elaboración de tutoriales, bibliografía en líneas etc.) en reuniones departamentales o facultativas, grupos de investigación, o de forma individual y directa a profesores a fin de estimular el interés por el servicio. 
- Difundir la oferta del servicio en notas de prensa, distribuir folletos informativos, posters, presentaciones en video y la página web de la Universidad para publicitar el servicio.

La cooperación desde un enfoque sistémico necesaria para la implementación de este modelo de integración de servicios bibliotecarios, tecnológicos y formaticos se experimenta en las siguientes cuatro fases del servicio:

\section{a. Cooperación directa en el diseño e implementación del servicio}

Aunque el modelo dispone de un marco de referencia para su diseño, su implementación está condicionada a las características propias del entorno, disponibilidad de recursos económicos, nivel de aplicación tecnológicas y la experiencia del grupo de profesionales involucrados. En este sentido, el trabajo en equipo es necesario tanto en el diseño e implantación del modelo. Debido a que el docente es quién determinará y seleccionará gran parte de los contenidos; el especialista en sistemas informáticos desarrollará las aplicaciones que faciliten el acceso y uso de los recursos; y el gestor de los recursos de información (bibliotecario) asumirá la sistematización y organización de los recursos de información.

\section{b. Cooperación para sostenibilidad del servicio (costo - beneficio)}

Generalmente un servicio de esta índole se encuentra inmerso dentro del presupuesto de la biblioteca o es financiado por algún departamento o facultad quien recibe el servicio. En otros casos se trata de un servicio subvencionado como parte de un proyecto educativo o formativo.

El concepto de cooperación para sostenibilidad del servicio no supone un trabajo en conjunto, sino más bien una relación costo - beneficio entre partes (el ofertante del servicio y demandante y consumidor de este) en función de objetivos comunes. Es decir la oferta del servicio visto como un mecanismo para reducir costos, evitar la duplicidad de esfuerzos y asegurar la sostenibilidad de un servicio.

\section{c. La cooperación directa e indirecta para promoción y difusión del servicio}

Complementando las modalidades anteriormente referidas, Mary R. Barton y Margaret M. Waters (2004-2005), proponen dos métodos basados en la cooperación estratégica para lograr la promoción y la mercadotecnia de un servicio. Considerando que estos son aplicables en el contexto del diseño e implementación del modelo de servicio propuesto, se describen a continuación.

\section{Método descendente \\ Consiste en una comunicación directa vía-vía. El medio son los profesores, estudiantes y los gestores del servicio que difunden la importancia de este ante los Vicerrectores, Decanos y Administradores. \\ Método ascendente \\ La biblioteca inicia el trabajo de cooperación directa con el profesorado que recibe algún tipo de asesoría o un menú de alternativas de servicios de apoyo a sus actividades docentes. En esta forma se crea la necesidad del servicio y por consiguiente se consigue compartir y mantener el objetivo del servicio a largo plazo. Asimismo este docente (ya cliente del servicio) actúa como un canal para la difusión de la existencia y utilidad del servicio hacia otros docentes de otras disciplinas.}




\section{d. La cooperación para la evaluación global del servicio}

La evaluación de servicio requiere de la colaboración de los usuarios en sus diferentes niveles, a fin de que estos puedan manifestar su opinión y valoración en relación al servicio. Hecho por el cual se requiere mantener relaciones de cooperación con los líderes de estos grupos.

\subsubsection{Promoción y publicidad}

La actividad de promoción-venta del servicio de forma directa con el usuario se reconoce como la comercialización del servicio. La mejora y/o la innovación del o los servicios nos permiten poder aumentar la demanda de éstos. Sin embargo, para lograr este objetivo se hace necesario estimular la prueba de la utilidad del servicio, a fin de generar su necesidad misma. Especialistas en mercadotecnia afirman que el éxito en la acogida de un servicio o producto se basa en la medida en que estos son promocionados dentro y fuera de su entorno.

En el caso de la biblioteca, los agentes clave son sus usuarios reales y potenciales, los proveedores de información que permiten llegar a otros entornos. De forma casi unánime en la bibliografía revisada para la elaboración de esta guía, los autores recomiendan que toda estrategia de promoción y comercialización del servicio en línea deba incluir de forma integral la promoción hacia los siguientes puntos medulares de la mercadotecnia.

\section{a. Publicidad visual}

Consiste en la comunicación impresa que se vale del uso de diferentes recursos visiblemente atractivos. Se trata de instrumentos divulgativos que se caracterizan por describir el fin y utilidad de un servicio en pocas palabras. Existe una diversidad de ellos tales como plegables, botones, bolsas, lápices, carteles, afiches, poster, etc. La elaboración de este tipo de materiales implica una inversión de tiempo en el diseño del concepto de la idea y el objeto visual. Es importante ser consecuente para el diseño de logos, colores, símbolos, que estratégicamente en su totalidad difunda el fin del producto y servicio como uno solo.

\section{b. Publicidad visual electrónica}

Este tipo de publicidad cumple con todas las características de la publicidad impresa, no obstante dada las facilidades tecnológicas, este tipo de publicidad puede presentar atributos sonoros y de movimiento, como un video, una presentación de diapositivas, etc. que pueden ser activadas.

\section{c. Relaciones públicas}

El aprovechamiento de eventos, encuentros, artículos, entrevistas, red de contactos son determinantes para la promoción del trabajo que se realiza, los servicios y productos que se disponen.

El elemento publicitario o de mercadotecnia es esencial, ya que sigue siendo necesario que las bibliotecas muestren sus servicios, sobre todo en centros universitarios, donde las especialidades son muchas y hay un constante flujo de usuarios, que a su vez tienen diferentes necesidades de información, que suelen aumentar a medida que se dan a conocer más recursos y servicios. 
Es posible aportar una serie de ecomendaciones generales para el diseño de estrategias para la promoción del servicio:

- Innovar y realizar cambios en el servicio. Darles nuevas utilidades, nuevas funciones, nuevos usos.

- Mostrar la originalidad del servicio. Incluir nuevos atributos al servicio, hacerlo más atractivo a los ojos, nuevo diseño, nuevos colores sin caer en el abuso.

- Personalizar el servicio para cada curso, cada objetivo y según las características de la clientela.

- Atribuir al servicio nuevos valores agregados que hagan sentir al usuario importante, por ejemplo incluir una mayor asesoría personalizada.

\subsection{Práctica del servicio}

La práctica de aplicación de ofertas de servicios en línea corresponde al ejercicio iniciado con las aplicaciones de la social media en las diferentes tareas dentro de la biblioteca. Sin embargo estas aplicaciones se caracterizan por el uso personalizado. José Antonio Merlo (2008 p.1-2) ${ }^{198}$ destaca los siguientes diez diferentes tipos de uso esta herramienta de la web social.

\section{Función}

1. Navegador

2. Cooperación

3. Interoperabilidad

4. Flexibilidad y sencillez de uso

5. Etiquetado

6.Participación (carácter abierto)

7. Variedad y diversidad

8.Personalización

9. Experimentación

10. Desinterés como base.

\section{Utilidad /aplicación}

Herramienta

Método facilitador para el intercambio de experiencias

Fundamento de comunicación entre sistemas para intercambio de datos

Recurso para para publicar contenidos

Opción para la inclusión de datos

Principio para la socialización

Fundamento para la manifestación sin limites

Posibilidad de ajustar a necesidades concretar

Norma de renovación y actualización de contenidos, estructuras, formas, etc.

Incluye como elemento definitorio la búsqueda del bien común 
En esta misma línea también Merlo Vega $\left(1999\right.$, p.1) ${ }^{199}$ destaca la posibilidad de integrar estas diez aplicaciones en los siguientes cuatro objetivos concretos.

a. Aplicación dirigidas al desarrollo de las colecciones

b. Aplicaciones para la organización y presentación de los recursos de información que conforman la o las colecciones

c. Aplicaciones como medio de difusión de los nuevos recursos de información o ya existentes en la colección

d. Aplicaciones en la actividad profesional en las tareas propias del trabajo de las bibliotecas

En el contexto específico de la propuesta concreta del modelo sugerido en la presente guía, es necesario adicionar la anterior clasificación, una nueva opción orientada a la enseñanza en línea y orientada a los siguientes objetivos

a) Comunicación visto como medio de acercamiento e interacción al usuario

b) Capacitación de usuarios en todas sus formas (presencial, híbrida y/o electrónica) como recurso para la alfabetización informacional

c) Acceso a las fuentes de información como mecanismo de acceso al conocimiento contenido en los repositorios.

El acoplamiento de las áreas antes indicadas a los elementos que integran el modelo de servicio propuesto en esta guía es viable, dada la existencia de fundamentos teóricos; la demanda de servicios telemáticos para fines educativos, la aceptación evidente de las prácticas ya existentes y la flexibilidad del modelo para utilizar o incorporar cualquier herramienta Web 2.0 sin perder de vista los objetivos y metas definidos durante el diseño de la oferta del servicio. En la siguiente figura se ilustra a modo general el acoplamiento y/o fusión de las áreas de aplicación de la Web 2.0 para fines educativos y los elementos el servicio propuesto.

Elementos del Modelo en correspondencia con los objetivos de las prácticas actuales

\begin{tabular}{|c|c|}
\hline Referencia digital & $\bullet$ Comunicación \\
\hline Actividades ALFIN & $\bullet$ Capacitación \\
\hline Repositorios para la educación & •Acceso a las fuentes \\
\hline
\end{tabular}

Figura 121. Fusión de las áreas de aplicación de la Web 2.0 para fines educativos al modelo de servicio con la práctica identificada. Fuente: Elaboración propia. 
Con el objetivo de fundamentar lo antes referido, en las siguientes páginas se presentan un conjunto de prácticas de servicios en línea ofrecidos por bibliotecas, archivos y mediatecas ubicadas en los Países Bajos. Estas prácticas han sido desarrolladas como recursos alternativos para solventar las limitaciones en los procesos de comunicación asincrónica y sincrónica; crear las facilidades de generar medios y recursos para la formación de usuarios y como medios para ampliar la cobertura de acceso a los soportes del conocimiento.

El inventario de estas experiencias fue realizado por un grupo de profesionales de los Países Bajos ${ }^{200}$, Los ejemplos extraídos han sido traducidos e interpretados para fines de esta guía. Igualmente ha sido verificada la funcionalidad de cada uno de los enlaces institucionales. Cabe destacar que no deben ser vistos como posibles patrones estándares, sino como un conjunto de iniciativas válidas, coherentes diseñadas en correspondencia a los objetivos propios de cada institución, la disponibilidad de recursos y realidades de los entornos en que están inmersas.

Prácticas de uso de recursos Web 2.0 en la biblioteca

\begin{tabular}{|c|c|}
\hline Recurso social media & Empleo \\
\hline $\begin{array}{l}\text { Aplicación: } \\
\text { Blogger } \\
\text { (Referencia digital) }\end{array}$ & $\begin{array}{l}\text { Aplicación: Weblogs } \\
\text { Alcance del servicio: Comunicación e Interoperabilidad } \\
\text { Usuarios: Cualquier usuario potencial } \\
\text { Objetivo: Establecer un proceso de comunicación dinámica e interactiva } \\
\text { con todos los usuarios potenciales de la biblioteca } \\
\text { Práctica de uso: http://www.biebblog.nl } \\
\text { Costos: Desarrollo y alojamiento del blog } \\
\text { Ventajas: Es posible mantener una comunicación interactiva. } \\
\text { Se desarrolla de forma dinámica desde lo interno de la biblioteca (el foco } \\
\text { de centralización del servicio es la biblioteca) } \\
\text { Desventajas: La actualización y evaluación del blog requiere una seria } \\
\text { inversión de tiempo y energía }\end{array}$ \\
\hline $\begin{array}{l}\text { Aplicación: } \\
\text { RSS-feed en el sitio Web } \\
\text { (Comunicación y Acceso a la } \\
\text { colección) }\end{array}$ & $\begin{array}{l}\text { Aplicaciones involucradas: RSS, Hyves } \\
\text { Alcance del servicio: gestión de diversa información } \\
\text { Widgets (aplicación extras) y Gadgets (aparatos) } \\
\text { Usuarios: Visitantes del blog, facebook y Hyves página } \\
\text { Objetivo: Visualización y enlace de RSS con otras aplicaciones como } \\
\text { Facebook en Hyves } \\
\text { Práctica de uso: La aplicación de búsqueda de hyves } \\
\text { http://informatiezoeken.hyves.nl y el website yourminis: } \\
\text { http://www.yourminis.com } \\
\text { Desde el sitio del sistema yourminis.com }{ }^{201} \text { es posible combinar } \\
\text { aplicaciones RSS-feed y hacer aplicaciones extras (widget) que son } \\
\text { cargadas desde un sitio web o bien Hyves } \\
\text { Costos: El uso del sitio Web yourminis.com es gratis } \\
\text { Inversión de tiempo (60 minutos) por parte del personal para que a través } \\
\text { del sitio yourminis.com instalar un RSS-feed y generar un reproductor } \\
\text { widget y gadget sea colocados en el sistema Hyves }\end{array}$ \\
\hline
\end{tabular}

200 El documento está disponible en http://www.bnbibliotheek.nl/sites/default/files/Hoe_verder_na\%2023_dingen_ebook_0.pdf.

201 Yourminises ees mucho más que un lector de RSS -es un servidor de widgets. Yourminispermite modificar con su propio conjunto de widgets-RSS, imágenes de Flickr, YouTube, calendarios y facilita manejar información sobre el clima, precios de las acciones, etc. 


\begin{tabular}{|c|c|}
\hline Recurso social media & Empleo \\
\hline & $\begin{array}{l}\text { Ventajas: La instalación de un reproductor básico en el RSS-feed resulta } \\
\text { rápida. Otros RSS-feeds pueden ser actualizados con el mismo } \\
\text { reproductor } \\
\text { Desventajas: El diseño de un flash es limitado. El uso de listas en Hyves } \\
\text { son interesantes, pero la ausencia de un control estadístico se desconoce } \\
\text { su uso }\end{array}$ \\
\hline $\begin{array}{l}\text { Aplicación: } \\
\text { Netvibes Universum } \\
\text { (Comunicación y Acceso a la } \\
\text { colección) }\end{array}$ & $\begin{array}{l}\text { Aplicaciones involucradas: RSS, Netvibes, Catálogo de la biblioteca } \\
\text { Alcance del servicio: gestión de diversa información } \\
\text { Usuarios: Usuarios de la biblioteca } \\
\text { Objetivo: Proporcionar información sobre los diferentes recursos } \\
\text { disponibles en la biblioteca. Proporcionar a los usuarios las facilidades de } \\
\text { generar aplicaciones personales con Netvibes para la gestión de la } \\
\text { información necesaria. } \\
\text { Práctica de uso: Netvibes universum } \\
\text { http://www.netvibes.com/cmb / http://www.netvibes.com/digicmb } \\
\text { Costos: Inversión de tiempo por parte del personal } \\
\text { Ventajas: La aplicación en Netvibes resulta fácil tanto para el diseño } \\
\text { como para compartir información. } \\
\text { Desventajas: Limitaciones para mejorar o hacer cambios en el diseño. }\end{array}$ \\
\hline $\begin{array}{l}\text { Aplicación: } \\
\text { (Comunicación y Acceso } \\
\text { información) }\end{array}$ & $\begin{array}{l}\text { Aplicaciones involucradas: Flickr } \\
\text { Alcance del servicio: Colección de fotos, gestión de archivo } \\
\text { Usuarios: Usuarios de la biblioteca } \\
\text { Objetivo: Ofrece el acceso parcial a la colección de fotos de la biblioteca, } \\
\text { posibilitando a los usuarios el uso y agregar aportes } \\
\text { Práctica de uso: Aplicación de Flickr para la difusión de la colección de } \\
\text { fotos del archivo nacional de los Países Bajos } \\
\text { http://www.flickr.com/photos/nationaalarchief } \\
\text { Costos: El uso completo de la aplicación Web Flickr.com tiene un costo de } \\
25 \text { euros al año } \\
\text { La inversión de tiempo por parte del personal para colgar y hacer la } \\
\text { descripción de las fotos } \\
\text { Ventajas: Flickr es una aplicación fácil de trabajar. Los usuarios de Flickr } \\
\text { pueden aportar fotos a la colección del Archivo Nacional } \\
\text { Desventajas: La digitalización y colocación de una colección de fotos } \\
\text { cuesta mucho tiempo. }\end{array}$ \\
\hline $\begin{array}{l}\text { Aplicación: } \\
\text { Delicious } \\
\text { (Comunicación y Acceso a } \\
\text { repositorio) }\end{array}$ & $\begin{array}{l}\text { Aplicaciones involucradas: Delicious } \\
\text { Alcance del servicio: Listas y enlaces } \\
\text { Usuarios: Lectores de revistas } \\
\text { Objetivo: Ofrecer a los lectores de las revistas electrónicas un resumen } \\
\text { con enlace a la revista } \\
\text { Práctica de uso: Delicios-account Gestión de revistas: } \\
\text { http://delicious.com/biblionmediacoach } \\
\text { Costos: El uso de sitio Web delicious.com es gratis } \\
\text { Inversión de tiempo (10 minutos por revista) por parte del personal de la } \\
\text { biblioteca para la insertar los enlaces en el sistema } \\
\text { Ventajas: Los lectores de revistas electrónicas pueden salir y luego } \\
\text { localizar rápidamente el enlace de la revista y regresar a la revista sin } \\
\text { problema } \\
\text { Los errores de ortografía en los enlaces de la revistas pueden ser }\end{array}$ \\
\hline
\end{tabular}




\begin{tabular}{|c|c|}
\hline Recurso social media & Empleo \\
\hline & $\begin{array}{l}\text { fácilmente corregidos } \\
\text { Desventajas: Cuesta mucho tiempo la redacción y asignación de } \\
\text { descriptores temáticos para revistas, así como colgar estos en la } \\
\text { aplicación Delicious. }\end{array}$ \\
\hline $\begin{array}{l}\text { Aplicación: } \\
\text { Wiki - Centro de Información y } \\
\text { conocimiento } \\
\text { (Comunicación y Acceso a } \\
\text { información) }\end{array}$ & $\begin{array}{l}\text { Aplicaciones involucradas: Wiki } \\
\text { Alcance del servicio: Intercambio de conocimientos; gestión de listas; } \\
\text { comunidad virtual } \\
\text { Usuarios: Todo individuo interesado en determinado tema de la Wiki } \\
\text { Objetivo: Reunir todos los blog de valor académico y técnico de los Países } \\
\text { Bajos } \\
\text { Práctica de uso: De wiki-site van NL biblioblogs: } \\
\text { http://nlbiblioblogs.pbworks.com } \\
\text { Costos: El uso de la herramienta Wiki-systeem del sitio Web PBworks.com } \\
\text { es gratis. El costo significativo corresponde a la inversión de tiempo de los } \\
\text { encargados de la actualización del sitio Wiki } \\
\text { Ventajas: Resulta fácil y sencillo la actualización del contenido del Wiki } \\
\text { Desventajas: El proyecto fue una iniciativa de voluntarios y después de un } \\
\text { tiempo se descontinuo. }\end{array}$ \\
\hline $\begin{array}{l}\text { Aplicación: } \\
\text { Wiki - Sistema de manejo de } \\
\text { contenidos } \\
\text { (Content Management } \\
\text { Systeem' } \\
\text { (Comunicación, Formación y } \\
\text { Acceso a Repositorio) }\end{array}$ & $\begin{array}{l}\text { Aplicaciones involucradas: Wiki } \\
\text { Alcance del servicio: CMS, Website } \\
\text { Usuarios: Usuarios reales de la mediateca } \\
\text { Objetivo: Informar a los usuarios de la mediateca sobre la disponibilidad } \\
\text { de los diferentes recursos y servicios de información } \\
\text { Práctica de uso: Sitio Wiki de la mediateca de la organización Fontys } \\
\text { http://www.fontysmediatheken.nl/wiki } \\
\text { Costos: Adquisición de derecho a un dominio anual para la Wiki. Este } \\
\text { puede variar entre } 50 \text { y } 250 \text { euros. Costos profesionales para el diseño e } \\
\text { implementación de la Wiki. Tiempo de personal de la biblioteca } \\
\text { responsable de la actualización } \\
\text { Ventajas: Resulta fácil agregar o actualizar los contenidos. Todos los } \\
\text { empleados de la biblioteca pueden agregar contenidos y actualizar la Wiki } \\
\text { Desventajas: Resulta complejo para los empleados de la biblioteca, la } \\
\text { sistematización de los aportes en la Wiki por usuarios externos. }\end{array}$ \\
\hline $\begin{array}{l}\text { Aplicación: } \\
\text { Twitter Ning } \\
\text { (Comunicación, y Acceso a } \\
\text { información) }\end{array}$ & $\begin{array}{l}\text { Aplicaciones involucradas: Ning } \\
\text { Alcance del servicio: Servicio de información a la comunidad de usuarios; } \\
\text { Servicio de Alerta } \\
\text { Usuarios: Usuarios reales y potenciales de la biblioteca. } \\
\text { Objetivo: Informar a los usuarios sobre las nuevas adquisiciones de la } \\
\text { biblioteca } \\
\text { Práctica de uso: Twitter para la biblioteca de la ciudad de Breda: } \\
\text { http://twitter.com/biebbreda } \\
\text { Costos: La apertura de cuenta en twitter es gratis. El costo significativo } \\
\text { corresponde a la inversión de tiempo de los encargados de la } \\
\text { actualización Twitter } \\
\text { Ventajas: Es una aplicación rápida; Desde el sitio Web twitterfeed.com } \\
\text { resulta fácil desde la dirección transferir y/o actualizar contenidos en RSS } \\
\text { Desventajas: El servicio requiere una actualización constante e inmediata. }\end{array}$ \\
\hline $\begin{array}{l}\text { Aplicación de programa: RSS- } \\
\text { feed Twitter }\end{array}$ & $\begin{array}{l}\text { Aplicaciones involucradas: Weblog; RSS; Twitter } \\
\text { Alcance del servicio: Informar y promocionar servicios, comunicación }\end{array}$ \\
\hline
\end{tabular}




\begin{tabular}{|c|c|}
\hline Recurso social media & Empleo \\
\hline $\begin{array}{l}\text { (Comunicación, Formación y } \\
\text { Acceso a Repositorio) }\end{array}$ & $\begin{array}{l}\text { inmediata } \\
\text { Objetivo: Informar sobre las actividades, novedades y cursos ofrecidos } \\
\text { por la biblioteca a los estudiante y docentes seguidores de Twitter de la } \\
\text { biblioteca } \\
\text { Usuarios: Usuario reales de la biblioteca } \\
\text { Costos: La apertura y uso de una cuenta Twitter es gratis. El costo } \\
\text { significativo corresponde a la inversión de tiempo de los encargados de la } \\
\text { actualización Twitter } \\
\text { Práctica de uso: Twitteraccount Mediateca: } \\
\text { http://twitter.com/librariantf } \\
\text { Twitterfeed: http://www.twitterfeed.com } \\
\text { Ventajas: Es una nueva oferta de servicio de respuesta inmediata y sin } \\
\text { costo adicionales. } \\
\text { Desventajas: No todos las aplicaciones RSS-feeds son operan con twitter }\end{array}$ \\
\hline $\begin{array}{l}\text { Aplicación: } \\
\text { Google como un sistema de } \\
\text { gestión de contenidos CMS } \\
\text { (Comunicación, y Acceso a } \\
\text { Repositorio) }\end{array}$ & $\begin{array}{l}\text { Aplicaciones involucradas: Google Sites } \\
\text { Alcance del servicio: Creación de un sitio Web } \\
\text { Genera un sistema de gestión de contenidos (CMS) } \\
\text { Objetivo: Facilitar a los usuarios de la biblioteca un acceso rápido al sitio } \\
\text { Web de la misma } \\
\text { Usuarios: Usuarios reales de la biblioteca } \\
\text { Práctica de uso: Repositorio para la educación. Biblioteca de la Ciudad de } \\
\text { Eindhoven } \\
\text { http://sites.google.com/site/onderwijswinkelbe/ } \\
\text { Costos: No hay costos implicados. Crear un cuenta en Google -site es } \\
\text { gratis } \\
\text { Ventajas: El diseño de una página Web en Google resulta fácil y rápido; } \\
\text { no hay dependencia del departamento de informática y de un servidor } \\
\text { para instalación de la página } \\
\text { Desventajas: Los sitios de Google no son siempre profesionales }\end{array}$ \\
\hline $\begin{array}{l}\text { Aplicación: } \\
\text { Google Apps } \\
\text { (Comunicación) }\end{array}$ & $\begin{array}{l}\text { Aplicaciones involucradas: Google Gmail, Google Docs, Agenda y Chat } \\
\text { Alcance del servicio: E-mail, tareas compartidas, Chat } \\
\text { Objetivo: Facilitar un medio de comunicación sencillo y funcional de } \\
\text { correo electrónico entre los empleados de la biblioteca. } \\
\text { Usuarios: Usuarios de la biblioteca } \\
\text { Práctica de uso: http://www.bibliotheekmaasland.nl/index. } \\
\text { php?option=com_content\&task=view\&id=1405 } \\
\text { Video con Google Apps : http://www.youtube.com/ } \\
\text { watch?v=Xcd-BYf1QXM en http://essentials-media. } \\
\text { matchpoint.nl/index.php?item=487 } \\
\text { Costos: El uso de Google Apps es gratis, sin embargo los costos } \\
\text { corresponden a la contratación de un especialista para la configuración } \\
\text { del Google-mailserver } \\
\text { Ventajas: No se requiere comprar o alquilar un servidor; es una aplicación } \\
\text { libre de spam y protegida de virus; alcance mundial; garantía de respaldo } \\
\text { y seguridad de los correos; colaboración integrada; actualización de } \\
\text { aplicaciones es automática; disponibilidad de tutoriales y archivos } \\
\text { soporte } \\
\text { fácil manejo } \\
\text { Desventajas: Google Apps ofrece diferentes paquetes y versiones que }\end{array}$ \\
\hline
\end{tabular}




\begin{tabular}{|c|c|}
\hline Recurso social media & Empleo \\
\hline & todavía no son aplicables en la biblioteca \\
\hline $\begin{array}{l}\text { Aplicación: } \\
\text { CU@MSN } \\
\text { (Comunicación y Formación) }\end{array}$ & $\begin{array}{l}\text { Aplicaciones involucradas: MSN, Catálogo de la biblioteca } \\
\text { Alcance del servicio: Chat, sistema de búsqueda, formación de usuarios } \\
\text { Usuarios: Alumnos de educación primaria. Grupo } 7 \\
\text { Objetivo: Orientar a los estudiantes de educación primaria en el uso de } \\
\text { los recursos MSN para la búsqueda de información y realización de } \\
\text { trabajos de cursos } \\
\text { Práctica de uso: Sitio Web CU@MSN de la biblioteca } \\
\text { Altena: http://www.bibliotheekaltena.nl/ } \\
\text { Costos: La apertura de una cuenta en MSN es gratis } \\
\text { Ventajas: La aplicación corresponde al nivel de usuarios del servicio; La } \\
\text { iniciativa de la aplicación MSN resulta ser sistema fácil y aplicable en el } \\
\text { sector de todas las escuelas de educación básica } \\
\text { Desventajas: El éxito del servicio depende de las aplicaciones y trabajo en } \\
\text { equipo con otras escuelas }\end{array}$ \\
\hline $\begin{array}{l}\text { Aplicación: } \\
\text { YouTube } \\
\text { (Comunicación y formación) }\end{array}$ & $\begin{array}{l}\text { Aplicaciones involucradas: Video; Screencasts } \\
\text { Alcance del servicio: Tesauros; Guías y Manual de instrucciones; Servicio } \\
\text { de Referencia (Respuesta automáticas) } \\
\text { Objetivo: Responder a la preguntas de los usuarios mediante el uso de } \\
\text { videos } \\
\text { Práctica de uso: Canal de video de la mediateca. } \\
\text { http://www.youtube.com/mediatheektf } \\
\text { El proyecto plan está disponible en: } \\
\text { http://www.fontysmediatheek.nl/wiki/home/ } \\
\text { Projecplan_Screencast_als_FAQ } \\
\text { Costos: El uso de Youtube es gratis. Los costos implicados corresponden } \\
\text { al uso de un estudio de cámara para las grabaciones y ediciones de los } \\
\text { videos. El costo aproximado de una licencia, la inversión de tiempo } \\
\text { completo de dos empleados de la biblioteca para la generación de seis } \\
\text { manuales de instrucciones } \\
\text { Ventajas: El uso de video resulta atractivo para los usuarios y las } \\
\text { preguntas de los usuarios son respondidas rápidamente. } \\
\text { Desventajas: La aplicación de este instrumento requiere mucho trabajo y } \\
\text { tiempo }\end{array}$ \\
\hline $\begin{array}{l}\text { Aplicación: } \\
\text { Ning como una Intranet } \\
\text { (Comunicación) }\end{array}$ & $\begin{array}{l}\text { Aplicaciones involucradas: Ning } \\
\text { Alcance del servicio: Website; CMS; Intranet } \\
\text { Objetivo: Constituir una red de comunicación dinámica e interna para } \\
\text { facilitar la comunicación entre los empleados de la biblioteca } \\
\text { Usuarios: Dirección y empleados de la biblioteca } \\
\text { Costos: La aplicación básica de Ning.com es gratis. Otras facilidades están } \\
\text { sujetas a costos. Los gastos incurridos en esta experiencia } \\
\text { correspondieron al tiempo invertido en el diseño y mantenimiento de la } \\
\text { intranet } \\
\text { Ventajas: La instalación de una intranet vía el sitio Web de Ning.com } \\
\text { resulta rápida } \\
\text { El sitio Web de Ning ofrece otras aplicaciones de uso } \\
\text { Desventajas: Limitaciones para copias de respaldo de los datos } \\
\text { registrados en la intranet. }\end{array}$ \\
\hline Aplicación: & Aplicaciones involucradas: LibraryThing \\
\hline
\end{tabular}




\begin{tabular}{|l|l|}
\hline Recurso social media & Empleo \\
\hline LibraryThing para listado de & Alcance del servicio: Lista de enlaces a libros; Catalogación de libros \\
libros & Objetivo: Hacer disponible un listado visualmente atractivo de libros que \\
permitan crear una comunidad de usuarios con intereses comunes
\end{tabular}

\subsection{Directrices generales}

El útimo apartado de este capítulo ofrece directrices básica para cada uno de los tres componentes del sistema: referencia digital, alfabetización informacional y repositorios para la educación. Se quieren ofrecer las pautas necesarias que se deben tener en cuenta para el desarrollo de estos servicios y su integración en las plataformas de enseñanza E-learning. De esta forma, se sintetizan los factores determinantes en el diseño de cada servicio y las características correspondientes a cada uno de los factores.

\subsubsection{Directrices básicas para el componente de la referencia digital}

El concepto aplicado a este componente de referencia digital corresponde a la comunicación asincrónica y sincrónica, por lo que en adelante la atención es centrada al servicio de Pregunte al bibliotecario. Sobre este servicio de comunicación, existen diferentes aportes de manuales y guías disponibles en pdf y en Internet, por lo que este inciso se limita a ofrecer algunas directrices generales y muy puntales para ser consideradas al momento de diseñar este componente del modelo propuesto.

\section{Factores determinantes en el diseño y caracterización del servicio}

El diseño del servicio de referencia del modelo propuesto en esta guía, radica en aplicar una visión sistémica en relación a los objetivos y su vinculación directa con los otros elementos. Esto permitirá estar alertas a los posibles cambios en el ámbito social, cultural y las condiciones económicas que impactan en el diseño y las características del servicio. Asimismo considerando la base teórica presentada en el apartado 4.4.3, así como las prácticas expuestas en el estudio de caso, capítulo 7 y el inventario de iniciativas anteriores, nos permite fijar los siguientes factores básicos y características generales para el diseño y caracterización del servicio: 


\begin{tabular}{|l|l|}
\hline \multicolumn{2}{|c|}{ Orientación: Comunicación } \\
\hline Factores determinantes en el diseño & Posibles características del servicio \\
\hline Disponibilidad y desarrollo tecnológico & Sincrónico o asincrónico \\
\hline $\begin{array}{l}\text { Diseño, organización y presentación de la } \\
\text { información }\end{array}$ & Ventanas, iconos, listas de enlaces \\
\hline $\begin{array}{l}\text { Valor agregado } \\
\text { Medios de comunicación }\end{array}$ & $\begin{array}{l}\text { Instrucción, agrupación de contenidos por } \\
\text { materias, buscadores }\end{array}$ \\
\hline Alcance & $\begin{array}{l}\text { Presencia y contacto permanente de la } \\
\text { biblioteca con el usuario }\end{array}$ \\
\hline Gestión - administración & Restringido y direccionado a un grupo meta \\
\hline Fabla 38. Directrices generales para el diseño del componente \\
Fuente: Elaboración propia.
\end{tabular}

Una vez definido el alcance y características del diseño, es determinante elaborar un manual que describa el procedimiento para la organización del ciclo de la comunicación pregunta-respuesta a fin de generar un esquema lógico de funcionamiento del servicio. En este contexto, el manual debe responde a las siguientes preguntas:

- ¿Cómo se efectúa el contacto con el usuario?

- ¿Cómo se realiza la recepción de la pregunta?

- ¿Qué criterios se utilizan para definir la pregunta?

- ¿Qué estructura y estilo se deben usar para las respuestas?

- ¿Cuáles son los límites de la atención en línea?

- ¿Cuáles son los problemas durante el chat y cómo podemos superarlos?

- ¿Cómo mantener una comunicación simultáneamente con varios usuarios?

- ¿Como se procede y debe realizar el cierre de la sesión de chat con el usuario?

- ¿Cómo se organizan los cierres de turnos entre bibliotecarios?

- ¿Cómo y cuándo usar el sistema de mensajería instantánea y transferencia de preguntas? 
- ¿Cuáles son los procedimientos de transferencia de preguntas?

- ¿Qué tipo de recursos de apoyo debe disponer obligatoriamente el bibliotecario responsable del servicio?

La creación de servicios de referencia digital está muy bien estructurada en la obra resultante de la tesis doctoral de Merlo Vega (2009) en la que establece 50 aspectos que deben tenerse en cuenta para la planificación y creación de un servicio de referencia ${ }^{202}$. Este medio centenar de recomendaciones son organizadas en torno a los siguientes aspectos:

1. Agentes: a) Bibliotecarios, b) Usuarios

2. Técnicas: a) Sistemas de comunicación, b) Proceso de referencia

3. Recursos: a) Colección de referencia, b) Productos informativos

4. Gestión: a) Diseño, b) Planificación, c) Administración, d) Evaluación

En la globalidad de estos elementos se recogen las pautas o recomendaciones que se deben tener en cuenta para la creación de un servicio de referencia digital, conviertiéndose en una lista de comprobación muy útil como herramienta para la implementación del servicio.

\subsubsection{Directrices básicas para el componente de la alfabetización informacional}

En el apartado 4.5.6 se ha mencionado la existencia de catorce modelos actualmente vigentes para diseñar el servicio ALFIN ${ }^{203}$. Asimismo, se ha indicado que el diseño de este servicio está influenciado por los entornos y adquiere características propias para su funcionamiento. En el caso específico de la formación de usuarios en línea, la cooperación facilita el uso de estándares y el aprendizaje de las buenas prácticas, el intercambio de experiencias, materiales de formación y facilita la actualización constante con el uso de nuevas aplicaciones tecnológicas.

En esta línea, las directrices ofrecidas en esta guía para el diseño del Servicio de alfabetización informacional orientan prestar atención a los siguientes puntos:

\section{Estudio previo: necesidades y factibilidad del servicio}

El diseño del servicio de formación debe responder a una necesidad y/o demanda, hecho que impone la necesidad de realizar un estudio para identificar las demandas del el grupo meta a quién será dirigido el servicio. Asimismo la ejecución de este estudio permitirá planificar y organizar estratégicamente la estructura, forma y contenido del servicio de formación y adecuando la oferta a las necesidades de cada programa de curso.

Es importante destacar que el estudio de necesidades de capacitación debe aportar al análisis de factibilidad del diseño e implementación del servicio, por tanto se recomienda la revisión de los siguientes aspectos:

\footnotetext{
${ }^{202}$ Merlo Vega se basa en normas internacionales, que complementa con los resultados de su investigación doctoral, así como con experiencias prácticas.

${ }^{203}$ El Informe APEI 5 (2010) sobre alfabetización informacional incluye una revisión actualizada de estas corrientes.
} 


\begin{tabular}{|c|c|}
\hline Aspectos generales & Descripción \\
\hline \multicolumn{2}{|r|}{ Análisis de la demanda } \\
\hline ¿Cuáles son las demandas? & $\begin{array}{l}\text { Identificación de las necesidades o los problemas de } \\
\text { conocimientos a resolver. Para este fin pueden ser } \\
\text { usadas encuestas, entrevistas, Blogs, etc. }\end{array}$ \\
\hline \multicolumn{2}{|r|}{ Identificación del grupo meta } \\
\hline ¿Quiénes? & $\begin{array}{l}\text { Identificación y caracterización del grupo demandante } \\
\text { (tipología, nivel de conocimiento, características } \\
\text { socioculturales, etc.) }\end{array}$ \\
\hline \multicolumn{2}{|c|}{ Planteamiento de objetivos y metas } \\
\hline ¿Qué hacer? & Objetivos concretos \\
\hline \multicolumn{2}{|r|}{ Estrategias de acción } \\
\hline $\begin{array}{l}\text { ¿En que áreas se concentra } \\
\text { la estrategias? }\end{array}$ & $\begin{array}{l}\text { Nivel o tipo de alfabetización que se atenderá } \\
\text { a.- Alfabetización informática } \\
\text { b - Alfabetización bibliotecaria } \\
\text { c.- Alfabetización en los medios }\end{array}$ \\
\hline \multicolumn{2}{|c|}{ Definición y delimitación de la oferta } \\
\hline $\begin{array}{l}\text { ¿Qué diseño a seguir para } \\
\text { programas de } \\
\text { alfabetización? }\end{array}$ & $\begin{array}{l}\text { Programas y proyectos } \\
\text { Servicios de autoaprendizajes (videos, demos, etc.) } \\
\text { Capacitaciones: } \\
\text { *. Cursos de orientación al uso de las bibliotecas } \\
\text { *.Cursos sobre el uso de los recursos tecnológicos } \\
\text { *.Cursos sobre determinados softwares } \\
\text { * Cursos de citación, etc. }\end{array}$ \\
\hline \multicolumn{2}{|r|}{ Evaluación } \\
\hline $\begin{array}{l}\text { Para qué evaluar? } \\
\text { Qué evaluar } \\
\text { Quién realiza la evaluación? }\end{array}$ & $\begin{array}{l}\text { Objetivo y enfoque de la evaluación, es decir qué se } \\
\text { desea medir } \\
\text { Tipos de evaluación (usabilidad, contenido, procesos } \\
\text { de comunicación, aplicación tecnológica, etc.) }\end{array}$ \\
\hline
\end{tabular}




\section{2.- Selección o ajuste de un modelo teórico para la planificación de cursos}

Existen diferentes modelos para el desarrollo de proyectos o programas de formación de habilidades y destrezas, los que han sido debidamente descritos en el apartado 4.4.4 de esta tesis. Asimismo, se ha concluido que el origen de estos modelos integra las experiencias y prácticas precedentes a ellos. Sin embargo, las variantes entre uno y otro programa ALFIN, se fijan de acuerdo al nivel y características del grupo meta. El servicio de formación debe ser debidamente diseñado, de tal forma que el usuario pueda adquirir conocimientos, que le permitan adquirir las siguientes capacidades y habilidades transversales y por consiguiente participar en el ciclo de transferencia del conocimiento.

\begin{tabular}{|l|l|}
\hline Buscar & $\begin{array}{l}\text { Formulación y análisis de necesidades } \\
\text { Identificar posibles fuentes }\end{array}$ \\
\hline Acceder & $\begin{array}{l}\text { Localización de fuentes individuales } \\
\text { Evaluar }\end{array}$ \\
\hline Usar & $\begin{array}{l}\text { Interpretación, análisis, síntesis y evaluación de la información y rechazo de fuentes } \\
\text { Aplicación de la información a sus objetivos }\end{array}$ \\
\hline Citar & $\begin{array}{l}\text { Reconocer y dar crédito a la autoridad de los contenidos (información) } \\
\text { utilizados }\end{array}$ \\
\hline Publicar & $\begin{array}{l}\text { Presentación y comunicación del trabajo resultante } \\
\text { Evaluación de los logros conseguidos }\end{array}$ \\
\hline
\end{tabular}

El segundo componente del modelo integrador Biblioteca/E-learning está formado por las acciones realizadas por los servicios de alfabetización informacional que ofrezca la biblioteca. La diferencia en el planteamiento debe ser que deben orientar estos servicios formativos hacia el espacio desde el que se van impartir, que son las plataformas de enseñanza telemática. Por una parte, las acciones de alfabetización informacional serán similares a las que realizan las bibliotecas, como en los casos de los tutoriales, guías, FAQ, etc. En estos casos, los contenidos pueden ser los mismos, incluso los formatos y la forma de diseñarlos y bastará con integrarlos en las plataformas según las posibilidades de las mismas. Por otra parte, los servicios de formación en información también se deben ofrecer partiendo de las propias tecnologías, es decir, empleando las posibilidades para la creación de formularios, encuestas, juegos, objetos de aprendizaje, etc. que contemplen las aplicaciones de enseñanza telemática. Así se obtienen mejores resultados, ya que se diseñan los recursos formativos con las propias herramientas de la plataforma E-learning. 


\subsubsection{Directrices básicas para el componente de los repositorios para la educación}

El concepto de repositorio se ha venido empleando en esta tesis doctoral como el conjunto de recursos informativos, procesados mediante estándares normalizados y disponibles en línea. Habitualmente, se emplea el concepto de repositorio como almacén donde se alojan contenidos, aunque desde el punto de vista bibliotecológico se deben concebir los repositorios como aquellos servidores que cumplen estos requisitos:

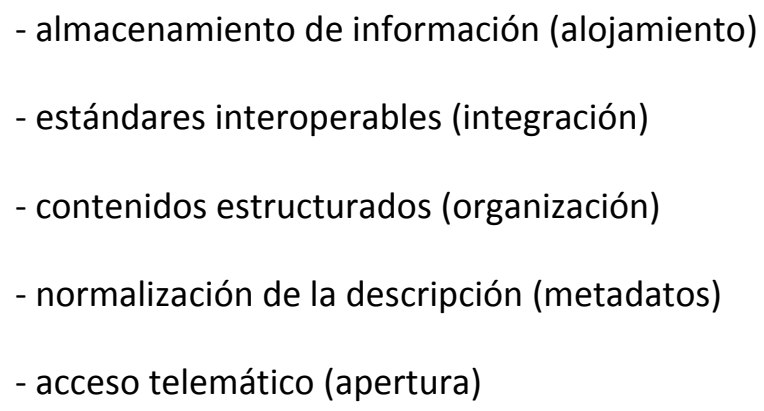

La literatura profesional sobre repositorios es ingente, tanto desde el punto de vista informático, como desde la perspectiva del acceso abierto o bien como almacenamiento de recursos pedagógicos. En el modelo integrador que se desarrollado en esta investigación intervienen elementos a) informáticos, relativos a las plataformas E-learning, b) informativos, sobre recursos de apoyo al aprendizaje y la investigación, como artículos científicos, y c) pedagógicos, al ser los repositorios de objetivos de aprendizaje una herramienta excepcional tanto como recurso de aprendizaje como recurso informativo.

Las directrices para el diseño de una oferta de acceso a repositorios para la educación, es un tarea que debe ser realizada tomando en cuenta las experiencias de buenas prácticas. De la revisión de literatura sobre el tema, se retomó el aporte teórico metodológico de Mary R. Barton, Margaret M. Waters $(2005)^{204}$, para la caracterización y clasificación de los repositorios para fines educativos en los siguientes cuatros grandes grupos:
a) repositorios de revistas electrónicas
b) repositorios de libros electrónicos
c) repositorios de mapas (GIS)
d) repositorios de objetos de aprendizaje.

Estos grupos contemplan la diversidad de contenidos que pueden ofrecerse como apoyo al aprendizaje y a la investigación, ya que incluyen tanto revistas y libros, como objetos gráficos y, sobre todo, objetos de aprendizaje, creados exclusivamente para la enseñanza. La Biblioteca puede ser tanto creadora como gestora de este tipo de repositorios.

Por último, es necesario señalar que el acceso a los contenidos de cualquiera de los repositorios anteriormente señalado, requiere una revisión previa de la oferta a partir de los siguientes aspectos: 


\begin{tabular}{|c|c|}
\hline Identificación de la demanda & $\begin{array}{l}\text { Evaluación de las necesidades de la comunidad } \\
\text { universitaria }\end{array}$ \\
\hline $\begin{array}{l}\text { Existencia, revisión de } \\
\text { experiencias existentes }\end{array}$ & $\begin{array}{l}\text { Aprendizaje de las buena prácticas } \\
\text { Búsqueda de alianzas }\end{array}$ \\
\hline Definición del modelo & $\begin{array}{l}\text { Diseño de la propuesta del modelo de servicio, } \\
\text { delimitando objetivamente su alcance } \\
\text { Determinación de la relación costo-beneficios del } \\
\text { servicio } \\
\text { Definición de políticas recopilación, sistematización de } \\
\text { contenidos, su distribución y mantenimiento } \\
\text { Elaborar manuales que orienten la gestión, prestación } \\
\text { del servicio }\end{array}$ \\
\hline $\begin{array}{l}\text { Delimitación de los recursos } \\
\text { tecnológicos (selección de } \\
\text { programas y desarrollo de } \\
\text { aplicaciones) }\end{array}$ & $\begin{array}{l}\text { Uso de formatos semánticos XML } \\
\text { Uso de recursos de descripción referenciales RDF } \\
\text { Uso de arquitectura común de intermediarios } \\
\text { =Common Object Request Broker Architecture } \\
\text { Uso de protocolos para la diseminación del contenido } \\
\text { de los metadatos } \\
\text { Uso de protocolos para la diseminación de contenidos } \\
\text { de los metadatos OAI Open archives Iniciative) }\end{array}$ \\
\hline Implementación del servicio & $\begin{array}{l}\text { Formar el equipo de profesionales responsables del } \\
\text { servicio } \\
\text { Definición e implementación de un plan de acción } \\
\text { Definición y ejecución de una estrategia de difusión y } \\
\text { proyección del servicio (marketing) } \\
\text { Desarrollo de proceso evaluativos para la revisión del } \\
\text { servicio }\end{array}$ \\
\hline
\end{tabular}




\section{Capítulo 9 Conclusiones y recomendaciones generales}

\subsection{Introducción}

El presente capítulo tiene como fin presentar las conclusiones y recomendaciones generales originadas a partir de la realización de todo el trabajo de tesis doctoral. Las conclusiones se presentan agrupadas de acuerdo al orden temático abordadas en los apartados. El conjunto de conclusiones presentadas corresponden al enfoque crítico y perspectiva personal de la doctoranda, la que es sustentada en el análisis teórico-conceptual realizado y en el trabajo práctico ejecutado, que fueron orientados a la identificación de las relaciones simbióticas entre la biblioteca y el E-learning.

Finalmente este capítulo ofrece una serie de recomendaciones generales para el diseño e implementación del modelo de oferta de servicios en línea, que son sustentadas en la Parte $V$ Análisis de servicios en línea (capítulos 5 y 6,) y en el capítulo 8. Las recomendaciones que a continuación se incluyen deben ser valoradas como marco de referencia con enfoque sistémico, cuyo objetivo motiva la orientación de los diseños, implementación y evaluación de servicios telemáticos a la modalidad de educación semipresencial y E-learning.

\subsection{Conclusiones}

\subsubsection{Evaluación del modelo de biblioteca}

Las conclusiones relativas a las bibliotecas y sus sistemas de prestación de servicio que aquí se presentan inciden en la función de apoyo a la enseñanza y al aprendizaje que las bibliotecas universitarias mantienen, como parte de su esencia y como una característica definitoria de las mismas.

1. Las bibliotecas universitarias están actuando como apoyo al aprendizaje. La nueva biblioteca universitaria de cara al mundo académico virtual responde al modelo Centro de Recursos para el Aprendizaje y la Investigación (CRAI) y al modelo Centro Virtual de Información y Conocimiento (VKC). Estos modelos de bibliotecas además de proporcionar el acceso a los recursos tradicionales de la biblioteca y los nuevos recursos electrónicos, también ofrece servicios en línea que orientan a la comunidad universitaria en cómo localizar, acceder y utilizar estos recursos. Cabe destacar que la estructura multifuncional de estos modelos demanda que el bibliotecario sea capaz de asumir roles formativos, educativos y comunicativos.

2. Las bibliotecas se implican de forma activa en la enseñanza. Los resultados del inventario de prácticas de servicios telemáticos de apoyo a procesos de enseñanza aprendizaje evidencia la participación empírica de la biblioteca. La revisión de estas prácticas demuestra la viabilidad de implementar el modelo de servicio propuesto en esta tesis doctoral. Los casos estudiados sirven para demostrar que las bibliotecas universitarias son ejes de apoyo para los procesos de enseñanza/aprendizaje. 
3. Existen diferencias en la implicación de las bibliotecas en la enseñanza. Las diferencias marcadas entre los servicios digitales que ofrecen los distintos modelos de bibliotecas en Europa y América Latina se encuentran significativamente representadas por la disponibilidad de recursos económicos y las políticas nacionales e institucionales. En dependencia de los entornos y disponibilidad de estos recursos, son determinados el nivel de desarrollo de los servicios, calidad de conexión, tipo y diversidad de aplicaciones y el pago por el acceso a las fuentes de información científicas gestionadas por entidades comerciales.

4. La biblioteca universitaria asume como un responsabilidad el apoyo a la enseñanza. En el actual siglo XXI, el rol de la biblioteca universitaria no se limita a facilitar el acceso a la información organizada. Actualmente asume responsabilidades de apoyo a la docencia, tales como la elaboración de guías tutoriales, digitalización de materiales para cursos, elaboración de bibliografías especializadas con enlaces a las fuentes y otros.

5. La biblioteca universitaria ocupa un posición propia en el proceso de enseñanzaaprendizaje. La biblioteca adquiere un espacio para su participación en la tareas educativas, mediante la presencia de cursos de formación de habilidades y destrezas (alfabetización informacional $=$ ALFIN) dentro de los programas de estudios. Esto exige un cambio creativo y proactivo en el perfil del bibliotecario que deberá alfabetizarse y asumir nuevos roles formativos, educativos y comunicativos. Asimismo representa un momento oportuno para introducir el modelo propuesto en esta tesis.

\subsubsection{E-learning}

Las conclusiones relacionadas con el contexto teórico y las plataformas E-learning se orientan hacia la expansión de los sistemas de enseñanza en línea en línea en las universidades, donde se han instalado de forma permanente dadas las posibilidades que ofrecen.

6. El E-learning es un servicio que deben ofrecer las universidades. El concepto E-learning se puede conceptualizar y materializar como un sistema de servicio cuyo objetivo principal es la formación particular o grupal de individuos. Aunque este modelo educativo puede valerse de estándares definidos, éste adquiere sus características propias de organización de acuerdo a los objetivos, institucionales y sobre todo la tipología de sus usuarios, por cuanto estos representan ser el punto de partida para la generación de contenidos, servicios y nivel de aplicación de la tecnología.

7. El E-learning se realiza de forma estructurada para conseguir resultados positivos. Las estructuras organizativas E-learning tienen fundamento en los aspectos teóricos de gestión de información. Esto permite orientar la organización y estructura del conocimiento, el contenido y soporte de información, lo que resulta determinante en el proceso de 
construcción y/o mejoramiento de programas LMS de gestión de contenidos. Los sistemas de E-learning son maleables y se acomodan a las diferentes tipologías de cursos de formación que se quieran ofrecer.

8. El E-learning está normalizado de forma internacional. Las plataformas E-learning actualmente desarrolladas y disponibles cumplen con los estándares reconocidos internacionalmente. Estos estándares facilitan que los programas sean diseñados en correspondencia con los usuarios, los contenidos y las tecnologías. Las áreas actualmente más trabajadas son los procesos y servicios de comunicación, el manejo de contenidos y la operatividad del sistema.

9. El E-learning es un sistema. Las plataformas de enseñanza en línea están conformadas por diferentes elementos o partes integrantes de un todo. Se reconocen tres tipos de servicios Elearning: los dirigidos a la gestión administrativa del curso y a facilitar la orientación, los servicios de comunicación y el acceso a los contenidos. En esta línea de servicios se identifican dos niveles jerárquicos: los docentes y los estudiantes, pero junto a ellos se encuentran otros dos perfiles: informáticos y bibliotecarios.

10. E-learning y Biblioteca comparten metodologías y procesos. Los aspectos metodológicos y funcionales de E-learning para la prestación de servicios resultan compatibles con la biblioteca. Un ejemplo concreto corresponde a los fundamentos teóricos que justifican y clasifican los servicios digitales de E-learning que también es aplicable a los servicios de la biblioteca.

\subsubsection{Puntos de encuentros entre la biblioteca y E-learning}

Se debe concluir que existen elementos de convergencia entre Biblioteca y E-learning, como se expresará en las siguientes afirmaciones conclusivas relativas a esta integración.

11. Transferencia de conocimiento. Los puntos de encuentro entre la biblioteca y E-learning se concentran en el proceso de transferencia de conocimiento, es decir, los principios de formar, educar a través de procesos que permitan al individuo acceder a la información, procesar el conocimiento y apropiarse de él para crear sus propias oportunidades.

12. Integración de servicios. Aspectos metodológicos y funcionales de E-learning para la prestación de servicios resultan compatibles con la biblioteca. Un ejemplo concreto corresponde a que los fundamentos teóricos para el diseño, clasificación y prestación de servicios digitales de E-learning también pueden ser aplicados a los cursos ALFIN. 
13. Cooperación en formación. En la actualidad, hablar con un bibliotecario sobre Moodle, Blackboard, Share Point, y otros programas LMS y LMC, es establecer una conversación en torno a sus experiencias prácticas y creativas de como ellos colaboran con docentes en cursos semipresenciales y E-learning.

14. Compartir recursos. Los recursos de información disponibles en la biblioteca pueden ser aprovechados para proyectos de educación a distancia y E-learning. Para esto se requiere la apropiación de la tecnología y el trabajo en conjunto de los docentes y bibliotecarios a fin de organizar la información y contenidos idóneos, definir el sistema de enlace y formas de acceso.

15. Necesidad de prácticas ejemplares. Aunque existen iniciativas de proyectos para la prestación de servicios digitales asociados a prácticas E-learning, éstas han surgido de forma espontánea y son desconocidas. Ante esta situación es recomendable realizar estudios que permitan apropiarnos de las buenas prácticas, a fin de mejorar los servicios en línea ya existentes en beneficio de los educadores y educandos.

16. Servicios bibliotecarios telemáticos. La oferta de servicios digitales de la biblioteca que pueden ser aprovechados en procesos E-learning se orientan a hacia tres ejes principales: La creación de puntos de acceso a la información (servicio de referencia digital); alfabetización informacional. (formación de habilidades, destrezas y capacidades en el usuario), y el abastecimiento de información(acceso y uso de los repositorios para la educación).

17. Referencia digital. La creación de puntos de acceso a la información debe contemplarse como el punto de partida y encuentro, a través el cual el usuario se involucra de forma directa con otros puntos de acceso a los diferentes servicios de información. El desarrollo e implementación del servicio de referencia digital requiere la aplicación de directrices internacionales que garanticen una gestión del servicio en forma eficiente y eficaz.

18. Comunicación directa. Los servicios de referencia se deben concebir de forma amplia, incluyendo todas las acciones encaminadas a que el usuario transmita sus consultas y la biblioteca dé respuesta oportuna. Las tecnologías permiten la referencia sincrónica, con lo que la comunicación es directa. Esta inmediatez es un elemento de valor añadido en las plataformas de enseñanza en línea, como ha podido verse en el estudio de casos.

19. Alfabetización informacional. La biblioteca es formadora de habilidades, destrezas y capacidades en el usuario. La alfabetización informacional vista como un servicio digital, requiere la elaboración de programas y planes de formación, que exigen la ejecución de un 
estudio de viabilidad y desarrollo de procesos de alfabetización internos, a fin de actualizar y preparar el personal que participará (actor) en la formación de habilidades como parte de un aprendizaje continuo en los usuarios.

20 Formación como misión. La nueva misión de las bibliotecas académicas es la alfabetización informacional en entornos virtuales, este proceso tiene repercusiones significativas y determinantes en la calidad y veracidad de la producción de la información. La práctica de estos programas permitirá conseguir resultados de calidad en el proceso de enseñanza/aprendizaje y adquirir habilidades y conocimientos necesarios en procesos de formación e investigación.

21. Modelos para la formación. Los modelos más relevantes para proyectos y programas de alfabetización desarrollados en las dos últimas décadas son: BIG6, SCONUL, CAUL/ANZIIL y el modelo del IFLA /ALA. Aunque obedecen a iniciativas, realidades y tiempos diferentes, parte del ciclo de trasferencia del documento. Las tres variantes centrales son: Acceso-UsoEvaluación.

22. Acceso a los recursos. Es importante garantizar que el prototipo de infraestructura tecnológica permita a los usuarios el acceso de los servicios las 24 horas del día. En este sentido, se hace necesario que la elaboración de diseños de los puntos de accesos sean amigables, sencillos, rápidos y eficientes, a fin de evitar los problemas técnicos de conexiones y el tráfico virtual. Sin duda alguna, la implementación de programas educativos E-learning y proyectos académicos de investigación se ven beneficiados con las nuevas capacidades de servicio que ofrecen las bibliotecas, por cuanto facilitan el ciclo de transferencia de información, conocimiento y el diálogo directo entre docente-estudiante; investigadorinvestigador.

23. Repositorios de información. Las bibliotecas son proveedoras de información, siendo ésta una de sus misiones constantes. La implicación de la biblioteca en los programas formativos ha derivado en que se desarrollen servicios orientados hacia la provisión de recursos. Las bibliotecas no sólo ofrecen información de la forma tradicional (selección, procesamiento, difusión), sino que desarrollan y mantienen colecciones digitales que ofrecen a sus usuarios través de repositorios documentales.

24. Repositorios de aprendizaje. Las bibliotecas crean recursos de aprendizaje y mantienen repositorios documentales. Los recursos de aprendizaje deben ser ofrecidos mediante repositorios o comunidades específicos, ya que este tipo de documentación son de gran utilidad para los docentes, como metodología didáctica, y para los estudiantes, como 
recursos de aprendizaje. Los estudios de caso muestran que las bibliotecas universitarias están implicadas en la oferta de repositorios de objetos de aprendizaje.

\subsubsection{Implementación del modelo}

El modelo integrador Biblioteca/E-learning es aplicable como se resumen en la última conclusión:

25. Modelo sostenible. Dentro de las universidades se observa una fuerte tendencia a la incorporación de programas de educación a distancia semipresencial y E-learning. En este contexto la apropiación de experiencias y prácticas por parte de la biblioteca para el desarrollo de servicios en plataformas E-learning dirigidas al apoyo de actividades docentes e investigación, se convierte en una fortaleza para su posicionamiento a nivel institucional.

\subsection{Recomendaciones generales}

Las 25 conclusiones con las que se cierra esta investigación sintetizan el trabajo realizado en aras de defender la integración protagonista de las bibliotecas en los procesos de aprendizaje. La convergencia Biblioteca/E-learning que se defiende en esta tesis doctoral parte de la orientación de tres servicios bibliotecarios telemáticos hacia una utilidad de apoyo para docentes y estudiantes. A partir de las conclusiones se pueden establecer cinco recomendaciones generales:

A. Servicio. La vocación de servicio es una característica de las bibliotecas, cuya actividad sólo es concebible en función de la existencia de los usuarios a los que atiende. Los servicios bibliotecarios deben estar, a su vez, al servicio de las universidades, lo que implica apoyar de forma directa y decidida los programas formativos de la entidad y resolver las demandas de información de la comunidad que la integra. El servicio se debe prestar de esta forma:

\footnotetext{
- atendiendo necesidades de información (referencia)

- enseñando a usar los recursos (alfabetización)

- ofreciendo recursos (repositorios)
}

B. Adaptación. Los cambios en las aplicaciones tecnológicas acontecen de forma acelerada hecho que demanda una constante revisión de la infraestructura tecnológica, la evaluación y actualización del diseño del sitio URL y la revisión de la oferta de servicios en relación a la demanda, a fin de anticipar cualquier inconsistencia con los objetivos y posicionamiento institucional. En esta línea se recomienda considerar: 
- Acceso, navegación y uso de los contenidos

- Tecnologías de comunicación

- Gerencia del servicio mismo

- E-learning y la biblioteca

C. Cooperación. El intercambio de experiencias es esencial. El conocer ¿qué se está haciendo?, ¿quiénes están trabajando en ello? y ¿qué podríamos aprender de esto? representa un reto en el proceso de cambios tecnológicos constante y el medio para el aprendizaje y actualización profesional. Es necesario hacer un inventario de experiencias y buenas prácticas a fin de conocer y valorar la utilidad de los productos generados (objetos de aprendizaje, guías, tutoriales), los aspectos de organización involucrados, aspectos de almacenamiento, entre otros, a fin de ser utilizado como marco de referencia para toma de decisiones. Los niveles cooperativos deben ser los siguientes:

- comunidad académica (profesores y alumnos)

- comunidad de servicios (personal de la universidad no docente)

- comunidad profesional (otras bibliotecas)

D. Infraestructura tecnológica. La tendencia a cambios en las aplicaciones tecnológicas en todas las áreas del conocimiento obliga a los organismos e instituciones a modernizar sus infraestructuras tecnológicas. La tecnología es la base de la enseñanza en línea y de los servicios bibliotecarios digitales y es la clave para ofrecer nuevos servicios o bien renovar los servicios tradicionales. En este contexto se recomienda que los modelos de bibliotecas adquieran mayor presencia en el mundo virtual a través de las siguientes acciones:

- La conformación de repositorios académicos

- La transformación de sistemas de bibliotecas más dinámicos que puedan operar como una red de VKC/CRAI

- Apoyo a la generación de documentos electrónicos / digitales

- La creación de programas de alfabetización informacional y servicios de apoyo al proceso de enseñanza virtual

- Desarrollo de aplicaciones y programaciones informáticas que permitan el mejoramiento de servicios de información digital 
- El uso de normativas y procesos de certificación para el procesamiento y organización de la información a fin de alcanzar un alto nivel de credibilidad en el ámbito nacional e internacional

- La selección cuidadosa de los contenidos ofrecidos en los diferentes servicios y productos se convierte en un criterio que garantiza la calidad de los mismos. En este sentido se recomienda la definición de políticas claras de desarrollo de los contenidos y colecciones digitales

E. Evaluación. Se recomienda desarrollar procesos de evaluación constante, tanto en el diseño del sitio Web de la biblioteca como del servicio mismo, a fin de garantizar su sostenibilidad. Se recomienda tomar en consideración la propuesta metodológica para la evaluación de servicios en línea incluida en el capítulo cinco de esta tesis. La evaluación deberá enfocarse hacia los siguientes tópicos, que son necesarios para la mejora de los servicios:

- métricas cuantitativas, que expresen el uso de los servicios y recursos

- métricas cualitativas, que transmitan la satisfacción de los usuarios

- análisis de datos, que midan la calidad de los servicios y el cumplimiento de objetivos

Las conclusiones y recomendaciones con las que se termina este trabajo de investigación doctoral transmite de forma pretendida una idea que se repite a lo largo de toda la tesis: las bibliotecas universitarias cumplen una función de apoyo a la educación, por lo que deben orientar sus servicios hacia la obtención de información, la educación documental y la provisión de recursos. Las universidades han incorporado a sus servicios las plataformas de enseñanza en línea, como parte integrante de sus metodologías didácticas. Las bibliotecas, por tanto, deben integrar sus servicios en estas plataformas E-learning para cumplir con su función de ser informadoras, formadoras y provisoras. La convergencia de los servicios bibliotecarios telemáticos en la enseñanza universitaria E-learning es la vía para que las bibliotecas sean verdaderos centros de apoyo a la enseñanza y al aprendizaje. 


\section{BIBLIOGRAFÍA CITADA}

El presente listado de recursos bibliográficos incluye las referencias de los documentos utilizados y debidamente citados durante la ejecución de la presente tesis. La elaboración y organización de las referencias corresponden se basan en la aplicación de la norma ISO 690 12ae ed. 1987.

1. ACRL Distance Learning Section Guidelines Committee (2008). Standards for distance learning library services (2008). s.p

Disponible en:

http://www.ala.org/ala/mgrps/divs/acrl/standards/guidelinesdistancelearning.cfm [Consultado:18-2-2010]

2. ABADAL, Ernest (2012). Acceso abierto a la ciencia. Barcelona: Editorial UOC. 51p. Colección El profesional de la información.

Disponible en: http://eprints.rclis.org/bitstream/10760/16863/1/2012-acceso-

abierto-epi-uoc-vfinal-autor.pdf. [Consultada 30-10-2012]

3. ABADAL, Ernest; Rius, Lluís. (2006). Revistas científicas digitales: característica e indicadores. En: Revista de Universidad y Sociedad del conocimiento, vol. 3, no. 1, 2006. p. 6-20.

Disponible en: http://www.uoc.edu/rusc/3/1/dt/esp/abadal_rius.pdf [Consultado:18-2-2010]

4. AGUDO PRADO, Susana.(2010). El uso comunicativo de las TIC en educación social. Revista de Educación Social. s.p, 2010. ISSN 1698-909.

Disponible en : http://www.eduso.net/res/?b=14\&c=129\&n=372

[Consultado:20-3-2012]

5. AGUIRRE, Sandra; Quemada, Juan (200?). Mediadores e interoperabilidad en Elearning. 9p. Disponible en pdf:

http://jungla.dit.upm.es/ saguirre/publications/virtualEduca2004.pdf

[Consultado:24-3-2012]

6. AKEROYD, John. (2005). Information management and e-learning: Some perspectives. Aslib Proceedings: New Information Perspectives. Volumen: 57, no.2, 2005. p. 157167.

Disponible en:

http://www.qou.edu/english/scientificResearch/eLearningResearchs/information.pdf [Consultado:15-11-2011]

7. ALA. Definición dada por la ALA. (2009). Reference and User Services Association. MARS digital reference guidelines Ad Hoc Committee. Guidelines for implementing and maintaining virtual reference services. 10p.

Disponible en:

http://www.ala.org/ala/mgrps/divs/rusa/resources/guidelines/virtual-referencese.pdf. [Consultado:15-09-2009] 
8. ALFARED. Glosario [en línea]. Foro Red. Alfabetización informacional. [en línea]. Disponible en: http://www.alfared.org/glosario. [Consultado 02-12-2012]

9. ALONSO ARÉVALO, Julio. (2006). SIDRA: La Biblioteca Digital. [en línea]. Universidad de Salamanca, 2006, 61 p. (material de curso) Disponible en: http://eprints.rclis.org/archive/00007730/01/BD.pdf [Consultado 05/05/2008]

10. ASSOCIATION OF COLLEGE AND RESEARCH LIBRARIES A DIVISION OF THE AMERICAN LIBRARY ASSOCIATION (2000). The Information Literacy Competency Standards for Higher Education. Disponible en:

http://www.ala.org/acrl/sites/ala.org.acrl/files/content/standards/standards.pdf Chicago, Illinois. 18 p. [Consultado: 30-10-2012]

11. ALFONZO SÁNCHEZ, Ileana R. La educación a distancia. (200X?) Disponible en: http://www.bvs.sld.cu/revistas/aci/vol11_1_03/aci02103.htm [Consultado 20-3-2012]

12. ALI, Amjad. (2004). Learning in the information Age.-New Delhi: Ess Publications, 2004. 302p. ISBN: 81-700-393-8

13. ÁLVAREZ ÁLVAREZ, José Valentín. (2003). Uso de estándares E-learning en espacios educativos. En: Revisita Fuentes. Revista de la Facultad de Ciencias de la Educación. vol. 5, 2003, p.153-172.

Disponible en: http://huespedes.cica.es/huespedes/revfuentes/campo_02.htm [Consultado:18-2-2010]

14. ANGELOZZI, Silviana. Competencias del bibliotecario referencista en el siglo XXI. Escuela de Bibliotecología. Universidad Nacional de Córdoba. Buenos Aires, 2011. 10p. Disponible en: http://www.abgra.org.ar/documentos/pdf/competencias_angelozzi-PPT.pdf [Consultado:20-3-2012]

15. ANGLADA I DE FERRER, L. (2008). Biblioteca digital ¿mejor, peor o sólo distinto?. En: Anales de Documentación, Norteamérica. no. 3, 2008. p.25-39 Disponible en: http://revistas.um.es/analesdoc/article/view/2521/2511 [Consultado:24-3-2012]

16. ARANGO, Ángela María. (200X?). Un breve paseo por la biblioteca digital. (200?). (s.f, s.p) Disponible en html:

http://www.javeriana.edu.co/relato_digital/r_digital/bibliografia/virtual/arangocompleto.htm. [Consultado 27-3-2012]

17. AYUSO GARCÍA, María Dolores; PEÑALVER MARTíNEZ, Ángel; MARTíNEZ NAVARRO Victoria. (2006). Evaluación de fuentes de información para servicios de referencia en Internet. Una propuesta a partir de "pregunte, las bibliotecas responden. 2006. En: Anales de Documentación no.9, 2006. p.17-42. Disponible en: http://dali.mcu.es/portalnb/jspui/bitstream/10421/1152/1/com_013.pdf [Consultado:18-2-2010] 
18. BARAHONA, Juan Carlos; Zuleta, René; Calderón, Olga. (2008). Herramienta para la evaluación de la calidad de la prestación de servicios por medios digitales.(200?) 37.p Disponible en: http://web.media.mit.edu/ barahona/main/publications [Consultado:23-3-2012]

19. BARBERENA, Elsa, BLOCK, Carmen, etc. (2007). De cómo a través de los servicios de la biblioteca digital-biblioteca virtual se educa al usuario de las artes. 2 do. Congreso Iberoamericano de bibliotecología bibliotecas y nuevas literaturas en el espacio virtual. Buenos Aires, 14-17 de abril de 2007. 4 pág.

Disponible en:

http://www.chubut.edu.ar/descargas/barberena_block_guerrero_vidal.pdf [Consultado:15-9-2009]

20. BARRY, C. (2008). Las habilidades de información en un mundo electrónico: La formación investigadora de los estudiantes de doctorado. Anales de Documentación, Norteamérica, 2, feb. 2008. p 237-258

Disponible en: http://revistas.um.es/analesdoc/article/view/2731.

[Consultado:12-8-2011]

21. BARTON, Mary R.; WATERS, Margaret M. (2005) Cómo crear un Repositorio Institucional: Manual LEADIRS II. The Cambridge-MIT Institute (CMI), 2004-2005. 169p. Disponible en: http://www.recolecta.net/buscador/documentos/mit.pdf [Consultado:15-11-2011]

22. BARRUECO, José Manuel; SUBIRATS COLL, Imma. (2003). OAI-PMH: Protocolo para la transmisión de contenidos en Internet. 13 p. En: El profesional de la información, 2003

23. BARRUECO CRUZ, J.M.; KRICHEL, T.(2003). Subject description in the Academic Metadata Format, 2003. En: VI Congreso del Capítulo Español de ISKO,Salamanca (Spain),May 2003.(Published) [Conference Paper]. [Consultado: 02-12-2012]

24. BAWDEN, DAVID. (2002). Revisión de los conceptos de alfabetización informacional y alfabetización digital. Department of Information Science. City University London. En: Anales de Documentación, no. 5, 2002. p.361-408. Serie: Traducciones. Disponible en: http://revistas.um.es/analesdoc/article/viewFile/2261/2251

[Consultado:15-9-2009]

25. BEIJNEN VAN, Jeroen; ZWEERTS, Tanja; BELLAARD, Carla; [et.al.] (2002). Hoe verder na 23 dingen? Een inventarisatie van toepassingen, varianten en aanvullingen :Cubiss: Brabantse Netwerk Bibliotheek, 2010. 197p.

Disponible en:

http://www.bnbibliotheek.nl/sites/default/files/Hoe_verder_na\%2023_dingen_ebook_0.pdf. [Consultado:15-11-2011] 
26. BELLIDO, Luis; LÓPEZ DE VERGARA, Jorge; [et.al.]. (2011). Metodología para la evaluación de servicios de telecomunicaciones desde la perspectiva del usuario. (2011)7p. Disponible en:

http://jungla.dit.upm.es/ jlopez/publicaciones/telecomid04lbt.pdf [Consultado:23-3-2012]

27. BODEN, Debbi. (200?). Gaining a pilot's license: supporting researchers at Imperial Collage London through the postdoctoral information literacy online tutorial. (2007). En: Advanced User's: Information Literacy and Customized Services / Oliver Kohl-Frey, Bernd Schmid-Ruhe (Eds.). Konstanz 2008, p. 165-173. Disponible en: http://kops.ub.uni-konstanz.de/bitstream/handle/urn:nbn:de:bsz:352-opus59122/Boden_Debbie_konstanz_1db_2oct07_format_neu_SZ.pdf?sequence=1. [Consultado:15-9-2009]

28. BONEU, Josep M. (2007). Plataformas abiertas de e-learning para el soporte de contenidos educativos abiertos. p. 36 - 47 En: Revista de Universidad y Sociedad del Conocimiento (rusc) vol. 4, no. 1, 2007. Monográfico: Contenidos educativos en abierto. ISSN 1698-580

Disponible en: http://www.uoc.edu/rusc/4/1/dt/esp/boneu.pdf [Consultado:20-3-2012]

29. BONILLA, Karla Vanessa. (2008). Documento de Grado. Estudio del modelo Centro Virtual de Información y Conocimiento (Virtuele Kennis Centrum = VKC). Universidad de Salamanca, 2008. 110p.

30. BONILLA, Karla Vanessa; KOLKMAN Frank. (2006). Uso potencial de las nuevas tecnologías para la transferencia de información y comunicación (ICT) en el proceso de modernización de las bibliotecas Centroamericanas: Congreso Centroamericano: 28 y 29 de noviembre 2006, San Salvador, El Salvador. 219 p. Disponible en : http://igitur-archive.library.uu.nl/DARLIN/2007-0301-200927/memoria.pdf. [Consultado: 02-12-2012]

31. BONILLA, Karla Vanessa . (1995) Desarrollo de la automatización en las unidades de información: Estudios de casos de Nicaragua y España. En: Revista AIBDA. Ene-jun 1995. V. 16(1) p. 35-48. Turrialba, Costa Rica. 1995.

Disponible en: http://www.metabase.net/docs/bn-cr-r/009886.html. [Consultado: 02-12-2012]

32. BOPP, Richard E.; SMITH, Linda C.. (2001). Reference and Information Services: An Introduction. Richard E Bopp; Linda C. Smith. Englewood, Colorado: Libraries Unlimited, 2001. 611p. ISBN: 1-56-308-624.

33. BRUCE, Christine. (2003). Las siete caras de la alfabetización en información en la enseñanza superior. En: Anales de Documentación, no. 6, 2003. p.289-294. Disponible en: http://redalyc.uaemex.mx/pdf/635/63500619.pdf

[Consultado:15-9-2009] 
34. BUENDÍA GARCIA, Félix; HERVÁS JORGE, Antonio. (2006). Evaluation E-learning platforms through SCORM specifications. 2006. IADIS Virtual Multi Conference on Computer Science and Information Systems 2006. p.53-58. ISBN: 972-8924-13-5. Disponible en: http://koyama.inf.upv.es/joomla/documentosAEEVA/Proyecto/MULTI2006.pdf [Consultado:18-2-2010]

35. BUNGE, Charles A.; BOPP, Richard E. (2001) - History and varieties of reference services. In BOPP, Richard E. - Reference and information services: an introduction (3rd ed.). Englewood: Libraries Unlimited, 2001. ISBN 1-56308-624-7. p. 3-15.

36. BUSTAMANTE DONAS, Javier (2001). Hacia la cuarta generación de Derechos Humanos: repensando la condición humana en la sociedad tecnológica. s.p. En: Revista Iberoamericana de Ciencia, tecnología, sociedad e innovación CTS+I. No. 1 Sept. -diciembre 2001: Organización de Estados Iberoamericanos. Madrid, 2001. Disponible en: http://www.oei.es/revistactsi/numero1/bustamante.htm [Consultado: 27-3-2012]

37. CALDERÓN REHECHO, Andoni. (2010).Informe APEI sobre alfabetización informacional. Gijón: Asociación Profesional de Especialistas en Información, 2010. Serie: Informe APEI 5 - 2010. D. L.: AS-06633-2008, Edición: APEl. Director editorial: José Antonio Merlo Vega, Diseño y maquetación: Digitales José \& Cícero, S.L. ISBN: 978-84-6936104-7

38. CALÉS DE JUAN. José María. (2001). Enseñanza virtual: el modelo de la UNED. Boletín de la Red Iris. No. 54-55. 2001. 7p.

Disponible en:

http://e-spacio.uned.es/fez/eserv.php?pid=bibliuned:985\&dsID=n02calesVE01.pdf [Consultado:15-11-2011]

39. CARR-CHELLMAN, A.; Duchastel, P. (2000). The ideal online course. British Journal of Educational Technology, vol. 23, no.3. Julio 2000. p.229-241.

Disponible en: http://www.personal.psu.edu/khk122/woty/F2FHybridOnline/CarrChellaman\%202000.pdf. [Consultado:15-9- 2009]

40. CASTILLO SÁEZ, Erika (2005). Alfabetización en información y participación ciudadana. Tercer seminario de bibliotecas y centros de documentación gubernamentales: Las Bibliotecas en el contexto del Gobierno Electrónico y la Participación Ciudadana. Santiago de Chile, 25 de agosto de 2005. 10 p. Disponible en: http://www.gestiopolis.com/recursos5/docs/eco/alfaben.pdf. [Consultado:15-9-2009]

41. CATTS Ralph; LAU Jesús. (2008). Hacia unos Indicadores de Alfabetización Informacional: Marco conceptual. Organización de las Naciones Unidas para la Educación, la Ciencia y la Cultura UNESCO. UNESCO: París, 2008. 44 p. Disponible en: http://wikialfin.pbworks.com/f/IndicadoresAlfinUNESCOborrador\%255B1\%255D.pdf. [Consultado en:15-11-2011] 
42. CAUSTON Laurie; DAY, Michael; DUVAL, Erik. (2002). Metadata Watch Report \#8 and Standards Framework Report \#4 Creator Makx Dekkers. PricewaterhouseCoopers, 31 January 200218 p. Disponible en: SCHEMAS-PwC-WP2/WP3-D29/D35-Final20020131. [Consultado: 02-12-2012]

43. CÉSPEDES, Zulia Ramírez (2009). Criterios e indicadores para evaluar bibliotecas digitales 2006. 34 p. Disponible en pdf: http://eprints.rclis.org/bitstream/10760/9264/1/http__bvs.sld.cu_revistas_aci_vol1 4_6_06_aci04606.htm.pdf. [consultado:15-9-2009]

44. CHEN, Hsin-Liang; Williams, James Patrick. (2009). Use of multi-modal media and tools in an online information literacy course: collegue studente's attitudes and perceptions. En: The Journal of academic librarianship. Vol. 35, no. 1. 2009. p.14-24. Disponible en:

http://www.sciencedirect.com/science/article/pii/S0099133308001936 Consultado:20-3-2012

45. CODINA, Lluís (2000-2). Evaluación de recursos digitales en línea: conceptos, indicadores y métodos. En: Revista Española de Documentación Científica vol. 23. No.1. 2000, p.9-44. Disponible en: http://eprints.rclis.org/handle/10760/12077\#.T2iamhEf5ic. [Consultado:20-3-2012]

46. CODINA, Lluís (2003). Metodología de análisis y evaluación de recursos digitales en línea.(V6) 54 p. Barcelona: COBDC Disponible en Word:

Disponible en: http://www.digidocweb.net/metodos.htm\#i [Consultado:18-02-2010]

47. CODINA, Lluís. Evaluación de recursos digitales en línea: conceptos, indicadores y métodos. Revista Española de Documentación Científica, 2000, vol. 23. No.1 p.9-44. Disponible en : http://redc.revistas.csic.es/index.php/redc/article/view/315. [Consultado 02-12-2012]

48. COMBA, Valentina Elvira. E-tutorship and e-learning-re-skilling librarians for interactive communication in virtual environment. En: Conferencia Library and Information Profession, 18-20 August 2009, Bologna Italy: K.G.Saur. p.279-288. (Published) [Book Chapter]. Disponible en: http://eprints.rclis.org/bitstream/10760/14238/1/e_tutorship_rev.pdf [Consultado:15-9-2009]

49. CORDÓN GARCIA, José Antonio; Gómez Díaz, Raquel; Alónso Arévalo, Julio. (2011).Gunterberg 2.0: la revolución de los libros electrónicos. Gijón: Treas, 2011 287p. ISBN: 978-84-9704-552-0. Serie: Biblioteconomía y administración cultural, 229.

50. CORDÓN GARCÍA; José Antonio; GÓMEZ DÍAZ; Raquel; ALÓNSO ARÉVALO, Julio.(2011). Gunterberg 2.0: la revolución de los libros electrónicos. Gijón: Treas, $2011287 p$. 
51. CUBILLO. Mariela Ferrada. (2005). La satisfacción del usuario remoto de la biblioteca. En: Biblios. Año 6, No. 21-22, 2005. p.26-41 Disponible en: http://eprints.rclis.org/bitstream/10760/6726/1/2005_05.pdf [Consultado:15-9-2009]

52. DAQING He; PengYefei. (2010). Supporting information Access in e-learning by integrating digital libraries and ontology. En: Online information review. vol. 34, no.5, 2010. p. 725.Disponible en:

http://www.emeraldinsight.com/journals.htm?articleid=1886709\&show=pdf [Consultado:15-9-2011]

53. DAVIS, Beath; Carmean, Colleen; Wagner, Ellen D. (2009). The evolution of the LMS: from management to learning, deep analysis of trens shaping the future of e-learning. The E-learning Guil, Santa Rosa, C.A., 2009. 21 p.

Disponible en: http://www.blackboard.com/resources/proed/Guild-LMSreport.pdf. [Consultado:02-12-2012]

54. DE AREAS, Judith Licea. (2007). La evaluación de la alfabetización informacional: principios, metodología y retos. En: Anales de Documentación, no. 10 2007. p.215232. Disponible en pdf: http://revistas.um.es/analesdoc/article/view/1161/1211 [Consultado:15-09-2009]

55. Declaración de Toledo sobre la alfabetización informacional. 2006. Bibliotecas por el aprendizaje permanente. Disponible en: http://www.webcitation.org/5NrAiGhSS. [Consultado 02-12-2012]

56. DE LA FUENTE, María Lourdes. (2005). La alfabetización informacional y la gestión del conocimiento. En: Revista AIBDA. vol. 26, no. 2 2005. p.1-37

57. DE VOLDER, Carolina. (2008). Los repositorios de acceso abierto en Argentina: situación actual En: Información, cultura y sociedad. 2008, n.19 pp. 79-98 ISSN 18511740. Disponible en: http://www.scielo.org.ar/pdf/ics/n19/n19a05.pdf. [Consultado: 23-3-2012]

58. DÉLANO S., Marialyse. (1988). La Biblioteca del Congreso Nacional de Chile: una Experiencia de Modernización. [en línea]. 64th IFLA General Conference, Amsterdam, Aug 16 - 21, 1998, 9 p.

Disponible en: http://www.ifla.org/IV/ifla64/087-100s.htm [Consultado:5-5-2008]

59. DELGADO, Kenneth, (2005). Las plataformas en la educación a distancia. Universidad Nacional Mayor de San Marcos. Perú. En: Revista Iberoamericana de Educación, 2005. ISSN: 1681-5653. 5p.

Disponible en: http://www.rieoei.org/deloslectores/1300Delgado.pdf [Consultado:15-11-2011] 
60. DOWNES, Stephen. (2004). The Learning Marketplace. Meaning, Metadatos and Content Syndication in the Learning Object Economy [en línea]. Moncton, New Brunswick: el autor, 2004. 339 p.

Disponible en: http://www.downes.ca/files/book3.pdf [Consultado: 23-3-2012]

61. DOYLE, C. (1992). Outcome Measures for Information Literacy. Within the National Education Goals of 1990: Final. Report of the National Forum on Information Literacy. Summary of Findings (ERIC document no. ED 351033) US Department of Education, Washington, DC, 1992. 18p.

Disponible en: http://www.eric.ed.gov/PDFS/ED351033.pdf [Consultado:15-11-2011]

62. EBBERS, Mike; CREUZET, Armelle; ERASMUS, Tonie Erasmus [et.al] (2001) Build a Portal with Domino: A S/390 Example International Business Machines Corporation 2001.286 p. ISBN 0738422401

Disponible en: http://www.redbooks.ibm.com/redbooks/pdfs/sg246231.pdf [Consultado:24-3-2012]

63. EISENBERG. Michael B. (2008). Information literacy: Essential skills for the information age. DESIDOC. Journal of Library \& information technology. vol. 28, no. 22008 p.3947. Disponible en: http://publications.drdo.gov.in/ojs/index.php/djlit/article/viewFile/166/77 [Consultado:15-09-2009]

64. FARKAS, Meredith. (2007). Social software in libraries: building collaboration, communication and community online. Medford, N.J.: Information Today, 2007. USA. xxiv, 320 p. ISBN:978-1-57387-275-1

65. FERET, Blazer; MARCINEK, Marzena. (1999). The future of the academic library and the academic librarian: a Delphi study. $14 \mathrm{p}$.

Disponible en: http://unlvlib.pbworks.com/f/Academic+Library+of+2005.pdf [Consultado:15-9-2009]

66. FERRADA CUBILLOS, Marielo. (2005). La satisfacción del usuario remoto de la biblioteca. En: Biblios. Año 6, no. 21-22 Ene-Ago. 2005. p. 28 Disponible en: http://eprints.rclis.org/bitstream/10760/6726/1/2005_05.pdf [Consultado:15-09-2009]

67. FERRAN FERRER, Núria; MINGUILLON ALFONSO, Juliá (2007) El papel de las bibliotecas digitales en el acceso a los recursos educativos abiertos. En: Jornadas Españolas de Documentación (2007) volumen:10,Publisher: FESABID, p. 287-293 ISBN:9788493033576. Disponible en: http://www.fesabid.org/santiago2007/descargas/comunicaciones/nferranf_minguillo n.pdf. [Consultado:24-3-2012]

68. FERREIRA DA CUNHA, Carmen Isabel; (2008).A escola na sociedade da informacaon: blended learning: uma experiencia na ensino secundario. Tesis de maestría. Facultad 
de Ciencias. Universidad de Porto. 40 p. Disponible en:

http://www.fc.up.pt/qui/contactos/funcionarios.php?tipo=tmest\&dep=4\&item=19

6. [Consultado:24-3-2012]

69. FERRER SAPENA, Antonia; PESET MANCEBO, Fernanda; MORENO NúÑEZ, María T.; LLORET ROMERO, Nuria. (2005). Guía metodológica para la implementación de una biblioteca digital universitaria. Gijón: TREA, 2005, 202 p. ISBN 84-9704-147-X. Biblioteconomía y administración cultural, no.113.

En: Información, Cultura y Sociedad. no.15, 2006. Pp.119-122

Versión en línea ISSN1851-1740. Disponible en:

http://www.scielo.org.ar/scielo.php?script=sci_arttext\&pid=S1851-

17402006000200010. [Consultado:27-3-2012]

70. FERRONI, Beatriz J. (2004).Alfabetización en información:¿asumen los bibliotecarios que es parte de su misión incluir a todos en la Sociedad del Conocimiento?. 2004. 7p. En: Congress:70th IFLA General Conference and Council 22-27 Agosto 2004. Buenos Aires, Argentina.

Disponible en: http://archive.ifla.org/IV/ifla70/papers/018s-Ferroni.pdf [Consultado:20-3-2012]

71. FOIX, Cristian; ZAVANDO, Sonia. (2002) Estándares E-learning: estado del arte Chile: Intec, 2002. $21 \mathrm{p}$.

72. FRANSE, Jos (2005). Bibliotheekonderwijs via het web; een eerste verkenning. Universiteitsbibliotheek Maastricht, $57 \mathrm{p}$. Disponible en: http://arno.unimaas.nl/show.cgi?fid=4481 [Consultado:18-2-2010]

73. GAMA, Olga Patricia (2008). Propuesta de un modelo de diseño del Servicio de referencia virtual para una biblioteca universitaria. Pontificia universidad Javeriana, Departamento Ciencia de la Información. Bogotá, 2008 123p.

Disponible en pdf:

http://www.javeriana.edu.co/biblos/tesis/comunicacion/tesis65.pdf [Consultado 02-12-2012

74. GARCÍA - REYES, Francisco Javier de Jorge. (2002).La biblioteca digital: impacto y transformaciones en los servicios bibliotecarios. 61 diapositivas Disponible en: https://docs.google.com/ [Consultado:15-09-2009]

75. GARCÍA ARETIO, Lorenzo. Fundamento y Componentes de la Educación a Distancia p. 29-39. En: Revista Iberoamericana de Educación a Distancia Volumen 2, № 1, Junio de 1999 ISSN:1138-2783. E-ISSN: $1390-3306$

76. GARCÍA GÓMEZ, Juan Carlos. Portales de internet: concepto, tipología básica y desarrollo En: El profesional de la información, vol. 10, nos. 4 7-8, julio - agosto 2001. Disponible en:

http://www.elprofesionaldelainformacion.com/contenidos/2001/julio/2.pdf [Consultado:24-3-2012] 
77. GARCÍA PEÑALVO, Francisco José (2006). Profesionales emergentes: especialistas en E-learning. [en línea] Curso extraordinario. Universidad de Salamanca. 2006. 96 diapositivas.

Disponible en: http://www.slideshare.net/odiefer/1introduccin-al-elearningfrancisco-j-garca-pealvo. Grupo de Investigación e Interacción y E-learning. [Consultado:24-011-2012]

78. GARCÍA PEÑALVO, Francisco José. (2010).El estado actual de los sistemas e-learning. Ediciones Universidad de Salamanca Disponible en:

http://campus.usal.es/ teoriaeducacion/rev_numero_06_2/n6_02_art_garcia_penal vo.htm. [Consultado: 02-12-2012]

79. GARMENDIA BONILLA, Loviana. (2005). La alfabetización informacional como estímulo investigativo: una estrategia en la gestión de la información y el conocimiento. En: Biblio. vol. 6, no.21-22, 2005. 12 p.

Disponible en: http://eprints.rclis.org/bitstream/10760/6728/1/2005_02.pdf [Consultado:15-09-2009]

80. GARNSEY, Beth A.; POWER, Ronald R. (2003). Los servicios de referencia a través del correo electrónico en la biblioteca pública. En: Boletín de la Asociación Andaluza de bibliotecarios. vol.18, no. 071, 2003. p.57-76.

Disponible en: http://redalyc.uaemex.mx/pdf/353/35307106.pdf [Consultado:15-09-2009]

81. GARZÓN CLEMENTE, Rebeca. [En linea]. La metamorfosis del concepto de alfabetización en la educación mediada por tecnologías. En: Buenas Prácticas de elearnin. Coordinado por Ana Landeta Etxeberría.UDIMA Universidad a Distancia de Madrid. Disponible en: http://www.buenaspracticas-elearning.com/ [Consultado 0212-2012]

82. GEBRUIKSONDERZOEK. Forum: werkgroep Gebruiksonderzoek. (200?). Presentatie en Power Point. 22 diapositivas. Disponible en: Intranet de la WUR. Documento interno de la Biblioteca de la Universidad de Wageningen.

83. GÓMEZ HERNÁNDEZ, José A. (2007). Alfabetización informacional: cuestiones básicas. En: Anuario ThinkEPI, 2007. p. 43-50

Disponible en: http://www.thinkepi.net/alfabetizacion-informacional-cuestionesbasicas. [Consultado:15-9-2009]

84. GONCALVEZ, Marcos André; Moreira, Bárbara ; [et.al.]. (2007). What is a good digital library; a quality model for digital library. En: Information Processing and Management, Elsevier, 2007. Vol. 43, 2007, p.1416-1437. Disponible en: http://comminfo.rutgers.edu [Consultado:18-2-2010] 
85. GONZÁLEZ FERNÁNDEZ-VILLAVICENCIO, NIEVES. ALFIN en la biblioteca de la Universidad de Sevilla: distintas soluciones con un mismo objetivo. 2009. Ponencia presentada en: VII Jornadas CRAI: Competencias informacionales e informáticas en el ámbito universitario. 4 y 5 de junio 2009. la Universidad Politécnica de Madrid. Disponible en: http://www.slideshare.net/nievesglez/programas-alfin-en-labiblioteca-de-la-universidad-de-sevilla [Consultado:25-3-2012]

86. GONZÁLEZ LORCA, Jesús; RODRÍGUEZ MUÑOZ, José Vicente. (2002). La tecnología de flujo de trabajo en el contexto de la biblioteca digital. Universidad de Murcia, 2002. En: Anales de Documentación. no.5, p.157-175. Versión en línea: ISSN 1697-7904. Disponible en: http://redalyc.uaemex.mx/pdf/635/63500505.pdf [Consultado:5-5-2008]

87. GONZÁLEZ, Julia; WAGENAAR, Robert.(2003).Tuning Educational: structures in Europe.Informe final: fase uno. 339p. Universidad de Deusto, Bilbao, España, 2003. http://www.relint.deusto.es/TUNINGProject/spanish/doc_fase1/Tuning\%20Educatio nal.pdf. [Consultado:20-3-2012]

88. GRODZINS Lipow, Anne. (2003). The future of reference: point of need reference service: no longer afterthought. En: Reference services review. vol. 3, no.1 2003. p. 31 -35. ISSN: 0090-7324

89. GRUPO DE TRABAJO DE REFERENCIA VIRTUAL. (2011). Consejo de Cooperación bibliotecaria. Ministerio de Cultura. Gobierno de España. Manual de Chat del servicio: Pregunte: las bibliotecas responden con la aplicación de QUESTIONPOINT.Disponible en: http://www.pregunte.es/manuales/Manual_del_Chat.pdf. [Consultado:25-11-2011]

90. GUTIÉRREZ PEQUEÑO, José Miguel. (2008). universidad de Valladolid. la educación y los medios de comunicación social: de la aldea global a la galaxia internet. En: Tabanque revista pedagógica, 21, 2008. p. 223-238 ISSN: 0214-7742. Disponible en: dialnet.unirioja.es/descarga/articulo/3002676.pd. [Consultado: 23-11-2012]

91. HAPKE, Thomas. (200?). Between Dewey and Dewey information. Literacy in Germany between a librarian's and a more Holistic view. . (200?) p. 43-71. Disponible en: http://eprints.rclis.org/bitstream/10760/12797/1/Hapke_Thomas_KWIL2007_Hapke _format_neu_SZ-1.pdf. [Consultado:15-9-2009]

92. HEERY, Rachel; ANDERSON, Sheila. (2005). Digital repositories review. Project Report. Joint Information Systems Committee. Link to official URL Disponible en: http://www.jisc.ac.uk/uploaded_documents/digital-repositoriesreview-2005.pdf. [Consultado:24-3-2012]

93. HOLMES, Bryn; Gardner, John. (2006). E-learning: concepts and practice.-London: Sage Publications Ltd, 2006 xiii, 186 p. ISBN:1412911109 
94. IFLA. The International Federation of Library Associations and Institutions (IFLA). Recomendaciones para el servicio de referencia digital, Abril 2009.

Disponible en: http://archive.ifla.org/VII/s36/pubs/drg03-s.htm [Consultado:20-3-2012]

95. IFLA. The International Federation of Library Associations and Institutions (IFLA).Manifesto sobre Internet de la IFLA. Declaración aprobada por la Junta de Gobierno de la IFLA el 27 de marzo del 2002 en La Haya, Los Países Bajos. Proclamada por la IFLA el 1 de mayo del 2002. Disponible en: http://archive.ifla.org/III/misc/ims.htm. [Consultado: 5-10-2011]

96. IFLA. SECTION OF PUBLIC LIBRARIES (2000).The Public Library Service:Guidelines for Development. IFLA Section of Public Libraries June 2000. Disponible en: http://archive.ifla.org/VII/s8/proj/gpl.htm\#7 [Consultado 23-11-2012]

97. INOUE, Verónica. (1999). La visión de Elliott Masie respecto al desarrollo del Elearning en Latinoamérica. Entrevista a Elliot Masie 1999. p.1 Disponible en: http://www.learningreview.com/articulos-y-entrevistas-elearning/ [Consultado: 23-11-2012]

98. IRIARTE NAVARRO, Leonel; DUCH, Manuel Marco; MORÓN MARTÍN, Daniel [et.al.] (2005). Generación de una biblioteca de objetos de aprendizaje (LO) a partir de contenidos preexistentes. 2005. 10p.

Disponible en: http://www.um.es/ead/red/M2/leonel22.pdf [Consultado:15-9-2009]

99. JAOLOBEANU, Mihai Ed.;NISTOR, Nicolae; ENGLISH, Susan; [et.al.] (2003). Toward the virtual university: international online perspective. USA: Library of Congress Cataloging in Publication Data, 2003. 316 p. ISBN-10: 1931576920.

100. KETTING, Evert. (2002). Kenniscentra in Nederland Sociaal en Cultureel Planbureau Een inventariserend onderzoek naar kenmerken en groei van het aantal kenniscentra. Den Haag, 2002. Serie: Werkdocument 88.Documento Disponible en: www.scp.nl [Consultado:23-11-2011]

101. KNIPPENBERG, Harrie; WIBORG, Jan (2008). Onderzoek universiteitsbibliotheek 2008. Op zoek naar wetenschappelijk informatie. Radboud Universitiet Nijmegen, 71 p. Disponible en: http://www.ru.nl/ubn/over_de_organisatie/publicaties/onderverdeling/onderzoek/ [Consultado:18-2-2010]

102. KOHL FREY, Oliver; SCHMID RUHE, Bernd. (2007). Advanced users: information literacy and customized services. Konstanz Workshop on information literacy. Nov. 89, 2007. En: Bibliotheek aktueel. Sonderheft. 17. 41 p. Disponible en:http://www.ub.unikonstanz.de/fileadmin/Dateien/Informationskompetenz/KWIL/CFP_KWIL_2007.pdf [Consultado:15-9-2009] 
103. KOLH-FREY, Oliver. (2007). Information literacy for graduate and postgraduate students: experiences from the University of Konstanz. p.135-141. Disponible en: http://kops.ub.uni-konstanz.de/bitstream/handle/urn:nbn:de:bsz:352-opus59241/KWIL_okf_20070927_format_neu_SZ.pdf?sequence=1 [Consultado:15-9-2009]

104. KRIEK, F.; LIGTERMOEt, D.M. (1990). Eindrapport. Evaluatie van digitale informatieproyecten in openbare bibliotheken. Research voor beleid BV. Nederlandse Bibliotheek en Lektuur Centrum, Den Haag, 1990. 36p.

105. KRÜGER, Nicole. (200?). Econdesk-getting the content of need at het point of need. (200?). p.175-183. Disponible en: http://kops.ub.uni-konstanz.de/bitstream/handle/urn:nbn:de:bsz:352-opus59283/Krueger_Nicole_EconDesk_schriftliche_Fassung_KWIL_format_neu_SZ.pdf?se quence=1. [Consultado:15-9-2009]

106. LACOMBE ROCHA, Claudia. (2007) e-ARQ: Modelo de Requisitos para Sistemas Informatizados de Gestión Archivística de Documentos. Seminario: El documento electrónico, su gestión y los servicios a la ciudadanía desde una perspectiva archivística Chile - 29, 30 y 31 de mayo de 2007. 22 diapositivas.

Disponible en:

http://www.documentoseletronicos.arquivonacional.gov.br/Media/publicacoes/gest ao/chile_earq_ctde.pdf. [Consultado:23-3-2012]

107. LACOMBE ROCHA, Claudia. 2007. Metadatos: Concepto, Funciones y Tipos. Seminario: El documento electrónico, su gestión y los servicios a la ciudadanía desde una perspectiva archivística Chile $-29,30$ y 31 de mayo de 2007. 18 diapositivas. Disponible en: http://www.documentoseletronicos.arquivonacional.gov.br/Media/publicacoes/gest ao/chile__metadatos.pdf. [Consultado:23-3-2012]

108. LAGO CABRERA, Juan. (2006). Situación actual de estándares e-learning y aplicación en entornos de software libre. Fundación IAVANTE, consejería de Salud de Andalucía. En: Educación médica. vol. 9, sup. 2. Barcelona, 2006.

10 p. ISSN: 1575-1813. Disponible en: http://scielo.isciii.es/pdf/edu/v9s2/original4.pdf. [Consultado:15-11-2011]

109. LANKES R., David. [s.f]. Digital Reference: The First Mature Digital Library Service. Information Institute of Syracuse.[en linea] Disponible http://www.DavidLankes.org http://www.ala.org/lita/sites/ala.org.lita/files/content/conferences/forum/2003/. [Consultado: 23-11-2012]

110. LANKES R. David; SHOSTACK, Pauline (2003). The Necessity of Real-Time: Fact and Fiction in Digital:Reference Systems. En:Reference and User Services Quarterly 2002, vol.41, no.4, 2003. Disponible en: http://quartz.syr.edu/rdlankes/Publications/Journals/nescRT.pdf 
111. LANKES, R. David. (2005). Digital reference research: fusing research and practice. En: Reference \& user services quarterly, vol. 44, no. 42005 p.320 -326. Disponible en: http://quartz.syr.edu/rdlankes/Publications/Journals/fusingresearchandpractice.pdf. [Consultado:15-11-2011]

112. LANKES, David R.; GROOS, Melissa; MCCLURE, Charles R. (2002). Statistics, Measures, and Quality Standards for assessing digital reference library Services: guidelines and procedures. Information Institute of Syracuse; School of Information Studies; Syracuse University, Syracuse, New York. 2002. 104p. Disponible en : http://quartz.syr.edu/rdlankes/Publications/Books/Quality.pdf. [Consultado 20-112012]

113. LANKES, David R.; GROOS, Melissa; MCCLURE, Charles R. (2003).Cost, Statistics, Measures, and Standards for Digital Reference Services: A Preliminary View. Librarytrends, Vol. 51, No. 3, Winter 2003, p. 401-413 02003 The Board of Trustees, University of Illinois. Disponible en: https://www.ideals.illinois.edu/bitstream/handle/2142/8478/librarytrendsv51i3i_opt .pdf?sequence=1. [Consultado 20-11-2012]

114. LAU, Jesús. (2006). Guidelines on information literacy for lifelong learning: final draft. México: Universidad Veracruzana, 2006. 57 p. Disponible en: http://archive.ifla.org/VII/s42/pub/IL-Guidelines2006.pdf [Consultado:15-11-2011]

115. LEVY, Alon Y.; Kirk, Thomas. (1995). Data Model and Query Evaluation in global information systems. En: Journal of intelligent system, 5 1995. Kluwer Academic Publishers. Boston, Manufactured in The Netherlands. p.121-143. Disponible en: http://www.springerlink.com/content/r675468361m4w27q/ [Consultado:15-11-2011]

116. LIBERATORE, Gustavo. (2004) Los servicios bibliotecarios en línea y la formación universitaria a distancia en Argentina: acceso a la información y formación. En: World Library Information Congress: 70th IFLA General Conference and Council. 22-27 agosto 2004. 10 p.

Disponible en: http://www.scielo.br/pdf/ci/v33n3/a12v33n3.pdf [Consultado:15-9-2009]

117. LOMAN, Marc; GERRITSMA, Wouter. (2005). Informatie op maat in de bibliotheek Wageningen UR. Wageningen. 11 p. Disponible en: http://igiturarchive.library.uu.nl/DARLIN/2005-0316013029/LUWPUBRD_00328195_A502_001.pdf [Consultado:15-8-2009]

118. LÓPEZ GUZMÁN, Clara; ARRIAGA ARREDONDO, Alberto; CASTRO THOMPSON, Alberto.(2006). 3R- Red de Repositorios Universitarios de Recursos Digitales. Informe técnico . Etapa I. Investigación. Thompson; et.al. UNAM, México, 2006. 75 p. http://eprints.rclis.org/bitstream/10760/12757/1/3R_primer_informe.pdf [Consultado: 13-11-2012] 
119. LOPEZ GUZMÁN, Clara (2000). Modelo para el desarrollo de bibliotecas digitales especializadas. Instituto Tecnológico Autónomo de México, 2000. Disponible en: http://www.worldcat.org/title/modelo-para-el-desarrollo-de-bibliotecas-digitalesespecializadas/oclc/51244643 [consultado 25-09-2012]

120. LÓPEZ GUZMAN, Clara. (2005). Los repositorios de objetos de aprendizajes como soporte para los entornos e-learning. 2005 Trabajo presentado en Programa de Doctorado en Procesos de Formación en Espacios Virtuales. 142 p. Disponible en: http://gredos.usal.es/jspui/bitstream/10366/56649/1/DIA_Repositoriosobjetos.pdf.p df. [Consultado:15-9-2009]

121. LÓPEZ GUZMAN, Clara; GARCÍA PEÑALVO, Francisco J. (2006). Repositorio de objetos de aprendizaje: bibliotecas para compartir y reutilizar recursos en los entornos Elearing. En: Biblioteca Universitaria. Julio-diciembre 2006. Vol. 9. No. 02 p.99-107. Disponible en: http://dgb.unam.mx/revista/Revista\%20online/ne-200602/Vol9No2_jul.dic2006_p_99-107.pdf. [Consultado:23-3-2012]

122. LORCA GONZÁLEZ, Jesús; RODRíGUEZ MUÑOZ, José Vicente (2002). La tecnología de flujo de trabajo en el contexto de la biblioteca digital.

Universidad de Murcia. 2002. En: Anales de Documentación, no. 5, 2002. p. 157-175

123. LORENZO GARCÍA, Aretio. (1999). Historia de la Educación a Distancia (History of Distance Education). Universidad Nacional de Educación a Distancia UNED, España 1999. Disponible en: Revista Iberoamericana de Educación a Distancia (RIED). http://www.biblioteca.org.ar/libros/142131.pdf [Consultado: 02-12-2012]

124. LYNCH, Clifford A.(2003). Institutional Repositories: Essential Infrastructure for Scholarship in the Digital Age. [en linea] En: ARL Bimonthy Report, no. 226. Disponible en: http://www.arl.org/resources/pubs/br/br226/br226ir.shtml. [Consultado: 13-11-2012]

125. LLORÉNS LARGO, Faraón. (2012). Visión estratégica de las $\mathrm{Cl} 2$ en las universidades españolas, 2012. En: X Jornadas CRAI 28 y 29 de junio 2012. Disponible en: http://biblioteca.unirioja.es/crai2012/index.shtml. [Consultada 30-10-2012]

126. MAC KEE DE MURIAL, Nelly (2005). Los centros de recursos para el aprendizaje y la investigación: CRAI. [en línea]. En: Proceedings. XII Coloquio Internacional de Bibliotecarios. Guadalajara, 2005. 14 p. Disponible en: http://eprints.rclis.org/archive/00009065/ [05/05/2008] y http://eprints.rclis.org/bitstream/10760/9167/1/mackee_crai.pdf. [Consultado:20-3-2012]

127. MANSO RODRÍGUEZ, Ramón Alberto (2010). Servicio de referencia virtual: propuesta de un modelo basada en criterios de calidad y herramientas web 2.0. Universidad de Granada. Facultad de Comunicación y Documentación. 2010. Tesis doctoral 2010. p.240. Tesis doctoral ISBN: 9788469410530.

Disponible en: http://hera.ugr.es/tesisugr/19562871.pdf. 
[Consultado 22-11-2012]

128. MANSO RODRÍGUEZ, Ramón Alberto (2007). Del escritorio tradicional al virtual: nuevas posibilidades para el servicio de referencia. ACIMED 2007; vol.15, no. 2. Disponible en: http://bvs.sld.cu/revistas/aci/vol15_02_07/aci08207.htm [Consultado 23-11-2012]

129. MARÍN, Toral; Barrero García, F.; MARTÍNEZ TORRES, M.R, [et.al]. (2006). Determinación de las variables de diseño en el desarrollo de una herramienta Elearning. S.L. En: Píxel-Bit. Revista de Medios y Educación. Universidad de Sevilla. no.027. 2006. p.99-113.

Disponible en: ttp://www.sav.us.es/pixelbit/pixelbit/articulos/n27/n27art/art2708.htm [Consultado:8-3-2010]

130. MARKLEES, Sharon; STREATFIELD. (200?)David. Three decades of information literacy: redefining the parameters. . (200?) 1p.

Disponible en: http://www.informat.org/pdfs/Streatfield-Markless.pdf [Consultado:15-9-2009]

131. MARTÍNEZ, Dídac. (2010) El Centro de Recursos para el Aprendizaje CRAI. El nuevo modelo de biblioteca universitaria, 2010. Universidad Politécnica de Cataluña. 14 p. Disponible en: www.aab.es/pdfs/gtbu_crai.pdf www.ucm.es/BUCM/biblioteca/doc6202.pdf. [Consultado:02-12-2012]

132. MARTíNEZ, José Ángel; Lara, Pablo. (2006). Interoperabilidad de los contenidos en las plataformas E-learning: normalización, bibliotecas digitales y gestión del conocimiento. En: Revista de Universidad y Sociedad del Conocimiento. vol.3, no. 2, 2006. ISSN: 1698-580X.

Disponible en: http://redalyc.uaemex.mx/pdf/780/78030206.pdf [Consultado:15-9-2009]

133. MARTÍNEZ ROLDÁN, David; HERVÁS JORGE, Antonio. (2008). E-learning como estrategia de internacionalización de la educación superior. Universidad Politécnica de Valencia En: Revista Electrónica de Tecnología Educativa Edutec-e. ISSN:11359250. no. 27,2008

134. MASIE, Elliott. (2002). Making Sense of Learning Specifications \& Standards: Elliott Masie, The MASIE Center; S3 Working Group Membership. A Decision Maker's Guide to their Adoption March 8, 2002. Saratoga Springs NY 12866 USA. Disponible en: http://www.staffs.ac.uk/COSE/cosenew/s3_guide.pdf. [Consultado: 02-12-2012]

135. MEIJ, Bart van der;WESTERKAMP, Kees. (2007). De Digitale Bibliotheek Rotterdam:Essentials,2007.192 p. ISBN: 9789077252055 
136. MEIJER de, F. (2005) Google: wetenschappelijk verantwoord? En: PNPi. no.1, 2005. p.13-14. Disponible en: http://frans.demeijer.com/publicaties/Issue2005-22-1-13-14.pdf [Consultado 15-09-2009]

137. MÉNDEZ, Eva; SENSO, José A. (2004). Metadatos: concepto y motivación. Material de curso Introducción a los metadatos: estándares y aplicación. Unidad de autoformación. SEDIC. Disponible en: http://www.sedic.es/autoformacion/metadatos/tema1.htm. [Consultado: 13-11-2012]

138. MENDONZA, Jorge A. (2003). E-learning, el futuro de la educación a distancia. Soluciones IT. 20034 p.Disponible en: http://www.informaticamilenium.com.mx/paginas/mn/articulo78.htm. [Consultado:14-11-2011]

139. MERLO VEGA, José Antonio. (2000). El servicio bibliotecario de referencia. En: Anales de Documentación, no. 3, 2000. p.93-126.

Disponible en: http://revistas.um.es/analesdoc/article/view/2471/2461 [Consultado:5-9-2009]

140. MERLO VEGA, José Antonio. (1999). 50 aplicaciones bibliotecarias de Internet. Universidad de Salamanca, España, 1999. 106, p.38-47. Serie: Educación y biblioteca. Disponible en: http://gredos.usal.es [Consultado: 02-12-2012]

141. MERLO VEGA, J. A. (2008, 18 de febrero). Las diez claves de la web social. Consultado de la World Wide Web. . Universidad de Salamanca, España, 2008. 4 p. http://www.thinkepi.net/las-diez-claves-de-la-web-social/ [Consultado: 02-12-2012]

142. MERLO VEGA, José Antonio; MERLO VEGA, María Jesús. (1988). Servicios de información en línea para el desarrollo local. FESABID, España. 1988 p. 587-596. [Consultado: 1-12-2012]

143. MERLO VEGA, José Antonio. (2009). Información y referencia en entornos digitales: desarrollo de servicios bibliotecarios de consulta. Universidad de Murcia Servicio de Publicaciones, 2009. 401 p. ISBN: 978-84-8371-918-3

144. MERLO VEGA, José Antonio. (2011). Ciencia 2.0: aplicación de la web social a la investigación. José Antonio Merlo Vega; Antonia Angosto Castro; José Pablo Gallo León, Madrid, España: REBIUN, 2011. 74 p.

[Consultado: 02-12-2012]

145. MIDDLETON, Michael (1999).De la gestión de la información a la gestión del conocimiento: perspectivas sobre el desarrollo. En: El profesional de la información 1999. ISSN: $1386-6710$ 
146. MONTI SHARON, Félix San Vicente (2006). Evaluación de plataformas y experimentación en Moodle de objetos didácticos (nivel A1/A2) para el aprendizaje E/LE en E-learning. Universidad de Bolonia. p.3 En: Revista electrónica de didáctica / Español lengua extranjera, no. 8, 2006.

147. MORA Marcos, Mari Carmen; ROVIRA Fontanals Cristòfol. (2005). Evaluación de la usabilidad en sistemas de información Web municipales: metodología de análisis y desarrollo. p. 215-432. En: Memoria de ISKO. CAPÍTULO ESPAÑOL. CONGRESO 70: 2005: Barcelona. Disponible en: http://www.mcmarcos.com/pdf/2005_evaluacion- municipales-isko.pdf. [Consultado: 18-2-2010]

148. MORALES GARCÍA, Ana María; SEBASTIÁN, Mercedes Caridad; GARCÍA LÓPEZ, Fátima. (2008). Impacto social e idoneidad de los servicios de los telecentros españoles en la sociedad de la información: metodología de evaluación a partir de indicadores y método de análisis multivariable p.70-86. En: Ci. Inf. Brasilia. Vol. 37, no.2. 2008 Disponible en: http://www.scielo.br/pdf/ci/v37n2/a06v37n2.pdf [Consultado:18-2-2010]

149. MORIS, Anne; Jacobs, Neil; Davies, Eric. (1999). Document delivery beyond 2000. Los Ángeles: Taylor Graham publishing, 1999. 181 p. ISBN: 094756876X

150. MORRISON, David. Building successful portals. En: Group computing magazine, mayo-junio, 2000. Citado por Juan Carlos García Gómez Disponible en: http://archives.groupcomputing.com/index.cfm?fuseaction=viewarticle\&C ontentID=110. [Consultado:24-5-01]

151. MOSCOSO, Purificación. (200?). La nueva misión de las bibliotecas universitarias ante el espacio europeo de enseñanza superior. Universidad de Alcalá. (200?).15 p. Disponible en: http://www.rebiun.org/doc/ponencia_moscoso.pdf [Consultado:15-10-2011]

152. MÜHLBACHER, Susane; HAMMWÖHNER, Rainer, [etc]. (200?). Workplace information literacy in the scientific field: an empirical analysis using the semantic differential approach. (200?). p.115-133.

Disponible en: http://kops.ub.uni-konstanz.de/bitstream/handle/urn:nbn:de:bsz:352-opus59236/Muehlbacher_Susanne_KWIL_Mue_Artikel101002_final_version_format_neu _SZ.pdf?sequence=1. [Consultado:15-11-2011]

153. MURIEL GARRETA, Enric Mor; GALOFRÉ, Maria.(2007). Diseño centrado en el usuario en entornos virtuales de aprendizaje, de la usabilidad a la experiencia del Estudiante. Universidad del país Vasco, 2007. 10 p. En: IV Simposio Pluridisciplinar sobre Diseño, Evaluación y Desarrollo de Contenidos Educativos Reutilizables (SPDECE07). Disponible en: http://spdece07.ehu.es/actas/Mor.pdf. [Consultado: 02-12-2012] 
154. MURILLO ALFARO, Félix ( 2000) ¿Qué es el Comercio Electrónico? Instituto Nacional de Estadística e Informática, Perú.2000, 39 p.

Disponible en: http://blog.pucp.edu.pe/media/avatar/111.pdf

[Consultado:24-8-2011]

155. NAVARRA, Leonel Iriarte; DUCH; Manuel Marco; PERNIAS PECO, Pedro. Generación de una biblioteca de objetos de aprendizaje (LO) a partir de contenidos preexistentes. En: Revista de Educación a Distancia. Universidad de Murcia. 11 p. E-ISSN: 1578-7680.

Disponible en:

http://redalyc.uaemex.mx/redalyc/src/inicio/ArtPdfRed.jsp?iCve $=54709509$ [Consultado:24-8-2011]

156. NAVARRO BUENDÍA, Marcos.(200?). Evaluación de plataformas E-learning de licencia pública. (200?).14 p.

Disponible en pdf: http://www.uv.es/ticape/docs/nabuen/PFC.pdf [Consultado:15-11-2011]

157. NIET, Marco. De Poort tot kennis in Europa. En: Informatie professional, 2001, vol.5. no. 5. p. 28-31. Disponible en: http://igitur-archive.library.uu.nl/DARLIN/2005-0606200251/NietIP052001.pdf. [Consultado:5-11-20101]

158. ONTALBA-RUIPÉREZ, José Antonio. (2000). Bibliotecas digitales españolas: análisis de las primeras realidades. [en línea]. Universitat Oberta de Catalunya, Barcelona, 2000, 11 p. Disponible en: http://eprints.rclis.org/archive/00011319/01/FESABIDBibDigitales.pdf [Consultado: 05-05-2008].

159. ONTALBA Y RUIPÉREZ. José Antonio. (2002, p.2) Contenidos en comunidades virtuales: análisis de las herramientas y servicios de información. Biblioteca Virtual de la UOC. 2002. 14 p. Disponible en:

http://openaccess.uoc.edu/webapps/o2/bitstream/10609/331/1/12883.pdf [Consultado:4-11-2010]

160. OROZCO, Mabel Rocio.(2011). CRAI: Centro de Recursos para el Aprendizaje y-la Investigación. [en linea] 2011.9 p. Disponible en:

http://www.slideshare.net/dianyeliperdomo/c-r-a-i-centro-de-recursos-para-elaprendizaje-y-la-investigacion. [Consultado:23-3-2012]

161. OPPENHEIM , C.; Smithson, D. (1999). What is the hybrid library?. En: Journal of information Science. US: Institute of Library and Information Professionals, 1999, vol. 25, no. 2 p. 97-112. ISSN 0165-5515

162. PAYNE, Philip; CONYER, Angela (2005). Measuring the impact of higher education libraries: the LIRG/SCONUL Impact Implementation Initiative. Library and Information Research vol. 29, no.91. 2005. 11 p. ISSN 0141-6561. Disponible en: http://eprints.bbk.ac.uk/148/1/Payne1.pdf [Consultado:23-3-2012] 
163. PÉREZ, Dora. [s.f]. La biblioteca digital Biblioteca de la Universitat Oberta de Catalunya. [en línea]. Barcelona, [s.f.], 12p. Disponible en: http://www.uoc.edu/web/esp/articles/La_biblioteca_digital.htm [consultado 05-05-2008]

164. PÉREZ RODRÍGUEZ, Yudit; MILANÉS GUISADO, Yusnelkis. (200?). La biblioteca universitaria: reflexiones desde una perspectiva actual. (200?). s.p. Disponible en: http://bvs.sld.cu/revistas/aci/vol18_3_08/aci04908.htm [Consultado 15-9-2009]

165. PÉREZ SALAZAR, G.; ANGULO, Y. (2007). Evaluación del programa de acceso a servicios digitales en bibliotecas públicas: una perspectiva desde la brecha digital. En: Global Media Journal, México, vol. 4, no.7. 2007. p. 81-100. Disponible en: pdf:http://www.gmjei.com/journal/index.php/GMJ_El/article/viewFile/100/86 [Consultado:14-11-2011]

166. PINTO, María. (2009). Marcos teóricos para la aplicación de ALFIN en distintos ámbitos. Ponencia inaugural del II Seminario ALFIN de Vilanova, Barcelona, 2009. Disponible en: http://www.slideshare.net/alfinred/ponencia-inaugural-del-iiseminario-alfin-de-vilanova-2009-por-mara-pinto.

[Consultado:23-3-2012]

167. PIRIZ, Nancy; TEDESCO, Claudia. (2008). El desafío de implementar un proyecto Elearning: evaluación del proyecto de e-learning. 200821 diapositivas. Disponible en: http://www.slideshare.net/strabaldo/evaluacion-de-un-proyecto-elearning-ppt-presentation. [Consultado:15-11-2011]

168. POMERANTZ, J., MON, L.; MCCLURE, C. R. (2008). Evaluating remote reference service: A practical guide to problems and solutions. portal: Libraries and the Academy, vol.8, no,1. p. 15-30. Disponible en: http://muse.jhu.edu/journals/pla/ [Consultado 20-10-2012]

169. POVEDA POLO, Ángel.. (2011). Los objetos de aprendizaje: aprender y enseñar de forma interactiva en biociencias = Learning tools: learning and teaching in an interactive way in biosciences. En: ACIMED, vol 22, no. 2, 2011 Disponible en:http://www.acimed.sld.cu/index.php/acimed/article/view/149/120 [Consultado:1-10-2012]

170. QUIROGA F. Celiar. (2005). Material de curso básico para auxiliares de biblioteca. Universidad de la Salle. Bogotá, 2005. 66 diapositivas Disponible en: http://ascolbi.org/eventos/Curso_Basico/documentos/promocion_y_divulgacion\%20 _servicios.pdf. [Consultado:15-11-2011]

171. RAAD VAN ADVIES VOOR BIBLIOTHEEWEZEN EN INFORMATIEZORGING -RABIND (1990) Informatieverzorging voor en door het bedrijfsleven: tien actiepunten: advies 6. Den Haag: RABIN, 1990. 64 p. 
172. RADER, HANNELORE B. (2000). Alfabetización informacional en el entorno de servicio de referencia: preparándonos para el futuro. En: Anales de Documentación, no. 3, 2000. p. 209-216. Serie: traducciones.

Disponible en: http://redalyc.uaemex.mx/pdf/635/63500312.pdf [Consultado:15-9-2009]

173. RAMÍREZ CÉSPEDES, Zulia. (2006). Criterios e indicadores para evaluar bibliotecas digitales 15 p. En: ACIMED, vol.14, no. 6, 2006.

Disponible en: http://bvs.sld.cu/revistas/aci/vol14_6_06/aci04606.htm [Consultado:18-2-2010]

174. REBIUN. Adquisición de competencias en información. Una materia necesaria en la formación universitaria. Documento marco de REBIUN para la CRUE. 3 p. Disponible en: www.rebiun.org/ [Consultado: 02-12-2012]

175. REBIUN; COMISIÓN MIXTA CRUE-TIC. (2009) Competencias informáticas e informacionales en los estudios de grado. Comisión mixta CRUE-TIC y REBIUN Abril 2009. 13 p. Disponible en: http://www.rebiun.org/doc/documento_competencias_informaticas.pdf [Consultado: 30-10-2012]

176. RECIO, Marcos Juan Carlos (2006). Estrategia para crear, formar y evaluar servicios virtuales en la sociedad del conocimiento. 2006. $14 \mathrm{p}$.

Disponible en: http://eprints.ucm.es/7050/1/Estrategias_para_crear.pdf [Consultado:18-2-2010]

177. REMPEL, Hanah. (200?). Information literacy at the point of net literature review workshops. (200?). p.157-164. Disponible en: http://ir.library.oregonstate.edu/xmlui/handle/1957/8231?show=full [Consultado:15-9-2009]

178. RESOBA, Tatiana V; HOLOV, Yuri E. (2002). Migrar de la biblioteca de hoy a la biblioteca de mañana: ¿Re- o E-volución? En: International Federation Library Associations And Institutions. 66th IFLA Counciland General Conference (Jerusalem, Israel, 13-18 August), 2000. Disponible en: http://www.ifla.org/IV/ifla66/papers/063110s.htm Consultado 27-04-2012

179. RIEGER, Oya Y.; HORNE, Angela, K; REVELS, Ira ( 2005). Linking course web site to library collections and services. En: The Journal of Academic Librarianship, vol. 30, no.3, 2005. p. 205-211. Disponible en: http://www.sciencedirect.com/science/article/pii/S0099133304000461 [Consultado:18-2-2010]

180. ROIG VILA, Rosabel. (2010). Curso de formación del B-learning.[en linea]. Universidad de Alicante. Curso GITE, 2 Jun 2010

Disponible en: www.slideshare.net/.../presentacion-blearning Consultado [23-11-2012] 
181. ROSENBERG, Marc. (2001). E-Learning: Strategies for Delivering Knowledge in the Digital,USA: . The McGraw Hill Companies, 2001344 p. ISBN 0-07-136268-1.

182. RUBENS, Wilfred. (2003). De (prille) geschiedenis van e-learning: omiten in verwondering. 2003. 13 p. Disponible en pdf:

http://www.te-learning.nl/omzieninverwondering.pdf. [Consultado:14-11-2011]

183. RUBIO, María José (2003). Enfoques y modelos de evaluación de E-learning / Focus and models of evaluation of the e-learning. En: RELIEVE. vol. 9, no.2. p.101-120. Disponible en: http://www.uv.es/RELIEVE/v9n2/RELIEVEv9n2_1.pdf [Consultado:18-2-2010]

184. SAMPSON, Demetrios; MANOUSELIS, Nikos (2005). A flexible evaluation Framework for web portals based on multi-criteria analysis. En: Web Portals: the New Gateways to Internet Information and Services: Idea Group Inc. 2005. p.185-211 ISBN10: 159140438X, EISBN13: 9781591404408 Disponible en: http://www.irma-international.org/viewtitle/31175/ [Consultado:5-5-2011]

185. SÁNCHEZ DÍAZ, Marlery; VEGA VALDÉS, Juan Carlos. (2002). Bibliotecas electrónicas, digitales y virtuales: tres entidades por definir. Cuidad de la Habana, 2002. En: ACIMED, vol.10, no.6, p.9-10. ISSN 1024-9435. Disponible en: http://scielo.sld.cu/scielo.php?script=sci_arttext\&pid=S102494352002000600005. [Consultado:5-5-2008]

186. SÁNCHEZ GARCÍA DE LAS BOYONAS, Salvador; MELERO MELRO, Remedio. (200?) La denominación y el contenido de los Repositorios Institucionales en Acceso Abierto: base teórica para la Ruta Verde. (200?) 14 p. Disponible en: http://eprints.rclis.org/bitstream/10760/7613/1/Denominaci\%C3\%B3n_contenido_0 A.pdf. [Consultado:24-3-2012]

187. SÁNCHEZ SUÁREZ, José A. (200?). Las bibliotecas universitarias en un entorno de enseñanza virtual. XI Jornadas Catalanes d’informató i Documentació. 2008. p.17-29. Disponible en pdf: http://www.cobdc.org/jornades/11JCD/actes11jcid/comunicacions/pag_17.pdf [Consultado:15-9-2009]

188. SATTAR Chaudhry, Abdus (2006). Role of libraries in promoting E-learning: a review of Singapore initiatives. En: Pakistan Journal of Library \& Information Science. No.7, 2006. p.57-67.

Disponible en: http://www.pu.edu.pk/departments/10-pjlis07.pdf [Consultado:18-2-2010]

189. SAVENIJE, Bas. (2007).The future of the library: the crucial importance of accessibility. DARLIN, 2007. 8 p.

Disponible en: http://igitur-archive.library.uu.nl/DARLIN/2005-0307110757/UUindex.html. [Consultado:14-8-2008] 
190. SAVENIJE, Bas; Grygierezyk, Natalia.(1999) The Roquade Project: a gradual revolution in academic publishing. 1999. p. 211-216. En: Proceedings of the 23rd International Online Information Meeting. Learned Information Europe Ltd. Disponible en: http://www.kb.nl/staff/savenije/publicaties/21_1999_Roquade.pdf [Consultado:14-11-2011]

191. SCHAPIRO, Jeremy J.; HUGHES, SHelley K. Information Literacy as a Liberal. En: EDUCOM REVIEW 1996, vol. 31; no. 2, p. 31-35. Disponible en: http://net.educause.edu/apps/er/review/reviewarticles/31231.html [Consultado:233-2012]

192. SCHNECKENBERG, Dirk. (2004). El E-learning transforma la educación superior. En: Educar, no. 33, 2004. p.143-156. Disponible en: http://www.raco.cat/index.php/educar/article/viewFile/20793/20633 [Consultado:14-11-2011]

193. SHANNON, Donna M. (2002) The Education and Competencies of School Library Media Specialists: University of South Carolina, Scholar Commons School En: Library Media Research, Volume 5, 2002. s.p. Disponible en: http://www.ala.org/aasl/aaslpubsandjournals/slmrb/slmrcontents/volume52002/sha nnon / [Consultado:23-3-2012]

194. SHARIFABADI, Saeed Rezaei (2006). How digital libraries can support e-learning. En: The Electronic Library, vol. 24, no.3, 2006. p 389-401. ISSN: 0264-0473

195. SIEVERTS, Eric; MARREZ de, Peter; SIKKENGA, Harmen; [et.al.] (2005). Wetenschappelijk bibliotheken: meer informatie, strakkere structuren. En: Informatie professionel, jaar 9, december 2005. p.16-33.

196. SILVERAL, Claudia. (2005). La alfabetización digital: una herramienta para alcanzar el desarrollo y equidad en los países de América Latina y el Caribe. En: ACIMED. Vol. 12, no. 1, 2005. 8 p. Disponible en:

http://www.bvs.sld.cu/revistas/aci/vol13_1_05/aci04105.pdf [Consultado:15-9-2009]

197. SMELIK, Jos. (2004). Bibliotheek Wageningen UR: een ander gebruikersonderzoek. En: Informatie Professional No. 8, 2004. p.28-31.

198. SNVELY, Loane; COOPER, Natasha. (1997). The information literacy: debate. p. 9-13 En: The Journal of Academia Librarianship. Ene. 1997.

Disponible en: http://www.sciencedirect.com/science/article/pii/S0099133397900665 [Consultado:15-9-2009] 
199. SAORÍN PÉREZ, Tómas. (2002). Modelo conceptual para la automatización de bibliotecas en el contexto digital. Universidad de Murcia. Facultad de Ciencias de la Documentación. Departamento de Información y Documentación, 2002. Tesis Doctoral 286 p. Disponible en: http://digitum.um.es/jspui/bitstream/10201/84/1/SaorinPerez.pdf?sequence=1. [Consultado: 23-11-2012]

200. SOMOZA Fernández, Marta. (2002) Análisis de los tutoriales Web creados por bibliotecas universitarias. Tesis. Programa de Doctorado de Información y Documentación: Universidad de Barcelona. p.25-147

Disponible en: http://tdx.cat/bitstream/handle/10803/769/MSF_TESIS.pdf?sequence=1 [Consultado:15-9-2009]

201. SUMAR (Paraguay) Servicios de Organización y Tecnología.

Disponible en:

http://sumar.com.py/index.php?option=com_content\&task=blogcategory\&id=25\&lte mid=38. [Consultado:4-03-2010]

202. SUN Microsystems. (200?). E-learning interoperability Standard. Geoff Collier and Robby Robson, Eduworks Corporation, California. (200?). 25 p. Serie White paper. Disponible en: http://www.ufr-mig.ups-tlse.fr/NTIC/veille/elearning_Sun.pdf [Consultado:15-9-2009]

203. SUNYER,Silvia. (2006). Centros de Recursos para el Aprendizaje y la Investigación (CRAI), y servicios bibliotecarios estratégicos para una Europa basada en el conocimiento. p. 327-337. En: Intangible Capital Humano. México, vol 2. no.4, 2006. ISSN: 1697-9818. Disponible: http://redalyc.uaemex.mx/pdf/549/54920401.pdf. [Consultado: 1-12-2012]

204. SUÑÉ LLINÁS, Emilio. (2008). Declaración de derechos del ciberespacio. Emilio Suñe Llinás. Universidad Complutense de Madrid, España. 2008 20p.Disponible en: http://www.ecopilas.es/media/II\%20Convenci\%C3\%B3n\%20Derecho\%20Inform\%C3 \%A1tico/doc\%20conferencias/DCHOCIBER.pdf. [Consultado: 1-12-2012]

205. STRAW, Joseph E.(2001) From magicians to teachers: the development of electronic reference in libraries: 1930-2000. En: The Reference librarian, 2001, no. 74 p.1-12

206. SWETT GREEN, Samuel. (1876). Personal relations between librarians and readers. [en línea]. En: Library Journal, 1876.

Disponible en: http://polaris.gseis.ucla.edu/jrichardson/DIS220/personal.htm [Consultado: 02-12-2012]

207. TALAVERA IBARRA, Ana María. Una biblioteca virtual: nace o se hace? Santiago de Chile, 24-26 octubre 2001. 15 p. VIII Conferencia Internacional de Bibliotecología: Biblioteca Digital: Perspectivas, Experiencias y Oportunidades.

Disponible en:

http://www.hacienda.go.cr/centro/datos/articulo/una\%20biblioteca\%20virtual\%20n 
ace\%20o\%20se\%20hace.pdf. [Consultado: 20-3-2012]

208. TEDESCO, Claudia. (2008). El desafío de implementar un proyecto E-learning: evaluación del proyecto de e-learning. (2008). 21 diapositivas. Disponible en: http://www.slideshare.net/strabaldo/evaluacion-de-un-proyecto-e-learning-pptpresentation [Consultado:15-11-2012]

209. TYCKOSON, David. (2003). On the desirableness of personal relations between librarians and readers: the past and future of reference service. En: Reference Services Review. vol. 31, no. 1. p. 12 - 16 Disponible en: http://dx.doi.org/10.1108/00907320310460834 [Consultado: 20-05-2012]

210. TYCKOSON, David. (2001). What Is the Best Model of Reference Service?. David A. Tyckoson. En: LIBRARYTRENDS. The Board of Trustees, University of Illinois. vol. 50, no. 2, 2001. p. 183-196.

211. TORAL, Marín, S.L.; BARRERO GARCÍA, F.; MARTíNEZ TORRES, M.R.; [et.al.]. (2006). Determinación de las variables de diseño en el desarrollo de herramientas E-learning. Pixel. no. 27, Ene. 2006 p. 99-113. Disponible en: http://redalyc.uaemex.mx/pdf/368/36802708.pdf. [Consultado:14-11-2011]

212. TORRES VARGAS, Georgina Araceli; SÁNCHEZ AVILANEDI, María Dolores. (2005). EI servicio de referencia de la biblioteca digital. En: Investigación bibliotecológica. vol. 19,39. julio-Diciembre 2005 p. 120 Disponible en: http://www.ejournal.unam.mx/ibi/vol19-39/IBIO3907.pdf [Consultado:14-11-2011]

213. TRAMULLAS SAZ, Jesús. (2002). Propuestas de concepto y definición de la biblioteca digital. [en línea]. coord. por Purificación García Delgado, José Hilario Canós Cerdá. EnL III Jornadas de Bibliotecas Digitales: (JBIDI'02). El Escorial (Madrid) Noviembre 1819, 2002., 2002, p. 11-20 p. 11-20. ISBN 84-688-0205-0 Disponible en: http://eprints.rclis.org/bitstream/10760/15118/1/04_2002.pdf [Consultado:5-5-2008]

214. TRAMULLAS SAZ, J.(2004). Bibliotecas digitales: una revisión de conceptos y técnicas.En: Bibliodocencia, 1, 2, 2004, 26-31. Disponible en: http://tramullas.com/papers/bidipe.pdf [Consultado 18-02-2008]

215. UCEDA, Fátima (2010). Evaluación del Servicio de Referencia Virtual de los Centros de los centros de Información de la UPC aplicando las directrices internacionales de IFLA y ALA (RUSA). Piura, 2001. 23 p. Disponible en: http://www.altamira-peru.org/documentos/ponenciasiv/fatima-uceda.pdf [Consultado 02-12-2012]

216. UNIVERSIDAD AUTONOMA DE BARCELONA. Competencias transversales.[en línea].Sitio web de consulta del Espacio Europeo de Educación Superior (Bolonia). Universidad Autónoma de Barcelona. Disponible en: http://www.uab.es/servlet/Satellite/bolonia/profesorado/competencias- 
transversales-1231747994766.html. Consultado: 2-11-2012]

217. URIBE TIRADO, Alejandro (2005-8) Diseño, implementación y evaluación de una propuesta en alfabetización informacional mediante un ambiente virtual de aprendizaje a nivel universitario: caso escuela Interamericana de Bibliotecología. Universidad de Antioquia. (Tesis de maestría en informática: línea educativa (20052008) $105 \mathrm{p}$.

Disponible en: http://eprints.rclis.org/bitstream/10760/12606/4/1.pdf [Consultado:20-3-2012]

218. URIBE TIRADO, Alejandro (2010). La Alfabetización Informacional en la Universidad. Descripción y Categorización según los Niveles de Integración de ALFIN. Caso Universidad de Antioquia. En: Revista Interamericana de Bibliotecología. (200?). vol. 33, 1 enero-junio (2010) p 31-83.

Disponible en:

http://eprints.rclis.org/bitstream/10760/14231/1/ALFIN_EN_LA_UNIVERSIDAD.pdf. [Consultado:14-11-2011]

219. VALDÉS PAYO, Lilibeth. (2007). Alfabetización informacional: una breve reflexión sobre el tema. 2007. 14 p.

Disponible en: http://scielo.sld.cu/pdf/aci/v17n2/aci06208.pdf [Consultado:15- 9-2009]

220. VANOUPLINES, Patrick. (2007). Informatiegeletterdheid in de bibliotheek. En: De Vlaamse Vereniging voor Bibliotheek, Archief en Documentatie vzw (VVBAD) p.1017. Disponible en: http://www.vvbad.be/sites/www.vvbad.be/files/artikel/file/200706_Vanouplines.pdf . [Consultado:14-11-2011]

221. VEGA, Arturo Martín. (2008). Apuntes para crear servicios de información de supervivencia. Madrid, España. 2008. p.105-122. En: CAPA. Vol. 13, no.1, 2008. ISSN: 1981-8920

Disponible en pdf: http://www.uel.br/revistas/uel/index.php/informacao/article/view/1676/1428 [consultado: 30-3-2012]

222. VÍLCHEZ QUESADA, Enrique (2005). E-learning: un nuevo concepto educativo. V Festival Internacional de Matemática: de costa a costa: Matemática como lenguaje para interpretar nuestro entorno. 2005. p. 4-8

Disponible en: http://www.cientec.or.cr/matematica/memoriaV.html [Consultado:18-2-2010]

223. VÍLCHEZ QUESADA, Enrique (2006). Entornos de aprendizaje virtual. Matemática como lenguaje para interpretar nuestro entorno.[en linea]. 2006. 29 p. Disponible en pdf: http://www.cientec.or.cr/matematica/memoriaV.html [consultado:18-2-2010] 
224. VLAANDEREN, Marie José. (2001). Het zoeken van wetenschappelijk informatie op Internet. Universiteitsbibliotheek Eramus Universiteit, 2001. 34p.

Disponible en: http://repub.eur.nl/res/pub/16113/Zoeken_op_Internet_sept04.pdf [Consultado:15-7-2010]

225. WARD, David. (2003). Using virtual reference: transcripts for staff training. En: Reference services review, vol. 3,no.1 2003 p. 46-56.

Disponible en:

http://www.emeraldinsight.com/journals.htm?articleid=861722\&show=pdf http://www.deepdyve.com/lp/emerald-publishing/using-virtual-referencetranscripts-for-staff-training-FI2yKkoAOd [Consultado:14-11-2011]

226. WASIK, Joann M. (1999). Building and Maintaining Digital Reference Services. ERIC Digest.1999. $17 \mathrm{p}$.

Disponible en pdf: http://www.eric.ed.gov/PDFS/ED427794.pdf [Consultado:14-11-2011]

227. WATER, D.J. (1988). What are digital libraries. Washington, DC, 1998. Serie: CLIR issue no. $4,1988.11 \mathrm{p}$.

228. WATSTEIN, Sarah Barbara. (2003). Scenario planning for the future of reference: five white papers posit the future and raise the bar for us all. En: Reference services review, vol. 3, no.1 2003 p. 36-38.

Disponible en:

http://www.deepdyve.com/lp/emerald-publishing/scenario-planning-for-the-futureof-reference-five-white-papers-posit-q9cg5szh9l

[Consultado:14-11-2011]

229. WEBBER, Sheila. (2007) Information literacy education for masters students: the search / teach exercise. p.185-192.

Disponible en:

http://kops.ub.uni-konstanz.de/bitstream/handle/urn:nbn:de:bsz:352-opus59298/webber_kwil_2.format_neu_SZ.pdf?sequence=1

[Consultado:15-11-2011]

230. WEISE, Frieda 0.; BORGENDALE, Marilyn.(1986). EARS: Electronic Access to Reference Service. Health Sciences Library; University ofMaryland at Baltimore. 1986. vol.74, no. 4 p. 300-304. Disponible en: http://www.ncbi.nlm.nih.gov/pmc/articles/PMC406264/pdf/mlab00376-0026.pdf [Consultado 02-12-2012]

231. WHITE, Andrew; Djiva Kaml, Eric. (2006). E-metrics for library and information professionals: how to use data for managing and evaluating electronic resource collections. New York: Neal-Schuman, 2006. 249p. ISBN: 1-55570-514-6 
232. XIE, Hong Iris.(2008). User's evaluation of digital libraries (DL's): their uses, their criteria, and their assessment. p.1346-1373. En: Information Processing and Management. Vol. 44, 2008. Disponible en:

http://www.sois.uwm.edu/xie/IrisArticles/Articles/dl_eva_comparison_ipm_clean.pd f. [Consultado:14-11-2011]

233. YIN, Robert K.; CAMPBELL, Donald T.(1984) Case study research: design and methods. 3. ed. Beverly Hills, Calif. :Sage Publications, 1984. XVI, 181 p. 


\section{ANEXOS}

\section{Anexo 1. Gestores del servicio de referencia}

La presenta encuesta está dirigida al personal involucrado con el servicio de Referencia Digital de la biblioteca. El objetivo de la encuesta es la realización de un análisis descriptivo y de funcionamiento que permita aplicar parámetros de medición de oferta y demanda, a fin de identificar la viabilidad de este servicio para ser integrado como parte o módulo en los programas de estudios E-learning.

\begin{tabular}{|l|l|}
\hline Email: & \\
\hline Institución: & \\
\hline País: & \\
\hline Dirección & \\
URL: & \\
\hline
\end{tabular}

\section{IDENTIDAD DEL SERVICIO}

1.1 ¿Cómo se identifica el servicio de Referencia en línea en la Web de la Biblioteca?

Palabra. ¿Cuál

Otro. ¿Cuál ?

1.2 ¿Qué otros servicios son integrados dentro del servicio de Referencia digital?

Servicios de preguntas y respuestas (Infopoint, Servicedesk )

Colecciones en línea (directorios, diccionarios, enciclopedias, etc.)

Orientación general sobre temas especializados.

Servicio de comunicación sincrónica ( Chat)

Servicio de preguntas frecuentes

Otro

Cuál ?.

1.3 Topología de usuarios. De la siguiente lista, marque con una $\mathrm{X}$ las categorías de usuarios que demanda el servicio.

\begin{tabular}{|l|l|l|l|l|l|}
\hline Usuarios & Novatos & Con experiencia & Experto & Externos & Internos \\
\hline Docentes & & & & & \\
\hline Trabajadores & & & & & \\
\hline Estudiantes & & & & & \\
\hline Otros & & & & & \\
\hline
\end{tabular}

1.4 Componentes básicos. Indique los componentes básicos que se utilizan para la gestión del servicio de referencia digital.

Ordenadores (computadores)

Programas (softwares)

Teléfono fax Email Chat Skype Otros

Portales RSS Blogs colaborativos Wikis

Otros: 
1.5 ¿Cuántos profesionales se desempeñan en la prestación del servicio.

Indicar número ¿Cuál es la formación académica de éstos?:

¿Qué funciones específicas desempeña el encargado del servicio de Referencia Digital?.

1.6 ¿Cuál es el objetivo del servicio de Referencia Digital?. De la lista que seguidamente se presenta indicar con un $\mathrm{X}$ los que se aplican.

Responde a necesidades concretas de información

Facilitar de forma eficiente y eficaz respuesta a preguntas concretas

Actuar como intermediario y direccionar adecuadamente las demandas de información entrantes dentro de la biblioteca.

Otros. Mencione.

1.7 ¿Utiliza el servicio de Referencia Digital estándares para el desarrollo y/o prestación del servicio?

1.8 ¿Existe alguna política para el trabajo en red (network) dentro y fuera de la institución?

1.9 ¿Cómo son integrados tecnológicamente los recursos de información de la biblioteca al servicio de referencia digital?

\section{ACTUALIZACIÓN}

2.1 Actualización y vigencia de los enlaces. Favor señalar con una $\mathrm{X}$ la frecuencia son verificados la actualización de los contenidos y la vigencia de los enlaces ofrecidos por el servicio de Referencia Digital.
a. Cada dos semanas
b. Cada mes
c. Cada semestre

d. Irregular

e. Sin idea

\section{ACCESIBILIDAD}

3.1 Cuenta el servicio de Referencia Digital facilidades para la localización y acceso al servicio e información por partes de personas con incapacidades física, auditivas o visuales.

Sí___ No___Explique :

\section{ORGANIZACIÓN DE LOS CONTENIDOS}

4.1 ¿Qué enlaces que facilitan y agilizan la navegación? Citar un ejemplo:

4.2 ¿Qué tipos de enlaces que facilitan y agilizan la búsqueda interna?

Citar un ejemplo: 
4.3 Menciones qué sistemas complementarios se vale el Servicio de Referencia Digital para facilitar el acceso a la información. Tablas de contenido Índices Mapas de sitios Otros:

4.4 ¿Ofrece el servicio diferentes lenguajes (idiomas) para facilitar la accesibilidad y difusión de los contenidos? Sí No Citar un ejemplo:

4.5 Jerarquización. Favor indicar la existencia relaciones directa o indirecta entre las secciones y contenido de la Web de su institución con el servicio de Referencia Digital.

\section{SERVICIOS BASICOS DE LA WEB}

5.1 Servicios básicos de la web. De la lista que a continuación se presenta indicar los servicios que se vinculan directamente con el servicio de Referencia Digital.

\begin{tabular}{|c|c|}
\hline Directorio de recursos web & Sí __ No ___ Me gustaría ___ \\
\hline Objetos de aprendizaje multimedia & Sí __ No ___ Me gustaría ___ \\
\hline Grupo / comunidades virtuales & Sí___ No ___ Me gustaría \\
\hline Acceso a diversos Metadatos & Sí __ No ___ Me gustaría \\
\hline Espacios personalizados & Sí __ No ___ Me gustaría \\
\hline $\begin{array}{l}\text { Recursos metadatos basados en el uso de la } \\
\text { web }\end{array}$ & Sí __ No ___ Me gustaría ___ \\
\hline Portales & Sí___ No ___ Me gustaría \\
\hline Servicio de orientación al estudiante & Sí __ No ___ Me gustaría \\
\hline Email & Sí__ No ___ Me gustaría __ \\
\hline Chat & Sí __ No ___ Me gustaría \\
\hline Skype & Sí __ No ___ Me gustaría \\
\hline Videoconferencias & Sí __ No ___ Me gustaría \\
\hline Foros de discusión & Sí __ No ___ Me gustaría \\
\hline Messenger & Sí __ No ___ Me gustaría \\
\hline Facebook & Sí __ No ___ Me gustaría \\
\hline Blogs colaborativos & Sí __ No ___ Me gustaría \\
\hline Wikis & Sí __ No ___ Me gustaría \\
\hline Flickr & Sí __ No ___ Me gustaría \\
\hline RSS & Sí __ No ___ Me gustaría ___ \\
\hline Google académicos & Sí __ No ___ Me gustaría \\
\hline $\begin{array}{l}\text { Diversos (noticias, variedades, } \\
\text { entretenimientos, etc.) }\end{array}$ & Sí __ No ___ Me gustaría \\
\hline \multicolumn{2}{|c|}{$\begin{array}{l}\text { 5.2 Acceso a los servicios. Indique el tiempo aproximado de respuesta que se establece en el } \\
\text { proceso de comunicación entre responsable del servicio y usuario. } \\
\text { Segundos ___ Minutos __ Hora__ Otro }\end{array}$} \\
\hline \multicolumn{2}{|c|}{$\begin{array}{l}5.3 \text { Exactitud de respuesta. Indique con una } \mathrm{X} \text { el promedio o rango de aproximación de las } \\
\text { respuestas ofrecidas a los usuarios. } \\
\text { Rango entre } 80 \text { y } 100 \% \text { __ Rango entre } 50 \text { y } 60 \% \text { _ Rango mínimo__ }\end{array}$} \\
\hline
\end{tabular}




\section{CONTENIDO}

6.1 Parámetros de calidad. Señalar de la lista que a continuación se presenta, aquellos aspectos considerados al momento de diseñar y ofrecer el servicio de Referencia digital.

\begin{tabular}{|c|c|}
\hline Adecuación entre la consulta y la agenda temática. & Sí___ No _ \\
\hline Factibilidad de contacto entre el usuario y la fuente (persona, link, etc.). & Sí __ No \\
\hline $\begin{array}{l}\text { Posibilidad de manifestar opiniones sobre el contenido de la Web a } \\
\text { responsable o administrador. }\end{array}$ & Sí ___ No. \\
\hline $\begin{array}{l}\text { Presencia de indicaciones que orienten al usuario dónde está, indicando el } \\
\text { número de recursos que tiene cada sección. }\end{array}$ & Sí ___ No __ \\
\hline Índices de contenido de textos, personajes, gráficos, l & Sí ___ No \\
\hline Presencia de etiquetas en el contenido, tales como términos, iconos, etc. & Sí ___ No. \\
\hline
\end{tabular}

\section{DISEÑO DE INTERFAZ}

7.1 Aspectos físicos y ergonómicos. Favor indicar de la lista que a continuación se presenta aquellos aspectos considerados en el diseño del servicio.

\begin{tabular}{|c|c|}
\hline Consistencia y contraste en el uso de colores & Sí__ No ___ \\
\hline Homogeneidad de estilos & Sí__ No ___ \\
\hline Tipo de letras & Sí__ No __ \\
\hline Tamaño de letras & Sí__ No ___ \\
\hline Líneas de texto & Sí__ No ___ \\
\hline Ancho de pantalla & Sí__ No __ \\
\hline Márgenes & Sí___ No _ \\
\hline Legibilidad. Claridad o contraste adecuado entre el texto y el fondo & Sí__ No ___ \\
\hline Flexibilidad para realizar una acción de diferentes maneras & Sí__ No ___ \\
\hline $\begin{array}{l}\text { Adecuación del uso de imágenes o sonido en el recurso completando la } \\
\text { información textual }\end{array}$ & Sí__ No __ \\
\hline $\begin{array}{l}\text { Velocidad o tiempo de descarga de la publicación, considerándose el tiempo } \\
\text { promedio de descarga por página de } 25 \text { segundos. }\end{array}$ & Sí__ No __ \\
\hline $\begin{array}{l}\text { Posibilidad de manifestar opiniones sobre el contenido de la Web a } \\
\text { responsable o administrador }\end{array}$ & Sí__ No __ \\
\hline
\end{tabular}

\section{SISTEMA DE BÚSQUEDA Y RECUPERACION}

8.1 Descripción del sistema de búsqueda. ¿Qué sistemas de búsqueda se utilizan para que los usuarios puedan recuperar y acceder a los diferentes recursos de información desde la Web del servicio de Referencia Digital? 


\section{USABILIDAD}

\begin{tabular}{|c|c|}
\hline $\begin{array}{l}9.1 \text { ¿Existe control sobre la inversión de tiempo } \\
\text { utilizado por usuario? }\end{array}$ & Sí__ No _ _ \\
\hline $\begin{array}{l}9.2 \text { ¿Existe control sobre el número de errores } \\
\text { cometidos? }\end{array}$ & Sí__ No___ \\
\hline \multicolumn{2}{|c|}{$\begin{array}{l}9.3 \text { ¿Se ha realizado en los dos últimos años algún estudio de medición de la satisfacción de los } \\
\text { usuarios del servicio? (nivel subjetivos) Sí__ NO__Cuándo? }\end{array}$} \\
\hline \multicolumn{2}{|c|}{$\begin{array}{l}\text { 9.4 Indicar qué instrumentos se utilizan para la evaluación del servicio. } \\
\text { Entrevista directa } \mathrm{Si} \_ \text {No ___ Encuesta. Sí__ No __ } \\
\text { Breve evaluación después ofrecida el servicio. Sí__ No__ Otro. }\end{array}$} \\
\hline $\begin{array}{l}9.5 \text { ¿Es posible reutilizar los recursos del servicio } \\
\text { para la prestación de otros servicios? }\end{array}$ & $\begin{array}{l}\text { Sí__ No } \\
\text { Favor brindar un ejemplo }\end{array}$ \\
\hline \multicolumn{2}{|c|}{ 9.6 En su opinión y partiendo del anterior punto, ¿̇cuál es el punto más fuerte del servicio? } \\
\hline \multicolumn{2}{|c|}{$\begin{array}{l}\text { 9.7 Desde su punto de vista ¿cómo podría el servicio de referencia digital, contribuir en } \\
\text { procesos E-learning? Argumente su respuesta. }\end{array}$} \\
\hline \multicolumn{2}{|c|}{$\begin{array}{l}9.8 \text { ¿Interfiere de alguna forma el servicio de referencia digital en la capacitación ofrecida por el } \\
\text { servicio de "Formación de habilidades y destrezas? Por favor argumente su respuesta. }\end{array}$} \\
\hline
\end{tabular}




\section{Anexo 2. Evaluación de formación de habilidades y destrezas (Gestores del servicio)}

La presenta encuesta está dirigida al personal involucrado con actividades o servicios en línea (Intranet o Internet) dirigidos a la formación de habilidades y destrezas de los usuarios de la biblioteca. El objetivo de la encuesta es la realización de un análisis descriptivo y de funcionamiento, a fin de identificar la viabilidad de este servicio para ser integrado como parte o módulo en los programas de estudios E-learning.

Aspectos generales

\begin{tabular}{|l|l|l|}
\hline Institución: & \multicolumn{2}{|l|}{} \\
\hline País: & \multicolumn{2}{|l|}{} \\
\hline Dirección URL: & $50 \%$ presencial y $50 \%$ virtual \\
\hline $\begin{array}{l}\text { Modalidades E-learning. Favor indicar con una X cuáles son las modalidades de cursos a } \\
\text { distancia ofrecidos por la Universidad. }\end{array}$ & \\
\hline Nombre del curso. & $100 \%$ en línea & \\
\hline Carreras universitarias & & \\
\hline $\begin{array}{l}\text { Cursos post universitarios de } \\
\text { actualización }\end{array}$ & & \\
\hline $\begin{array}{l}\text { Cursos de orientación y /o } \\
\text { complementarios }\end{array}$ & \\
\hline
\end{tabular}

\section{IDENTIDAD DEL SERVICIO}

1.1 Reconocimiento del servicio en la Web. Indicar ¿cómo se identifica el servicio de ALFIN en la Web de la Biblioteca?

Palabra. ¿Cuál ?

Icono ¿Cuál ?

Otro ¿Cuál ?

1.2 Cobertura temática de los cursos. Indique las áreas temáticas a que responde los cursos de Formación de Habilidades. (En caso de estar incluidos como crédito o materia dentro de un plan de estudios de la universidad, especificar cuál o cuáles)

1.3 Señale con una $X$ los Cursos que actualmente se imparte. 
Cursos de orientación e introducción a la biblioteca

Cursos de técnicas de búsquedas eficientes en sistema de la biblioteca

Cursos de técnicas de búsquedas eficientes en bases de datos

Curso sobre manejo y uso de recursos informativos

Curso sobre técnicas de citaciones

Otro

Otro

1.4. Indique la modalidad del o de los Presenciales cursos

Orientación de usuarios

Manejo y uso de recursos informativos

Técnicas de citaciones

Técnicas de búsquedas y recuperación

de información

1.5 Topología de usuarios. De la siguiente lista, marque con una $\mathrm{X}$ los usuarios que demanda este servicio.

\begin{tabular}{|l|l|l|l|l|l|}
\hline Usuarios & Novatos & Con experiencia & Experto & Externos & $\begin{array}{l}\text { Interno } \\
\mathrm{s}\end{array}$ \\
\hline Docentes & & & & & \\
\hline Trabajadores & & & & & \\
\hline Estudiantes & & & & & \\
\hline Otros & & & & & \\
\hline
\end{tabular}

1.6 Componentes básicos. Marque con una $\mathrm{X}$ los componentes que integran los servicios de Formación de Habilidades y destrezas.

Profesional - especialistas en temas concretos

Infraestructura tecnológica (systems and software for digital service)

Sistema de información (la información en sí)

Proceso de comunicación (pregunta - respuesta)

Capacitación - para el personal

Educación de usuario - referencia digital

Estándares para el desarrollo / prestación del servicio

Políticas y estándares para el trabajo en red (network)

Procesos de evaluación constantes

1.7 Objetivos de los cursos. Indicar con una $\mathrm{X}$ ¿ंcuáles son los objetivos que se perciben a través de los cursos impartidos?

1. Reconocer una necesidad de información

2. Determinar el alcance de la información requerida

3. Acceder a ella con eficiencia

4. Evaluar la información y sus fuentes

5. Incorporar la información seleccionada a su propia base de conocimientos 


\begin{tabular}{|l|l|}
\hline 6. Utilizar la información de manera eficaz para acometer tareas específicas & \\
\hline $\begin{array}{l}\text { 7. Comprender la problemática económica, legal y social que rodea al uso de la } \\
\text { información }\end{array}$ & \\
\hline 8. Acceder a ella y utilizarla de forma ética y legal & \\
\hline 9. Clasificar, almacenar, manipular y re-elaborar la información reunida o generada & \\
\hline $\begin{array}{l}\text { 10. Reconocer la alfabetización en información como prerrequisito para el } \\
\text { aprendizaje a lo largo de la vida. }\end{array}$ & \\
\hline $\begin{array}{l}\text { 1.8 Recursos informativos. Favor indicar los recursos que ofrece la biblioteca para facilitar el } \\
\text { desarrollo de los cursos E-learning. }\end{array}$ & \\
\hline Colección en papel (primaria y secundaria) & \\
\hline Colecciones especiales en papel & \\
\hline Colecciones especiales (formato digital) & \\
\hline Bases de datos internas de referencias (documentos digitalizados) & \\
\hline Bases de datos externas de documentos digitalizados & \\
\hline Recursos multimedia & \\
\hline Material académico de programas virtuales & \\
\hline Aulas virtuales & \\
\hline Información gris & \\
\hline Portales, RSS, Teleconferencias, Blogs colaborativos, Wikis, Flickr, RSS & \\
\hline Información administrativa institucional & \\
\hline Google académicos & \\
\hline Diversos (noticias, variedades, entretenimientos, etc.) & \\
\hline
\end{tabular}

2. ACTUALIZACIÓN

2.1 Actualización y vigencia de los enlaces. Favor indicar con una $\mathrm{X}$ la frecuencia de actualización de los contenidos y el control de la vigencia de los enlaces.

a. Cada dos semanas _ _ b. Cada mes___ c. Cada semestre___ d. Irregular___

\section{ACCESIBILIDAD}

3.1 Sistemas de utilizados. ¿Qué tipo y nombre de programa(s) se utilizan para el manejo del contenido?.

LMS:

$\operatorname{LCM}(\mathrm{s})$ :

LMS y LCM:

¿Qué tipo de interoperabilidad existe entre el sistema de la universidad (LMS)y el de la biblioteca (CMS) para el intercambio de información de apoyo a la docencia y/o desarrollo de los cursos propios de la biblioteca? Explique brevemente:

¿Es posible ajustar los contenidos a las características, nivel académico y comportamiento de los alumnos? Explique brevemente:

3.2 ¿Existen facilidades en los cursos para la participación de personas con incapacidades?

\begin{tabular}{|l|l|}
\hline Incapacidad visual: & \\
\hline Incapacidad auditiva: & \\
\hline Otra incapacidades físicas: & \\
\hline Otras. Explique: & \\
\hline
\end{tabular}




\section{ORGANIZACION DE LOS CONTENIDOS}

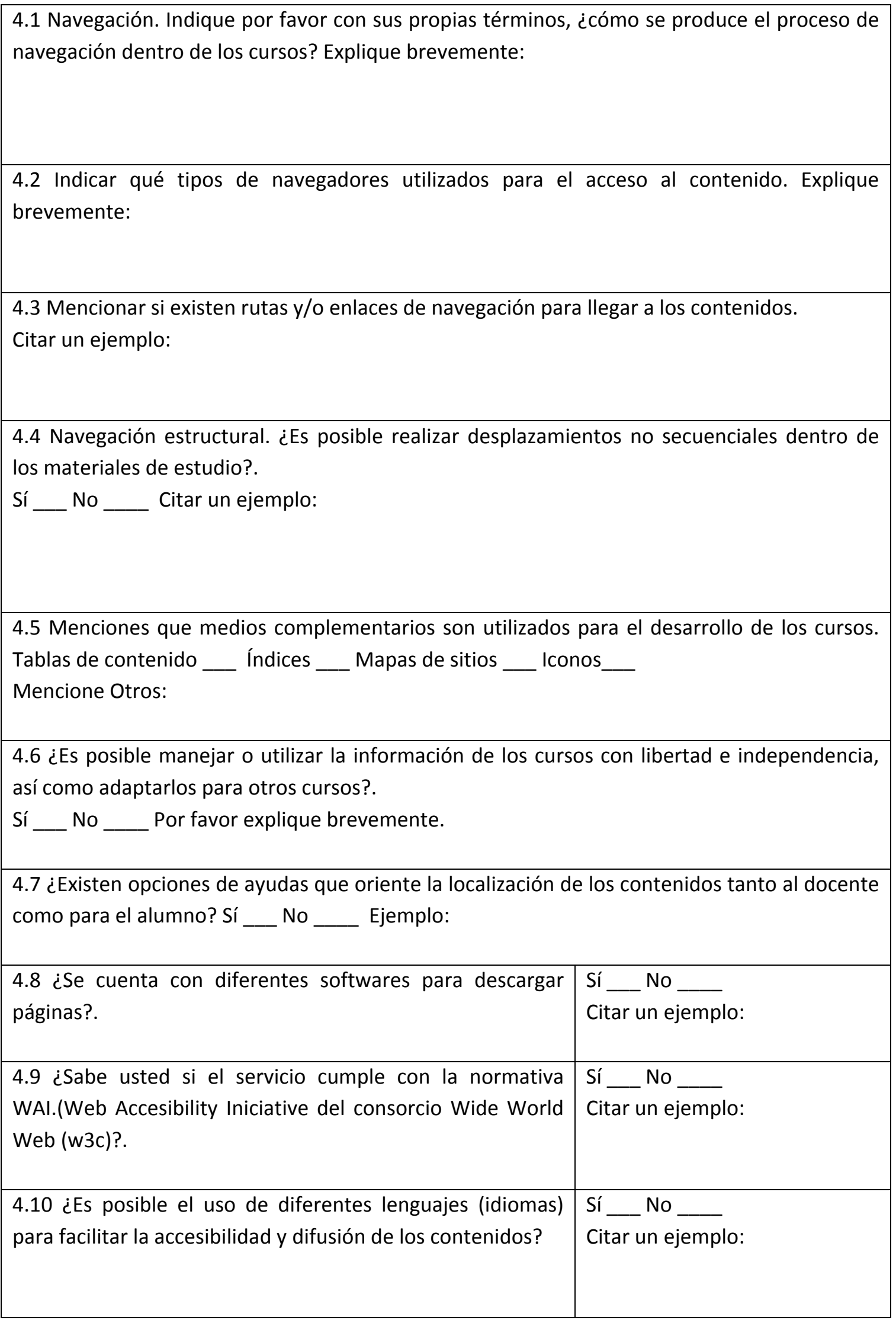




\section{SERVICIOS BASICOS DE LA WEB.}

5.1 Servicios básicos de la Web. De la lista que a continuación se presenta indicar los servicios que se ofrecen dentro del programa de Formación de Habilidades y destrezas.

\begin{tabular}{|c|c|}
\hline Directorio de recursos Web & Sí__ No ___ Me gustaría ___ \\
\hline Objetos de aprendizaje multimedia & Sí__ No ___ Me gustaría \\
\hline Grupo / comunidades virtuales & Sí__ No ___ Me gustaría ___ \\
\hline Acceso a diversos Metadatos & Sí__ No ___ Me gustaría \\
\hline Espacios personalizados & Sí__ No ___ Me gustaría \\
\hline Recursos Metadatosbasados en el uso de la Web & Sí__ No ___ Me gustaría ___ \\
\hline Portales & Sí__ No ___ Me gustaría __ \\
\hline Servicio de orientación al estudiante & Sí__ No ___ Me gustaría ___ \\
\hline Email & Sí__ No ___ Me gustaría __ \\
\hline Chat & Sí__ No ___ Me gustaría \\
\hline Skype & Sí__ No ___ Me gustaría __ \\
\hline Videoconferencias & Sí__ No ___ Me gustaría __ \\
\hline Foros de discusión & Sí__ No ___ Me gustaría \\
\hline Messenger & Sí__ No ___ Me gustaría ___ \\
\hline Facebook & Sí__ No ___ Me gustaría ___ \\
\hline Blogs colaborativos & Sí__ No ___ Me gustaría ___ \\
\hline Wikis & Sí__ No ___ Me gustaría \\
\hline Flickr & Sí__ No ___ Me gustaría __ \\
\hline RSS & Sí__ No ___ Me gustaría \\
\hline Google académicos & Sí__ No ___ Me gustaría ___ \\
\hline $\begin{array}{l}\text { Diversos (noticias, variedades, entretenimientos, } \\
\text { etc.) }\end{array}$ & Sí__ No ___ Me gustaría ___ \\
\hline \multicolumn{2}{|c|}{$\begin{array}{l}5.2 \text { Acceso a los servicios. Indique el tiempo aproximado de respuesta que se establece en el } \\
\text { proceso de comunicación entre los cursantes y los gestores de los cursos. Segundos } \\
\text { Minutos _ Hora_ }\end{array}$} \\
\hline
\end{tabular}




\section{CONTENIDO DE LOS RECURSOS DIGITALES}

\begin{tabular}{|c|c|}
\hline $\begin{array}{l}\text { 6.1 Parámetros de calidad. Señalar de la lista que a continuación s } \\
\text { aspectos considerados al momento de hacer disponible los recursos par } \\
\text { cursos o tareas de aprendizaje. }\end{array}$ & desarrollc \\
\hline Autoridad de autores reconocida & Sí_No No__ \\
\hline Adecuación entre la autoría y la agenda temática. & Sí__ No ___ \\
\hline Adscripción del autor a la organización que pertenece & Sí_No \\
\hline $\begin{array}{l}\text { Correspondencia temática con la misión, visión y objetivos de la } \\
\text { institución }\end{array}$ & Sí_No ___ \\
\hline Factibilidad de contacto entre el autor-usuario de la fuente. & Sí__ No ___ \\
\hline Reconocimiento y credibilidad de la fuente & Sí__ No ___ \\
\hline $\begin{array}{l}\text { La interconexión de los contenidos y las referencias bibliográficas, } \\
\text { artículos. }\end{array}$ & Sí__ No __ \\
\hline $\begin{array}{l}\text { Uso de estándar Digital Object Identifier = DOI usado por editoriales } \\
\text { técnicas y científicas. }\end{array}$ & Sí__no __ \\
\hline $\begin{array}{l}\text { Posibilidad de manifestar opiniones sobre el contenido de la Web a } \\
\text { responsable o administrador }\end{array}$ & Sí__ No __ \\
\hline $\begin{array}{l}\text { Identificación básica de las diferentes secciones de la publicación (autor, } \\
\text { título y fechas) Uso de estándares como Ideal, libqual. Etc. }\end{array}$ & Sí__ No ___ \\
\hline $\begin{array}{l}\text { Posibilidad de recorrido secuencial. Seguir un contenido de forma total, } \\
\text { parcial de forma secuencial. Por ejemplo: }<\text { siguiente }><\text { adelante }><\text { atrás }>\end{array}$ & Sí__ No __ \\
\hline $\begin{array}{l}\text { Presencia de indicaciones que orienten al usuario dónde está, indicando } \\
\text { el número de recursos que tiene cada sección. }\end{array}$ & Sí__ No __ \\
\hline $\begin{array}{l}\text { Navegación estructural. Es la posibilidad de realizar desplazamientos no } \\
\text { secuenciales }\end{array}$ & Sí__ No __ \\
\hline Índices de contenido de textos, personajes, gráficos, lugares, etc. & Sí__ No __ \\
\hline $\begin{array}{l}\text { Presencia de etiquetas en el contenido de términos, iconos o rótulos que } \\
\text { diferencias del documento }\end{array}$ & Sí__ No __ \\
\hline
\end{tabular}

\section{DISEÑO DE INTERFAZ}

\begin{tabular}{|c|c|}
\hline \multicolumn{2}{|c|}{$\begin{array}{l}\text { 7.1 Aspectos físicos y ergonómicos. Favor indicar de la lista que a continuación se mencion } \\
\text { aquellos aspectos considerados en el diseño de los cursos y los servicios de ALFIN. }\end{array}$} \\
\hline Consistencia y contraste en el uso de colores & Sí ___ No __ \\
\hline Homogeneidad de estilos & Sí ___ No ___ \\
\hline Tipo de letras & Sí __ No __ \\
\hline Tamaño de letras & Sí__ No __ \\
\hline Líneas de texto & Sí__ No __ \\
\hline Ancho de pantalla & Sí__ No ___ \\
\hline Márgenes & Sí __ No __ \\
\hline Legibilidad. Claridad o contraste adecuado entre el texto y e & Sí__ No ___ \\
\hline
\end{tabular}




\begin{tabular}{|c|c|}
\hline Flexibilidad para realizar una acción de diferentes maneras & Sí ___ No __ \\
\hline $\begin{array}{l}\text { Adecuación del uso de imágenes o sonido en el recurso completando la } \\
\text { información textual }\end{array}$ & Sí__ No __ \\
\hline $\begin{array}{l}\text { Velocidad o tiempo de descarga de la publicación, considerándose el } \\
\text { tiempo promedio de descarga por página de } 25 \text { segundos }\end{array}$ & Sí_ No _ \\
\hline $\begin{array}{l}\text { Posibilidad de manifestar opiniones sobre el contenido de la Web a } \\
\text { responsable o administrador }\end{array}$ & Sí __ No _ \\
\hline
\end{tabular}

\section{POSICIONAMIENTO}

8.1 Identificación del servicio en la Internet. ¿Qué término utiliza usted para identificar el servicio de cursos ofrecidos por la biblioteca? Indique para cada caso.

Web de la Universidad dentro de la Biblioteca

dentro de la Google / Yahoo Otros:

\section{SISTEMA DE BÚSQUEDA Y RECUPERACION}

9.1 ¿Existe un sistema de búsqueda para recuperar y acceder al diferente recurso?

9.2 ¿Cuáles son las disponibilidades de formatos para acceder a los contenidos?

PDF_ HTML__ ASCCI_ DOC_ DOT_ OTROS

\section{USABILIDAD}

10.1 ¿Es posible acceder a los cursos desde cualquier punto del interior o exterior de la entidad? Sí No

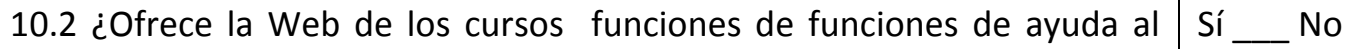
usuario?

10.3 ¿Cómo se constata y valora el aprendizaje por los usuarios del servicio?.

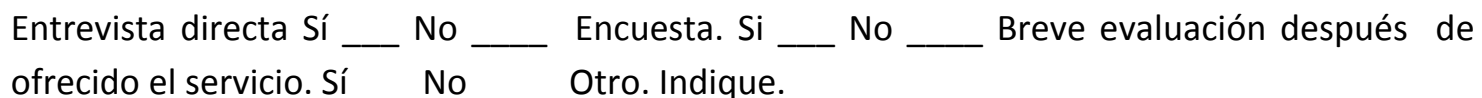

Anual Irregular No todavía

10.4 ¿Es posible reutilizar los módulos de estudio para otros cursos?.

Sí No 


\section{Anexo 3. Gestores de servicios de repositorios educacionales}

La presente encuesta ha sido elaborada con el objetivo de recopilar la información necesaria para la realización de un análisis descriptivo y de funcionamiento de los repositorios académicos, a fin de identificar la viabilidad de este servicio para ser integrado como parte o módulo en los programas de estudios E-learning.

Concepto: Entiéndase como Repositorios Académicos aquellos recursos o fuentes de información digital asociados a un propósito educativo que ha sido reunida, organizada, sistematizada y accesible para su uso a través de Internet.

Aspectos Generales de la institución

Nombre de la institución:

Código ISO de país: Dirección URL:

Nombre del Repositorio:

¿Quién es el dueño del repositorio?

Cobertura temática del repositorio:

Objetivo

Características:

Logo / Lemas

\section{IDENTIDAD DEL SERVICIO}

1.1 Reconocimiento del Repositorio. Cómo se identifica el Repositorio dentro de la Web institucional.

Palabra. ¿Cuál

Icono ¿Cuál ?

Otro ¿Cuál ?

1.2 Topología de usuarios. De la siguiente lista, seleccione la categoría de usuario de la biblioteca que utilizan los repositorios.

\begin{tabular}{|l|l|l|l|}
\hline Usuarios & Sin experiencia & Con experiencia & Experto \\
\hline Docente & & & \\
\hline Trabajador & & & \\
\hline Estudiante & & & \\
\hline Otros & & & \\
\hline
\end{tabular}


1.3 Indique de los cursos a continuación citados aquellos que exigen la consulta a algún repositorio para la educación.

Cursos de orientación e introducción a la biblioteca

Cursos de técnicas de búsquedas en el sistema de la biblioteca

Cursos de técnicas de búsquedas en bases de datos externas

Curso sobre manejo y uso de recursos informativos

Curso sobre técnicas de citaciones

Otros

\begin{tabular}{|l|l|}
\hline $\begin{array}{l}\text { 1.4 Recursos informativos. Favor indicar con una X los recursos de información } \\
\text { contenido en los repositorios. }\end{array}$ & \\
\hline Colección en papel (primaria y secundaria) & \\
\hline Colecciones especiales en papel & \\
\hline Colecciones especiales (formato digital) & \\
\hline Bases de datos internas de referencias (documentos digitalizados) & \\
\hline Bases de datos externas de documentos digitalizados & \\
\hline Recursos multimedia & \\
\hline Material académico de programas virtuales & \\
\hline Información gris & \\
\hline Otros. Mencione & \\
\hline
\end{tabular}

\section{ACTUALIZACIÓN}

2.1 Actualización y vigencia de los enlaces. Indicar con una $\mathrm{X}$ la frecuencia de actualización de los contenidos y el control de la vigencia de los enlaces.

Cada dos semanas b. Cada mes c. Cada semestre d. Irregular

\section{ACCESIBILIDAD}

3.1 Sistemas de utilizados. ¿Qué tipo y nombre de programa(s) se utilizan para manejo de contenido en el Repositorio. IMS: LCM(s)?

3.2 Facilidad de localización y acceso a los contenidos. Favor indicar que facilidades ofrecen los cursos para la participación de participantes con incapacidades.

Incapacidad visual:

Incapacidad auditiva:

Otra incapacidades físicas:

Otras. Explique: 


\section{ORGANIZACION DE LOS CONTENIDOS}

\begin{tabular}{|c|}
\hline $\begin{array}{l}\text { 4.1 Navegación. ¿Experimentan problemas de navegación dentro de los repositorios? } \\
\text { Sí __ No __ En ocasiones }\end{array}$ \\
\hline 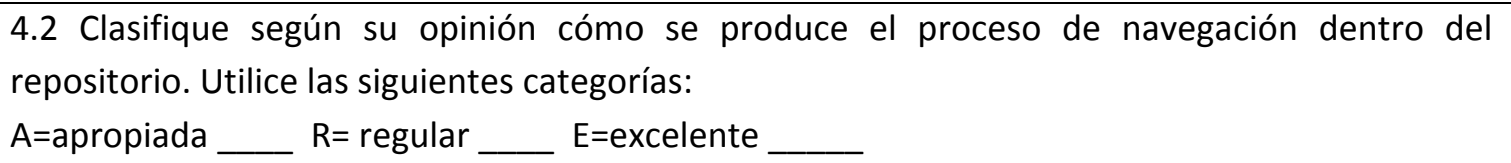 \\
\hline 4.3 ¿Qué ruta de navegación se utiliza para Ilegar a los contenidos? Citar un ejemplo: \\
\hline $\begin{array}{l}4.4 \text { ¿Existen enlaces que facilitan y agilizan la navegación? } \\
\text { Sí __ No ___ Citar un ejemplo: }\end{array}$ \\
\hline $\begin{array}{l}4.5 \text { ¿Existen enlaces que facilitan y agilizan la búsqueda interna? } \\
\text { Sí ___ No ___ Citar un ejemplo: }\end{array}$ \\
\hline $\begin{array}{l}4.6 \text { ¿Qué medio de ayuda se utiliza para ubicar los contenidos? } \\
\text { Tablas de contenidos _ Índices__ Mapas de sitios __ Iconos o rótulos _ _ } \\
\text { opciones de ayudas__ Otros: }\end{array}$ \\
\hline $\begin{array}{l}4.7 \text { ¿Es posible manejar, utilizar la información del repositorio con libertad e independencia? } \\
\text { (descargar, copiar, limpiar, transferir, etc.) } \\
\text { Sí __ No ___ Citar un ejemplo: }\end{array}$ \\
\hline $\begin{array}{l}4.8 \text { ¿Tiene usted problemas de software para descargar páginas?. } \\
\text { Sí __ No ___ Citar un ejemplo: }\end{array}$ \\
\hline $\begin{array}{l}4.9 \text { ¿Es posible utilizar diferentes lenguajes (idiomas) para facilitar la accesibilidad y difusión de } \\
\text { los contenidos de los cursos?. } \\
\text { Sí __ No ___ Citar un ejemplo: }\end{array}$ \\
\hline
\end{tabular}

\section{SERVICIOS BASICOS DE LA WEB.}

5.1 Servicios básicos de la Web. De la lista que a continuación se presenta indicar que otros servicios están vinculados al repositorio.

\begin{tabular}{|c|c|}
\hline Directorio de recursos Web & Sí___ No ___ \\
\hline Objetos de aprendizaje multimedia & Sí___ No __ \\
\hline Grupo / comunidades virtuales & Sí___ No __ \\
\hline Acceso a diversos Metadatos & Sí___No \\
\hline Espacios personalizados & Sí___ No __ \\
\hline Recursos Metadatosbasados en el uso de la Web & Sí___ No ___ \\
\hline Portales & Sí___ No __ \\
\hline Servicio de orientación al estudiante & Sí___ No __ \\
\hline Email & Sí___ No __ \\
\hline Chat & Sí___ No __ \\
\hline Skype & Sí___ No ___ \\
\hline Videoconferencias & Sí _ No _ _ \\
\hline Foros de discusión & Sí _ No __ \\
\hline Messenger & Sí __ No __ \\
\hline Facebook & Sí__ No __ \\
\hline Blogs colaborativos & Sí___ No \\
\hline Wikis & Sí___ No \\
\hline
\end{tabular}




\begin{tabular}{|c|c|}
\hline Flickr & Sí__ No ___ \\
\hline RSS & Sí__ No _ _ \\
\hline Google académicos & Sí__ No _ _ \\
\hline $\begin{array}{l}\text { Diversos (noticias, variedades, entretenimientos, etc.) } \\
\text { otros }\end{array}$ & Sí___ No __ \\
\hline \multicolumn{2}{|c|}{$\begin{array}{l}\text { 5.2 Acceso a los servicios. Indique el tiempo aproximado de respuesta entre el usuario y el } \\
\text { responsable del servicio (repositorio) } \\
30 \text { minutos __ Una hora__ } 6 \text { horas __ } 12 \text { horas __ } 24 \text { horas }\end{array}$} \\
\hline \multicolumn{2}{|c|}{$\begin{array}{l}5.3 \text { Exactitud de respuesta. Indique con una } \mathrm{X} \text { el promedio o rango aproximado de exactitud de } \\
\text { respuesta recibida. } \\
\text { Rango entre } 80 \text { y } 100 \% \text { __ Rango entre } 50 \text { y } 60 \% \text { _ Rango mínimo ___ }\end{array}$} \\
\hline
\end{tabular}

\section{CONTENIDO DE LAS COLECCIONES DIGITALES}

6.1 Parámetros de calidad. Señalar de la lista que a continuación se presenta, aquellos aspectos que cumple el repositorio.

\begin{tabular}{|c|c|}
\hline Autoridad de autores reconocida & Sí___ No ___ \\
\hline Adecuación entre la autoría y la agenda temática. & Sí__ No _ \\
\hline Adscripción del autor a la organización que pertenece & Sí___ No ___ \\
\hline Factibilidad de contacto entre el autor-usuario de la fuente & Sí__ No _ \\
\hline Reconocimiento y credibilidad de la fuente & Sí ___ No __ \\
\hline $\begin{array}{l}\text { Posibilidad de manifestar opiniones sobre el contenido de la Web al } \\
\text { responsable o administrador }\end{array}$ & Sí__ No __ \\
\hline $\begin{array}{l}\text { Identificación básica de las diferentes secciones de la publicación } \\
\text { (autor, título y fechas). }\end{array}$ & Sí __ No __ \\
\hline $\begin{array}{l}\text { Posibilidad de recorrido secuencial. Seguir un contenido de forma total, } \\
\text { parcial de forma secuencial. Por ejemplo: } \\
\text { <siguiente }><\text { adelante><atrás }>\end{array}$ & Sí ___ No __ \\
\hline $\begin{array}{l}\text { Presencia de indicaciones que orienten al usuario dónde está, } \\
\text { indicando el número de recursos que tiene cada sección. }\end{array}$ & Sí _ No _ _ _ \\
\hline Índices de contenido de textos, personajes, gráficos, lugares, etc. & Sí ___ No . \\
\hline
\end{tabular}

\section{DISENO DE INTERFAZ}

7.1 Aspectos físicos y ergonómicos. Indicar que aspectos físicos y ergonómicos son notables en el sitio Web del repositorio.

\begin{tabular}{|c|c|}
\hline Consistencia y contraste en el uso de colores & Sí___ No ___ \\
\hline Tipo de letras & Sí__ No ___ \\
\hline Tamaño de letras & Sí___ No ___ \\
\hline Líneas de texto & Sí___ No ___ \\
\hline Anchura de pantalla & Sí __ No __ \\
\hline Márgenes & Sí___ No ___ \\
\hline Legibilidad. Claridad o contraste adecuado entre el texto y el fondo & Sí___ No ___ \\
\hline Flexibilidad para realizar una acción de diferentes maneras & Sí _. No __ \\
\hline
\end{tabular}




\begin{tabular}{|l|l|}
\hline $\begin{array}{l}\text { Adecuación del uso de imágenes o sonido en el recurso completando la } \\
\text { información textual }\end{array}$ & Sí __ No _ \\
\hline $\begin{array}{l}\text { Velocidad o tiempo de descarga de la publicación, considerándose el } \\
\text { tiempo promedio de descarga por página de } 25 \text { segundos. }\end{array}$ & So \\
\hline $\begin{array}{l}\text { Posibilidad de manifestar opiniones sobre el contenido de la Web a a } \\
\text { responsable o administrador }\end{array}$ & Sí o _
\end{tabular}

\section{POSICIONAMIENTO}

8.1 Identificación del servicio en la Internet. ¿Qué término utiliza usted para identificar el servicio dentro de la Web de la Universidad? Biblioteca

Google / Yahoo Otros:

\section{SISTEMA DE BÚSQUEDA Y RECUPERACION}

\subsection{Descripción del sistema de búsqueda.}

¿Qué alternativas del sistema de búsqueda se utiliza para localizar la información en el repositorio?

En todo el contenido del recurso. Sí No

En la descripción del recurso. Sí No

En lenguajes controlados y libre. Sí No

Solamente el lenguaje controlado. Sí No

Términos semejantes por aproximación. Sí No

Uso de operadores boléanos. Sí No

Existe cuido de la semántica de los metadatos. Sí No

Otros:

Indique que disponibilidad de formatos para los contenidos usted demanda PDF HTML $\mathrm{ASCCl}$ DOC DOT OTROS

\section{USABILIDAD}

\section{Acceso al recurso desde cualquier punto del interior o exterior de la entidad} Sí __ No _ _ Citar un ejemplo:

Flexibilidad de copiar, pegar

Sí __ No ___ Citar un ejemplo: 
Ofrece la web del servicio funciones de funciones de ayuda al usuario Sí No Citar un ejemplo:

Realiza la biblioteca algún estudio de medición de la satisfacción de los usuarios del servicio (nivel subjetivo)

Entrevista directa Sí No Encuesta. Sí No

Breve evaluación después de ser ofrecido el servicio. Sí No Otro: 